Department of Architecture and Built Environment

\title{
A modelling study of segmentation of naturally ventilated tall office buildings in a hot and humid climate
}

\author{
PEI-CHUN LIU \\ B.Arch (Hons), M.Sc (Hons)
}

Thesis submitted to the University of Nottingham

for the degree of Doctor of Philosophy

November 2012 


\section{Abstract}

The prevailing paradigm in indoor environment control of office buildings often excludes natural ventilation, due to the fact that its dynamic nature may not be compatible with the close control of mechanical conditioning systems. The challenges will be greater in terms of the potential high magnitudes of wind and buoyancy forces at high levels of tall buildings. This research is concerned with the prospect of tall office buildings that are purely naturally ventilated. It is proposed that "segmentation" might offer the least risky approach for natural ventilation design of non-domestic tall buildings.

Accordingly, the generic design procedure are proposed for investigating the influence of segmentation on ventilation air flows: firstly, the single-cell envelope flow model is adopted to evaluate the steady-state bulk flows through openings under a specified design condition; secondly, dynamic thermal modelling with an air flow network module is used, because of the particular importance of the coupling between the airflow and thermal process for evaluating the year-round ventilated cooling potential of targeted spaces. The chosen thermal model utilizes a multi-cell airflow network model (AFN) since the targeted buildings can no longer be described by a single-cell model; thirdly, computational fluid dynamics (CFD) simulation is suggested in the later design stage to cope with insufficient resolution of local airflow distribution in previous modelling stages; finally, the overall performance of comfort ventilation is then interpreted in relation to adaptive thermal comfort theory by the use of Building Bioclimatic Charts, which offers a way of rapidly testing whether or not natural ventilation is likely to produce comfortable conditions.

The novelty of this work lies not in the methodology, which uses available modelling tools, but in the evaluation of naturally ventilated tall buildings with reference to segmentation in the climatic context of Taiwan. The effect of segmentation is evaluated by comparing the overall ventilation performance under three different building configurations, namely the isolated, segmented and non-segmented tall buildings. The overall objectives are to determine whether the magnitudes of air flow rates and the resultant flow velocity can achieve the desired comfort ventilation over a range of specified conditions. Potential scenarios where the design goals may not be ensured are identified. The feasibility for naturally ventilated tall office buildings in hot and humid climates is clarified accordingly.

Keywords: Natural Ventilation, Tall Office Buildings, Segmentation, Dynamic Thermal Simulation, Air Flow Network Model, Ventilated Cavity 


\section{List of Publications}

\section{- Refereed journal articles}

- Pei-Chun Liu, Hsien-Te Lin, Jung-Hua Chou, 2009. Evaluation of buoyancydriven ventilation in atrium buildings using computational fluid dynamics and reduced-scale air model. Building and Environment 44(9):1970-1979

- LIU, P.C., ETHERIDGE, D. and FORD, B. 2012. A modelling study of segmentation of naturally ventilated tall office buildings in a hot and humid climate. International Journal of Ventilation 11(1):29-42

\section{- Published proceedings}

- $\quad$ LIU, P.C., ETHERIDGE, D. and FORD, B. 2011. Modelling on the naturally ventilated tall office buildings of a hot and humid climate: The thermally conflated mass flow network approach. In: ICWE13 (International Conference on Wind Engineering) 13th International Conference, Amsterdam, The Netherlands, 10-15 July 2011.

- $\quad$ LIU, P.C., FORD, B. and ETHERIDGE, D., 2010. Buoyancy-driven Ventilation in respect of Tall Office Buildings in a Hot and Humid Climate. In: IAQVEC (Indoor Air Quality, Ventilation and Energy Conservation in Buildings) 7th International Conference, Syracuse, New York, USA, 15-18 August 2010.

- Pei-Chun Liu, Hsien-Te Lin, Jung-Hua Chou, 2008. Evaluation of BuoyancyDriven Ventilation in an Atrium Building Using Computational Fluid Dynamics and Reduced-scale Model. In:ISWE3 (The 3rd International Symposium on Wind Effects in Buildings and Urban Environment, Tokyo, Japan, 4-5 March 2008. 


\section{Acknowledgement}

This thesis could never be done without help of so many amazing people around. I would like to express my most profound gratitude to:

- My principle supervisor, Professor Brian Ford, for his invaluable support, supervision, suggestions and encouragement throughout this research work.

- My second supervisor, Dr. David Etheridge, for his precious guidance, supervision and supportive comments all through my research.

- Ministry of Education, Taiwan, for their financial support and continuous concerns during my study.

- Environmental design group of Department of Architecture and Built Environment, Midlands Energy Graduate School and Graduate School of University of Nottingham, for their generous grants that allow me to attend the prestigious international conferences.

Especially gratitude to:

- All my friends and colleagues both in the UK and Taiwan, for their selfless sharing, utmost care and uncountable encouragement during my difficult times.

Finally but most importantly appreciation to:

- My parents, sister and brother, for their trustfulness, patience and comfort throughout my everyday life abroad.

Pei-Chun, Liu

October 2012 


\section{Table of contents}

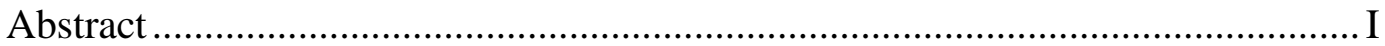

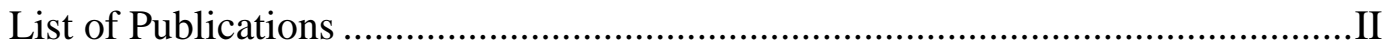

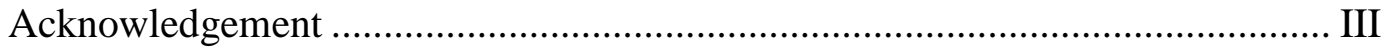

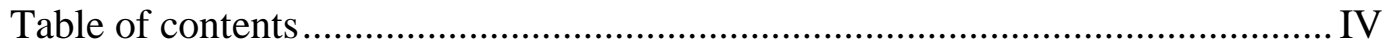

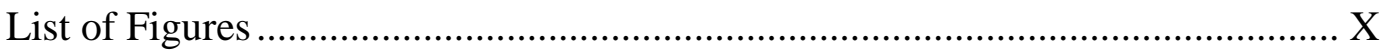

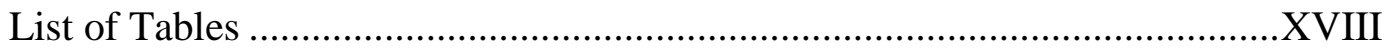

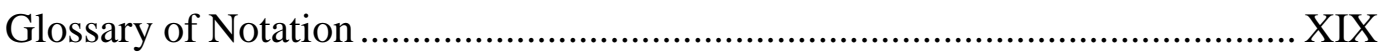

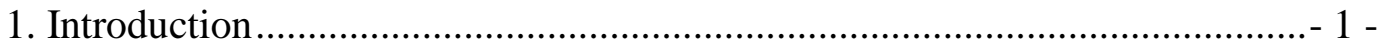

1.1 Prospects of natural ventilation in tall office buildings.......................... 1 -

1.2 Review of naturally ventilated tall office buildings in hot and humid

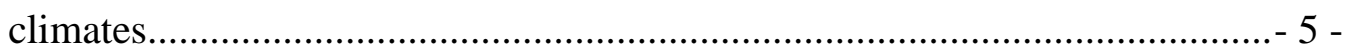

1.3 Research issues and objectives of this study .................................... 11 -

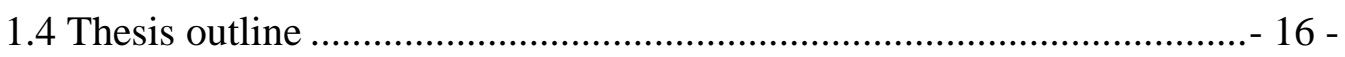

2. The Naturally Ventilated Tall Office Building Design................................ 19 -

2.1 Chapter overview .................................................................. 19 -

2.2 Case studies on naturally ventilated tall office buildings..................... 21 -

2.2.1 Commerzbank.................................................................. - 21 -

2.2.2 Deutsche Post office ............................................................ - 28 -

2.2.3 Liberty Tower of Meiji University ....................................... - 37 -

2.2.4 Menara UMNO Tower ......................................................... - 43 - 
2.3 Naturally ventilated tall office building design in the climatic context of Taiwan -58 -

2.3.1 The weather pattern of Taiwan $-58-$

2.3.2 Summary of lessons learned from case studies $-62-$

2.3.3 Options, limitations, and design considerations of naturally ventilated tall office buildings in Taiwan $-66-$

2.4 The prototype building and proposed building configurations of this study .69 -

2.4.1 The prototype building $-73-$

2.4.2 The proposed building configurations - $76-$

2.5 Summary $88-$

3. Methodology $89-$

3.1 Chapter overview $89-$

3.2 A method overview and recent applications of ventilation performance

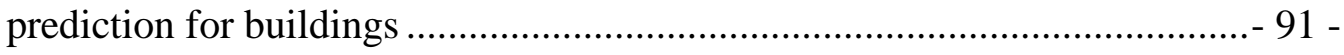

3.3 Plan for natural ventilation design of tall office buildings ..................... 95 -

3.4 Tools for natural ventilation assessment of this study $98-$

3.4.1 The envelope flow model $-98-$

3.4.2 The integrated building simulation program: ESP-r. $101-$

3.4.3 Computational Fluid Dynamics $-105-$ 3.5 Criterion for ventilation performance assessment $110-$ 
3.5.1 The minimum required flow rates for cooling...... $-110-$

3.5.2 The desired air flow pattern. $-111-$

3.5.3 Adaptive thermal comfort theory for a hot and humid climate - 112 -

3.5.4 The Building Bioclimatic Charts $-115$

3.6 Summary remarks $119-$

4. The preliminary investigations: The envelope flow model approach $120-$

4.1 Chapter overview $-120-$

4.2 Investigations of initial opening size $-122-$

4.3 The monthly off-design condition of the proposed building configurations .$124-$

4.3.1 The effect of segmentation $-124-$

4.3.2 The seasonal variation of ventilation $-129-$

4.3.3 Parametric study with respect to the ambient weather conditions- 132 -

4.4 Summary $137-$

5. The main investigations: The thermally coupled mass flow network approach..139 -

5.1 Chapter overview $139-$

5.2 The natural ventilation performance of the base case building configuration in the main investigation $141-$

5.2.1 The effect of segmentation 141

5.2.2 The probability for ventilated cooling $151-$

5.2.3 The investigation of desired flow pattern $-154-$ 
5.3 Revision of design: The open wind floor strategy $-157-$

5.3.1 The effect of segmentation $158-$

5.3.2 The probability for ventilated cooling $161-$

5.3.3 The probability for desired flow pattern $-165-$

5.3.4 The investigations of comfort wind environment of the lifted case- 167

5.4 Comparisons between the base case and revised building configurations of the main investigations $-173-$

5.4.1 Investigations of neutral point level (NPL) $173-$

5.4.2 Viable periods of time for comfort ventilation. $-175-$

5.5 Summary $-180-$

6. Computational Fluid Dynamics (CFD) $-183-$

6.1 Chapter overview $183-$

6.2 The adequacy of the use of wind pressure coefficient $\left(\mathrm{C}_{\mathrm{P}}\right)$ dataset in ESP-r.$186-$

6.2.1The theoretical background of air flow network and $\mathrm{C}_{\mathrm{P}}$ in ESP-r- 186 -

6.2.2 The modelling of surface $C_{P}$ of proposed building configuration- 190 -

6.2.3 Simulation results on adequacy of wind pressure coefficient dataset within ESP-r $-196-$

6.3 Whole building CFD simulation $201-$

6.3.1 The modelling technique of Single domain CFD modelling within ESP$r$ and the stand alone FLUENT-CFD - 201 - 
6.3.2 The initial whole building CFD investigations: The single domain CFD within ESP-r $-205-$

6.3.3 The main CFD investigations: The stand-alone FLUENT-CFD- 210 -

6.4 The feasibility for comfort ventilation of the proposed generic design by the use Building Bioclimatic charts (BBCCs) $-225-$

6.5 Summary $-231-$

7. Parametric Studies $-234-$

7.1 A method overview for parametric study $-234-$

7.2 Plan for parametric study on ventilation related parameters $-237-$

7.3 The influence of ventilation related parameters on the overall comfort environment of the proposed building configuration $241-$

7.3.1 The impact of building segmentation $241-$

7.3.2 The influence of envelope opening sizes $-245-$

7.3.3 Internal heat gains $-250-$

7.3.4 Wind pressure coefficient $-252-$

7.4 Temperature related parameters and the resultant flow rates $255-$

7.4.1 The isolated case $-255-$

7.4.2 The segmented case $-258-$

7.4.3 Sensitivity analysis with reference to building segmentation height- 263

7.5 Summary $-268-$

8. Conclusions $-272-$ 
8.1 Summary of the thesis

8.2 Concluding remarks $-274-$

8.2.1 Design procedure for naturally ventilated tall office buildings - 274 -

8.2.2 Design performance in terms of building segmentation............ - 276 -

8.2.3 Considerations for naturally ventilated tall office building design in the climatic context of Taiwan $-280-$

8.3 Originality and contribution to knowledge $286-$

8.4 Suggestions for future work $289-$

Reference $-293-$ 


\section{List of Figures}

Figure 1-1: Typical energy consumption of office buildings in Taiwan ........................ - 1 -

Figure 1-2: The temperature fluctuation of typical weeks in Taipei .......................... - 10 -

Figure 1-3: Research flow charts and thesis outline ................................................ - 18 -

Figure 2-1: The Commerzbank Headquarter, Frankfurt, Germany. Source: Davies et al., 2002. $-21-$

Figure 2-2: Annual temperature profile in Frankfurt, Germany. $-21-$ Figure 2-3: The natural ventilation mode in Commerzbank. Source: Lambot and Davids, 1997. $-25-$

Figure 2-4: The Deutsche Post office, Bonn, Germany. Source: Brochure of Deutsche Post DHL Corporate Communications, 2009................................................................ - 28 -

Figure 2-5: Annual temperature profile in Bonn, Germany ...................................... - 28 Figure 2-6: Natural ventilation strategy at the Deutsche Post Tower. Source: Ruba Salib (2008) $-31-$

Figure 2-7: Extraction vents on the topmost levels of the nine-storey-high skygardens. a) Internal view of the skygarden vents; b) External view of the skygarden vents. Source:

Ruba Salib (2008). $-32-$

Figure 2-8: The natural ventilation strategy at the Post Tower. Source: (Murphy / Jahn, 2003) $-32-$

Figure 2-9: Airflow across the interior spaces showing the air intake and extract ventilation grilles. Source: Top: (Jahn, 2003); Bottom: (Ruba Salib, 2008)............... - 33 Figure 2-10: Summermode and wintermode ventilation strategy (during extreme temperatures). Source: (Welfonder, 2006) $-33-$

Figure 2-11: Liberty Tower of Meiji University, Tokyo, Japan. Source: Chikamoto \& Kato, 2002. -37 -

Figure 2-12: Annual temperature profile in Tokyo, Japan......................................... - 37 -

Figure 2-13: The natural ventilation system. Source: CTBUH (2012) ...................... - 39 Figure 2-14: Automatically controlled ventilation window. Source: Chikamoto and Kato (2002) $-40-$

Figure 2-15: Floor plans: Typical floor plan (Top), Wind floor on the 18th level (Bottom). -40 - 
Figure 2-16: The wind fence on 18th floor. a) Wind pass through this floor; b) Exhaust opening on the top of escalator void. Source: Chikamoto T. \& Kato, S. (2002) .......... - 40 Figure 2-17: The monthly energy consumption for removing cooling load (MJ/m2).

Source: Chikamoto and Kato (2002) ....................................................................... - 41 -

Figure 2-18: Menara UMNO, Penang, Malaysia; Vertical wing-walls protruding from the Southwest and Northeast elevations. Source: Jankassim (2004).......................... - 43 Figure 2-19: Annual temperature profile in Penang, Malaysia ................................. - 43 Figure 2-20: Typical floor plan of the Menara UMNO. Source: Baird (2001)........... - 45 Figure 2-21: The Menara UMNO Tower North (left) and West (right) Elevations. Source: Jankassim (2004). $-45-$

Figure 2-22: The cross sectional floor-by-floor basis ventilation strategy. Source: CTBUH (2012). $-47-$

Figure 2-23: Typical plan showing the location of balconies and airlocks. Sources:

Powell (1999). $-48-$

Figure 2-24: The Torre Cube. Guadalajara, Mexico. Source: Pagliari (2006).......... - 51 -

Figure 2-25: Annual temperature profile in Guadalajara, Mexico. $-51-$

Figure 2-26: The Torre Cube typical floor plans. Source: Pagliari (2006). $-53-$

Figure 2-27: The internal (atrium) and external views of The Torre Cube. Source: Pagliari (2006) $-53-$

Figure 2-28: Double-skin façade in the Torre Cube (showing the brise-soleil). Source:

Left: (Pagliari, 2006); Right: (Adria, 2005).............................................................. - 55 -

Figure 2-29: Natural ventilation strategy ................................................................... - 55 -

Figure 2-30: The potential application of the Torre Cube design strategy for the super

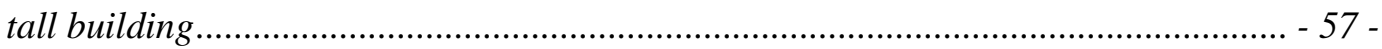

typology. Source: Salib (2008) ............................................................................... - 57 -

Figure 2-31: Year-round temperature distribution of Taipei, Taiwan ......................... - 58 -

Figure 2-32: The thermal comfort distribution by the use of building bioclimatic chart. (a) December to February; (b) March to May; (c) June to August; (d) September to November $-61-$

Figure 2-33: The prototype building. a) A current proposed design in Taipei, Taiwan; b)

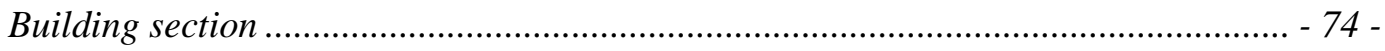

a) China Steel Corporation Headquarter,Taiwan ..................................................... - 75 Figure 2-34: a) A design of Taipei; b) The prototype building: simplified base case plan. $75-$ 
Figure 2-35: The generic diagram for naturally ventilated floor plan_Potential design option 1 $-78-$

Figure 2-36: The generic diagram for naturally ventilated floor plan_Potential design option 2 $-78-$

Figure 2-37: Ranges of floor plate efficiency of typical multi-storey office buildings (BCO, 2009). $-80-$

Figure 2-38: The generic diagram of the plan and sectional treatment for naturally ventilated tall office buildings. (a) The building plan, (b) The base case, (c) Lifted case...82 -

Figure 2-39: The single-cell models: (a) Isolated spaces, (b) Non-segmented and (c) segmented atrium buildings (Etheridge and Ford, 2008) $-83-$

Figure 2-40: The base case models of main investigations. a) The development of prototype building, b) Plan, c) Section and proposed ventilation strategy .................. - 86 -

Figure 2-41: The proposed building sections. (a) The base case; (b) The refined case.- 87

Figure 2-42: The air intake scenario of the lifted case. (a) Single, (b) 2 sides, (3) 4 sides.87 -

Figure 3-1: The proposed generic design procedure for naturally ventilated tall office

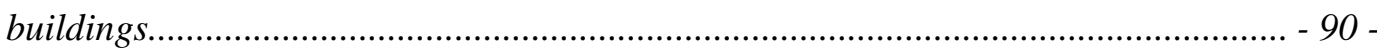

Figure 3-2: The mass and energy flow of the main building configuration. ............. - 104 Figure3-3: The building bioclimatic chart for a hot and humid climate under different ventilation condition .......................................................................................... - 118 Figure 4-1: Modes of operation of the preliminary building configurations ............ - 123 Figure 4-2: The monthly volume flow rates at each floor with the opening size of 9

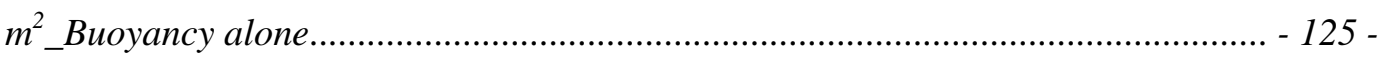

Figure 4.3: The top-down flow reversal under warmer seasons_ The buoyancy alone case - 126 -

Figure 4-4: The monthly flow rates at each floor with the opening size of $9 \mathrm{~m}^{2}$ Wind and buoyancy combined. $-128-$

Figure 4-5: Monthly volume flow rates at each floor with varied opening size across floor levels_Buoyancy alone. - 129 -

Figure 4-6: The monthly average weather condition of Taipei $-131-$ Figure 4-7: The monthly flow rates by floor levels under different ventilation conditions (FL denotes floor level).... $-131-$ 
Figure 4-8: The monthly flow rates by floor levels under different building configuration ( $F$ denotes floor level) $-132-$

Figure 4-9: The fresh air flow rates against floor height for different building

configurations with different ambient temperature and wind velocity $-136-$

Figure 4-10: The resultant flow rates by floor level with reference to different ambient temperature. a) Non-segmented case; b) Segmented case. $-136-$

Figure 5-1: Key input assumptions for the main investigations of this study...... $-142-$

Figure 5-2: The monthly volume flow rates against height_Wind and buoyancy combined - 146 -

Figure 5-3: The monthly volume flow rates against height_Buoyancy alone. -147 Figure 5-5: The probability for ventilated cooling of the 12 storey segmentation. a) Wind and buoyancy combined, b) Buoyancy-only - 152 -

Figure 5-6: The thermal environment of the base case on a typical day. a) Mid-season; b) Hot summer (Free-running) - 154 -

Figure 5-7: The monthly volume flow rates against height by different natural ventilation conditions. -155 -

Figure 5-9: The monthly volume flow rates against height_ The lifted case under the wind and buoyancy combined condition. $-160-$ Figure 5-10: The monthly volume flow rates against height by different ventilation conditions_revised models with the open wind floor. $-161-$ Figure 5-11: The probability for ventilated cooling. (a) Buoyancy alone, (b) Wind and buoyancy combined -164 Figure 5-12: The thermal environment of the base \& lifted case between $25^{\text {th }} \sim 28^{\text {th }}$ of March under varied ventilation condition $-165-$ Figure 5-13: The probability for desired flow pattern. (a) Buoyancy alone, (b) Wind and buoyancy combined. - 166 -

Figure 5-14: The air intake scenario of the lifted case. (a) Single, (b) 2 sides, (c) 4 sides.167 -

Figure 5-15: The monthly volume flow rates against height_Buoyancy alone. $-169-$ Figure 5-16: The monthly volume flow rates against height_Wind and buoyancy combined $-171-$

Figure 5-17: The free running temperatures of the lifted case with different ventilation inlet under the wind and buoyancy combined condition $-172-$ Figure 5-18: The free running temperatures of the atrium nodes. $-175-$ 
Figure 5-19: The seasonal number of hours for comfort ventilation by different ventilation conditions_Base case $-176-$

Figure 5-20: The seasonal number of hours for comfort ventilation by different ventilation conditions_Lifted case $177-$

Figure 5-21: The monthly number of hours for comfort ventilation by building configuration $179-$

Figure 5-22: The percentage for comfort ventilation by different building configurations and ventilation conditions. - 179 Figure 6-1: Resultant flow rates with reference to different Cp arrangements in March...189 -

Figure 6-2: The computational domain $-191-$

Figure 6-3: Power law wind velocity profile..... $-195-$

Figure 6-4: The gridding system of windward building surface in TPU (right) and FLUENT (left). - $196-$

Figure 6-5: Testing results of windward surface. (L) CFD results; $(R)$ TPU database ......198 -

Figure 6-6: Testing results of leeward surface. (L) CFD results; $(R)$ TPU database - 198 Figure 6-7: Testing results of side surfaces. (L) CFD results; $(R)$ TPU database .... - 199 Figure 6-8: Testing results of top surface: $C F D$ results. - 199 Figure 6-9: The surface averaged wind pressure coefficients from different dataset - 200 Figure 6-10: Building geometry and gridding system of the single CFD domain adopted in ESP-r. $-206-$

Figure 6-13: The temperature distribution at 2 pm of 22th March under mass flow rates of $1.7,4.2$, and $6.7\left(\mathrm{~m}^{3} / \mathrm{s}\right)$...... - 209 -

Figure 6-14: The air flow speed distribution at 2 pm of $22^{\text {nd }}$ March under mass flow rates of $1.7,4.2$, and $6.7\left(\mathrm{~m}^{3} / \mathrm{s}\right)$...... - 209 -

Figure 6-15: The building geometry and gridding system. (a) Base case, (b) Lifted case..214 -

Figure 6-16: The statistical distributions (Frequency and Cumulative) of inlet velocity magnitude. (a) March-May, (b) June-August $-215-$

Figure 6-17: Contours of velocity magnitude (Y=6 m). (a) $2 \mathrm{~m} / \mathrm{s}$, (b) ) $6 \mathrm{~m} / \mathrm{s}$ $-218-$

Figure 6-18: Contour of total temperature against building height_ 12 storey. a) $2 \mathrm{~m} / \mathrm{s}$; b) $6 \mathrm{~m} / \mathrm{s}$ - 218 - 
Figure 6-19: Velocity vectors coloured by velocity magnitude_Y=6 m. (a) $2 \mathrm{~m} / \mathrm{s}$, (b) 6 $\mathrm{m} / \mathrm{s}$ -219 -

Figure 6-20: Velocity vectors coloured by velocity magnitude_Z $Z=0.75 \mathrm{~m}$. (a) $2 \mathrm{~m} / \mathrm{s}$, (b) 6 $\mathrm{m} / \mathrm{s}$ $-220-$

Figure 6-21: Contour of total temperature of a building plan in the mid-level. a) $2 \mathrm{~m} / \mathrm{s}$; ) $6 \mathrm{~m} / \mathrm{s}$ $-220-$

Figure 6-22: Mass flow rates through vents of office spaces under different building configuration. $222-$

Figure 6-23: Contours of velocity $(Y=6 \mathrm{~m})_{\text {_ }}$ total volume flow rates of $60\left(\mathrm{~m}^{3} / \mathrm{s}\right)$ through the inlet. (a) Base case, (b) Lifted case. $-223-$

Figure 6-24: Velocity vectors coloured by velocity magnitude $(Y=6 \mathrm{~m})$ _ total volume flow rates of $60\left(\mathrm{~m}^{3} / \mathrm{s}\right)$ through the inlet. (a) Base case, (b) Lifted... $-223-$ Figure 6-25: Contours of total temperature $(Y=6 \mathrm{~m})_{-}$total volume flow rates of $60 \mathrm{~m}^{3} / \mathrm{s}$ through the inlet. (a) Base case, (b) Lifted case $-224-$

Figure 6-26: Contours of total temperature of an occupied space in the mid-level ( $Z=9$ $m)_{-}$total volume flow rates of $60 \mathrm{~m}^{3} / \mathrm{s}$ through the inlet. (a) Base case, (b) Lifted case.....224 -

Figure 6-27: The hourly data points in March_The bottom level office space - 227 Figure 6-28: The hourly data points over the occupied hours in March_The bottom level office space - 227 -

Figure 6-29: The hourly data points of May_ The top level office space. $-228-$ Figure 6-30: The hourly data points over the occupied hours in May_ The top level office space ... - 228 -

Figure 6-31: The hourly data points of August_The top level office space -229 Figure 6-32: The hourly data points over the occupied hours in August_the top level office space $-229-$ Figure 6-33: The hourly data points over the occupied hours between March and May_ The bottom level office space. $-230-$ Figure 6-34: The hourly data points over the occupied hours between June and August_ The bottom level office space $-230-$ Figure 7-1: The monthly standard deviation of flow rates under different ventilation conditions. $-243-$

Figure 7-2: The seasonal standard deviation of flow rates under different ventilation conditions $-243-$ 
Figure 7-3: The resultant variation of flow velocities with reference to the seasonal standard deviation of flow rates by different building segmentation. $-243-$

Figure 7-4: The low wind speed distributions in the climatic context of Taipei..... $-244-$ Figure 7-5: The effect of inlet/outlet sizes to the resulting flow rates. The 8 storeys segmentation case.... $-248-$

Figure 7-6: The effect of inlet/outlet sizes on flow rates/Wind and buoyancy combined casel 10 storey $-248-$

Figure 7-7: The effect of inlet/outlet sizes to flow rates/ Buoyancy alone case/ 10 storeys 248 -

Figure 7-8: The deviation of flow velocities in terms of different external opening arrangements $-249-$

Figure 7-9: The effect of wind under the maximum opening design condition (inlet $=40$

$m^{2}$; outlet $=20 \mathrm{~m}^{2}$ ). - 249 -

Figure 7-10: The range of influence with reference to flow velocity of different envelope opening arrangements under different ventilation condition.. - 249 Figure 7-11: Volume flow rates against opening height by ranges of internal heat gains..$251-$

Figure 7-12: The free running temperature of the 3rd-level office by different arrangements of internal heat gains on typical days of mid-season and hot summer- 251 Figure 7-13: The hourly wind speed and wind direction on $19^{\text {th }}$ of June..... - 253 Figure 7-14: The influence of $\triangle C_{P}$ on the resultant flow rates and the hourly basis standard deviations between three modelling cases - 254 Figure 7-15: The estimated air flow speed from the ventilation bulk flow on typical days of the mid-season and hot summer............................................................................. - 254 Figure 7-16: Section of the isolated case................................................................ - 255 Figure 7-17: The daily plot of volume flow rates against external and ventilated cavity temperatures_Isolated cases. The $R^{2}$ is provided in the top-right corner of the graph. (a) March; (b) August - 257 Figure 7-18: Illustration of the calculated hourly volume flow rates through the DSF cavity against the root temperature difference between the DSF cavity and ambient temperature for the buoyancy alone condition. $257-$ Figure 7-19: The temperature plot of selected building spaces in the typical weeks. (a) The bottom floor of spring period; (b) The top floor of summer period..... - 259 - 
Figure 7-20: Correlation analysis for the $T_{\text {external }}$ v.s volume flow rates_2 $22^{\text {th }}-28^{\text {th }}$ March .259 -

Figure 7-21: Correlation analysis for the $T_{\text {external }}$ v.s volume flow rates_1 $19^{\text {th }}-25^{\text {th }}$ June.....$260-$

Figure 7-22: Correlation analysis for the temperature difference between indoors and outdoors v.s volume flow rates_2 $22^{\text {th }}-28^{\text {th }}$ March. (a) The bottom floor; (b) The top floor..$262-$

Figure 7-23: Correlation analysis for the temperature difference between indoors and outdoors v.s volume flow rates_ $19^{\text {th }}-25^{\text {th }}$ June. (a) The bottom floor; (b) The top floor.....$262-$

Figure 7-24: The correlation between flow rates and external temperature against floor levels by different building segmentation height. (a) January; (b) March; (c) July.. - 264 Figure 7-25: The correlation between flow rates and temperature difference between indoors and outdoors by different building segmentation height. (a) January; (b) August.$265-$

Figure 7-26: Correlation between the temperature related parameters and flow rates_7 storeys segmentation case. (a) January; (b) August .................................................... - 267 - 


\section{List of Tables}

Table 1-1: Research objective and expected outcomes.............................................. - 15 -

Table 2-1: The natural ventilation strategies of the five case studies.......................... - 65 -

Table 3-1: Construction details ............................................................................... - 104 -

Table 3-2: AFN Nodes of the 20 storey case ........................................................... - 104 -

Table 3-3: Routes of CFD approach for natural ventilation design of the current study....109 -

Table 4-1: Calculated areas for summer design condition....................................... - 123 -

Table 6-1: Issues being investigated by the use of CFD approach in this Chapter... - 185 -

Table 6-2: Details for the grid dependency tests ........................................................ - 193 -

Table 6-3: The Root Mean Square Deviation of the grid dependency tests............... - 193 -

Table 6-4: Boundary conditions in FLUENT 6.3.26 ................................................ - 195 -

Table 6-5: modelling details of the whole domain flow field around the target building....195 -

Table 6-6: Solution variables of BES-CFD coupled approach ................................. - 206 -

Table 6-7: Boundary conditions for the full CFD simulation................................... - 212 -

Table 6-8: Mesh sizes for the grid dependency tests of the 12 storey case................ - 213 -

Table 6-9: Scenarios of the full CFD simulation..................................................... - 214 -

Table 7-1: Plan for Sensitivity Analysis of Ventilation Related Parameters ............. - 240 - 


\section{Glossary of Notation}

\begin{tabular}{|c|c|c|}
\hline Symbol & Meaning & Unit \\
\hline$\Delta P_{0}$ & Reference pressure & (pa) \\
\hline$\Delta P_{i}$ & Pressure difference through opening $i$ & (pa) \\
\hline$\Delta T$ & Temperature difference between indoors and outdoors & $(\mathrm{K})$ \\
\hline$A$ & Opening area & $\left(\mathrm{m}^{2}\right)$ \\
\hline$C_{d}$ & Discharge coefficient & $(-)$ \\
\hline$C_{P}$ & Wind pressure coefficient & $(-)$ \\
\hline$C p$ & Specific heat of air & $(\mathrm{J} / \mathrm{kgK})$ \\
\hline$C p_{n}$ & \multicolumn{2}{|l|}{ Pressure coefficient of grid number $N$ in current modelling session } \\
\hline$C p_{n-1}$ & \multicolumn{2}{|l|}{ Pressure coefficient of grid number $N$ in previous modelling session } \\
\hline$g$ & Gravitational force per unit mass & $\left(\mathrm{m} / \mathrm{s}^{2}\right)$ \\
\hline$H$ & The rate of internal heat gains & $(\mathrm{W})$ \\
\hline$K$ & Terrain dependent constants & $(-)$ \\
\hline$N$ & Total number of gridding system & \\
\hline$P_{d}$ & Dynamic wind pressure & $(\mathrm{Pa})$ \\
\hline$P_{E O}$ & Outdoor Reference pressure & (pa) \\
\hline$P_{I}$ & Indoor Reference pressure & (pa) \\
\hline$P_{w}$ & Surface (static) pressure of the wind & (pa) \\
\hline$P_{x}$ & Static pressure at a given point on the building surface & $(\mathrm{Pa})$ \\
\hline$Q$ & Total ventilation rate & $\left(\mathrm{m}^{3} / \mathrm{s}\right)$ \\
\hline$q_{i}$ & Flow rate through opening $i$ & $\left(\mathrm{~m}^{3} / \mathrm{s}\right)$ \\
\hline $\mathrm{R}^{2}$ & Correlation coefficient & $(-)$ \\
\hline$S_{i}$ & Flow sign & $(-)$ \\
\hline$T_{E}$ & External temperature & $(\mathrm{K})$ \\
\hline$U$ & External wind velocity & $(\mathrm{m} / \mathrm{s})$ \\
\hline$U_{10}$ & Wind speed measured in open countryside at height of $10 \mathrm{~m}$ & $(\mathrm{~m} / \mathrm{s})$ \\
\hline$U_{h}$ & Local wind speed at a height $Z_{h}$ above the ground & $(\mathrm{m} / \mathrm{s})$ \\
\hline$U_{r d}$ & Wind speed at some reference level $r$ and from direction $d$ & $(\mathrm{~m} / \mathrm{s})$ \\
\hline
\end{tabular}




$\begin{array}{llr}U_{\text {ref }} & \text { Reference wind speed taken at building height in the upstream } \\ & \text { undisturbed flow } & (\mathrm{m} / \mathrm{s}) \\ z & \text { Opening height } & (\mathrm{m}) \\ Z_{\text {node }} & \text { Height of node } & (\mathrm{m}) \\ \Delta z & \text { Height difference between two openings } & (\mathrm{m}) \\ \rho & \text { Air density } & \left(\mathrm{kg} / \mathrm{m}^{3}\right) \\ \rho_{E} & \text { Outdoor air density } & \left(\mathrm{kg} / \mathrm{m}^{3}\right) \\ \rho_{I} & \text { Indoor air density } & \left(\mathrm{kg} / \mathrm{m}^{3}\right) \\ \sigma & \text { Standard deviation } & \\ \sigma_{\mathrm{Cp}} & \text { Root mean square deviation of wind pressure coefficient } & (-)\end{array}$

$\begin{array}{ll}\text { AFN } & \text { Air flow network } \\ \text { BES } & \text { Building energy simulation } \\ \text { BBCCs } & \text { Building bioclimatic charts } \\ \text { EFM } & \text { Envelope flow model } \\ I P & \text { Influence coefficient } \\ \text { NPL } & \text { Input } \\ \text { Off-design condition } & \text { Neutral point level } \\ & \text { The steady result upon specific boundary } \\ \text { Open wind floor } & \text { conditions of a particular design } \\ & \text { The floor with open plan layout for } \\ O P & \text { receiving the wind driving flows } \\ \text { Wind core } & \text { Output } \\ \overline{I P} & \text { The vertical core of the building designed } \\ \overline{O P} & \text { for receiving wind driving flows } \\ \triangle O P & \text { Mean values of input } \\ \Delta I P & \text { Mean values of output } \\ \Delta I P_{B C} & \text { Changes in output } \\ \Delta O P_{B C} & \text { Changes in input } \\ & \text { Base case values of input } \\ & \text { Base case values of output }\end{array}$




\section{Introduction}

\subsection{Prospects of natural ventilation in tall office buildings}

A significant amount of the electricity consumed in office buildings of Taiwan goes towards fully air-conditioned commercial and institutional buildings. The situation is even more alarming in the case of tall buildings where greater energy consumption is required to provide comfort (Huang, 2006; Yang, 2004). Lin (2006) and Lin et al. (2007) claimed that the cooling load in Taiwan is the main cause for peak power demand and sometimes causes power shortages. They suggested that the air-conditioning load accounts for around $45 \%$ of the energy consumed in a typical office building of Taiwan on a daily basis (Fig.1-1).

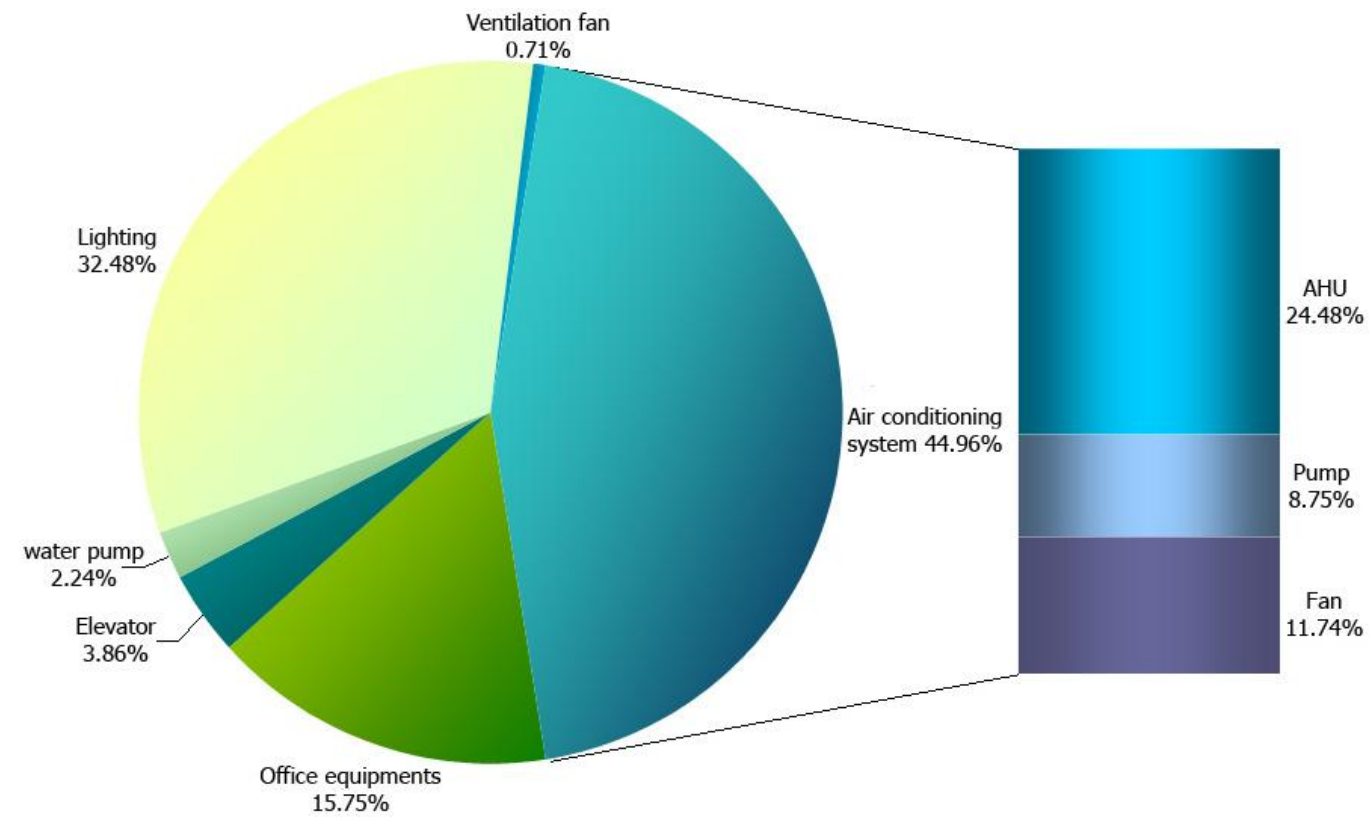

Figure 1-1: Typical energy consumption of office buildings in Taiwan

Natural ventilation for low-rise buildings is widely acknowledged to be an energy efficient ventilation strategy with several advantages such as popularity, lower cost than other ventilation systems, and minimum maintenance (Liddament, 1996). 
The design of non-domestic tall buildings which adopt a purely natural ventilation strategy is now increasingly common in many parts of the world (mainly in the mild climate). However, the adoption of natural ventilation in tall buildings for a hot and humid climate is less common. This is not surprising in view of the potential risks to a successful design as suggested by Etheridge and Ford (2008).

The aim of natural ventilation for this research is to provide sufficient fresh air and thermal comfort for the occupants, meanwhile avoiding possible failures during operation such as cold draught and condensation in tall office buildings of a hot and humid climate under the free-running mode. The ideal scenario for this research goes toward the tall buildings which can deliver acceptable internal thermal condition through natural ventilation alone. For the purpose of ventilated cooling, the fresh air flow rates obtained are sufficiently high for indoor air quality. That is, the effect of ventilated cooling is of interest in this particular study. There are three ways in which natural ventilation can improve thermal comfort. First, indoor air can be cooled by increasing amount of outdoor air as long as external temperatures are lower than internal temperatures (sensible cooling). Second, natural ventilation can be used to cool the building structure, where the building thermal mass may play an important role in conjunction with night-time ventilation. Third, the ventilation flow can cool the human body directly by convection and evaporation (personal cooling).

The issues to be investigated in this study, in terms of natural ventilation in a hot and humid climate, can be directed to the following aspects. Firstly, air conditioning in a hot and humid climate costs a considerable amount of energy to maintain the desired thermal comfort. The central hypothesis of this study is that, by appropriate natural ventilation strategies, building design will be able to reduce energy consumption and provide comfortable conditions in tall office buildings, for at least part of the year. The natural ventilation systems may reduce both capital and operating costs compared to air conditioning systems while maintaining ventilation rates that are consistent with acceptable indoor air quality. 
Secondly, natural ventilation is being increasingly proposed as a means of saving energy and improving indoor air quality within commercial buildings, particularly in the "green buildings" community. These proposals are often made without any engineering analysis to support the claimed advantages, e.g., without calculating expected ventilation rates or air distribution patterns. In addition, proven design approaches and procedures are not available in Taiwan to incorporate natural ventilation into commercial/office building system designs. Natural ventilation strategies in tall buildings are less likely to reach the Taiwan marketplace until design procedures and tools are made available. Thereby, this study investigates the strategies to tall buildings and demonstrates applicability for a variety of weather pattern and building configurations.

Thirdly, Ji et al. (2009) stated that modern non-domestic buildings tended to be large and deep plan with sealed façades for security and noise control. In such cases, where traditional forms of natural ventilation are unlikely to deliver sufficient ventilation performance, 'advanced natural ventilation' strategies (though the principles stay the same) should be considered and referred to specific building configuration design. Lomas (2007) used the term 'advanced natural ventilation' to encompass special building shape which utilised the stack effect to drive an air flow. For this particular study, the segmentation concept is applied in the atrium and ventilated double-skin facades of the proposed building configuration. The naturally occurring wind pressure and/or the buoyancy force (stack effect) are considered. The term 'segmentation' is defined where a tall building is divided into several sections to prevent the likely great pressure difference acting over the full height of vertical segments. The effect of segmentation on the resultant flow rates of associated office space is of interest. It is hoped to achieve a natural system that gives as much control as possible in the tall office buildings of a hot and humid climate.

Furthermore, sustainable high-rise buildings that provide comfortable, healthy and efficient work environments are clearly desirable as the densification of cities to meet the needs of the world's increasing population proceeds. Nevertheless, the 
issue of potentially high winds at higher levels of tall buildings needs to be addressed when natural ventilation at higher elevations is considered. While natural ventilation is becoming more common in Europe (the mild climate), opportunities have yet to be evaluated for its application in tall commercial/office buildings of a hot and humid climate as well.

The above research issues are then summarized as following research questions:

1) What is the potential for natural ventilation in tall buildings in hot and humid climates?

2) What building configurations may be adopted to promote viable natural ventilation strategies for tall buildings?

3) What design procedures can be adopted to achieve these natural ventilation strategies?

4) How do the ventilation related parameters relate to overall thermal conditions and to thermal comfort criteria in the occupied spaces?

In this Chapter, the prospects of natural ventilation in a hot and humid climate are addressed. The challenges and research questions for naturally ventilated tall buildings are raised. Previous studies of naturally ventilated tall office buildings particularly for a hot and humid climate are reviewed in Section 1.2. The cooling mechanism (design options) being explored for this particular study and tools available for ventilated cooling design are summarized accordingly. The objectives and issues to be investigated are then presented in Section 1.3. A research flow chart (Fig. 1-2) is provided for illustrating the structure of this thesis. The overall aims of this study are clarified accordingly. 


\subsection{Review of naturally ventilated tall office buildings in hot and humid climates}

Over years, a number of naturally ventilated towers have been built and evaluated using the concept of atria and double facades. The main advantages of a double skin or ventilated cavity are that it can provide a thermal and acoustic buffer between interior and exterior. As suggested by Irwin et al. (2008), double shells protect operable windows at higher elevations from high wind speeds and reduce acoustical problems from operable windows at the same time. One early example of such a building is the Commerzbank building in Frankfurt. The building features a double facade, with operable windows in the interior shell. To control stack effect, the building is subdivided into independent segments which also include four-story atria with gardens. A detailed case study for the Commerzbank is presented in Chapter 2.

From the aspect of atria design, Megri and Al-Dawoud (2007) compared the energy performance between the integration of HVAC system with covered atrium and an atrium open to the sky at the courtyard top. The multi-zones simulation program was adopted for investigating the effect of glazing type, glazing percentage and number of storeys under the hot and humid weather condition. Two real building applications were addressed in terms of integration between passive ventilation system and the architectural design. Though both case studies (Argonne National Laboratories and Foxconn Building project in China) were mixed-mode buildings, they demonstrated the possibility of natural ventilation in the hot and humid climates upon the viable weather conditions by the adoption of an open atrium and hollow walls and flooring respectively.

Lomas (2007) proposed four generic building types for the natural ventilation in the large educational buildings. The generic building types (Edge-in/Centre-out; Edge-in/Edge-out; Centre-in/Edge-out; Centre-in/Centre-out) were defined in his study with reference to inlet and outlet locations of the ventilation system. The simple equations for sizing the lightwell, plenum and stacks at the preliminary 
architectural design stage were obtained through the design experience of these buildings. It was suggested that a central supply route (lightwell) along with perimeter exhaust stacks could offer more benefit than other three generic building types. Some constrains for the Centre-in/Edge-out strategy (such as buildings with deeper floor plans and densely occupied condition as well as limitations in building site) were also identified.

With regard to double facades, they have been used extensively in office buildings of mild climates to promote natural ventilation of the interior, using the driving force of thermal buoyancy generated within the glazed cavity. For example, the Deutsche Post Office tower in Bonn adopted ventilated facades along with sky gardens as spent-air shafts, which provide the driving force for natural ventilation and help to control varying diurnal and seasonal ventilation requirements (Blaser, 2004). In this building, the vertical continuity of the cavity along the double-skin façade allows the stack effect to draw heat off at high levels, hence decreasing the likelihood of overheating. However, the DSF mechanism only comprises part of the ventilation concept. The overall ventilation strategy relies on cross-ventilation where air enters the building through the DSF, flows through the offices and into the corridors which act as exhaust air collectors, allowing the stale air to pass into the central atrium (sky gardens). Air is finally exhausted through windows and vents located on the topmost level of the ninestorey-high sky gardens. Unfortunately, ventilated facades have a tendency to overheat, particularly in hot and humid climates, and raise the cooling load of the adjacent occupied spaces (Ford and Schiano-Phan, 2005). Strategies adopted to mitigate this tendency can lead to higher envelope costs.

Many studies have also addressed issues of a ventilated cavity in a hot and humid climate. Hensen et al. (2002) suggested that an airflow network method was suitable for assisting the decision-making of building design and it might also benefit from CFD or vice-versa. Additionally, their study found that the cooling load would increase with floor height for the higher air temperature in the cavity of the double-skin façade. This also led to the suggestion that it would be 
advantageous to divide the cavity into segments with inlet and outlet openings at various heights. The challenges for coupling a double-skin façade to a natural ventilation system, due to the temperature and airflow fluctuations in the façade construction, were demonstrated as well. They concluded that the airflow was not only highly erratic in magnitude but could even take place in reversed direction. Another point was addressed that CFD might be of benefit for the prediction of the wind pressure distribution on the façade.

Additionally, Ding et al. (2005) proposed an atrium type building with a doubleskin façade and a solar chimney attached to the DSF cavity. It was assumed that the natural ventilation performance could be enhanced by the stack effect produced from the solar chimney without the encouragement of wind. Reduced scale model experiments and full-scale CFD model were adopted to evaluate the natural ventilation performance. Though their system secured the ventilation rates and was profitable to obtain favourable pressure difference distribution, it necessitated a chimney reaching at least $11 \mathrm{~m}$ above the building, which is a significant aesthetic constraint.

Gratia and Herde (2007) examined how natural ventilation could be provided during a sunny summer day in an office building with double-skin façade. The possibility of natural ventilation during daytime in relation to the orientation of the double skin and the speed and direction of wind was investigated. However, their results could not be generalized to other configurations of double-skin facades and were not sufficient for technical design as well. Furthermore, Wong et al. (2008) looked into the possibilities of natural ventilation of an 18-storey office building in a hot and humid climate using a double-skin façade. Their research revealed a close link between natural ventilation design and the function of double-skin façade by using the concept of stack effect and solar chimney. The feasibility of passive ventilation and significant energy savings was demonstrated for multi-storey buildings. 
Haase et al. (2009) proposed a ventilated DSF system for warm and humid climates using a combined thermal and airflow simulation, TRNSYS and TRNFLOW (coupled with COMIS). The simulation results were compared with on-site measurement data which confirmed the temperature reduction effect of different ventilated façade designs. However, the simulated dependence on incident radiation was not observed in the measurements, which showed a shift in the peak value with respect to incident solar radiation. Also, the simulated results on external and internal glazed surface temperatures were more sensitive to the incident radiation than the measured data. Further research was suggested to explain this dependency. More recently, Zhou and Chen (2010) reviewed the problems and possibilities for applying ventilated double-skin façade to buildings in a hot-summer and cold-winter zone in China. The main research methods for ventilated facades were discussed. They suggested that the current problem with double-skin façade was that they require adequate dynamic operation to achieve the desired performance. This depended closely on the chosen ventilation rates within its cavity, location of shading system, geometry and size of cavity ect.

The prevailing paradigm in indoor environment control of office buildings often excludes natural ventilation, due to the fact that its dynamic nature may not be compatible with the close control of mechanical conditioning systems. The literature reviews above addressed tools and design strategies available for naturally ventilated tall buildings. However, they rarely interpreted their observations with reference to occupant comfort. Because of the potential magnitudes of wind and buoyancy forces in tall buildings, the challenges for natural ventilation design are even greater. This research is concerned with the prospect of purely naturally ventilated tall office buildings. It is proposed that "segmentation" might offer the least risky approach for envelope design of nonresidential tall buildings. The overall objectives are to identify potential conditions where thermal comfort may not be ensured. The naturally available driving forces of wind and buoyancy are investigated separately or in combination. The wind alone case is not specifically investigated because the stack effect in tall 
buildings is a natural phenomenon and cannot be avoided. Although cooling by wind alone condition is often taken to be a design core (e.g. Japan) with very large openings when temperature differences $(\Delta T)$ are small, it is the vertical segment height that matters. Additionally, the wind alone case is not applicable for cases with significant stack height difference in the air flow network module of ESP-r because the buoyancy force caused by $\Delta T$ and stack effect cannot be ignored. Exclusion is the isolated case (where the ventilation of each floor is independent of the others) with small $\Delta T$ as well as limited stack effect due to constrain in the opening height difference between the air inlet and outlet.

Furthermore, the cooling mechanism for comfort being explored in this particular study, for a hot and humid climate, includes the direct cooling of indoor space (sensible cooling) and the physiological cooling of the human body (personal cooling). The sensible cooling is evaluated by the heat being removed with the ventilation air; while the direct physiological cooling effect can be achieved with the introduction of air at a relatively high speed $(1 \sim 2 \mathrm{~m} / \mathrm{s})$ even in high levels of humidity and indoor air temperature. The higher air speed increases the rate of sweat evaporation from the skin and minimizes occupant discomfort when their skin perspires. In another word, air movement not only increases the evaporative rate at the skin surface (in higher temperatures), it also determines the convective heat and mass exchange of the human body with the surrounding air, which affects thermal comfort.

As for the night-time ventilation, it is a strategy used to cool down the building structure (with high thermal mass and exposed structure) from lower external air temperatures. This strategy employs the building's thermal mass as an intermediate storage medium, allowing the structure to absorb the heat built up during the day and to flush it away during the night. Whilst night ventilation is not the typical solution for cooling in hot and humid climates, it still may have 
advantage for the purge and decrease of indoor pollutants. For the typical office buildings in Taiwan, the occupants work in the fully sealed environment from 8:00 am to 6:00 pm or more with the mechanical cooling systems being operated for full occupied period. Previous studies (Rajapaksha and Hyde, 2012) have identified the advantages of night purge and pre-cooling from the aspect of energy-saving operation of HVAC systems for tall office buildings in particular. The temperature fluctuation of typical weeks in summer, winter, and mid-season of Taiwan is plotted as Figure 1-2. The graph below suggests that the average temperature difference between day and night varies from 2 to 7 degrees depends on seasons, where the night-time cooling may not be significant especially for the summer with averaged high external temperature.

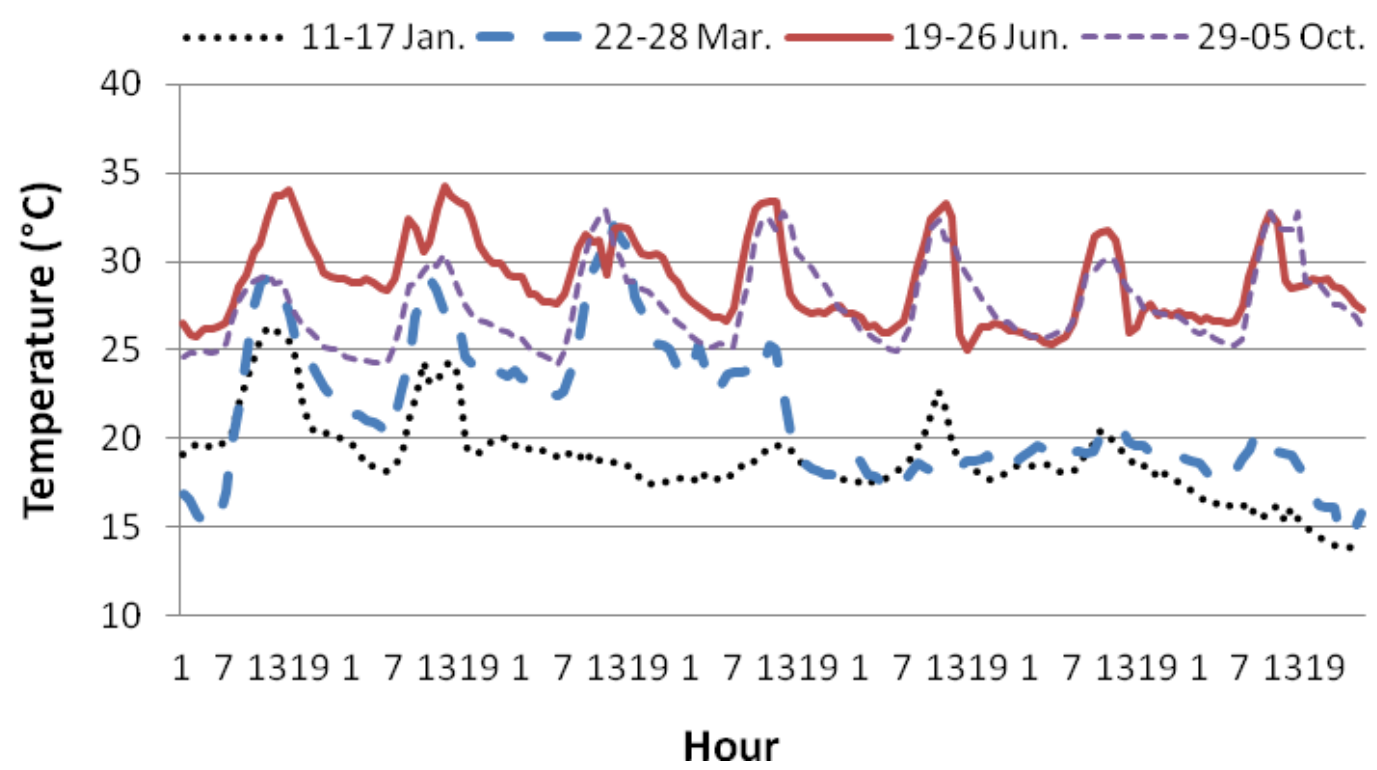

Figure 1-2: The temperature fluctuation of typical weeks in Taipei 


\subsection{Research issues and objectives of this study}

A design procedure to evaluate the climate suitability for natural ventilation in tall office buildings is desirable. The inherent cooling effects due to the ventilation air flow with reference to sensible as well as personal cooling are of interest in this study. One of the aims is to examine the minimum required fresh air flow rates for ventilated cooling in terms of indoor thermal comfort. The desired flow pattern for ensuring the fresh and cooler air to be driven into the occupied space is investigated as well. The statistical distribution of the volume flow rates needed to offset the given internal heat gains to achieve thermal comfort during overheated periods is elucidated. The general objectives and expected outcome for this research are presented as table 1-1. The eleven objectives provide a general approach to design a natural ventilation system in tall office buildings of a hot and humid climate. These objectives can be catalogued into four distinct design phases, which are conceptual design (issues 1, 2 and 3), design development (issues 4, 5 and 6), performance evaluation (issues 7 and 8) and design optimization (issues 9, 10 and 11) respectively.

Firstly, this study will start with the conceptual design phase. The main concerns for this stage include the building configuration, ventilation strategies and conceptual airflow pattern. Secondly, the tool for design development phase of this study is the theoretical envelope flow model. The initial sizing of openings is investigated in this design phase. The main issue for this phase is that the designed airflow rate should be determined for different ventilation purposes. The off-design condition under various boundary conditions is evaluated accordingly.

Thirdly, the detailed performance evaluation will be carried out by a dynamic thermal simulation program with air flow network (AFN), ESP-r, which is expected to provide overall evaluation of ventilation performance on an hourly basis. The effect of segmentation on the resultant flow rates of different building 
configurations can then be compared. Simulation results will then be interpreted using the building bioclimatic charts for revealing the level of thermally comfortable conditions in tall buildings. Further CFD technique is needed in terms of the optimum plan depth for indoor air quality issue and local discomfort. The overall the aim is to check to what extend that CFD approach can help with the proposed design procedure of naturally ventilated tall office buildings aside from all other models mentioned in the previous sections.

Finally, the discussion is directed to design optimization with regard to natural ventilation performance. A parametric study is conducted for identifying the sensitivity of calculations to boundary conditions. The inter-model comparison is carried out in terms of building segmentation. A generic design for naturally ventilated tall office buildings is proposed with reference to plan arrangement and sectional treatment. Evaluation of the internal environment for occupants of the proposed building configuration is addressed by the use of building bioclimatic charts. It is important to identify whether or not the natural ventilation system can provide an acceptable environment for the occupants during the majority of the time. The expected outcomes and contributions of this study are summarized as follows:

\section{(1) Determining the ventilation requirements}

In the context of naturally ventilated tall buildings, the preliminary design lies in sizing and locating the main components: the lightwell(s); the stacks; and the air inlets and outlets to and from space. The ventilation purposes should be identified and the design conditions to be used in sizing the ventilation openings are determined accordingly. The design criteria at this stage are to maintain thermal comfort during warm and still-air summer conditions which invariably dictate the maximum free area of opening required. Similar approach was adopted by Lomas (2007) for the design of an advanced naturally ventilated building form.

\section{(2) Developing boundary conditions}


The primary boundary conditions for the natural ventilation assessment include the weather data and internal heat gains. To assess the inherent potential for natural ventilation in a hot and humid climate, the statistical analysis of the hourly basis weather data is required. The viable period of time for the ambient weather condition to achieve ventilated cooling can then be identified. The assumptions on internal heat gains and operation schedule for a typical office building of a hot and humid climate are needed for the preliminary evaluation as required in the chosen modelling tools.

\section{(3) Conceptual air flow pattern design}

The desired air flow pattern is defined to encourage fresher and cooler air into the occupied spaces. The air flow network for natural ventilation is developed for the proposed building configuration in the conceptual design stage.

\section{(4) Development of ventilation openings}

The locations of ventilation openings are defined along with desired airflow paths during the design development phase. The arrangement of the opening height is of interest.

\section{(5) Initial Sizing of ventilation openings}

The zero wind speed condition can be the worst scenario for natural ventilation. For the initial cases investigated in this research, the effect of wind is therefore ignored. Further simulations on wind and buoyancy combined ventilation are taken for examining the influence of wind effect. The explicit method of the envelope flow model (CIBSE AM10, 2005) is adopted for sizing the openings under different ventilation conditions.

\section{(6)Off-design condition}

The implicit method of the envelope flow model (CIBSE AM10, 2005) is used to calculate ventilation performance under off-design conditions. The information required for this calculation includes the values of opening height $(z)$, opening area $(A)$ and wind pressure coefficient $(C p)$ for each opening. The opening area $(A)$ is obtained from the explicit calculation in previous step. Thereafter, the wind 
velocity $(U)$ and outdoor temperature $\left(T_{E}\right)$ are changed for the boundary condition interested and the goal is to test the robustness of the design.

\section{(7) Analysis of design performance}

The flow rates and flow pattern for ventilated cooling are evaluated in the third design stage, performance evaluation. The periods of time with insufficient ventilation performance are identified. The optimum segmentation height with reference to the building configuration adopted is examined as well. In addition, non-domestic buildings tend to have a deeper plan. Spaces further away from the source of the proposed natural ventilation system may not achieve the expected cooling effects and the required air quality. That is, the optimum floor plan depth for the desired air flow distribution should be investigated by the use of CFD approach.

\section{(8) Refinement of design}

Following the initial investigation with the proposed base case building configuration, potential situations where design goals might not be met are identified. The design parameters (e.g. opening size and building configuration) are then modified for optimum design performance. Inter-model comparison by the use of dynamic thermal simulation with an air flow network is then carried out with reference to segmentations and building configurations.

\section{(9) Parametric study of optimization}

The sensitivity of calculations to boundary conditions should be identified by the use of parametric study. Parametric studies are used to demonstrate the range of influence for design factors. Considerations and measures needed to be taken are elucidated accordingly.

\section{(10) The generic design of naturally ventilated tall office buildings}

The design solutions for naturally ventilated tall office buildings with reference to building plan and sectional treatment are proposed. The building plan design is discussed in terms of floor-plate sizes and core distributions. The sectional treatment focuses on the adoption of skygarden and segmented ventilation cavity. 


\section{(11) Suggestions on satisfactory environment for occupants}

It is required to identify whether or not the natural ventilation system can provide an acceptable environment for the occupants for the majority of time. The acceptable comfort boundaries especially for a hot and humid climate are reviewed and defined for the thermal comfort assessment of this study.

Table 1-1: Research objective and expected outcomes

\begin{tabular}{|c|c|c|}
\hline $\begin{array}{l}\text { Phase of design } \\
\text { \& tools used }\end{array}$ & Objectives & Expected outcomes \\
\hline \multirow{3}{*}{$\begin{array}{l}\text { I. Conceptual } \\
\text { design (sketch } \\
\text { and notes) }\end{array}$} & $\begin{array}{l}\text { 1) Determine ventilation } \\
\text { requirements }\end{array}$ & $\begin{array}{l}\text {-- Identifying ventilation purposes. } \\
\text {-- Determining the design conditions to be } \\
\text { used in sizing the ventilation openings. }\end{array}$ \\
\hline & $\begin{array}{l}\text { 2) Develop boundary } \\
\text { conditions }\end{array}$ & $\begin{array}{l}\text {-- Reviewing the potential driving forces in } \\
\text { terms of weather data. } \\
\text {-- Defining requirements on internal heat } \\
\text { gains and operation schedule for a typical } \\
\text { office building of a hot and humid climate. }\end{array}$ \\
\hline & $\begin{array}{l}\text { 3) Conceptual airflow } \\
\text { pattern design }\end{array}$ & $\begin{array}{l}\text {-- Developing the desired flow pattern with } \\
\text { reference to the proposed building } \\
\text { configuration. }\end{array}$ \\
\hline \multirow{3}{*}{ 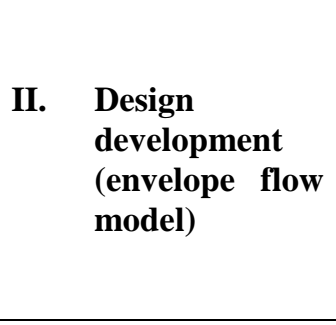 } & $\begin{array}{l}\text { 4) Development of } \\
\text { ventilation openings }\end{array}$ & $\begin{array}{l}\text {-- Determining the locations of ventilation } \\
\text { openings required in the planned airflow } \\
\text { paths. }\end{array}$ \\
\hline & $\begin{array}{l}\text { 5) Sizing initial } \\
\text { ventilation openings }\end{array}$ & $\begin{array}{l}\text {-- The explicit method of the envelope flow } \\
\text { model for sizing the openings is adopted. }\end{array}$ \\
\hline & 6) Off-design condition & $\begin{array}{l}\text {-- The implicit method of the envelope flow } \\
\text { model for investigating the preliminary off- } \\
\text { design condition }\end{array}$ \\
\hline \multirow{2}{*}{$\begin{array}{l}\text { Performance } \\
\text { evaluation } \\
\text { (ESP-r with } \\
\text { airflow } \\
\text { network } \\
\text { \&CFD) }\end{array}$} & $\begin{array}{l}\text { 7) Analysis of design } \\
\text { performance }\end{array}$ & $\begin{array}{l}\text {-- Evaluating the flow rates and flow pattern } \\
\text { for ventilated cooling. } \\
-- \text { Identifying periods of time with } \\
\text { insufficient ventilation performance. }\end{array}$ \\
\hline & 8) Refinement of design & $\begin{array}{l}- \text { Determining potential situations where } \\
\text { design goals might not be met and to modify } \\
\text { the design parameters. }\end{array}$ \\
\hline \multirow{3}{*}{$\begin{array}{ll}\text { IV. } & \text { Design } \\
& \text { optimization }\end{array}$} & $\begin{array}{l}\text { 9) Parametric study of } \\
\text { optimization }\end{array}$ & $\begin{array}{l}\text {-- Identifying sensitivity of calculations to } \\
\text { boundary conditions. } \\
-- \text { Inter-model comparison in terms of } \\
\text { building segmentation. }\end{array}$ \\
\hline & $\begin{array}{l}\text { 10) The generic design of } \\
\text { naturally ventilated } \\
\text { tall office buildings }\end{array}$ & $\begin{array}{l}- \text { The design solutions for naturally } \\
\text { ventilated tall office buildings with } \\
\text { reference to building plan and sectional } \\
\text { treatment. }\end{array}$ \\
\hline & $\begin{array}{l}\text { 11) Suggestions on } \\
\text { satisfactory } \\
\text { environment for } \\
\text { occupants }\end{array}$ & $\begin{array}{l}\text {-- Identifying whether or not the natural } \\
\text { ventilation system to provide an acceptable } \\
\text { environment for the occupants for the } \\
\text { majority of time. }\end{array}$ \\
\hline
\end{tabular}




\subsection{Thesis outline}

This thesis starts with the reviews on issues of naturally ventilated tall office buildings of a hot and humid climate in Chapter 1. The design objectives and issues to be investigated are identified accordingly. For Chapter 2, five case studies worldwide are used to demonstrate the potential gaps between theory and practical applications. The research issues for naturally ventilated tall office buildings in the climatic context of Taiwan are then discussed. The base case building configurations are defined according to literature reviews and case studies. The test models are then interpreted with reference to the generic diagram for naturally ventilated tall office buildings. The core distributions in building plan and the sectional treatments are considered. The novelty of this work lies not in the models used (which are available), but in the manner they are used (e.g. evaluation of segmented and non-segmented tall buildings). The design procedure and tools available for natural ventilation assessment for this study are described in Chapter 3.

Three modelling approaches are proposed for investigating the segmentation effects in tall office buildings. Firstly, a single-cell envelope flow model (EFM) was adopted for evaluating the off-design conditions of three types of building configuration, namely isolated, non-segmented and segmented tall buildings with no internal partitions. The steady-state bulk flows through openings were evaluated under a specified design condition. Detailed discussions are presented in Chapter 4.

In Chapter 5, further dynamic effect with multi-cell model is then examined using the dynamic thermal simulation with an air flow network (ESP-r). Segmented and non-segmented atrium buildings with ventilated double facades are adopted as the main building configurations in the second stage for coping with the potential magnitude of impinging wind at high levels. Additionally, the chosen thermal model utilised a multi-cell airflow network model because of the buildings would no longer be described by a single-cell model. 
For Chapter 6, the CFD approach is adopted to investigate to what extend that it can help with the proposed design procedure of naturally ventilated tall office buildings aside from all other models mentioned in the previous sections. The potential pros and cons of using advanced tools are clarified. The whole building simulation will be carried out for investigating the airflow distribution of selected scenario. The detailed air flow speed distribution is needed for ensuring the selection of the comfort boundary. The overall ventilation performance is then interpreted by plotting the calculated dry-bulb temperature and relative humidity values from ESP-r. The air flow speed distributions from CFD modelling are used to confirm the selection of the comfort boundary of the building bioclimatic charts. The suggestions are then directed to selection of modelling tools during different design stage and its corresponding adequacy for the research questions at hand.

The sensitivity analysis is carried out in Chapter 7 for examining the impact of input parameters on different simulation outputs. The relationship and relative importance of parameters can then be known. The optimum ventilation performance through proper selection of design variables and conditions can be achieved as well. The influence of input parameters on the resultant flow rates and flow patterns of associated spaces is of interest in this study.

It is important to understand how the overall building design affects indoor thermal comfort and, ultimately, the energy used in the operation of the building. The feasibility for naturally ventilated tall office buildings under the proposed building configuration in Taiwan is clarified. The concluding remarks in Chapter 8 are directed to the control of segmentation. The criteria include desired flow pattern and sufficient flow rates for cooling, and satisfactory comfort environment for occupants. The overall objectives are to determine whether the magnitudes of flow rates and desired flow pattern through openings can be achieved over a range of specified conditions. Potential conditions where the design goals may not be ensured are identified. Detailed research flow charts and thesis outline are illustrated as Figure 1-3. 


\section{Ch2: Case studies \&}

test models

- Case studies

-- Commerzbank, Frankfurt, Germany

-- Deutsche Post Office, Bonn, Germany

-- Liberty Tower of Meiji University

-- Menara UMNO, Penang, Malaysia

-- Torre Cube, Guadalajara, Mexico

- Test models

-- Preliminary investigations

--Main investigations

\section{Ch3: Methodology}

- Generic design procedure

- Tools for naturally ventilated tall

office buildings assessment

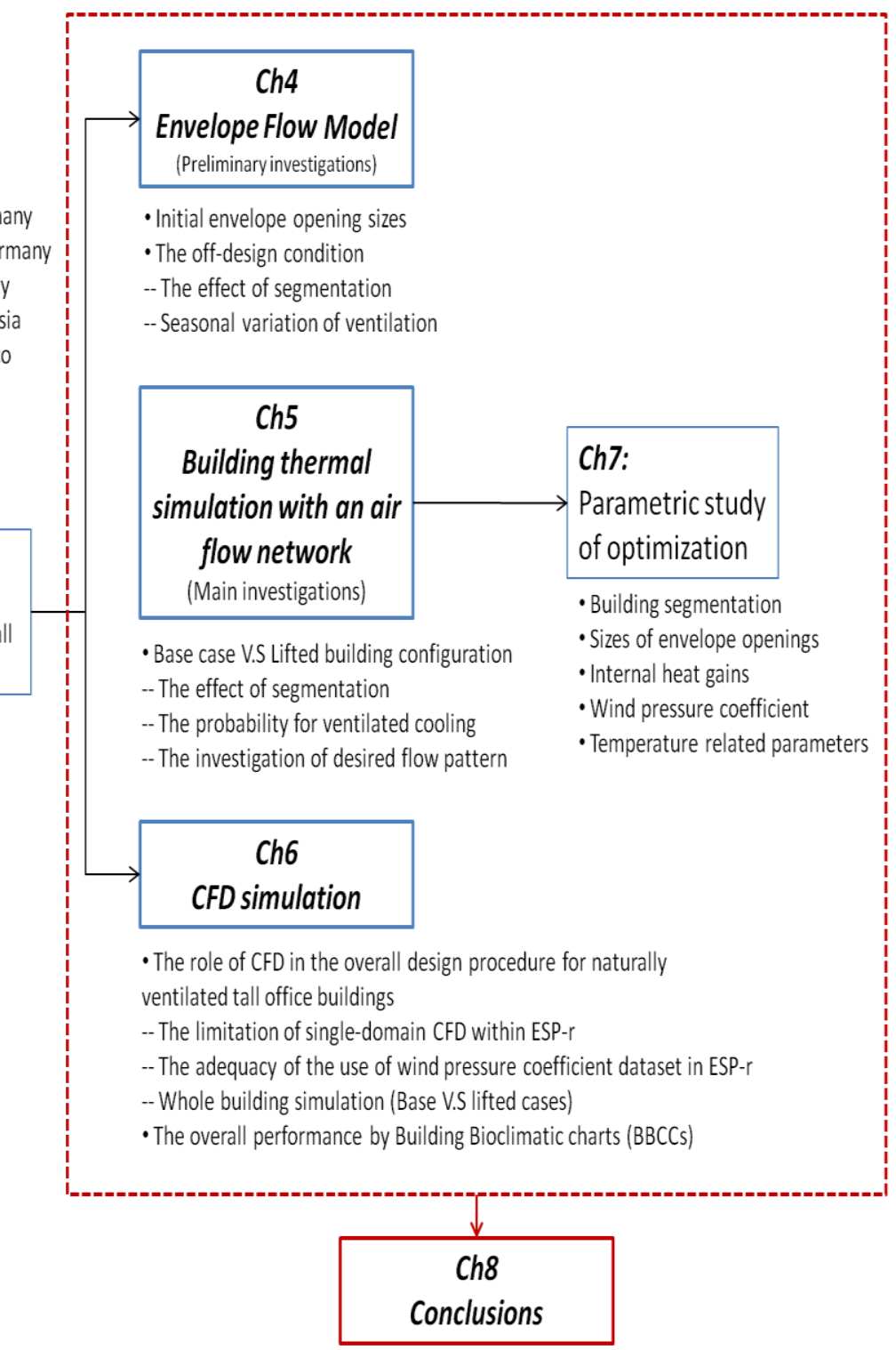

Figure 1-3: Research flow charts and thesis outline 


\section{The Naturally Ventilated Tall Office Building Design}

\subsection{Chapter overview}

Given that the HVAC systems in tall office buildings typically account for 33 percent or more (depends on climate region) of overall building energy consumption, the increased efficiency or possibly elimination of these systems could be argued to be a step forward toward sustainability of tall office buildings. The reduction of the reliance on mechanical ventilation through the introduction of natural ventilation strategies is therefore the main focus of this research. It is extremely rare for a significant tall office building to totally rely on natural ventilation due to the potential failure of the system. Therefore the precedent case studies presented here are all mixed-mode buildings, for which natural ventilation is employed for periods where the external conditions allow. The ideal scenario for this research then goes toward the tall buildings which can deliver acceptable internal thermal condition through natural ventilation alone during the viable period of time in Taiwan. The building projects presented in this chapter demonstrate the combination of strategies for natural ventilation, with mechanical ventilation systems, are a viable alternative to full air conditioning in many parts of the world.

Naturally ventilated tall buildings, though not completely unknown, are nevertheless very unusual. Lambot and Davids (1997) pointed out the reasons which included the difficulty of coping with high winds and the potential safety hazard of opening windows in high levels. Tall buildings on the traditional American model usually have deep plans, in which many of the occupants are too far from the perimeter of the building to benefit from natural light and ventilation. Permanent artificial light and air conditioning are therefore the norm. In Germany, however, planning regulations specify that all office workers should have a view out of the building, which inevitably means a shallower plan. 
Nevertheless, the risk and challenges associated with natural ventilation in tall buildings are considerably higher than those of low-rise structures. The aspects to be considered include the potential greater magnitudes of wind and buoyancy effects at higher levels. Consequently, further cares should be taken with regard to envelop and opening design for natural ventilation in tall buildings. The general objective of this chapter is to learn from the past and to propose a conceptual building configuration for naturally ventilated tall buildings in a hot and humid climate. The system effectiveness and ventilation strategies being employed in each case study are reviewed for the benefit of applying similar techniques to tall buildings in Taiwan. The natural ventilation design issues for Taiwan in particular are addressed accordingly. A generic building configuration is developed for the investigation of corresponding ventilation performance. 


\subsection{Case studies on naturally ventilated tall office buildings}

\subsubsection{Commerzbank}
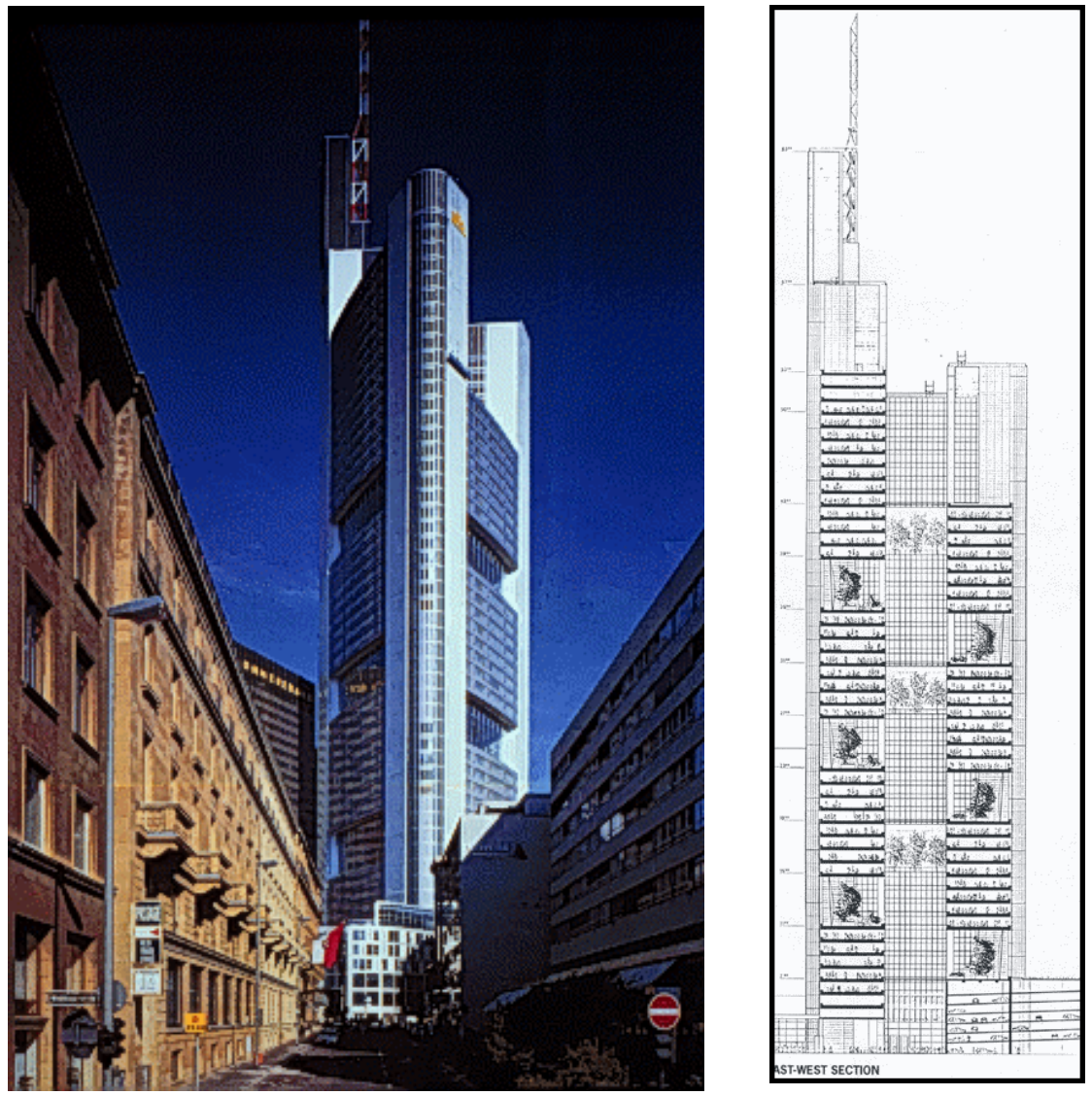

Figure 2-1: The Commerzbank Headquarter, Frankfurt, Germany. Source: Davies et al., 2002.

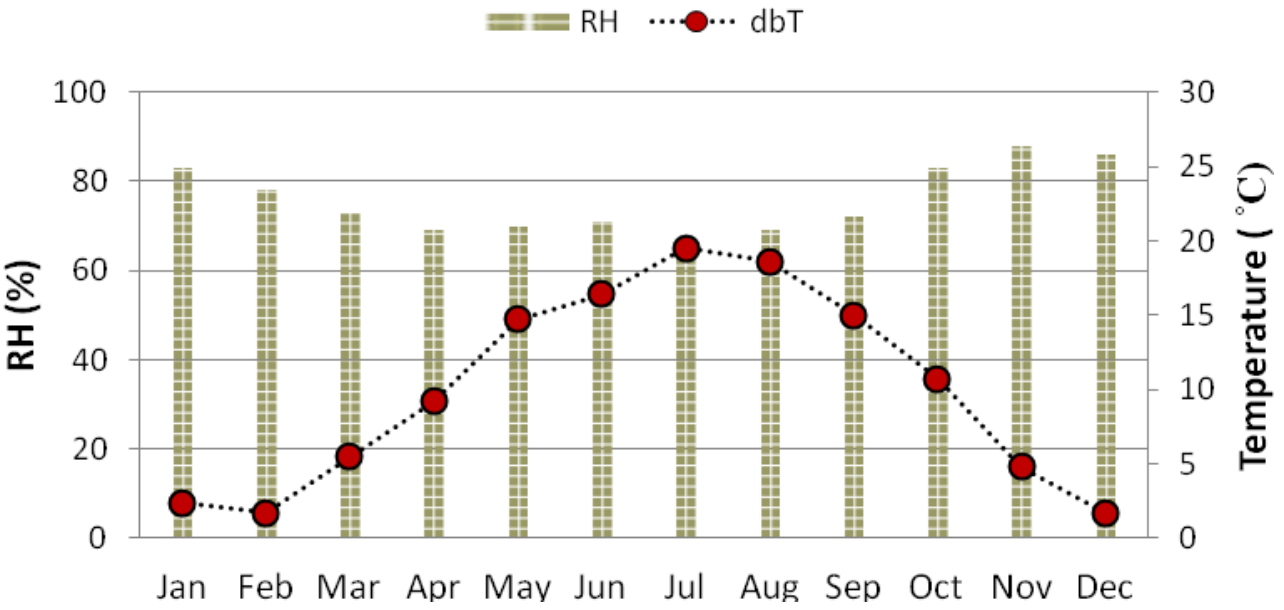

Figure 2-2: Annual temperature profile in Frankfurt, Germany 


\subsection{1-1 Overview of building design}

"The 'doughnut' plan of the Commerzbank tower (as presented in Figure 2-1), with its central atrium and four-storey-high gardens opening up views from the interior, cleverly combines the structural advantages of a deep plan with the environmental advantages of a shallow plan" (Lambot and Davids, 1997). The Commerzbank was the first skyscraper to seriously address all of the ecological and social issues that required innovative designs in building skin and ventilation systems. It opened up the possibility of using natural ventilation. The Commerzbank is located in Frankfurt, Germany where the weather pattern is presented as Figure 2-2. Frankfurt has a temperate-oceanic climate with relatively cool winters and warm summers. In general, the city of Frankfurt experiences year round mild weather. Its average annual temperature is $10.1{ }^{\circ} \mathrm{C}$, with monthly mean temperatures ranging from $1.4{ }^{\circ} \mathrm{C}$ in February to $19.3{ }^{\circ} \mathrm{C}$ in July.

Commerzbank has a rounded equilateral triangular plan with a central segmented, 200-meter-high atrium. These 12-storeys segments are a repeating module throughout the building section. Each segment contains a four-storey-high sky garden on one side of the triangle plan, with offices on the remaining two sides. This leaves a central triangular atrium in the middle that run the height of the building, only separated by steel and glass diaphragms for every twelve floors. The three corners of the triangle plan accommodate the structural elements as well as the service core (Davies et al., 2002). A single-glazed pane on the outside, a naturally ventilated cavity containing heavy-duty blinds and a double-glazed opening pane on the inside are adopted in Commerzbank's final design. It is an ordinary double-glazed opening window with an external shading device protected by a fixed glass screen. Internal offices overlooking the atrium are naturally ventilated by the fresh air that flows through the atrium. 


\section{$\underline{\text { 2.2.1-2 Natural ventilation strategies }}$}

The building was designed to utilize natural ventilation for a large proportion of the operating cycle, using mechanically assisted air conditioning only under extreme conditions. Each section of the building has to be either in natural ventilation mode or in air-conditioned mode with chilled ceilings; there can be no mixing of the two. Under certain conditions, opening the window with the ceiling chilling on could cause condensation. Consequently, the building management system (BMS) decides when to switch from one mode to the other. When the building is in natural ventilation mode, the occupants can control the temperature and ventilation of their personal space by simply opening and closing the windows. Lambot and Davids (1997) addressed an important psychological benefit of being able to control the local environment. When the occupant knows that a nearby window can be opened to fresh air, they are usually willing to tolerate slightly higher or lower temperatures than if the ventilation is outside their control. This means that the comfort boundary can be slightly extended, with a consequent saving of energy.

In order to make the air flow more manageable, the atrium is divided up into 12storey-high sections by triangular glass floors (decks). Each section includes three gardens, one on each of the three faces of the building. There is always a windward garden to admit the air and a leeward garden to exhaust it. Sometimes the air travels up the atrium, sometimes down. The atrium is therefore a quasiexternal space and the offices overlooking it can be ventilated by opening windows in the normal way. Outward-facing offices are ventilated directly from outside by means of a motorized inner window which is situated behind an outer protective pane. This creates a $200 \mathrm{~mm}$ ventilated cavity, which also contains a motorized blind. All of the offices have these motorized bottom-hinged windows which can be controlled both by the occupants and the BMS. The 14 (m) high garden façades can also be opened in good weather to ventilate the atrium space (connected to two other gardens) and indirectly provide fresh air to the offices facing the atrium (Fig. 2-3). 
The air change in the cavity increases with rising solar insolation on the façade. The sun heats the glass, the frame and the blinds, and the surrounding air is warmed by these surfaces and experiences uplift. The warmer the façade elements compared to the surrounding air, the stronger the uplift effect and the stronger the air circulation in the cavity. Consequently, more heat is extracted from the surface of the blinds and the sun shading effect of the façade improves with increasing solar insolation. It was suggested that the motorized windows would provide effective means of ventilation for nearly $60 \%$ of the total hours of usage (Lambot and Davids, 1997). In periods of bad weather, or excessive heat or cold, each 12storey village is provided with its own back-up air-handling unit to supply fresh air mechanically. A mechanical air supply and exhaust system serves the central corridor zones of each storey at all times.



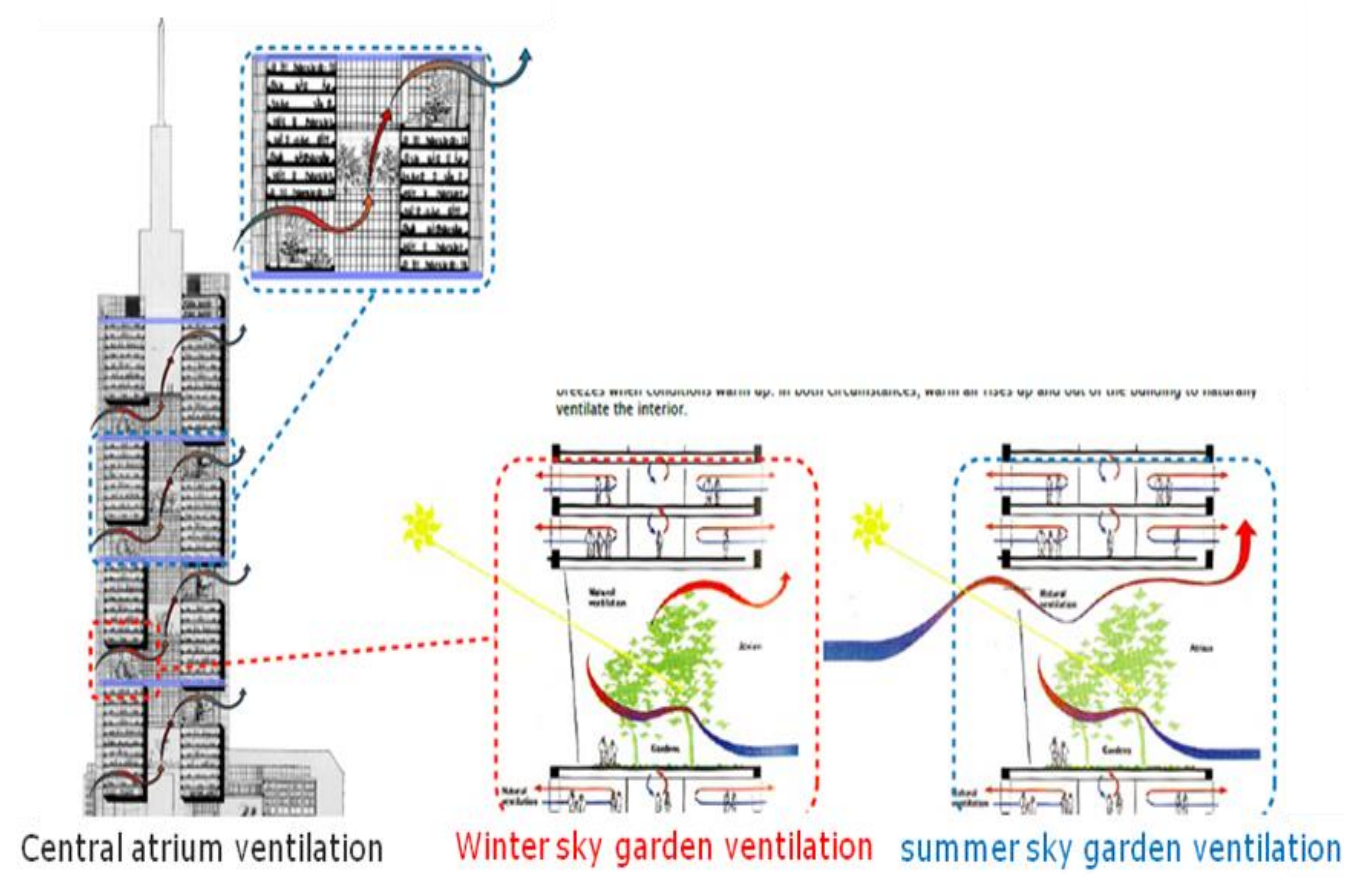

Figure 2-3: The natural ventilation mode in Commerzbank. Source: Lambot and Davids, 1997.

\subsection{1-3 The mixed-mode strategy and overall performance}

Comfort was the critical factor though it proved impossible to maintain ideal comfort conditions all year round relying on natural ventilation alone in the Commerzbank. Early in the design process of this project, therefore, it was decided that this would be a 'mixed mode' building, switching from natural ventilation to air conditioning according to the weather conditions. It was predicted that air conditioning would be required for about 160 days of the year. Computer modelling suggested that natural ventilation would be effective for up to $60 \%$ of the year. Office design temperatures were set at $20{ }^{\circ} \mathrm{C}(\max .40 \% \mathrm{RH})$ minimum in winter and $27{ }^{\circ} \mathrm{C}(\max 60 \% \mathrm{RH})$ maximum in summer. There was an installed heating load of 4.5 MW and an installed cooling load of $5 \mathrm{MW}$. It was predicted that this 'ecological skyscraper' would consume approximately 25 to 30 
\% less energy than a comparable conventional building (Lambot and Davids, 1997).

The monitoring data by Gonçalves and Bode (2010) mentioned that the satisfactory conditions of the microclimate inside the villages, namely the control of the windows of the internal facing offices, were left to the occupants rather than the BMS since 2002. The occupants were used to opening the windows for natural ventilation. Interestingly, with more control over their naturally-ventilated environment, some occupants grew more tolerant to internal summer temperatures in excess of the $26^{\circ} \mathrm{C}$ design temperature - and preferred this rather than closing the windows and switching to artificial cooling. Alternatively, the nine weather sensors that were originally located in each sky garden were replaced by a single one at the top of the building, aiming for better accuracy in recording wind data compared with the measurements taken from inside the gardens and, therefore, achieving more precision in the control of the windows on the three external faces The control of the internal environmental conditions was thus simplified as the building became increasingly "manual", resulting in higher energy savings (Gonçalves and Bode, 2010).

Since 2008, there has been an increase in the number of work stations from 2,400 to 2,820 . This increased population led to changes in the internal layout of the usable floors. The external facing offices were combined with the central corridor to create more of an open-plan layout. The entire space is now naturally ventilated using the same single-sided system through the double-skin façade, and has shown to continue to work effectively even with this increased depth. After a decade of monitoring, the building's energy consumption shows how natural ventilation in a tall office building can substantially minimize energy use and offset changes that might incur an increase in energy use such as the increase in occupancy density (Gonçalves and Bode, 2010). 


\subsection{1-4 The considerations for implementation of case study in Taiwan}

The following points should be considered if the same design approach as applied in the Commerzbank is implemented in Taiwan. First, the amount of floor areas taken for atrium and sky gardens is considerable and may not be appreciated by property companies who lack of green concern in Taiwan. The design of Commerzbank also requires a significantly larger façade area for the total floor area as compared to a typical office building, further increasing costs of building project. Second, from the technical point of view, the configuration and layout of Commerzbank does not specifically acknowledge prevailing winds or the asymmetry of the sun's path. The consideration for building orientation should be reviewed when the same building configuration is to be applied in the climatic context of Taiwan. Third, there is a further concern that sufficient flow rates may not be achieved for the inward offices when sky garden windows are closed during winter. For the case in Taiwan, where the winter is relatively mild, the investigations of the impact of window sizes in sky garden on the overall ventilation performance is desirable. With the combination of volume of the gardens and atrium, along with natural infiltration, sufficient air changes rates may be provided for adjacent office spaces for their lower fresh air requirements in winter. The optimum opening size can also eliminate the issue of cold draught during winter. 


\subsubsection{Deutsche Post office}
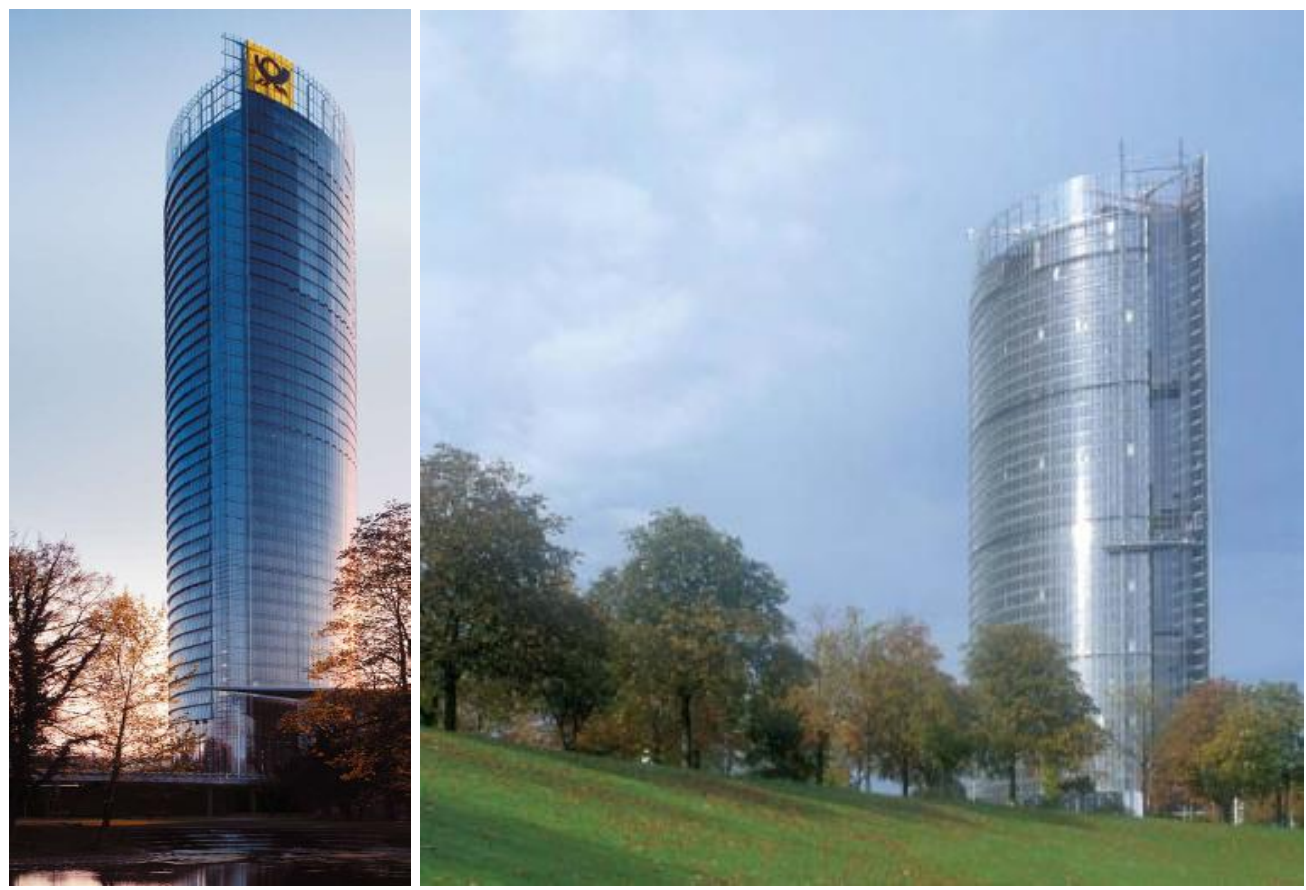

Figure 2-4: The Deutsche Post office, Bonn, Germany. Source: Brochure of Deutsche Post DHL Corporate Communications, 2009

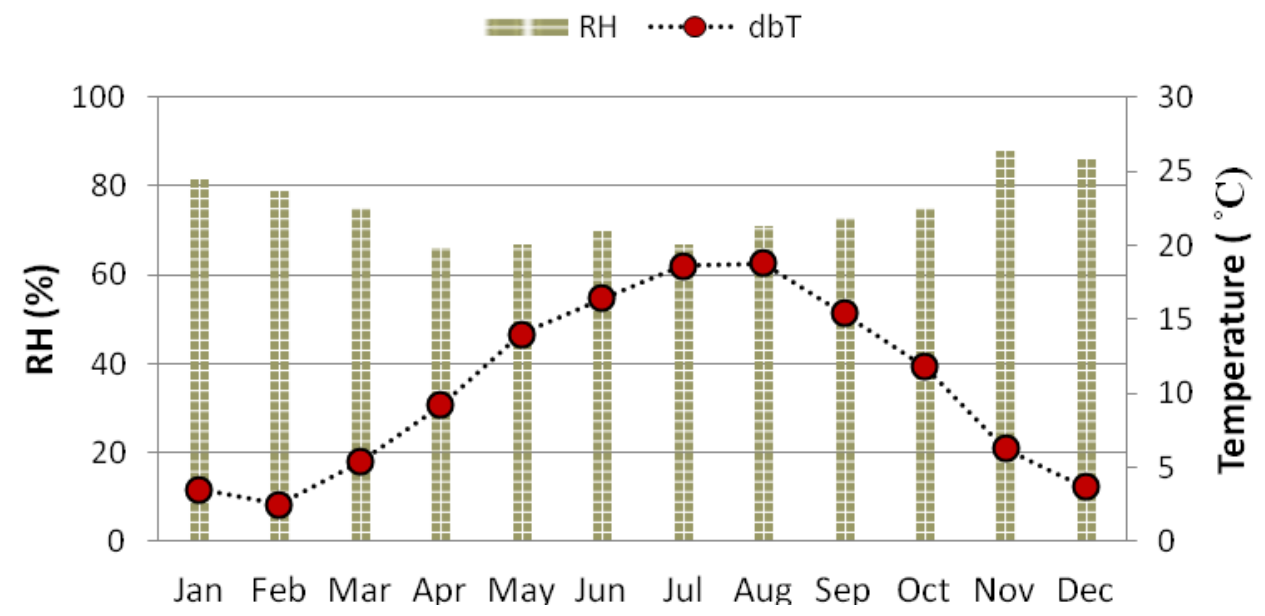

Figure 2-5: Annual temperature profile in Bonn, Germany 


\subsection{2-1 Overview of building design}

The Post Tower represents a new typology for an office tower. It is a fully glazed 41-storey office designed by Murphy / Jahn in 2003, which is located in Bonn, Germany (Fig. 2-4). Bonn experiences four fairly distinctive seasons, with January being the coldest month, when daytime temperatures average around $3{ }^{\circ} \mathrm{C}$, climbing to $10{ }^{\circ} \mathrm{C}$ by the end of March. During the winter months and coldest spells, snowy weather is light at most. Precipitation levels are surprisingly slightly higher, but by no means excessive in August. Summer temperatures regularly top $20{ }^{\circ} \mathrm{C}$, rising to more than $25{ }^{\circ} \mathrm{C}$ at times (Fig. 2-5). The prevailing winds come from the Southeast during most of the year and from the East and West from April through to July. The average annual wind speed in Bonn is $3.1(\mathrm{~m} / \mathrm{s})$.

The Deutsche Post tower consists of two offset elliptical segments. The north and south half shells are separated by $7.2(\mathrm{~m})$ wide spaces (the atrium), which are divided by glass floors into nine-story sky gardens and serve as communication floors. The service core is accommodated within the atrium as well. The façade is adaptable and switchable. It controls its environment by design and not through additional technical equipment. For each elliptical segment, it accommodates cellular offices around the building perimeter and with conference rooms towards the central atrium. The atrium itself is bridged by glazed steel bridges at each floor. The same glazed floor structure has been used in the skygardens for every nine floors (Eisele and Kloft, 2003). The outer skin has control flaps allowing natural ventilation in all seasons. The outer skin protects the inside against rain, wind and noise. The interior facades, which are facing the atrium, are equally fully glazed as well. 


\subsection{2-2 Natural ventilation strategies}

The building's twin-shell façade is made entirely out of glass. The twin-shell façade enables natural ventilation of the offices whenever the outside temperature permits, primarily in spring and fall. The outer skin of the façade protects against rain, wind and noise, while sunscreens are located in the intermediate space. In winter and summer especially, a ventilation system reinforced by a heating-andcooling component ensures comfort levels all along the interior façade. The building's ventilation strategy also relies on the stack effect. The spent air in the atrium is finally extracted out through vents located on the topmost level of every nine-storey-high sky gardens (Fig. 2-6 and Fig. 2-7).

However, the double-skin facade mechanism only comprises part of the ventilation concept. The overall ventilation strategy relies on cross-ventilation where air enters the building through the double-skin façade, flows through the offices and then into the corridors via the inward facing double-layer glass walls of the offices as shown in Figure 2-8. The corridors act as exhaust air collectors, allowing spent air to pass into the central spaces via the raised floor grilles. The ventilation grilles for air exhaustion can be seen on the inner walls of the central atrium at each slab level (Fig. 2-9 \& 2-10). For conditioning, air is taken from the controlled airspace between the shells through the windows or a special detail at the slab edge, heated or cooled by a convector in the raised floor and distributed from there along the displacement principle (Fig. 2-9). This system supports the basic heating and cooling through the integrated piping system in the coffered exposed concrete slabs (Blaser, 2004). 


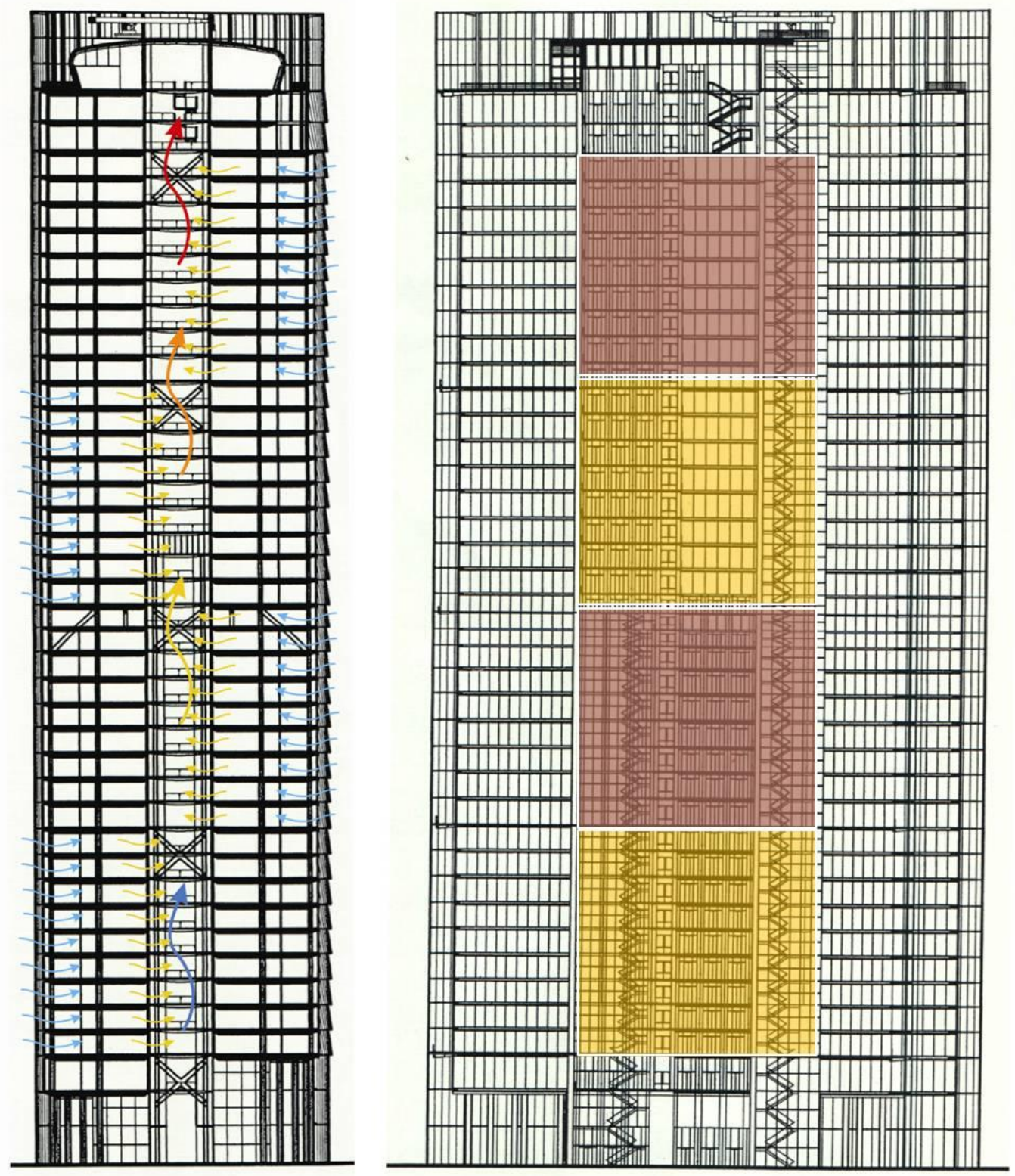

Figure 2-6: Natural ventilation strategy at the Deutsche Post Tower. Source: Ruba Salib (2008) 


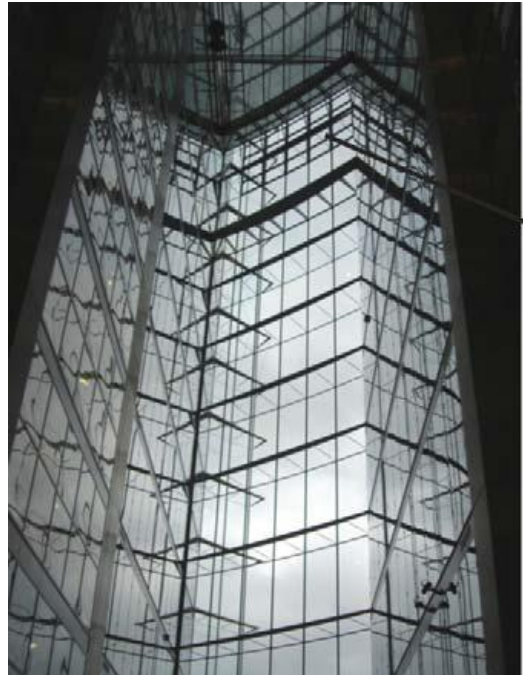

(a)

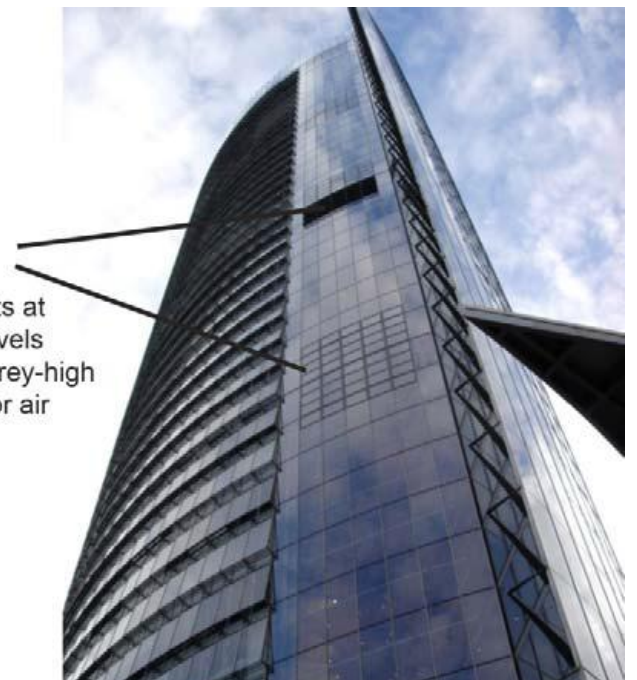

(b)

Figure 2-7: Extraction vents on the topmost levels of the nine-storey-high skygardens. a) Internal view of the skygarden vents; b) External view of the skygarden vents. Source: Ruba Salib (2008)

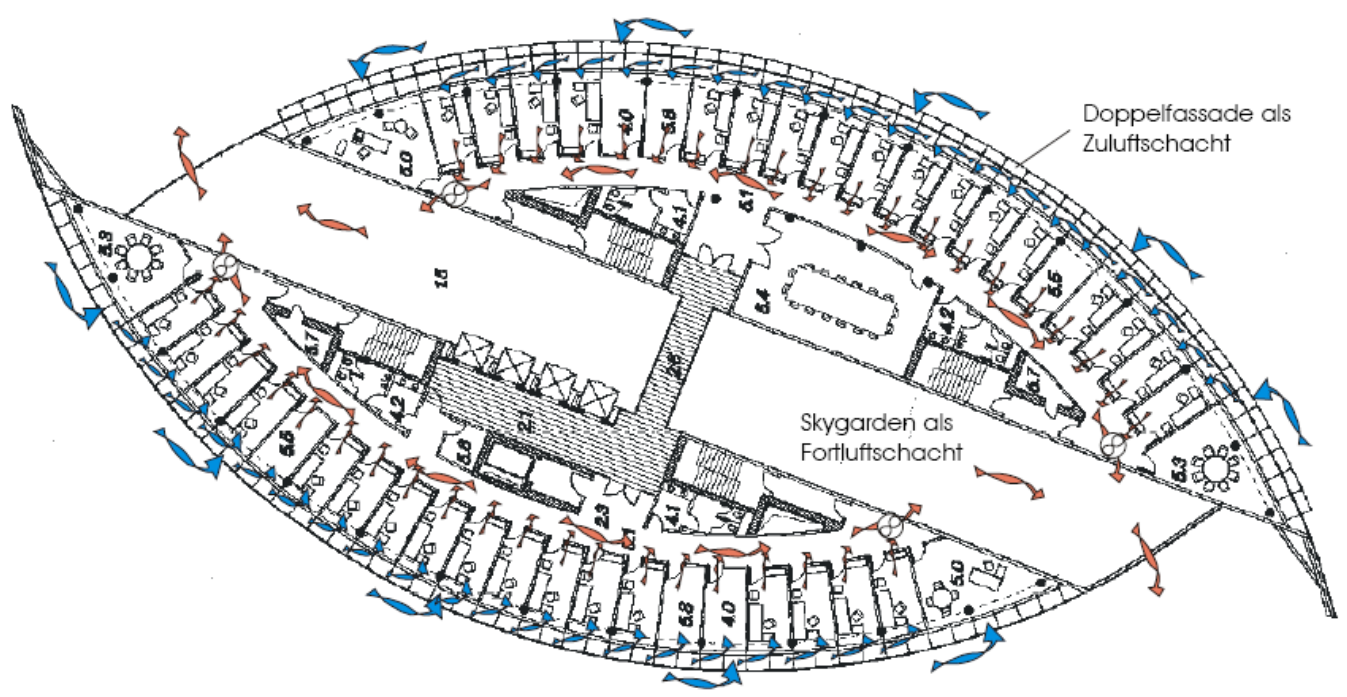

Figure 2-8: The natural ventilation strategy at the Post Tower. Source: (Murphy / Jahn, 2003) 


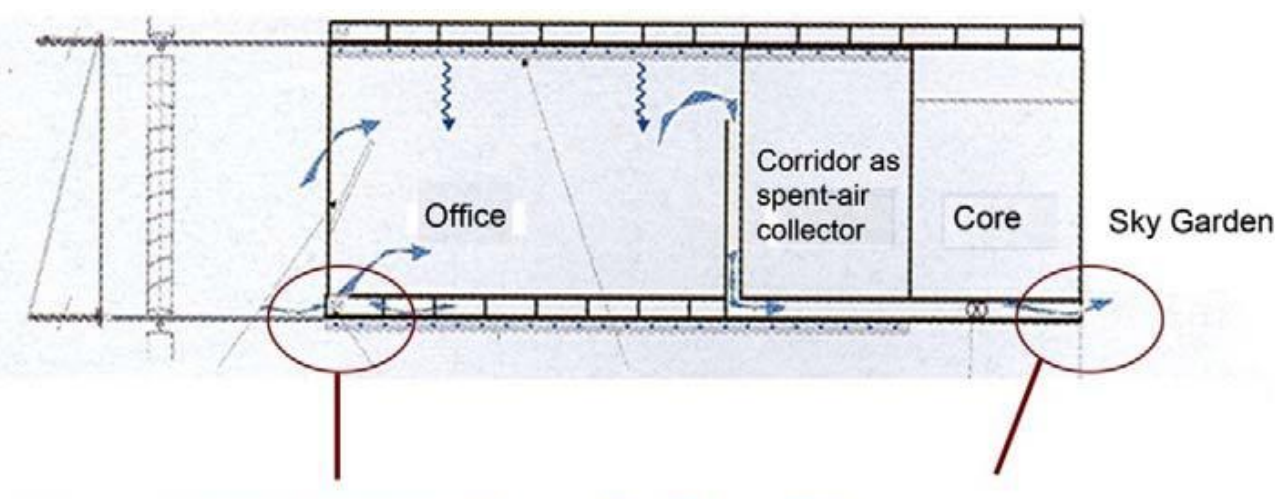

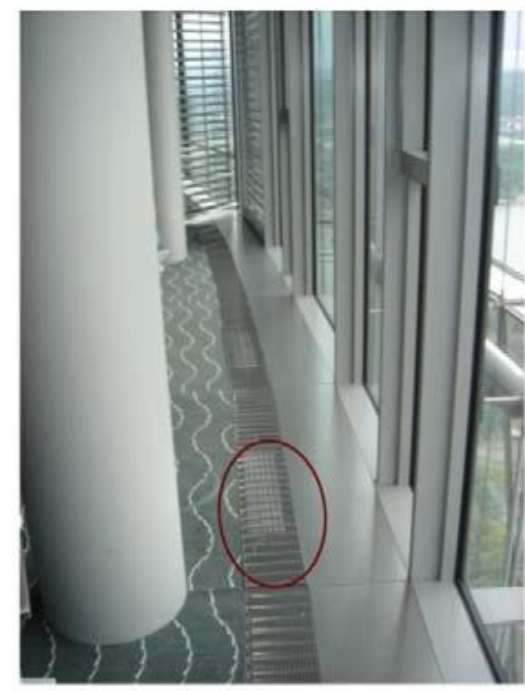

Air intake ventilation grilles

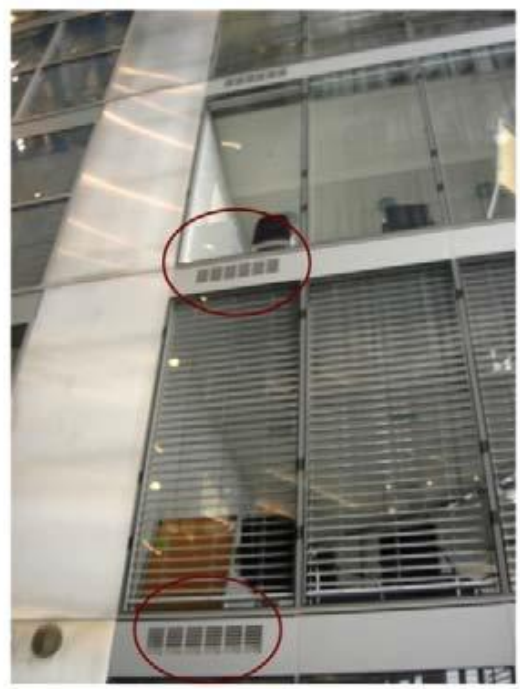

Air extract ventilation grilles (spent air extracted to skygardens via vents loacted at slab level)

Figure 2-9: Airflow across the interior spaces showing the air intake and extract ventilation grilles. Source: Top: (Jahn, 2003); Bottom: (Ruba Salib, 2008)
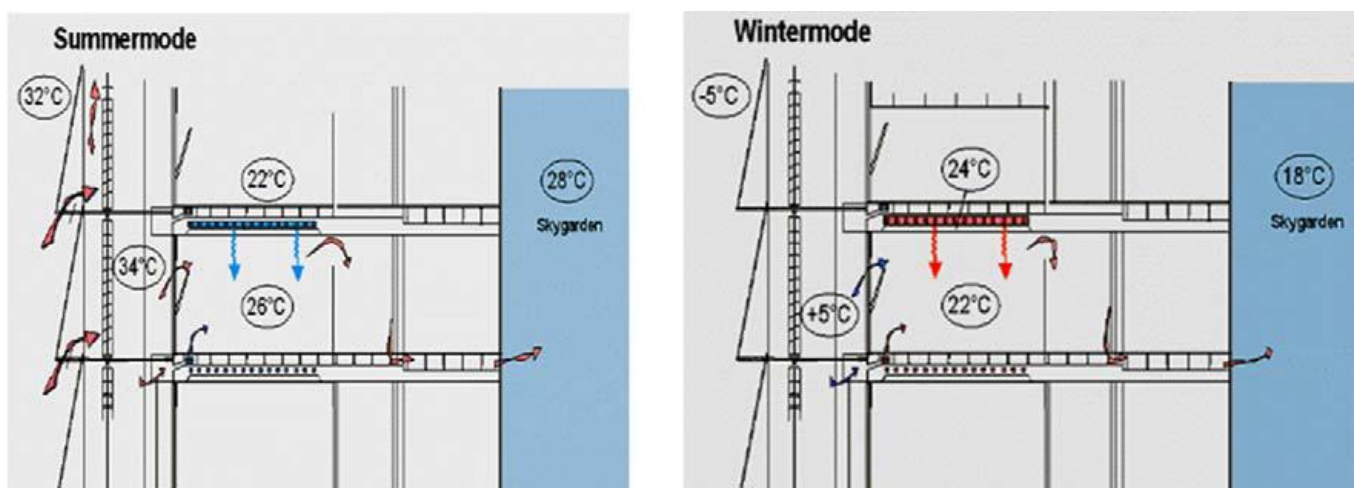

Figure 2-10: Summermode and wintermode ventilation strategy (during extreme temperatures). Source: (Welfonder, 2006) 


\subsection{2-3 The mixed-mode strategy and overall performance}

As summarized by Salib and Wood (2012), Post Tower is designed as a Zoned/ Complementary-Changeover building. The typical office floor of the Post Tower uses the twin-shell façade space as the intake air distribution and the inner skygardens as exhaust collection. A mechanical floor is eliminated through this ventilation concept, using decentralized air intake units in the standard underfloor convectors. During the extremes of summer or winter, thermal conditioning of the offices is augmented by both perimeter fan coil units and radiant ceilings. Perimeter fan coil units are located below the floor, adjacent to every other façade module and can be individually controlled in each office. The fan coils draw in outside air from the double-skin façade and then heat or cool the air according to the demand. All these savings are transferred for covering the additional costs for the more complex facades. The use of building envelope for the air distribution allows the reduction of the technical building equipment for the space conditioning. The integrated comfort concept allows an individual temperature and airflow control per room even in summer, which is not usual in a typical office environment.

A computerized BMS controls the operation of the outer façade flaps with reference to external temperature, rain, noise, and wind speed. The control of vents on the outer façade maintains a low pressure difference to ensure proper ventilation rates. The whole building is operating under the designed temperatures range of $22{ }^{\circ} \mathrm{C}$ and $26{ }^{\circ} \mathrm{C}$ in the offices spaces and $18{ }^{\circ} \mathrm{C}$ and $28{ }^{\circ} \mathrm{C}$ in the sky gardens under the monitoring of BMS. The radiant concrete slabs, the sunshades located in the double-skin cavity, the dimming of the artificial lighting, and the vents located in the exterior façade of the sky garden are controlled as well. While the building has a high level of centralized control, office occupants can override the BMS to ensure their individual comfort through a control panel located next to every door. This allows users to operate the blinds, control lighting levels, operate windows, and regulate internal temperatures. Through the controlled external skin, 
the users up to the 40th floor can decide when they want to open the window, and the function of the shading is ensured. If the occupants decide to open the inner façade windows, the BMS will automatically switch off the perimeter fan coil units. As a result of the collaboration of building envelope, building structure and building environmental system, the energy demand of this building is predicted to be less than $100 \mathrm{kWh} / \mathrm{m}^{2}$ for heating, ventilation, cooling and artificial lighting.

A study was conducted by Dassler in 2003, which evaluated the efficacy of this design. The survey suggested that though the energy levels did not achieve the aggressive benchmarks, they remained very impressive. The building was designed to utilize $65 \mathrm{kWh} / \mathrm{m}^{2}$ for ventilation, heating, and lighting. The benchmark is an 83 percent reduction in energy consumption compared to a typical air-conditioned building and a 63 percent reduction compared to a "Good Practice Office Building." The highly efficient radiant slabs, the exterior sunshades, and the use of natural ventilation and decentralized mechanical conditioning actually consumed $75 \mathrm{kWh} / \mathrm{m}^{2}$ during the year 2003. This is a 79 percent reduction compared to a typical air-conditioned office building.

\subsection{2-4 The considerations for implementation of case study in Taiwan}

The following issues should be considered if the same design approach is applied in Taiwan. First, air temperatures in the façade cavity might be higher than external temperatures during the summer of Taiwan, and this presents a disadvantage, possibly causing spaces to overheat. This is likely to occur if the façade cavity is not ventilated sufficiently, the blinds are not being used, or relatively hotter air between the blinds and outer skin is allowed to penetrate the office interiors. 
Second, the upper part of the nine-story-high façade section may experience an over-pressure that drives air out of the openings because of the stack effect in the intermediate space of the double-skin façade; while the under-pressured zone at the bottom of the façade cavity may pull relatively colder air inwards. Consequently, the lower levels of the nine-story-high sections may receive more fresh air than the top levels, and the air in the top part of the façade cavity may be warmer than in the bottom, and may sometimes cause the overheat problem of top floors in summer in particular. Some measure has been taken for this issue in Post Tower by pre-cooling fresh air using the fan coil units.

Third, the significant depth of the double-skin façade (1.2-1.7 meters) of this case could make the solution commercially unviable in other buildings, especially for those with restricted floor plates on constrained sites. In addition, the loss of usable floor space through the sky gardens could be deemed financially restricting by some developers. As concluded by Salib and Wood (2012), the design of a double-skin façade requires the commitment of a dedicated, long-term owner committed to the higher initial costs. In the case of Post Tower, the client realized the value of an investment in a headquarters that would minimize long-term energy consumption, while providing high quality office space with a high level of individual control. Finally, relative humidity should be carefully considered when using radiant surface cooling such as activated structural slabs in combination with natural ventilation. If outside air with a high relative humidity, such as Taiwan, is introduced to an interior space with chilled radiant slabs, there is a possibility for condensation to form on the radiant surface. 


\subsubsection{Liberty Tower of Meiji University}

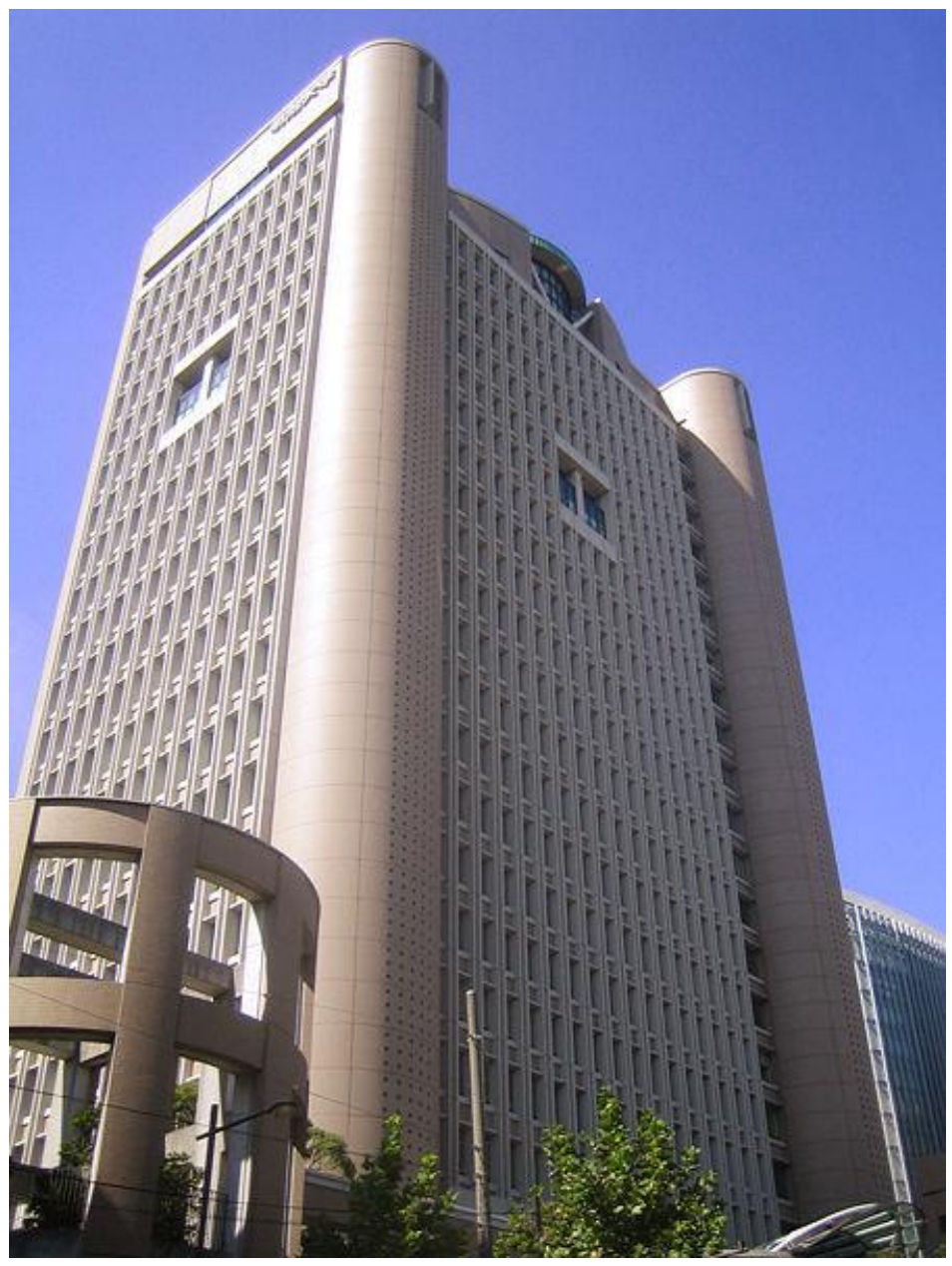

Figure 2-11: Liberty Tower of Meiji University, Tokyo, Japan. Source: Chikamoto \& Kato, 2002

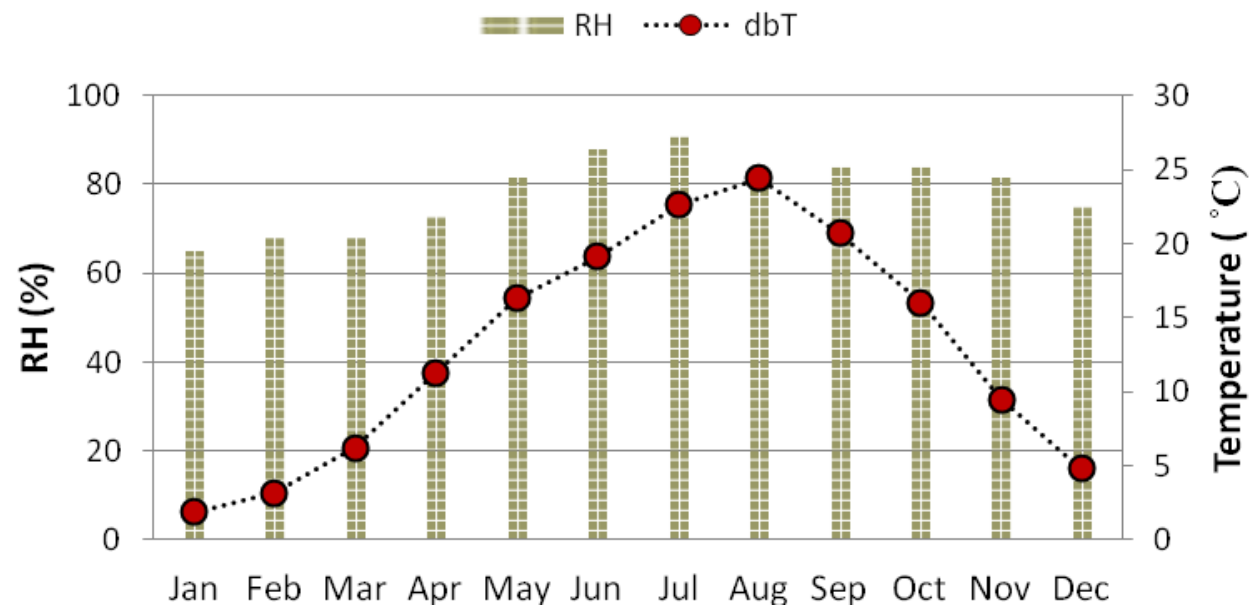

Figure 2-12: Annual temperature profile in Tokyo, Japan 


\subsection{3-1 Overview of building design}

The Liberty Tower of Meiji University is a high-rise building located at the centre of Tokyo Metropolitan area (Fig. 2-11). The centre Tokyo lies in the humid subtropical climate zone with hot humid summers and generally mild winters with cool spells. The region experiences a one-month seasonal lag, with the warmest month being August, which averages $27.5{ }^{\circ} \mathrm{C}$, and the coolest month being January, averaging $6.0{ }^{\circ} \mathrm{C}$. There's about $20{ }^{\circ} \mathrm{C}$ difference between summer and winter. The annual temperature profile is shown as Figure 2-12. Tokyo has four distinct seasons, mild spring and fall, hot summer, and winter with a few snowfalls. Relative humidity is around $70 \% \mathrm{RH}$ in summer and around $50 \% \mathrm{RH}$ in winter. The on-site measurement for wind speed and direction was taken and mean wind speed on the site was $1.9(\mathrm{~m} / \mathrm{s})$.

The Liberty Tower has a rectangular plan with its longitudinal-axis oriented along the northeast-southwest direction, and its main façade faces the southeast. The four semi-cylindrical structure located at each corner of the building accommodate staircase shafts and other circulation elements. Elevators and other service areas are placed along the north-western facade of the building. The plan features a central escalator shaft between $1^{\text {st }}$ and $17^{\text {th }}$ floors, known as 'Wind Core', which serves as major means of transit for students. The $18^{\text {th }}$ floor of the tower is referred to as the 'Wind Floor', which accommodate the mechanical facilities and serves as key element for natural ventilation of the building.

\subsection{3-2 Natural ventilation strategies}

The overall ventilation strategies rely on both wind and stack effect to drive air in and out of the building. The central core is beneficial for stack effect and the wind floor is designed to enhance driving forces from the wind. As air enters the building and flows across the occupied space, it is then led to the 'Wind Core' or escalator voids which utilize the stack effect to exhaust out of the building on the $18^{\text {th }}$ floor, namely the 'Wind Floor' (Fig. 2-13). The occupied rooms along the 
perimeter of the building feature single-glazed fixed windows with automaticallycontrolled opening at the bottom part for air entry (Fig. 2-14 and 2-15a). The intake air through the envelope openings is then led to the wind core. On the 18th floor, there are openings to exhaust the air, which passes through 4 wind paths designed toward 4 different directions, and are finally led to outside of the building (Fig. 2-15b). As the wind floor open to 4 directions, the driving force is expected to be stable through the year regardless of wind direction. A wind fence (Fig. 2-16) is placed near the exhaust openings to prevent outdoor air passing through the 'Wind Floor' from distributing the smooth flow of exhaust air through the top of the wind core.

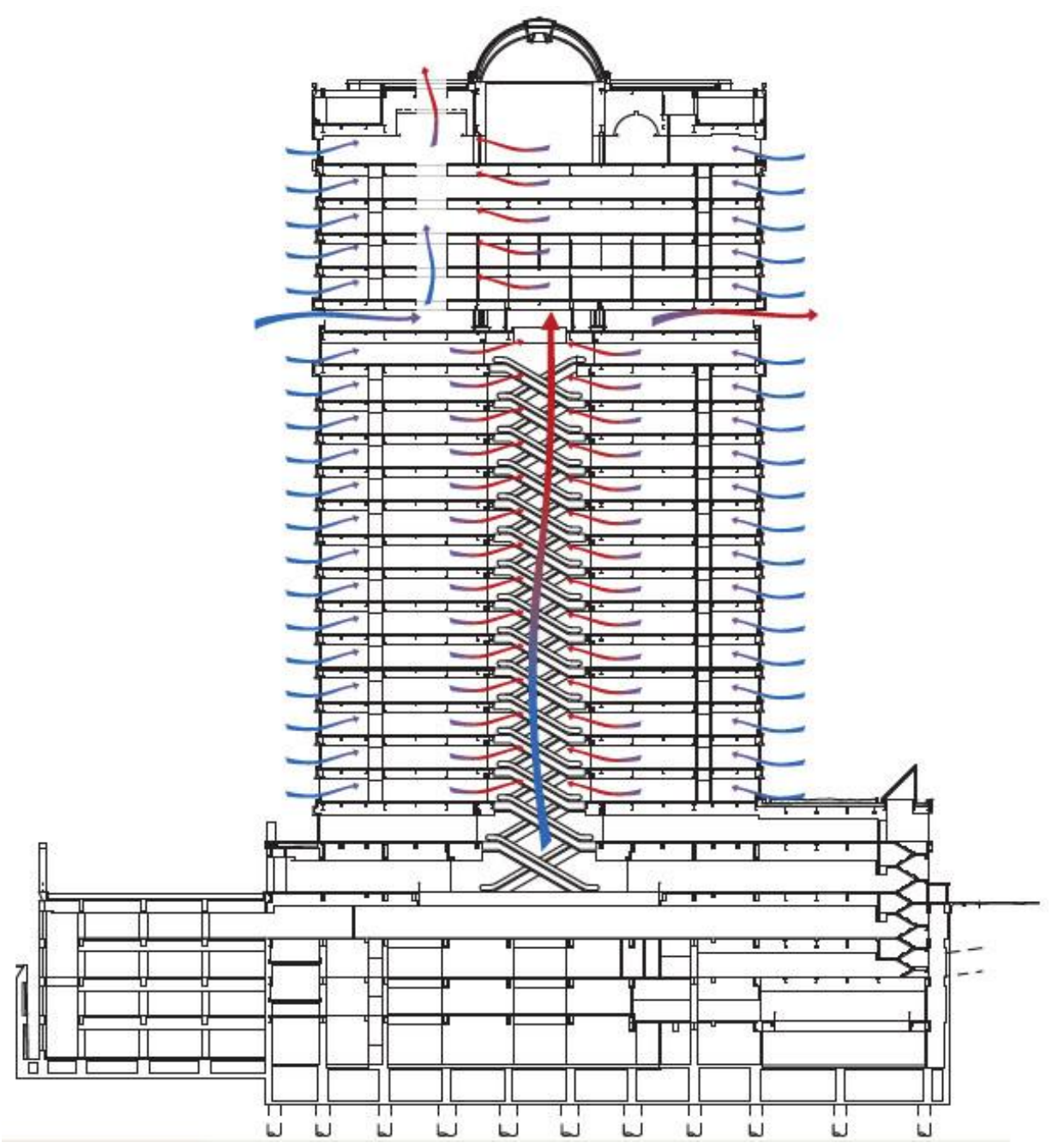

Figure 2-13: The natural ventilation system. Source: CTBUH (2012) 


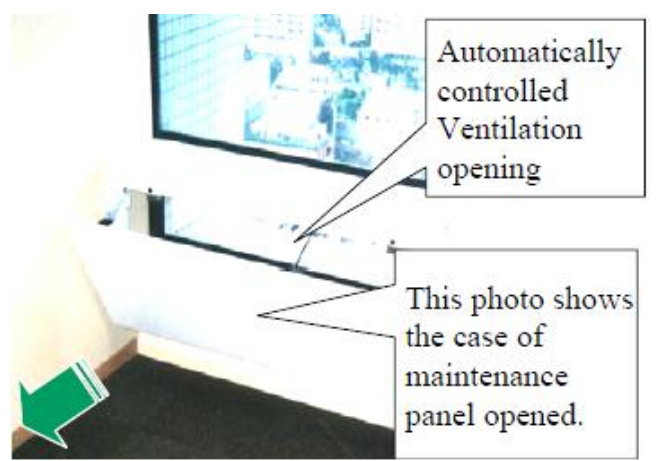

Figure 2-14: Automatically controlled ventilation window. Source: Chikamoto and Kato (2002)
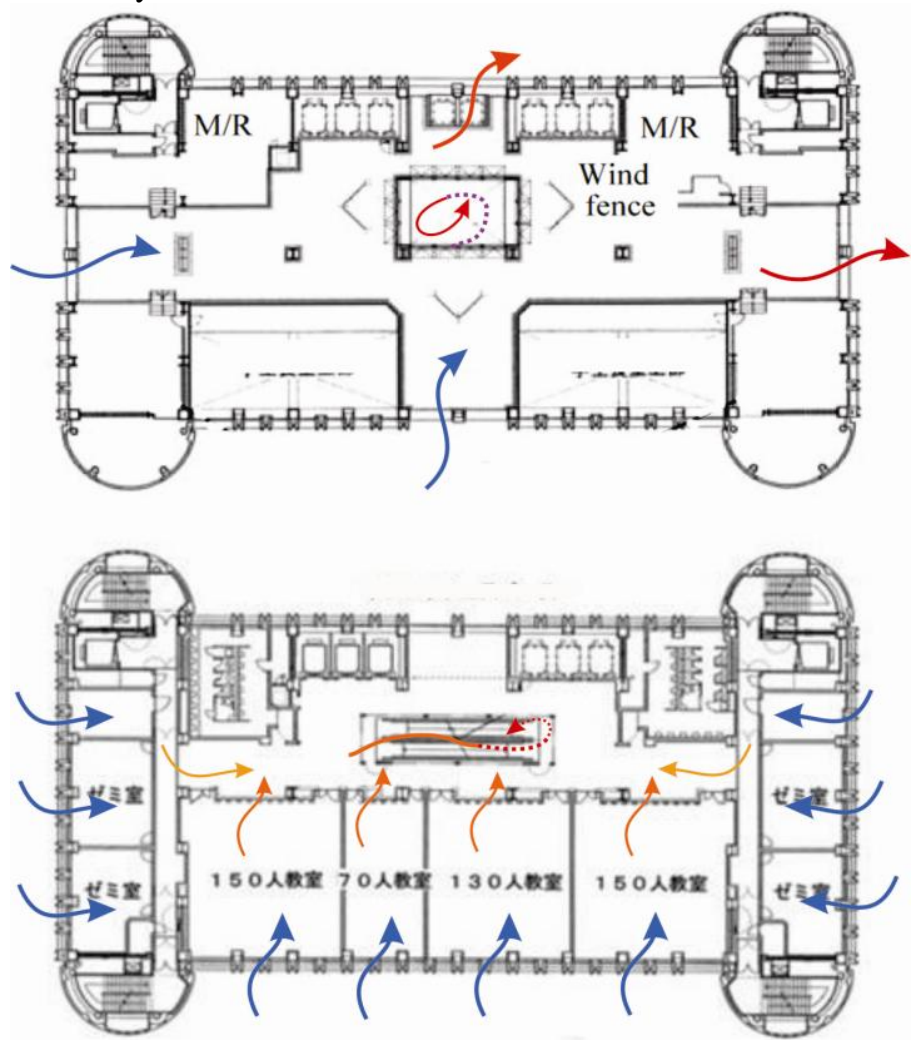

Figure 2-15: Floor plans: Typical floor plan (Top), Wind floor on the 18th level (Bottom).

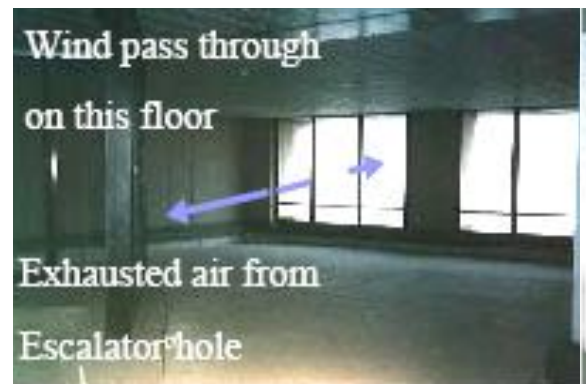

(a)

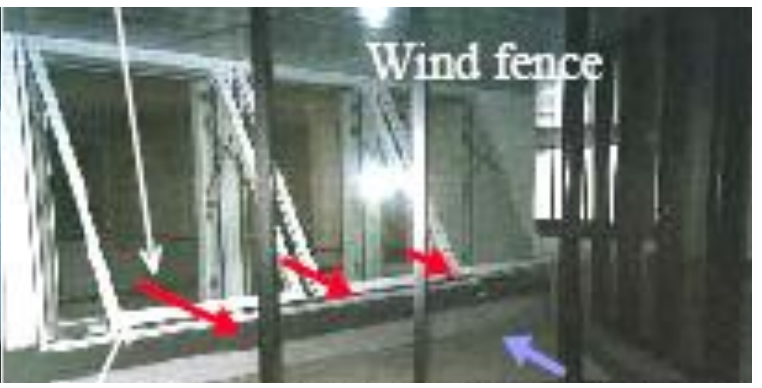

(b)

Figure 2-16: The wind fence on 18th floor. a) Wind pass through this floor; b) Exhaust opening on the top of escalator void. Source: Chikamoto T. \& Kato, S. (2002) 


\subsection{3-3 The mixed-mode strategy and overall performance}

The Liberty Tower has a changeover mixed-mode system which switches between natural and mechanical ventilation on a seasonal or daily basis. The natural ventilation mode is inactive during the heating season. The building is naturally ventilated during the cooling season between 8 am and $10 \mathrm{pm}$ when outside weather conditions allow. The building has a central BMS which automatically controls the operations of perimeter ventilation openings and exhaust openings of the $18^{\text {th }}$ floor. The operations of these openings depend on the dry-bulb temperature, relative humidity, wind speed and precipitation values measured by the use of sensors and meters places on roof of the tower. Night ventilation is activated when external temperature falls between $10{ }^{\circ} \mathrm{C}$ and $28{ }^{\circ} \mathrm{C}$ during the non-occupied hours of the cooling season. The building also features manually operated inlets which can be controlled by the occupants during the overtime period, on holidays and in case of emergency. The façade of the tower features recessed glass panel and sun-shading devices integrated within the window casement. Solar control is also achieved by internal blinds which limit the intensity of direct solar radiation. The energy saving monitored during April and November of 1999 is presented as Figure 2-17. Total annual cooling load was $415 \mathrm{MJ} / \mathrm{m}^{2}$, for which $17 \%$ was reduced by the use of hybrid ventilation system.

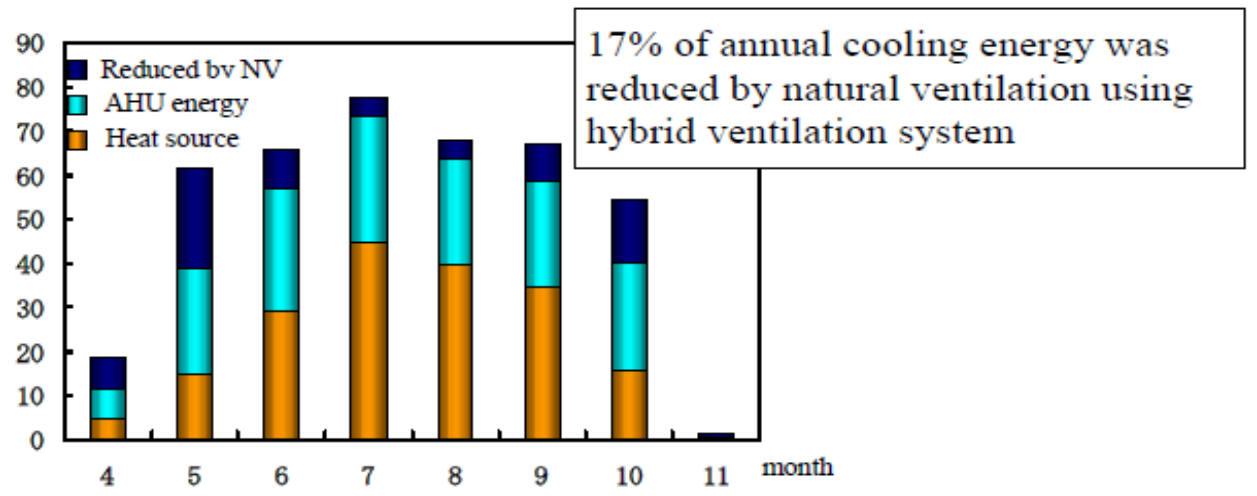

Figure 2-17: The monthly energy consumption for removing cooling load $(\mathrm{MJ} / \mathrm{m} 2)$. Source: Chikamoto and Kato (2002) 


\subsection{3-4 The considerations for implementation of case study in Taiwan}

The following points should be taken into consideration if the design approach of the Liberty Tower is implemented in Taiwan. First, the air flow rates may be in excess of those required for comfort because of the combination use of "Wind Floor" and "Wind Core" that might lead to the development of an extreme stack effect in the escalator core. Second, the motorized ventilation openings are fully controlled by the BMS in result of the inability of occupants to control their own environment. Consequently, the comfort range for occupants may be limited and result in user dissatisfaction. Third, the complete free flow of air around the building, including an 18-story void, creates significant hazards for fire and smoke control. The fire safety issues are needed to be addressed in accordance with the local regulatory level. In the case of Liberty Tower, automatic fireproof and smoke proof shutters are distributed around the 18th floor atrium openings in emergency events. Finally, from the aspect of building segmentation, the 'open wind floor' is placed in the $18^{\text {th }}$ level of the building, where only 5 floors are above the wind floor. The full benefit of the segmentation concept may be questioned. It is supposed that the concept of the 'open wind floor' may be regarded as an alternative for building segmentation. More detailed engineering analysis (i.e. the optimum segmentation height for ventilated cooling) is required to demonstrate the claimed benefits for natural ventilation with above hypothesis. 


\subsubsection{Menara UMNO Tower}
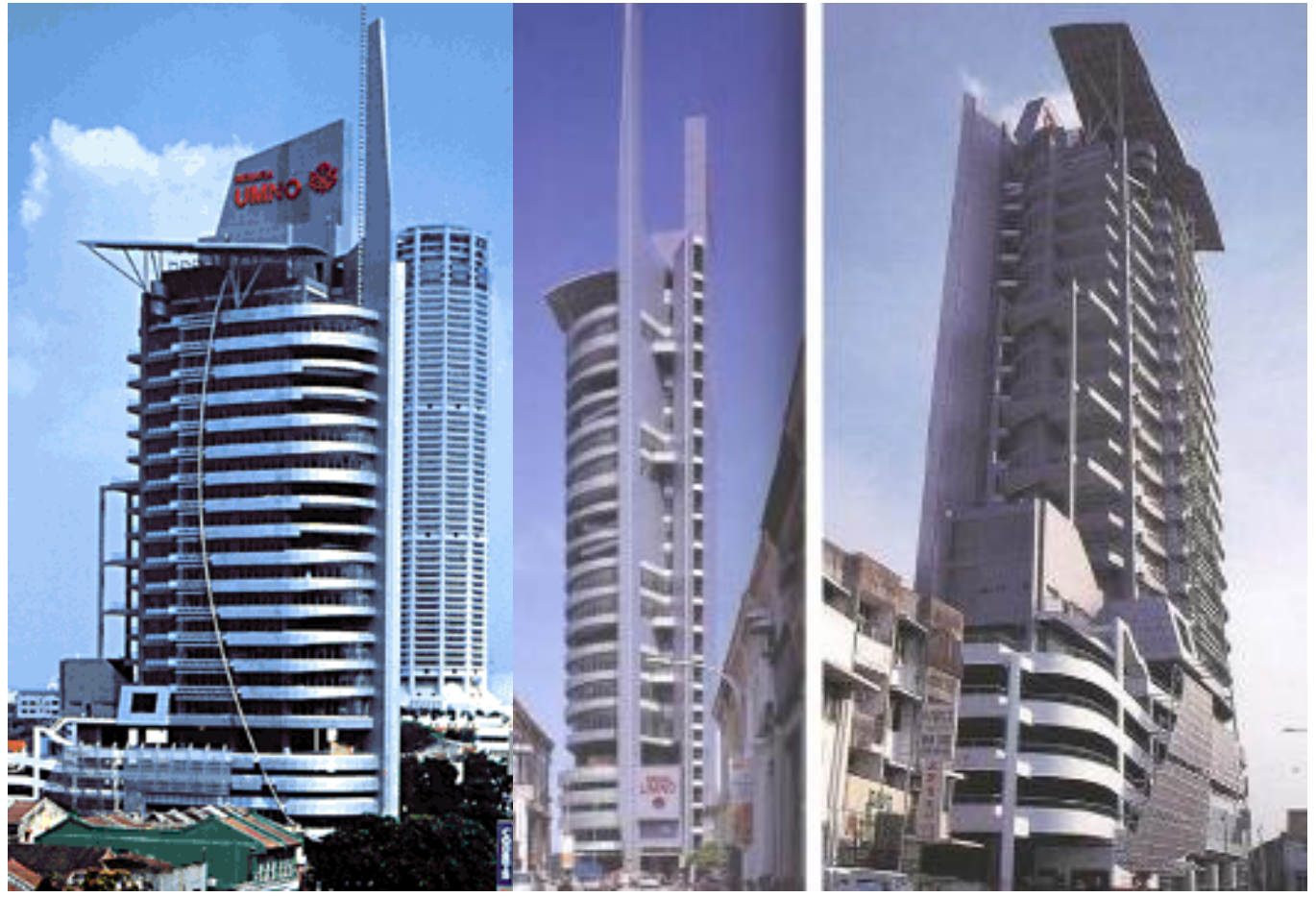

Figure 2-18: Menara UMNO, Penang, Malaysia; Vertical wing-walls protruding from the Southwest and Northeast elevations. Source: Jankassim (2004)

\section{Monthly average weather data _ Penang, Malaysia}

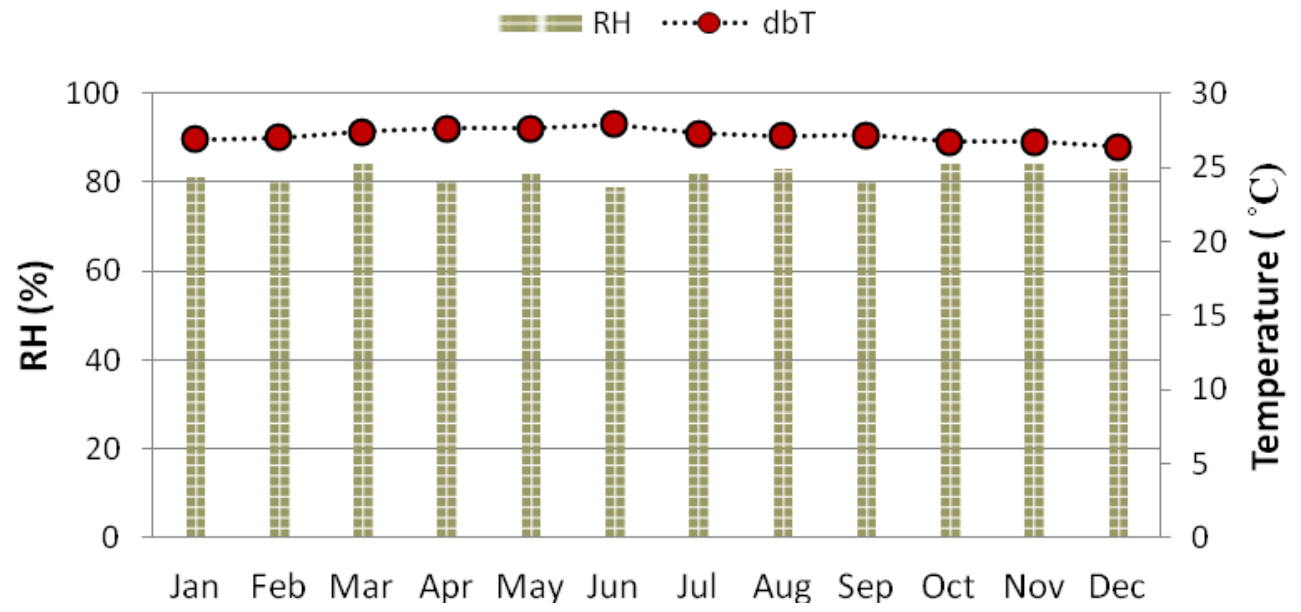

Figure 2-19: Annual temperature profile in Penang, Malaysia 


\subsection{4-1 Overview of building design}

The Menara UMNO, designed by the Malaysian architects T.R Hamzah and Yeang, is a 21- storey 'bioclimatic' tower located on the island of Penang (Fig. 218). Penang enjoys a year-round tropical rainforest climate which is warm and sunny, along with plentiful rainfall, especially during the Southwest Monsoon from April to September. The average annual temperature (Fig. 2-19) in Penang is $27^{\circ} \mathrm{C}$, while the mean annual precipitation is $2670 \mathrm{~mm}$ and the average relative humidity can reach up to $70 \%$ - 90\%.. Penang's climate has little seasonal and diurnal variations and no distinct hot or cold seasons. The hottest months are between December and April with mean temperatures ranging between $26.2{ }^{\circ} \mathrm{C}$ and $27.6{ }^{\circ} \mathrm{C}$, while the coolest months are between June and October with mean temperatures ranging between $26.3{ }^{\circ} \mathrm{C}$ and $27.3{ }^{\circ} \mathrm{C}$. The temperatures fluctuate between $27^{\circ} \mathrm{C}-30^{\circ} \mathrm{C}$ during the day, and $22^{\circ} \mathrm{C}-24^{\circ} \mathrm{C}$ during the night, mounting to an average temperature difference of $5{ }^{\circ} \mathrm{C}$ to $6{ }^{\circ} \mathrm{C}$ between the day and night. The mean surface winds over Penang are generally mild, with the average wind speed of $1.5 \mathrm{~m} / \mathrm{s}$, and a maximum speed of less than $8 \mathrm{~m} / \mathrm{s}$.

Menara UMNO accommodates fourteen floors of office spaces, atop a sevenstory podium. The building is almost rectangular in plan, with a gentle curve along the south-west corner of the tower (Fig. 2-20). The long axis of the building is oriented along the northeast and southwest direction, in line with two of the prevailing wind directions. The service core (containing the lift lobbies, staircases, and toilets) is placed along the south-east façade of the building, constituting a thickly buffered party wall that shades the offices from the morning sun (Royal Australian Institute of Architects, 1998). This configuration allows the public and circulation areas to receive day lighting and natural ventilation, thus reducing the energy demand. The remainder of the floor area on each level is devoted to openplan offices. The typical office floor has a gross area of $615 \mathrm{~m}^{2}$ and a 2:1 aspect ratio. The depth of the plan is about 14 meters, excluding the service core. Several sky courts and balconies are incorporated within the plan to serve as a social space where occupants can enjoy the cooling breezes as well as to provide solar shading. 


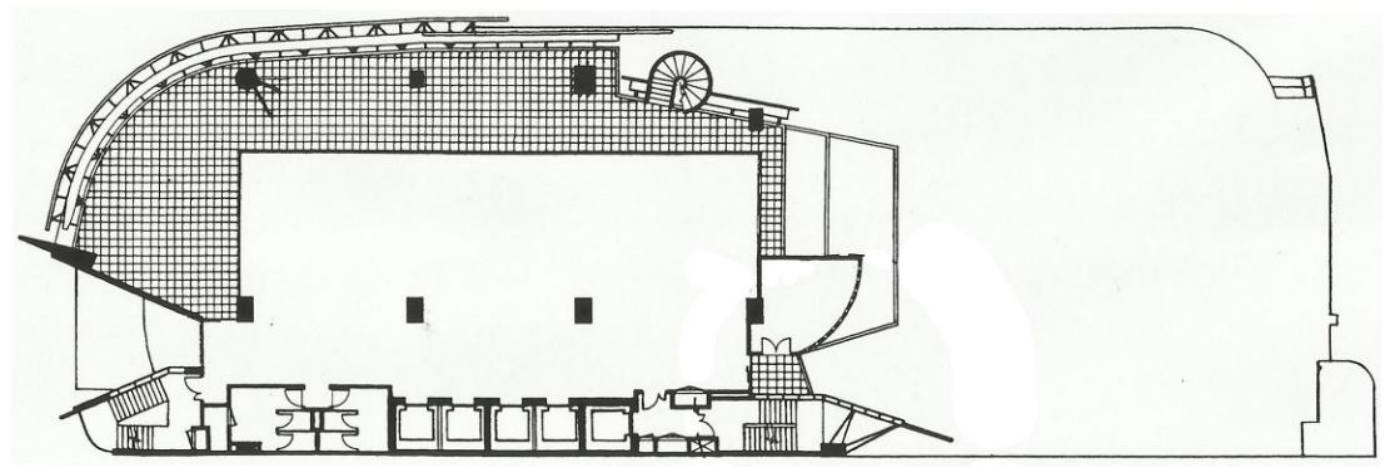

Figure 2-20: Typical floor plan of the Menara UMNO. Source: Baird (2001)

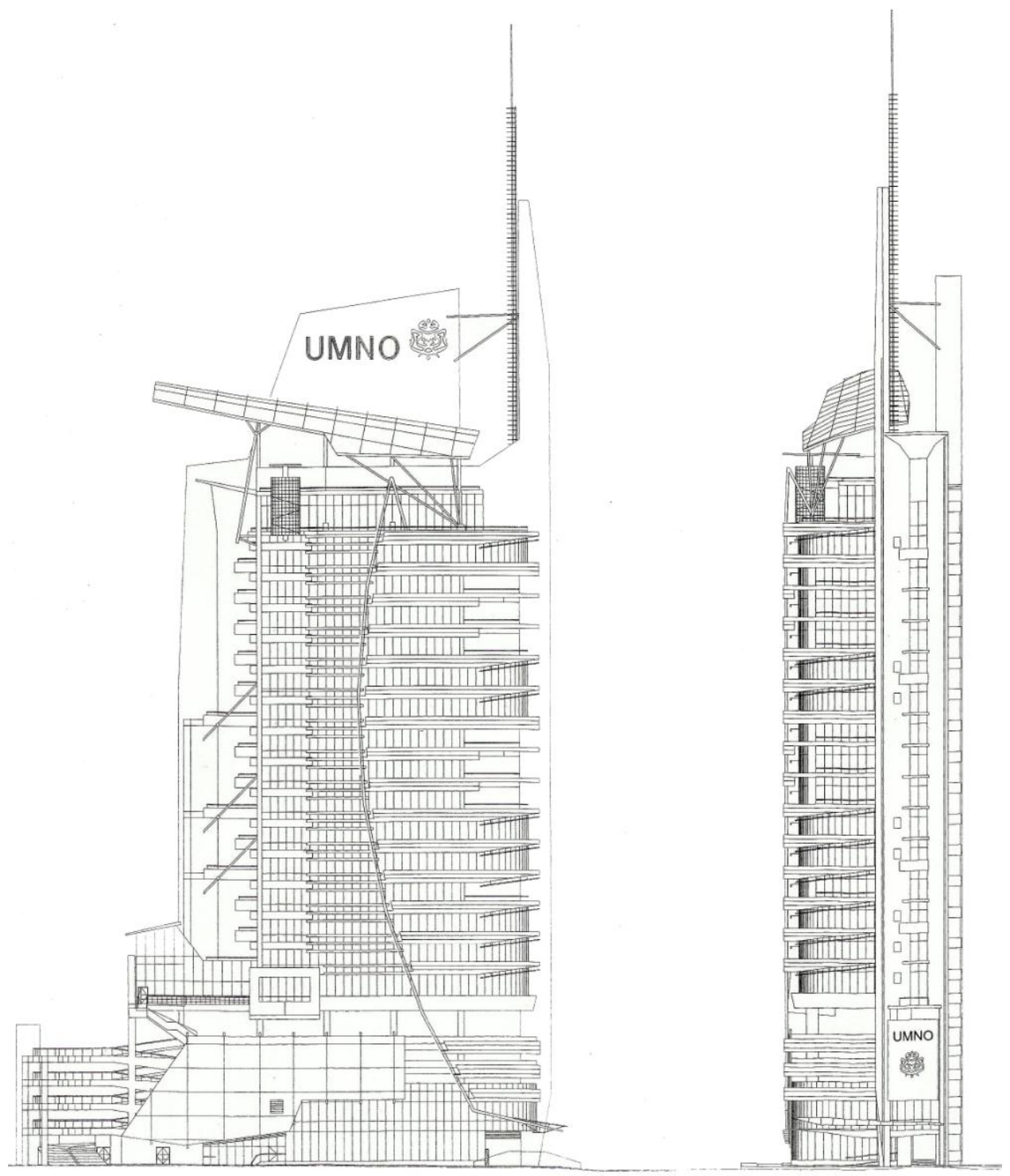

Figure 2-21: The Menara UMNO Tower North (left) and West (right) Elevations. Source: Jankassim (2004) 


\subsection{4-2 Natural ventilation strategies}

The warm and humid climate of Malaysia has necessitated the use of airconditioning in most of its office buildings. However, the poor rental rates in Penang at the time of the development of Menara UMNO did not justify the installation of a central air- conditioning system due to its economic impracticality. As a result, the UMNO tower was initially designed for tenants to install individual split unit air-conditioning. The natural ventilation strategy was then conceived as a backup system to the building in the incident of a power failure. Despite the fact that a central air-conditioning system was subsequently installed prior to construction, all office floors can still be naturally ventilated under suitable external weather. Due to the site limitations and the orientation of the building, a series of wind "Wing Walls" were developed to fully maximize the use of prevailing winds (Fig. 2-22). The Wind Wall device is a shortened wall, which runs vertically up the building in order to capture a wider range of wind directions and increase the airflow rates into the occupied space. These devices funnel air flow into the internal spaces by establishing pressure difference across the office plan. The objective of the natural ventilation solution in Menara UMNO was to generate a high air-change rate for achieving comfort conditions through air movement and temperature control. The building exploits wind-induced natural ventilation not solely for the purpose of air-displacement and fresh air supply, but also for internal comfort conditions (Powell, 1998).

The overall natural ventilation strategy in the building is primarily dependant on wind- driven forces to channel air across each floor plate with the aid of 'wingwall' devices (cross-ventilation on a floor-by-floor basis). Air is funnelled into the building from the windward side, and is then directed to a zone with special balconies that serve as pockets with "airlocks". The location of these balconies and airlocks are shown as Figure 2-23. These airlocks have adjustable doors and windows with manual control for the rate and the distribution of natural ventilation within the space. Menara UMNO is the first high-rise office building which employs the Wing Wall device for the purpose of natural ventilation. 


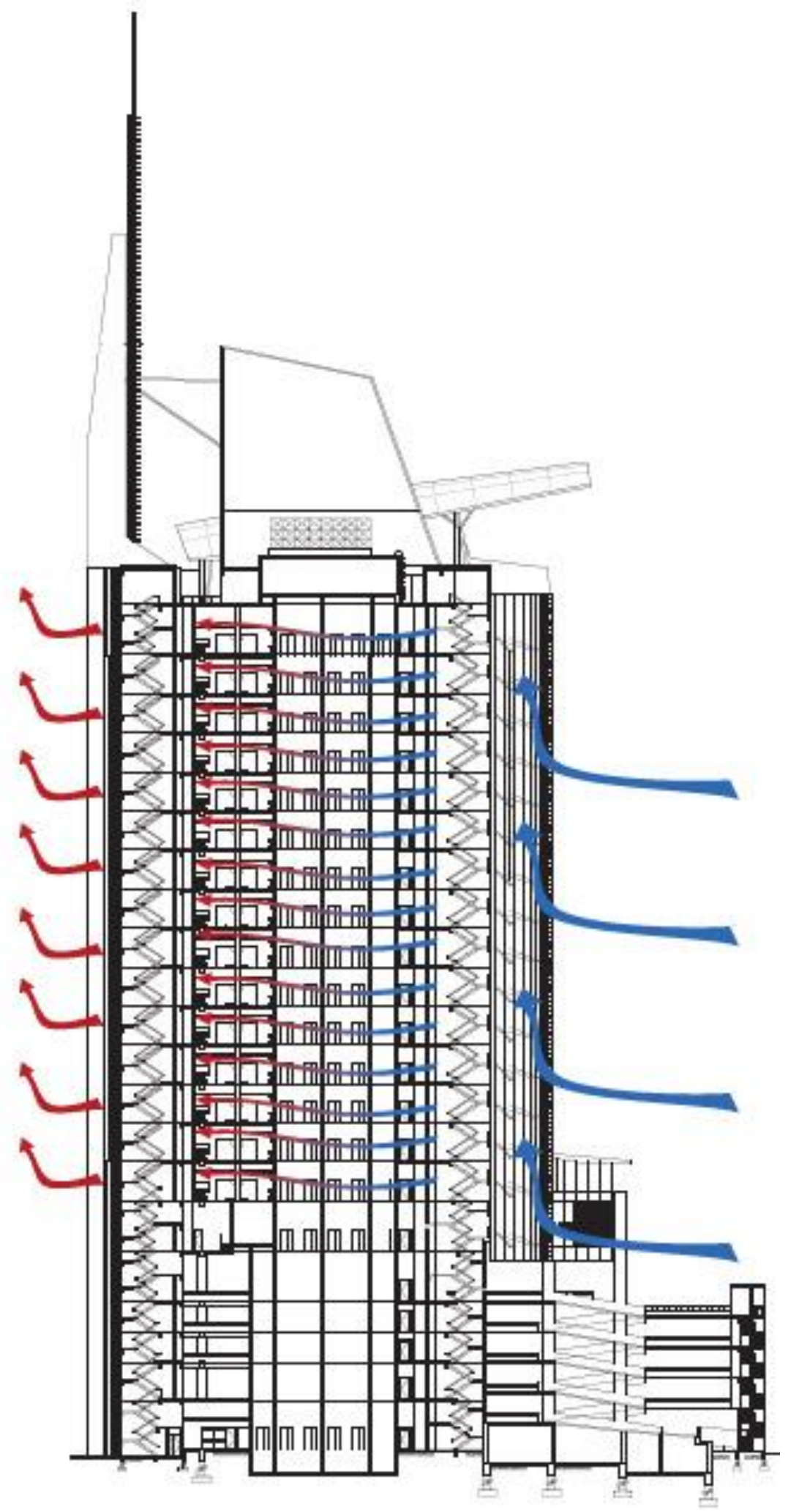

Figure 2-22: The cross sectional floor-by-floor basis ventilation strategy. Source: CTBUH (2012) 

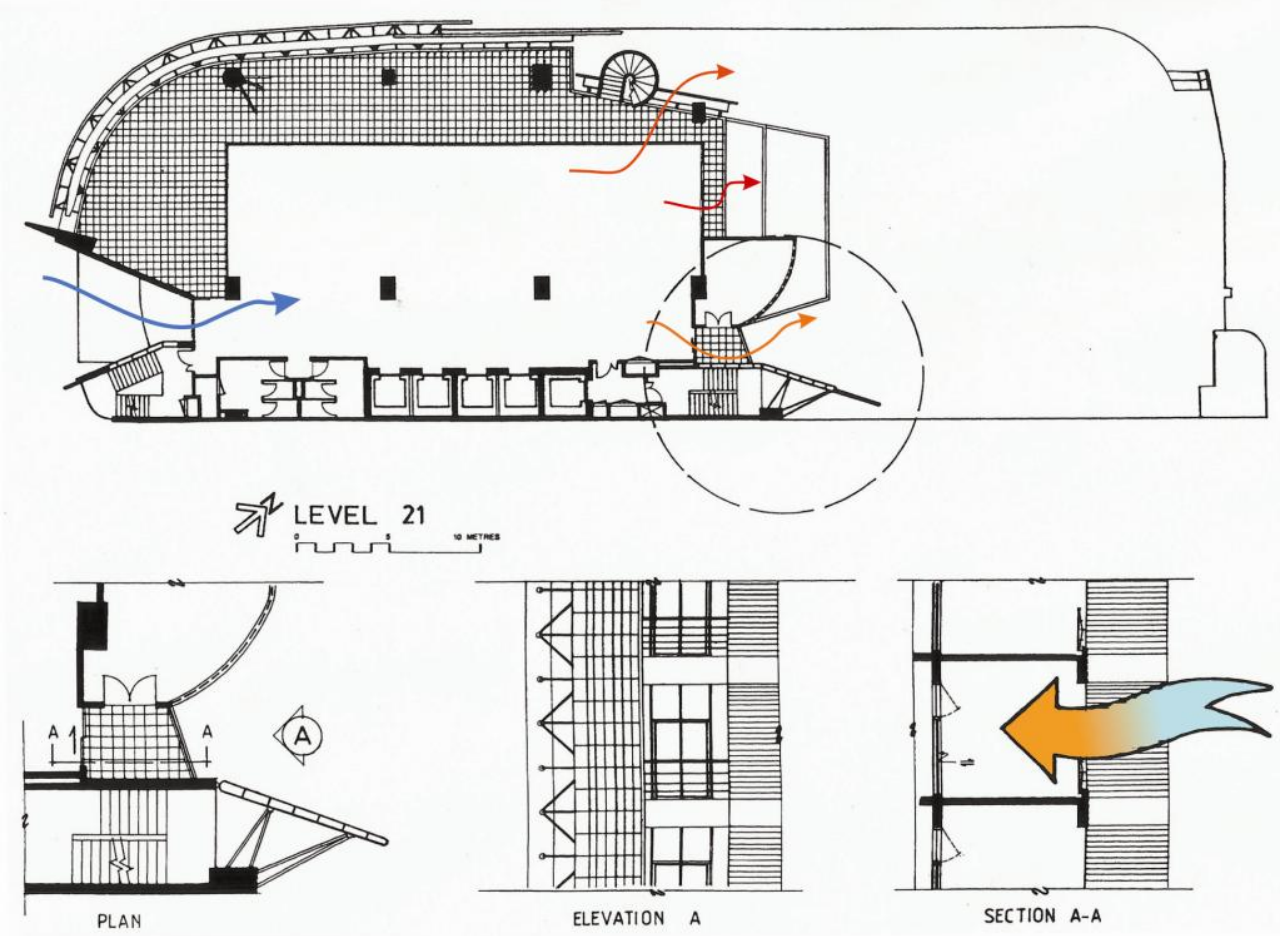

Figure 2-23: Typical plan showing the location of balconies and airlocks. Sources: Powell (1999)

\subsection{4-3 The mixed-mode strategies and overall performance}

Menara UMNO was originally designed as a Contingency Mixed-Mode building to be naturally ventilated for up to 100 percent of the year with the provision for tenets to install individual air-conditioning units. Subsequently, a central airconditioning system was installed during construction and Menara UMNO operates as a Complementary-Changeover building. An active, user-controlled system allows occupant to choose between natural or mechanical ventilation modes. The building does not have a central building management system (BMS) to control the operation of the windows or the amount of airflow into the interior. However, the active and passive systems in the building have independent controls which can be operated by the users. The control for the active AHU is on 
floor-by floor basis, and the occupants have access to windows that can be opened in most office spaces.

During the design development of Menara UMNO, CFD simulations were conducted to test the effectiveness of various ventilation strategies. The analysis suggested that comfort ventilation could not be achieved solely based on buoyancy-induced ventilation because of the limited floor-to-floor height on a floor-by-floor basis of ventilation system. The effectiveness of Wing Walls on the overall thermal performance of the building was investigated. The air change rates of the occupied spaces were evaluated under different boundary conditions in aim of identifying the potential scenario of when and how the sufficient $\mathrm{ACH}$ can be supplied for different ventilation needs (either indoor air quality of cooling).

A post occupancy survey was conducted in 1998 which measured the level of thermal comfort by the use of Predicted Mean Vote (PMV) of Fanger. The study revealed occupants on floors 6,7 , and 8 tended to feel slightly warm, with an average scoring of 0.9 PMV (Jahnkassim, 2004). Another post occupancy study conducted in July 2004 (Ismail and Sibley, 2006) consisted of a questionnaire distributed to occupants in order to record the perceptions of the environmental qualities of their work space. Their study revealed that natural ventilation had an 83 percent of positive response. For the thermal comfort, however, there was only $57 \%$ positive response and with negative feedback on temperature at work stations, elevator lobbies, and restrooms. Despite of the results from the thermal comfort survey, none of the respondents were dissatisfied with their overall working environment.

\subsection{4-4 The considerations for implementation in Taiwan}

Some potential areas of concern should be addressed when implementing the design strategies of Menara UMNO. First, the location of the service core along the edge of the building has resulted in a greater plan depth along the main wind flow axis (approximately 14 meters). This might have adverse effects on natural 
daylight, especially for workers who are located at a far distance from windows and ventilation openings. Second, the ventilation concept mainly relies on winddriven natural forces, lower air flow rates $(<1 \mathrm{ac} / \mathrm{h})$ would be observed if the ambient wind speeds are low or the windows are not fully opened. Third, buoyancy effect alone would not provide a significant ventilated cooling because of the limited ceiling height and low temperature difference between indoor and outdoor during the summer time of Taiwan. Given the natural ventilation design of the building on a floor-by-floor basis, it diminishes the possibility of designing a tall building that relies exclusively on stack effect. The sole use of natural ventilation may not provide optimal occupancy comfort in the case of high humidity levels under tropical conditions. Fourth, the effect of wind driven rain under monsoon season will need to be taken into account in developing a natural ventilation strategy. Finally, the development of future adjacent high-rises may negatively affect wind flow and speeds and thus the wind "Wing Walls" strategy. 


\subsubsection{Torre Cube}

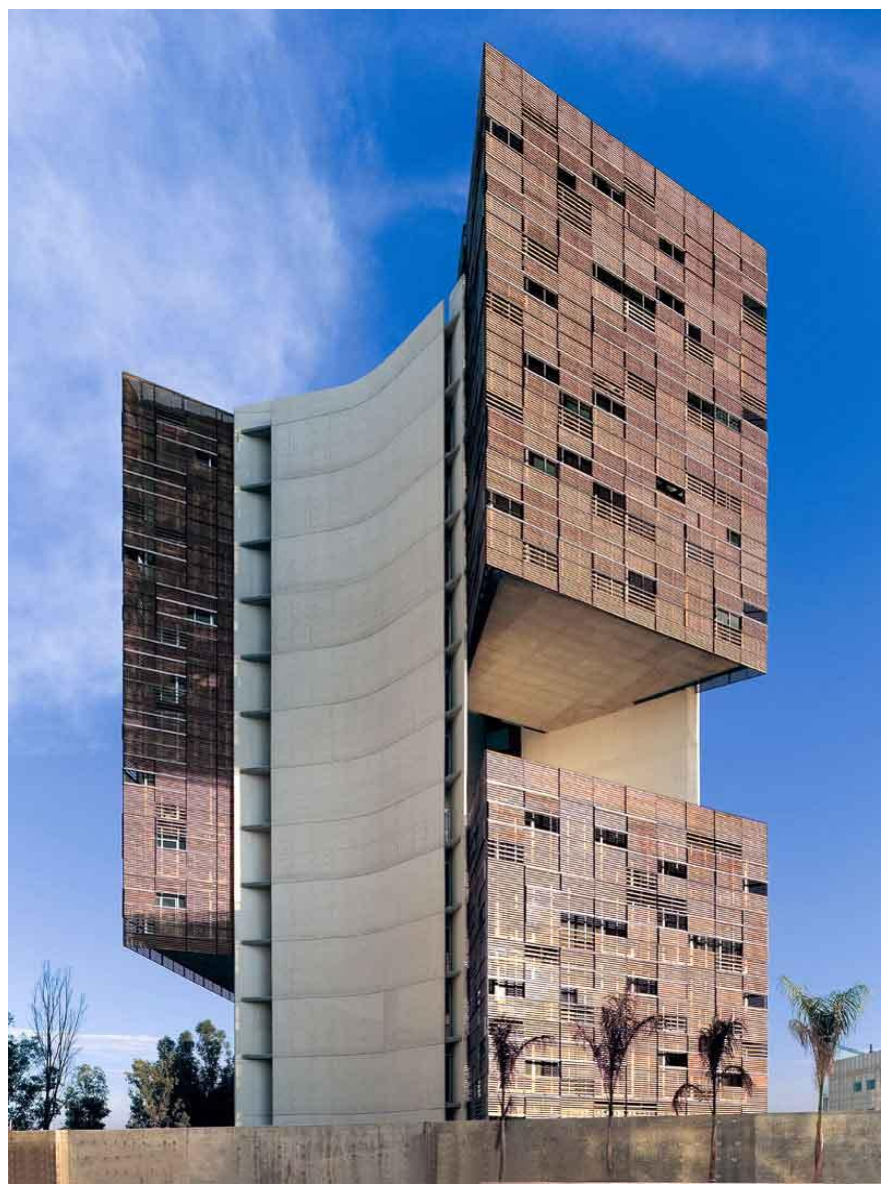

Figure 2-24: The Torre Cube. Guadalajara, Mexico. Source: Pagliari (2006)

Monthly average weather data _ Guadalajara, Mexico $=\mathrm{RH} \quad \cdots \cdot \cdots \mathrm{dbT}$

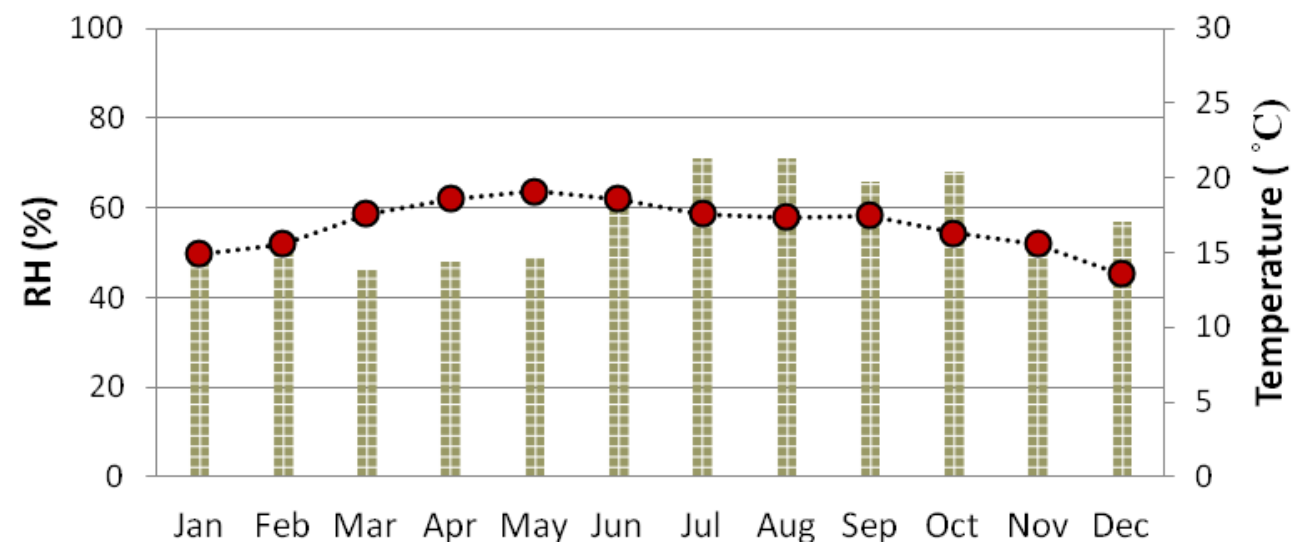

Figure 2-25: Annual temperature profile in Guadalajara, Mexico 


\subsection{5-1 Overview of building design}

The 'Torre Cube' is a 16-storey (70 meter) high office tower located in the Guadalajara, Mexico. The building was designed by the Catalan architects Carme Pinos, and completed in 2005 (Fig. 2-24). Guadalajara is located in a relatively humid sub-tropical climate, featuring dry, mild winters and warm, wet summers. Although the temperature is warm year-round, it experiences a strong seasonal variation in precipitation. There is plenty of sun throughout the year and summer temperatures quickly rise to $30{ }^{\circ} \mathrm{C}$ and often approach $35^{\circ} \mathrm{C}$ during the months of April and May. The wet season approaches shortly after May bringing extra moisture resulting in cooler days and warm nights. While the daytime winter weather tends to be mild, averaging around $25^{\circ} \mathrm{C}$, the temperature quickly drops to around $5{ }^{\circ} \mathrm{C}$ at night. The annual weather profile is shown as Figure 2-25.

From the very beginning of the design process, the project was driven by the desire to eliminate the need for air-conditioning and to create naturally ventilated and daylit offices (Cenicacelaya, 2006). The tower consists of three triangularshaped, timber-clad office wings that are dramatically cantilevered from three concrete cores. Apart from being the primary supporting structure, these cores also contain all the service facilities and vertical circulation elements within the building (e.g. stairwells, lifts, and toilets). The post-tensioned cantilevered office slabs allow for open-plan, column-free interior spaces with minimal obstructions (Fig. 2-26). The triangular-shaped office spaces are approximately $12 \mathrm{~m}$ in depth (measuring from the outer skin to the central void). Both the offices and the service shafts are arranged around a central open space which functions as a light well and serves an important role for natural ventilation. The central void (Fig. 227 ) is connected to the exterior by the omission of office floors which creates sky gardens in each office wing. These sky gardens, or "porches", serve to bring natural light and ventilation into the central void. These three storey porches also provide generous shade, allow for air circulation, and function as communal terraces for social gatherings (Slessor, 2006). 


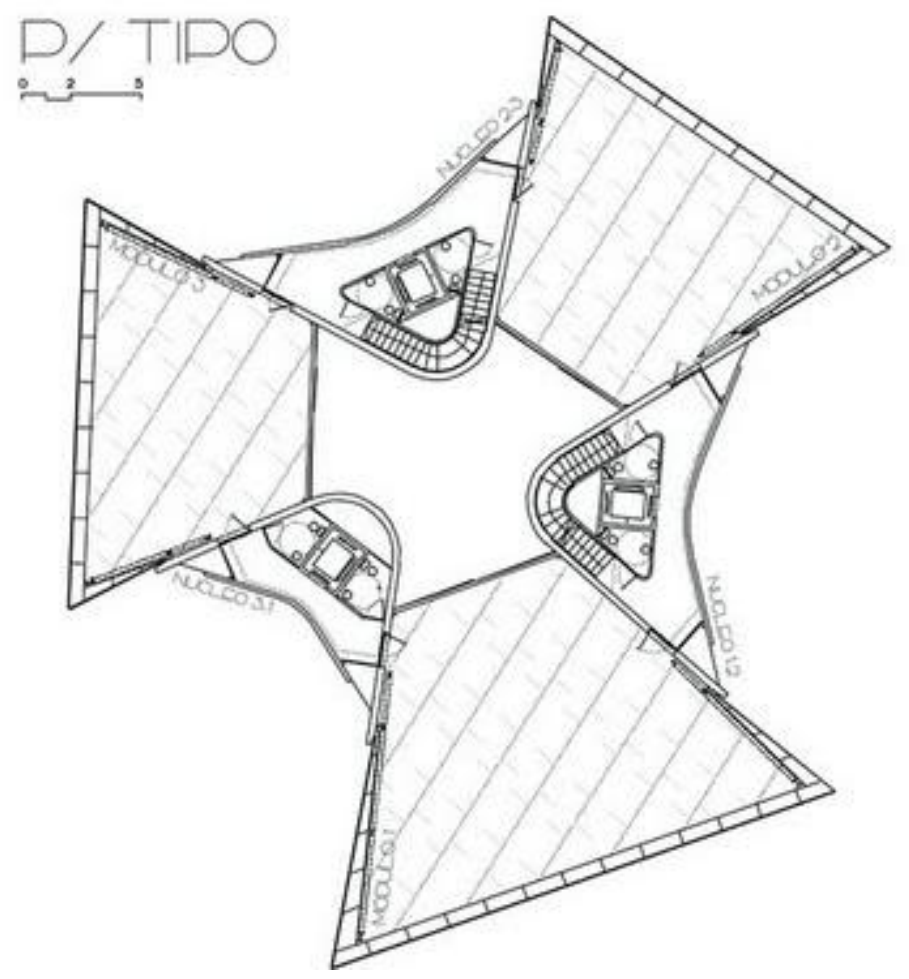

Figure 2-26: The Torre Cube typical floor plans. Source: Pagliari (2006)
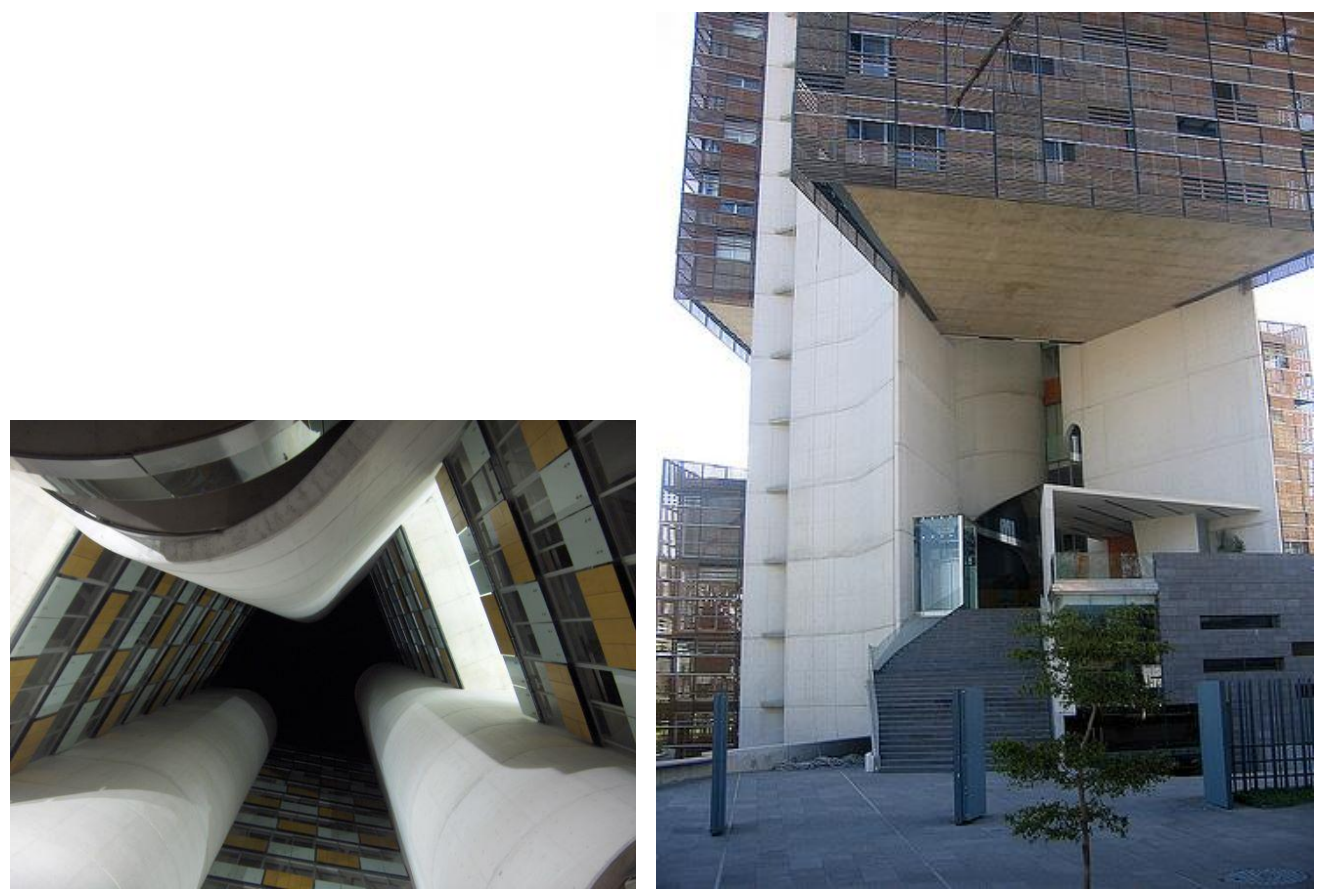

Figure 2-27: The internal (atrium) and external views of The Torre Cube. Source: Pagliari (2006) 


\subsection{5-2 Natural ventilation strategies}

The mild Guadalajara climate allows for natural ventilation throughout the entire year, without any reliance on mechanical ventilation, heating or cooling. The office spaces have a double-skin façade (Fig. 2-28) which facilitate natural ventilation and employ an open rain screen/brise-soleil, providing protection against glare and solar heat gain. The inner skin is comprised of a floor-to-ceiling glazed curtain wall with operable sliding windows; the outer skin, on the other hand, consists of a diaphanous screen of wooden latticework made from thin treated pine battens on a steel frame acting directly as a brisesoleil, protecting the office spaces from glare and solar heat gain. In addition, this outer screen acts as a buffer against wind-driven ventilation into the offices, reducing the speed of the air flow.

The wooden latticework panels can slide horizontally by the occupants, giving a degree of flexibility to the amount of shade and controlling the flow of air into the offices. Since both elements can be manually controlled (the wooden screen and the sliding glazed windows), the occupants have direct control over the amount of sun, light and air entering the office. The intermediate zone between the two façade layers has grated floor panels which permit access into this space, but does not impede vertical air flow in the space itself.

The building's overall ventilation strategy relies on the through-draft between the outer windows and the central light well (McGuirk, 2006). Air is drawn into the office space through the sliding windows from the façade and exhausted into the atrium through the sliding windows in the inner-facing façade (Fig. 2-29). The upward movement of air caused by the stack effect creates a negative pressure which pulls air out of the offices to be exhausted at the top of the building. The ventilation strategy of Torre Cube can thus be summarized as a combination of cross ventilation assisted by significant stack effect in the central atrium. 

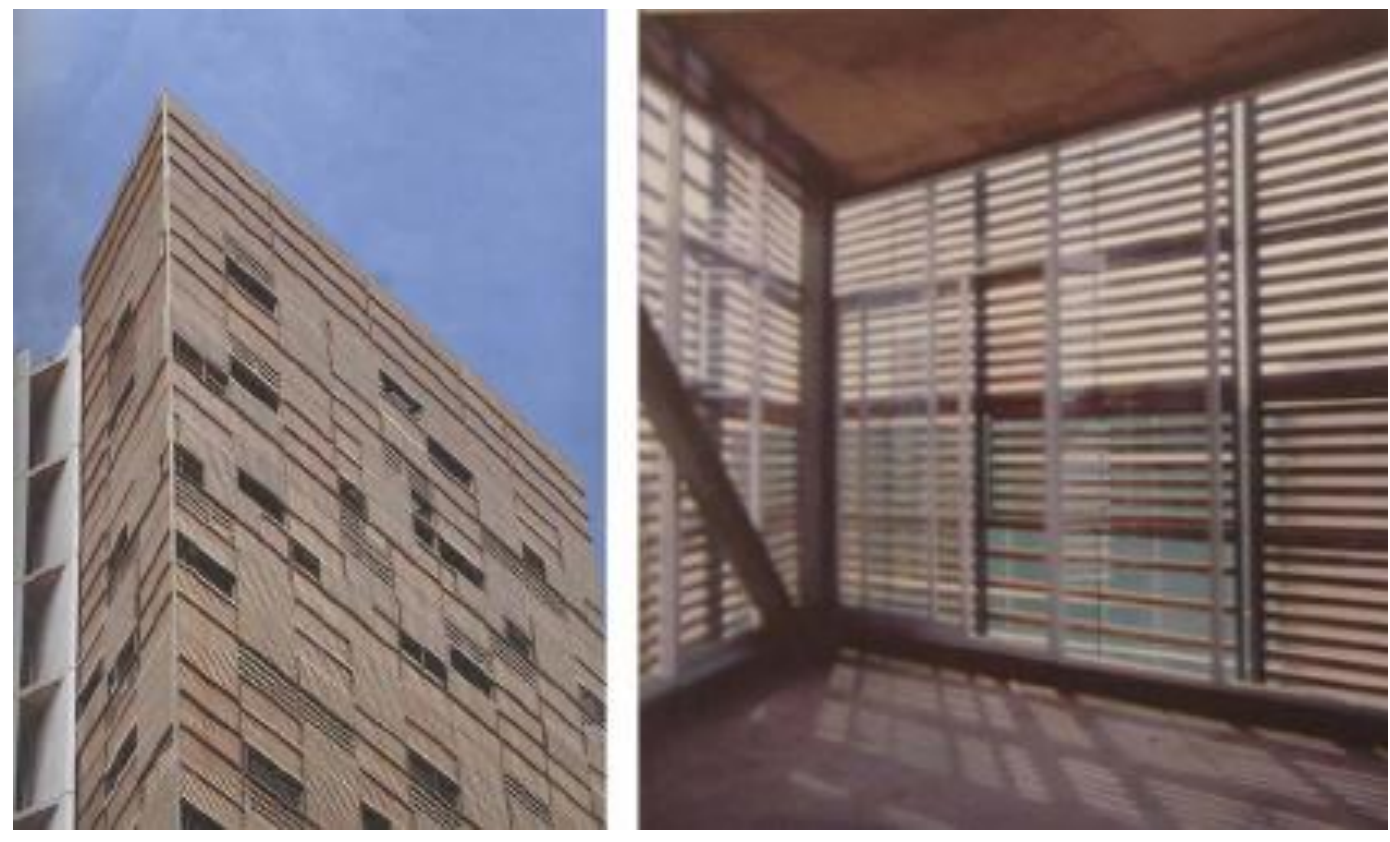

Figure 2-28: Double-skin façade in the Torre Cube (showing the brise-soleil). Source: Left: (Pagliari, 2006); Right: (Adria, 2005)
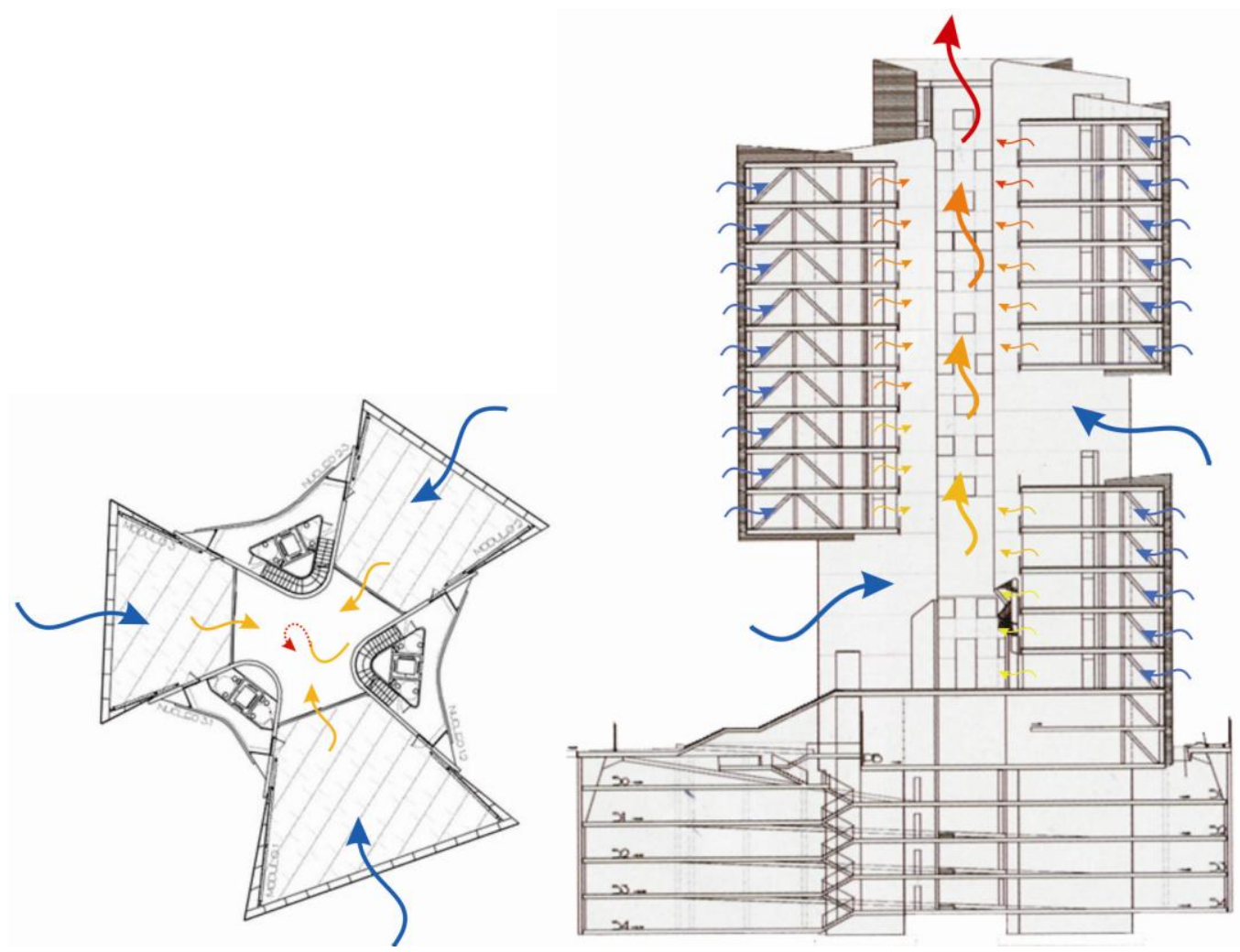

Figure 2-29: Natural ventilation strategy. 


\subsection{5-3 The mixed-mode strategies and overall performance}

The Torre Cube is entirely dependent on natural ventilation (and solar shading devices) to cool down the building, thus there is no mechanical ventilation or mixed-mode systems operating. Even during winter, the climate is mild enough that there is no need for heating to warm up the interior. The design does incorporate duct work to all office spaces that would allow individual tenants to install air-conditioning units for their spaces. However, to date, no tenant has taken this action. The building employs low-tech solutions to its ventilation needs and thus there is no BMS system in place. Office occupants manually operate all the windows and wooden lattice screens of the façade. This allows the users direct control over the amount of air and sunlight entering the office spaces.

\subsection{5-4 The considerations for implementation in Taiwan}

The following points are potential areas of concern that should be addressed when implementing the design strategies of this case study. First, if strong winds are blowing from a specific direction, wind becomes the predominant driving force for natural ventilation in that particular office wing. In this case, the office wing facing the prevailing wind may be better ventilated than the others, unless the stack buoyancy in the central atrium is sufficient to draw air from the perimeter windows of those office wings. Second, the three-story sky gardens within the office wings may influence the effectiveness of the central atrium, being used as an exhaust device, by interrupting the stack buoyancy in the void.

Third, the direct control of the windows may lead to preferential ventilation for some office occupants over others. For example, office workers closer to the external façade may choose to close the windows, which result in insufficient ventilation rates for occupants at the inner side of office space. Fourth, the timber screens of the Torre Cube would be unlikely to stand up to the greater wind speeds experienced at significant heights, or give a satisfactory longevity for durability, cleaning and maintenance in other climates such as Taiwan. 
Fifth, a comprehensive analysis of surrounding environment is desirable when applying this design approach to different urban context. Existing and future developments would significantly affect the wind patterns around the building. It is then suggested that CFD and wind tunnel testing may be helpful for predicting air flow patterns around the building and evaluating control strategies associated with various design alternatives for natural ventilation. It should be noted that this particular ventilation strategy works primarily because of the mild local climate and with only 16 stories in height. It is unlikely that these strategies would work in climates with larger annual temperature and humidity variations, or with buildings of greater height. Figure 2-30 demonstrate one of the potential typology of super tall buildings being derived from this building configuration.

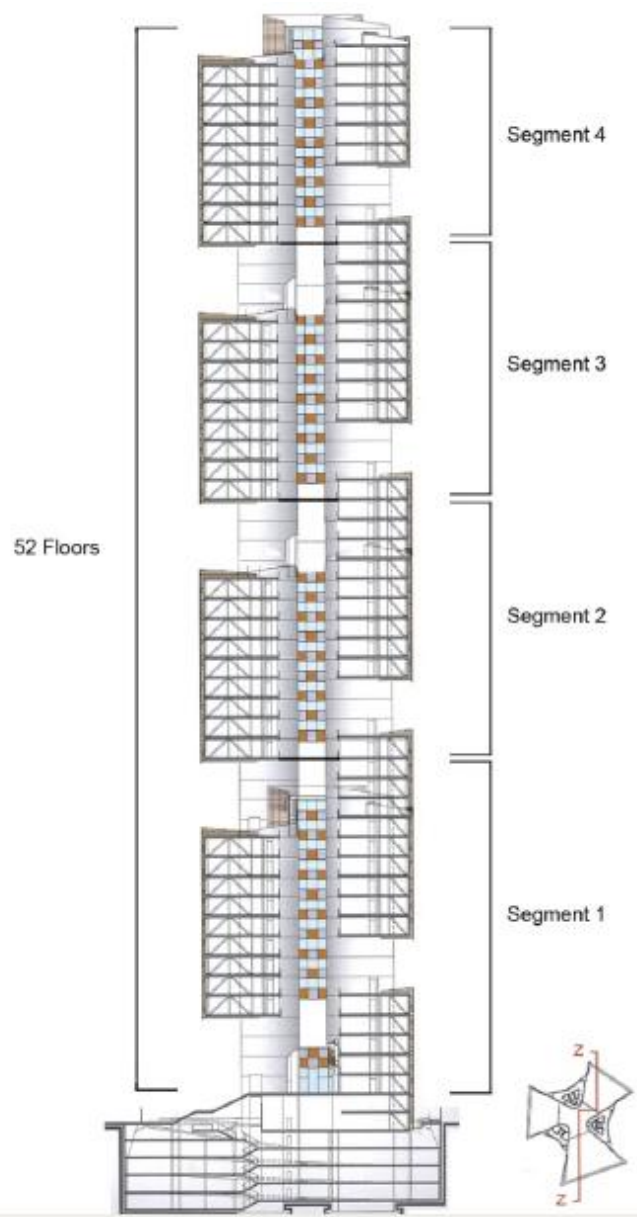

Figure 2-30: The potential application of the Torre Cube design strategy for the super tall building typology. Source: Salib (2008) 


\subsection{Naturally ventilated tall office building design in the climatic context of Taiwan}

\subsubsection{The weather pattern of Taiwan}

The Tropic of Cancer $\left(23.5^{\circ} \mathrm{N}\right)$ runs across the middle of Taiwan and divides the island into two climates, the tropical monsoon climate in the south and subtropical monsoon climate in the north. High temperature and humidity, massive rainfall and tropical cyclones in summer characterize the climate of Taiwan. Taiwan's annual average temperature is about $24^{\circ} \mathrm{C}$ in the south and $22{ }^{\circ} \mathrm{C}$ in the north. In July, the warmest month, the island's temperature goes up to $27{ }^{\circ} \mathrm{C}$ with the north slightly warmer than the south. In the winter, the coldest average temperature for the north is about $15{ }^{\circ} \mathrm{C}$ in February while that for the south is around $19{ }^{\circ} \mathrm{C}$ in January. Northern Taiwan thus experiences a greater range of temperature throughout the year than its southern counterpart. The year-round temperature distribution of Taiwan is presented as Figure 2-31.

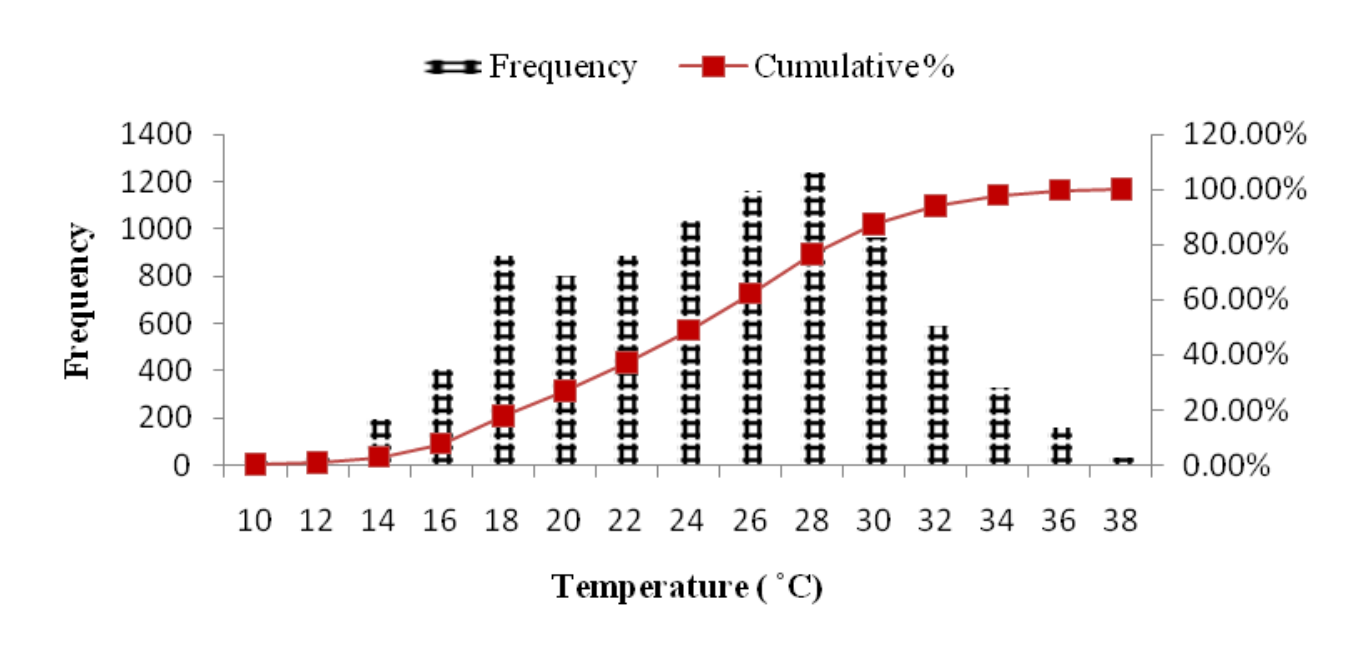

Figure 2-31: Year-round temperature distribution of Taipei, Taiwan 
The building bioclimatic charts (BBCCs) are used to demonstrate the potential year-round comfort distribution in terms of weather data in Taipei. More detailed background knowledge for the BBCCs is presented in Section 3.5.4. Generally speaking, the comfort zone can be extended (the blue outline of Figure 2-32) if an internal velocity of $1.5 \mathrm{~m} / \mathrm{s}$ is applied. The $1.5 \mathrm{~m} / \mathrm{s}$ criterion is defined according to Givoni (1994), where different building design strategies and ventilation system are adopted. The hourly external temperature and relative humidity was plotted in the chart where the comfort boundary was applied with reference to different internal wind speed. One thing to be noted is that the internal temperatures may be higher if significant internal and solar heat gains are applied. In this stage of analysis, it is assumed that internal and solar gains are low. The air change rate under the $1.5 \mathrm{~m} / \mathrm{s}$ internal velocity would vary in terms of the actual envelope opening design. The results are presented as Figure 2-32, which suggest the preliminary potential of comfort ventilation; while the actual performance of the office building may vary case by case, especially when significant solar gains are considered. 


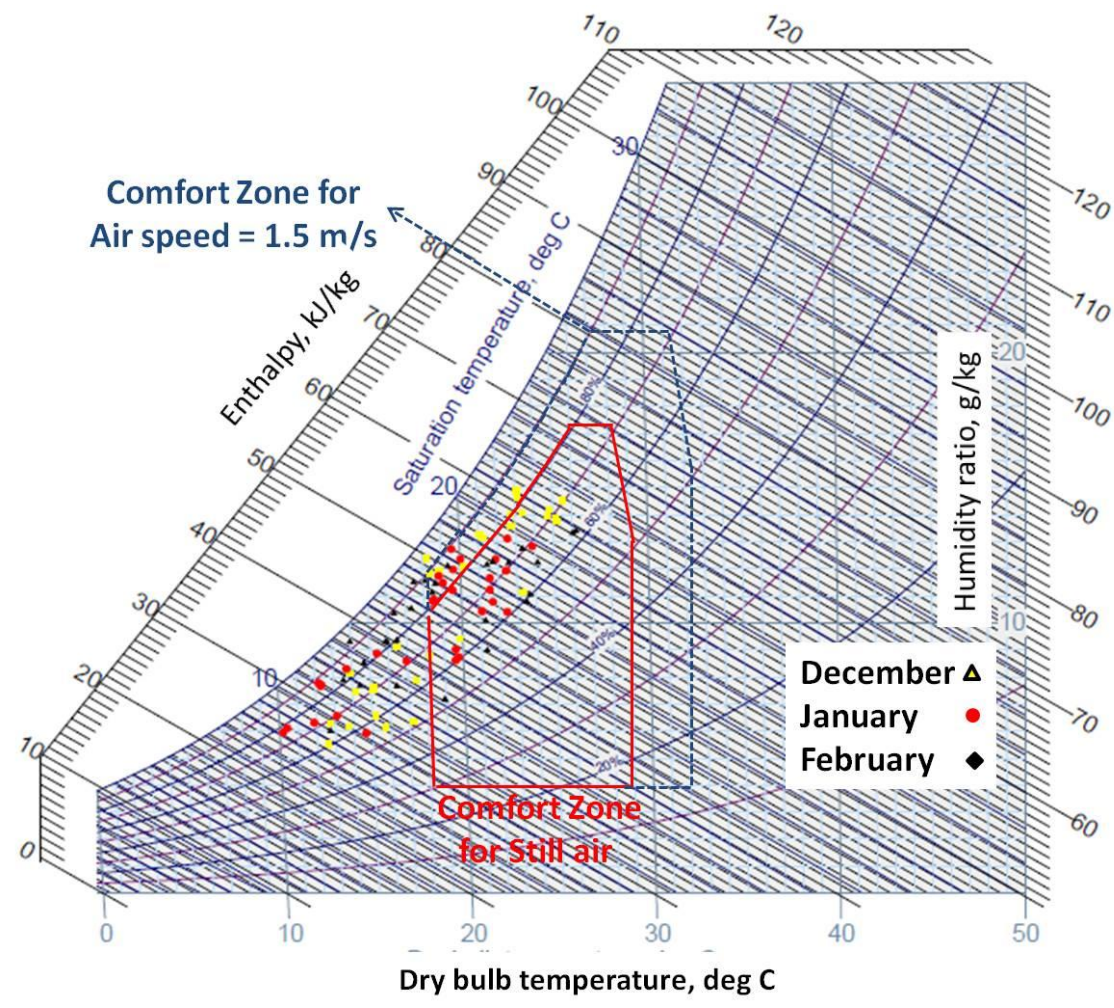

(a)

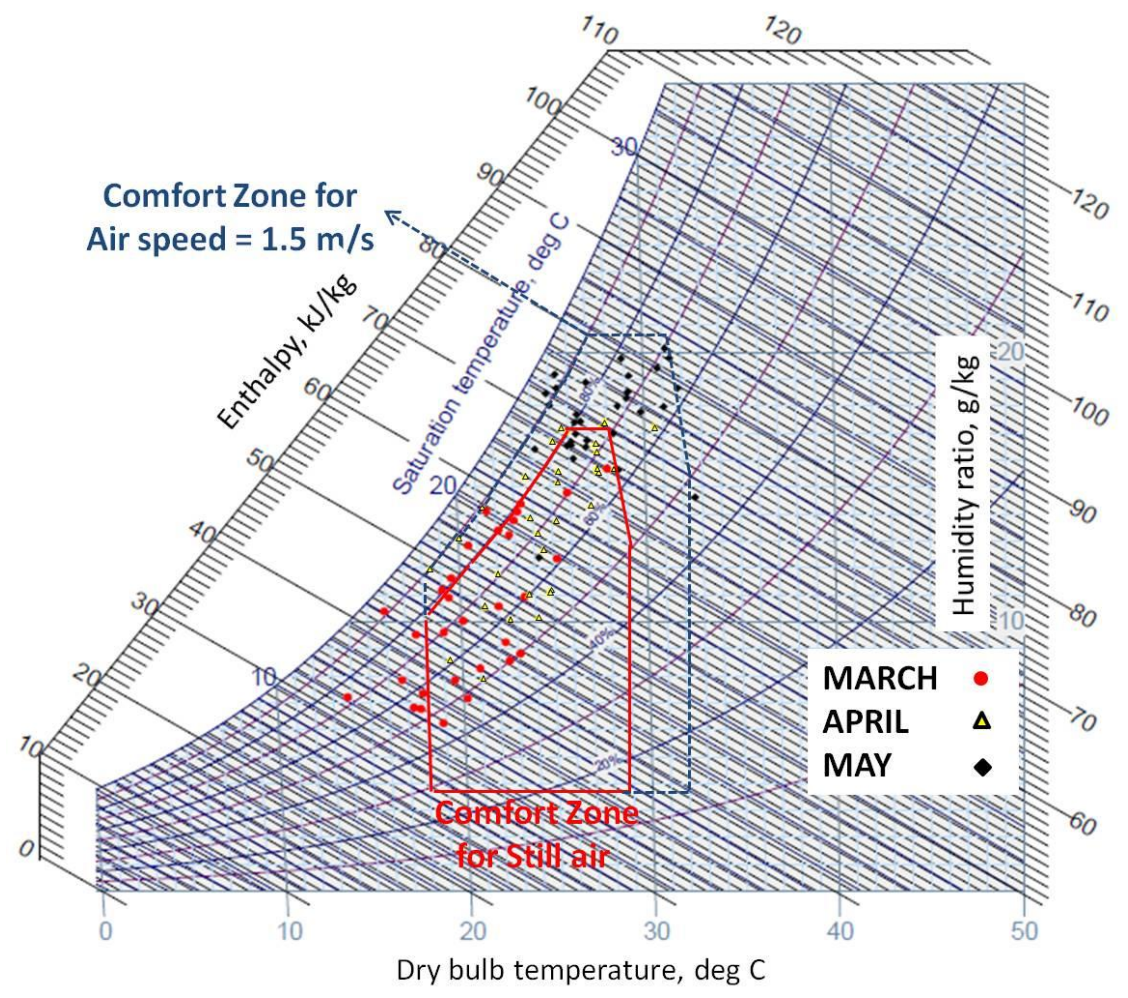

(b) 

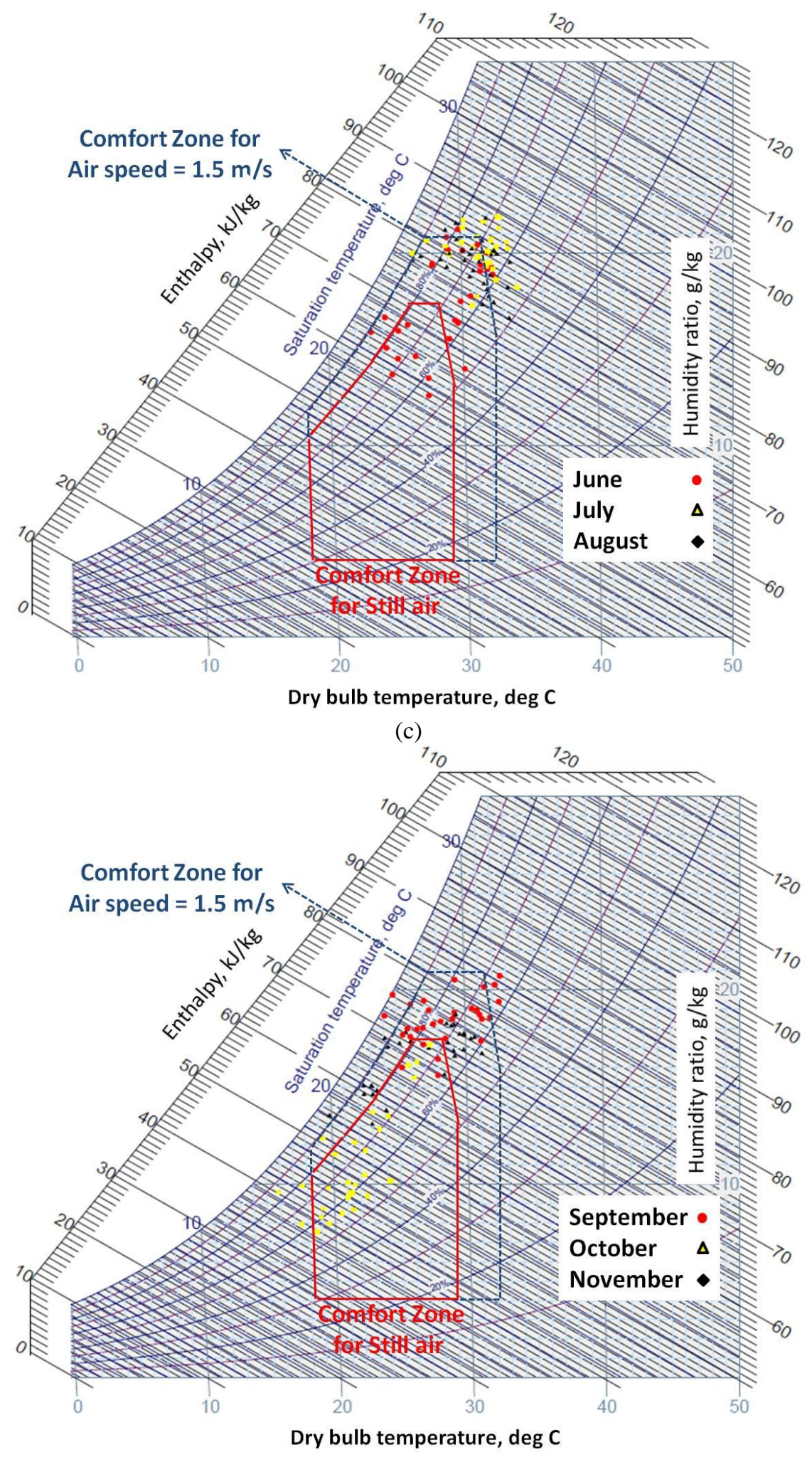

(d)

Figure 2-32: The thermal comfort distribution by the use of building bioclimatic chart. (a) December to February; (b) March to May; (c) June to August; (d) September to November 


\subsubsection{Summary of lessons learned from case studies}

The critical parameters for efficient design (in terms of economic implication and occupants' perspective) of tall buildings as suggested by Strelitz (2007) are storey height and size of both the floor plate and core. Issues in terms of space, ease of use, capital cost, architectural fit and performance for tall buildings design were raised in their study With regard to natural ventilation + mechanical ventilation design in tall buildings (ie mixed mode), the cost of installing two ventilation systems, is seen as a disadvantage. It was suggested that the cost was far too high to be balanced by savings in running costs, but the investment was thought to be worthwhile nevertheless in terms of sustainability and satisfactory environment for occupants. The social and environmental costs should be taken into consideration as the scale of tall building increases, which enhance the importance of exploiting natural and renewable energy source.

The spatial configuration of a tall building is key to natural ventilation design. The development of high-rise buildings in the US in the 1890s demonstrated how shallow plan depth and the incorporation of open (central) courts allowed tall buildings to rely exclusively on natural ventilation before the advent of airconditioning. The Chrysler and the Empire state building illustrate how the shallow wall-to-core depth allows sufficient daylight and natural ventilation (Oldfield, 2008). Case studies as presented in Section 2.2, demonstrate that 100 years later applications of naturally ventilated tall buildings (all mixed-mode buildings). The design options for natural ventilation with reference to building plan and sectional treatment of the five case studies are summarized as follows:

The spatial configuration of the four studied cases, namely Commerzbank, Deutsche Post Tower, Liberty Tower of Meiji University and Torre Cube, adopts the concept of central atrium. In these three cases, the use of atrium allows for wind and buoyancy forces to act together at the same time. As demonstrated by the Commerzbank, the use of a central atrium and sky gardens allows for outward facing offices to be directly ventilated from the outsides and for offices facing the 
atrium to be indirectly ventilated through the sky gardens through the stack effect. However, the overall ventilation performance would be determined by the ambient weather conditions, for which the wind and buoyancy force may conflict with each other under specific boundary conditions. Detailed engineering analysis is required to identify the period of time when the natural ventilation is not available.

The incorporation of sky gardens in the design of naturally ventilated tall office buildings is addressed in the Commerzbank, Post Tower and Torre Cube. For the Commerzbank, the sky gardens are used as air intake and the extraction. Each building segment includes three gardens, one on each of the three faces of the building. There is always a windward garden to admit the air and a leeward garden to exhaust it. The air travels up and down the atrium according to the weather conditions. In the Deutsche Post Tower, on the other hand, sky gardens are only used as extraction chimneys which allow the stack effect to exhaust air to the top of the atrium outlet. Additionally, sky gardens also function as buffer zones in both cases which mediate the temperatures between the exterior and interior. In such a scenario, the sky gardens offer some of the benefits as presented by double-skin facades. These include thermal insulation, protection against undesirable weather conditions, exterior noise and high wind speed. In the case of the Torre Cube, however, the three-story sky gardens within the office wings may reduce the effectiveness of the central atrium as an exhaust device by interrupting the stack buoyancy in the void. The central void as well as the duplication of some services in three off-centre structural cores results in the reduction of efficiency of the net-to-gross usable floor area and commercial viability of the project.

From the aspect of segmentation, the Commerzbank and Post Tower demonstrate how segmentation prevents temperature differences from acting over the full height of the building. Therefore, the risk associated with the large buoyancy pressure difference at the top and bottom of the atrium is reduced. In this respect, 
segmentation minimizes the risk of receiving significantly warmer air at top floors than those at the bottom consequently. Although, the design of natural ventilation on a floor-by-floor basis as demonstrated by the Menara UMNO can eliminate the above concern, sufficient flow rates may not be delivered when the external weather conditions are not viable (e.g. under low wind speed).

Furthermore, with the presence of wind, the cold draught occurred in the bottom floor should be taken into consideration. One concern is in terms of sizing of inlet and outlet. The pressure difference due to the wind forces would be determined by the wind pressure coefficient at the location of the inlet and outlet. By the use of segmentation, the complexity associated with sizing the openings of the spaces connected to the atrium is reduced accordingly. Consequently, segmentation allows for the design of each segment in isolation. That is, although the Torre Cube is only 16 stories in height, the potential typology of super tall buildings can be derived from this building configuration as well (Fig. 2-30). The summary of the natural ventilation strategies being applied in the five case studies during different period of time of a year is illustrated as Table 2-1.

Nevertheless, the feasibility and viable period of time for the adoption of natural ventilation in the five case studies are not addressed in detail in the available references. The claimed ventilation performance is supposed to be achieved by the use of appropriate modelling tools in the associated design stage. The overall objectives of this study are to determine whether the magnitudes of air flow rates and the desired flow pattern through openings can be achieved over a range of specified conditions. Potential conditions where the thermal comfort condition may not be ensured should be identified. Additionally, it is supposed that different modelling tool should be applied according to the research questions at hand under different design stages. The pros and cons of proposed modelling tools of this study are discussed in Chapter 3. 
Table 2-1: The natural ventilation strategies of the five case studies

\begin{tabular}{|c|c|c|c|c|c|}
\hline & 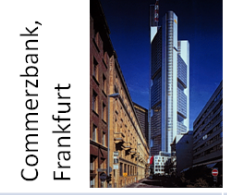 & 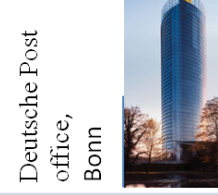 & 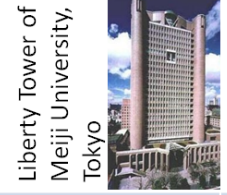 & 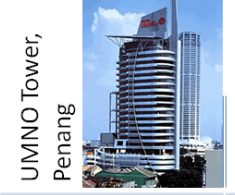 & 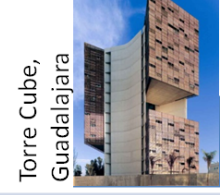 \\
\hline $\begin{array}{l}\text { Climate } \\
\text { classification }\end{array}$ & Temperate & Temperate & Temperate & Tropical & $\begin{array}{l}\text { Temperate (Mild } \\
\text { Seasonal Variation) }\end{array}$ \\
\hline Building height & $\begin{array}{l}259 \text { meters } \\
\text { (56 fl oors) }\end{array}$ & $\begin{array}{l}163 \text { meters } \\
\text { ( } 42 \mathrm{fl} \text { oors) }\end{array}$ & $\begin{array}{l}119 \text { meters } \\
\text { ( } 23 \text { fl oors) }\end{array}$ & $\begin{array}{l}94 \text { meters } \\
\text { ( } 21 \text { fl oors) }\end{array}$ & $\begin{array}{l}60 \text { meters } \\
\text { ( } 17 \mathrm{fl} \text { oors })\end{array}$ \\
\hline Plan depth & $\begin{array}{l}16.5 \text { metres (from } \\
\text { the central void) }\end{array}$ & 12 metres & 20 metres & 14 metres & $\begin{array}{l}\text { 9-12 meters (from } \\
\text { the central void) }\end{array}$ \\
\hline Ventilation type & $\begin{array}{l}\text { Mixed-Mode: } \\
\text { Complementary- } \\
\text { Changeover }\end{array}$ & $\begin{array}{l}\text { Mixed-Mode: Zoned/ } \\
\text { Complementary- } \\
\text { Changeover }\end{array}$ & $\begin{array}{l}\text { Mixed-Mode: } \\
\text { Complementary- } \\
\text { Changeover }\end{array}$ & $\begin{array}{l}\text { Mixed-Mode: Zoned/ } \\
\text { Complementary- } \\
\text { Alternate }\end{array}$ & $\begin{array}{l}\text { Fully natural } \\
\text { ventilation }\end{array}$ \\
\hline $\begin{array}{l}\text { Natural } \\
\text { ventilation } \\
\text { driving forces }\end{array}$ & $\begin{array}{l}\text { Cross and stack } \\
\text { ventilation }\end{array}$ & $\begin{array}{l}\text { Cross and stack } \\
\text { ventilation }\end{array}$ & $\begin{array}{l}\text { Cross and stack } \\
\text { ventilation }\end{array}$ & $\begin{array}{l}\text { Wind-driven cross } \\
\text { ventilation }\end{array}$ & $\begin{array}{l}\text { Cross and stack } \\
\text { ventilation }\end{array}$ \\
\hline Segmentation & Yes & Yes & No & No & Yes \\
\hline $\begin{array}{l}\text { Double-skin } \\
\text { facades }\end{array}$ & $\begin{array}{l}\text { Depth: } 200 \mathrm{~mm} \text {; } \\
\text { Horizontal continuity: } \\
1.5 \text { meters; } \\
\text { Vertical continuity: } \\
2.4 \text { meters (between } \\
\text { floor spandrel panels) }\end{array}$ & $\begin{array}{l}\text { Depth: } 1.7 \text { meters } \\
\text { (south façade)1.2 } \\
\text { meters } \\
\text { (north façade); } \\
\text { Horizontal continuity: } \\
\text { Fully continuous; } \\
\text { Vertical continuity: } \\
\text { Approx } 32 \text { meters } \\
\text { (sky garden height) }\end{array}$ & None & None & None \\
\hline $\begin{array}{l}\text { Use of atrium or } \\
\text { sky garden }\end{array}$ & $\begin{array}{l}\text { Segmented central } \\
\text { atrium and 4-story } \\
\text { high sky gardens }\end{array}$ & $\begin{array}{l}\text { Three 9-story high } \\
\text { sky gardens } \\
\text { and one } 11 \text {-story } \\
\text { sky garden }\end{array}$ & Central escalator core & None & $\begin{array}{l}\text { Central } \\
\text { atrium and 4-story } \\
\text { high sky gardens }\end{array}$ \\
\hline $\begin{array}{l}\text { Night-time } \\
\text { ventilation }\end{array}$ & Yes & Yes & None & Yes & None \\
\hline $\begin{array}{l}\text { Percentage of } \\
\text { time for natural } \\
\text { ventilation }\end{array}$ & $80 \%(+/-5 \%)$ & Unknown & Unknown & Unknown & $100 \%$ \\
\hline & 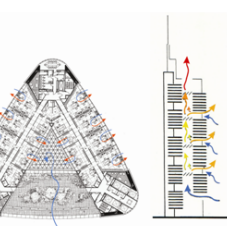 & 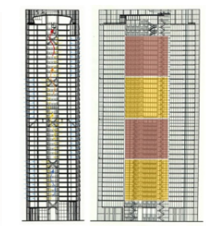 & 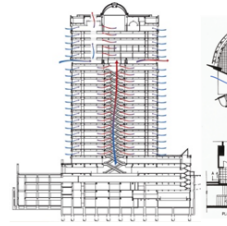 & $\sum_{1}^{0} \quad \begin{array}{l}1 \\
2\end{array}$ & 算 \\
\hline
\end{tabular}




\subsubsection{Options, limitations, and design considerations of naturally ventilated tall office buildings in Taiwan}

Taiwan is located the sub-tropical area with a hot-and-humid climate. The monsoon and typhoon occur often throughout the year which complicates the natural ventilation design. Issues needed to be concerned include the thermal comfort control over challenging ambient temperature and humidity condition and the effective cooling effect with respect to ambient wind speed. For the natural ventilation in tall office buildings, the challenges for control are even greater with regard to potential great magnitude of wind and buoyancy forces in tall buildings. The cooling mechanism being explored in this particular study, for a hot and humid climate, includes the direct cooling of indoor space (sensible cooling) and the physiological cooling of the human body (personal cooling). For this particular study, the overall aim is to ensure that the proposed tall building configurations can deliver acceptable comfort environment for the occupant through natural ventilation alone.

Nevertheless, current design fashion of tall office buildings in Taiwan often excludes natural ventilation due to its potential risk to a successful design. The isolated office spaces with mechanical ventilation are commonly seen in terms of close control of indoor thermal comfort. The building regulations with reference to ventilation design consider the minimum air change rates for indoor air quality mainly. In the regulatory level of Taiwan building industry, some concerns over the opening sizes and locations are defined with relation to the level of interference to the surrounding buildings. Special focuses with respect to the wind engineering of tall building are considered in terms of structural safety. For the green building assessment system of Taiwan, the rewards for natural ventilation design are evaluated in terms of percentage of floor areas with viable natural ventilation. General design strategies are provided without detailed technical data for further performance evaluation. 
The case studies present various approaches to tall building design in their projects from other parts of the world, which are beneficial for deriving lessons for design in Taiwan. The case studies identify the differences between natural ventilation approaches in different climate zones and cultural contexts. The German model, in particular, is characterized by an architectural approach that challenges the conventional method of design, as observed through the introduction of atria and sky gardens with a resulting reduction of rentable area; while opening up the building more to the outside in terms of views, daylight, and natural ventilation. The overall environmental quality of a building is improved by having access to daylight through narrower plans, views towards the outside and transparency between internal and external environments, energy performance of facades, and the integration between natural and mechanical ventilation. Although natural ventilation in office buildings is increasingly common, the norm is to provide a mixed mode solution even in temperate climates. The Commerzbank Headquarters, however, shows that the various technical barriers and arguments for the successful use of natural ventilation in tall office buildings can be overcome and to work extremely effectively.

From the aspect of façade design, the double-skin façade has been widely adopted in Europe, followed by Asia, mainly as a means of improving the thermal performance of building envelope for fully air-conditioned buildings. The effectiveness of the double-skin façade needs to be assessed on a case by case basis, as it related to local climatic conditions, the characteristics of the building form, and aspects of occupation and integration with the operation of building technical systems. Nevertheless, the performance of the facades in most office buildings of Taiwan has been associated with the type of glass, showing the use of high energy-performance glass and double-glazed facades without the considerations of double skins and possibilities of natural ventilation. 
Apart from the basic characteristics of the facades, the attributes related to the label of the 'green' building are drawn from the energy efficiency of building technical systems, more than architectural design, and are mainly related to the format of green certificates. The potential of the building form and the appropriate treatment of the facades in accordance with the local climate have not been addressed in depth as a mean to improve the environmental performance of the building. The deep floor plates are still an issue, being the main limitation for better daylight performance and natural ventilation. In the case of natural ventilation, robust adjustable apertures need to be designed for the facades of tall buildings, and lots of examples of different approaches have been demonstrated in the case studies. It could be one step towards less energy-intensive buildings though the efficiency is highly related to the building form.

Occupant interaction and some level of control over the environmental conditions of the internal spaces in tall buildings have been found to be important. Lessons have been learned in the Commerzbank, Menara UMNO, Torre Cube, and Deutsche Post Tower, for which energy consumption can be substantially reduced when compared to fully automated controls. The selected case studies differ from the conventional model of tall buildings with regard to environmental control and occupant involvement. They can inform and inspire more environmentally challenging buildings but they are not universal solutions. For this particular study, different building configurations are evaluated by various modelling approaches according to the research questions being raised. The considerations for the natural ventilation design in the climate context of Taiwan are derived accordingly. 


\subsection{The prototype building and proposed building configurations of this study}

The key considerations for the generic building configuration design of naturally ventilated tall office buildings for this particular study are discussed with reference to floor-plate sizes, core distributions and sectional treatments. The prototype building and the proposed building configuration of this study are described in detail in Section 2.4.1 and Section 2.4.2. The key concerns for the development of proposed building configurations are summarized as follows.

\section{(1) Plan depth}

British Council for Offices (2009) suggested two types of building plan in terms of plan depth. Firstly, the deep plan building is defined when the distance of window to window (atrium) ranges between 15 to $21 \mathrm{~m}$ (can be deeper) or window to core is between 7.5 to $12 \mathrm{~m}$ or more. This plan type provides large, flexible floor plates. However, the increased depth may require mechanical environmental controls to maintain internal conditions. Key considerations for deep plan buildings include higher running costs, lack of daylight, flexible and efficient space and ability to occupy space densely while maintaining consistent internal conditions. The second plan type, namely the shallow plan, has the characteristic of window to window (atrium) distance of 12 to $15 \mathrm{~m}$ or with window to core of less than 6 to $7.5 \mathrm{~m}$. The shallow plan building will allow the potential use of natural ventilation, but will need to be integrated with the external envelope to allow its controlled use. Key considerations for shallow plan type are the lower running costs, if non-air-conditioned, and potential occupant control via

opening windows. The capital costs per $\mathrm{m}^{2}$ are more expensive than the deep plan of a tall building.

Another definition for the maximum plan depth for natural ventilation and daylighting was proposed by Baker and Steemers $(1996,2000)$ in the LT Method, for which the concept of the passive and non-passive zone was used. In their 
definition, the passive zone was defined as an area in the building within a maximum distance from a perimeter wall, or an area under a roof; the non-passive zones, on the contrary, were those away from the envelope. In the LT Method, the passive zone depth is normally twice the floor to ceiling height, or $6 \mathrm{~m}$ as a default. Many of the advantages and disadvantages are linked between the passive and non-passive zone. For example, the passive zones can enjoy the benefit of daylight and natural ventilation and some useful solar gain in the winter, but may suffer from the unwanted solar gains or heat loss through the envelope in summer. The non-passive zone vise-versa may require mechanical ventilation and artifical lighting, but do not suffer the envelope loss.

\section{(2) Core distributions}

Core design is fundamental both to space efficiency and the building's operational effectiveness. Vertical circulation, services distribution and support functions for the floor plate are typically grouped in cores. Issues for core design include virtical circulation, configuration, floor-plate design, function of service core, service core types and placement, elevator design etc. The core integrates functions and service needs for occupants of multi-storey buildings. It is normally composed of toilet facilities, elevator banks, janitors' closet, utilities, mechanical facilities, smoke shafts and stair. The location and arrangement of cores are discussed according to the proposed building geometry. Considerations for core distribution should be taken with reference to typical floor-plate efficiency, flexibility in the layout and the view outward. Two typical arrangements of service core in tall buildings as suggested by Yeang (2000) are summarized and discussed as follows.

\section{- $\quad$ Centre core arrangements:}

Placing the core at the centre of the building will create a ribbon of usable space between the core and the building's perimeter. The relative size of the site and the

core will determine the depth of the this usable space. The central core 
arrangement offers several advantages in a tall building. First, it maximises the usable space at the bulding's perimeter, allowing a greater proportion of the workspace to be naturally lighted. It also places the core in a structurally efficient location where it can provide for the building's stability. In addition, when the central core combines with a square building plan, bearing exterior and core walls, this location permits a floor plan free of columns and thus totally flexible for office layout. Consequently, it allows for efficient sub-division of the floor plate to accommodate two or more sub-tenancies on a floor without sacrificing usable space. This arrangement allows extremely convenient access for all side and in some cases may be equidistant for the distribution of horizontal utility runs from the core. However, the central interior location limits the depth of offices in the mid-zone of each floor. From the aspect of natural ventilation, the centre core arrangement may lead to the single-sided ventilation for the offices in the perimeter zone. The office spaces near the central core can only obtain the indirect ventilation and may suffer from some air qualty issue if the window-tocore distance is over $7.5 \mathrm{~m}$ as suggested in the deep plan building. However, the introduction of a tall atrium with internal ventilation openings may help to resolve the issue. More discussions are provided in Section 2.4.2.

\section{- Offset core arrangement:}

The centre core arrangement will not suit every occupier or every site. It breaks up the floor plate by blocking views and access across its centre. Central cores may be particularly inappropriate on small sites where the resulting depth of floor would be inflexibly small. Many potential sites do not offer outlook in all directions and cores may be planned adjacent to party walls where workspace would be compromised. Cores may be set at the edge of the floor plate, either in one location or distributed at a number of smaller satellties. This arrangement frees the usable accommodation from the obstructions of the fixed service risers. The resultant floor plate is deeper and allows views and access across the centre. The offset core allows all window or building perimeter space to be used for 
offices. More flexibility in maximum depth and arrangement of spaces are introduced. It also offers the opportunity of developing small secluded space in the relatively narrow portion of the floor plan where the core is close to the exterior walls. Nevertheless, the off-centre core design may present some problems of access and less flexibility of tenant distribution. It is less convenient for the far sides and corners of the building to reach the service cores. Additionally, the potential implications of 'offset cores' for a natural ventilation strategy include the cross-ventilation on floor-by-floor basis for the shallow plan building and the single-sided ventilation if the window-to-window distance is over $7.5 \mathrm{~m}$. A demonstration of this type of natrual ventilation strategy is illustrated as Fiure 2-36 in Section 2.4.2.

\section{(3) Sectional treatments}

The sectional treatment in this subsection is discussed with reference to the adoption of segmented atrium and ventilation cavities. Lessons learned from case studies of Section 2.2 demonstrate how the sky garden can be used as air intake and extraction as applied in the Commerzbank., so that natural ventilation can be achieved in the inward facing offices. In the Deutsche Post Tower, however, the skygarden is only used as extraction chimney. The exhaust air is driven by stack effect out of the top of the building. On the other hand, the sky garden in both cases functions as the buffer zone which regulates the temperatures between the exterior and internal spaces. This offers some benefits as presented by the doubleskin facades, which can provide thermal insulation, protection against undesired weather condition and high wind speed at high levels. 


\subsubsection{The prototype building}

The configuration of the prototype building (the main models) is developed according to a current design in Taipei, Taiwan (Fig. 2-33 and Fig. 2-34). Some modifications are made to utilize the natural ventilation strategies. The architectural feature of the base model is a central atrium with segmentation strategy for the preliminarily investigations (as presented in Chapter 4); while a combination of an external ventilated facade and a central atrium along with the segmentation concept is proposed in the further revised building model (Chapter 5). The potential generic floor plans for naturally ventilated tall buildings of this study are illustrated as (Fig. 2-35 and Fig. 2-36) and corresponding research issues are tabulated as Table 1-1.

The prototype building is square in plan and is divided into four portions with similar configuration, but with different orientation as illustrated in Figure 2-34a. For each portion of the prototype building, an external ventilated facade and a central atrium are proposed as Figure 2-34b. The floor areas of individual office spaces of the initial design are $400 \mathrm{~m}^{2}(20 \mathrm{~m}$ by $20 \mathrm{~m})$ and with floor to ceiling height of $3(\mathrm{~m})$. One thing to be noted is that the revised design reduced the floor area to a $12(\mathrm{~m})$ by $12(\mathrm{~m})$ square plan for modelling cases in Section 5.3 and 5.4.

The cross sectional areas of the atrium are $100 \mathrm{~m}^{2}$ and with segments run up the height of the proposed building configurations. One air flow inlet $\left(9 \mathrm{~m}^{2}\right)$ is located in the ground level of the central atrium. The external envelope of the building is a ventilated double-skin façade (DSF) with one outlet $\left(10 \mathrm{~m}^{2}\right)$ at the top of the DSF cavity and vents connected to individual office spaces. The DSF-vents are located in the higher-end of the office wall while the atrium-vents are in the lower-end of the wall opposite to the DSF-vent side. The initial size of each vent is $9 \mathrm{~m}^{2}(0.5 \mathrm{~m}$ by $18 \mathrm{~m})$ in terms of the summer design condition and is fully opened throughout the simulation. Only one ventilated DSF envelope is applied in the eastern side of the building during the simulations, for simplification. The 
ventilated DSF system is characterized by the outer and inner double glazing and a ventilated cavity in between ( $1 \mathrm{~m}$ depth). The internal walls other than the DSFside and atrium-side are assumed to be adiabatic. The other external wall applied in the southern side is double-glazed without opening. Detailed construction materials used in the simulation are listed as table 3-1.

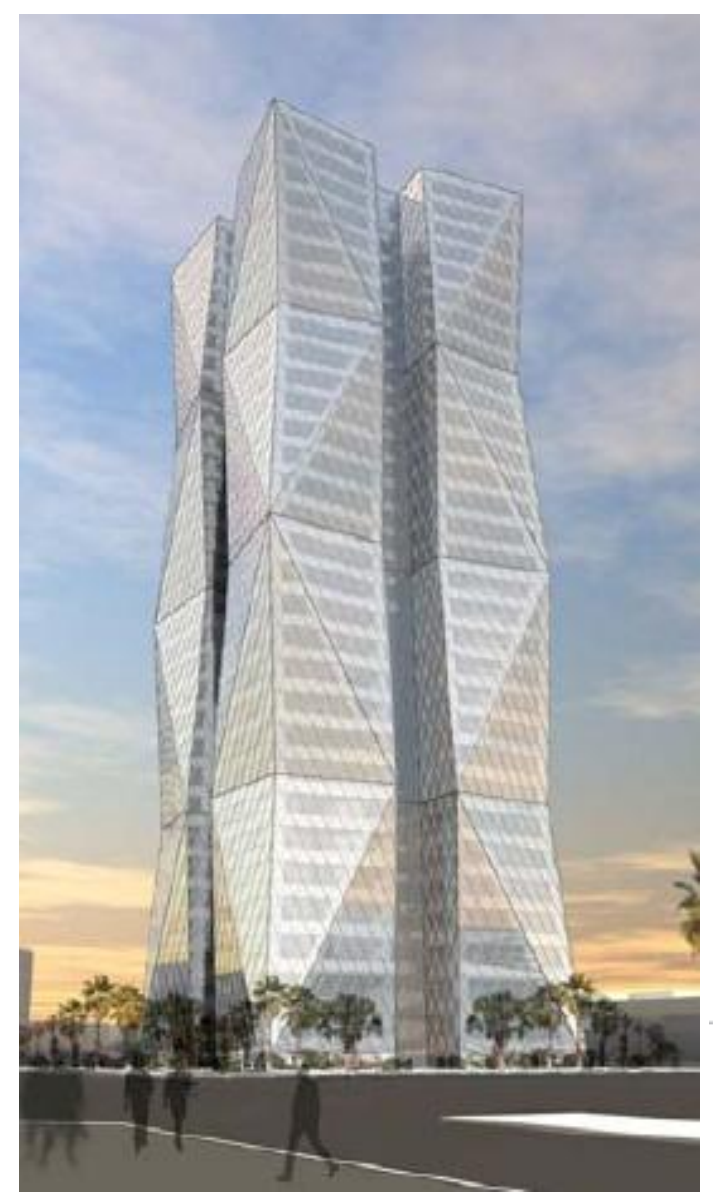

(a)

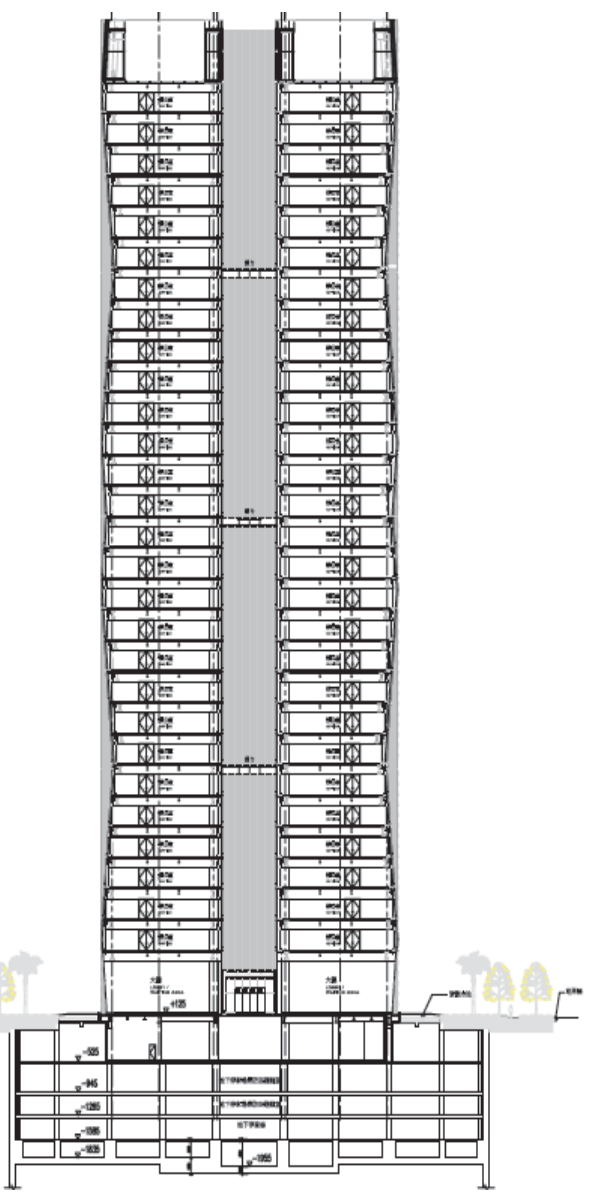

(b)

Figure 2-33: The prototype building. a) A current proposed design in Taipei, Taiwan; b) Building section 


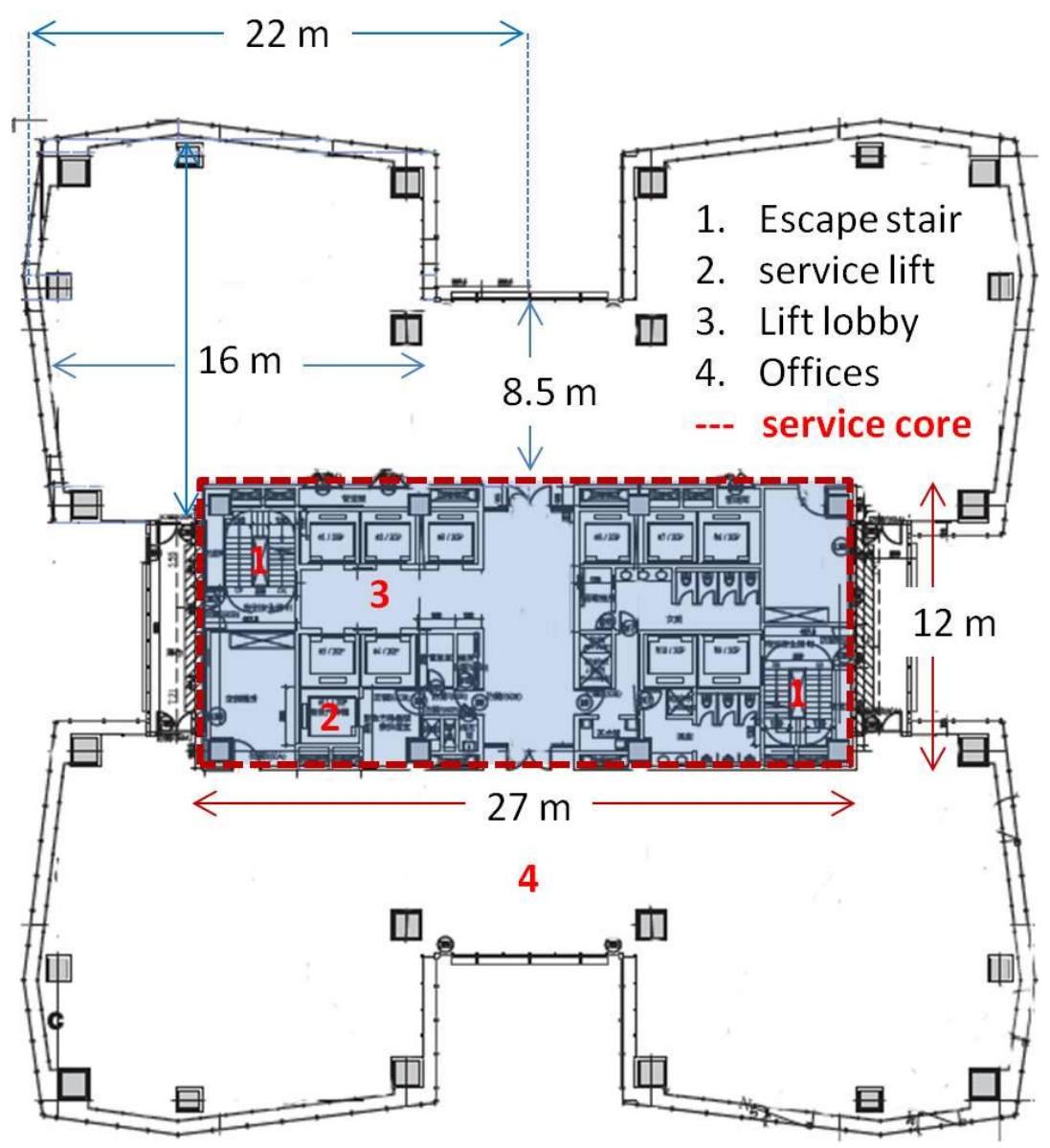

a) China Steel Corporation Headquarter,Taiwan

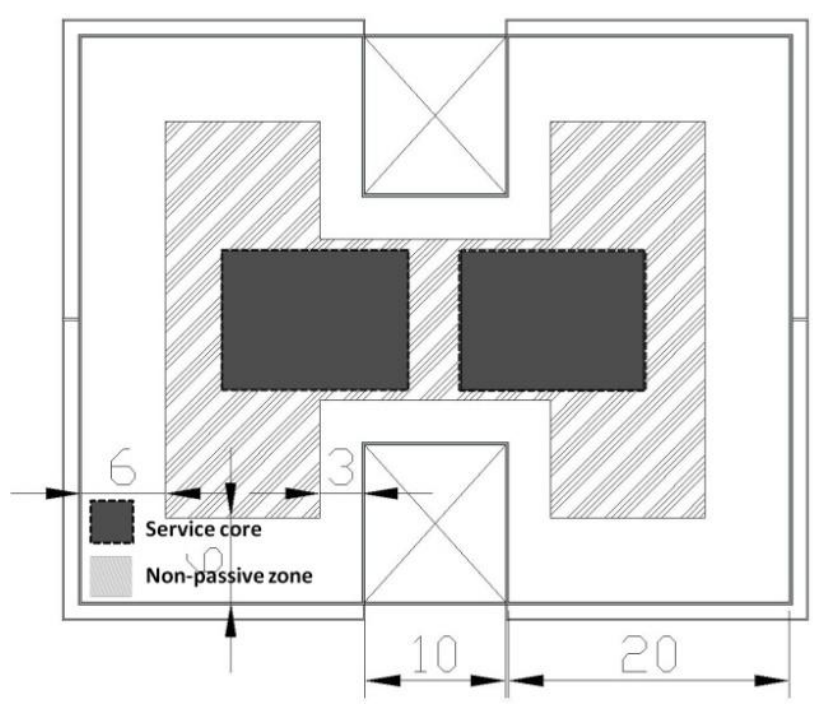

b)

Figure 2-34: a) A design of Taipei; b) The prototype building: simplified base case plan. 


\subsubsection{The proposed building configurations}

According to the above reviews in Section 2.4, it is found that the window to core distance of the original deisgn ranges between 8 to $16 \mathrm{~m}$ for each quarter portion of the whole building plan as shown in Figure 2-34a. Consequently, the present plan layout lies between the shallow and deep plan in terms of the definition in the BCO guide (2009). Moreover, with regard to the zoning for passive areas, as defined in the LT Method, the passive zones of the simplified building plan layout for the original design is illustrated as Figure 2-34b. The distribution of the nonpassive zones as shown in the graph suggests the need for further modification of the plan depth to encourage natural ventilation throughout the floor. On the other hand, though the current design falls short of the definition for receiving natural ventilation, it is supposed that a deeper plan depth along with the concept of ventilated vertical segments can still enjoy the advantages of shallow plan building as addressed above if detailed engineering analysis (e.g. CFD) supports the claimed benefits.

To account for the above questioning, the proposed bulding configuration for natural ventilation is developed according to a current design in Taipei, Taiwan. Some modifications are made to utilize the natural ventilation strategies. The architectural feature of the base case model is a combination of an external ventilated facade and a central lightwell. For the present plan layout, the prototype building is square in plan and is divided into four portions with similar configuration, but with different orientation. As learned from the case studies in Section 2.2, the vertical circulation element (elevator shaft and staircase cores) and service facilities of the Commerzbank and Liberty Tower are pushed to the corners or sides of the tower, thus allowing for unobstructed air flow across office spaces. Another consideration is that the office partitions and furniture might have a direct impact on the performance of natural ventilation within spaces. Detailed CFD approach is required for the evaluation of local air flow distribution. As a general idea, the functions of core may be gathered into a single core or distributed to a number of smaller cores. The position of the core determines the usable space of the building. 
For this particualt study, two potential options of plan layout for natural ventilation with reference to the proposed building configuration in second modelling stage are illustrated as Figure 2-35 and Figure 2-36. For design option 1 (Fig. 2-35), the centre core arrangement is adopted. An access corridor is provided which divids the centre core into two parts and serves the floor with single or possible multiple tenants. However, the centre-core configuration may not be the most appropriate design for buildings with smaller typical floor plates, buildings with certain site conditions, or buildings with special functions such as trading floors. In terms of the implications for natural ventilation in the building plan with centre core, the single-sided ventilation strategy may be employed along with the tall ventilated cavities in the atrium and the double-skin facades. The cross ventilation is less likely to be applied because of the blockage of the ventilation path from the central core. The illustration of the potential ventilation path of the centre core arrangement is presented as Figure 2-35. One thing to be noted is that, the single-sided and cross ventilation on floor-by-floor basis (refer to the isolated case in Section 2.4.2-1) are not investigated in the main investigations of this study (refer to the ESP-r models in Section 2.4.2-2); while the it is evaluated in Chapter 4 by the use of Envelope Flow Model.

As for the second potential design option (Fig. 2-36), the core is distributed into four smaller cores and is pushed to the four corner of the building layout. The centre atrium can then be extended or remains as it is in the centre core arrangement. The core can open to the exterior environment and allow for natural ventilation. Also, the core can shade the office space from the sun. The usable area can usually be organized into one space. Nevertheless, its use is limited on large floor plates because travel distances to the fire stairs and elevators do not meet code requirements. From the aspect of natural ventialtion, the offset core with shallower plan depth may have the potential for cross ventilation; while the single-sided ventilation along with the concept of ventilated cavities as applied in the centre core may also be employed. Figure 2-36 demonstrates one of this ventilation strategy. 


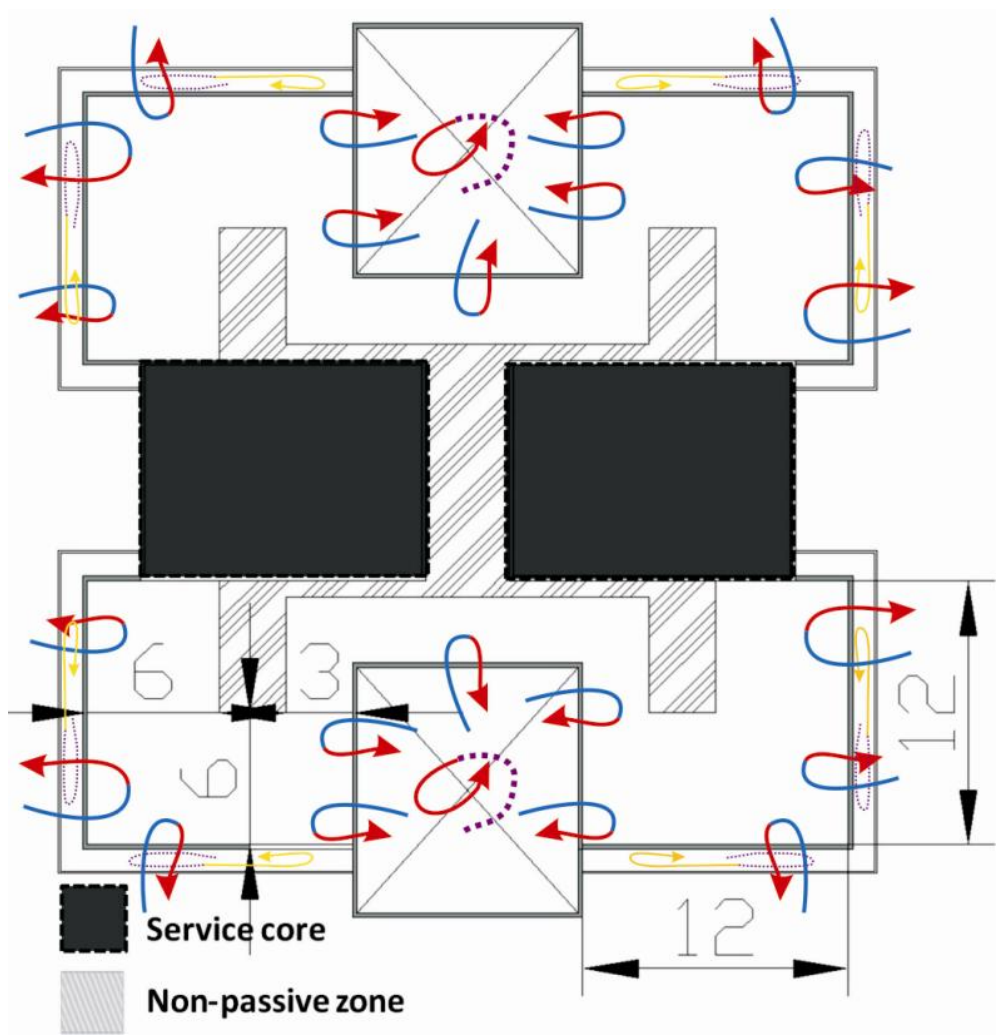

Figure 2-35: The generic diagram for naturally ventilated floor plan_ Potential design option 1

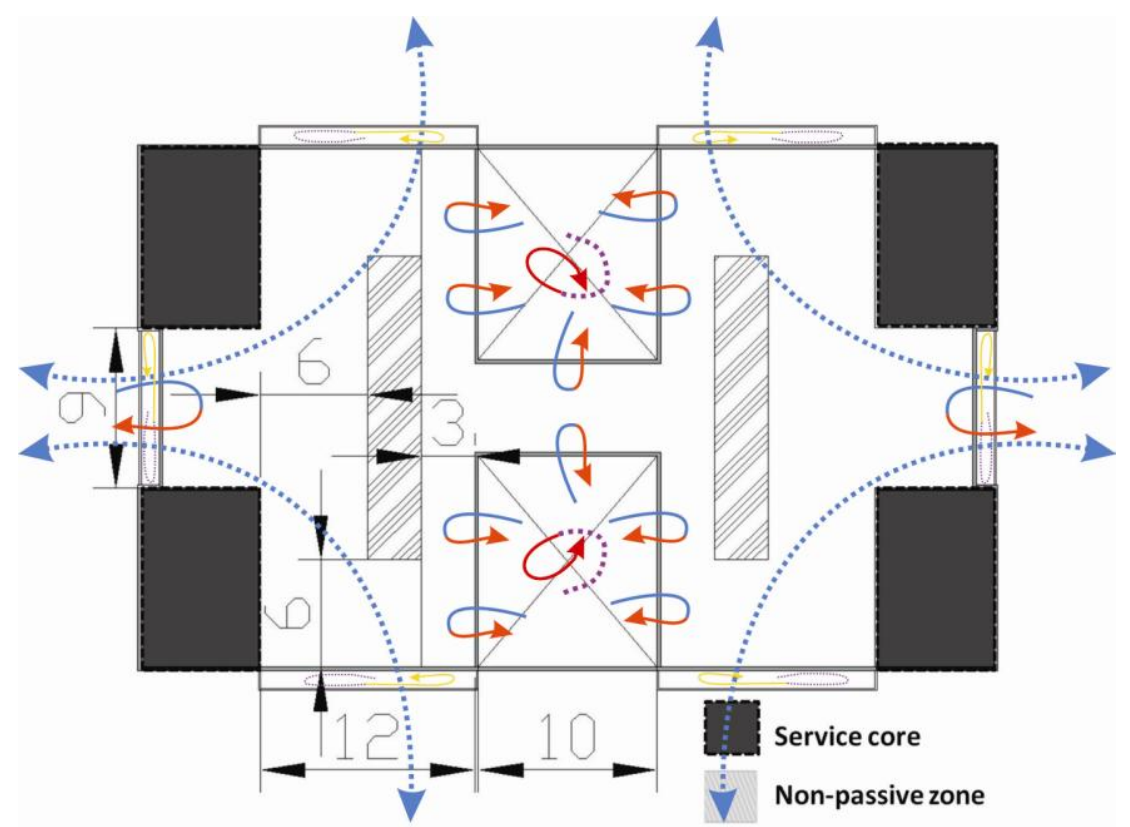

Figure 2-36: The generic diagram for naturally ventilated floor plan_ Potential design option 2

For the base case building configurations (Fig. 2-40a), two defferent plan depths for a quarter portion of office are adopted and presented as Figure 2-40b. For one, 
the floor areas of individual office spaces (quarter portion) are $400 \mathrm{~m}^{2}$ (20 m by $20 \mathrm{~m}$ ) and with floor to ceiling height of $3 \mathrm{~m}$; while the other is revised to a shallower plan with $12 \mathrm{~m}$ by $12 \mathrm{~m}$ in area. The cross sectional areas of the corresponding atrium are $5 \mathrm{~m}$ by $20 \mathrm{~m}$ (or $12 \mathrm{~m}$ ) for each quarter portion of building plan and with diverse height according to the segmentation proposed. The external envelope of the building is a ventilated double-skin façade which is characterized by the outer and inner double glazing and a ventilated cavity in between $(1 \mathrm{~m}$ depth). One thing to be noted is that the window to core distance of $12 \mathrm{~m}$ is adopted for the modelling throughout Section 5.3, 5.4 and Chapter 6; while the $20 \mathrm{~m}$ case is adopted in Section 5.2. It is therefore the criteria for the corresponding required flow rates for cooling are varied. The total heat gains (defined by watt per square metre) needed to be removed with the ventilation air are caclulated by Equation 3-1, for which the required flow rates are derived.

Furthermore, the floor plate efficiency is evaluated by the ratio of net internal area (NIA) to gross internal area (GIA) for a typical floor as defined by the British Council for Offices (BCO) in 2009. The suggested ranges for floor plate efficiency of typical multi-storey office buildings are presented as Figure 2-37. To take the potential design option 1 for example, the GIA for the porposed building plan is $1156 \mathrm{~m}^{2}$ while with NIA of $726 \mathrm{~m}^{2}$, when the core areas of the original design and two proposed atrim are applied. Accordingly, the floor plate efficiency of $63 \%$ is then derived, for which the number of storeys over 40 floors is required for achieving the requirement as addressed in the cost model. Generally speaking, the distribution of the passive zones as presented in Figure 2-35 and 2-36 identifies the potential application for conventional single-sided and cross ventilation. It is supposed that a deeper plan depth along with the concept of ventilated vertical segments can be applied so as to improve the overall floor plate efficiency. Nevertheless, the advantages of shallow plan building to the this building typology can only be applied if detailed engineering analysis supports the claimed benefits. 


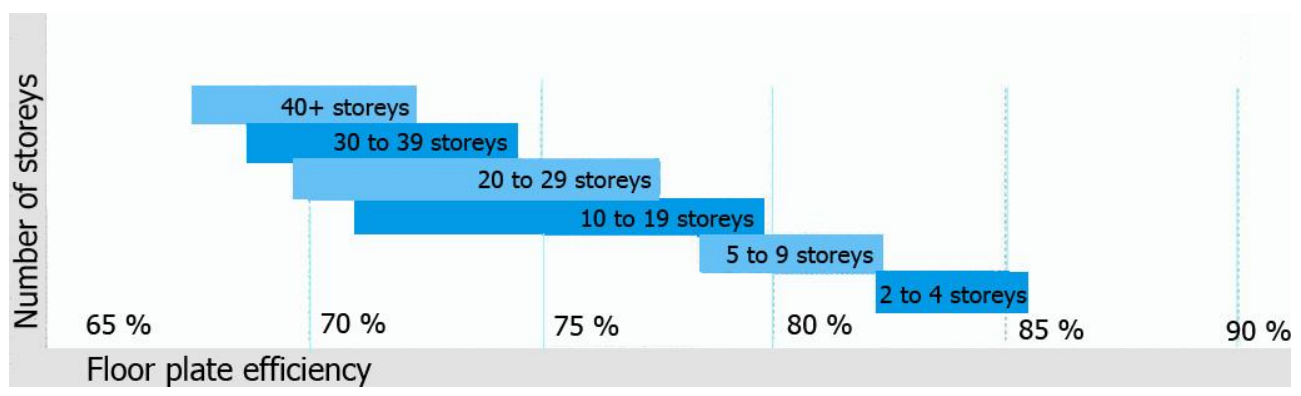

Figure 2-37: Ranges of floor plate efficiency of typical multi-storey office buildings (BCO, 2009)

In the current study, the segmentation is proposed within the atrium and doubleskin-facades. To comply with the proposed square building geometry, the open atria solution is selected for current study, because they can be used to assist the operation of mixed mode and natural ventilation solutions in shallow plan. Furthermore, the floor plate efficiency can be improved and more creative space planning options are available by the employment of building shapes based on atria. Atria can also provide the opportunity to create a social hub for occupant interaction.

Additionally, the concept of ventilated cavity is adopted in present study in the double-skin facades for the additional benefit of providing a climatic buffer zone between internal environmentally controlled space and external environment. In the Deutsche Post Tower, the double-skin facades are segmented for every nine floors through the use of horizontal divisions at the level of skygardens. The segmentation can then prevent the temperature differences from acting over the full height of the building. Consequently, the potential risks associated with the greater magnutudes of pressure difference in the bottom and top floors can be avoided. The sectional treatment for the proposed generic design is illustrated as Figure 2-38. The segmentation concept is adopted in both the cnetral atrium and ventilated facades of building envelope (Fig. 2-38a). 
Furthermore, the concept of 'wind floor' as introduced in the Liberty Tower of Meiji University is adopted for the proposed building configuration. The viable height of building segmentation for achieving the desired ventilation performance are discussed in Section 5.3. The second generic building configuration is proposed along with the adoption of 'open wind floor' as presented in Figure 2$38 \mathrm{~b}$, which also demonstrate an alternative for the segmentation concept in tall ventilated cavities in correspond to the jurisdiction of fire safety issues in Taiwan.

This study is divided into two parts of investigations, namely the preliminary and the main investigation. Different modelling tools are used for different parts of investigation due to the research questions at hand as well as the complexty of the test models of the later investigation stage (the main investigation). In the preliminary investigations of this study, the single-cell envelope flow model is adopted for testing the ventilation performance of three basic configurations of tall office buildings. The effect of cross ventilation and building segmentation is identified accordingly. The building configurations are further revised to more complicated model with ventilated facades in the main investigations. This system is proposed to benefit from the tall ventilated cavities (the central atrium and double-skin facades) as well as the indirect cross ventilation through the occupied spaces. The building configurations being adopted for each part of investigation are described in detail in Section 2.4.2-1 and Section 2.4.2-2 respectively.
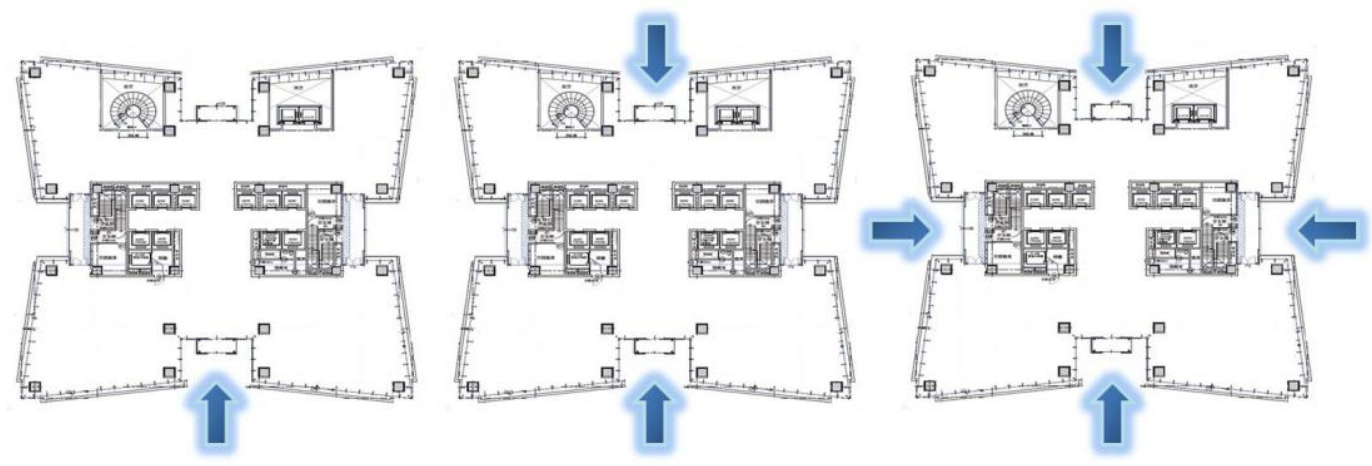

(a) 


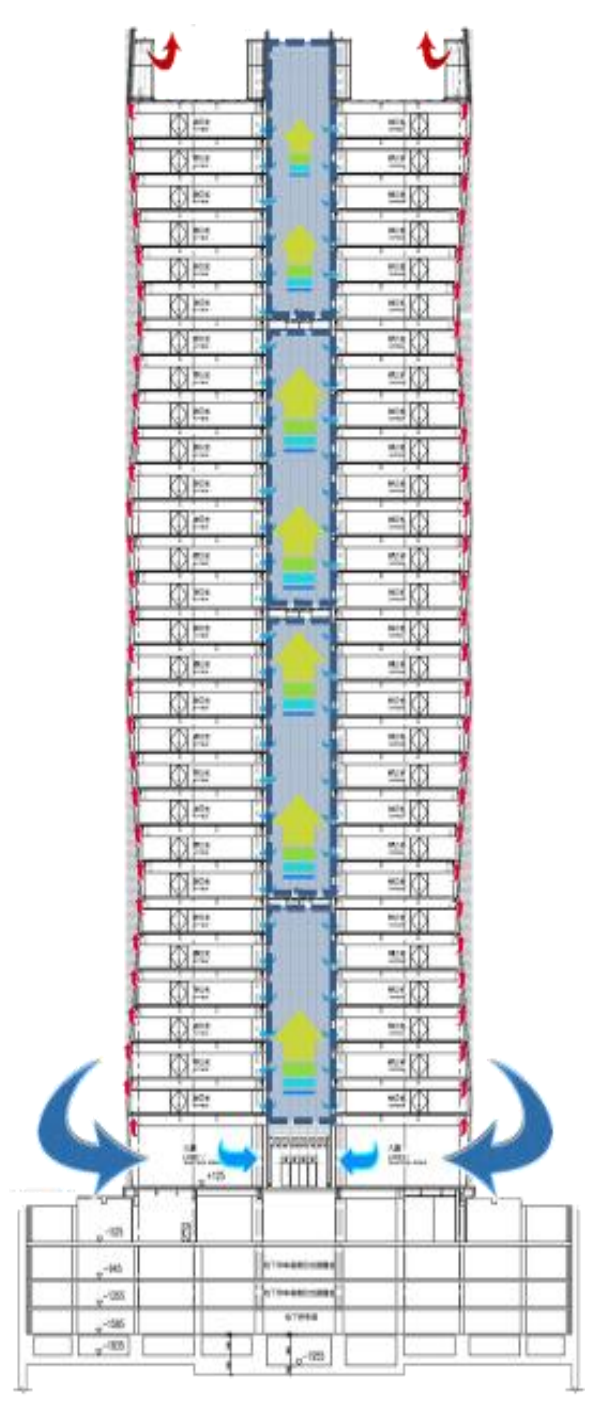

(b)

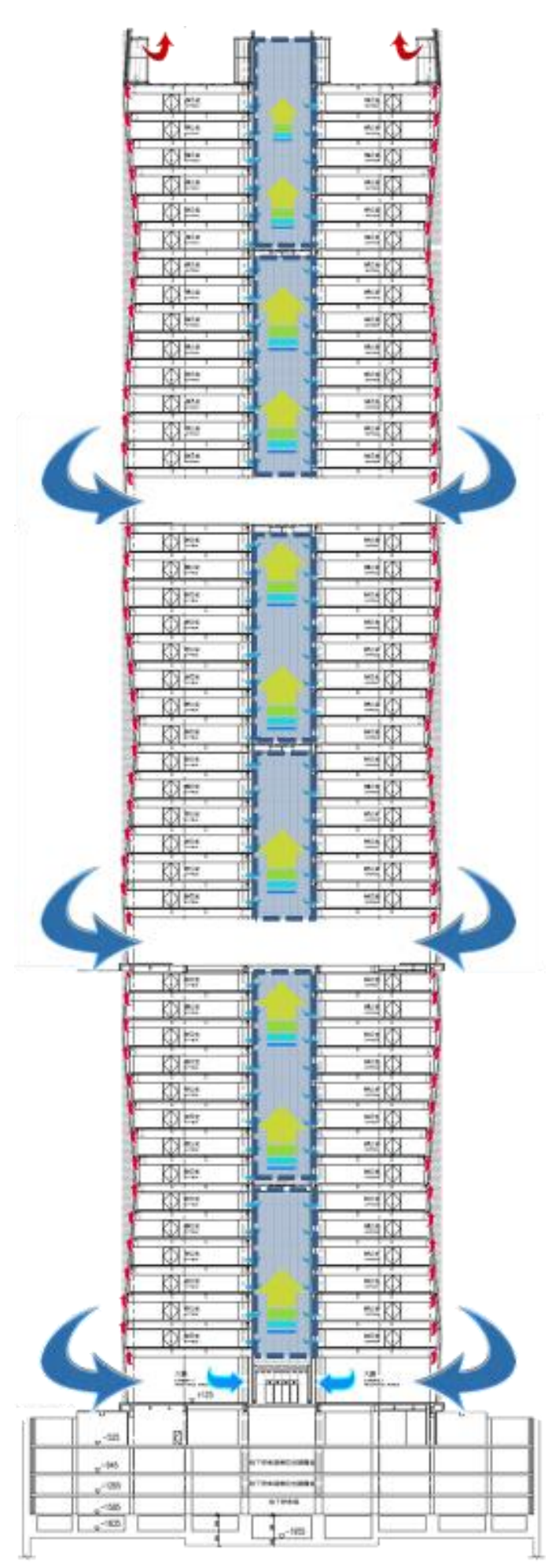

(c)

Figure 2-38: The generic diagram of the plan and sectional treatment for naturally ventilated tall office buildings. (a) The building plan, (b) The base case, (c) Lifted case 


\subsection{2-1 The preliminary investigations: Single-cell building configuration}

In this study, the preliminary investigations are undertaken using the single-cell envelope flow model. Detailed background information for the modelling tool is described in Section 3.3.1. Three types of conventional naturally ventilated tall office building design, namely isolated, non-segmented and segmented, are defined for this part of investigations. The synoptic diagrams are illustrated as Figure 2-39.

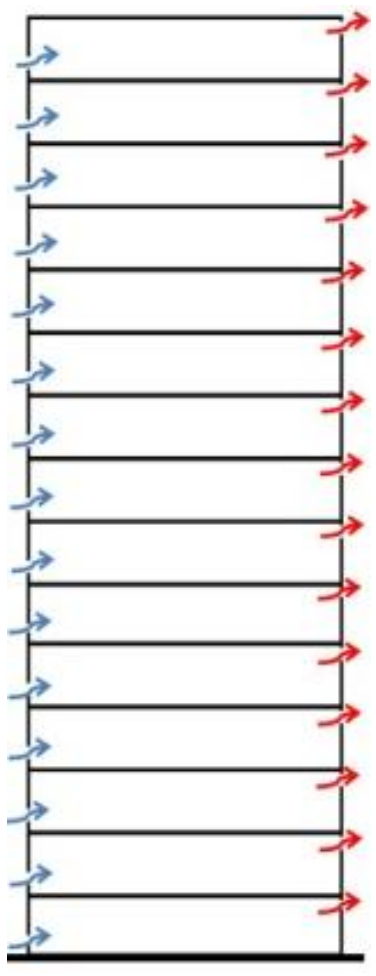

(a)

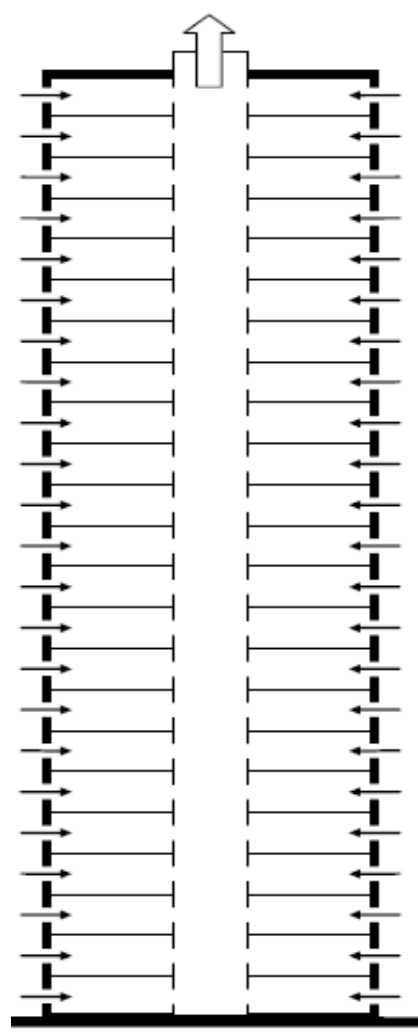

(b)

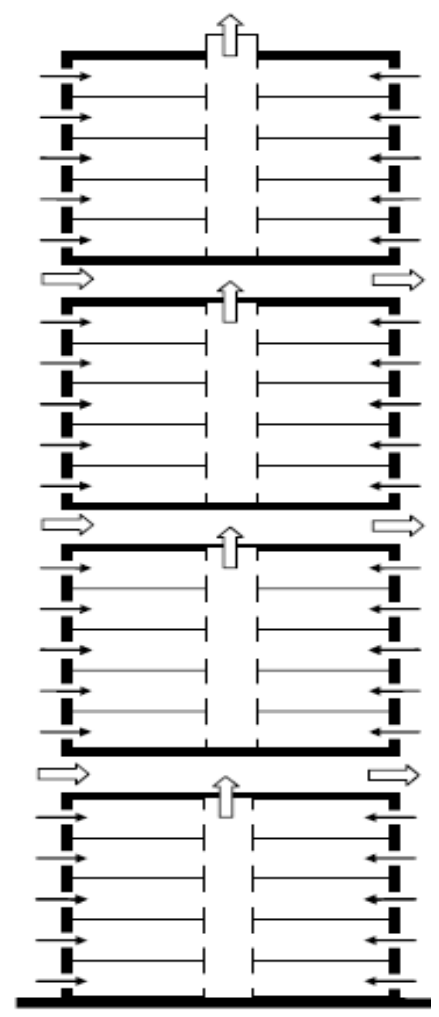

(c)

Figure 2-39: The single-cell models: (a) Isolated spaces, (b) Non-segmented and (c) segmented atrium buildings (Etheridge and Ford, 2008)

For the single-cell model, spaces for which have relatively large openings between them can be considered as connected in the sense that there is negligible pressure difference between them. Consequently, when the spaces in a building are connected by large internal openings, they effectively form a single-cell, with 
the flow through any opening dependent on the flow through the other openings. Such spaces are relatively common in naturally ventilated buildings, partly because of the desire to minimize internal resistance to flow and partly to enhance internal mixing. Figures 2-39(b) and 2-39(c) demonstrate one such strategy, based on the use of a tall atrium. The atrium is used to generate inward flow of fresh air into all of the occupied floors. However, this approach will cause problems to openings of lower floors in tall buildings due to the high pressure differences generated by buoyancy. In the preliminary investigations, the single-cell model is adopted for evaluating the ventilation performance over a range of specific ambient conditions. The effect of cross ventilation and building segmentation to the proposed building configurations (Fig. 2-39) is evaluated. The monthly average weather data over occupied hours is used to estimate the monthly averages of flow rates and temperatures. Time-averaged conditions are chosen to compare the suitability of the configurations for natural ventilation.

\subsection{2-2 The main investigations: Multi-cell building configuration}

The multi-cell model is one in which a building is represented by a series of zones or cells interconnected by flow paths. Flow equations are applied that relate the pressure difference acting across each flow path through openings. This is not only in the sense that partitions can increase the resistance to flow through the building, but also in the sense that they allow temperature differences between rooms to be defined. The equations that are solved and the assumptions that are made are in most respects the same as for single-cell EFM models (CIBSE AM10, 2005). The building configurations being adopted in the main investigation are illustrated as Figure 2-40 and 2-41. In the main investigations with the multi-cell building configuration, the explicit method of EFM is adopted to size the external openings; while the dynamic thermal simulation with an air flow network (AFN) further divides the whole building into zones or cells, where the internal openings are then assigned a value equal to the external openings. For the proposed base 
case models of the main investigations, the office spaces (cells) have one node in each; while the atrium and ventilated façade segments are divided into 5 zones. A detailed diagram showing the nodes used is presented as Figure 2-40c.

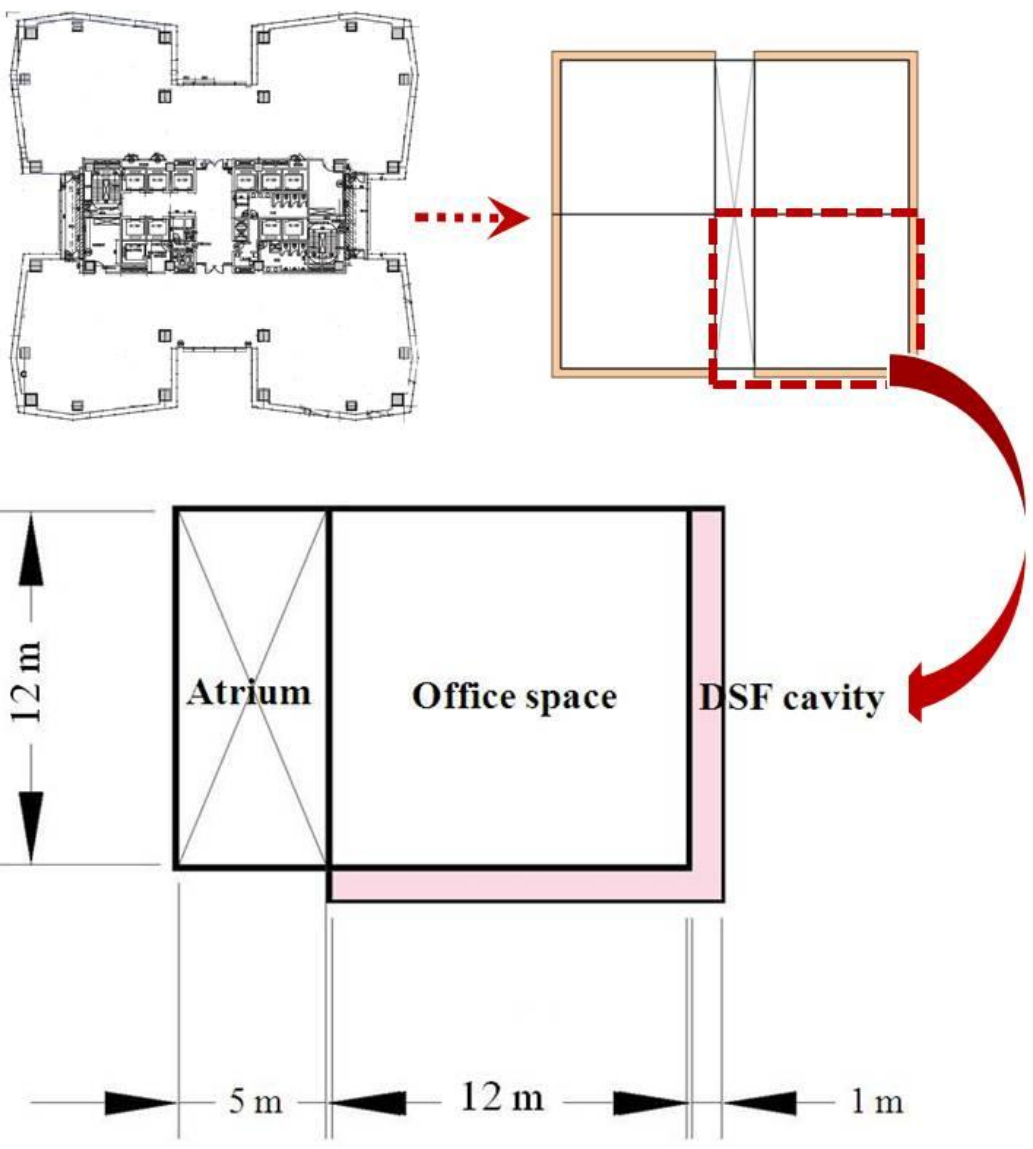

a) Development of prototype building

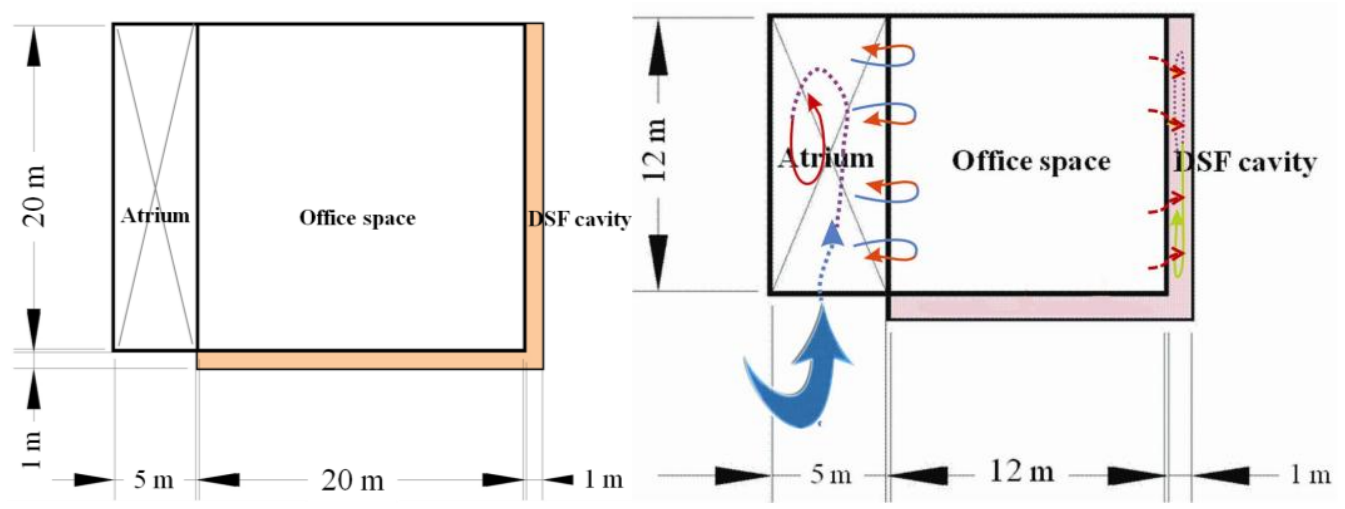

b) Portion of the base case models: Ddeep plan(left)\&Shallow plan (right) 


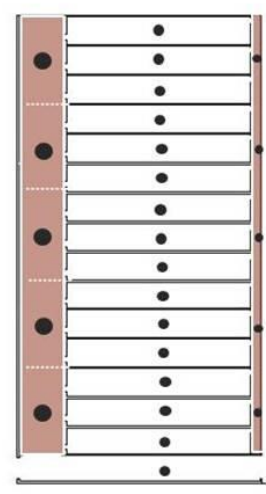

Non-segmented_15FL

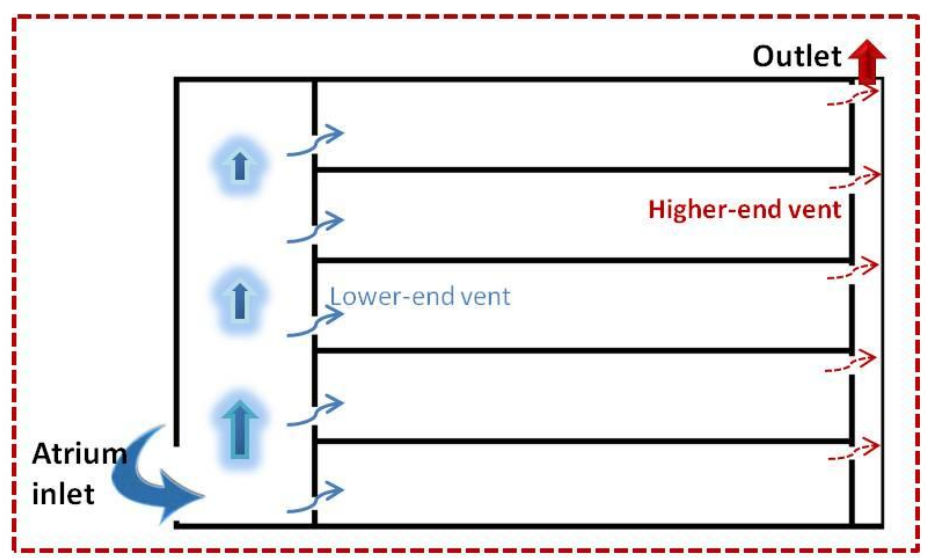

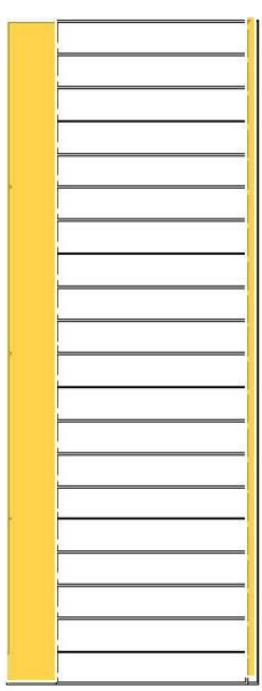

Non-segmented_20FL

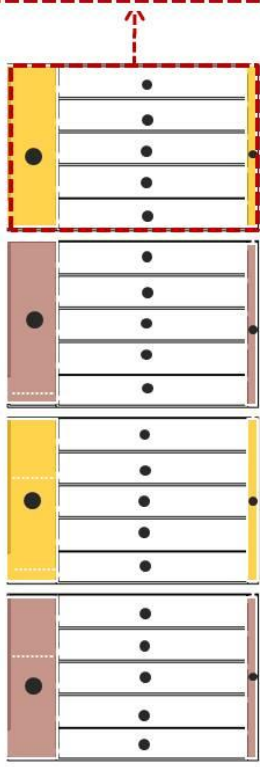

Segmented_5FL

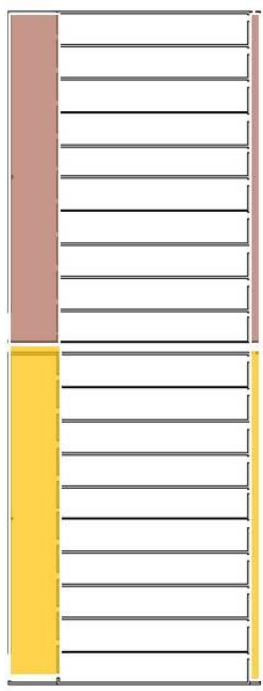

Segmented_10FL

c)

Figure 2-40: The base case models of main investigations. a) The development of prototype building, b) Plan, c) Section and proposed ventilation strategy

Further ventilation strategy, namely the 'open wind floor', is evaluated in the main investigations as well. The difference of the base case and refined building configuration design is illustrated as Figure 2-41. The 'open wind floor' can be regarded as an open ground floor in the bottom segment (lifted case) or a way for segmentation in the middle segments of a building. An open ground floor with different sizes of air intakes are shown as Figure 2-42. For the case with twosided air intake (Fig. 2-42c), namely in the south and the east, of the lifted case is revised from the base case building configuration of the main investigations. The 
architectural features of a segmented atrium and ventilated double-skin facades remained, but with an open floor in the lowest level of each segment. The dimension of floor plan is reduced to $12(\mathrm{~m})$ by $12(\mathrm{~m})$ for better practice of cross ventilation across floor plan.

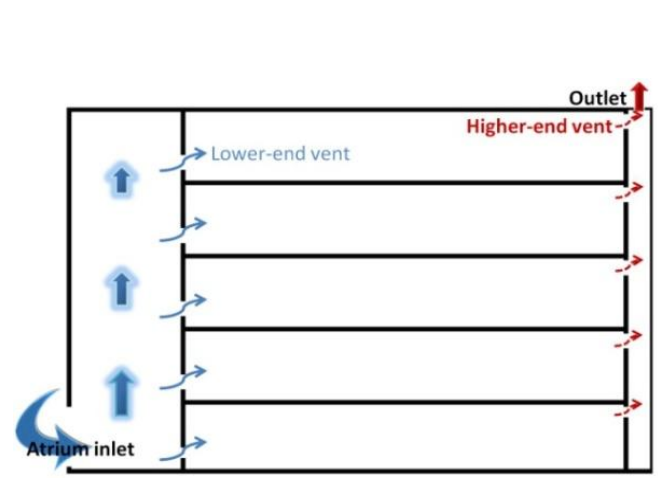

(a)

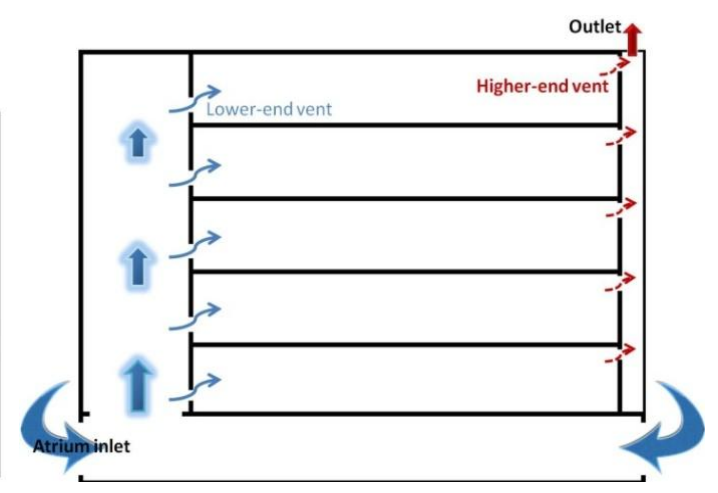

(b)

Figure 2-41: The proposed building sections. (a) The base case; (b) The refined case

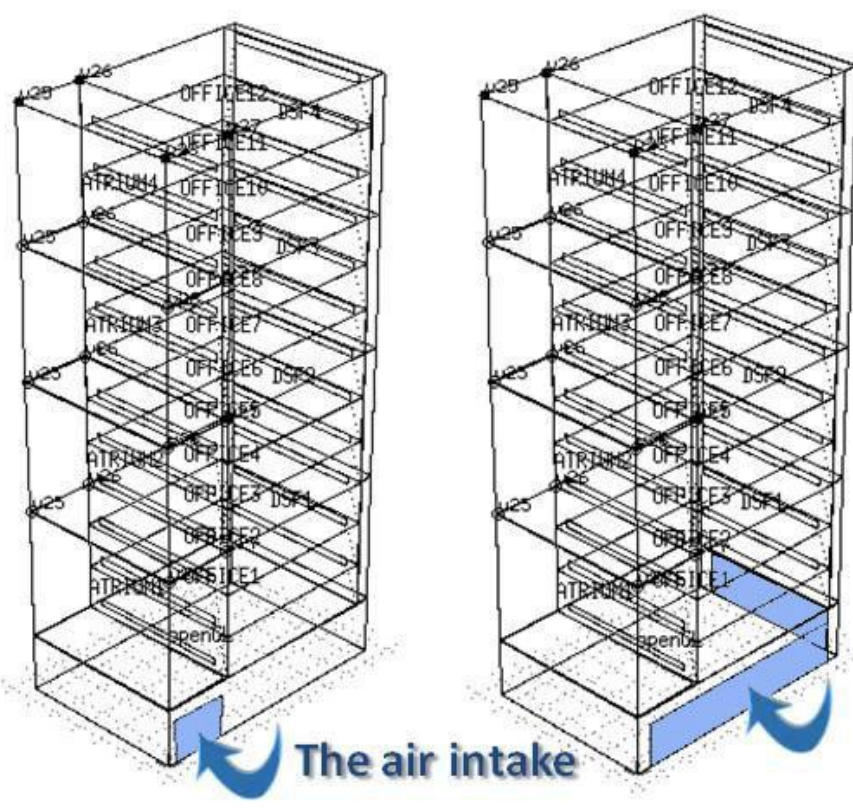

(a)

(b)

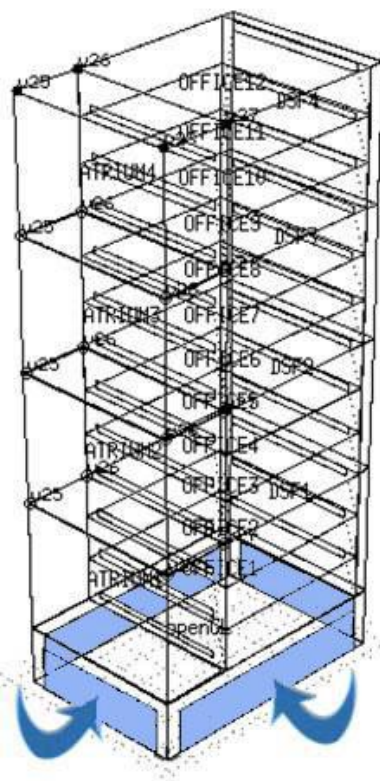

(c)

Figure 2-42: The air intake scenario of the lifted case. (a) Single, (b) 2 sides, (3) 4 sides 


\subsection{Summary}

This Chapter starts with overviews of naturally ventilated tall office buildings design in Section 2.1. The concerns for applicability of natural ventilation in tall office buildings are raised. Section 2.2 then continues with case studies of naturally ventilated tall buildings design worldwide. The design issues and ventilation strategies adopted in the real-world applications are reviewed. Their corresponding performances in terms of energy consumption are addressed as well. The issues of naturally ventilated tall office buildings design in the climatic context of Taiwan are raised in Section 2.3. The problems and limitations of natural ventilation design in tall office buildings of Taiwan are discussed. The proposed naturally ventilated building configurations for this study are determined for the corresponding modelling stage in Section 2.4. The assumptions and boundary conditions for the specific modelling tools are defined accordingly.

The five case studies addressed the passive cooling strategies adopted and their corresponding mechanical back-up in detail. However, sufficient technical references to demonstrate their claimed benefits in terms of thermal comfort are limited. Though those design is framed in the context of energy efficient, their viability for providing satisfactory daily delight to the end-users are still in doubt. It is supposed that the sensation and expectation for comfort ventilation should also take the cultural and geographical factors into consideration. Nevertheless, this issue is rarely addressed in these case studies as far as known.

In addition, although natural ventilation is considered as a global interest, but its detailed design issues are still specific to certain group of people in Taiwan at the moment. Maybe the regulatory authorities of Taiwan should be a more active partner in exploring the incentives of natural ventilation in building design (tall office buildings for this research in particular). The research outcomes can then be enjoyed by a broader audience. It is also supposed that the proposed design approach and procedure for naturally ventilated tall office buildings may be fed back on regulation levels in the near future. 


\section{Methodology}

\subsection{Chapter overview}

This Chapter focuses on the methodology being adopted for this particular study. A method overview and recent applications of ventilation performance prediction for buildings are reviewed in Section 3.2. The Phases involve in the natural ventilation design of tall buildings are outlined in Section 3.3. For which the descriptions of three modelling stages within design phase 2 and 3 (design development and performance evaluation) and the corresponding theoretical background of tools being adopted are presented in Section 3.4. For this particular study, the overall aim is to ensure that the proposed tall building configurations can deliver acceptable comfort environment for the occupant through natural ventilation alone. That is, the approach for overall assessment of comfort ventilation is raised in Section 3.5. The manner in which individual methods feed into the subsequent chapters is described as follows.

The overall design procedure for a naturally ventilated tall office of this particular study is presented as Figure 3-1, which include four design phases and with three different modelling stages in between. More specifically, the proposed design procedure is applied in the proposed main building configurations as stated in Section 2.4.2-2. The detailed results and discussion are presented in Chapter 5. The preliminary investigations of this study, however, is conducted by the implicit method of the envelope floe model (EFM) only; although the explicit method of EFM is adopted for sizing the envelope openings for both the preliminary (refer to Chapter 4 for more detailed result discussions) and main investigations. The CFD approach being adopted for this study aims to provide higher resolution of local performance (either temperature or air flow speed) of indoor spaces. The CFD results are then feedback to the Building Bioclimatic Charts for the assessment of thermal comfort. The overall ventilation performance of the proposed main building configurations is presented in Section 6.4. 


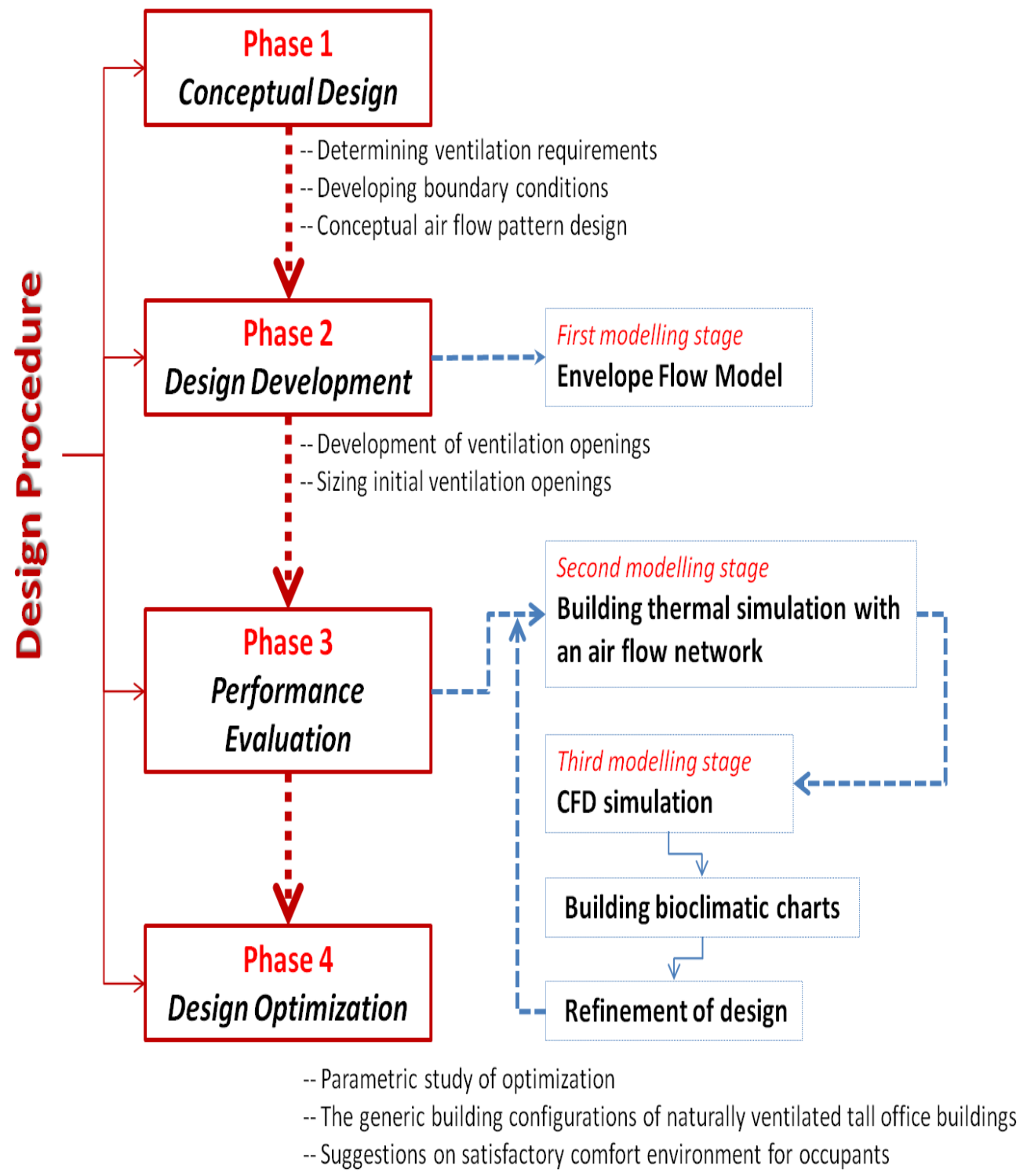

Figure 3-1: The proposed generic design procedure for naturally ventilated tall office buildings 


\subsection{A method overview and recent applications of ventilation performance prediction for buildings}

There are a range of design tools available for natural ventilation design. The design process is progressive and iterative, different tools being more suited to different stages in the development of the design. Among them, envelope flow models are the simplest tool and are recommended for the initial sizing of openings at the chosen design conditions. Envelope flow models solve the equations that govern the flow of air through openings in the envelope of a building. They rely on assumptions about the internal density (temperature) distribution. The basic equations for a single-cell can be illustrated by considering an opening in the envelope. Multi-cell envelope flow models are the general case of single-cell envelope flow models. They include the effect of the internal partitions, not only in the sense that partitions can increase the resistance to flow through the building, but also in the sense that they allow temperature differences between rooms to be defined. The equations that are solved and the assumptions that are made are in most respects the same as for single-cell models. In this research, the single-cell envelope flow model is chosen as the design tool at the first modelling stage for sizing the openings (explicit method of EFM); while the implicit method of EFM is only adopted to evaluate the off-design condition of the preliminary building configuration, for which the detailed results are presented in Chapter 4.

Chen (2009) and Chen et al. (2010) reviewed the tools for ventilation performance prediction in buildings. The model assessment was done in terms of capability and time cost. It was suggested that a multi-zone airflow network model was much preferred for giving the required information at a reasonable cost with reference to ventilation performance prediction in a moderately- or largesized building. He suggested that the experimental measurements with small scale and large-scale mock-ups would not be realistic in terms of their costs. The analytical and empirical models would not produce useful information for 
ventilation performance analysis as well. A CFD model, however, would need more computing time for such a building, which made the CFD model not attractive as a tool in the initial stage of design development. They then concluded that the multi-zone models might be the best choice for a whole building. In this research, the dynamic thermal simulation (multi-zone) with an airflow network is proposed for the second stage of modelling. The main building configurations as proposed in Section 2.4.2 are adopted for the evaluation of ventilation performance of a whole building. The results and discussions are presented in Chapter 5.

Nevertheless, the multi-zone models can only provide average characteristics of airflows due to the various assumptions used. The CFD models, however, provide the most detailed information about the performance of ventilation systems in a zone, and are the most accurate approach of the numerical models, but they are sophisticated and require very dedicated training of a user. Although it could be possible to apply the CFD models to a whole building, the computing time would be too long for initial stage of design development. Since the CFD models use approximations, it would be essential to validate the models. A validated CFD model would be a powerful tool for conducting a parametric study or for optimizing the design of ventilation systems in buildings. Chen (2010) then concluded that no universal model was available for predicting ventilation performance. Selection of an appropriate model would depend on the problem studied during different design stages.

As Chen et al. (2010) suggested, CFD would continue to be a research tool for predicting ventilation performance in buildings in the foreseeable future. It is consequently that the CFD models should be more reliable and faster. Reliability as described by Chen (2009) is a major issue at present since the validation by experimental data requires a lot of effort regardless the data are obtained by the CFD modellers or from the literature. The CFD speed will continue to improve as computers are becoming faster. At the mean time, the demand on computing time will increase not only because of the need for more sophisticated CFD models to 
model the more complicated ventilation problems, but also because more grid cells are adopted in the proposed ventilation problem. Now the question is to what extend that the CFD approach can help with the proposed design procedure of naturally ventilated tall office buildings for predicting ventilation performance in this particular study. This study aims to identify how tall buildings can deliver acceptable internal condition through natural ventilation alone. CFD is used to help evaluate the thermal comfort issues and the corresponding results are presented in Chapter 6. The proposed design procedure of the naturally ventilated tall office buildings for this particular study is derived from the overall research objectives as suggested in Table 1-1. A diagram to illustrate the design flow chart and issues being investigated for this study is presented as Figure 3-1. The three modelling stages involved in this study are described as follows.

For the first modelling stage, the explicit method of the envelope flow model is adopted to size the envelope openings. It is then suggested that the year-round feasibility with reference to the resultant air flow rates of the occupied space can be obtained by the use of dynamic thermal simulation with an air flow network in the second modelling stage. The statistical analysis is conducted to look at the probability of potential scenario, especially for the time when the design goal cannot be achieved. The local ventilation performance under the fixed boundary conditions (derived from second modelling stage in ESP-r) is then identified by the detailed full CFD simulation in the third modelling stage.

To be more specific for the three modelling stages, an explicit method of the envelope flow model approach is used to size the ventilation openings of the proposed main building configurations. The steady-state bulk flows through openings can then be evaluated under a specified design condition using the implicit method. The potential periods of time where the design condition cannot be met are addressed accordingly. One thing to be noted is that only the preliminary building configurations (Fig. 2-39) are evaluated using the implicit method of EFM. Further modelling tool, the dynamic thermal simulation with an air flow network, is adopted in the second modelling stage for the main building 
configurations (Fig. 2-40). The aim is to obtain more detailed information on the ventilation bulk flow of a more complicate model and its potential cooling effects for the corresponding thermal domain. The hourly variation of bulk flow and air flow direction through openings can then be found. The influence of revised building configuration (with ventilated double facades and open wind floors) are examined by the same modelling approach as well.

However, the envelope flow model and the thermally conflated mass flow network approaches assume that the air in a room is well mixed, which implies uniform distributions of air temperature and air flow patterns. For small rooms, such as small offices, hotel rooms, and bedrooms, such an assumption is often acceptable. For large spaces, like buildings with tall atriums and open working spaces as proposed in this study, the complete mixing assumption may not be valid. For further quality assurance of the natural ventilation system, the local ventilation performance should be considered. The CFD approach is then adopted in the third modelling stage for more detailed air temperature and air flow speed distributions. Finally, the calculated results, namely the temperature, relative humidity and indoor wind velocity, are plotted in the Building Bioclimatic Charts (BBCCs) for comfort ventilation assessment. The refinement of design, i.e. vertical segments and wind floor, is then developed for next run of performance evaluation, when the calculated ventilation performance is not satisfactory.

The novelty of this work lies not in the methods used (which uses available models), but in the evaluation of segmented and non-segmented tall buildings. The air flow patterns (and temperatures) observed with the proposed building configurations are compared, for otherwise identical conditions. Potential conditions where the design goals (thermal comfort) may not be ensured are identified. The overall ventilation performance is evaluated in terms of the required flow rates and flow patterns for cooling. 


\subsection{Plan for natural ventilation design of tall office buildings}

The key phases for the natural ventilation design of tall office buildings of this study are outlined as following sub-sections.

\section{(1) Design phase one: The conceptual design}

This study firstly starts with planning sketch and notes. The main concerns for this stage include the building configuration and ventilation strategies. The natural ventilation principle of buoyancy and wind are adopted separately or in combination in this study. However, the wind alone case is not discussed because of the stack effect in tall buildings is a natural phenomenon and cannot be avoided except for the isolated case with limited buoyancy effect. Due to the potential magnitudes of wind and buoyancy forces in tall buildings, the design challenges are much greater. Etheridge and Ford (2008) proposed that segmentation might offer the least risky approach for envelope design of non-residential tall buildings. For the preliminary investigations, the building configurations of the isolated floor and atrium type buildings are evaluated by the use of single-cell envelope flow model. The atrium type buildings are further divided into segmented and non-segmented cases as shown in Figure 2-39 (b) and (c). The steady-state bulk flows through openings are investigated under a specified design condition. Detailed results and discussions are presented in Section 4.3. The building configurations are revised further to accommodate the concept of segmentation along with ventilated cavities (double-skin facades and tall atrium), which is expected to provide more encouraging results for natural ventilation in tall buildings. Detailed descriptions on the building configurations adopted for this research are presented in Section 2.4.2. 


\section{(2) Design phase two: Design development}

This study aims to investigate the effect of air flow rates for ventilated cooling, where the air movement may also be helpful in improving people's sensation for thermal comfort. Detailed envelope design in this design phase focuses on sizing the openings. The air flow rates required will depend on the ventilation purpose. For cooling purposes, the incoming air should be at a lower temperature than the indoor air temperature for removing the internal heat gains. The minimum required flow rates for cooling purpose can be calculated from Equation (3-1) which is used as the input for evaluating the initial opening size in the explicit method of the envelope flow model approach. Detailed investigations of initial opening size are presented in Section 4.2.

$Q=\frac{H}{\rho C_{P} \Delta T}$

where $H$ is the rate of internal heat gains (W), $\rho$ is air density $\left(\mathrm{kg} / \mathrm{m}^{3}\right), C_{P}$ is specific heat of air $(\mathrm{J} / \mathrm{kgK}), Q$ is ventilation rate $\left(\mathrm{m}^{3} / \mathrm{s}\right)$ and $\Delta T$ is temperature difference between indoors and outdoors $(\mathrm{K})$.

\section{(3) Design phase three: Performance evaluation}

For the preliminary investigations of this study, the envelope flow model is adopted for evaluating the off-design conditions of the single-cell tall office building configurations (Fig. 2-39). Envelope flow models rely on assumptions

about the internal density distribution. The basic equations can be illustrated by considering an opening in the envelope (CIBSE AM10, 2005). In the approach of envelope flow model, basic ventilation strategies and flow pattern are decided. The initial design calculation, explicit method, is adopted for determining the sizes of openings needed to give the required flow rates. The maximum and 
minimum sizes of openings for maintaining control over a specific condition can be decided as well (refer to Section 4.2). More detailed investigation on fresh air flow rate can then be obtained by the implicit method which is useful for looking at off-design conditions as presented in Section 4.3.

For the main investigations with a more complicate building configuration (Fig. 2-40), the investigations are extended to include dynamic thermal modelling with an air flow network (AFN), since the buildings can no longer be described by a single-cell model. Dynamic thermal modelling is used, because of the particular importance of the thermal behaviour of the DSF. The dynamic thermal simulation program with an air flow network model, ESP-r (ESRU, 2002), is used in the second modelling stage to provide an overall evaluation of ventilated cooling potential and to give details on ventilation rates and general air flow patterns with the proposed building configurations. Following that, CFD approach is chosen for looking at internal air flow speed distribution in the third modelling stage. The selection of comfort boundary under different wind speed condition can then be determined. Potential local discomfort would be identified by plotting the temperature and relative humidity in the building bioclimatic charts (BBCCs) within different comfort boundaries (to be determined from the CFD simulation).

\section{(4) Design phase four: Design optimization}

The design optimization of this study is undertaken with reference to the parametric study in Chapter 7. The generic building configurations for naturally ventilated tall office building are developed according to the simulation results derived from Chapter 4, 5, and 6. The suggestions on satisfactory comfort environment for occupants from the ventilation design point of view are summarized in Section 7.5. 


\subsection{Tools for natural ventilation assessment of this study}

Different approaches (tools) are applied in the three modelling stages of this study. Detailed theoretical background for the tools being adopted in the three modelling stages are described as following subsections.

\subsubsection{The envelope flow model}

\subsection{1-1 Method overview}

For the first modelling stage, it is assumed that the internal heat gains are balanced by the heat removed with the ventilation air. The minimum required flow rates for cooling under specific weather condition can be calculated using Equation 3-1. The required opening sizes would then be calculated by the explicit method of solution of the envelope flow model (EFM) approach as described in CIBSE AM10 (2005).

For the explicit method, it is assumed that the openings have discharge coefficients that are independent of flow rate (Reynolds number). This is consistent with the fact that the explicit method is used to determine the sizes of purpose-provided openings for given flow rates. The implicit method determines the flow rates for given openings by an iterative procedure. This method is implemented in MS Excel with a very simple iterative procedure. Initially the user enters the values of opening height $(z)$, opening area $(A)$ and wind pressure coefficient $(C p)$ for each opening. The values of $A$ are obtained from the explicit calculation. Thereafter, the wind velocity $(U)$ and outdoor temperature $\left(T_{E}\right)$ are assigned according to the weather data. Once the acceptable peak temperature rise of $3.3^{\circ} \mathrm{C}$ has been decided, the flow rates required can then be calculated. The flow equations are comprised as Equation 3-2 to 3-4).

$\sum q_{i}=0$ 


$$
\begin{aligned}
& q_{i}=C_{d i} A_{i} S_{i} \sqrt{\frac{2\left|\Delta P_{i}\right|}{\rho}} \\
& \left|\Delta P_{i}\right|=\Delta P_{0}-\Delta \rho g Z_{i}+C_{P i} \times \frac{1}{2} \rho U^{2}
\end{aligned}
$$

The monthly averaged conditions are chosen for the single-cell envelope flow model (EFM) to evaluate the preliminary climate suitability. Consequently, the monthly average weather data is used to examine the natural ventilation performance under the steady state condition. For natural ventilation design, it is important to ensure that the system delivers the required quantity of air to the right places, at the right time. For the current study, however, the effect of segmentation is of interest. To use the averaged value is a compromise, but a simple and meaningful basis for comparison has to be chosen.

\subsection{1-2 Assumptions and limitations}

The main assumptions in the envelope flow model as suggested by Etheridge (2002) are described as follows.

(1) Wind pressure coefficient and reference wind speed for determining surface pressure distributions;

The wind pressure coefficient $C p$ is influenced by a wide range of parameters, including building geometry, facade detailing, position on the facade, the degree of exposure/sheltering, wind speed and wind direction. As it is practically impossible to take into account the full complexity of pressure coefficient variation, this study utilizes correlations based on wind tunnel experiments (Bowen, 1976) for low-rise buildings which are summarized in the AIVC Technical Report (1996). It is assumed that pressure coefficients do not vary over the external surface of a wall and the internal temperature is uniform, resulting in a constant internal surface pressure gradient. 
(2) Internal and external temperatures for determining internal surface pressure gradients due to buoyancy;

The external temperature is according to the mean monthly temperature from Central Weather Bureau of Taiwan. The internal temperature is set at $28^{\circ} \mathrm{C}$, the acceptable upper boundary for thermal comfort of the hot and humid climates according to literature reviews as addressed previously. These two values are adopted in the envelope flow model for acquiring the initial opening sizes and required fresh air flow rates in the explicit and implicit method respectively.

\section{(3) Distribution of openings in the surfaces;}

In the envelope flow model, the distribution of openings is specified by the user in terms of the heights of openings. The height is calculated from the ground level to the central of specific opening.

(4) Geometry (size and shape) of the openings;

The initial size of the opening can be obtained from the explicit method of the envelope flow model. The mean external temperature and reference wind velocity $\left(U_{r e f}\right)$ of summer, winter and mid-seasons are used in the explicit method. The calculated opening size from the explicit method is used as input to the implicit approach for modelling off-design conditions. 


\subsubsection{The integrated building simulation program: ESP-r}

\subsection{2-1 Method overview}

The dynamic thermal simulation program with an air flow network model, ESP-r (ESRU, 2002), is used to provide overall evaluation of ventilated cooling potential and to give details on ventilation rates and general air flow patterns with the proposed building configurations. It is a finite volume method in which the model is transformed into a matrix of state-space equations and the flows of energy in the problem enclosure, plant components and mass flow network are solved.

As described by Beausoleil-Morrison (2000), a building's thermal state affects air flow in two ways. Firstly, stack pressures caused by indoor-outdoor and interzone temperature differences create buoyancy forces, which can significantly affect envelope and internal air flows. Secondly, windows may be opened and closed and fans may be operated in response to temperatures within the building. However, these are not taken into account in this work. The openings are fully opened and naturally ventilated at all time for the proposed modelling. Similarly, the building's thermal state is affected by external and inter-zone air flows. Consequently, a realistic treatment of this interdependency demands a coupling of the thermal and air flow modelling domains.

Beausoleil-Morrison (2000) concluded that four principle steps are involved in the modelling process of ESP-r. First, the building is discretized into smaller volumes (usually zones) by nodes. Second, components are defined to represent leakage paths, and pressure drops associated with doors, windows, supply grills, ducts, fans, etc. Third, the nodes are linked together through components to form connections which establish a flow network. Lastly, a mass balance is expressed for each node in the building. The resulting system of equations is solved to yield the nodal pressures and the flows through the connections. 


\subsection{2-2 Modelling conditions and assumptions}

In this study, the prototype building is developed according to a current design in Taipei, Taiwan as described in Section 2.4.1. The main investigations are undertaken by the use of dynamic thermal simulation with an air flow network (ESP-r) in the second modelling stage; while the required envelop opening sizes are defined in the first modelling stage using the envelope flow model. The mass and energy flow of the main building configuration is illustrated as Figure 3-2.

For the main building configurations as proposed in Section 2.4.2, the internal openings are then assigned a value same as the external (envelope) openings. That is, one air flow inlet $\left(9 \mathrm{~m}^{2}\right)$ is located in the ground level of the central atrium. The external envelope of the building is a ventilated double-skin façade (DSF) with one outlet $\left(10 \mathrm{~m}^{2}\right)$ at the top of the DSF cavity and vents connected to individual office spaces. The DSF-vents are located in the higher-end of the office wall while the atrium-vents are in the lower-end of the wall opposite to the DSFvent side. The initial size of each vent is $9 \mathrm{~m}^{2}(0.5 \mathrm{~m}$ by $18 \mathrm{~m})$ in terms of the summer design condition and is kept constant throughout the simulation.

Only one ventilated DSF envelope was applied in the eastern side of the building during the simulations, for simplification. The ventilated DSF system is characterized by the outer and inner double glazing and a ventilated cavity in between ( $1 \mathrm{~m}$ depth). The internal walls, other than the DSF-side and atrium-side, are assumed to be adiabatic. The other external wall applied in the southern side is double-glazed without openings. Detailed construction materials used in the simulation are listed as Table 3-1. The office hours run from 7:30 to 18:30, 5 days a week. A total internal heat production of 30 (W per $\mathrm{m}^{2}$ floor area) is used during office hours. The external inlet $\left(9 \mathrm{~m}^{2}\right)$, internal vents $\left(9 \mathrm{~m}^{2}\right)$ and top outlet $\left(10 \mathrm{~m}^{2}\right)$ are fully opened at all times. The Typical Meteorology Year of Taipei from US DoE is used as the climatic boundary condition in all simulations. 
One thing to be noted was that a shading control, blinds within the DSF cavity, was imposed throughout the simulation when solar radiation exceeds $270 \mathrm{~W} / \mathrm{m}^{2}$. For the current study, the shading control within ESP-r is activated via a third party application, Window 5.2 (in North America). Optical properties are angular dependant (5 angles) and include overall solar band transmission at 5 angles. The shading and insulation module within ESP-r consult the model configuration file for zone geometry and shading construction. It then generates a file of temporal shading and insulation data to be used in the simulation. The shading data is used by the calculation engines to determine how much of radiation arriving at the outer surface is absorbed in each layer of the transparent construction at each time step, and how much is transmitted into the room. Separate calculations for shading tell the simulator whether it is necessary to modify the solar radiation arriving at surfaces of a building façade.

ESP-r's flow network solver dynamically calculates the pressure-driven flows between zones and cells. The flows at nodes are a function of nodal pressures and the connected components' characteristics. The boundary wind induced node in ESP-r is a function of wind velocity, wind direction and wind pressure coefficient $(C p)$. In the proposed building configuration, only the lower atrium inlet and outlet at the top of ventilated facades are directly interactive with the ambient environment, where the $C p$ values should be defined. The natural ventilation within office spaces is achieved by indirect cross ventilation. That is, an internal unknown pressure node is defined for each internal opening connecting between zones. Detailed descriptions on the node types are listed as Table 3-2. One thing to be noted is that the external wind velocity from the weather data of Taipei, Taiwan is modified to $0(\mathrm{~m} / \mathrm{s})$ for modelling the buoyancy alone ventilation in the ESP-r program. For the second stage, the monthly time-averaged values of flow rates and temperature were derived from the calculated hourly results over the occupied hours of a specific month. The effect of segmentation was investigated by comparing the averages under identical ambient conditions. In addition, the times with insufficient air flow rates and undesired air flow pattern were quantified. 


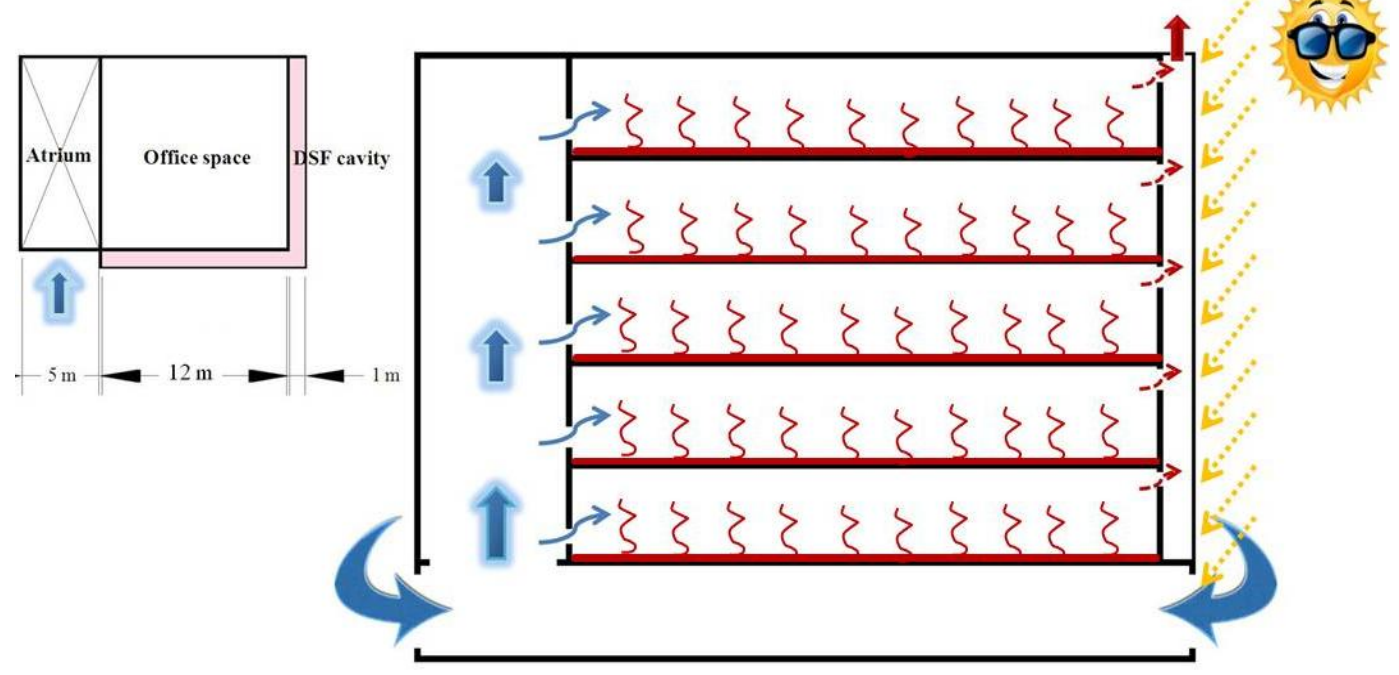

Figure 3-2: The mass and energy flow of the main building configuration.

Table 3-1: Construction details

\begin{tabular}{llll}
\hline Construction type & Thick $(\mathrm{mm})$ & U values & Boundary condition \\
\hline Internal wall & 162 & 1.731 & surface in another zone* \\
\hline DSF-glazing-external & 24 & 2.811 & similar to current** \\
\hline DSF-glazing-internal & 24 & 2.811 & surface in another zone \\
\hline Roof & 111 & 0.427 & Exterior*** \\
\hline Floor & 300 & 2.825 & surface in another zone \\
\hline Ground floor & 625 & 0.864 & ground \\
\hline
\end{tabular}

* ESP-r can automatically link adjacent surfaces based on the information available in zone geometry files. 'Surface in other zone' is the surface exposed to the temperature and radiation condition of a specified surface in a other zone (but one time step in arrears).

** The 'similar to current' boundary is exposed to the same conditions as the inside face except for the treatment of solar insulation. A temperature $\left({ }^{\circ} \mathrm{C}\right)$ and radiation $\left(\mathrm{W} / \mathrm{m}^{2}\right)$ offset may be imposed.

*** 'Exterior' is the surface exposed to external weather.

Noted: Ground (monthly profile) - exposed to a temperature defined by a standard monthly temperature profile embedded in ESP-r.

Table 3-2: AFN Nodes of the 20 storey case

\begin{tabular}{ccc}
\hline Node & No. of nodes & Node type \& pressure \\
\hline Inlet & 1 & Boundary: wind induced \\
Outlet & 1 & Boundary: wind induced \\
Office & 20 & Internal unknown* \\
Vent (in/out) & $20 / 20$ & Internal unknown* \\
Atrium & 4 & Internal unknown* \\
DSF & 4 & Internal unknown* \\
\hline
\end{tabular}

* For the internal unknown nodes, the temperature and pressure are unknown and are solved at each time step. 


\subsubsection{Computational Fluid Dynamics}

\subsection{3-1 The use of CFD for natural ventilation assessment}

Due to the increased interest in using natural ventilation to reduce energy demands and to improve indoor air quality, the application of computational fluid dynamics (CFD) models for natural ventilation design are popular at present (Chen, 2007). The advantages of CFD are its capacity to calculate parameters which are not easily being measured. The numerical procedures for the solutions of partial differential equations can be used to describe the physical parameters of buildings such as temperature, airflow velocity, and humidity, etc. Even though CFD has been applied to ventilation studies for over thirty years, engineers are still seeking more accurate, more reliable, and faster CFD models (Chen, 2009)

Simulation methods for natural ventilation fall into two broad categories: building energy simulation (BES) and computational fluid dynamics (CFD). BES tools include modules of thermal simulation and airflow network to solve the heat and mass transfer and airflow in the building systems. However, BES assumes the indoor air is well mixed. It can only provide the uniform results for targeted spaces, which does not meet the requirements for detailed indoor environment analyses. That is, the coupling strategies for natural ventilation between BES and CFD are highlighted. Previous studies (Beausoleil-Morrison, 2000; Clovis, 2001; Zhai et al., 2002; Zhai and Chen, 2003; Djunaedy et al., 2004; Djunaedy et al., 2005; Wang and Wong, 2008; Wang and Wong, 2009) suggested that the integration of CFD was motivated by quite a few factors and they were summarized by the ESP-r developing group in the ESRU as follows:

- The thermal and network air flow simulation domains can supply CFD with realistic and time-varying boundary conditions, thus improving CFD's ability to calculate room air flow and heat transfer.

- The thermal and network air flow domains can drop the well-mixed assumption by using CFD to predict the details of flow and temperature fields within zones.

- $\mathrm{CFD}$ can predict internal surface convection in response to local flow patterns. 
Inspired by previous studies (Holmes et al 1990, Chen et al 1995, Moser et al 1995, Negrão 1995, Schild 1997), Beausoleil-Morrison (2000) continued the development of CFD coupling within ESP-r which gave some intelligence to the coupled mechanism. In his study, the CFD model was integrated with the thermal and network air flow models within a single executable module but used its own customized solver. That CFD model exchanges information with the thermal and network air flow domains on a time-step basis. The general concept is that a thermal and a network air flow (optionally) representation of the whole building is established, while a CFD model is created for a single room. For each time-step, the boundary conditions for the CFD model are established by the thermal or network air flow domains. At the mean time, the CFD domain passes its results back to the thermal or network air flow domains once converged. Those data are used to calculate the surface temperatures, energy flows, and air flows throughout the thermal domain of the building.

Although Beausoleil-Morrison gave some indicators on which method should be used for a certain type of flow, and suggested a decision mechanism to be implemented in ESP-r, he didn't test the stability and convergence of each method he suggested. Djunaedy (2004) further proposed a procedure to select an appropriate approach for airflow simulation in buildings. Inter-model comparison and empirical results from previous studies are adapted as methodology for validation. His study claimed that there were at least three approaches representing different resolution level in airflow simulation:

I. Building energy balance models (BES) that basically rely on guessed or estimated values of airflow.

II. Zonal airflow network (AFN) models that are based on (macroscopic) zone mass balance and inter-zone flow-pressure relationships; typically for a whole building. 
III. Computational fluid dynamics (CFD) that is based on energy, mass and momentum conservation in all (macroscopic) cells that make up the flow domain; typically a single building zone.

Djunaedy et al. (2004) concluded that each approach had its own merits and drawbacks. For this particular study, designers may need all of the above approaches, but at different stages of the design process. A higher resolution (and more complex) approach may not be able to provide answers for the design issues that may be answered by a lower resolution (less complex) approach. Djunaedy et al. (2005) classified the performance indicators (PI) into three categories: energy related, load related and comfort related. Each of these categories will be used for different kinds of decisions in the building design process. These indicators are used as the basis for the selection of the most appropriate approach to simulate the problem at hand. Wang and Wong (2008) adapted static coupling strategy for wind-driven natural ventilation. Commercial software FLUENT is used as the external CFD program to couple with ESP-r. Detailed thermal comfort prediction model for indoor environment is finally provided for evaluation in the data interface.

The ventilation performance assessment of this study focuses mainly on the desired flow pattern and required flow rates for cooling in tall office buildings. The aim is to examine the physical phenomena of air flow within different building configurations under the naturally available driving forces. For large spaces, like buildings with tall atriums of this study, the complete mixing assumption may not be acceptable. One would need the distributions of air temperature, air speed, and air flow pattern to assess local ventilation performance. The tools for ventilation assessment as described in Chapter 3.3.1 and 3.3.2 provide the initial insight for natural ventilation performance of tall office buildings. However, only the bulk flow through the building envelope was addressed. For further quality assurance of the natural ventilation system, the local air flow distribution should be considered by the use of CFD approach. 


\subsection{3-2 The CFD approach adopted for current study}

The routes for CFD approach adopted for this study are listed as Table 3-3. The options available and proposed modelling procedures for the current study are outlined. Two different CFD approaches are selected, namely the thermally coupled CFD approach and the stand-alone CFD using the commercial program FLUENT. The purpose and the capability of each CFD approach are described as follows. In the thermally coupled CFD approach of ESP-r, the CFD model can be integrated within the thermal domain (zone basis). One zone is chosen to be modelled by CFD and the remaining of the building is simulated by the conventional approach (dynamic thermal simulation with an air flow network). The integration is optional and a CFD flag is placed in the zone operation file. Data on coupling type, geometry, gridding, solution variables, boundary conditions, solver parameters, output files etc. are required for the CFD model in ESP-r. In this study, two types of coupling are taken into consideration in terms of research questions at hand.

First, the surface convection heat transfer coefficients are calculated from the CFD-predicted flow and temperature fields. There is no interaction between the airflow network and CFD. In such cases, fixed mass flow rates are assumed for the opening boundaries. The aim for this type of coupling is to investigate the ventilated cooling effects and the corresponding temperature distribution within the examined space. One thing to be noted is that only one CFD domain is allowed to conflate with other thermal domains per simulation.

The second type of coupling chosen for this study focuses on the instant air flow distribution where the airflow network is coupled with particular CFD domain for specific time steps. In other words, the opening boundary conditions will vary with the corresponding mass flow connections during the specific time steps. The worst case scenario with reference to the required flow rates for cooling and desired flow pattern during the typical weeks of a year can then be known. In this scenario, fixed internal surface temperature from the thermally coupled mass flow network approach is defined for the solid boundaries. Following that, a stand- 
alone CFD is proposed to investigate the possible discrepancy between different modelling approaches. The potential pros and cons of using advanced tools are clarified. The whole building simulation will be carried out for investigating airflow distribution of the worst and optimum case scenario. The detailed air flow speed distribution is needed for ensuring the selection of comfort boundary.

Table 3-3: Routes of CFD approach for natural ventilation design of the current study

\begin{tabular}{|l|l|l|}
\hline \multicolumn{2}{|c|}{ Options available } & Descriptions of mechanisms \\
\hline \multirow{5}{*}{$\begin{array}{l}\text { Thermal } \\
\text { Coupling } \\
\text { within ESP-r }\end{array}$} & $\begin{array}{l}\text { The surface convection heat transfer coefficients are calculated } \\
\text { from the CFD-predicted flow and temperature fields and are } \\
\text { then fed back to the thermal domain. There is no interaction } \\
\text { between the air-flow network and CFD. }\end{array}$ \\
\cline { 2 - 4 } & $\begin{array}{l}\text { Air-flow } \\
\text { coupling }\end{array}$ & $\begin{array}{l}\text { The nodal air-flow network and CFD are integrated. A single air } \\
\text { flow network node is replaced by a CFD domain, thus dropping } \\
\text { the assumption of well-mixed conditions for that zone. There is } \\
\text { no interaction on the thermal level. }\end{array}$ \\
\cline { 2 - 4 } & $\begin{array}{l}\text { CFD-only } \\
\text { (coarse-grid) }\end{array}$ & $\begin{array}{l}\text { All boundary conditions are supplied by the user when CFD is } \\
\text { operated in stand-alone mode within ESP-r. But the options for } \\
\text { the turbulence model are limited in the coarse-grid CFD of ESP- } \\
\text { r. }\end{array}$ \\
\hline \multirow{5}{*}{$\begin{array}{l}\text { Stand-alone } \\
\text { CFD program } \\
\text { (FLUENT) }\end{array}$} & $\begin{array}{l}\text { External flow } \\
\text { field with } \\
\text { wind profile } \\
\text { inlet }\end{array}$ & $\begin{array}{l}\text { The modelling of surface wind pressure coefficient of the } \\
\text { proposed building configuration is achieved by simulation of } \\
\text { external flow field using the stand-alone CFD program } \\
\text { (FLUENT). }\end{array}$ \\
\cline { 2 - 3 } & $\begin{array}{l}\text { Whole } \\
\text { building } \\
\text { simulation } \\
\text { (fine-grid) }\end{array}$ & $\begin{array}{l}\text { The one-way static integration between ESP-r (dynamic thermal } \\
\text { simulation with an air flow network) and FLUENT-CFD is } \\
\text { adopted in this modelling stage. For which the ESP-r predicted } \\
\text { outputs are provided as boundary conditions for FLUENT-CFD. } \\
\text { Advanced turbulence models are also available. Further inter- } \\
\text { model comparisons can be evaluated with those from coarse } \\
\text { gridding results. }\end{array}$ \\
\hline
\end{tabular}




\subsection{Criterion for ventilation performance assessment}

In this study, the criteria for assessing the ventilation performance are evaluated with reference to the time when the required flow rates and desired flow pattern are achieved as well as the overall thermal comfort condition. The hourly temperature, relative humidity, and air flow speed from the CFD simulation are plotted in the building bioclimatic charts for further assuring the ventilated cooling effect. The simulated air flow speed distribution using CFD is expected to provide insight for the ultimate potential for personal cooling. Detailed descriptions on the criteria chosen for this study are outlined as follows.

\subsubsection{The minimum required flow rates for cooling}

For cooling purposes, the incoming air should be at a lower temperature than the indoor air temperature for removing the internal heat gains (sensible cooling). The minimum required flow rates for sensible cooling can be calculated from Equation 3-1 which is used as the input for evaluating the initial opening size in the explicit method of the envelope flow model approach. For the proposed test models, it is proposed that the combination of solar, occupant, lighting and equipment gains gives a value of $30 \mathrm{~W} / \mathrm{m}^{2}$. It is assumed that the internal heat gains are balanced by the heat removed with the ventilation air. For example, the base case model with floor areas of $400 \mathrm{~m}^{2}$ (Fig.2-40b), $H$ is about $12000 \mathrm{~W}$. When $\rho=1.2 \mathrm{~kg} / \mathrm{m}^{3}, C_{P}=1006 \mathrm{~J} / \mathrm{kgK}$ and $\Delta T=3.3 \mathrm{~K}$ (with set internal temperature of $28{ }^{\circ} \mathrm{C}$ ) are applied in the calculation, the ventilation rate of $3 \mathrm{~m}^{3} / \mathrm{s}$ may suffice for removing the internal heat gains. 


\subsubsection{The desired air flow pattern}

For the preliminary investigations, the atrium type buildings with vertical shafts which run up the entire height of the building are used to extract air. Segmented cases take a normally continuous element and break it down into shorter segments, thereby reducing the height in the stack effect equation. The commonly used ventilation strategy for the atrium type buildings is that air enters through the envelope and flows through the building before being exhausted from the atrium at high level. The conceptual air flow pattern design is illustrated in Figure 2-39. It is assumed that fresh (external) air enters each occupied space from the envelope opening, irrespective of the weather condition and building configuration, and finally flows out through the outlet at the top of atrium.

As for the main investigations, a conceptual air flow network for the proposed natural ventilation system is presented (Fig. 2-40c) and defined as follows. The ventilation strategy for the prototype building is Centre-in, Edge-out $(\mathrm{C}-\mathrm{E})$ in the terminology of Lomas (2007). With moderate setting of vents in the externalfacing and lightwell-facing side of the office space, air flow throughout the building is activated by the stack effect and ambient wind effect. It is assumed that fresh air enters from the lower inlet of the lightwell and feeds into each office space through its individual lightwell-vent. The stale air of each office space is expected to discharge into the high-end vents connected to the DSF cavity. Solar radiation is expected to pass through the building envelope, the ventilated façade, and the air within the DSF cavity is warmed up consequently. Finally, the accumulated warm and stale air will be exhausted through the outlet on top of the DSF cavity. The calculated flow rates are positive when follow the desired flow pattern in an air flow network. 


\subsubsection{Adaptive thermal comfort theory for a hot and humid climate}

One of the aims of this study is to evaluate the thermal comfort level of naturally ventilated tall office buildings. That is, a comfort-orientated indicator will then be adopted for investigating the performance of ventilated cooling. The perception of thermal comfort is heavily influenced by the social and cultural context of the occupants' expectations and their response to thermal stimuli (Harriman III and Lstiburek, 2009). People naturally adapt and may also make various adjustments to themselves and their surroundings to reduce discomfort and physiological strain. Occupants become adapted to the new environment after entering a building. When the temperature stays very uniform around the occupants, the building is perceived to be more comfortable, even if the temperature is slightly above or below the otherwise ideal range. As concluded by ASHRAE (2009), 'the value of using an adaptive model to specify set points or guide temperature control strategies is likely to increase with the freedom that occupants are given to adapt'.

Baker and Standeven $(1994,1996)$ proposed the term of 'Adaptive errors' and the associated concept of adaptive opportunity for the comfort criteria of passively cooled buildings. Their aim was to identify the key factor for discrepancy (scatter of field data) of field studies in free-running buildings with reference to thermal comfort. They found that the conventional comfort theory failed to account for the adaptive behaviour of the occupants and might consequently lead the designer into adopting the air-conditioning system. The findings provided an idea of allowing the neutral zone for thermal comfort to be extended, which encouraged the promotion for passive buildings. Following that, Wong et al. (2002) conducted a field survey to evaluate thermal comfort perception of the occupants in a naturally ventilated public housing in Singapore. The study investigated whether thermal perception was influenced by different sessions of the day, building height and flat types. The survey investigated the adaptive behaviour of the occupants in the usage of climatic control such as windows, fans and air- 
conditioning to modify the indoor environment. It was concluded that occupants were naturally acclimatized to the local hot and humid climate condition.

Additionally, a field study had been conducted in five naturally ventilated office buildings in south east of France during hot and cold seasons (Moujalled 2008). Their results suggested that the thermal sensations were well correlated with the operative temperature. The occupants were less sensitive to the rise of temperature during the warm season. The variability of indoor conditions in the naturally ventilated buildings during the warm season with the availability of thermal control contributed to a relaxation of expectation and greater tolerance of temperature rise. They also commented on the lack of reliability of the PMV index to predict thermal comfort in naturally ventilated buildings in both warm and cold season. In their study, the adaptive comfort algorithms of EN15251 and ASHRAE 55-2004 were in close agreement with the measured comfort votes. The use of the PMV to determine thermal comfort conditions, as indicated by the standard ISO7730, would result in overheating buildings during the cold season and air conditioning during the warm season; while the adaptive algorithms are more advantageous for both thermal comfort and energy use in buildings as they took the variability of indoor comfort conditions into consideration. However, other field studies in different building types and outdoor climate conditions are needed to confirm these results.

Furthermore, J.van Hoof (2008) argued that although the PMV model is still applied throughout every type of building all across the globe, it was found that the indoor temperature being regarded as most comfortable increases significantly in warmer climate contexts for naturally ventilated buildings, and decreases in colder climate zones. They found that the neutral temperature observed in airconditioned buildings differs from that observed in naturally ventilated buildings in the same climatic context. This led to the development of adaptive thermal comfort model, which is now an optional method alongside the PMV model in applications of naturally ventilated buildings. 
Many studies on acceptable comfort boundaries had been conducted in the context of the hot and humid climate. Busch (1992) presented a study of adaptive thermal comfort in Thailand which proposed acceptable indoor temperatures of 28 ${ }^{\circ} \mathrm{C}$ for air-conditioned offices and $31{ }^{\circ} \mathrm{C}$ for naturally ventilated offices. Givoni (1998) suggested that comfort ventilation is applicable mainly to regions and seasons when outdoor maximum air temperature does not exceed $28-32{ }^{\circ} \mathrm{C}$ with less than $10{ }^{\circ} \mathrm{C}$ diurnal temperature range. The boundaries of outdoor temperature and humidity within which indoor comfort can be provided by natural ventilation during the day and with indoor airspeed of $2 \mathrm{~m} / \mathrm{s}$ were presented as well. Additionally, Humphreys and Nicol (1998) observed that, through adaptive actions, an acceptable degree of comfort in residences and offices is possible over a range of air temperatures from about 17 to $31^{\circ} \mathrm{C}$. A separate study in Bangkok (Jitkhajornwanich et al., 1998) established an upper limit to thermal comfort of $31.5{ }^{\circ} \mathrm{C}, 5.5 \mathrm{~K}$ beyond the upper boundary presented by ASHRAE (2004). The thermally neutral temperature was $30.6{ }^{\circ} \mathrm{C}$ when the air speed was $1 \mathrm{~m} / \mathrm{s}$ and the relative humidity was between 50 and 60 percent and increased to $33.5{ }^{\circ} \mathrm{C}$ under more humid conditions (50-80 percent relative humidity) when the air speed was increased to $2 \mathrm{~m} / \mathrm{s}$. A survey conducted by Xia and Zhao (2000), directed toward occupants of 83 Beijing units, also found that 80 percent of occupants considered $30{ }^{\circ} \mathrm{C}$ to be tolerable.

de Dear and Brager (1998) proposed an adaptive thermal-comfort standard for naturally ventilated buildings, which is based on a review of 21,000 sets of raw data from 160 thermal comfort studies in 160 office buildings in four continents. With the 90 percent acceptability limits, the indoor comfort temperature increased with outdoor temperature. The comfort ranges were $23-28{ }^{\circ} \mathrm{C}$ at a monthly mean outdoor temperature of $25{ }^{\circ} \mathrm{C}$ and $26-31{ }^{\circ} \mathrm{C}$ for mean monthly temperatures above $33{ }^{\circ} \mathrm{C}$ (de Dear 1998, de Dear and Brager 1998, Brager and de Dear 2000). This adaptive standard has been incorporated into the ASHRAE thermal-comfort standard (ASHRAE_55 2004). 


\subsubsection{The Building Bioclimatic Charts}

Ssensible as well as personal cooling are proposed as the main cooling mechanisms of this study. For the personal cooling in summer, increased air movement from large openings can provide an enhanced perception of thermal comfort, but care has to be taken to avoid draughts, such as those that might blow papers off desks. As suggest by CIBSE AM10 (2005), an air speed of about 0.25 $\mathrm{m} / \mathrm{s}$ is sufficient to illustrate an important mechanism by which natural ventilation can maintain thermal comfort in summer. To create thermal comfort, the heat dissipation mechanisms of the human body as well as four environmental conditions that allow the heat to be lost should be considered. The considerations for the four conditions, namely air temperature, humidity, air movement, and mean radiant temperature (MRT), are described as follows.

First, the air temperature will determine the rate at which heat is lost to the air, mostly by convection. Above $37^{\circ} \mathrm{C}$, as suggested by Lechner (2009), the heat flow reverses and the body will gain heat from the air. Second, high humidity not only reduces the evaporative cooling rate, but also encourages the formation of skin moisture (sweat), which body senses as uncomfortable. Third, air movement affects the heat-loss rate by both convection and evaporation. In the summer, air velocity has a pronounced effect on heat loss. The air motion is noticeable but acceptable depending on the activity being performed. A draught is an undesirable local cooling of the human body by air movement, and can be a serious thermal comfort problem, depending on surrounding conditions. Air motion is also required to prevent excessive stratification, which tends to make heads warmer and feet colder, exactly opposite of what is comfortable. Finally, the goal is to maintain the MRT close to the ambient air temperature in general. In a wellinsulated and shaded building, the MRT will be close to that of the indoor air temperature. Furthermore, or whenever possible, additional control should be made available for the occupants of a building so that they can create the thermal 
comfort that is just right for them. Portable fans to promote air movement and operable windows are devices people can use to fine-tune their environment.

Certain combinations of air temperature, $\mathrm{RH}$, air motion, and MRT will result in what most people consider thermal comfort. The psychrometric chart involves only the temperature and humidity, while the MRT is assumed to be near the air temperature, and the air motion is assumed to be modest. The comfort zone defined in the psychrometric chart is not absolute, and may vary with culture, time of year, individual clothing, and physical activity etc. The comfort zone should be the goal of the thermal design of a building, where 80 percent of people in a specific region find comfortable. However, the comfort zone may shift when certain variables that had been held constant are allowed to change. i.e. an increase in MRT would require cooler air temperatures to compensate for the increased heating from radiation; the cooling effect of the air motion is offset by an increase in the air temperature, and the reversed situation when the air temperature is too high for comfort, the air motion is often used to raise the comfort zone.

The building bioclimatic chart (BBCC) was developed (Givoni, 1998) to integrate architectural strategies with human comfort needs. To compare this chart (BBCC) with the comfort zone and various types of discomfort outside that zone of the original psychrometric chart, the relationship between strategies and discomfort (climate) conditions is then clear. In order to assess the potential of naturally ventilated cooling in a hot and humid climate, the Building Bioclimatic Charts (BBCCs) is adopted which offers a way of rapidly testing whether or not natural ventilation is likely to produce comfortable conditions in the offices. The BBCCs approach undertaken by Givoni (1994) preserves all the psychrometric relationships encapsulated in the chart. The key component in the chart is that boundaries of climatic conditions within which various building design strategies and natural cooling systems can provide comfort (Givoni 1998). The Givoni BBCCs for hot-developing countries offer thermal comfort envelopes for two 
conditions: 'still air' (assumed to be less than $0.25 \mathrm{~m} / \mathrm{s}$ ), which lies between $18^{\circ} \mathrm{C}$ (winter) and $29^{\circ} \mathrm{C}$ (summer) and for 'a very light breeze' $(2.0 \mathrm{~m} / \mathrm{s})$, which extends the envelope to $32^{\circ} \mathrm{C}$. The upper (summer time) temperature limits decrease above $50 \%$ relative humidity $(\mathrm{RH})$ and upper bounds are placed on $\mathrm{RH}$ of $80 \%$ for still air and $90 \%$ for a very light breeze.

Lomas et al. (2004) examined the likely internal comfort conditions in an office using the Givoni BBCCs approach for developed countries and compared with the conditions predicted by a detailed thermal model. The differences were discussed and a strategy for producing BBCCs for different classes of non-domestic buildings and for representing the climatic boundaries was proposed. They retain the benefits of being plotted on a psychrometric chart but contain additional data. In their study, it is recommended that thermal simulation modelling could be used to derive BBCCs for many other types of non-domestic building cooled by different ventilation strategies. They also provide a route to explore a more precise definition of thermal comfort.

In this study, the Givoni BBCCs boundaries are considered reasonable according to previous studies on the adaptive comfort theory and thus are used to assess the performance of ventilated cooling. By the way of BBCCs, the effect of latent heat is taken into consideration, which is not available with the equation 3.2-1 only. Ultimately, the thermal comfort assessment is achieved by plotting the calculated temperature and relative humidity from ESP-r into BBCCs. The local air flow speed distribution from CFD modelling is then adopted to ensure the selection of specific boundary in the BBCCs. The acceptable comfort boundaries of a hot and humid climate for this study are illustrated as Figure 3-3. 


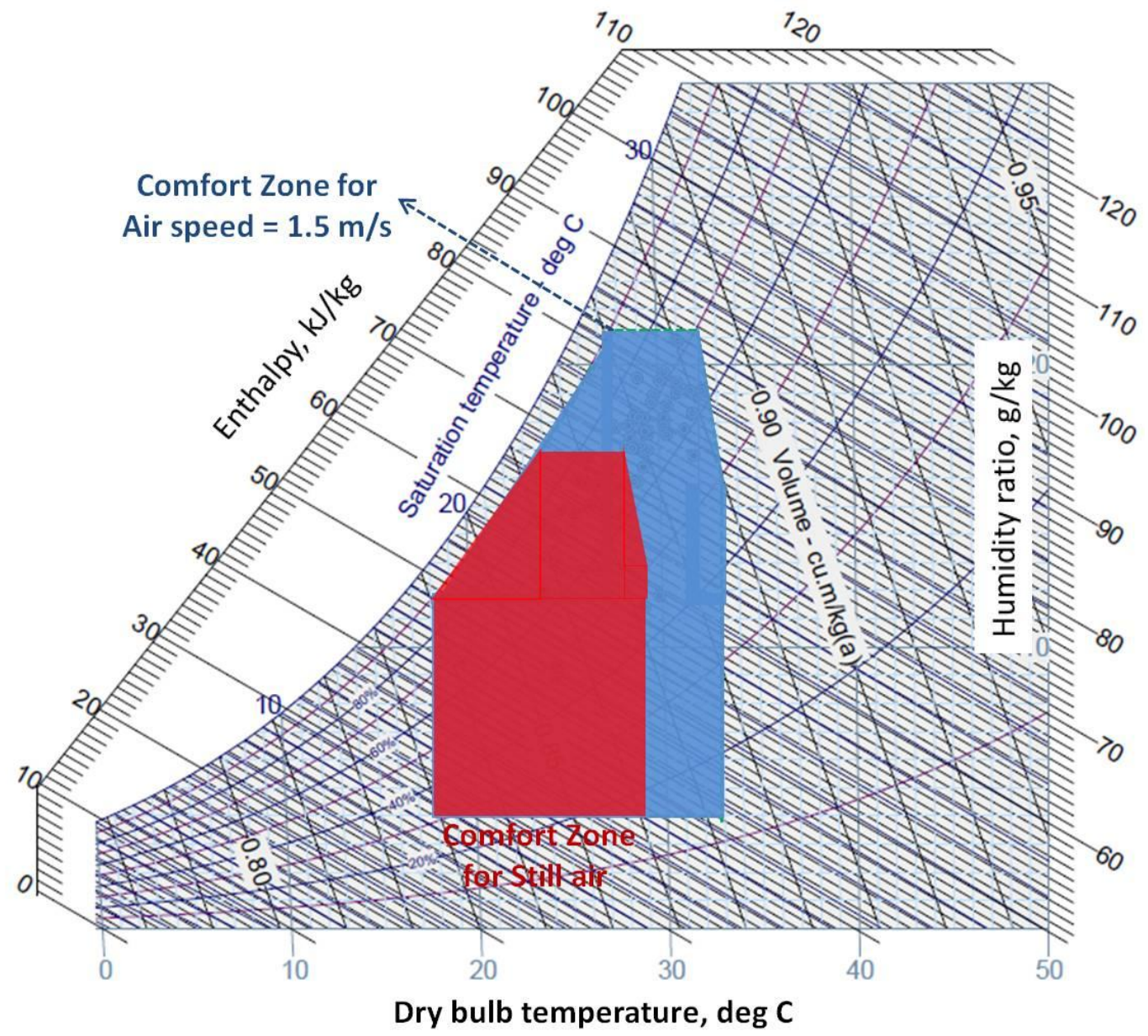

Figure3-3: The building bioclimatic chart for a hot and humid climate under different ventilation condition 


\subsection{Summary remarks}

This research is concerned with the prospect of purely naturally ventilated tall office buildings. It is hoped to achieve a natural system that gives as much control as possible. Segmented and non-segmented atrium buildings are adopted as study models. The aim is to ensure that the magnitudes of the air flow rates and the desired flow pattern through the envelope openings and consequently the thermal comfort can be achieved over a range of specified conditions. The investigations include two parts (preliminary and main investigation) with reference to the complexity level of building configurations. For the preliminary investigation of this study, a single-cell envelope flow model (EFM) is adopted for evaluating the off-design conditions of the three conventional typologies of tall office buildings. The steady-state bulk flows through openings are evaluated under a specified design condition.

For the main investigation, the evaluations are divided into three stages and the objectives are basically the same; while the resolution level might vary. A tall atrium and ventilated double skin facades are proposed along with the segmentation concept. Dynamic thermal modelling is used, because of the particular importance of the thermal behaviour of the DSF. The chosen thermal model utilises a multi-cell airflow network model (AFN) since the buildings can no longer be described by a single-cell model. The dynamic thermal simulation program (ESP-r) with air flow network module is to provide overall evaluation of ventilated cooling potential in the examined building.

One of the important tasks for natural ventilation simulation is to accurately predict the local airflow distribution. Thus, a computational fluid dynamics (CFD) simulation is proposed in the later design stage of this research. And more importantly is to evaluate the effect of air flow speed on personal cooling. The overall ventilation performance is then interpreted in relation to adaptive thermal comfort theory by the use of BBCCs. 


\section{The preliminary investigations: The envelope flow model approach}

\subsection{Chapter overview}

As presented in the methodology (Ch3), the envelope flow model (EFM) for this study is adopted to size the envelope openings using the explicit method of EFM and to evaluate the 'off-design' condition of the preliminary study model (Fig. 239) by the use of implicit method of EFM. The 'off-design' condition is defined by CIBSE AM 10 (2005), which indicate the design performance of a particular ventilation strategy under the specific weather condition. From the aspect of envelope openings, it is important to determine the maximum and minimum sizes of openings to enable adequate occupant control. The input data required for sizing the envelope openings are described in Section 3.3.1. In Section 4.2, the maximum sizes are determined by a summer design condition while the minimum sizes are from the winter condition. With the summer condition, this study adopts the averaged ambient wind speed over the occupied hours to represent the worst case. The design aim in the summer is to prevent internal overheating and to ensure the thermal comfort of the occupants. The ventilation rates required to achieve these goals will usually exceed that required for air quality issues.

The monthly off-design conditions of the proposed building configurations under the preliminary investigations are discussed in Section 4.3. For the preliminary investigation of this study, a single-cell envelope flow model (EFM) is adopted for evaluating the off-design conditions of three preliminarily building configurations, namely isolated, non-segmented and segmented tall buildings with no internal partitions (Fig. 2-39). The steady-state bulk flows through openings are evaluated under a specified weather condition. Firstly, the effect of segmentation on the resultant flow rates of corresponding office spaces is 
discussed in Section 4.3.1. The seasonal variation of ventilation is then investigated in Section 4.3.2.

Additionally, this chapter looks at the required flow rates which can flow along the desired path under the naturally available driving pressures. The fresh air flow rates of the three preliminary building configurations under different arrangements of ambient temperature and wind speed are examined in Section 4.3.3. The opening size for the summer design condition, as derived from Section 4.2 , is adopted in the three preliminary building configurations for comparison. The upper band of external temperature to cause flow reversal is investigated as well. The objective for this chapter is to investigate the effect of segmentation by the use of conventional typology of tall office buildings. The satisfactory flow rates as well as the desired flow pattern are investigated accordingly. The definition of satisfactory flow rates in this study includes the requirement for minimum flow rates for ventilated cooling, while the resultant flow velocity should not cause the uncomfortable air draught within the occupied spaces. The summary remarks in Section 4.4 are then directed to the potential scenario, where the design condition cannot be secured with reference to the proposed preliminary building configurations. 


\subsection{Investigations of initial opening size}

In this study, the required envelope opening size can be calculated by the explicit method of solution of the envelope flow model (EFM) approach as described in CIBSE AM10 (2005). It is important to determine the maximum and minimum sizes of openings to enable adequate occupant control. The maximum sizes are determined by a summer design condition while the minimum sizes are derived from the winter condition in this section. The purpose-provided openings are considered and it is assumed that the discharge coefficient $\left(C_{d}\right)$ of a given shape of opening is independent of Reynolds number.

In the general case, as presented in Figure 2-39, buoyancy and wind work at the same time. Thus the pressure difference across an opening at a given height $\mathrm{z}$ can be expressed as Equation 4.2-1. For the given assumption in terms of the discharge coefficient, Equation 4.2-2 is then obtained where $\Delta P$ denotes the pressure difference across the opening, $A$ for the area of the opening and $q$ for the volume flow rate. The equation can be rearranged to provide an expression for $q$ in terms of $\Delta P$ as in Equation 4.2-3. Alternatively, if the flow rates, discharge coefficients and positions are known for each opening, the equations can be solved to give the areas. This is known as the explicit solution and is usually used in early stage of a design.

$$
\begin{aligned}
& \Delta P=P_{E 0}-P_{I 0}-\left(\rho_{E}-\rho_{I}\right) g z+P_{W} \\
& C_{d} \equiv \frac{q}{A} \sqrt{\frac{\rho}{2 \Delta P}}=\mathrm{constant} \\
& q_{i}=C_{d i} A_{i} S_{i} \sqrt{\frac{2 \Delta\left|P_{i}\right|}{\rho}}
\end{aligned}
$$

Table 4-1 shows the calculations for a summer design condition with $\Delta T=3.3{ }^{\circ} \mathrm{C}$ and with the neutral height specified as being at the top of the occupied spaces. The minimum opening areas required for the design flow rates are then determined. For the purpose of inter-comparisons, the maximum opening area 
from calculations is adopted for each floor of the building in the preliminary investigations. The modes of operation of the preliminary building configuration are illustrated as Figure 4-1. The relationship between flow rate $q_{i}$ through an opening and a pressure difference $\Delta p_{i}$ is provided by magnitude $\left|\Delta p_{i}\right|$ and direction $S_{i}$ across an opening, by means of the discharge coefficient $C_{d i}$ and a specified geometric area $A_{i}$ as presented in Equation 4.2-3.

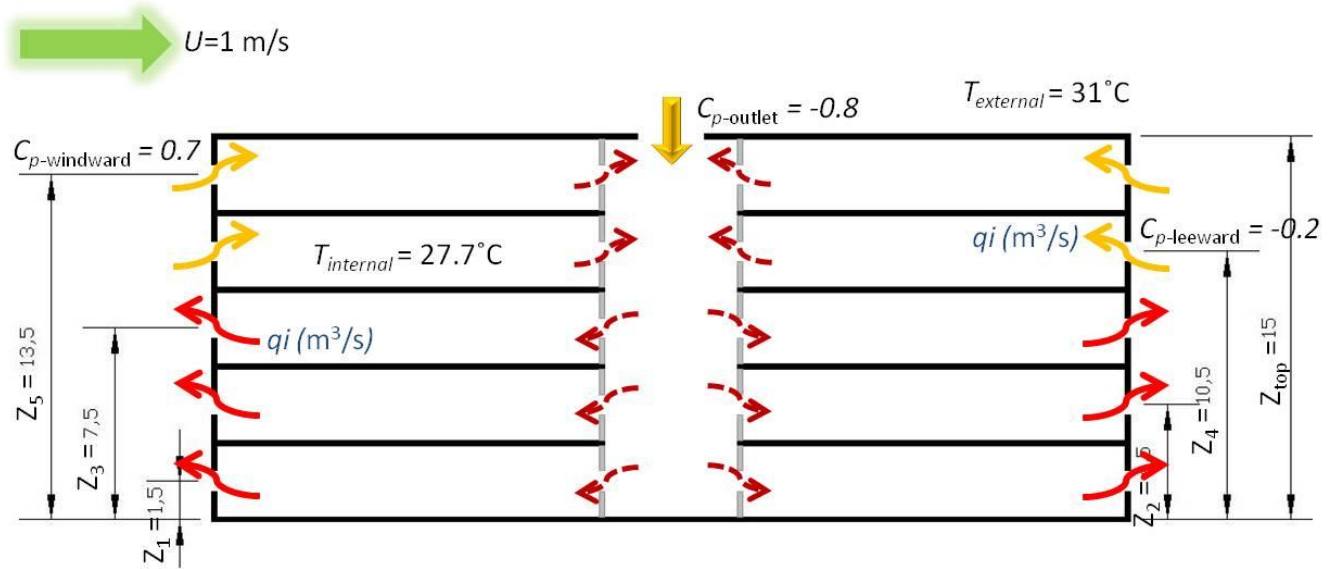

Figure 4-1: Modes of operation of the preliminary building configurations

Table 4-1: Calculated areas for summer design condition

\begin{tabular}{|c|c|c|c|c|c|c|c|c|}
\hline \multicolumn{2}{|c|}{ Opening location (1 12 FL) } & $\mathrm{Z}_{\mathrm{i}}(\mathrm{m})$ & $\mathrm{C}_{\mathrm{pi}}$ & $\mathrm{q}_{\mathrm{i}}\left(\mathrm{m}^{3} / \mathrm{s}\right)$ & $\begin{array}{c}\text { Flow } \\
\text { pattern }\end{array}$ & $\mathrm{S}_{\mathrm{i}}$ & $\mathrm{C}_{\mathrm{di}}$ & $A_{i}\left(m^{2}\right)$ \\
\hline \multirow{5}{*}{ Windward side } & 1 & 1.5 & \multirow{5}{*}{0.7} & 3 & outward & -1 & \multirow{11}{*}{0.65} & 2.69 \\
\hline & 3 & 7.5 & & 3 & outward & -1 & & 3.58 \\
\hline & 6 & 16.5 & & 3 & inward & -1 & & 8.91 \\
\hline & 9 & 25.5 & & 3 & inward & 1 & & 3.12 \\
\hline & 12 & 34.5 & & 3 & inward & 1 & & 2.27 \\
\hline \multirow{5}{*}{ Leeward side } & 1 & 1.5 & \multirow{5}{*}{-0.2} & 3 & outward & -1 & & 2.35 \\
\hline & 3 & 7.5 & & 3 & outward & -1 & & 2.89 \\
\hline & 6 & 16.5 & & 3 & inward & -1 & & 4.09 \\
\hline & 9 & 25.5 & & 3 & inward & 1 & & 4.06 \\
\hline & 12 & 34.5 & & 3 & inward & 1 & & 2.57 \\
\hline \multicolumn{2}{|l|}{ Top outlet } & 36 & -0.8 & 0 & - & 1 & & - \\
\hline \multicolumn{9}{|c|}{$\begin{array}{l}* \text { Boundary conditions: } \\
\text { The external temperature over occupied hours: } \mathrm{T}_{\text {external }}=31^{\circ} \mathrm{C} \\
\text { The internal temperature over occupied hours: } \mathrm{T}_{\text {internal }}=27.7^{\circ} \mathrm{C} \\
\text { The temperature difference over occupied hours: } \Delta \mathrm{T}=3.3^{\circ} \mathrm{C} \\
\text { The averaged ambient wind speed: } 1 \mathrm{~m} / \mathrm{s}\end{array}$} \\
\hline
\end{tabular}




\subsection{The monthly off-design condition of the proposed building configurations}

\subsubsection{The effect of segmentation}

The single-cell envelope flow model is adopted in the preliminary investigations for which monthly time-averaged flows are chosen to evaluate the suitability of the configurations. Consequently, the monthly average weather data over occupied hours is used to estimate the monthly averages of flow rates and temperatures. For natural ventilation design, it is important to ensure that the designed system delivers the required quantity of air to the right places, at the right time. Ideally therefore one would carry out calculations over a wide range of individual conditions. In this sense, the use of time-averages is a compromise. However, this study focuses on the effect of segmentation. Thus, the approach adopted is much simpler and should provide a meaningful basis for comparison in the preliminary investigations.

The maximum opening size $\left(9 \mathrm{~m}^{2}\right)$ obtained from the summer design condition of the explicit method is adopted for the calculations (refer to Section 4.2). It is assumed that the opening size is consistent to all floors throughout the proposed building configurations (Fig. 2-39). Figure 4-2 and 4-4 illustrate the monthly results of volume flow rates against floor height, for the buoyancy alone and wind and buoyancy combined conditions respectively. Some examples of modelling results are discussed as follows.

As stated above, the time-averaged results are chosen for comparison between different building configurations. For the buoyancy alone cases, the results as presented in Figure 4-2 show that the air flow follows the desired direction mainly in the lower floor levels during cooler seasons (January, February, November and December) and mid-seasons (March, April and October). Also, the volume flow rates decrease gradually with floor height and result in negative flow rates 
(opposite to the desired flow direction as presented in Fig. 2-39) in high levels under such external weather conditions. This is caused by limited stack effect in the higher floor levels. The desired flow pattern for this simulation case is that fresh (external) air enters each occupied space from the envelope opening and flows out through the outlet at the top of atrium as proposed in Figure 2-39. The value of volume flow rates appears positive when follow the designed flow direction; while the values are negative when air flows along the opposite direction to the design condition.
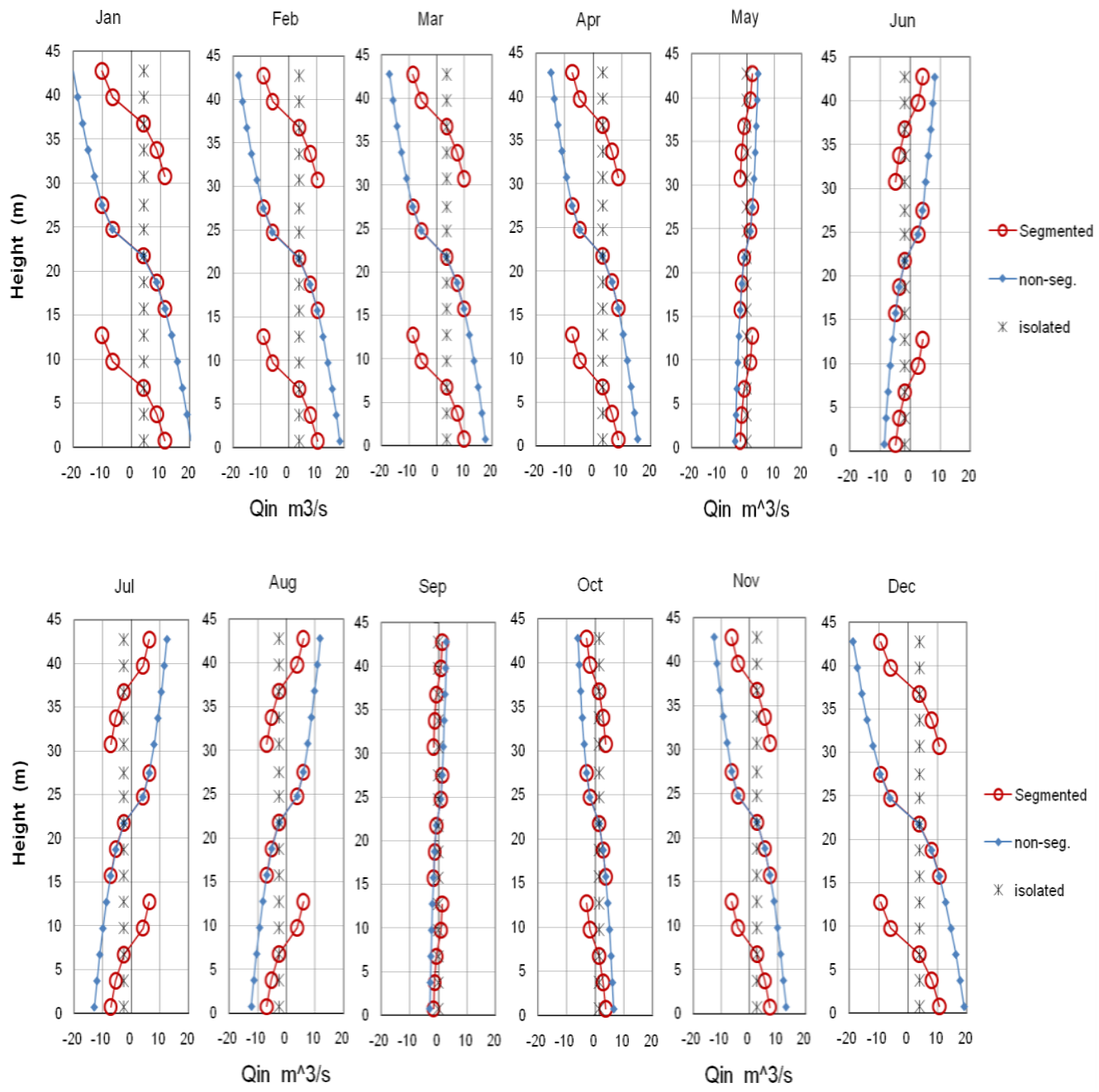

Figure 4-2: The monthly volume flow rates at each floor with the opening size of $9 \mathrm{~m}^{2}$ _Buoyancy alone 
However, the top-down flow reversal (opposite to those as illustrated in Figure 2$39 \mathrm{~b}$ and 1c) occurs in the warmer seasons, namely from May to September. Figure 4.3 demonstrates one of the potential scenarios of the top-down flow reversal. The reversed flow pattern as observed in the modelling is that the air flows in from the atrium-top opening and individual openings of upper floors and consequently exhausts through the envelope openings in the lower floor levels. Under such a scenario, though the amount of flow rates are secured for certain floors, the desired thermal comfort might not be achieved, because of the warmer air are driven into the occupied space.

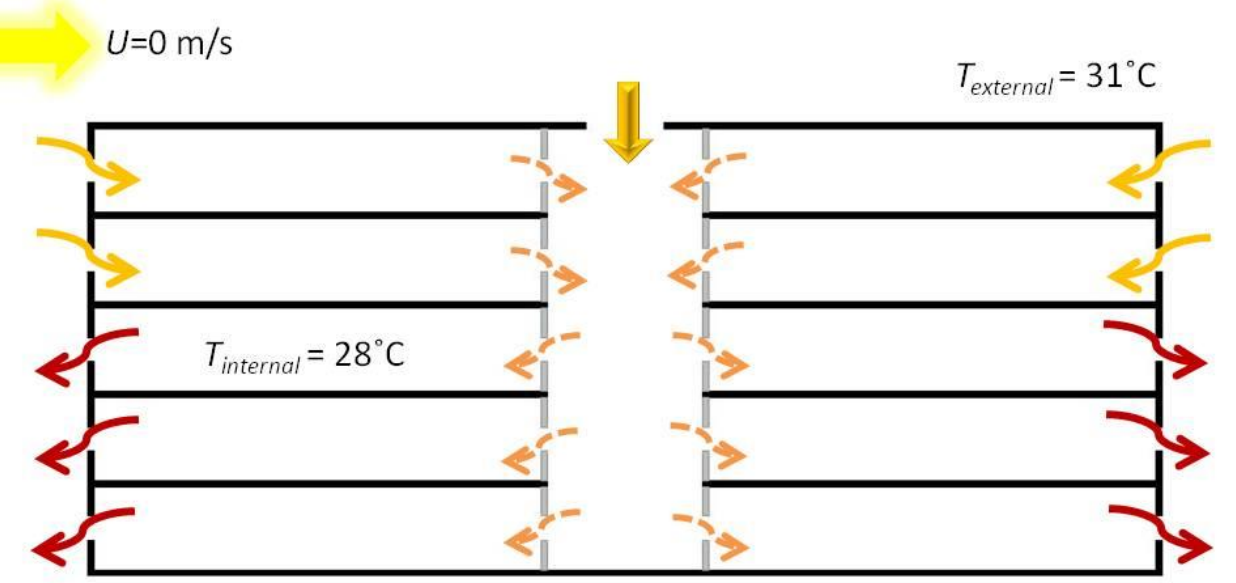

Figure 4.3: The top-down flow reversal under warmer seasons_ The buoyancy alone case

As for the wind and buoyancy combined cases (Fig. 4-4), the same conclusion is made for the non-segmented cases in terms of air flow pattern. The fresh (external) air would enter each occupied space from the envelope openings and then exhaust through the outlet at the top of the atrium, mainly in the lower floors of cooler seasons. Nevertheless, the positive flow rates are achieved for both the isolated and segmented cases irrespective of ambient temperature due to the presence of prevailing wind. The overall ventilation rates could be much improved by the wind effect, irrespective of building configurations adopted. However, when the required flow rates exceed $18\left(\mathrm{~m}^{3} / \mathrm{s}\right)$, the resultant air flow speed $(2 \mathrm{~m} / \mathrm{s})$ might 
cause uncomfortable draughts for occupants nearby openings (with the window size of $9 \mathrm{~m}^{2} / \mathrm{s}$ ). This occurs mainly in the winter and mid-seasons of the nonsegmented case (Fig. 4-4). It is therefore important to determine the maximum and minimum sizes of openings for the occupants to exercise adequate control.

Generally speaking, though the flow rates of the isolated cases are stable throughout floor levels and are relatively easier to exercise individual control compared to the atrium type buildings, the isolated case is heavily influenced by the external wind force. When the external wind velocity is low, it is unlikely for the isolated case to reach the required flow rates. In the extreme weather conditions where the external wind speed is relatively low, the non-segmented and segmented building configurations are much preferred for all floors to achieve the required fresh air flow rates.

For the wind and buoyancy combined condition, however, the isolated as well as the segmented case has better performance than the non-segmented one, for its relatively small variation of flow rates between floors. One thing to be noted is that the opening sizes used in these three building configurations are the same for inter-comparison. The opening sizes might be adjusted by occupants according to the sensation of thermal comfort.

Following that, varied external opening sizes are determined against building height using the explicit method of the envelope flow model as presented in Section 4.2. The summer design scenario under the no wind conditions (buoyancy only) is treated as the worst case. The revised volume flow rates against floor height are illustrated as Figure 4-5. The results suggest that the trends for air flow patterns are consistent with those cases with the same openings sizes of $9\left(\mathrm{~m}^{2}\right)$ throughout building height; while the volume flow rates are reduced by a considerate amount due to the smaller opening sizes adopted. 

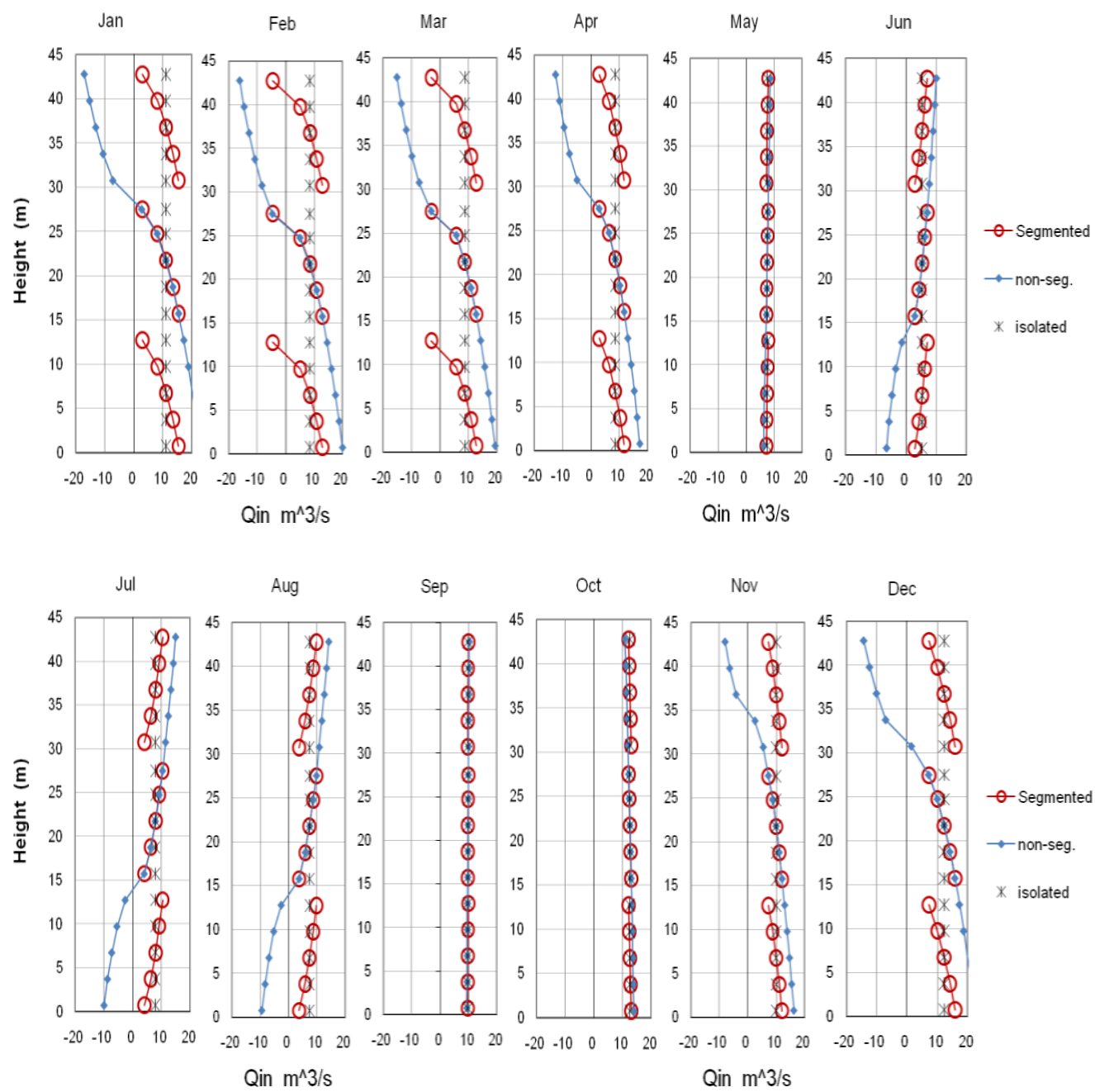

Figure 4-4: The monthly flow rates at each floor with the opening size of $9 \mathrm{~m}^{2}$-Wind and buoyancy combined

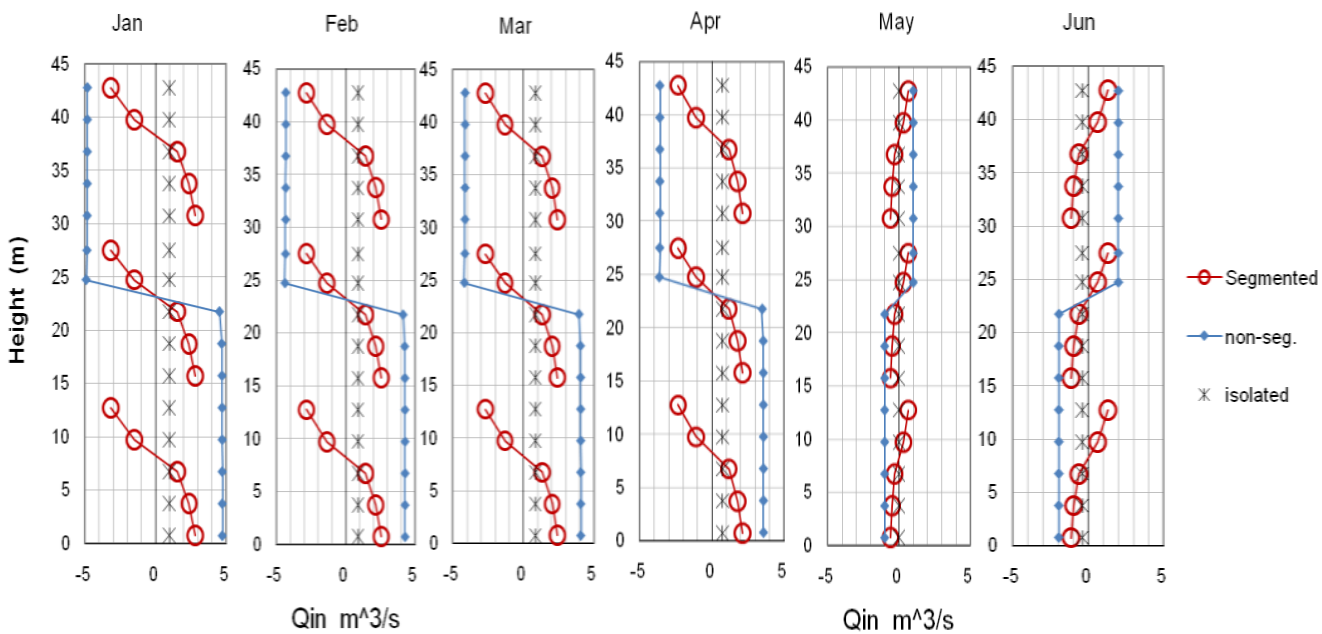




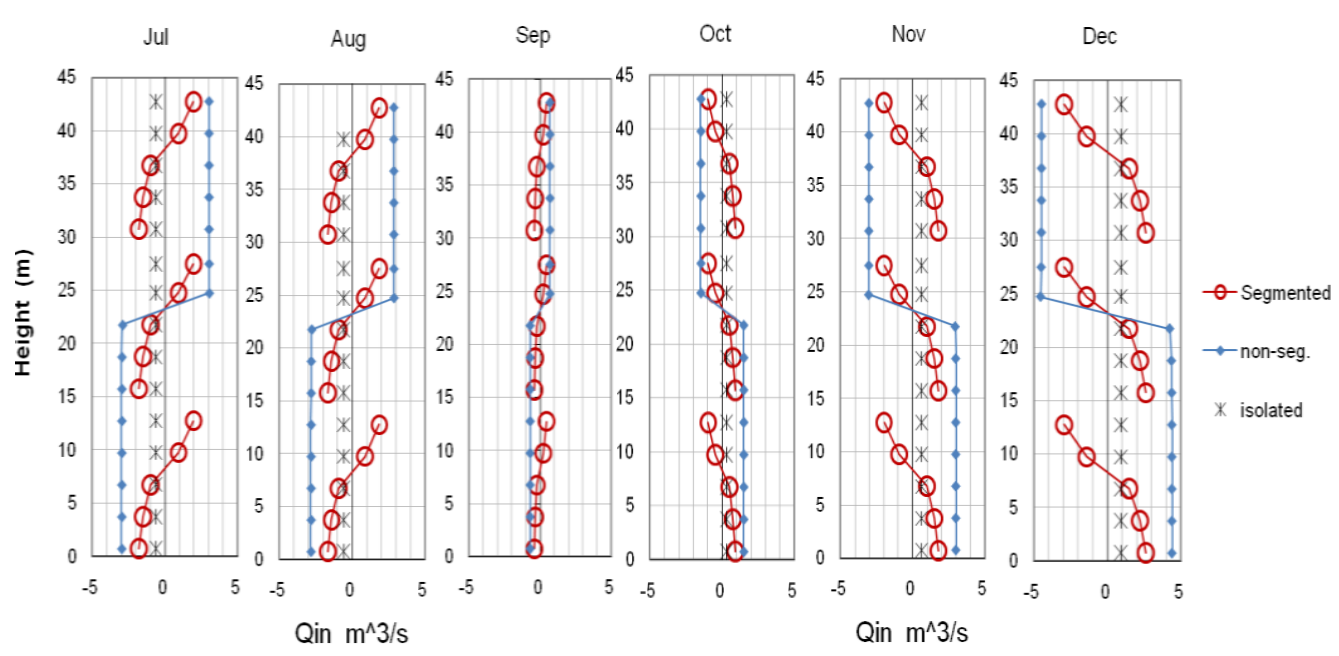

Figure 4-5: Monthly volume flow rates at each floor with varied opening size across floor levels_Buoyancy alone

\subsubsection{The seasonal variation of ventilation}

Seasonal variation of ventilation for the three different building configurations (Fig. 2-39) is examined under Taipei weather condition (Fig. 4-6). For the nonsegmented case (Fig. 2-39b) under the buoyancy alone condition (Fig. 4-7a), the monthly average flow rates decrease when the external temperature gets higher. The required flow rates for cooling as obtained from Equation 3.2-1 can be achieved from December to April for all floor levels except for the top-most floor of the non-segmented case. The required flow rates for the top-most floor is constrained by limited stack height compared to other floors under the low wind speed condition. As for the warmer months, namely between May and September, the negative flow rates occur due to the external temperature being close to or higher than the set internal temperature $\left(28^{\circ} \mathrm{C}\right)$. The set internal temperature $\left(28^{\circ} \mathrm{C}\right)$ was defined from the previous study on tolerable comfort temperature under the no-wind condition of a hot and humid climate (refer to Section 3.4.3). 
The effect of wind on the non-segmented building configuration can be seen in Figure 4-7b. With the help of wind, the flow rates are increased for all months, compared to those in Figure 4-7a with the buoyancy alone condition, in general. The monthly variation of flow rates against floors under different weather conditions are elucidated accordingly. For the buoyancy alone case (Fig. 4-7a), the resultant flow rates are positive from October to April; while the negative flow rates occur when the external temperature gets higher (from May to September). In this case, the desired flow pattern (positive flow rates) can only be achieved with the presence of prevailing wind through the hot summer between June and August (Fig. 4-7b).

Different building configurations, namely the segmented and isolated cases, are applied for examining the effect of segmentation. The monthly variation of ventilation under the Taipei weather condition is investigated. For the segmented case (Fig. 2-39c), the monthly variation pattern of ventilation is consistent with the non-segmented case. However, the positive flow rates (desired flow patterns) can be achieved for all floors during the hot summer (from June to August) under the wind and buoyancy combined condition. The difference of ventilation performance with reference to the building configuration adopted can be seen in Figure 4-7b and 4-8a. Also, the deviation of flow rates between floors is smaller for the segmented case compared to the non-segmented case under the same ventilation condition. As presents in Figure 4-8, high correlation in terms of the monthly ventilation performance is found between the isolated case and the topmost floor of segmented case. This can be explained by the stack height is limited in the higher floors of non-isolated atrium buildings. Wind is then the dominant force for resultant flow rates. 


\section{Monthly weather condition}

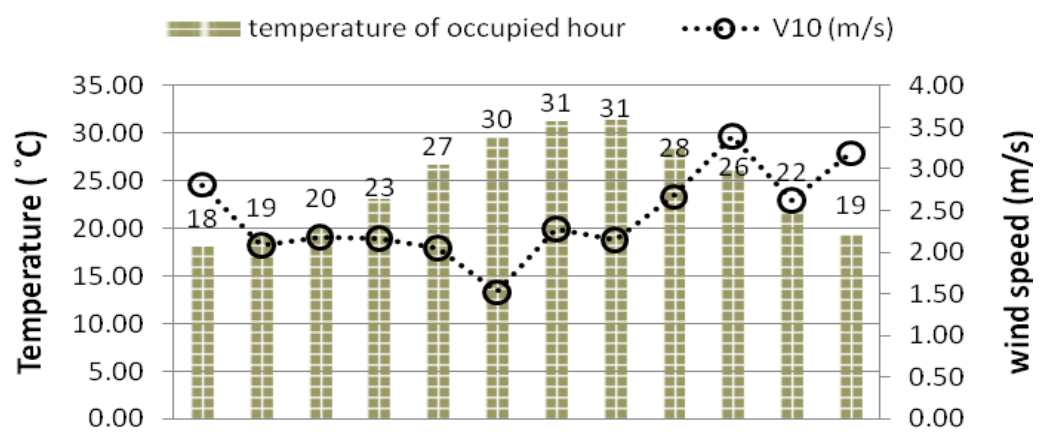

Jan Feb Mar Apr May Jun Jul Aug Sep Oct Nov Dec

Figure 4-6: The monthly average weather condition of Taipei

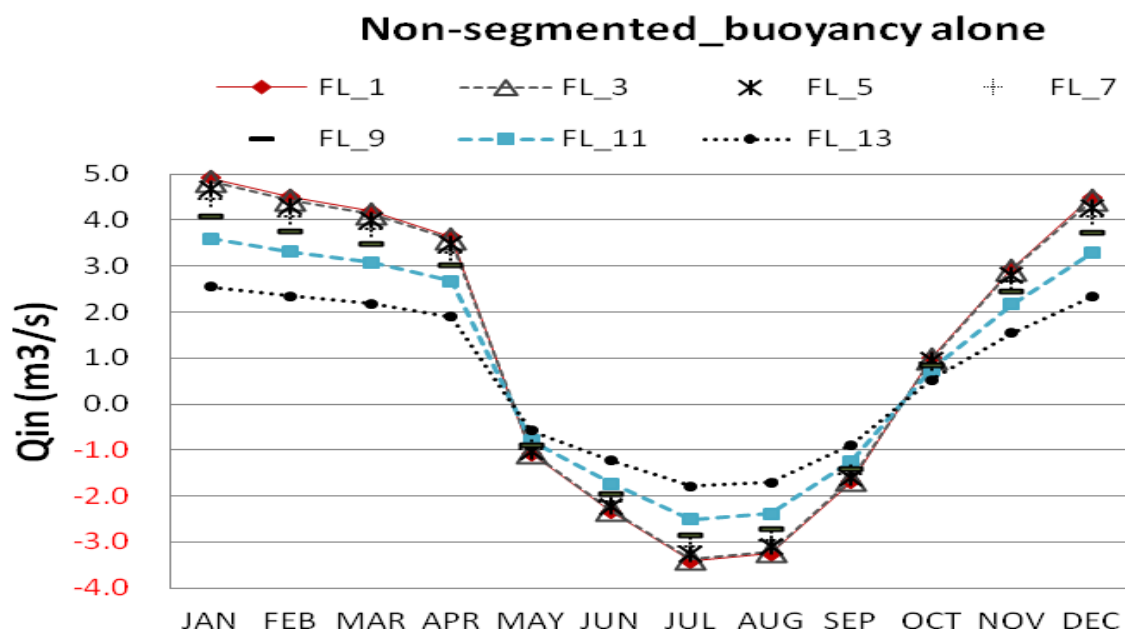

(a)

Non-segmented_wind \& buoyancy

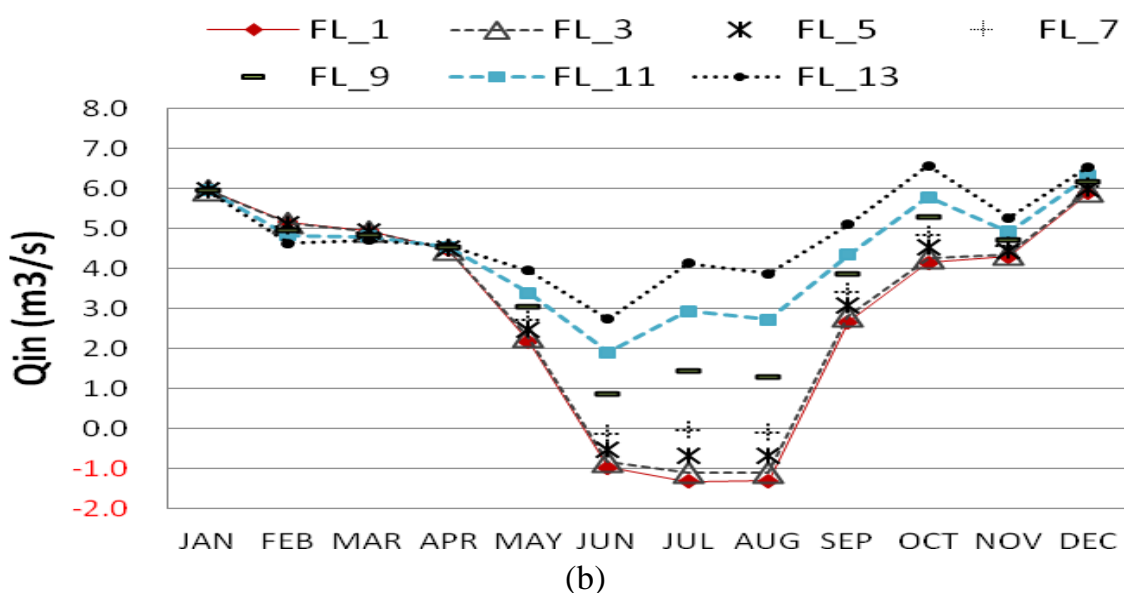

Figure 4-7: The monthly flow rates by floor levels under different ventilation conditions (FL denotes floor level) 


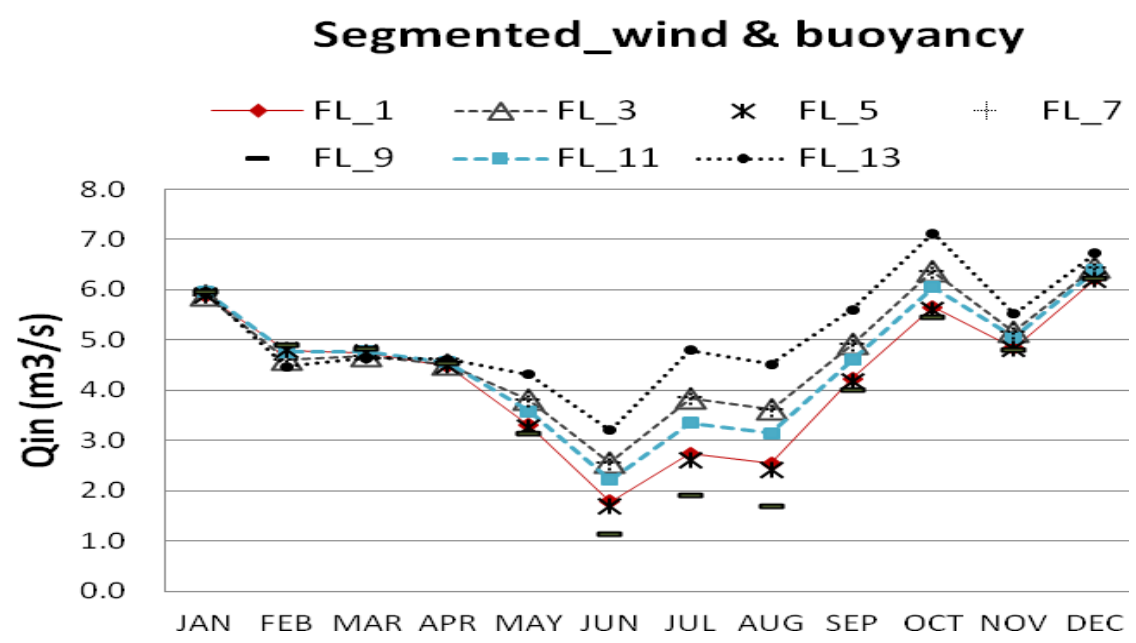

(a)

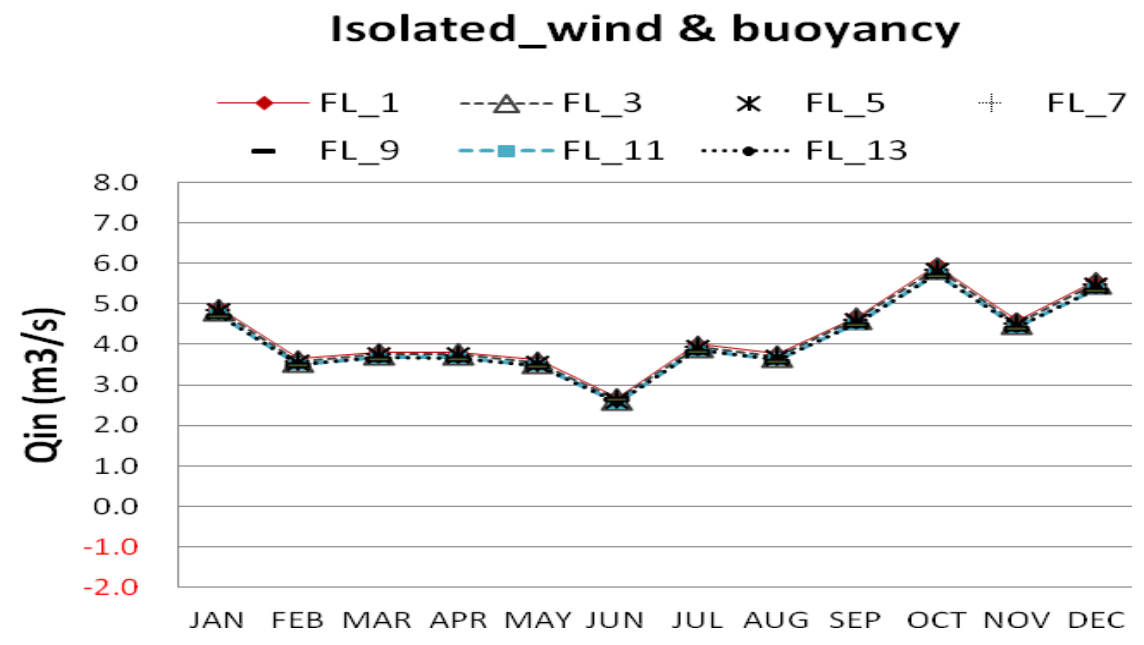

(b)

Figure 4-8: The monthly flow rates by floor levels under different building configuration (F denotes floor level)

\subsubsection{Parametric study with respect to the ambient weather conditions}

To clarify the main contributors to the resulting flow rates, the fresh air flow rates of three building configurations under different external temperature, namely $22^{\circ} \mathrm{C}, 26^{\circ} \mathrm{C}$ and $32^{\circ} \mathrm{C}$, are examined against wind speed (Fig. 4-9). The same opening size against building height, as derived from the summer design condition $\left(9 \mathrm{~m}^{2}\right)$, is adopted for comparison study. The modelling results suggest not surprisingly that temperature difference between indoors and outdoors is 
influential for the flow pattern control. The ambient wind effect has the positive influence on the volume flow rates with the wind attack angle of $0^{\circ}$.

For the case with external temperature of $22^{\circ} \mathrm{C}$ (Fig 4-9a), which has the highest occurring frequency $(35 \%)$ in November, we can see the volume flow rates decrease with floor height for all ranges of wind speed. The lower floor levels with larger stack height would result in higher flow rates consequently. The negative flow rate occur in high levels when the wind speed is lower than $2(\mathrm{~m} / \mathrm{s})$. It is also observed that the variation of flow rates between floors decreases when the ambient wind speed exceeds $3(\mathrm{~m} / \mathrm{s})$. The same flow pattern is observed with the external temperature of $26^{\circ} \mathrm{C}$ (Fig 4-9b). However, higher external wind speed is required for the higher floor levels to achieve the required flow rates and desired flow pattern under the scenario of higher external temperature.

In the envelope flow model approach, the internal temperature is assumed to be $28^{\circ} \mathrm{C}$. That is, the reversed flow pattern occurs when the external temperature exceeds the set internal temperature (Fig. 4-9). For the cases with the external temperature of $28^{\circ} \mathrm{C}$ (Fig. 4-9c), where the temperature difference between indoors and outdoors is limited, the undesired flow pattern occurs in the nonsegmented case even with wind speed of $3(\mathrm{~m} / \mathrm{s})$ applied. The much higher external wind velocity is needed for achieving the same volume flow rates, compared to the lower external temperature condition with the same building configuration being applied. For the cases with external temperature over $28{ }^{\circ} \mathrm{C}$ (Fig. 4-9d), the thermal comfort cannot be guaranteed. This is because the warmer ambient air is driven into the occupied space with flow reversal.

Additionally, the upper band of external temperature to cause reversed flow pattern can be acquired by the trial by error approach, which is an experimental method of problem solving. The concept of this approach is to learn from failure itself, to make a change, and then try again. According to the calculated results, the upper temperature band of the non-segmented strategy with a wind speed of 1 
$\mathrm{m} / \mathrm{s}$ is about $26.3{ }^{\circ} \mathrm{C}$ (Fig. 4-10a), for avoiding the occurrence of flow reversal (negative flow rates); while the temperature band for the segmented case to have reversed flow pattern rises to $27^{\circ} \mathrm{C}$ (Fig. 4-10b). This graph helps to rule out the period of time when natural ventilation is not applicable. The same approach can be applied to find out the upper temperature band of the examined building segmentation under specific external wind speed condition.

From the flow pattern design point of view, it is desirable to have fresh air flow from outside, through the occupied areas and then to the exhaust point. For the atrium type building with the single-cell concept, the non-segmented building configuration might have flow reversal in the higher floor levels during the warmer periods irrespective of ventilation conditions applied. The flow reversal is that the air flows in from the atrium-top opening and individual openings of upper floors, and it then exhausts out through the envelope openings in the lower floor levels. This would be improved by increasing windward wind speed. However, there are only 718 hours of a year $(8.2 \%)$ with wind speed over $5(\mathrm{~m} / \mathrm{s})$. To rule out the time with external temperature over $28^{\circ} \mathrm{C}$, only 578 hours $(6.6 \%)$ of a year can achieve the desired flow pattern in the higher floors of the non-segmented case. The segmented cases, however, are relatively easier for all floors to have the desired flow pattern under low wind speed compared to the non-segmented cases during the warmer seasons.

The above addressed trial by error approach can be applied to find out the minimum wind speed to achieve the desired flow pattern under various external temperatures. Under the worst case, the summer periods with zero ambient wind speed, the exhausted and warmer air would accumulate in the lower floors which might cause the thermal comfort issues. Although this could be solved by increasing the opening sizes, larger opening size is not always beneficial during the hot summer, because the cooling effect is constrained by the ambient temperature. 

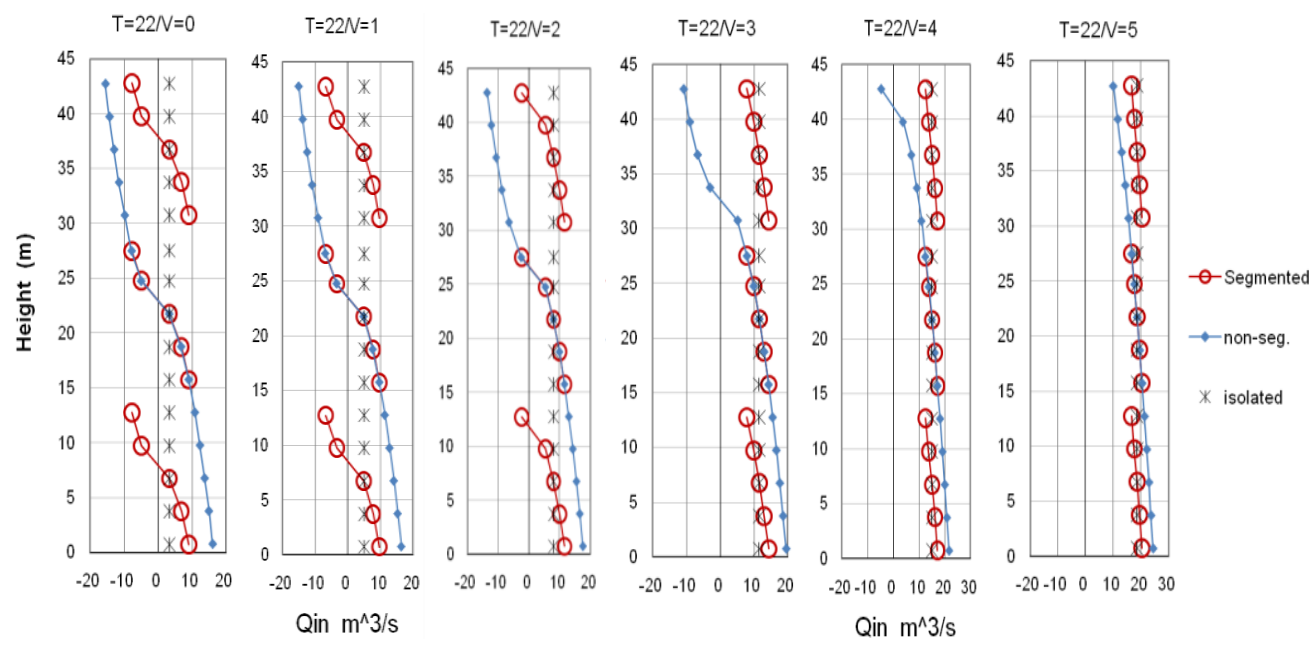

(a)
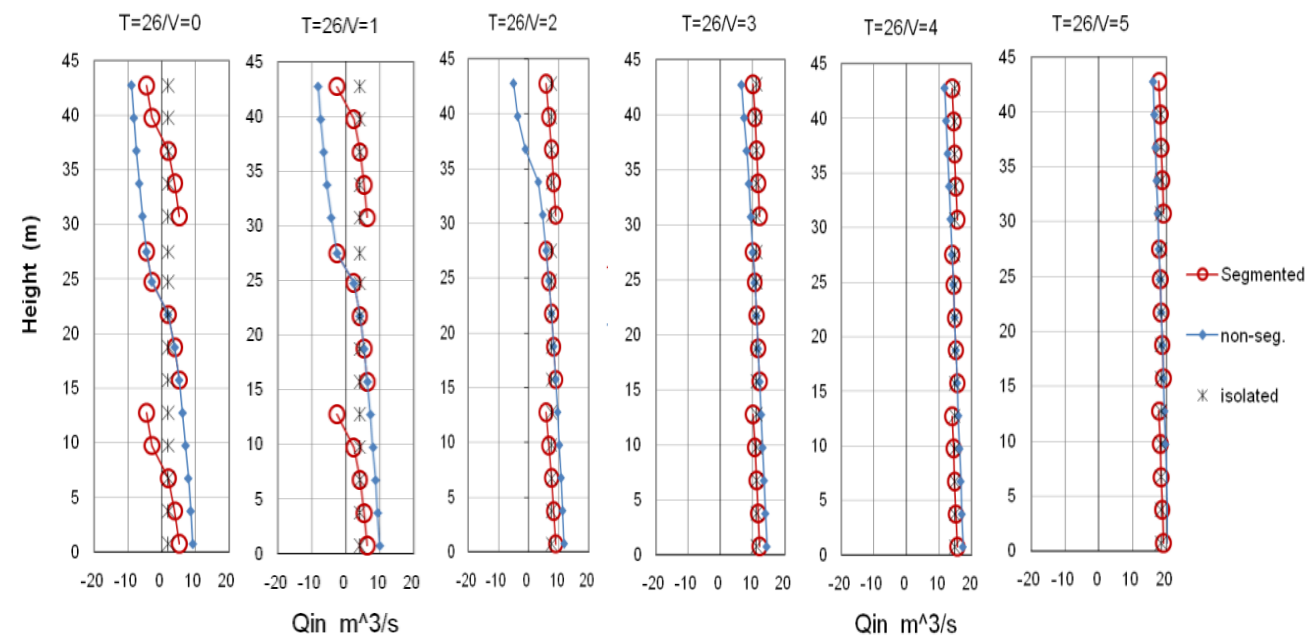

(b)

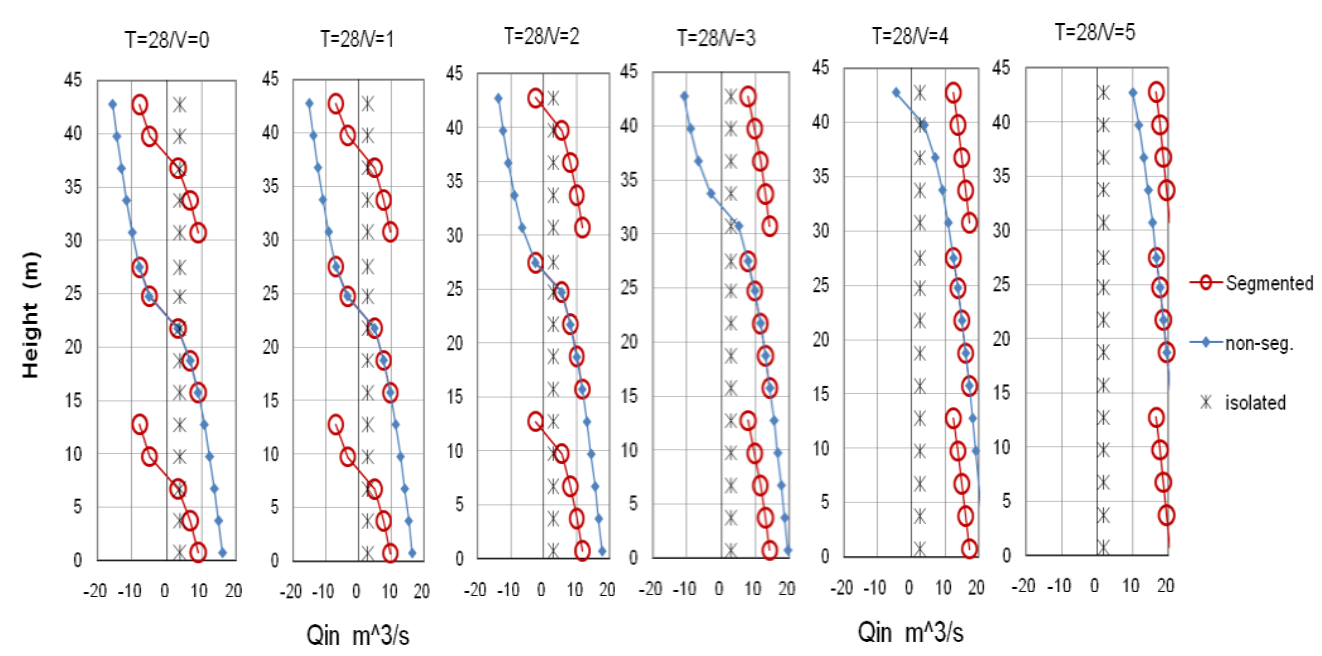

(c) 

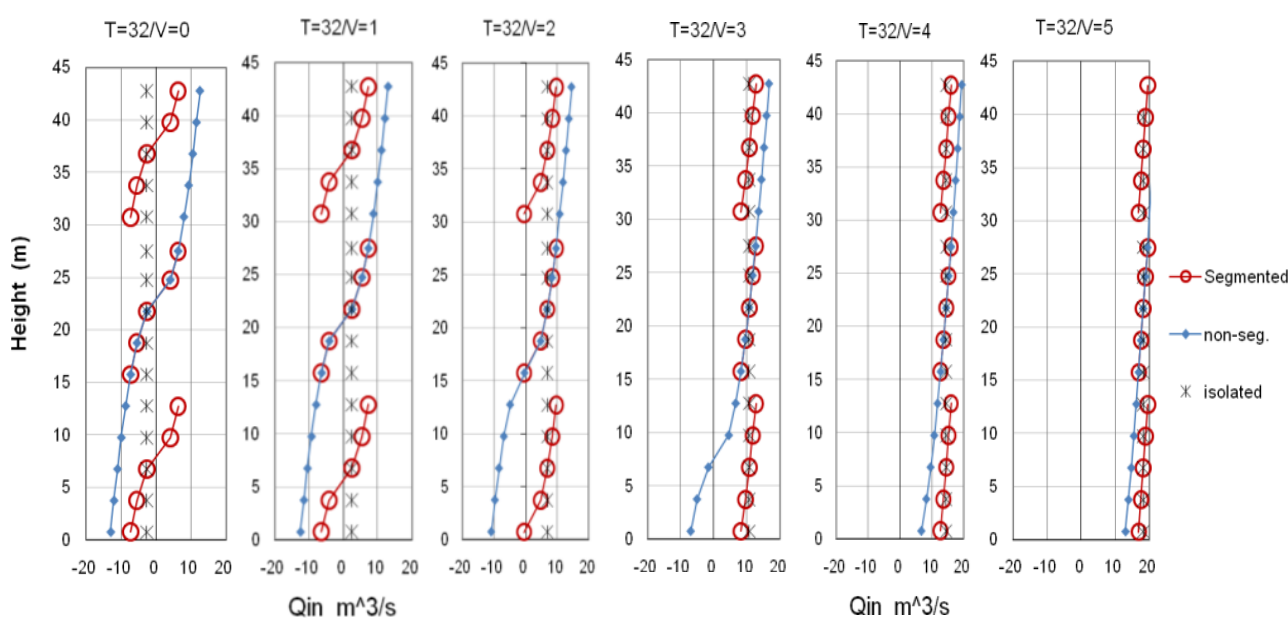

(d)

Figure 4-9: The fresh air flow rates against floor height for different building configurations with different ambient temperature and wind velocity

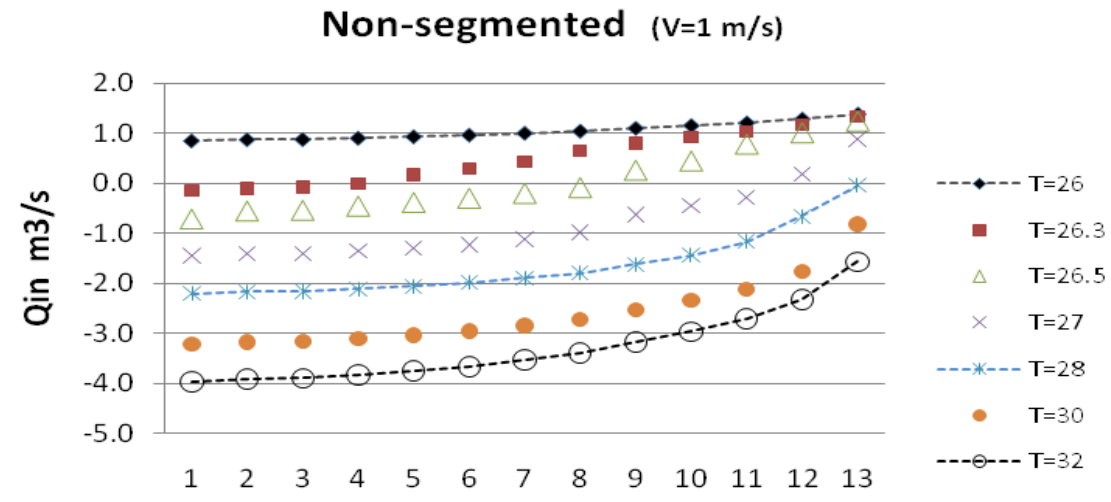

Floor level

(a)

Segmented ( $\mathrm{V}=1 \mathrm{~m} / \mathrm{s})$

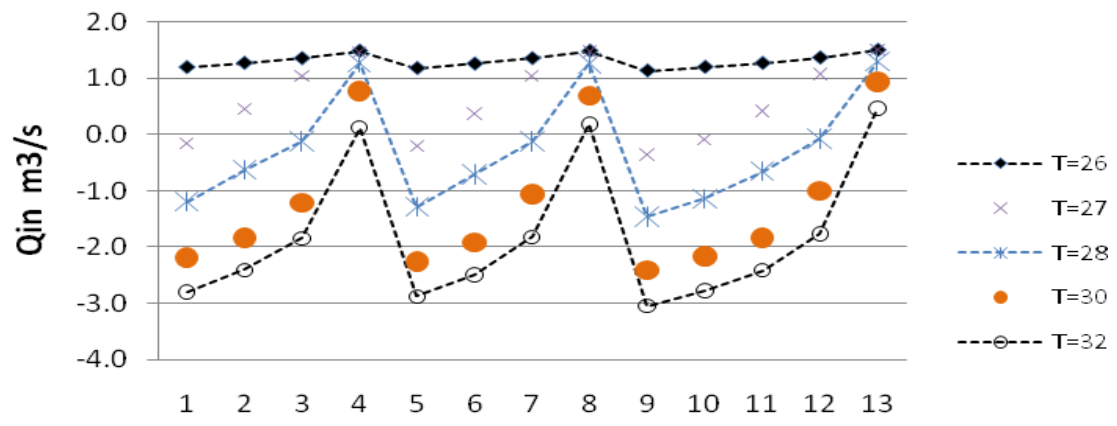

Floor level

(b)

Figure 4-10: The resultant flow rates by floor level with reference to different ambient temperature. a) Non-segmented case; b) Segmented case. 


\subsection{Summary}

This research is concerned with the prospect of purely naturally ventilated tall office buildings in the hot and humid climate of Taiwan. Specifically, the effects of segmentation are of interest. For the preliminary investigations using the single-cell Envelope Flow Model, three different building configurations, namely the isolated, segmented and non-segmented cases, are adopted. One thing to be noted is that the same building storey of 15 floors is used in the three building configurations in this chapter for the evaluation of segmentation effect. The optimum segmentation height is discussed in Chapter 5 with revised building configurations using the multi-cell model.

For this chapter, it can be concluded that the isolated cases tend to have stable flow rates across floors and are relatively easier for flow pattern control. To account for the worst case scenario with low external wind speed (the buoyancyalone case), the atrium type buildings are much preferred for supplying sufficient fresh air flow rates with the help of stack effect. Segmented cases, especially, are much preferred for their relatively small variation of flow rates between floors. The potential risk of large pressure difference acting through the full height of the building is reduced accordingly.

Furthermore, seasonal variation of ventilation for the three different building configurations is examined under Taipei weather condition, where the wind and buoyancy combined condition is applied. The monthly off-design conditions of the three building configurations are examined respectively. Consistency is found between the segmented and non-segmented case in term of the monthly variation pattern of ventilation. However, the positive flow rates (desired flow direction) for all floors during the hot summer (from June to August) can only be achieved with the help of the segmentation strategy; while the flow reversal (negative flow 
rates) occurs in lower floors when the external temperature gets higher. In addition, strong similarity in terms of the monthly ventilation performance is found between the isolated case and the top-most floor of segmented case. This can be explained by the fact that the stack height is limited in the higher floors of non-isolated atrium buildings. The wind force is then the dominant for resultant flow rates.

More parametric studies are needed for quantifying the influence of individual parameters on flow rates as well as flow patterns. Varied wind pressure coefficient against floor height should be applied for more realistic application in tall buildings. In this Chapter, general understanding of naturally ventilated tall office buildings with the proposed preliminary building configurations in a hot and humid climate is achieved by the single-cell envelope flow model approach. To cope with potential large wind and buoyancy pressures acting throughout the building, a ventilated tall atrium and double-skin facades are proposed along with the concept of segmentation in the next chapter of this study. The dynamic effects are evaluated by the use of dynamic thermal simulation incorporating an air flow network. Further results and discussions are provided in Chapter 5. 


\section{The main investigations: The thermally coupled mass flow network approach}

\subsection{Chapter overview}

For the present study, it is proposed that "segmentation" might offer the least risky approach for envelope design of non-residential tall buildings. The effect of segmentation on the resultant flow rates as well as the overall thermal comfort condition of corresponding office spaces is of interest in this study. For this chapter, the revised building configurations are proposed to counter environmental drivers (potential large wind and buoyancy pressures acting through the full height of the building), which necessitates for a more complex building geometry as presented in Figure 2-40. The evaluations are divided into three modelling stages with the same objectives but different resolution levels in terms of the research questions at hand. Detailed flow chart of the modelling procedure of this study is presented in Figure 3-1.

At the first modelling stage of this study, the explicit method of the single-cell envelope flow model (EFM) is adopted for sizing the envelope openings. For the second modelling stage, however, a segmented atrium and ventilated double skin facades are adopted (Fig. 2-40). Dynamic thermal modelling is used, because of the particular importance of the thermal behaviour of the DSF. The chosen thermal model utilised a multi-cell airflow network model because the buildings can no longer be described by a single-cell model.

For natural ventilation design, it is important that the designed system should deliver the required quantity of air to the right places, at the right time. The ventilation performance of this chapter is investigated with respect to the sufficient flow rates for cooling and the desired flow patterns, and particularly the effect of segmentation on the overall thermal condition of the occupied spaces is of interest. 
For the second modelling stage, the monthly time-averaged values of flow rates and temperature are derived from the calculated hourly results over the occupied hours of a specific month. The effect of segmentation is investigated under the identical ambient condition. The specific time with insufficient air flow rates and undesired air flow pattern is clarified. Basically, this is a compromise, but a simple and meaningful basis for comparison had to be chosen.

In Section 5.2, the discussions are directed to ventilation performance of the base case building configuration in terms of flow rates and flow patterns for cooling. For this purpose, the probability is defined as the percentage time that the desired flow pattern and ventilated cooling is achieved during the occupied hours. Further thermal comfort issues are examined using the building bioclimatic charts in Section 6.3.3. In Section 5.3, the revised building configuration with an open wind floor strategy is adopted. The issues for discussion in this section are carried out as those stated in Section 5.2. For the bottom segment of the building with an open wind floor, the lifted case is introduced.

The comparisons are then made with reference to the segmentation effect on the resultant flow rates of different building configurations, namely the base and revised case, in Section 5.4. The comparison with regard to the overall ventilation performance of different building configuration is discussed. The viable number of hours for comfort ventilation is investigated as well. Suggestions in terms of adoption of building configuration as well as segmentation are made with reference to the feasibility for comfort ventilation. 


\subsection{The natural ventilation performance of the base case building configuration in the main investigation}

\subsubsection{The effect of segmentation}

\subsection{1-1 The modelling conditions}

In this section, the systems under study are illustrated as Figure 5-1. More detailed input assumptions are identified in Section 2.4.2-2 (The main investigations: Multi-cell building configuration). The geometry and the key energy inputs to the systems are illustrated as Figure 3-2. The strategies utilising the naturally occurring wind pressures and/or the buoyancy force to drive an air flow are proposed along with the segmentation concept. It is hoped to achieve a natural system that gives as much control as possible. The monthly average volume flow rates through vents of associated office spaces are investigated. The effect of segmentation is then presented by plotting the resultant flow rates against height as well as the free running temperature data. The seasonal influence on the flow rates is examined as well.

The hourly basis simulation results of ESP-r, in terms of flow rates, are collected and then the daily averaged value is determined by averaging the data sets over the occupied hours $(07: 30 \sim 18: 30)$. The monthly averaged value is then derived from the daily averaged value of occupied hours. For the evaluation of overall ventilation performance on the thermal environment, the free running temperature data is presented on weekly basis, where the typical week is chosen for demonstrating the thermal condition of the examined spaces. The typical weeks of climatic context of Taipei is obtained by scanning the climate data for a week in each season. For which has the least deviation in heating degree days, cooling degree days and solar radiation. The heating and cooling base temperature are assumed to be $10{ }^{\circ} \mathrm{C}$ and $28{ }^{\circ} \mathrm{C}$ respectively. The weighting for heating degree days, cooling degree days and solar radiation could be given. The defaults are equal weightings for each. The typical week for the spring of Taipei is between $22^{\text {nd }}$ March and $28^{\text {th }}$ March. $19^{\text {th }}$ to $25^{\text {th }}$ of June and $29^{\text {th }}$ September to $5^{\text {th }}$ October 
are for the summer and autumn season respectively. Two typical winter periods are also identified, which are between $12^{\text {th }}$ and $18^{\text {th }}$ of February and from $29^{\text {th }}$ November to $5^{\text {th }}$ December. However, the winter periods are considered too cold and humid to apply natural ventilation as demonstrated in Figure 2-32a, which shows the thermal comfort distribution by the use of building bioclimatic charts. It is therefore the winter periods are not scheduled in the proposed modelling.
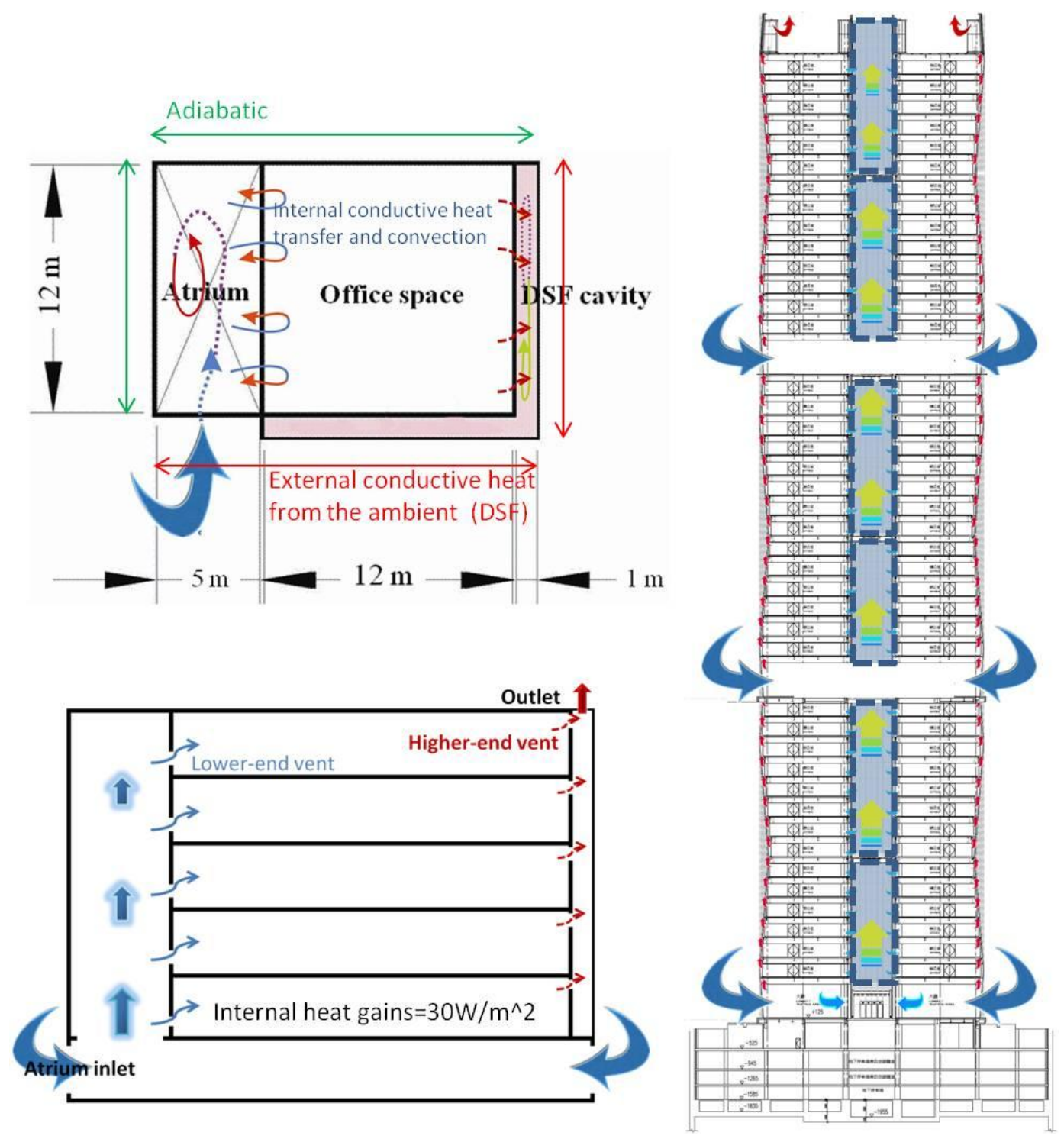

Figure 5-1: Key input assumptions for the main investigations of this study 
One thing to be noted is that a single atrium zone with different thermal mass assumption is evaluated before running a more complicated building configuration as shown in Figure 5-1. The aim is to ensure that the proper interpretation of simulated thermal environment as well as the ventilation bulk flow through the openings. The validation processes suggest that the simulated distributions of solar gains entering the zone is unable to justify, which may result in the underestimation of resultant indoor temperatures. Third-party software (TAS) for evaluation of building thermal environment is adopted to verify the solar gain distributions within ESP-r. The amount of temperature deviations within ESP-r programme is then justified and presented as Figure 5-4. To account for the perceived underestimation of solar gains within ESP-r, it is assumed that a certain level of shading control is activated within the atrium space. In this way, the air temperatures entering the office can be controlled and to ensure the proper interpretation of simulated thermal environment hereafter.

\subsection{1-2 The seasonal performance with reference to building segmentation height}

For the wind and buoyancy combined case, the simulation results for flow rates against building height (Fig. 5-2) suggest that larger segmentation is beneficial for increasing the overall flow rates through individual floor levels compared to the small segmentation case especially for the warmer months, namely between May and August. However, the impact of segmentation on the resultant flow rates of lower floor levels is limited when over 10 storey segmentation height. This can be explained by the total flow rates through the building being controlled by the inlet and outlet. The same inlet and outlet sizes are adopted in each segmentation cases for inter-comparison. Consequently, the volume flow rates through associated offices are constrained. For the buoyancy alone cases, the flow rates are reduced by a considerable amount and the reversed flow pattern occurs when the ambient 
temperature gets higher. In such a scenario, the warmer air might be driven into the occupied spaces and cause thermal discomfort. Additionally, the simulation results suggest that flow rates of all buoyancy alone cases would be affected much by the ambient weather conditions. A sensitivity study for the temperature related parameters is discussed in Section 7.4.

Some examples of modelling results are presented as Figure 5-2 and 5-3. In cases under the wind and buoyancy combined condition, it is found that the amount of flow rates in high levels would decrease against building height, namely between May and August; while it is relatively consistent in mid-levels of larger segmentation case, from March to August. During March and April, the flow rates of associated offices increases gradually with floor level irrespective of segmentation height adopted. For the warmer seasons, however, gradually decreasing flow rates are observed in the higher floor levels. As for the buoyancy alone cases (Fig. 5-3), we can see that the flow patterns are reversed (negative flow rates) for all floor levels between April and August. The mid-levels tend to have the least deviation between floors, compared to the bottom and top parts of floors. The bottom levels are influenced by the potential magnitudes of buoyancy force; while the top floors are greatly affected by the ambient weather conditions. Generally speaking, the design conditions (desired flow pattern, required flow rates and minimum variation across floors) for the buoyancy alone case can only be met when the weather conditions are favourable (March).

For the base case building configuration, pressure nodes inside the DSF cavity are placed at the height of each DSF-vent. The pressure difference at each node is calculated by the height difference between individual DSF-vent and top-outlet. Under the favourable weather condition, the stack effect of individual node decreases gradually from bottom to top of the DSF cavity, which results in reduction of flow rates of individual DSF-vent across floor levels. In such cases, the required volume flow rates for cooling in the higher levels might not be guaranteed. It is argued that enlarging the vent opening size of the higher levels 
might be able to increase the overall flow rates through openings. The eventual cooling effect, however, would be constrained by the ambient temperature, as well as sizes of inlet and outlet openings. Another concern is that the wind pressure coefficient $\left(C_{p}\right)$ for the outlet might vary particularly for the case with larger segmentation height or where the building segment is located at high levels. For the present study, the $C_{p}$ value for outlet (-0.8) is adopted and is consistent for all modelling cases. Further sensitivity analysis for identifying the influential range of $C_{p}$ values on the resultant flow rates is presented in Section 7.3.4.

For the cases with segmentation height over 10 storeys, the required flow rates can be ensured for most of middle floors during the warmer seasons (Fig. 5-2). As for the bottom and top floors of each segmentation case, with either buoyancy alone or combined conditions, detailed parametric study on how the resultant flow rates are affected by the external weather conditions are discussed in Sections 7.3 and 7.4. This study adopted the same opening size for modelling air flows through each floor. In reality, satisfactory flow rates between floors could be achieved by slightly varying the areas of openings according to occupants' needs. Generally speaking, the natural ventilation performance is better in the mid-seasons in terms of satisfactory flow rates and desired flow patterns through office spaces under the wind and buoyancy combined condition. Additionally, the results show that the base case building configuration with segmentation height over 10 storeys has minor difference on ventilation flow rates, irrespective of weather conditions (Fig. 5-2 \& Fig. 5-3). This might be due to the total flow rates being constrained by the size of inlet and outlet, and the flow rates through individual floors are reduced accordingly. 
March_wind \& buoyancy

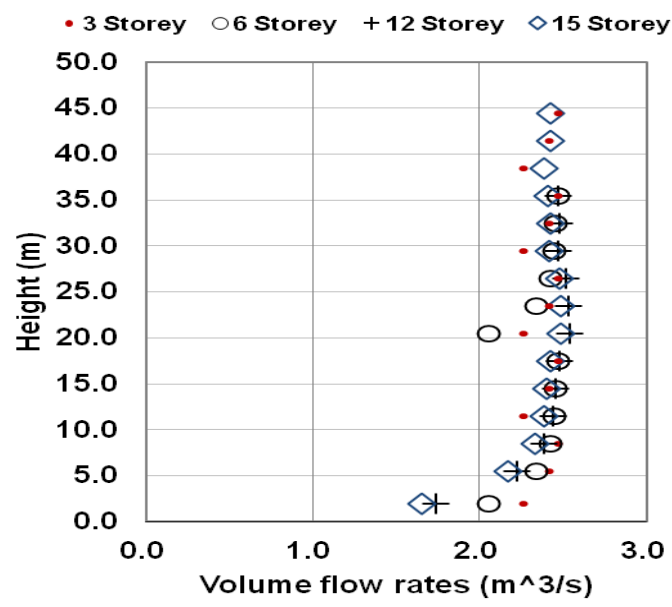

May_wind \& buoyancy

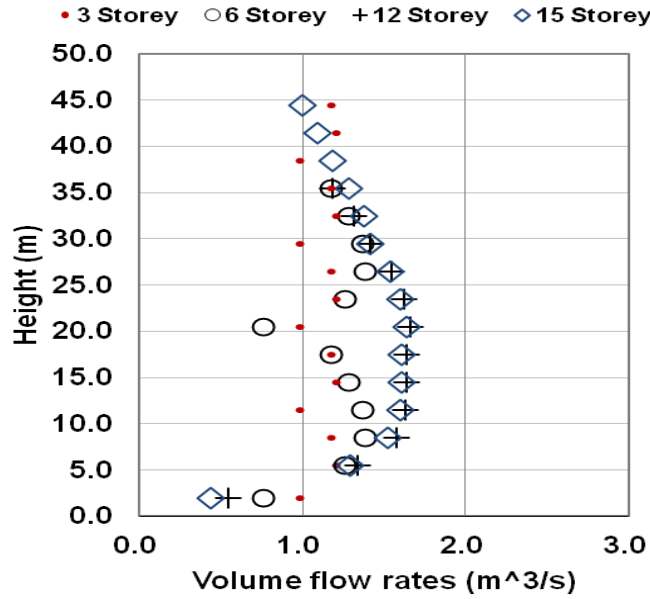

July_wind \& buoyancy

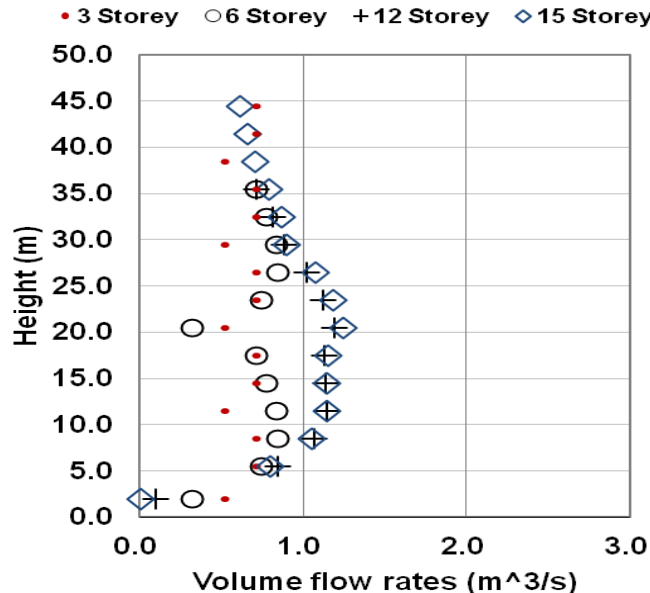

\section{April_wind \& buoyancy}

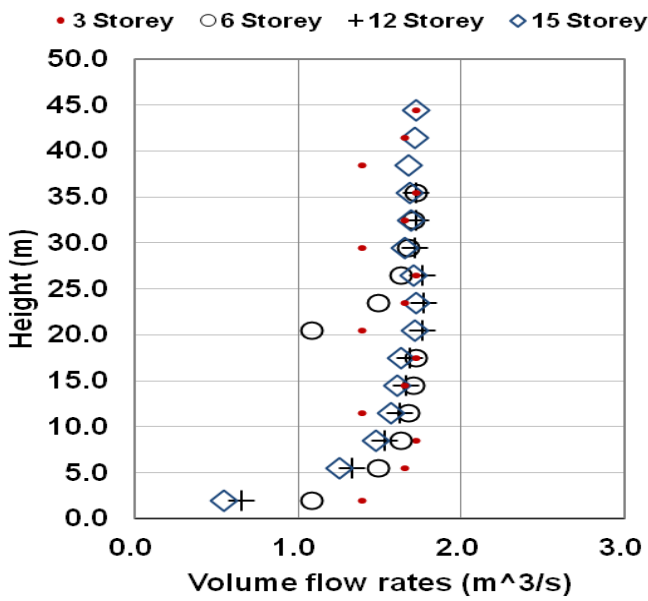

June_wind \& buoyancy

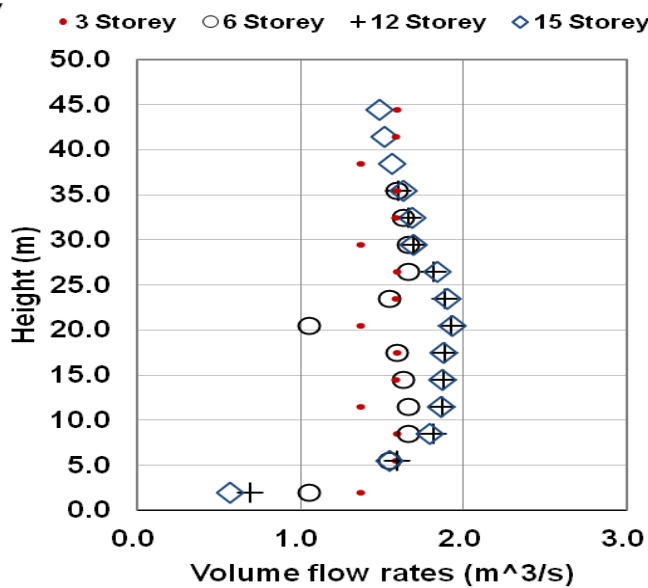

August_wind \& buoyancy

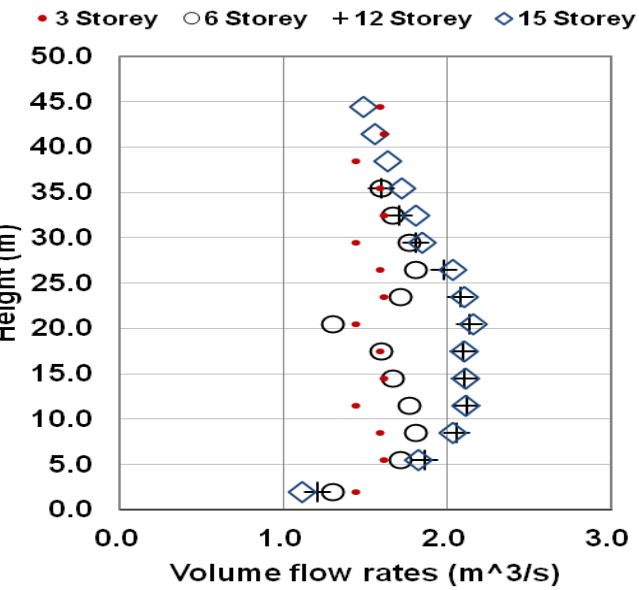

Figure 5-2: The monthly volume flow rates against height_ Wind and buoyancy combined 

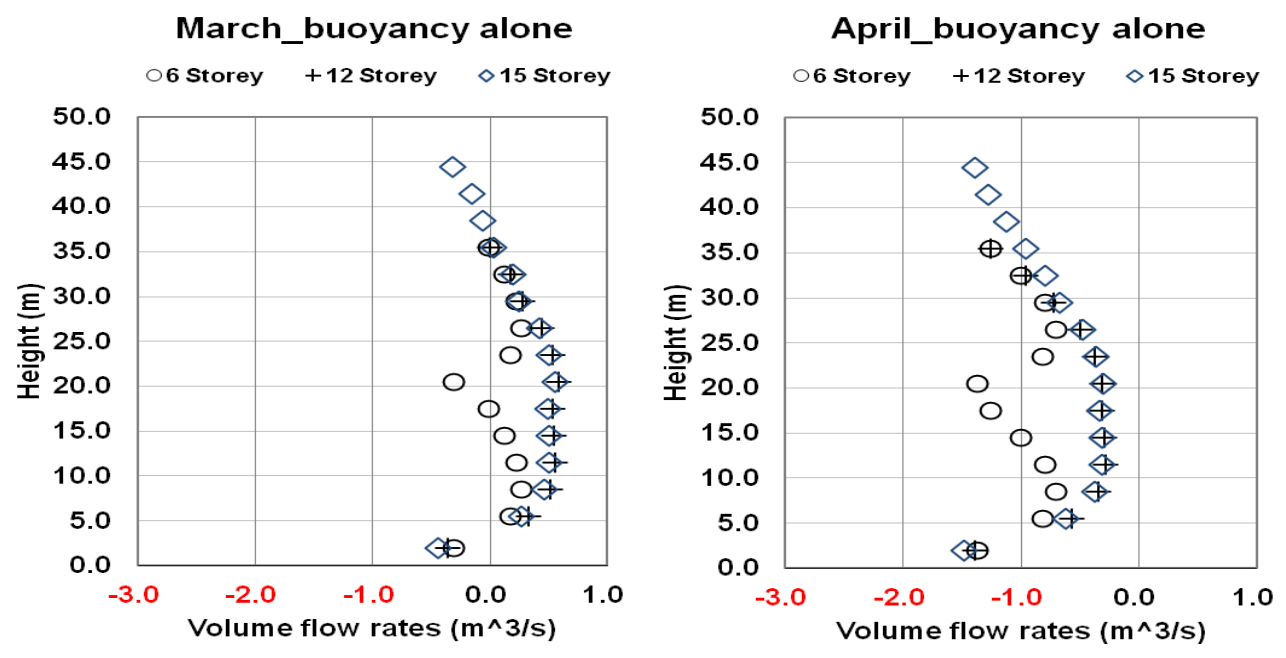

May_buoyancy alone
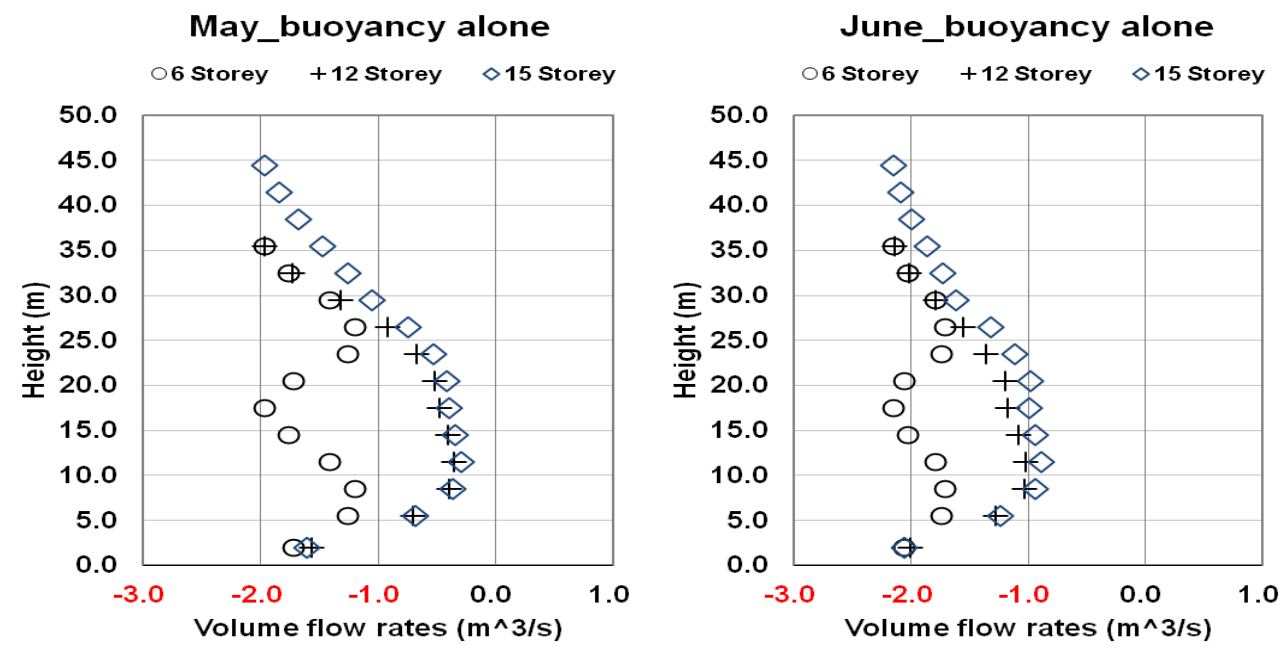

July_buoyancy alone
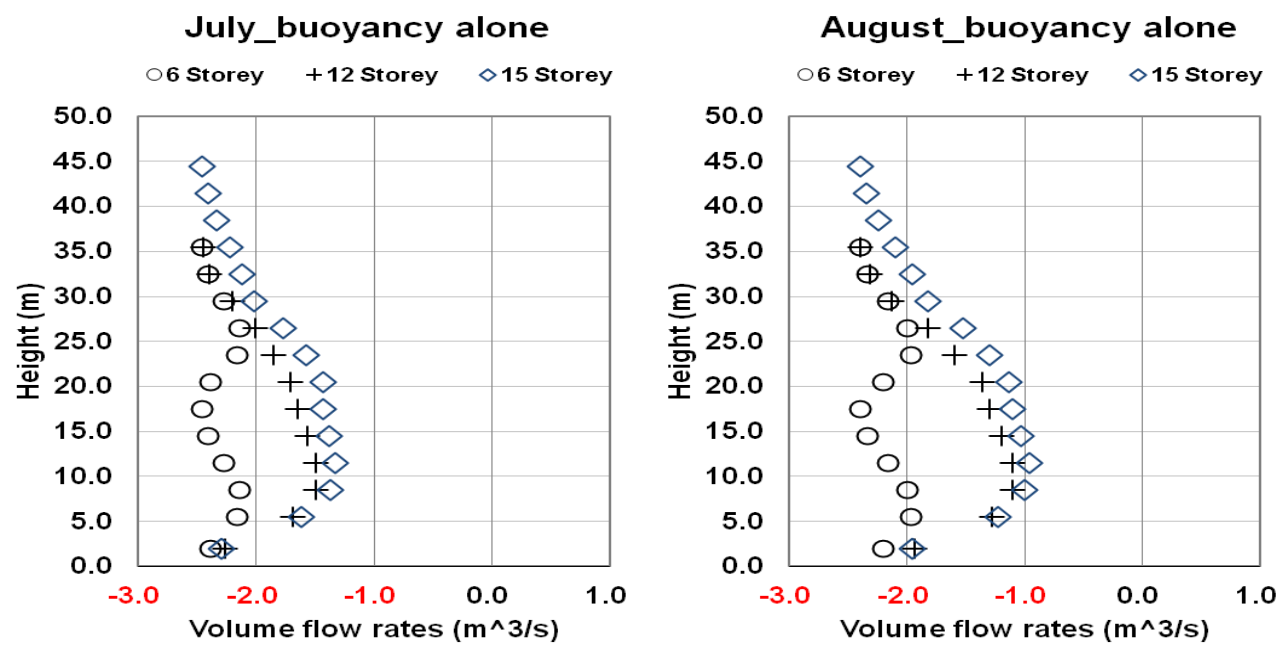

Figure 5-3: The monthly volume flow rates against height_Buoyancy alone 
The overall thermal environment of the 12 storey segmentation case under the wind and buoyancy combined condition is illustrated as Figure 5-4, which demonstrates the general free running temperature of the occupied spaces during the typical weeks of mid-season $\left(22^{\text {nd }} \sim 28^{\text {th }}\right.$ March $)$ and hot summer $\left(19^{\text {th }} \sim 25^{\text {th }}\right.$ June). For both simulation periods, the office and atrium temperatures follow the ambient temperature swing in general. It is assumed that the air temperatures of internal spaces would be more close to the ambient with the presence of high air change rate. For the case with smaller air change rates in the hot summer, the office temperature may be 1 to 3 degrees higher than the ambient because of the perceived internal gains, especially during the peak solar gains period (12:00 14:00). The hourly air change rates are plotted along with the free running temperature in Figure 5.4 as well. The temperature stratification is observed in the tall atrium, which is divided into four zones, and the atrium temperature increases against the height as expected. The effect of internal gains on the overall indoor thermal as well as the airflow environment is investigated in Section 7.3.3.

The thermal fluxes in the atrium are the result of the thermal balance among the ambient environment, the atrium, and the adjacent spaces. The air temperatures of the office nodes would be dominated by the air flowing through the atrium space (if following the desired flow pattern). The thermal simulation of heat transfer in an atrium includes solar gains, external conductive heat between the atrium and the ambient environment, internal conductive heat transfer between the atrium and the adjacent spaces, internal heat gains (lighting only), and the heat transfer through ventilation. For the main investigations in this study, the either side of the open atrium is connected with the office spaces. The opaque part of the atrium surfaces is massive and well insulated. It is assumed that the south-facing wall of the atrium is transparent with double-skin facades; while the top surface is shaded by the upper segment. The top transparent surface of the top atrium segment, however, should be provided with special care for preventing the extra solar heat gains. Nevertheless, the issue of the top segment is not evaluated in this study. It is expected that some sort of shading control would increase the overall 
percentage of comfort ventilation. The key input assumptions for a typical segment in the middle of the building are summarized in Figure 5-1 and Table 3-1.

\section{28 March_B+W_without solar correction}

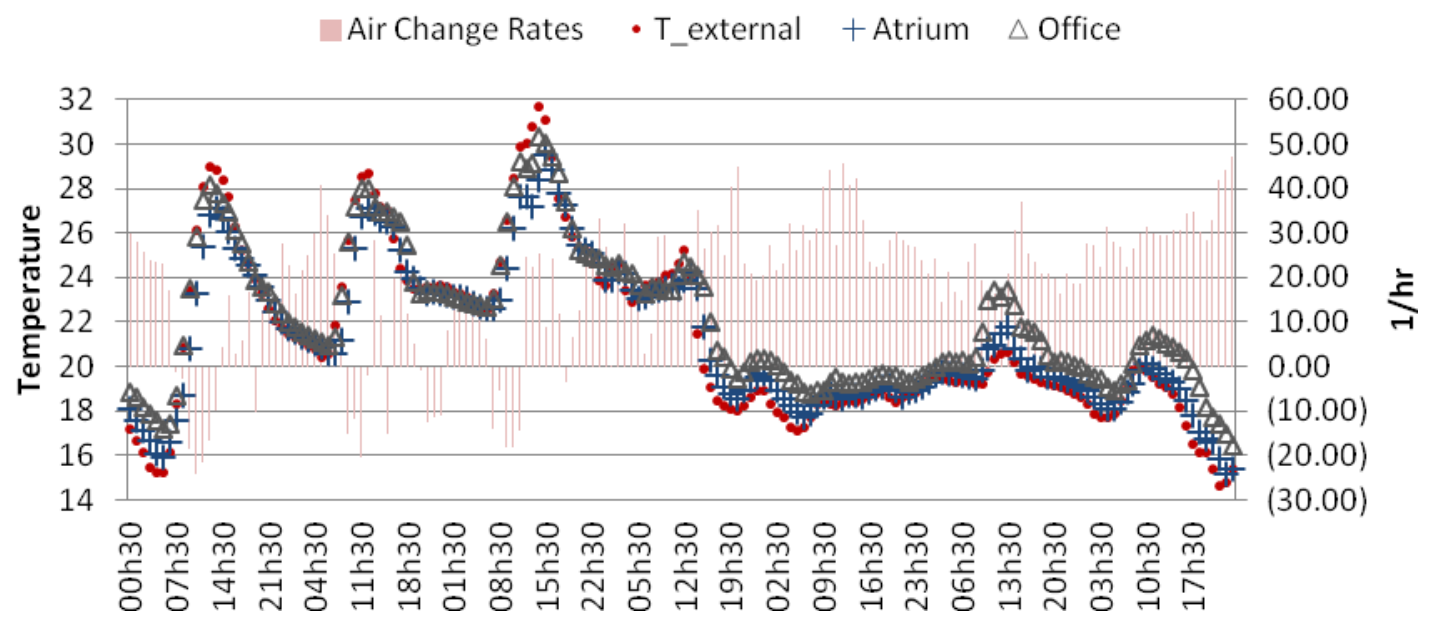

\section{28 March_B+W_with solar correction}

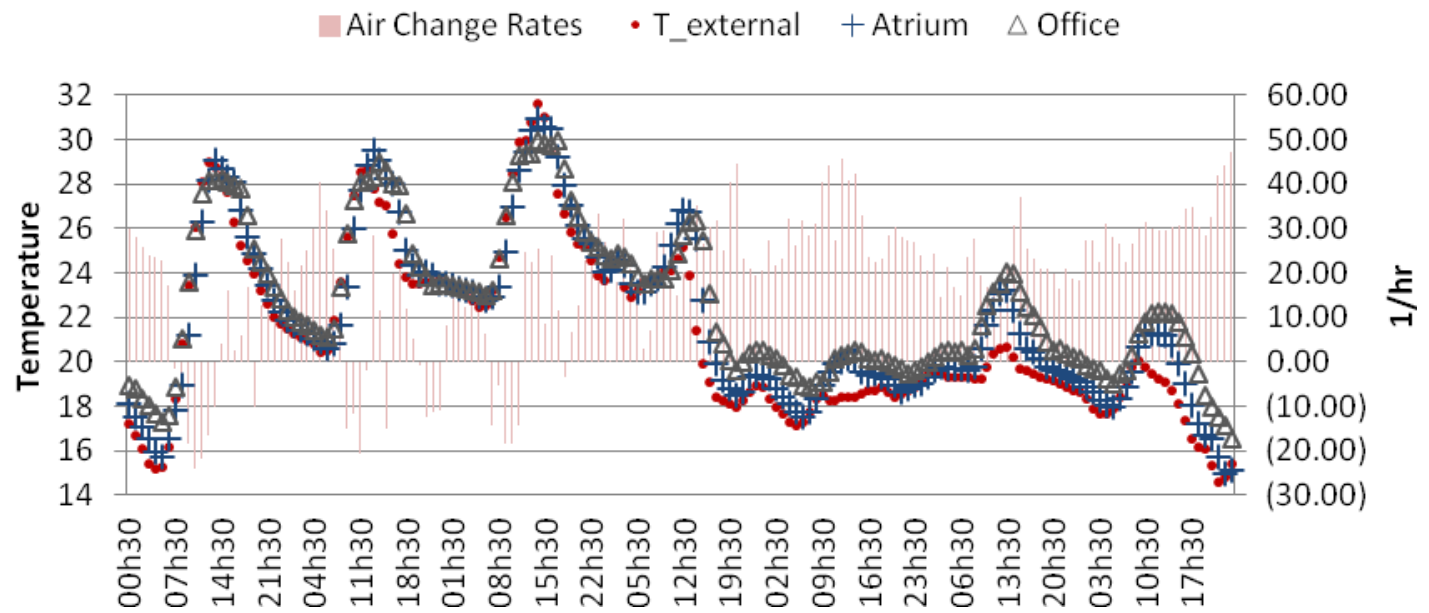

(a) 


\section{25 June _B+W_without solar correction}

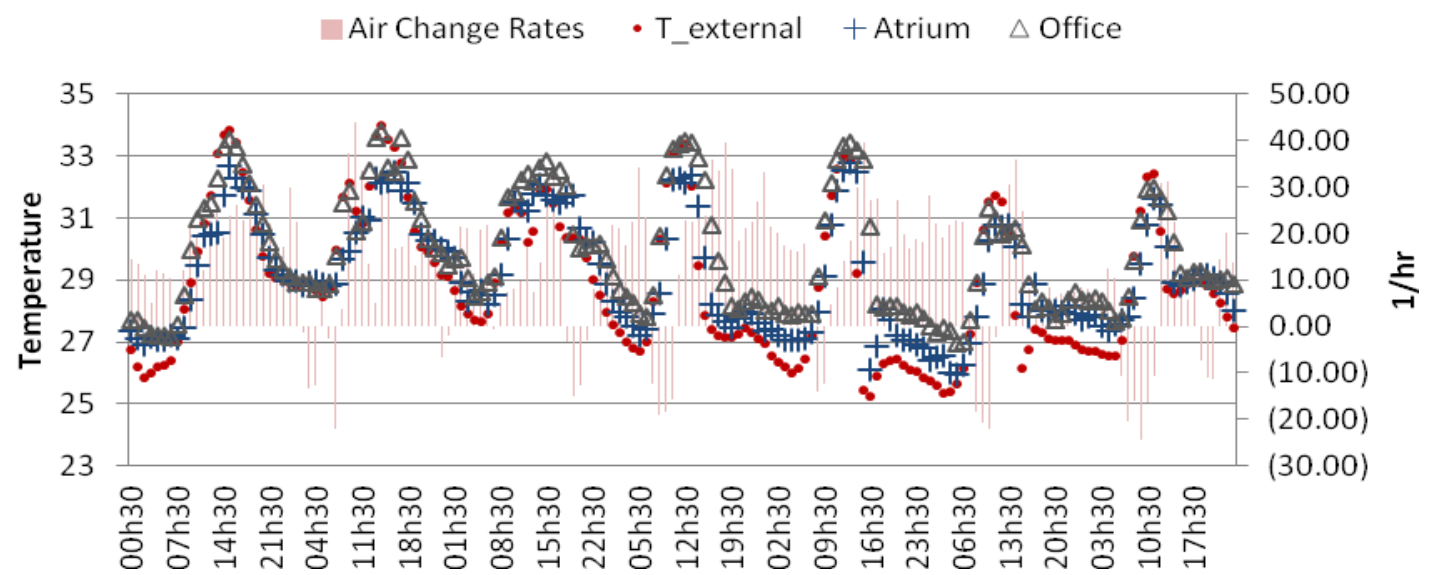

\section{25 June_B+W_with solar correction}

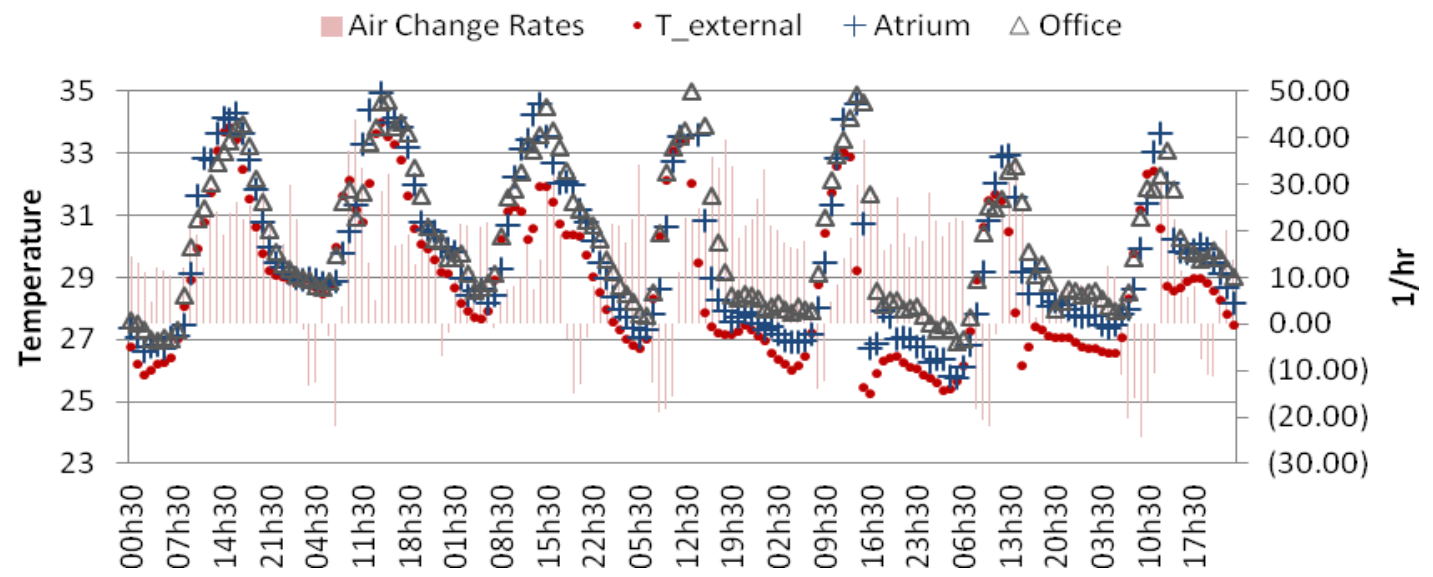

(b)

The temperature deviations between models with and without solar corrections

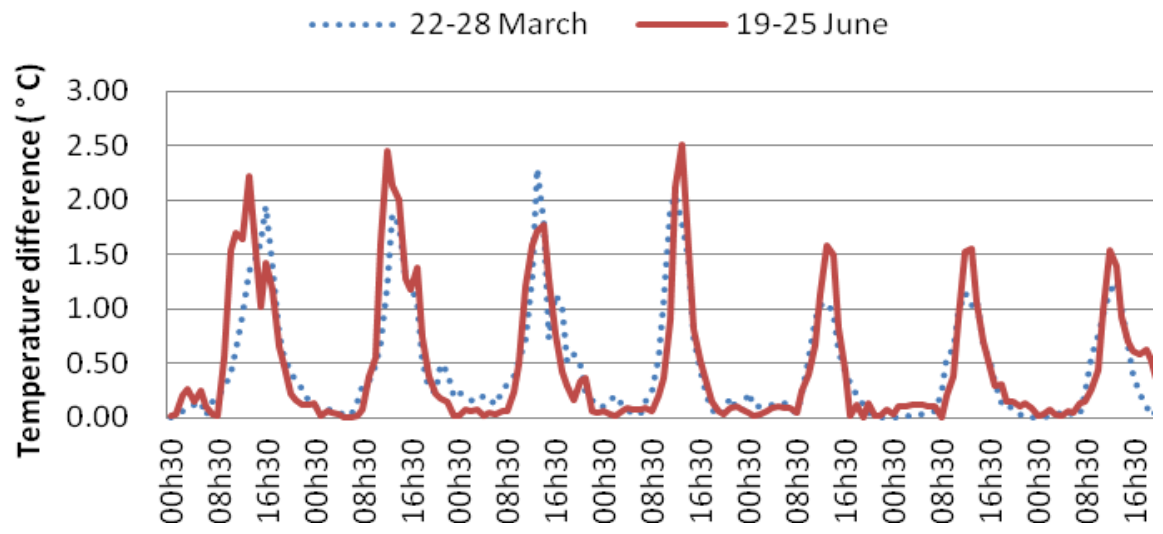

(c)

Figure 5-4: The thermal environment of the typical weeks. a) Mid-season; b) Hot summer; c) temperature deviations between models with and without solar corections 


\subsubsection{The probability for ventilated cooling}

To achieve the ventilated cooling in the free running building, sufficient cooler air being driven into the occupied space is required. For the present study, the initial required flow rates for cooling is defined according to a simple equation (3.2-1), where the internal heat gains are balanced by the heat removed with the ventilation air. As mentioned in the methodology (Section 3.2.2), the ventilation rate of $1.084\left(\mathrm{~m}^{3} / \mathrm{s}\right)$ would suffice for ventilated cooling in the proposed design with floor areas of $144 \mathrm{~m}^{2}$ when the $\Delta T$ of $3.3^{\circ} \mathrm{C}$ is applied. The probability is defined as the percentage time that the required flow rate is achieved during the occupied period. The preliminary seasonal potential for the 12 storeys segmentation case to have sufficient flow rates under different ventilation conditions is illustrated as Figure 5-5.

For the wind and buoyancy combined condition, the probability for cases with less segmentation height, 6 storeys segmentation, would decrease by $10 \%$ to $30 \%$, with reference to floor levels and simulation periods (Fig. 5-5a). The probability is defined as the percentage time that the minimum required flow rates for sensible cooling is achieved during the occupied period. The internal air temperature is set as $28^{\circ} \mathrm{C}$ in this case. As for the buoyancy alone cases, the probability for ventilated cooling would decrease with floor height and the variation between floors is larger than the wind and buoyancy combined cases (Fig. 5-5b). Consequently, the higher floor level might not be able to reach the required flow rate for ventilated cooling. It is also observed that the smaller segmentation cases can hardly achieve ventilated cooling under the buoyancy alone condition. A larger opening size might be required in such cases. However, the influence of opening size is insignificant when the resultant internal temperature is close to the ambient temperature, mainly in the hot summer. Generally speaking, the probability for all floors of the studied cases to reach the design condition is much higher in the mid-seasons. The ventilated cooling performance could be much improved with the help of prevailing wind force. 

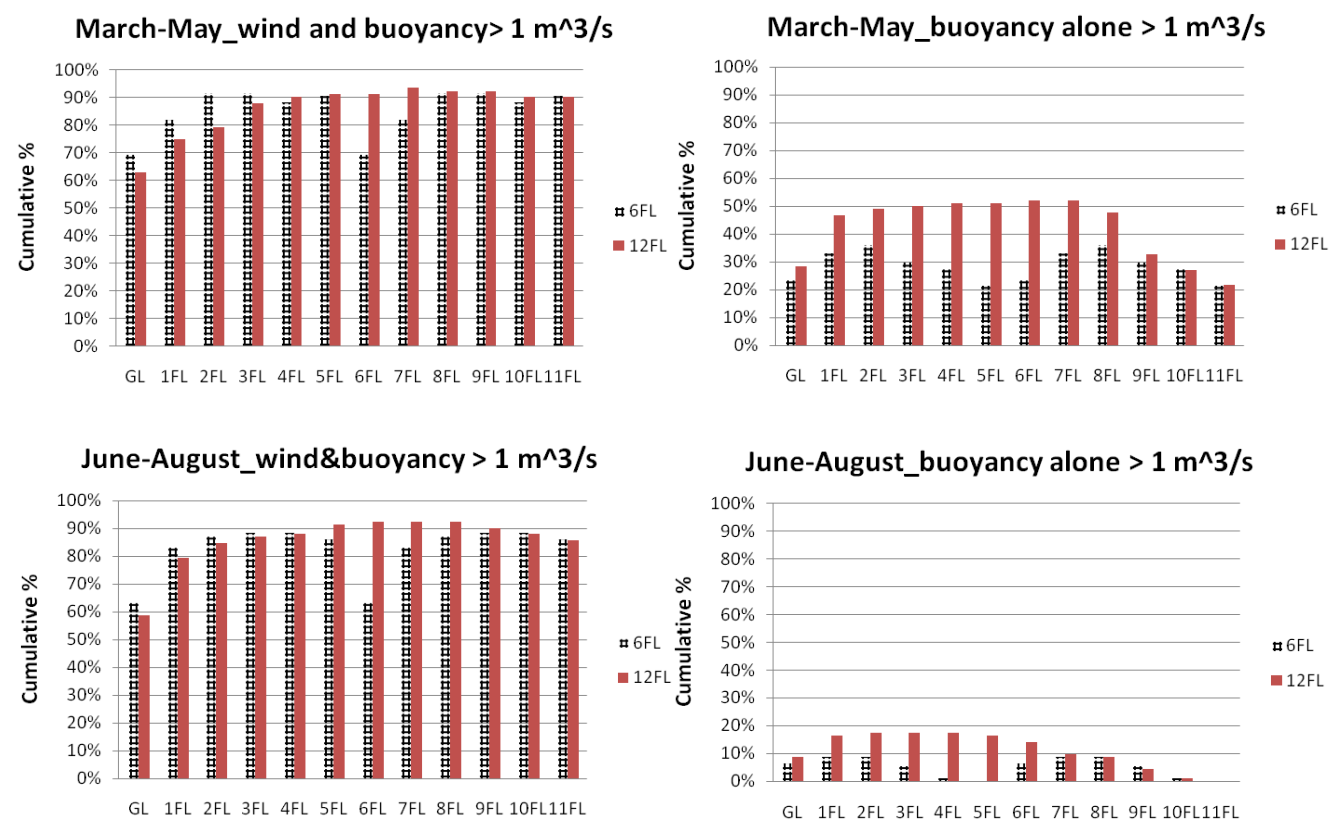

a)

b)

Figure 5-5: The probability for ventilated cooling of the 12 storey segmentation. a) Wind and buoyancy combined, b) Buoyancy-only

The thermal environment of a typical day during the mid-season and hot summer is selected for demonstrating the free running temperature of the occupied spaces. It is suggested that comfort ventilation can be achieved for all floors during most of the time of a typical date on $24^{\text {th }}$ of March (Fig. 5-6a); while it may be difficult for the top floor of the 12 storey segmentation case to achieve ventilated cooling during a typical day in summer (Fig. 5-6b). For a typical day in mid-season (Fig. 5-6a), the free running temperature of the bottom floor falls inside of the upper band of comfort temperature under the still wind condition $\left(29^{\circ} \mathrm{C}\right)$ in general. Although the temperature between 10: 30 and 15: 00 is slightly higher than the acceptable comfort temperature, the ventilation rate of $5 \mathrm{~m}^{3} / \mathrm{s}$ may help to create the personal cooling, where the maximum flow velocity through the openings should be around $1 \mathrm{~m} / \mathrm{s}$ if the internal opening size of $5 \mathrm{~m}^{2}$ is applied. The summer condition as shown in Figure 5-6b, however, may be more difficult to obtain the desired thermal comfort if the variable ventilation rates is not sufficient for personal cooling (i.e. with the resultant flow velocity less than $0.5 \mathrm{~m} / \mathrm{s}$ ). 
From the aspect of night ventilation, it may be an optional way for cooling during the mid-season because of the role of thermal mass in moderating the temperature swings. Figure 5-6a demonstrates the diurnal temperature swing of around $7{ }^{\circ} \mathrm{C}$ on a day in the mid-season of Taipei. In this case, the thermal mass may play a role for moderating the indoor temperature swings by coupling to external air and the occupied spaces. However, the ventilation rates during the night time (between 0:30 and 06:30 AM) on $24^{\text {th }}$ of March are relatively smaller than the day time. The potential for night ventilation would be reduced accordingly. One thing to be noted is that the effect of thermal mass to the overall thermal performance is not investigated in this study. The construction materials (Table 3-1) are assumed and kept fixed throughout the simulations. For a typical day in summer as presented in Figure 5-6b, it is more difficult to apply the night ventilation with the temperature fluctuation of less than $4{ }^{\circ} \mathrm{C}$, especially when the air temperature is around $30{ }^{\circ} \mathrm{C}$ throughout the day. During the occupied hours, where the temperatures are over $32{ }^{\circ} \mathrm{C}$ for most of time, the use of fans is required to promote air movement for potential personal cooling. For the proposed base case building configurations of the main investigation (Fig. 2-40), the ventilation inlets of the bottom segmentation may cause security problems when the building is unoccupied at night; while this may not be an issue for the upper building segments. The solution to ensure the ventilation rates as well as the security is to provide intruder proof grills/bars or independent louvered to the inlets.

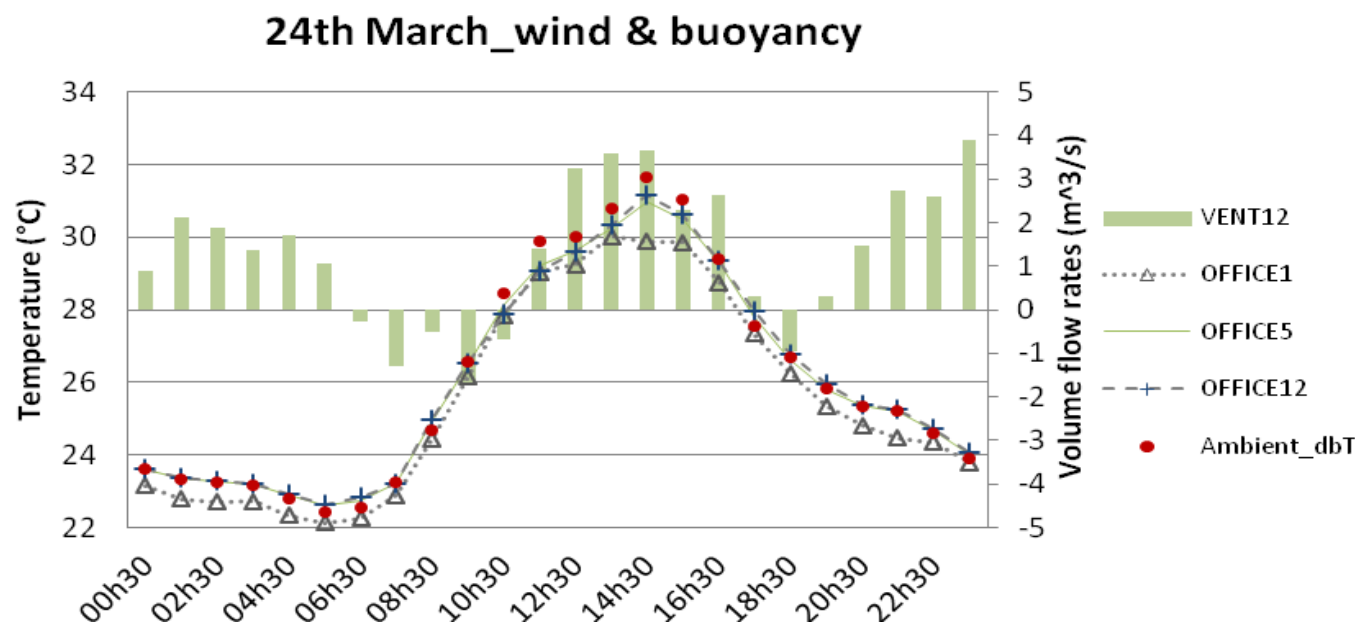

(a) 


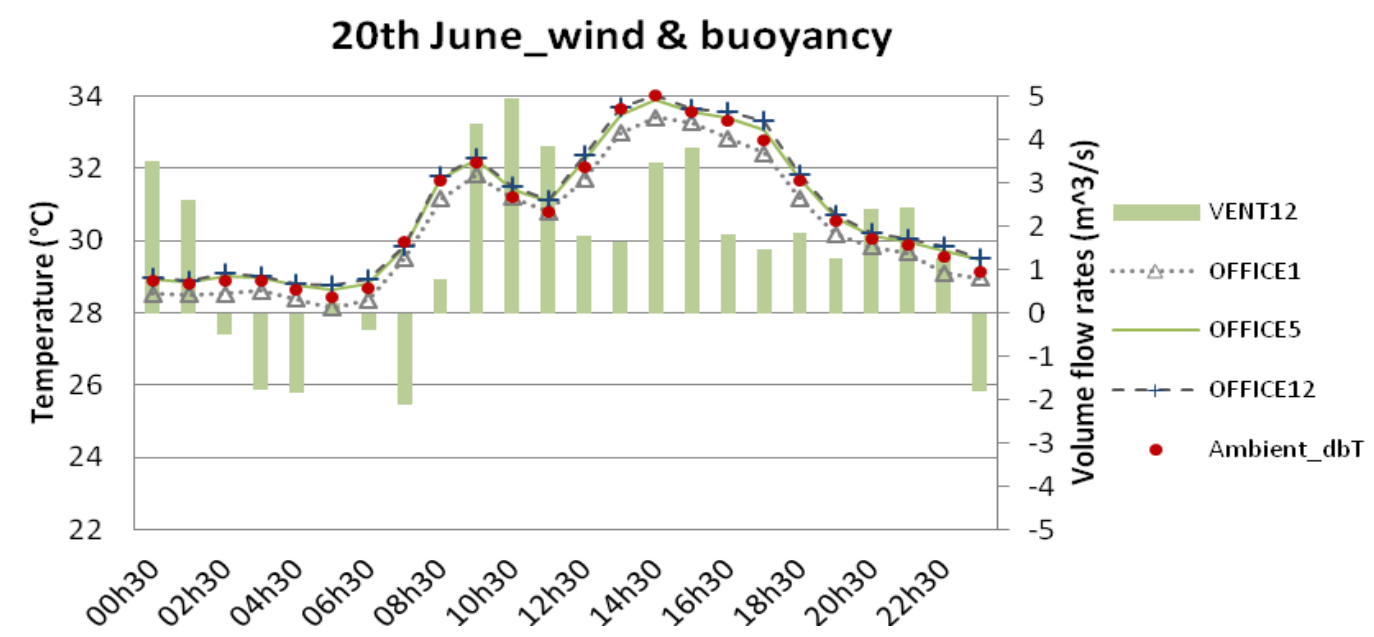

(b)

Figure 5-6: The thermal environment of the base case on a typical day. a) Mid-season; b) Hot summer (Free-running)

\subsubsection{The investigation of desired flow pattern}

The desired flow pattern for this study is examined in terms of the flow direction specified in the air flow network. The values of volume flow rates are positive (> $0 \mathrm{~m}^{3} / \mathrm{s}$ ) when the flow pattern follows the design flow direction. In the buoyancy alone scenario, the worst case, the flow rates are supposed to be influenced by the temperature difference between indoors and outdoors and the stack height between openings. To take the 10 storey segmentation case for instance, the monthly average flow rates under different ventilation strategies indicate that it is difficult to obtain the desired flow pattern under the buoyancy alone condition when the ambient temperature increases (Fig. 5-7). Also, with the gradually lessening volume flow rates against building height, the reversed flow patterns (negative flow rates) occur at the higher floor levels accordingly. The wind and buoyancy combined condition, on the other hand, is effective for achieving the desired flow pattern under the proposed building configuration. The desired flow pattern could be obtained for all floor levels irrespective of weather conditions with the presence of wind and buoyancy forces in combination. 

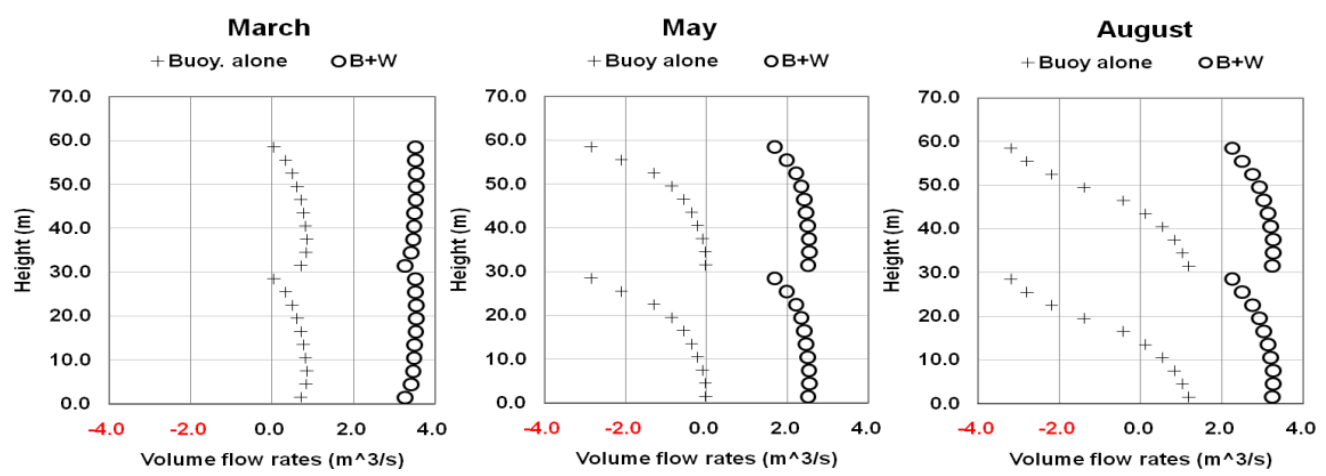

Figure 5-7: The monthly volume flow rates against height by different natural ventilation conditions

The probability for desired flow pattern is defined as the percentage time that the desired flow direction is achieved during the occupied period. The probability for the desired flow pattern under two different ventilation conditions is presented as Figure 5-8. According to the histogram analysis, the desired flow pattern could be obtained for over $80 \%$ of time under the wind and buoyancy combined condition, irrespective of simulation seasons and segmentation height. For the buoyancyonly cases, however, the percentage for desired flow pattern would be lowered by $20 \%$ in mid-seasons and tends to have larger variation between floors in the warmer seasons compared to the wind and buoyancy combined cases. The overall probability for desired flow pattern would be reduced to $30 \%$ for the warmer seasons with buoyancy alone strategy. 

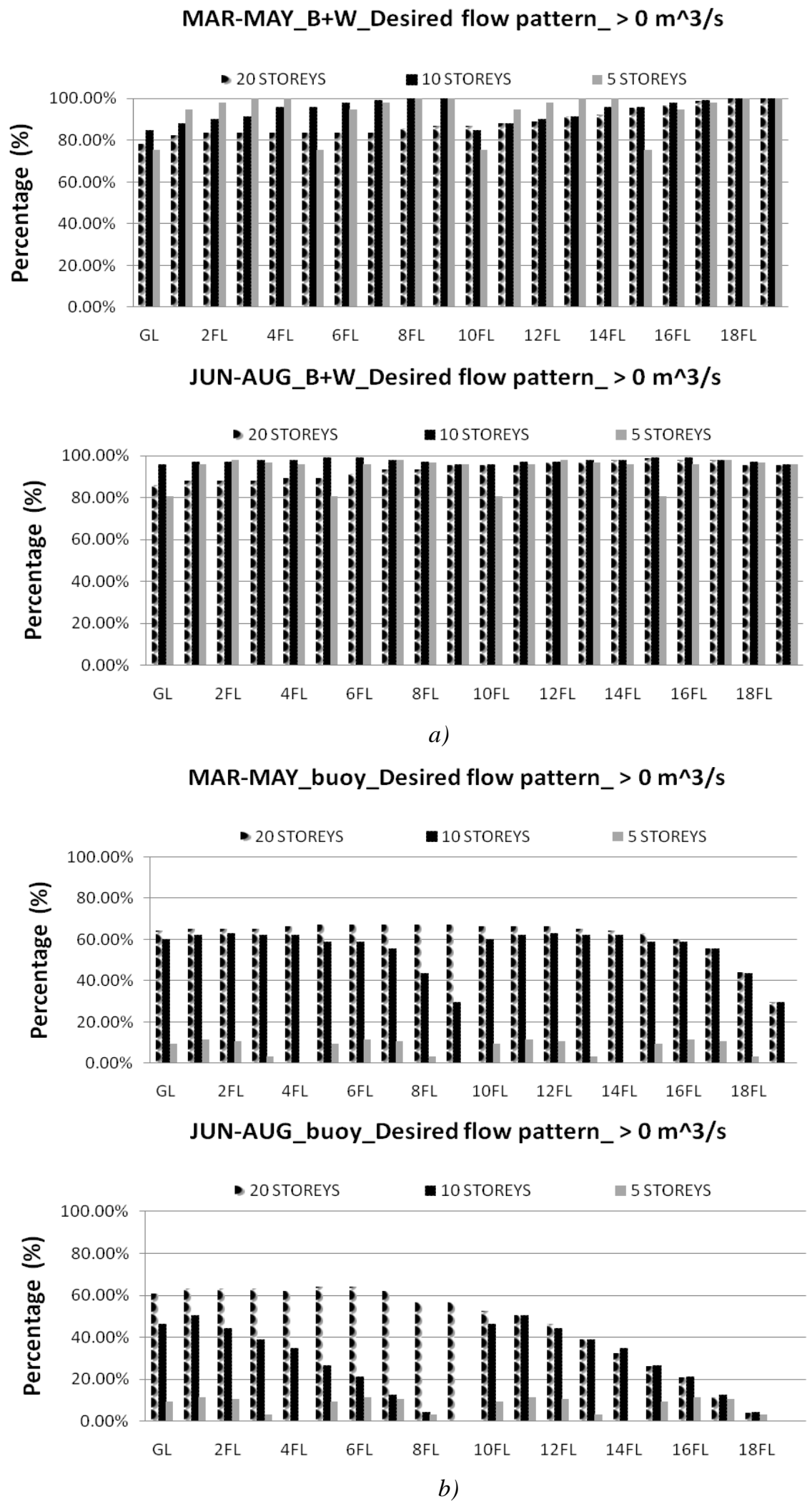

Figure 5-8: The probability for desired flow pattern. a) Wind and buoyancy combined, b) Buoyancy alone 


\subsection{Revision of design: The open wind floor strategy}

The planning and spatial configurations of tall buildings are regarded as key parameters which determine the possibility and efficiency of natural ventilation. As being demonstrated in the Liberty Tower of Meiji University, the combination use of "Wind Floor" and "Wind Core" may lead to the development of an extreme stack effect for natural ventilation. However, the 'open wind floor' is placed in the $18^{\text {th }}$ level of the building, where only 5 floors are above the wind floor. The full benefit of the segmentation concept may not be achieved as identified in the base case models of Section 5.2. It is therefore, for the revised design of this study (Fig. 2-41b), an open wind floor with two air intakes, namely in the south and the east, is introduced to the base case building configuration (Fig. 2-41a). The architectural features of a segmented atrium and ventilated double-skin facades remained, but with an open floor in the bottom level of each segment. The 'open wind floor' in this section is regarded as an alternative for building segmentation. The dimension of floor plan is reduced to $12(\mathrm{~m})$ by $12(\mathrm{~m})$ for better practice of cross ventilation across floor plan. The difference between the base case and revised building configuration design is illustrated as Figure 2-41.

Sapian (2004) investigated the effect of high-rise open ground floor to the natural ventilation performance. His study suggested that the pressure distribution on either windward or leeward side of building surfaces would be affected by the introduction of a void at floor level. It was also found, not surprisingly, that the difference of wind pressure coefficient between the windward and leeward openings was crucial for cross ventilation performance. In the present study, an open wind floor is introduced in the revised design. For the ground level with the open wind floor strategy, the "lifted" building configuration is introduced. For the building segments within the mid-level of the whole building, the open wind floor can be regarded as a service floor accommodating the mechanical systems or a refuge floor for fire safety. The aim of this section is to investigate the natural ventilation performance of the associated office rooms under the revised building 
configurations. The monthly ventilation performance of the cases with the open wind floor strategy is evaluated under different ventilation conditions. The comparisons are then made between the base case and revised design in Section 5.3.3 and Section 5.4.

\subsubsection{The effect of segmentation}

In this section of study, the monthly averaged flow rates against floor height of the open wind floor strategy are examined. Though the monthly average data sets are not necessarily representative with respect to instant ventilation performance, it is simple and easy for comparison in terms of the general ventilation performance of different segmentation cases. The reasoning for this is stated in Section 5.1. The monthly averaged data sets are evaluated over the occupied hours (7:30-18:30) during the month. The revised building configuration with 5 different segmentation heights, namely the 3, 6, 9, 12 and 15 storeys are adopted in this section. The aim is to look at the segmentation effect on the resultant flow rates as well as the overall thermal environment of the associated office spaces.

Some modelling results as presented in Figure 5-9 suggest that for the wind and buoyancy combined case, the larger segmentation is beneficial for increasing the overall flow rates through individual floors especially for the warmer months. However, the influence of segmentation on the resultant flow rates is limited when over 12 storey segmentation height. This could be explained by the total flow rates through the building being controlled by the inlet and outlet. By using the same inlet and outlet size for each segmentation case, the volume flow rates through the associated offices are constrained accordingly. It is also found that the smaller segmentation case ( 3 storeys) tends to vary with the weather condition more compared to the larger segmentation cases. This can be seen from the monthly averaged flow rates against height as presented in Figure 5-9.

Additionally, the 3 storey segmentation case presents the smallest deviation of flow rates across floors. Also, the deviation between the top and bottom floor 
would increase when larger segmentation height is adopted. At the mean time, the deviation of flow rates distribution between different segmentation cases increases when the external temperature gets higher (Fig. 5-9). Nevertheless, this study used the same opening size for modelling air flows through each floor. In reality, uniform flow rates between floors could be achieved by slightly varying the areas of openings according to occupants' needs.
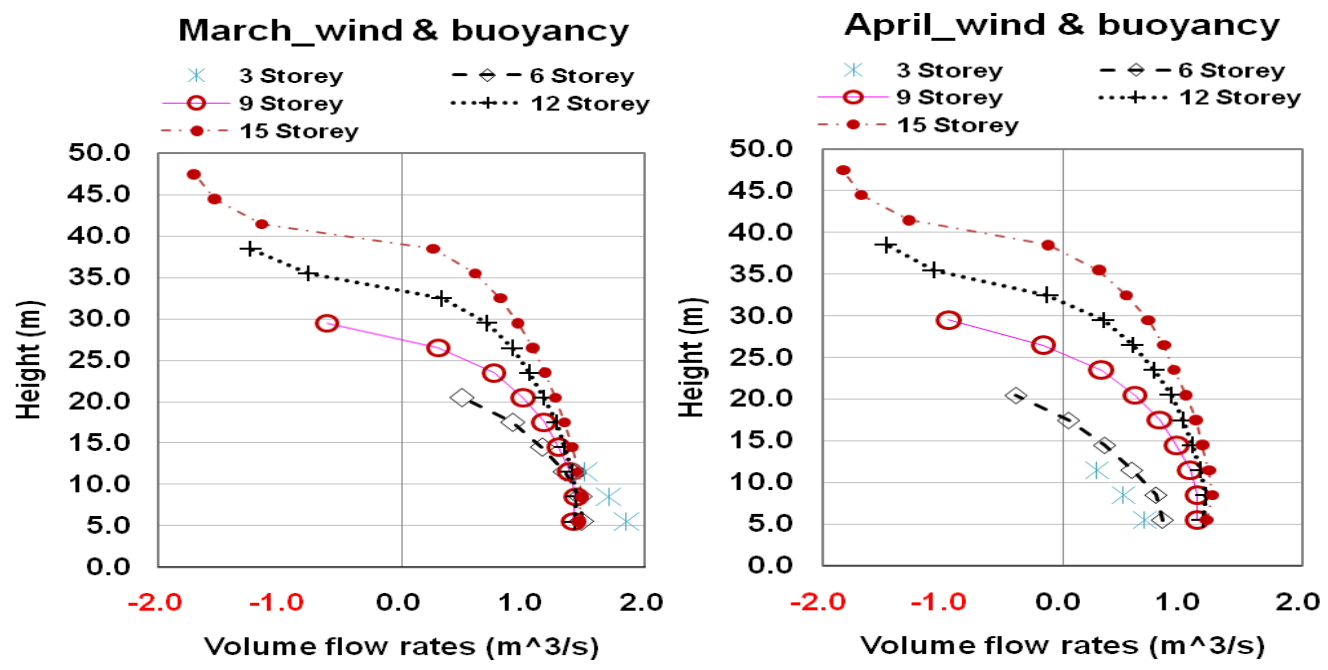

May_wind \& buoyancy
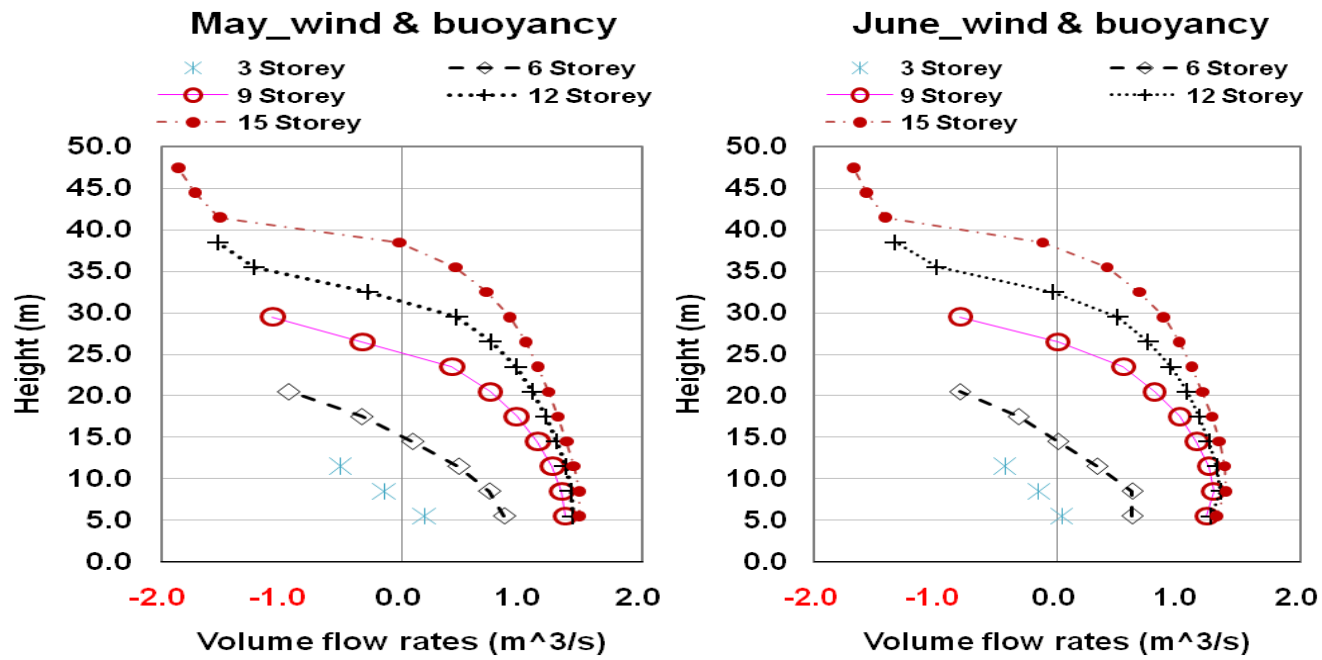

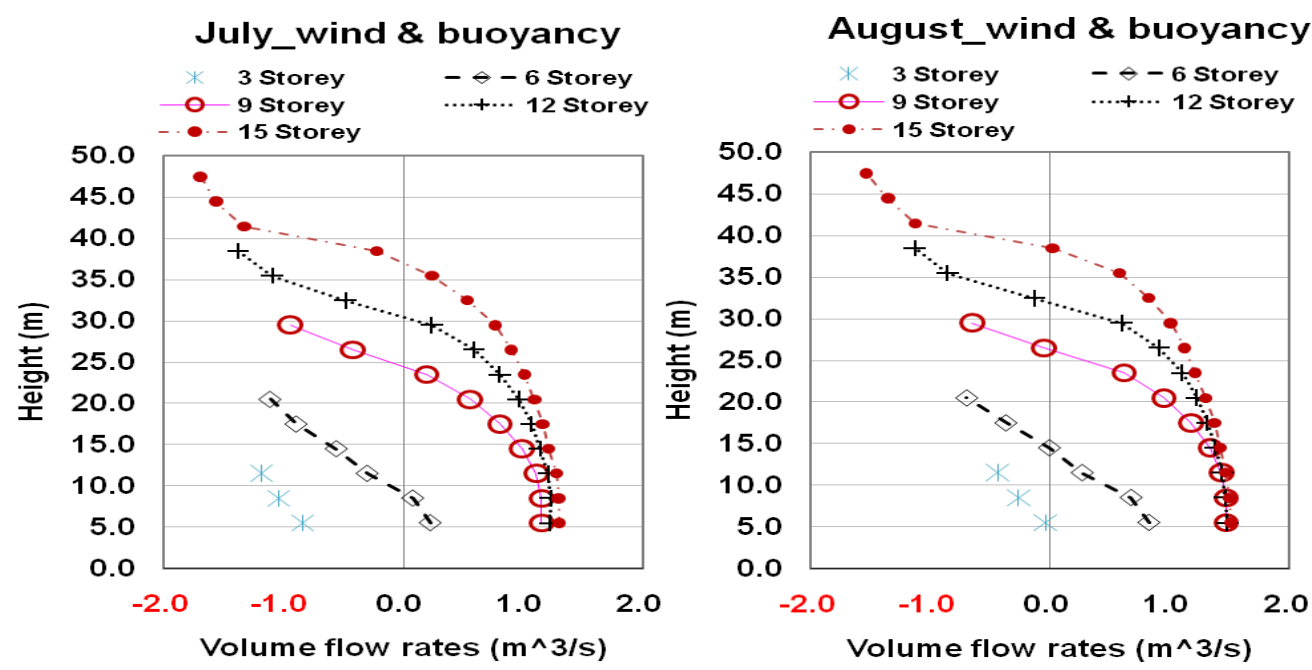

Figure 5-9: The monthly volume flow rates against height_ The lifted case under the wind and buoyancy combined condition

The effect of ventilation condition is also investigated in the revised building configuration. To take the 12 storey segmentation case for instance (Fig. 5-10), the monthly averaged flow rates under different ventilation conditions indicate that the flow reversal occurs at the higher floor levels, because of the gradually lessening volume flow rates against building height. The wind and buoyancy combined case performs relatively better than the buoyancy alone condition. The desired flow pattern could be obtained for all floor levels irrespective of weather conditions when with the presence of wind and buoyancy forces together. It can also be seen that the monthly variation of flow rates, namely from March to August, is insignificant in terms of flow rates of associated floor levels of the revised building configuration. The base case building configuration, however, tends to have larger deviation on the resultant flow rates according to the ventilation conditions applied. Different inlet conditions are investigated in Section 5.4 for clarifying the impact of ventilation inlets on the resultant flow rates against building height. The influence of open wind floor strategy is evaluated by comparing the ventilation rates as well as the overall thermal environment between the base case and the revised building configuration in Section 5.3.2 and Section 5.4. The problem of applying open wind floor strategy in the bottom segment of the whole building, namely the lifted case, is investigated in Section 5.3.4. 

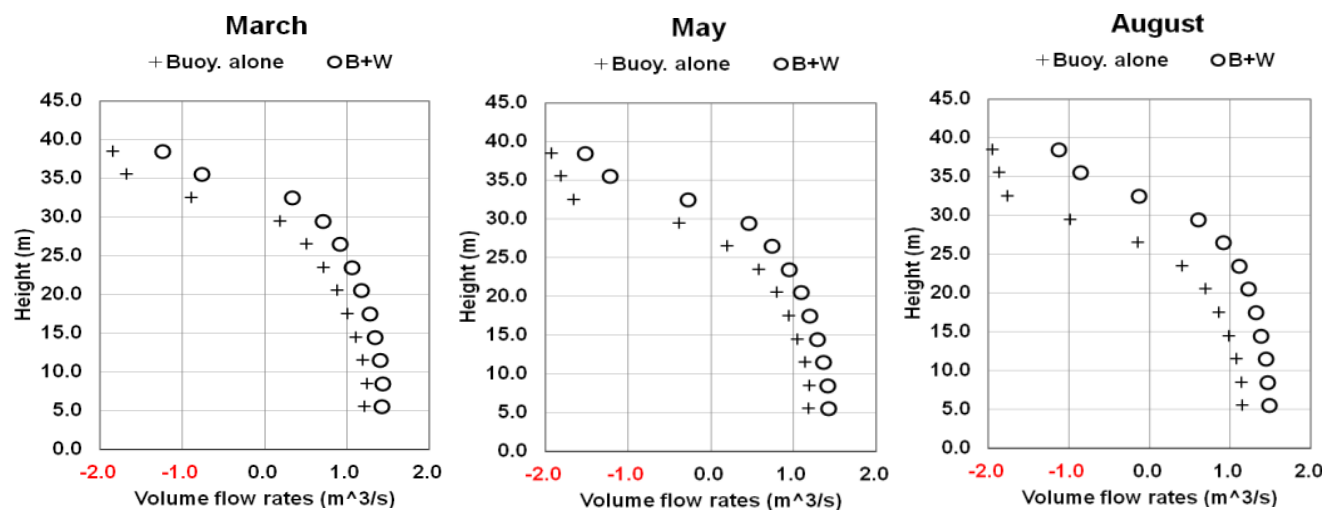

Figure 5-10: The monthly volume flow rates against height by different ventilation conditions_ revised models with the open wind floor

\subsubsection{The probability for ventilated cooling}

In this section, the overall ventilation performance of the lifted and base case are compared with reference to the probability for ventilated cooling as well as the overall thermal environment. One concern is that the air intake sizes are different for the investigations of the base and lifted case in this section. For example, there is only single air intake of $9 \mathrm{~m}^{2}$ in the base case model (Fig. 2-42a); while there are four air intakes from different orientation located in the lifted case in aims of enjoying the benefit of open wind floor strategy (Fig. 2-42c). This arrangement is necessary because that the ventilation performance may not have significant difference during the buoyancy alone condition with the same inlet size being applied in the base and lifted case (only the stack height may be different due to the lifted height of $4 \mathrm{~m}$ in the lifted case).

By using the same approach for estimating the minimum required flow rates for cooling, the ventilation rate of $1.1\left(\mathrm{~m}^{3} / \mathrm{s}\right)$ would suffice for removing the internal heat gains under the condition of $\Delta T=3.3^{\circ} \mathrm{C}$ for the revised building configuration design. One thing to be noted is that the $\Delta T$ of $3.3^{\circ} \mathrm{C}$ is defined under the summer design condition, which may present a typical ambient condition in the hot summer of Taipei. For other periods with larger diurnal temperature swing, lower ventilation rates are required to compensate the internal 
heat gains. The histogram analysis on the simulation results of the revised cases of this section is used to identify the probability for achieving the design goal (> 1.1 $\mathrm{m}^{3} / \mathrm{s}$ ). The probability is defined as the percentage time that the required flow rates is achieved during the occupied period. The preliminary seasonal potential for the 12 storey segmentation case to have sufficient flow rates under different building configuration and ventilation conditions is illustrated as Figure 5-11.

For the buoyancy alone cases as shown in Figure 5-11a, the percentages for ventilated cooling decrease with floor height and the variation between floors is larger than the wind and buoyancy combined cases. Consequently, the higher floor level may not be able to reach the required flow rate for ventilated cooling. Additionally, the deviation for ventilated cooling potential between floors of the revised case is significant, compared to the base case building configuration. Also, the overall ventilated cooling potential would be reduced by $25 \%$ during the warmer season. It is supposed that the air intake size plays an important role in the lifted case (18 times as compared to the base case) during the buoyancy-alone condition, which improves the overall probability for achieving the desired flow rates. For the wind and buoyancy condition, however, the fully open wind floor may not be always of benefit, because the combination of wind and stack effect may conflict with each other depending on the ambient weather condition. One thing to be noted is that the extra internal heat loads of $20 \mathrm{~W} / \mathrm{m}^{2}$ are applied in the open wind floor of the revised building configuration.

The poor ventilated cooling potential in the top one-third floors of the revised case might be due to the change of neutral point level (NPL) where the warmer air is driven into the occupied spaces when above the NPL. The flow reversal occurs accordingly. Further NPL issues are discussed later in Section 5.4.2. Generally speaking, the probability for all floors of the examined cases to reach the design condition is much higher in the mid-seasons. The lifted case is more sensitive to the ambient condition as compared to the base case model during the buoyancy alone condition (Fig. 5-11a). However, the seasonal deviation is insignificant for 
both building configurations under the wind and buoyancy combined condition (Fig. 5-11b). Perhaps not surprisingly, the potential for ventilated cooling can be much improved with the help of prevailing wind force.

The free running temperatures of the base and lifted case under different ventilation condition are presented in Figure 5-12. The results suggest that the temperature of the office space is closely related to the external temperature. For the buoyancy alone condition, the deviation between the base and lifted case is insignificant as expected (Fig. 5-12c\&d). For the wind and buoyancy combined condition, however, the lifted case is not always of benefit. Although sufficient flow rates are achieved for the both cases, more amount of warmer air is driven into the occupied spaces of the lifted case with 4-sided air intake along with the extra solar gains through larger envelope openings, which results in the office temperature is higher than the ambient in general (Fig. 5-12a\&b).

It is supposed that the resultant flow velocities through the openings may help with some personal cooling during the mid-season, even with a slightly higher temperature $\left(>29{ }^{\circ} \mathrm{C}\right)$. But the personal cooling is much more difficult to achieve when the temperatures of the occupied spaces are over $32{ }^{\circ} \mathrm{C}$ for most of the time in summer. As discussed in Section 5.2.2, the diurnal temperature swing of around $7{ }^{\circ} \mathrm{C}$ on a day in the mid-season of Taipei is observed. For which, a ventilation flow path of low resistance can be incorporated into the building for night ventilation. However, the night ventilation seems not to be a long-term approach for cooling with reference to the seasonal temperature fluctuations and the corresponding low ventilation rates, especially for the hot summer. 
March-May_buoyancy alone $>1 \mathrm{~m}^{\wedge} 3 / \mathrm{s}$

口 Lifted basecase

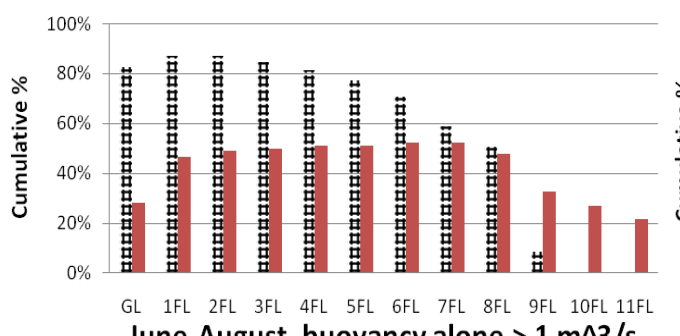

June-August_buoyancy alone $>1 \mathrm{~m}^{\wedge} 3 / \mathrm{s}$

a Lifted basecase

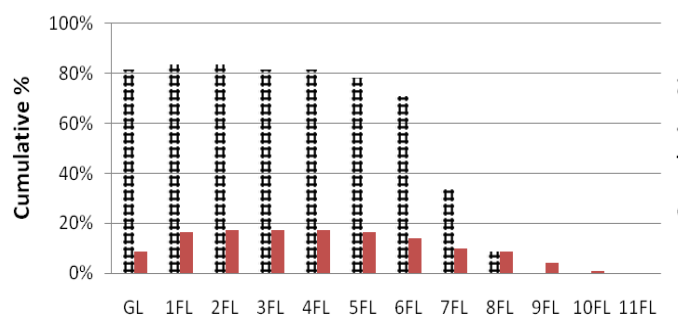

(a)
March-May_wind\&buoyancy $>1 \mathrm{~m}^{\wedge} 3 / \mathrm{s}$

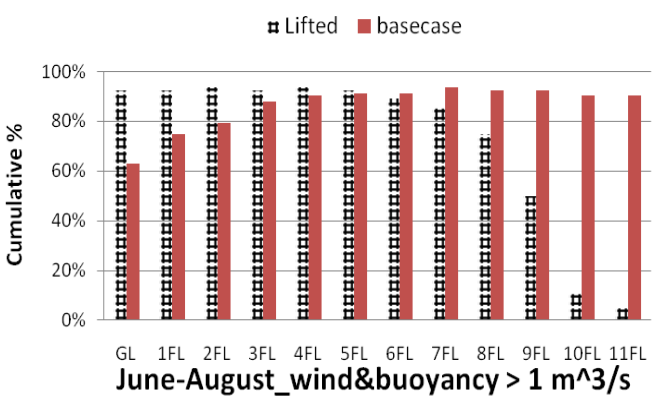

口Lifted basecase

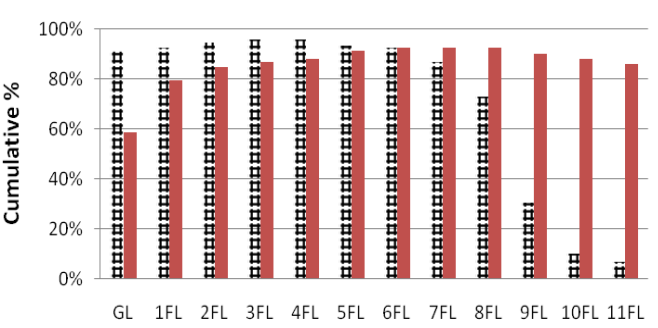

(b)

Figure 5-11: The probability for ventilated cooling. (a) Buoyancy alone, (b) Wind and buoyancy combined

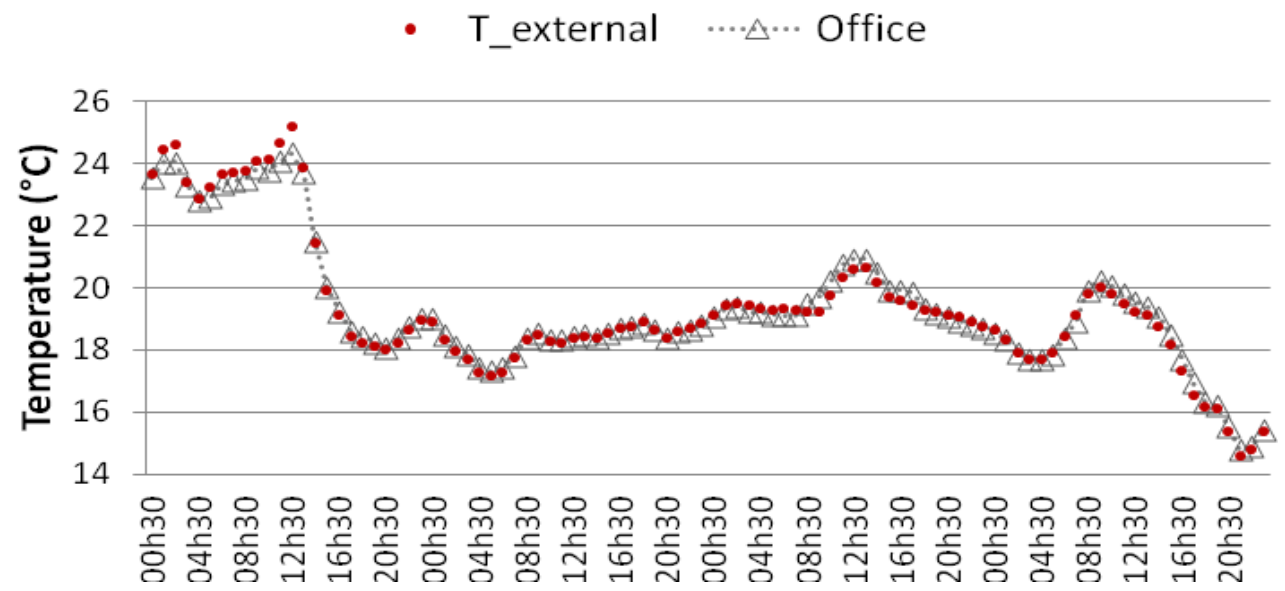

(a) The base case: Wind and buoyancy combined condition

- T_external …… Office

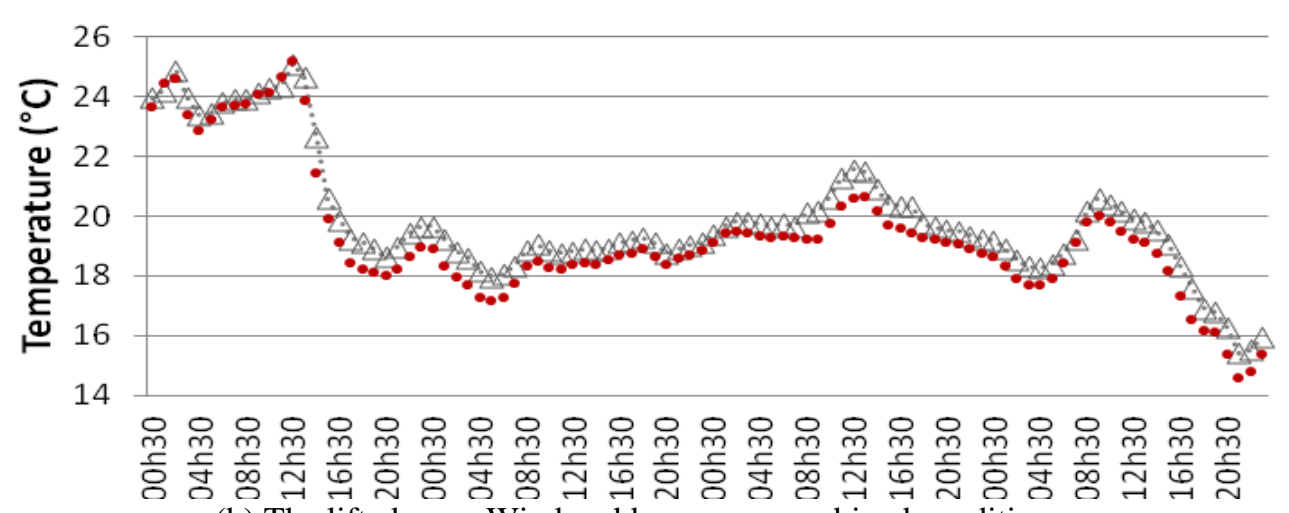

(b) The lifted case: Wind and buoyancy combined condition 


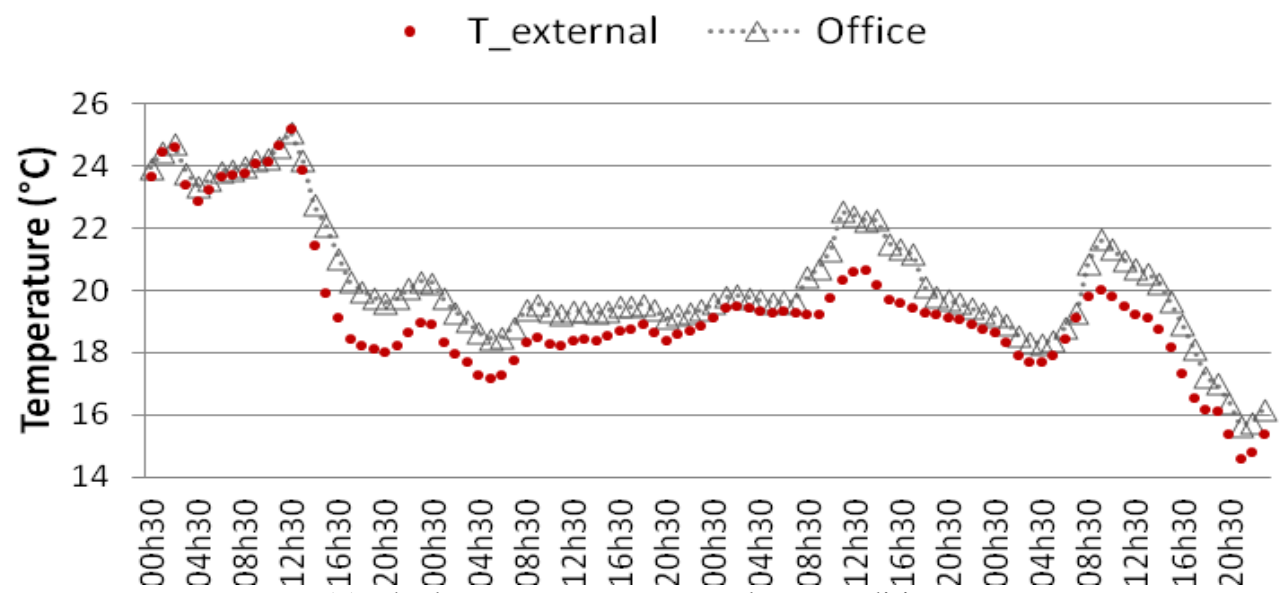

(c) The base case: Buoyancy alone condition

- T_external …… Office

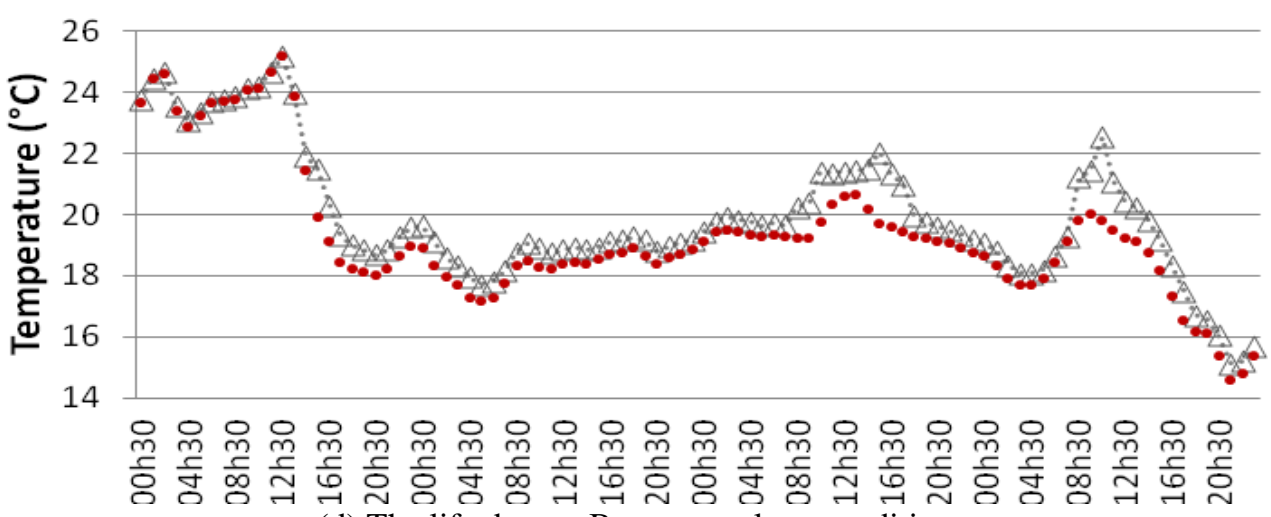

(d) The lifted case: Buoyancy alone condition

Figure 5-12: The thermal environment of the base \& lifted case between $25^{\text {th }} \sim 28^{\text {th }}$ of March under varied ventilation condition

\subsubsection{The probability for desired flow pattern}

The same approach as used in Section 5.2 is adopted for investigating the desired flow pattern of the revised building configuration. The values of volume flow rates are positive $\left(>0 \mathrm{~m}^{3} / \mathrm{s}\right)$ when the flow pattern follows the design flow direction. To take the 12 storey segmentation case in the bottom segment of the building (the lifted case) for example, the seasonal averaged flow rates under different ventilation conditions indicate that it is less likely for the base case building configuration to obtain the desired flow pattern under the buoyancy alone condition when the external temperature increases (Fig. 5-13). Also, with the gradually lessening volume flow rates across building height, the reversed 
flow patterns occur at the higher floor levels of both building configurations. Though the same phenomenon is found for the top two-third floors of both building configurations, the lifted case presents the better performance in terms of desired flow pattern in general. The difference found between these two building configurations may be because of the change of NPL in the lifted case, where an open floor with extra heat gains is introduced in the bottom floor of each building segment. The wind and buoyancy combined case, on the other hand, is effective for achieving the desired flow pattern under the lifted building configuration except for the top two floor levels. It is supposed that the moving of neutral point level (NPL) would cause the occurrence of flow reversal. Further discussions on the NPL issue is presented in Section 5.4.1. Generally speaking, the desired flow pattern could be obtained for all floor levels irrespective of simulation periods with the help of wind and buoyancy forces. The seasonal possibility for the base and lifted building configurations to achieve the desired flow pattern under different ventilation conditions is illustrated as Figure 5-13b.

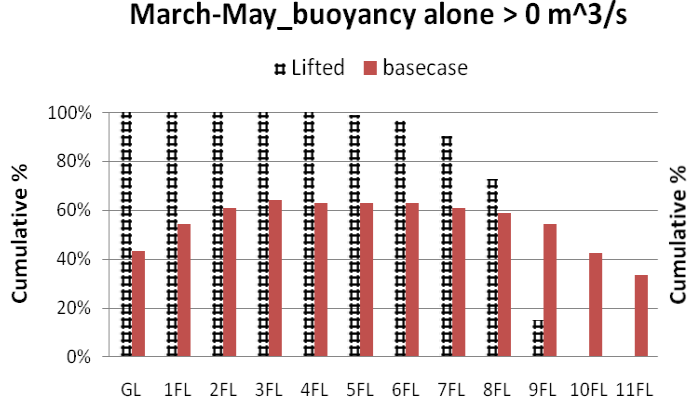

June-August_buoyancy alone $>0 \mathrm{~m}^{\wedge} 3 / \mathrm{s}$

\# Lifted basecase

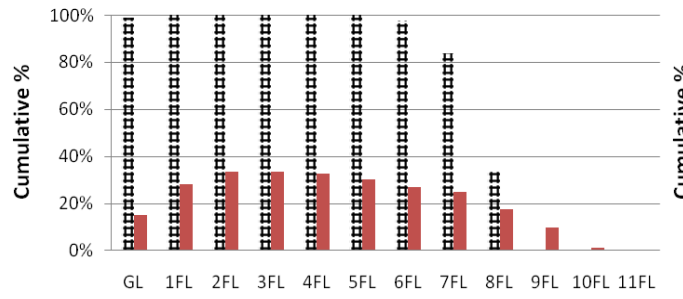

(a)
March-May_wind\&buoyancy $>0 \mathrm{~m}^{\wedge} 3 / \mathrm{s}$

$\square$ Lifted basecase

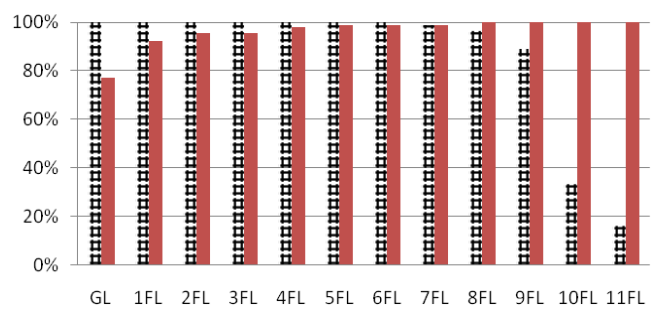

June-August_wind\&buoyancy $>0 \mathrm{~m}^{\wedge} \mathrm{3} / \mathrm{s}$

口 Lifted basecase

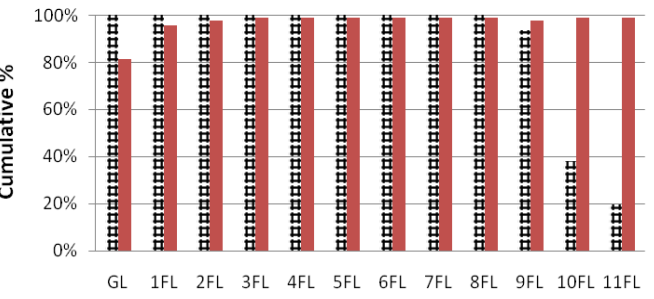

(b)

Figure 5-13: The probability for desired flow pattern. (a) Buoyancy alone, (b) Wind and buoyancy combined 


\subsubsection{The investigations of comfort wind environment of the lifted case}

For the ground level with the open wind floor strategy, the "lifted" building configuration is introduced. In the following subsections, the 12 story segmentation case is chosen for examining the impact of ventilation inlets on the resultant flow rates as well as the overall thermal environment of the occupied spaces. The lifted case with single, 2-sides and 4-sides air intakes is adopted to investigate the natural ventilation performance against floor height. The configuration and inlet conditions of the lifted case adopted in this section are presented in Figure 2-42 and Figure 5-14. The monthly ventilation performance of the cases with the open wind floor strategy on the ground level is evaluated under different ventilation conditions as follows.
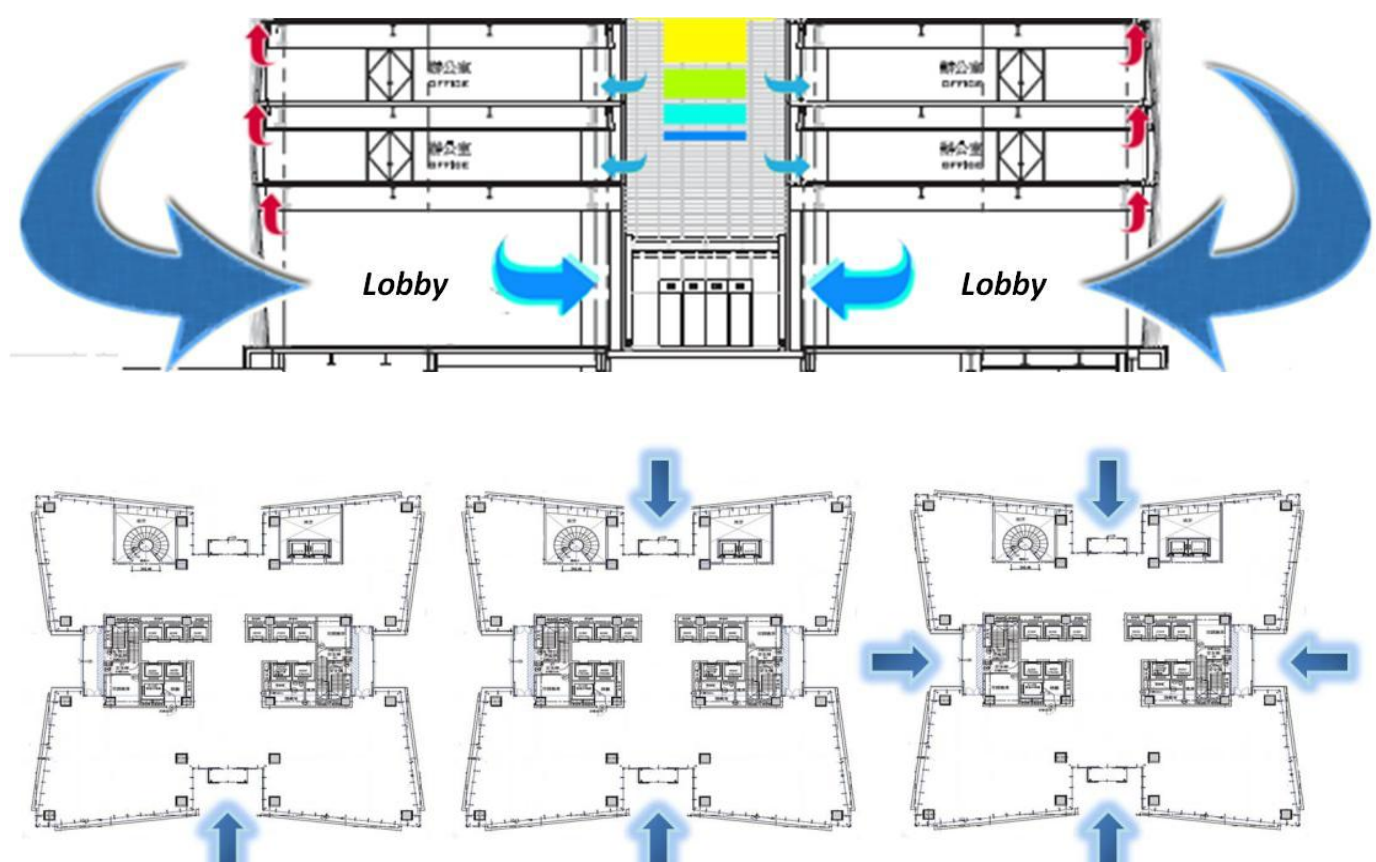

Figure 5-14: The air intake scenario of the lifted case. (a) Single, (b) 2 sides, (c) 4 sides

\subsection{4-1 The buoyancy alone condition}

For the buoyancy alone cases, the volume flow rates decrease with floor height for both building configurations in general. The desired flow pattern could be achieved for almost all floors of test cases in March irrespective of the size of air 
intake adopted. The design condition, positive flow rates, is hardly achieved when the external temperature is higher than the simulated internal temperature, particularly for the case with large air inlets (4-sides). The results as shown in Figure 5-15 suggest the impact of air intake size on the overall flow rates against building height. It is found that the optimum size of ventilation inlet is crucial for the desired flow pattern and satisfactory thermal environment, especially when the external temperature is getting higher.

To take the modelling results in March for example, the desired flow pattern can be achieved for the majority of floors for the all four cases. When the external temperature gets higher, namely from April, the case with larger inlet size is unlikely to have the desired flow direction. The base case presents similar performance as the lifted case with 2-sided air intake; while the completely open design (4-sided air intake) suffer from large flow reversal as compared with the design with 2 open sides. The open wind floor strategy with single air intake receives similar absolute flow rates as the base and 2-sided cases, but with the desired bottom-up flow direction for the bottom half of floors during the warmer season. From the desired flow pattern point of view, it is supposed that the open wind floor functions as the buffer zone which might regulate the incoming warm air to cool down to some extent under the favourable weather condition. Hence it may reduce the likelihood of flow reversal because of the moving of neutral point level (NPL) near to the top of the atrium. With the change of NPL for the otherwise test cases, the flow reversal occurs accordingly. According to the simulation results, the base case model could achieve the design condition mainly in the cooler seasons; while it is difficult for the base case model to obtain the same design condition with the low or no wind condition when the external temperature gets higher, mainly between April and August. On the other hand, the lifted cases with appropriate inlet opening size, namely the single air intake case, could achieve the desired flow pattern $\left(>0 \mathrm{~m}^{3} / \mathrm{s}\right)$ on the bottom two-thirds of segmentation; while the lifted case with 4-sided inlet is not always beneficial because of the moving of NPL to the bottom of the atrium. The undesired flow reversal occurs accordingly. 


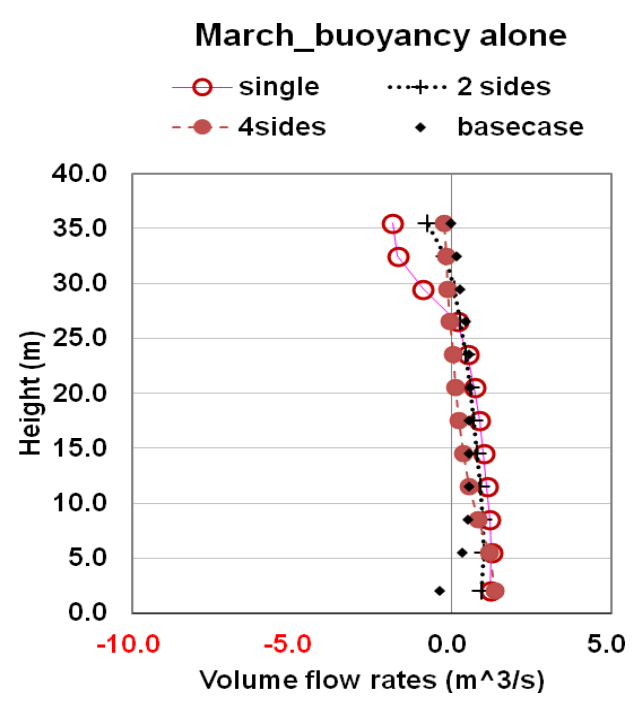

May_buoyancy alone

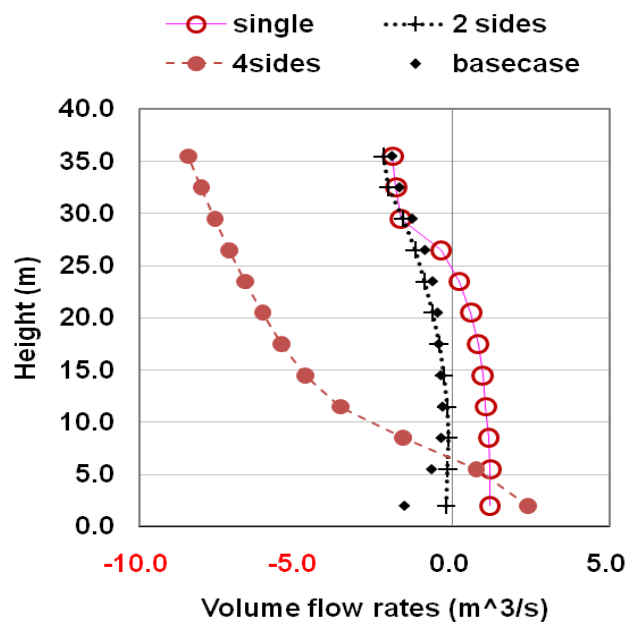

July_buoyancy alone

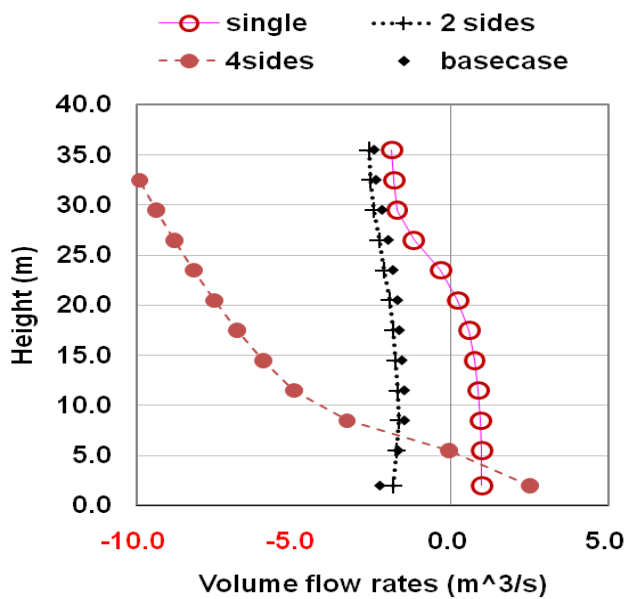

April_buoyancy alone

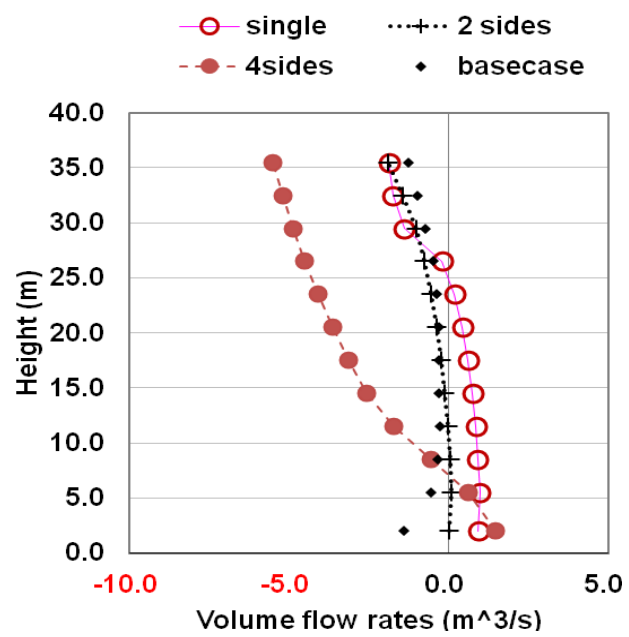

June_buoyancy alone

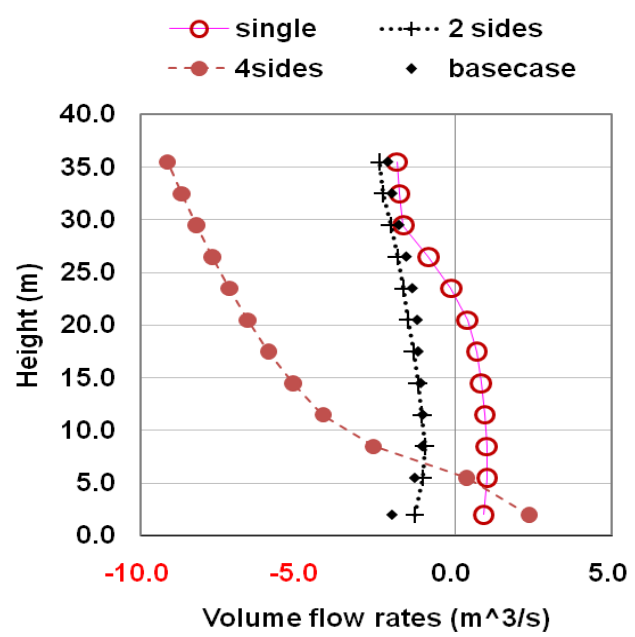

August_buoyancy alone

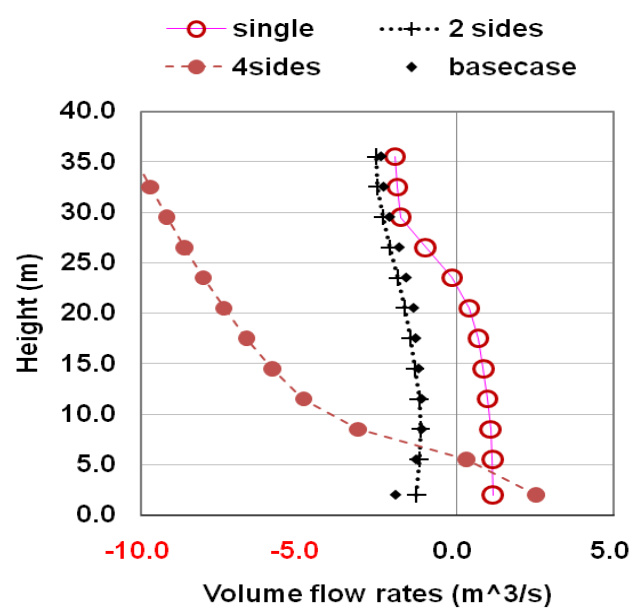

Figure 5-15: The monthly volume flow rates against height_Buoyancy alone 


\subsection{4-2 The wind and buoyancy combined condition}

For the wind and buoyancy combined cases, the base case and lifted cases with single and 2-sided air intake can obtain the desired flow pattern for almost all floors, except the top quarter floors, at all times. The same conclusion as stated in buoyancy alone condition could be made for the lifted case with 4-sided air intake, where the design condition is hardly achieved when the external temperature is not favourable. The ventilation rates of the base case model are comparatively larger than the lifted cases with single and 2-sided air intake, especially for the higher floor levels. For which the deviation of flow rates between floors is insignificant in the base case building configuration under the wind and buoyancy combined condition. The desired flow pattern could be obtained for all floors of the base case model, while it is unlikely to reach the design condition in the top quarter floors of the lifted cases when experiencing higher external temperature. The overall variation of flow rates against floors of the lifted cases is larger than those of the base case building configuration. Four selected cases can achieve the desired flow direction in March except for the topmost floors of the lifted case with single inlet (Fig. 5-16). The lifted case with 4-sided air intake is unlikely to obtain the desired flow direction with higher external temperature, namely after April. It is supposed that much warmer air being driven into the atrium through the 4-sided air intake, which causes the moving of NPL near to the bottom of the atrium, as compared with the otherwise cases, and the flow reversal occurs accordingly. It is therefore the lifted case with 2-sided air intake and the base case building configurations are much preferred in terms of desired flow pattern and its relatively smaller deviation between floors. The free running temperatures of the selected spaces with the 2-sided and 4-sided ventilation inlet conditions are illustrated as Figure 5-17. Similar thermal performance is found for the 2-sided and 4-sided cases (Fig. 5-17a\&b). For the summer time (Fig. 5-17c\&d), the office temperatures are quite close to the ambient when with sufficient flow rates $(>3$ $\mathrm{m}^{3} / \mathrm{s}$ ) passing through the occupied spaces. However, the thermal comfort cannot be guaranteed, resultant flow velocities from the bulk flows (opening size of $5 \mathrm{~m}^{2}$ 
applied) is not sufficient for personal cooling upon the presence of warmer air over $32{ }^{\circ} \mathrm{C}$.
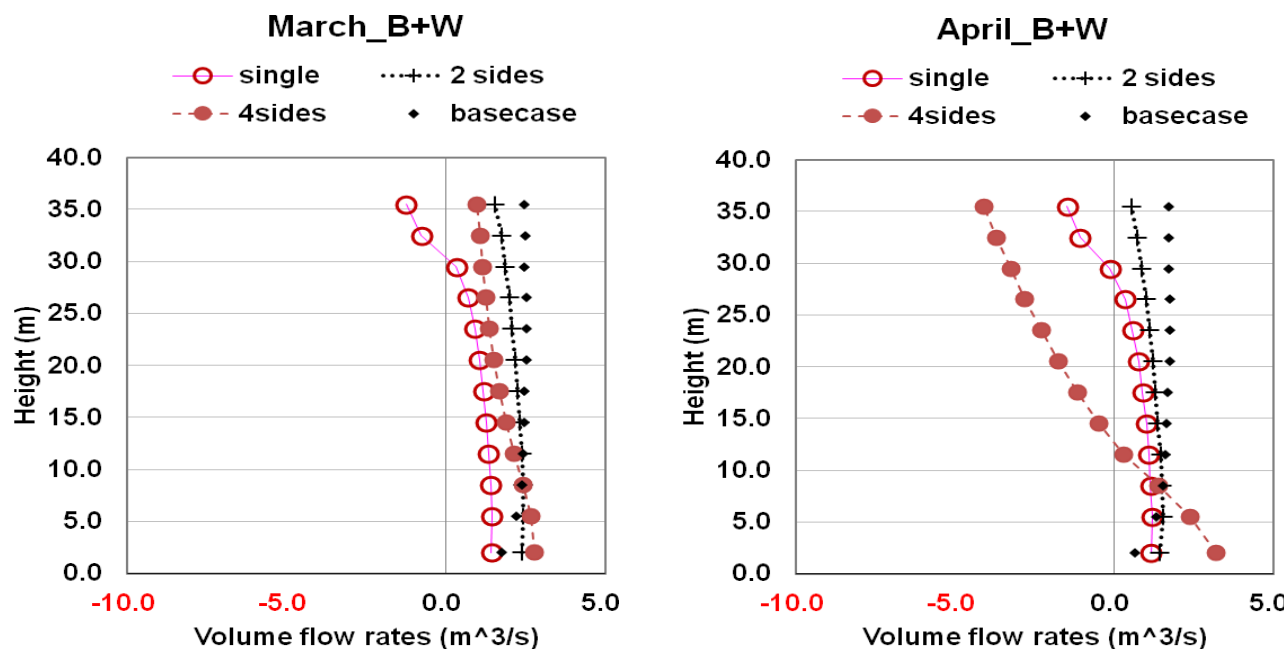

May_B+W
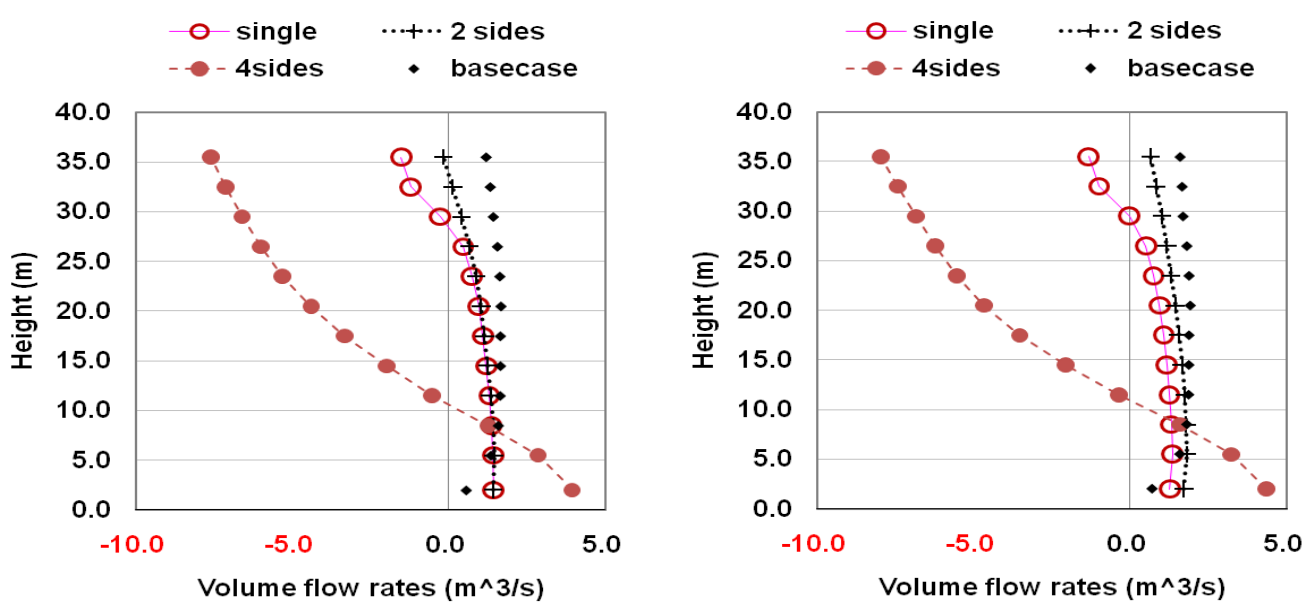

July_B+W
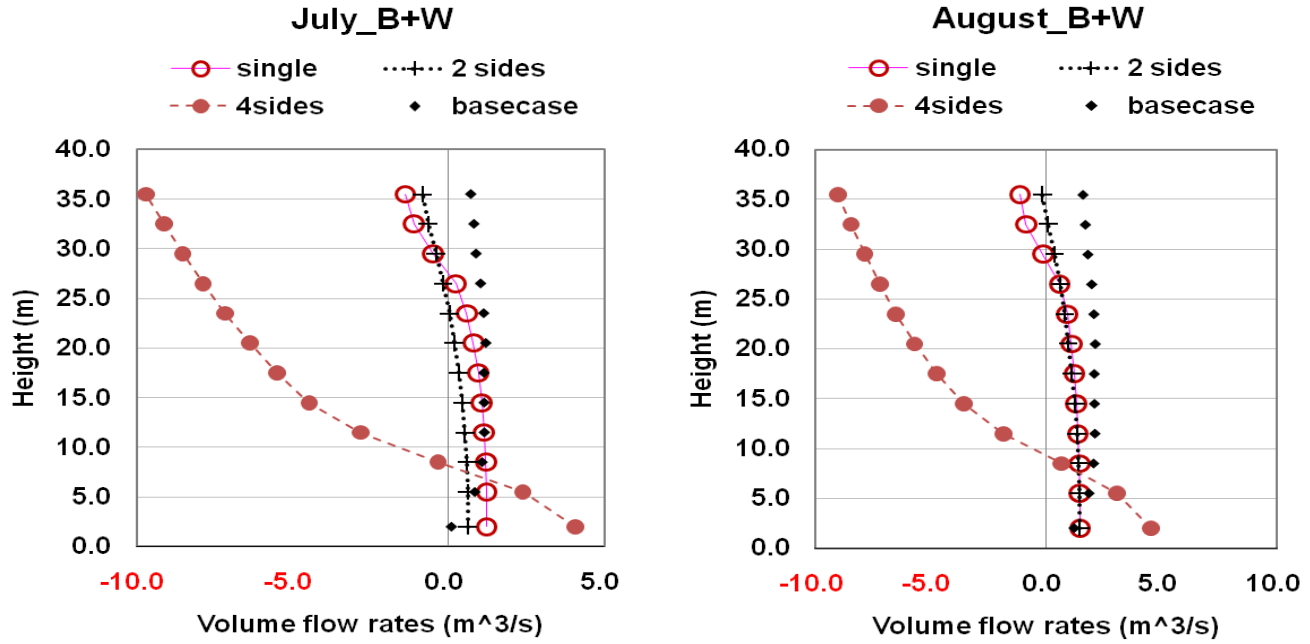

Figure 5-16: The monthly volume flow rates against height_Wind and buoyancy combined 


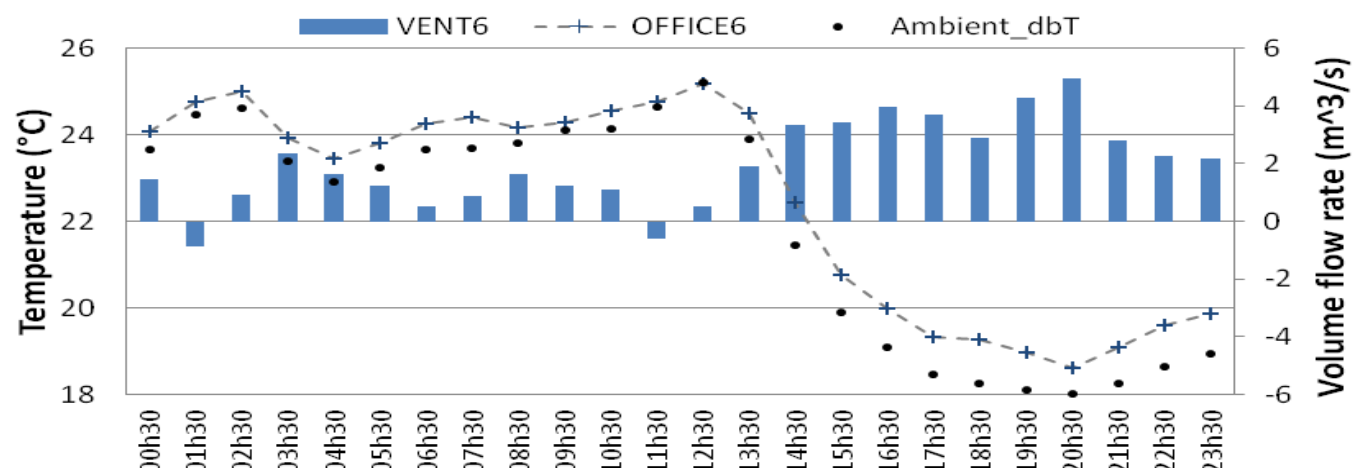

(a) The two-sided ventilation inlet condition on $25^{\text {th }}$ of March

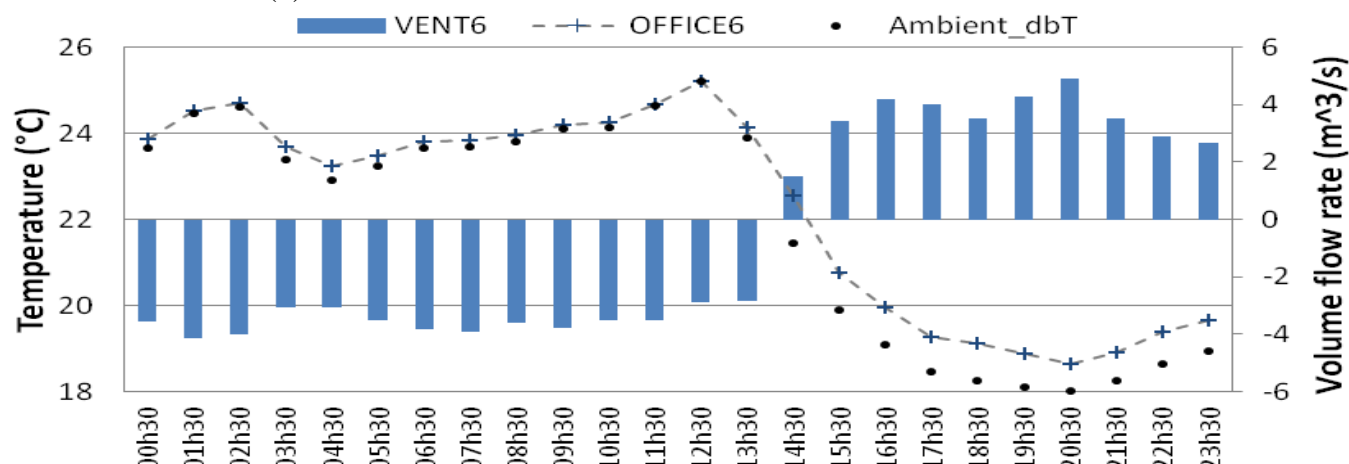

(b) The four-sided ventilation inlet condition on $25^{\text {th }}$ of March

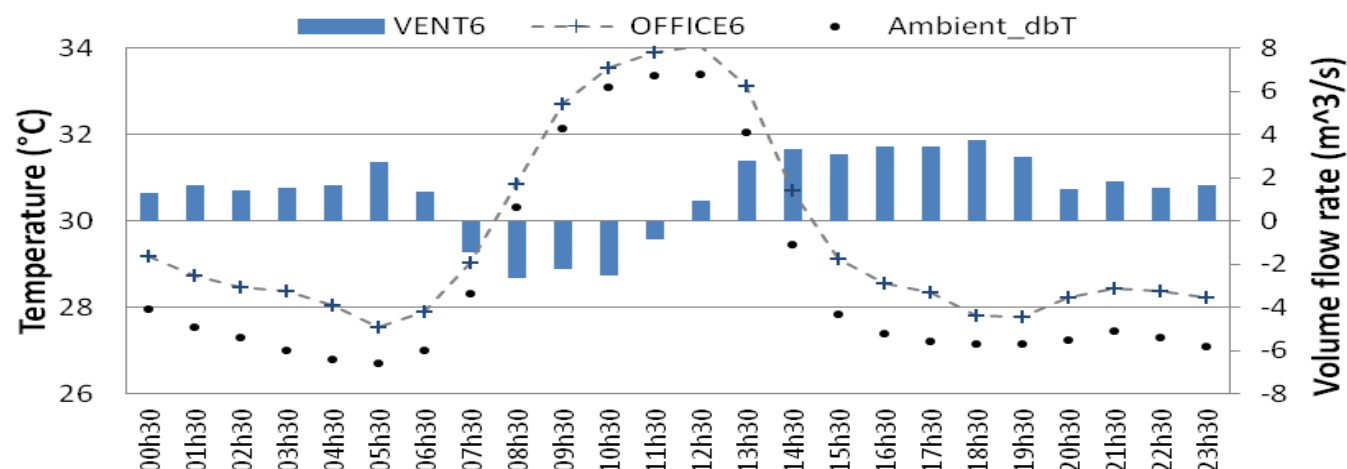

(c) The two-sided ventilation inlet condition on $22^{\text {nd }}$ of June

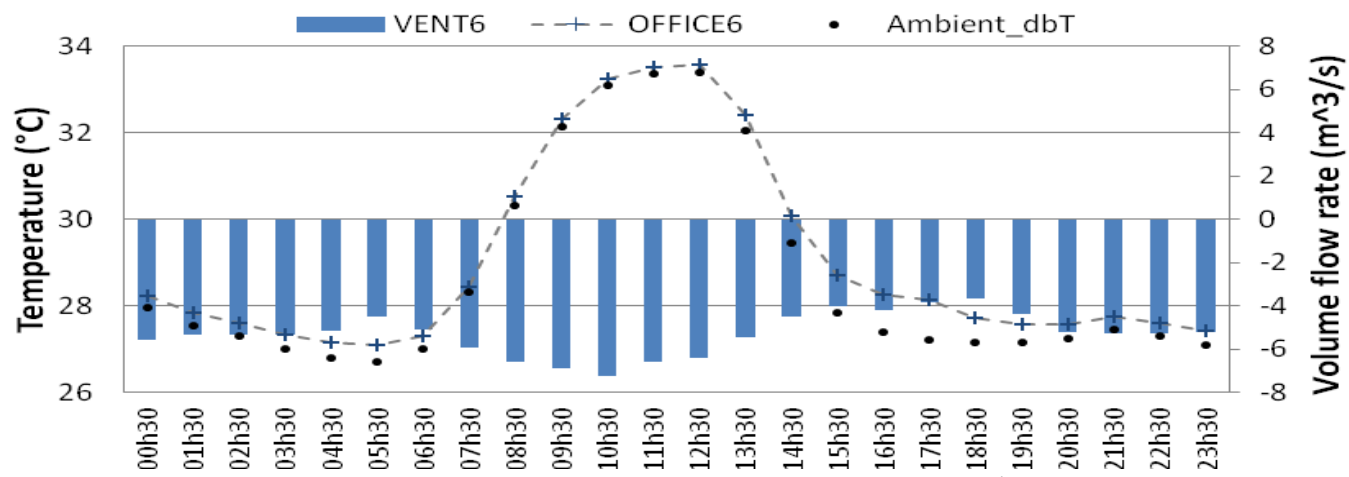

(d) The four-sided ventilation inlet condition on $22^{\text {nd }}$ of June

Figure 5-17: The free running temperatures of the lifted case with different ventilation inlet under the wind and buoyancy combined condition 


\subsection{Comparisons between the base case and revised building configurations of the main investigations}

\subsubsection{Investigations of neutral point level (NPL)}

To achieve the desired flow pattern, the NPL has to be forced above the height of the highest occupied floor, otherwise warm air from lower floors would exhaust through the top occupied floor, resulting in poor thermal comfort on the top floor. This is for the buoyancy alone case since the NPL cannot be easily defined for the wind and buoyancy combined case. For the atrium space of the base case building configuration, the hourly temperature of the atrium is plotted along with the ambient temperature over the occupied hours on the chosen day (Fig. 5-18).

The modelling results indicate that the warmer air would accumulate in the higher levels which cause 3 to 4 degree of temperature difference between the bottom and top atrium nodes of the base case on 25ht March (Fig. 5-18a). The same phenomenon is found for the lifted case, but the temperature difference between nodes is much smaller than those of the base case (Fig. 5-18b). This could be explained by having extra heat gains of $20 \mathrm{~W} / \mathrm{m}^{2}$ in the open floor (the bottom floor of the lifted case), where the air may be warmer in the bottom segment as compared with the base case building configuration. The temperature distribution within atrium nodes would cause the movement of neutral point level, which results in the variation of flow pattern, because of pressure difference between nodes. The simulated temperature from ESP-r can be used in the explicit solution of EFM to obtain the required opening size for remaining the neutral point level to be at the roof height. But this is not studied in this thesis because it is the building segmentation and preliminary feasibility for natural ventilation in tall buildings under the proposed building configurations that concerned. The range of opening sizes may be suggested for specific building configuration where all other boundary conditions are defined in the later design phase.

The simulated total flow rates through the air intake of both test cases are similar because of the employment of the same envelope opening size under the buoyancy alone condition, where only the stack height may cause minor 
difference to the resultant flow rates. However, the temperature variation pattern within the atrium of the base case is different from those observed in the lifted case. That is why the same neutral height level could not be achieved for both case with the same boundary conditions under the buoyancy alone condition. The boundary conditions of this section include the inlet and outlet sizes, ambient weather conditions and size of vent associated with offices. Different flow patterns through individual flow connection with fixed opening size for each floor are observed accordingly.

The equations 3-1 3-3 as described in the methodology (Ch3) are used to check whether the neutral height level could be fixed to the assumed upper roof level under the designed opening size. The assumption is made for ensuring the desired flow pattern where the air flow would go upward and exhaust through high level. If the required opening size exceeds the set conditions in simulations, the desired neutral height level (upper roof level) would not be achieved and the flow reversal occurs. It is also supposed that the extra heat gains in the wind floor would warm up the air flow entered from the inlet, which cause an influence on the neutral point level of the lifted case. The reasoning above demonstrates why different flow patterns are observed in the base case and lifted building configuration with buoyancy alone case applied under the same boundary conditions.

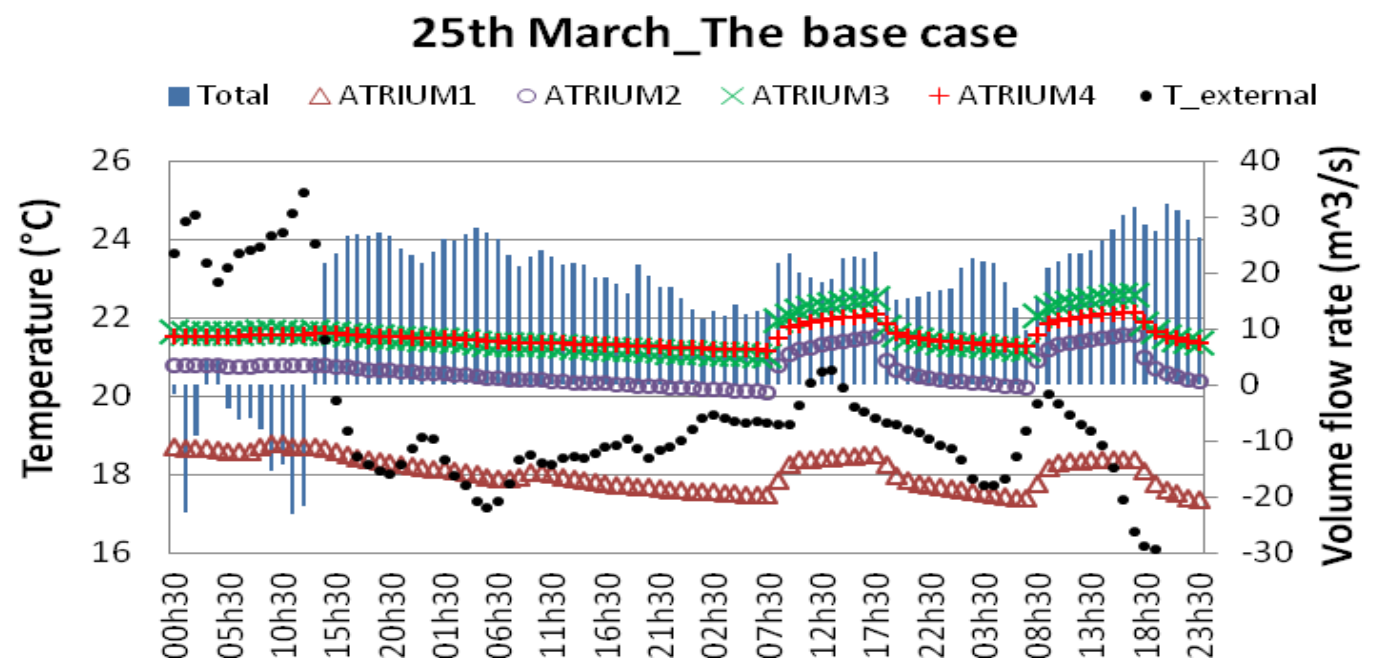

(a) The base case 


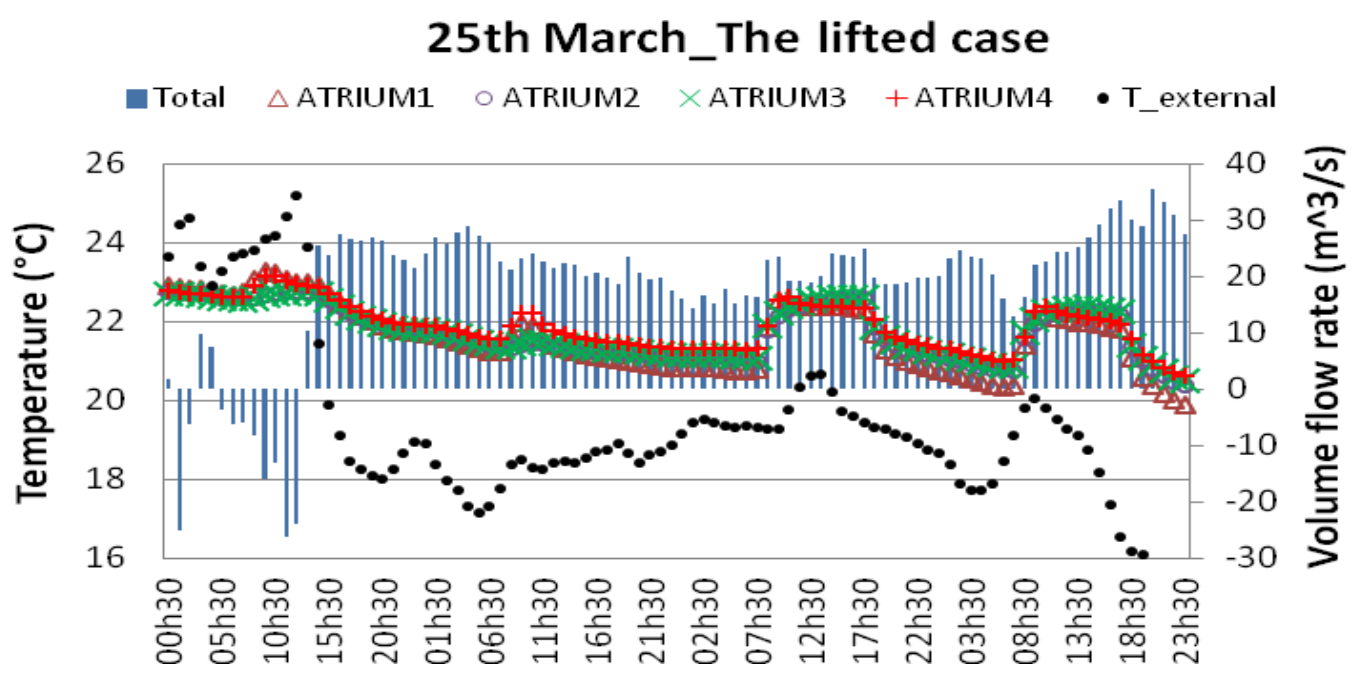

(b) The lifted case

Figure 5-18: The free running temperatures of the atrium nodes

\subsubsection{Viable periods of time for comfort ventilation}

In terms of ventilated cooling, though the minimum required flow rates are secured, the thermal comfort would not be guaranteed because the warmer air may be driven into the occupied space. The acceptable thermal comfort boundary in the climatic context of Taiwan should be evaluated further to establish the limit of convective cooling. In this section, the number of hours is examined for looking at the viable time for comfort ventilation. The acceptable upper band of temperature for Taipei, Taiwan is set to $28{ }^{\circ} \mathrm{C}$ under the still air condition in this study, with reference to the reviews on thermal comfort for hot and humid climates as stated in Section 3.4.3. Additionally, the required flow rates for cooling are the second criterion for comfort ventilation in this study. The indoor air flow speed can be acquired from the ventilation bulk flow accordingly. The equation used for the minimum flow rates for removing the internal gains is described in Equation 3-1.

The statistic analysis is conducted for both the base case and lifted building configurations, where the bottom segment of the whole building is concerned. The effect of wind and buoyancy is evaluated separately or in combination. The 
viable time for the base case building configuration with buoyancy alone strategy to achieve the design conditions $\left(T<28{ }^{\circ} \mathrm{C}\right.$ and $\left.q>1.1 \mathrm{~m}^{3} / \mathrm{s}\right)$ is illustrated in Figure 5-19. The statistical results suggest that the number of hours for comfort ventilation would increase slightly with floor level initially, and reach the maximum in the third or fourth level according to the ventilation strategies and season. It then decreases gradually with height irrespective of simulation period and ventilation strategies. Generally speaking, the averaged percentage for the buoyancy alone strategy to achieve the design condition is $38 \%$ and $9 \%$ for the mid-seasons and hot summer respectively. The viable time would be much improved with the help of wind, which increases the percentage to $68 \%$ and $28 \%$ respectively.
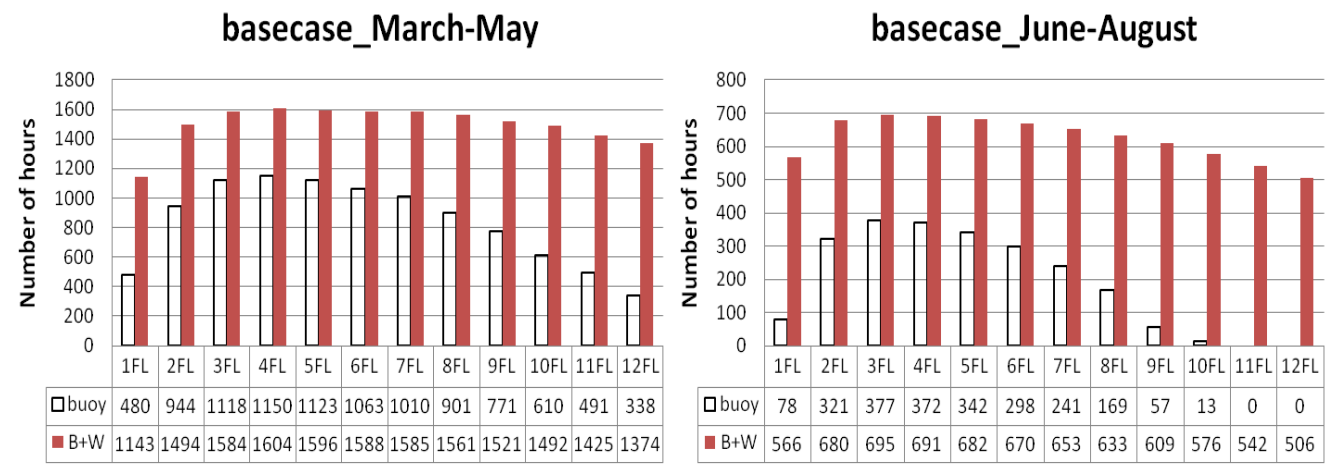

Figure 5-19: The seasonal number of hours for comfort ventilation by different ventilation conditions_Base case

As for the lifted case, however, it is not always advantageous for all seasons to reach the design condition when compared with base case building configuration. Two different opening configurations, namely the 2 sides and 4 sides, are adopted to construct the envelope of the wind floor for investigating the effect of inlet size. The simulation results suggest that the open floor strategy has little influence on the viable time for comfort ventilation in March and tends to have significant impact when the external temperature gets warmer, particularly for the case with large 4-direction inlets in the wind floor. The warmer air is driven into the office spaces during the hot summer and results in the reduction of feasibility for comfort ventilation. In this case, the resultant flow velocities from the bulk flow 
are of little help for personal cooling. Some examples of statistical results for comfort ventilation are presented as Figure 5-20.
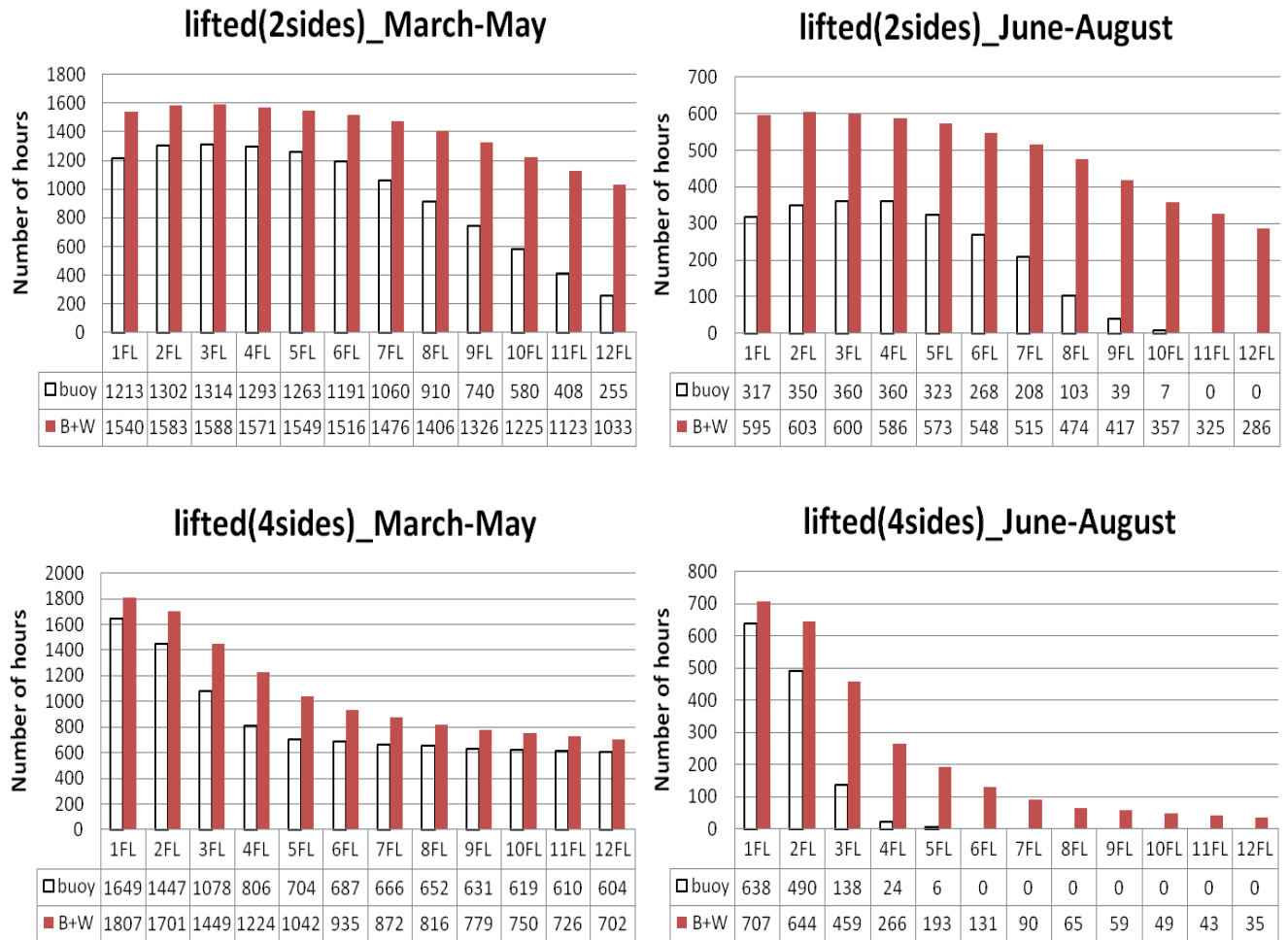

Figure 5-20: The seasonal number of hours for comfort ventilation by different ventilation conditions_Lifted case

Nevertheless, the monthly viable time for comfort ventilation is required for more practical application. The monthly viable hours for comfort ventilation with the wind and buoyancy combined strategy under three different building configurations are shown as Figure 5-21. For the cooler period, March, the deviation between three different cases is small for the bottom half of floor levels. The deviation is increasing in the top half of floors between the base case and lifted case with 2-side air intake, for which the total inlet size is 9 times of the base case. Also, the deviation between these two cases increases when the ambient temperature is higher. As for the lifted case with 4-side air intake, where the total inlet size is 18 times compared to the base case, the design condition would not be achieved for over $90 \%$ of the time for the top two-third of floors during the warmer season, namely between April and August. It is due to warmer 
air is being driven into the occupied space, which reduces the likelihood of cooling effect. Detailed viable numbers of hours to achieve comfort ventilation are presented in Figure 5-21.

It is obvious that the possibility for comfort ventilation decreases with higher ambient temperature. The lifted case with 2-sides air intake, for which the inlet size is 9 times of the base case, tend to have better ventilation performance for almost all floors with the buoyancy alone strategy. Its overall percentage for comfort ventilation ranges between $5 \%$ and $62 \%$. The wind and buoyancy combined strategy, however, is more beneficial for the base case building configuration. For the lifted cases with larger ventilation inlets, the warmer air may be driven into the occupied spaces through the ventilation path with the help from wind force. The monthly percentage for comfort ventilation of the base case ranges between $17 \%$ and $83 \%$. The statistical results are illustrated as Figure 5-22.
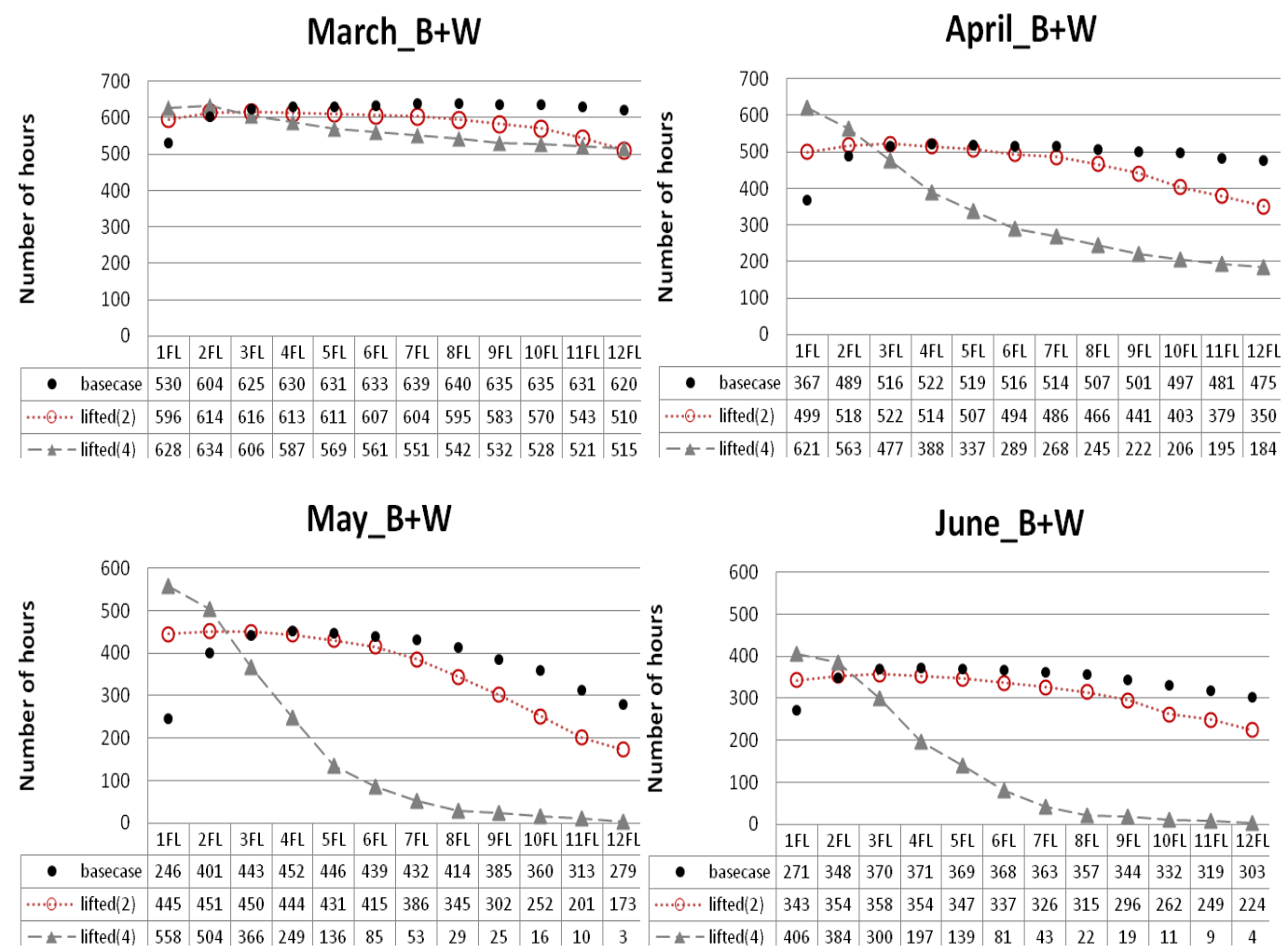
July_B+W

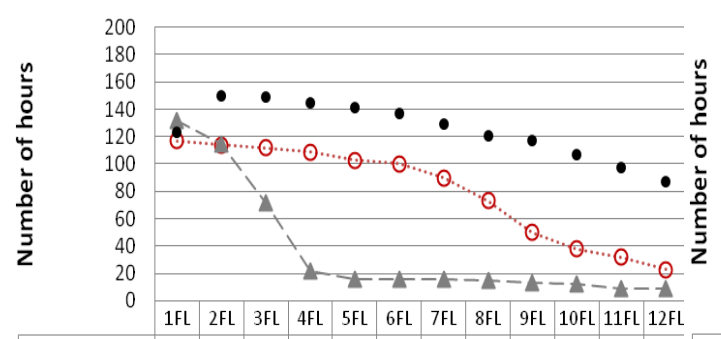

August_B+W

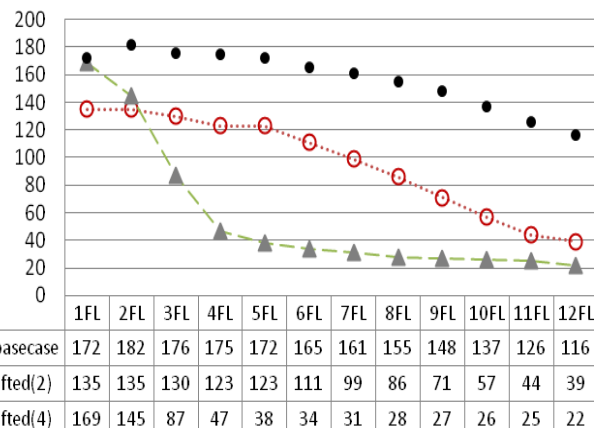

Figure 5-21: The monthly number of hours for comfort ventilation by building configuration

Buoyancy alone

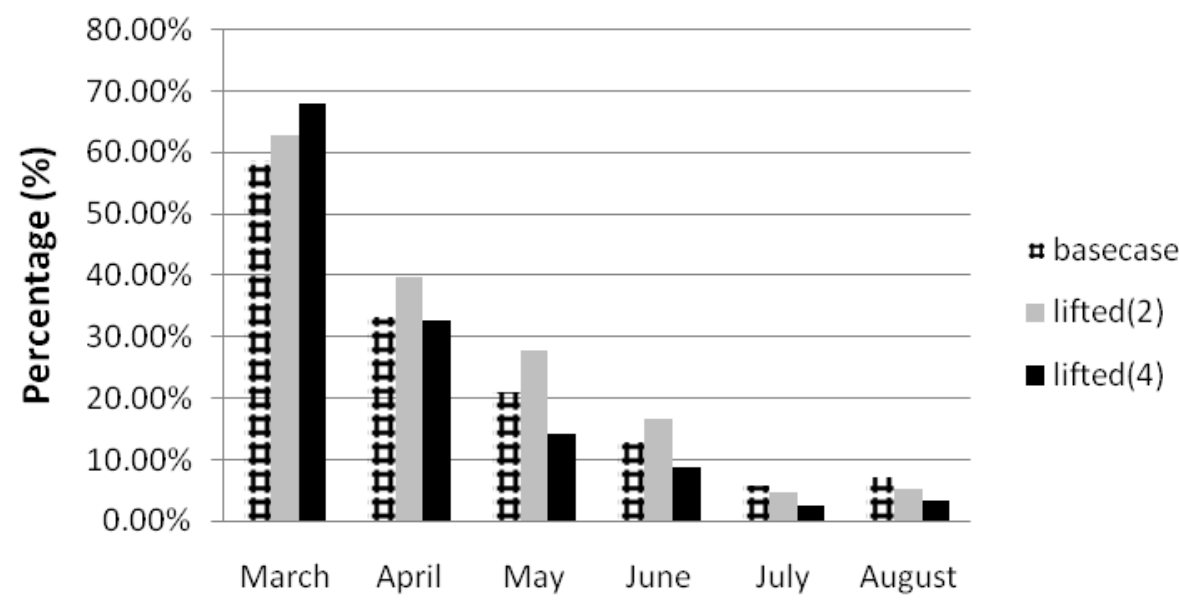

Wind and buoyancy combined

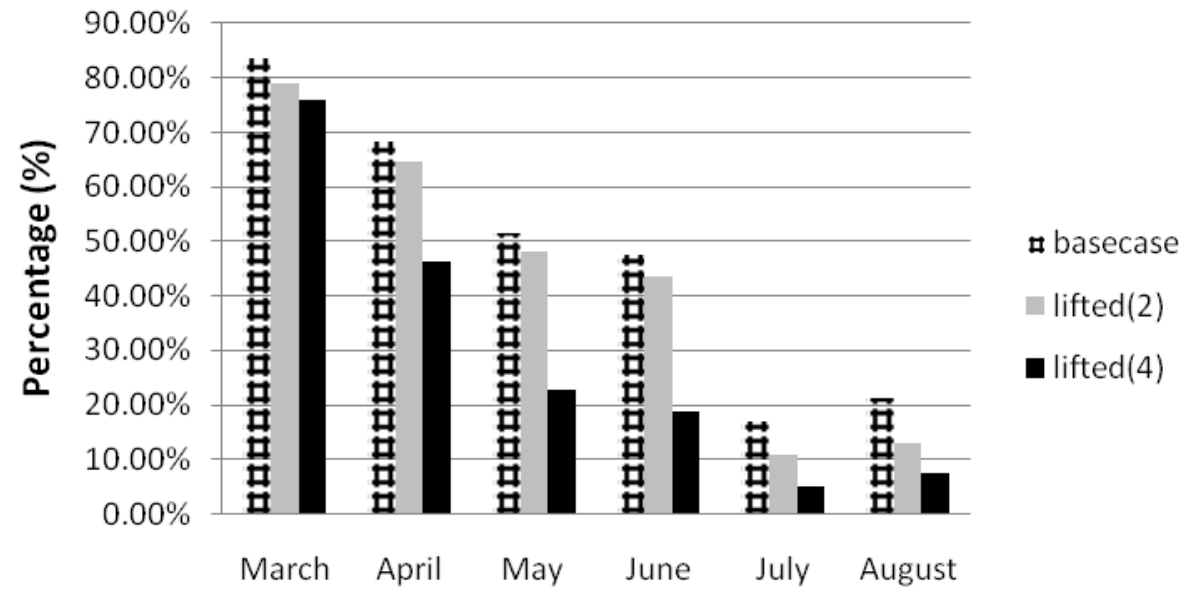

Figure 5-22: The percentage for comfort ventilation by different building configurations and ventilation conditions 


\subsection{Summary}

The air flow patterns (and temperatures) observed with the proposed building configurations are compared, for otherwise identical conditions in this chapter. Potential conditions where the design goals may not be ensured are identified. The overall ventilation performance is evaluated in terms of the required flow rates, desired flow patterns and the free running temperature for cooling. One thing to be noted is that a certain level of shading control is assumed within the atrium space. In this way, the air temperatures entering the office can be controlled and to ensure the proper interpretation of simulated thermal environment because of the underestimation of resultant indoor temperatures in ESP-r. More detailed descriptions are provided in Section 5.2.1-1

To cope with potential magnitude of impinging wind at high levels, a ventilated DSF is proposed along with the segmentation concept in the tall office building design for the main investigations of this study. The dynamic effects are evaluated by the use of dynamic thermal simulation with an air flow network in this chapter. In general, optimum segmentation could offer a major advantage for reducing the overall variation of flow rates between floors. The same conclusion was made in the preliminary investigation using the single-cell envelope flow model. This study used the same opening size for modelling air flows through individual floor. In reality, satisfactory flow rates between floors can be achieved by slightly varying the areas of openings according to occupants' needs.

From the desired flow pattern point of view, the larger segmentation could offer more opportunities for flow pattern control; while it is unlikely to obtain the expected performance with the buoyancy alone strategy when the ambient temperature increases. This situation is improved with the help of prevailing wind force. In terms of ventilated cooling potential, though the minimum flow rates for 
ventilated cooling are secured, the thermal comfort would not be guaranteed, because of the warmer air being driven into the occupied space. The illustrated free running temperatures in this chapter have demonstrated that the ventilation rates alone do not necessarily guarantee comfort. To set this in context, Building Bioclimatic Charts are proposed in Chapter 6 for the overall evaluation of comfort conditions under natural ventilation.

It is found that the 10 storey segmentation case demonstrates the feasibility of comfort ventilation for over $60 \%$ of mid-seasons in Taipei. The overall ventilation performance is evaluated in terms of the desired flow pattern and required flow rates. For the time when the design goal cannot be obtained, the control of air intake sizes as well as adjustment of segmentation by the use of damper between cavities can be adopted for regulating the ventilation rates. It is supposed that a seasonal control algorithm could be developed to provide the optimum desired flow pattern, sufficient flow rates and uniform air flow rates between floors; while this is not investigated in this study.

The aim for the lifted building configuration (the ground level with the open wind floor strategy) is to avoid undesired air draught through the inlet which might cause discomfort for the nearby space. It is found that the size of the air intake for the lifted cases is crucial, especially for the warmer season. The optimum inlet size can be achieved by sensitivity analysis in terms of desired flow rates, flow patterns and viable time for comfort ventilation of associated office spaces. For the buoyancy alone condition, the lifted case with the same inlet size, as applied in the base case, tends to have better ventilation performance in terms of desired flow direction and flow rates. The increase of inlet size in the lifted case is not always of benefit and would cause flow reversal when the external temperature gets higher, and this is closely related to the Neutral Point Level (NPL) within the tall atrium. That is, the lifted case with optimum size of air intake is advantageous 
for buildings blocked by its surrounding buildings where present the low or no wind condition.

As for the wind and buoyancy combined condition, the base case tends to have better performance in terms of the deviation of flow rates between floors compared to the lifted case with the same inlet size. Though the deviation could be reduced by adopting the 2-sided air intake, the warmer air might be driven into the occupied spaces under the unfavourable weather conditions. The free running temperatures as plotted against the atrium nodes also demonstrate this finding. Consequently, the base case building configuration is still of interest under the scenario of wind and buoyancy combined condition during the hot summer.

To conclude, the transformation between the base case and lifted building configuration can be achieved by the control of internal partitions or dampers. The ventilation rates alone cannot guarantee the overall thermal comfort environment though it is a reasonable approach for comparing the relative performance between different ventilation conditions as well as building configurations. The plots of the free running temperature of the selected occupied spaces have demonstrated this query. Consequently, the use of Building Bioclimatic Charts (BBCCs) is desirable for the overall assessment for comfort ventilation. The identification of the thermal comfort range is achieved by CFD modelling, where the local air flow speed distributions is crucial for the selection of comfort range in terms of personal cooling in the climatic context of Taiwan. 


\section{Computational Fluid Dynamics (CFD)}

\subsection{Chapter overview}

With the rapid advance in computer capacity and speed, CFD models have become a powerful modelling tool for predicting ventilation performance in buildings (Chen et al., 2010). In this chapter, the aim is to check to what extend that CFD approach can help with the proposed design procedure of naturally ventilated tall office buildings aside from all other models mentioned in the previous sections. The routes of CFD for natural ventilation design (Table 3-3) and its corresponding outcomes to the present research issues as listed in Section 1.3 are addressed accordingly.

An envelope flow model approach is used to examine the preliminary ventilation performance of tall-atrium buildings. The steady-state bulk flows through openings are evaluated under a specified design condition. The potential periods of time where the design condition cannot be met are addressed. A more complex modelling tool, the thermally coupled mass flow network approach, is adopted in the main investigations of this study. The aim is to obtain more detailed information on the ventilation bulk flow and its potential cooling effects for the corresponding thermal domain of the proposed main building configurations. The influence of revised building configurations with an open wind floor strategy is also evaluated. The statistical analysis is then carried out to examine the yearround probability for achieving the design condition, where the hourly variations of bulk flow and air flow direction through openings are evaluated.

However, as summarized by Chen (2009), the envelope flow model and the thermally coupled mass flow network approaches assume that the air in a room is well mixed, which implies uniform distributions of air temperature and air flow patterns. His study concluded that, for small rooms, such as small offices, hotel rooms, and bedrooms, such an assumption is often acceptable. For large spaces, like buildings with tall atriums and open working spaces, where the floor area is over $12 \mathrm{~m}$ by $12 \mathrm{~m}$ as used in this study, the complete mixing assumption may not 
be acceptable. One would need the distributions of temperature, velocity, and air flow pattern to assess local ventilation performance. The tools for ventilation assessment in Chapter 4 and 5 provide some insight for natural ventilation performance of tall atrium type buildings. However, only the bulk flow through the building envelope is addressed. For further quality assurance of the natural ventilation system, the local ventilation performance should be considered. Consequently, the necessities of CFD approach are identified as follows:

The first concern of this study is with respect to accuracy of resultant flow rates in the thermally coupled mass flow network model, where one of the dominating influential factors is the wind pressure coefficient $\left(C_{p}\right)$. It is in a sense that $C_{p}$ values across building height, particularly in tall buildings, might have significant difference to those suggested in the available database (Bowen, 1976; Liddament, 1986). For the base case model of the main investigations in this study (Fig.2-40), the $C_{p}$ values in the locations of inlet and outlet are required. The ranges of influence with reference to $C_{p}$ values on resultant flow rates are identified in Section 7.3.4 which suggests further investigation on the reliability of $C_{p}$ database within ESP-r. In this Chapter, the reliability of $C_{p}$ dataset is evaluated using the CFD approach. The simulations are carried out by the use of the stand-alone commercial CFD program, FLUENT 6.2.16. The results are then compared with the web-based TPU (Tokyo Polytechnic University) aerodynamic database which is developed from the wind tunnel testing. The same velocity profile and aspect ratio are selected for cross comparison. Detailed findings and analysis are presented in Section 6.2.

Secondly, the air flow network assumes one node per opening/zone which denote the air flow connection to be single direction per time step. In reality, uneven pressure difference is distributed throughout the space which causes local variation of flow pattern. Therefore, CFD approach is required for examining detailed air flow distribution of openings and its connected spaces as well. In Section 6.3.1 of this chapter, the thermally coupled single-domain CFD approach within ESP-r is proposed to evaluate the initial local ventilation performance of a 
particular occupied space. It is the coarse-grid CFD approach for which the grid size adopted in the CFD simulation is coarser than the conventional fine grid size for reducing the calculation time. The technical background and its adequacy for current research questions are described in Section 6.3.1 accordingly. Following that, FLUENT (with more sophisticated numerical models) is used to investigate the ventilation performance of the whole building under the selected boundary conditions. The potential pros and cons of using the stand-alone CFD program are compared with the thermally coupled single-domain CFD approach. Issues being investigated in this chapter are outlined as Table 6-1. For this study, the standalone CFD simulation by the use of commercial program (FLUENT) is applied for the following investigations:

- The adequacy of the use of wind pressure coefficient $\left(C_{P}\right)$ dataset in ESP-r

- The whole building natural ventilation performance in terms of local air flow and temperature distributions

- The selection of comfort boundary in the Building Bioclimatic Charts from the simulated indoor air flow velocity distributions of CFD

Table 6-1: Issues being investigated by the use of CFD approach in this Chapter

\begin{tabular}{|c|c|c|}
\hline $\begin{array}{l}\text { Issues to be } \\
\text { investigated }\end{array}$ & Descriptions & reference \\
\hline $\begin{array}{l}\text { Wind pressure } \\
\text { coefficient } \\
\left(C_{P}\right)\end{array}$ & $\begin{array}{l}\text { - The adequacy of the use of wind pressure coefficient } \\
\text { dataset in ESP-r } \\
\text { - Comparisons of } C_{P} \text { values among CFD, TPU } \\
\text { aerodynamic database and inbuilt database of ESP-r }\end{array}$ & Section 6.2 \\
\hline \multirow{2}{*}{$\begin{array}{l}\text { Whole } \\
\text { building } \\
\text { simulation }\end{array}$} & $\begin{array}{l}\text { Single CFD domain simulation with ESP-r: } \\
\text { - The necessity of coupling approach within ESP-r (BES- } \\
\text { CFD \& AFN-CFD) } \\
\text { - Resolution level on local air/temperature distribution } \\
\text { - Computing efficiency and technical convenience }\end{array}$ & Section 6.3.2 \\
\hline & $\begin{array}{l}\text { - Stand-alone CFD simulation:The indoor air velocity } \\
\text { distribution with reference to velocity inlet boundary } \\
\text { condition } \\
\text { - The lifted case with open wind floor on the bottom level } \\
\text { of building segment }\end{array}$ & Section 6.3 .3 \\
\hline BBCCs & $\begin{array}{l}\text { The feasibility for comfort ventilation of the proposed } \\
\text { generic design }\end{array}$ & Section 6.4 \\
\hline
\end{tabular}




\subsection{The adequacy of the use of wind pressure coefficient $\left(C_{P}\right)$ dataset in ESP-r}

\subsubsection{The theoretical background of air flow network and $C_{P}$ in ESP-r}

The theory for the air flow network as described by Hensen (1991) and Clarke and Hensen (2004) is that ESP-r involves calculation of fluid flow through the connections of a nodal network. The nodes of the network represent either internal or boundary pressures; the connections represent fluid flow paths. The single-direction steady flow is assumed. Information on potential fluid flows is given in terms of fluid type, node descriptions, flow component types, interconnections and boundary conditions. In this way a nodal network (or perhaps several decoupled sub-networks) of connecting resistances is constructed. The known pressures or pressure coefficient sets which represent the relationship between free-stream wind vectors and the zone surface pressures can then be attached to its boundaries. Each fluid flow component $(i)$ relates the fluid mass flow rate $\left(m_{i}\right)$ through the component to the pressure drop $\left(\Delta P_{i}\right)$ across it. Conservation of mass at each internal node is equivalent to the mathematical statement that the sum of the mass flow equals zero at such a node. A basic expression for turbulent flow through relatively large openings is the common orifice flow equation and is given by:

$\dot{m}=C_{d} A \sqrt{2 \rho \Delta P} \quad(\mathrm{~kg} / \mathrm{s})$

The mass flow simulation (mfs) module in ESP-r offers a component called: air flow opening. This component is actually identical to a common orifice flow component with fluid type set to air and with discharge factor $C_{d}$ equal to 0.65 . Furthermore, it is necessary to map the "free stream" wind velocity (as read from the climate file) onto the surface as a function of the wind's vertical velocity profile and the sheltering effect of remote and local façade obstructions for 
determining wind induced boundary pressures. This effect is usually accounted for by a dimensionless pressure coefficient:

$$
C_{P_{i}}=\frac{P_{i}}{1 / 2 \rho U_{r d}{ }^{2}}
$$

where $C_{P i}$ is the pressure coefficient for a surface location, $i$, corresponding to wind from direction $d, P_{i}$ is the surface pressure due to wind $(\mathrm{Pa}), \rho$ is the air density $\left(\mathrm{kg} / \mathrm{m}^{3}\right)$ and $U_{r d}$ is the wind speed $(\mathrm{m} / \mathrm{s})$ at some reference level $r$ and from direction $d$ (expressed relative to the external surface normal vector).

Furthermore, the airflow related equations used in ESP-r are defined as follows:

$$
\begin{aligned}
& P_{\text {node-internal }}=-\rho g Z_{\text {node }} \\
& P_{\text {node-boundary }}=\frac{1}{2} C_{P} \rho U^{2}-\rho g Z_{\text {node }} ; \rho=\frac{1.1881 \cdot 293.15}{273.15+T} \\
& P_{\text {stack }}=-\rho g \Delta z \\
& \Delta P_{\text {connection }}=P_{\text {possitive-node }}-P_{\text {negative-node }} \\
& Q=C_{d} A \sqrt{2 \rho \Delta P} \quad ; \text { where } \Delta P=P_{\text {connection }}+P_{\text {stack }}
\end{aligned}
$$

where $P_{\text {node-internal }}$ and $P_{\text {node-boundary }}$ are the pressure at node (includes stack pressure); $\rho$ is the outdoor air density estimated using the Boussinesq approximation for boundary node calculation, which is accurate as long as actual density variation is small; $g$ denotes the gravity; $U$ is the wind speed at the reference height (building height); $\Delta z$ is the height difference between two openings and $Z_{\text {node }}$ is the height of node. 
Wind pressure coefficients within ESP-r are based on published measurement results from AIVC (Liddament, 1986) and are available through a data file (pressc.db1) holding a collection of standard pressure coefficients sets. These sets can be used (with care) for low-rise buildings, which is an issue to be investigated later. Manual input of $C_{p}$ values (16 directions in a $22.5^{\circ}$ basis) is allowed. $\Delta P_{\text {connection }}$ is the pressure difference between total pressures at nodes. The connection of a positive side and a negative side is used to keep track of the direction of fluid flow; for example, the flow rate is positive in value when following the predefined flow direction. Additionally, the ratio between the local wind speed and the wind speed as read from the climate file is called the wind speed reduction factor. Besides direct numerical input, the mfs module offers several user selectable wind profiles for evaluation of the wind speed reduction factor.

In this section, the focus is to identify the adequacy of $\mathrm{C}_{\mathrm{p}}$ database embedded in ESP-r for modelling naturally ventilated tall office buildings. The stand-alone commercial CFD program (FLUENT) is adopted for the investigations. The CFD modelling results are compared with the TPU aerodynamic database of high-rise building and the dataset used in the ESP-r modelling for validation purpose. An aerodynamic database for high-rise buildings has been constructed by the Tokyo Polytechnic University in Japan as one part of the Wind Effects on Buildings and Urban Environment. Its objective is to provide structural design engineers with wind tunnel test data of wind loads on high-rise buildings. 22 models of high-rise buildings were tested in their database. Contours of statistical values of local wind pressure coefficients, graphs of statistical values of area averaged wind pressure coefficients on the wall surfaces and time series data of point wind pressure coefficients for 394 test cases are shown on their web site. These data can be used to calculate local wind pressures, area averaged wind pressure coefficient on wall surfaces, and even wind induced dynamic responses of high-rise buildings. The 
information required for the query of test results includes the Breadth v.s Depth, Breadth v.s Height, and the Alpha parameter for determining the exposure factor. One thing to be noted is that the same velocity profile and aspect ratio (building configuration) are selected for the comparison among CFD results, ESP-r dataset and the TPU aerodynamic database. The influence of pressure coefficient datasets on the resultant flow rates is discussed later in Section 7.3.4. One example from Figure 6-1 shows the potential range of difference on the calculated flow rates with reference to varied $C_{p}$ values, where the $C_{p}$ value is varied from 0.7 to 0.9 for the inlet while the value for the outlet is kept consistent as -0.8 . Two different sets of wind pressure coefficient arrangements demonstrate the influence of pressure difference between inlet and outlet of the proposed base case building configuration (Fig.2-40). Detailed evaluations on the adequacy of wind pressure coefficient datasets in ESP-r are discussed as follows.

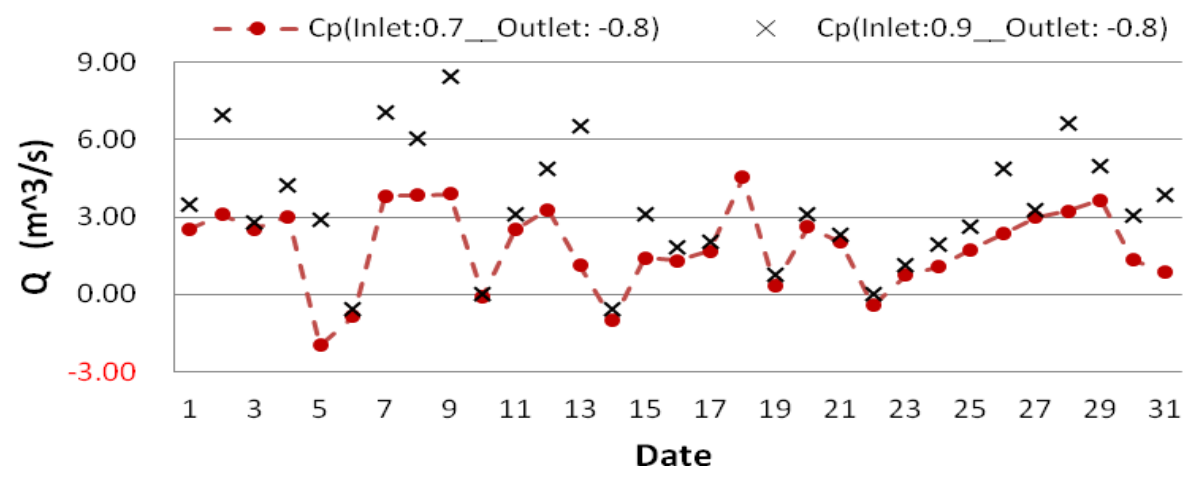

Figure 6-1: Resultant flow rates with reference to different $\mathrm{Cp}$ arrangements in March 


\subsubsection{The modelling of surface $C_{P}$ of proposed building configuration}

The full CFD simulation is adopted for this section by the use of commercial program, FLUENT. The information required for this problem type is described as follows.

\section{(a) Computational domain}

Yang et al. (2006) set the computational domain size as $5 H$ ( $H=$ building height) upstream, $10 H$ downstream, $5 H$ away from each side of the target building and $5 H$ above it. Tominaga et al. (2008) also suggested that for the single-building model, the lateral and the top boundary should be set $5 H$ or more away from the building. The distance between the inlet boundary and the building should be set to correspond to the upwind area covered by a smooth floor in the wind tunnel. The outflow boundary should be set at least $10 H$ behind the building. Similar requirements for the inlet and the top boundaries were suggested by COST (European Cooperation in the field of Scientific and Technical Research) group (Action C14 "Impact of Wind and Storms on City Life and Built Environment'" Working Group 2-CFD techniques). The above results were summarized by Franke et al. (2004) and Franke (2006).

Furthermore, Franke et al. (2004) and Franke (2006) summarized the conclusions from AIJ (Architectural Institute of Japan) and COST, both of which recommended similar grid resolution for actual building complex. They suggested that the minimum grid resolution should be set to about $1 / 10$ of the building scale (about $0.5 \sim 5 \mathrm{~m}$ ) within the region including the evaluation points around the target building. Moreover, the grids should be arranged so that the evaluation height (1.5-5.0 $\mathrm{m}$ above ground) was located at the $3^{\text {rd }}$ or higher grid from the ground surface (Yoshie et al., 2005a; Tominaga et al., 2005). The dimensions of the target building in this study is $\mathrm{x} \times \mathrm{y} \times \mathrm{z}=30 \times 30 \times 60 \mathrm{~m}$. The Breadth:Depth of 1:1, Breadth:Height of $1: 2$, and the Alpha parameter of 0.25 for determining the exposure factor are adopted for the query of test results of TPU database. For which the same velocity profile and aspect ratio (building configuration) are 
selected for the comparison among the CFD results, ESP-r dataset and the TPU aerodynamic database. The three-dimensional computation domain for this study is set as Figure 6-2, where $\mathrm{x} \times \mathrm{y} \times \mathrm{z}=900 \times 600 \times 360 \mathrm{~m} /(10 H ; 5 H ; 5 H)$.

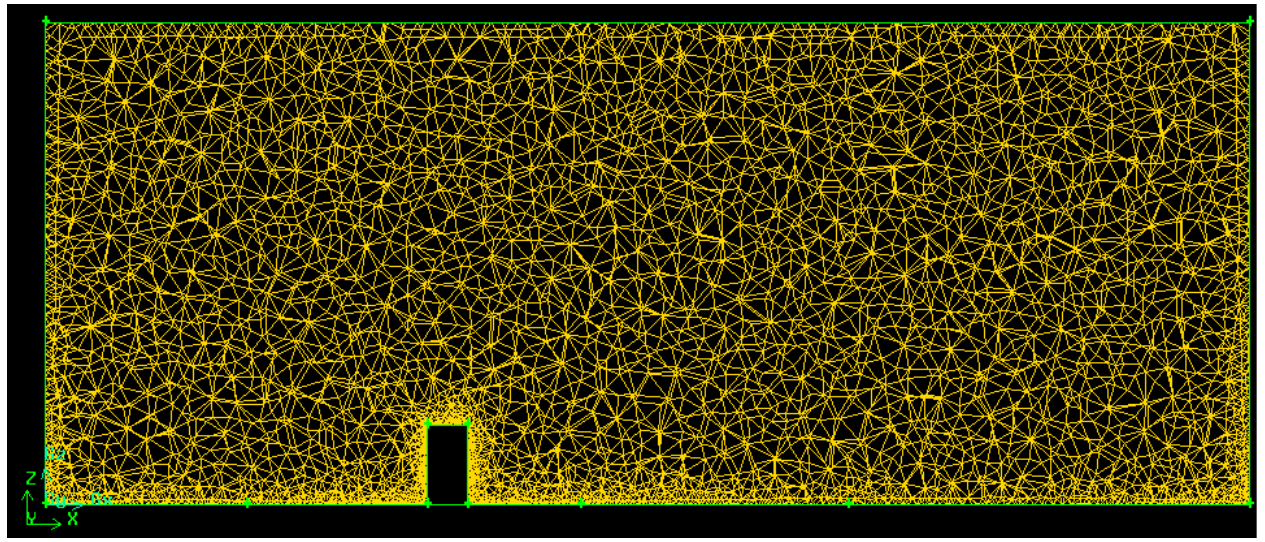

Figure 6-2: The computational domain

\section{(b) Grid dependency tests}

Tominaga et al (2008) suggested that the minimum of 10 grids was required on either side of a building to reproduce the separation flow around the upwind corners. Furthermore, grid shapes should be set up so that the widths of the adjacent grids were similar, especially in the regions with a steep velocity gradient. In these regions, it was desirable to set up a stretching ratio of adjacent grids of 1.3 or less. However, these recommended stretching ratios might change according to the shape of the building and its surrounding. Ferziger and Peric'(2002) also recommended that the number of fine meshes should be at least 1.5 times the number of coarse meshes in each dimension. It should be confirmed that the prediction result does not change significantly with different grid systems, the root mean square deviation $\left(\sigma_{\mathrm{Cp}}\right)$ is applied in this study to represent the differences between values predicted by the proposed models. The equation used is expressed as:

$$
\sigma_{C p}=\sqrt{\frac{\sum_{i=1}^{N}\left(C p_{n-1}-C p_{n}\right)^{2}}{N}}
$$


where $C p_{n-1}$ is the pressure coefficient of grid number $N$ in previous modelling session, $C p_{n}$ is the pressure coefficient of grid number $N$ in current modelling session and $N$ is the total number of gridding system.

The wind pressure coefficient defined in this section is provided as follows:

$$
\begin{gathered}
C_{p}=\frac{P_{x}-P_{0}}{P_{d}} \\
P_{d}=\frac{\rho U_{r e f}^{2}}{2}
\end{gathered}
$$

where $P_{x}$ is the static pressure at a given point on the building surface $(\mathrm{Pa}), P_{0}$ is the static reference pressure $(\mathrm{Pa}), P_{d}$ is the dynamic wind pressure $(\mathrm{Pa}), \rho$ is the air density $\left(\mathrm{kg} / \mathrm{m}^{3}\right)$ and $U_{\text {ref }}$ is the reference wind speed, which is taken at building height in the upstream undisturbed flow $(\mathrm{m} / \mathrm{s})$.

The mesh sizes and ranges of deviations of different testing are listed in Table 6-2 and 6-3 respectively.

For this section, the distribution of pressure coefficient over the building surfaces is the main concern. The gird independent tests suggest that the total cell number for over 860000 would decrease the overall discrepancy of $C_{p}$ values between different mesh sizes to $3.2 \%$ in general and is less than $2.5 \%$ for increasing the total cell number hereafter. It can be said that the impact of mesh size is insignificant when the total cell number is over 860000 because of the $C_{p}$ values usually range between -1 to 1 in most practical application in buildings. Considering the accuracy and efficiency of CFD simulations as well as the capacity of current modelling machine, the mesh size of 863400 is finally adopted for evaluating the adequacy of the use of wind pressure coefficient dataset in ESP-r. The comparison is done among the CFD results, ESP-r dataset and the TPU aerodynamic database. 
Table 6-2: Details for the grid dependency tests

\begin{tabular}{l|l|l|l|}
\hline Mesh name & $\begin{array}{l}\text { Mesh length scale of building } \\
\text { surface (m) }\end{array}$ & $\begin{array}{l}\text { Resolution on building } \\
\text { surfaces }\end{array}$ & $\begin{array}{l}\text { Total number of } \\
\text { cells }\end{array}$ \\
\hline Mesh1 & 3 & 10 & 348375 \\
Mesh2 & 2 & 15 & 625139 \\
Mesh3 & 2 & 15 & 863400 \\
Mesh4 & 1.5 & 20 & 1013700 \\
Mesh 5 & 1.5 & 20 & 1277830 \\
\hline
\end{tabular}

Note:

The mesh length scale on the ground is $0.6(\mathrm{~m})$ and the first cell height from the ground surface is $0.02(\mathrm{~m})$. The cell expansion factor is kept as 1.4 for Mesh $1,2 \& 4$; while it is 1.2 for Mesh $3 \& 5$.

Table 6-3: The Root Mean Square Deviation of the grid dependency tests

\begin{tabular}{|c|c|c|c|c|c|c|}
\hline & Testing type (pressure coefficient) & forward & leeward & $\operatorname{Side}(L)$ & $\operatorname{Side}(\boldsymbol{R})$ & Top \\
\hline Case 1 & $\begin{array}{l}\text { Standard k- } \varepsilon \text { v.s RNG k- } \varepsilon \text { (mesh0_1 } 1^{\text {st }} \\
\text { order_pressure outlet) }\end{array}$ & $0.24 \%$ & $4.1 \%$ & $1.3 \%$ & $1.4 \%$ & $2.2 \%$ \\
\hline Case 2 & $\begin{array}{l}\text { Pressure outlet v.s outflow (mesh0_ } \\
\text { Standard k- } \varepsilon_{-} 1^{\text {st }} \text { order) }\end{array}$ & $0.24 \%$ & $4.1 \%$ & $1.3 \%$ & $1.4 \%$ & $2.2 \%$ \\
\hline Case 3 & $\begin{array}{l}\text { Roughness height in the non-slip wall } \\
\text { (mesh1_RNG k- } \varepsilon \text { ) }\end{array}$ & $0.1 \%$ & $0.9 \%$ & $2.7 \%$ & $2.1 \%$ & $1.8 \%$ \\
\hline Case 4 & $\begin{array}{l}\text { Mesh1 v.s mesh2 (2 } 2^{\text {nd }} \text { order_RNG k- } \\
\varepsilon \text { outflow })\end{array}$ & $2.6 \%$ & $5.5 \%$ & $10.9 \%$ & $6.6 \%$ & $6.6 \%$ \\
\hline Case 5 & $\begin{array}{l}\text { Mesh2 v.s mesh3 }\left(2^{\text {nd }} \text { order_RNG k- }\right. \\
\left.\varepsilon_{-} \text {outflow }\right)\end{array}$ & $1.1 \%$ & $2.2 \%$ & $6.7 \%$ & $3.2 \%$ & $2.6 \%$ \\
\hline Case 6 & $\begin{array}{l}\text { Mesh3 v.s mesh5 ( } 2^{\text {nd }} \text { order_RNG k- } \\
\left.\varepsilon_{-} \text {outflow }\right)\end{array}$ & $0.63 \%$ & $1.7 \%$ & $5.3 \%$ & $2.5 \%$ & $2.1 \%$ \\
\hline
\end{tabular}

(c) Solution algorithm, turbulence models and convergence of solution

The steady calculation using the RANS models with first-order upwind scheme for the convection terms is initially applied in this testing. However, the firstorder upwind scheme is not appropriate for all transported quantities. Tominaga et al. (2008) concluded that the spatial gradients of the quantities tended to become diffusive due to a large numerical viscosity. COST also does not recommend the use of first-order methods like the upwind scheme except in initial iterations (Franke et al., 2004).

Additionally, to evaluate wind pressure distribution on a building by using CFD, it has been general practice to use k- $\varepsilon$ models. However, it is known that the use of the standard k- $\varepsilon$ model has disadvantages, such as overestimation of wind pressure coefficient and turbulent kinetic energy on the windward surface where wind impinges on the building as suggested by Endo et al. (2005). They 
investigated various modified $\mathrm{k}-\varepsilon$ models for the estimation of wind pressure distribution on a parallelepiped shaped building. It was found that the quality of prediction of wall surface wind pressure distribution of various buildings was improved by applying RNG and Durbin models when compared with the standard k- $\varepsilon$ model. Evola and Popov (2006) also showed the accuracy of RNG model for the study of natural ventilation issues inside and around a building compared with the standard k- $\varepsilon$ model. Their results were validated with experimental data. Another issue is that calculations needed to be finished after sufficient convergence of the solution. Tominaga et al. (2008) concluded that when the calculation diverges or convergence was slow, the points below should be examined:

- The aspect ratio and the stretching ratio of the grids may be too large.

- The relaxation coefficient of the matrix solver may be too small.

- Periodic fluctuations such as a vortex shedding may be occurring.

The testing of the solution algorithm and turbulence models is summarized as Table 6-3. The simulation results show that no significant different on the pressure coefficient when different turbulence models (Standard k- $\varepsilon$ v.s RNG k- $\varepsilon$ ) and outlet boundaries (pressure outlet v.s outflow) are applied. As seen from Table 6-3, their RMS deviation ranges between $4 \times \mathrm{e}^{-2}$ and $2 \times \mathrm{e}^{-3}$ as presented in case $1 \& 2$. The influence of roughness height and different element sizes are examined in case 3 and cases 4 respectively. According to the recommendations from literature reviews above, the RNG k- $\varepsilon$ model with three different mesh types is applied in the initial investigations of this study. The second order upwind discretisation scheme with a pressure relaxation coefficient up to 0.5 is used for achieving convergence. The convergence criterion used in this study is the rootmean-square (RMS) of normalized residual for all variables to be less than e-04.

\section{(d) Boundary conditions}

In this section, the vertical velocity profile $U(z)$ on city terrain is given by a power law: 
$\frac{U_{h}}{U_{10}}=K \cdot Z_{h}^{a}$

where $U_{h}$ is the local wind speed at a height $Z_{h}$ above the ground $(\mathrm{m} / \mathrm{s}) ; U_{10}$ is the wind speed measured in open countryside $(\mathrm{m} / \mathrm{s})$ at a standard height of $10 \mathrm{~m}$, and $K$ are terrain dependent constants. Here $K=0.21$, and $a=0.33$ for city terrain and $U_{10}=5(\mathrm{~m} / \mathrm{s})$ is used in this study.

The vertical velocity profile is plotted as Figure 6-3. Other boundaries for steady state solutions are listed as Table 6-4. The modelling details for the whole domain flow field around the targeted building are listed as Table 6-5.

Table 6-4: Boundary conditions in FLUENT 6.3.26

\begin{tabular}{lc}
\hline \multicolumn{1}{c}{ Boundary } & Settings \\
\hline Inlet & Power law velocity profile (Equation4) \\
Outlet & Normal gradient of all variables is zero, $\partial / \partial \mathrm{x}=0$ \\
Ground & No-slip rough wall (roughness height $=0.01 \mathrm{~m}$ ) \\
Building surfaces & No-slip rough wall (roughness height $=0.005 \mathrm{~m})$ \\
Upper domain & Symmetry (vertical velocity component $\mathrm{w}=0 \& \partial / \partial \mathrm{z}=0$ \\
Side domains & Symmetry (vertical velocity component $\mathrm{v}=0 \& \partial / \partial \mathrm{y}=0$ \\
\hline
\end{tabular}

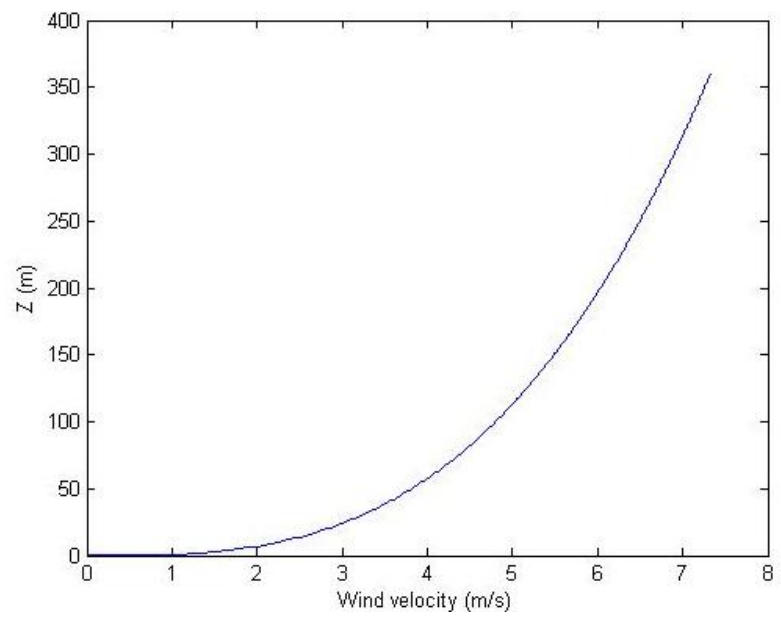

Figure 6-3: Power law wind velocity profile

Table 6-5: modelling details of the whole domain flow field around the target building

\begin{tabular}{|l|l|}
\hline \multicolumn{2}{|l|}{ The final setup and modelling details of the targeted building } \\
\hline Domain size & $\mathrm{x} \times \mathrm{y} \times \mathrm{z}=900 \times 600 \times 360 \mathrm{~m} /(10 H ; 5 H ; 5 H)$. \\
\hline Mesh type & Structured \\
\hline Turbulence model & RNG k- $\varepsilon$ \\
\hline Convective differencing scheme & $2^{\text {nd }}$ Order Upwind \\
\hline Resolution on the surface of target building & 15 cells in width; 30 cells in height \\
\hline Total number of cells & 863400 \\
\hline
\end{tabular}




\subsubsection{Simulation results on adequacy of wind pressure coefficient dataset within ESP-r}

The purpose of external flow field modelling using CFD (FLUENT) is to test the adequacy of the local wind pressure coefficient for the mass flow network modelling of ESP-r. The geometry of the examined building is $W: D: H=1: 1: 2$. The monitored points of the building surfaces are shown as Figure 6-4. Comparisons between the CFD simulation results and web-basis TPU aerodynamic dataset are achieved for the windward, leeward and side surfaces respectively (Fig.6-5 6-7). The simulated top surface result (Fig.6-8) is presented alone due to the lack of dataset in TPU database.
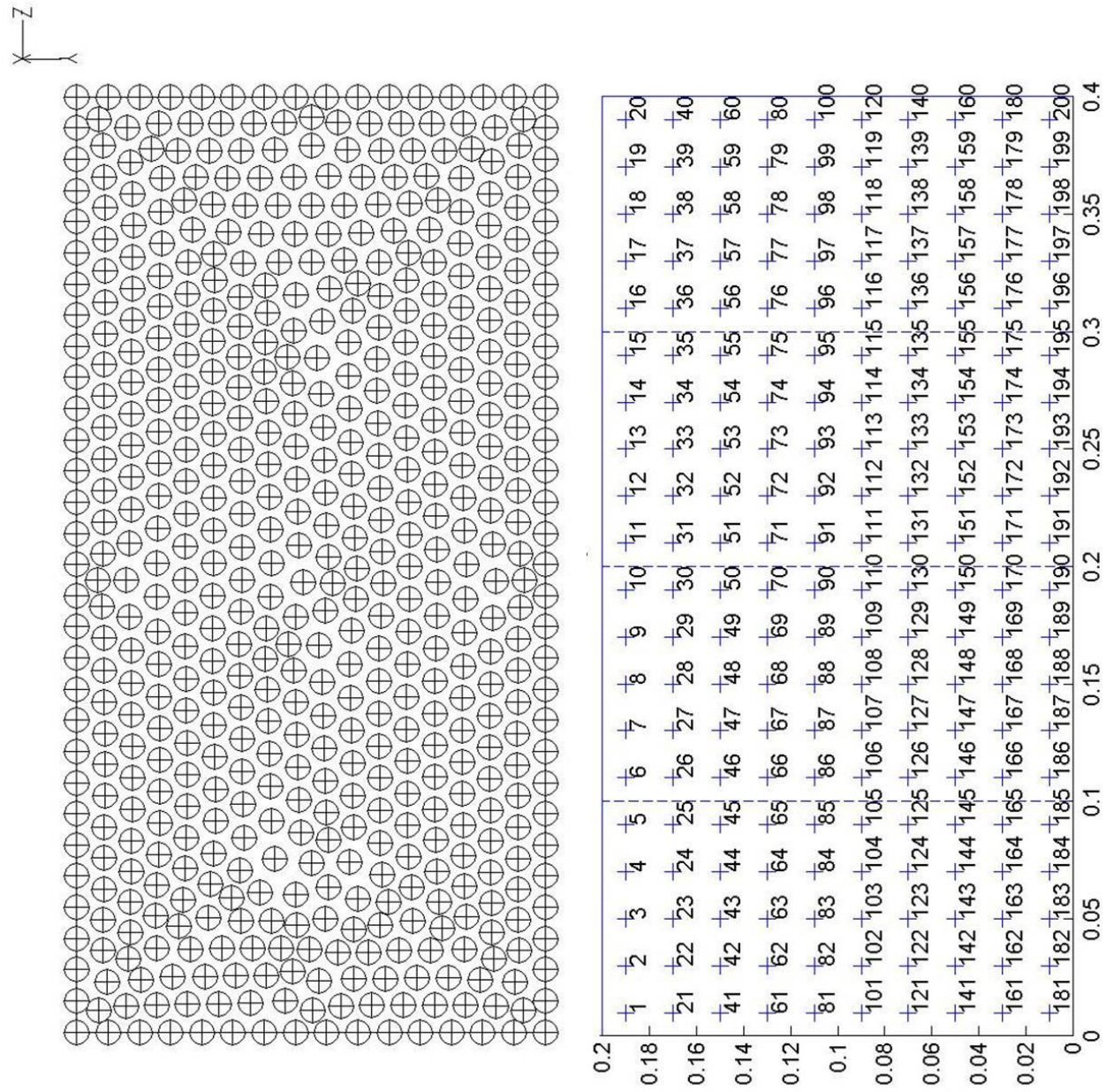

Figure 6-4: The gridding system of windward building surface in TPU (right) and FLUENT (left) 
For the base case model of the main investigations in this study (Fig.2-40), the $C_{P}$ values in the location of inlet and outlet are required. Consequently, the $C_{P}$ values in the lower section of each vertical surface (for inlet) and the side of top surface (for outlet) are considered. Following that, the surface averaged $C_{P}$ values in the locations of inlet (windward, leeward and side surfaces) and outlet (top surface) as used in ESP-r are plotted and compared with those from FLUENT CFD simulations and TPU datasets (Fig. 6-9). It is found that, for the windward surface (Fig.6-5), the simulated contour results fit well with the TPU dataset, though with discrepancies (roughly of 0.1 in values) for the higher part of the building surface. The $C_{P}$ value of 0.7 in the inlet is adopted for the windward surface of the ESP-r model which is 0.1 and 0.2 higher in value than the CFD simulations and TPU datasets respectively. As for the leeward (Fig. 6-6) and side surfaces (Fig. 6-7), larger mismatch is observed between the simulated results and the TPU dataset for the target locations. The discrepancy of the $C_{P}$ values between the ESP-r, CFD and TPU datasets for different building surfaces is shown as Figure 6-9.

The comparison results show that the credibility of modelled flow rates using the thermally coupled mass flow network approach is justifiable, if the driving wind force is either from the windward or leeward direction; while the resultant flow rates caused by wind from side directions might be questionable. Additionally, though the TPU dataset for the top surface is absent, the contour line could be extended from the side surfaces for the rough distribution of $C_{P}$ on top surface. In this way, minor mismatch is found between CFD simulations (Fig. 6-8) and empirical results from TPU for the top surface. Generally speaking, the $C_{P}$ value $(-0.8)$ adopted for the outlet of the ESP-r model is reliable because it has relatively small variation between three different datasets. 


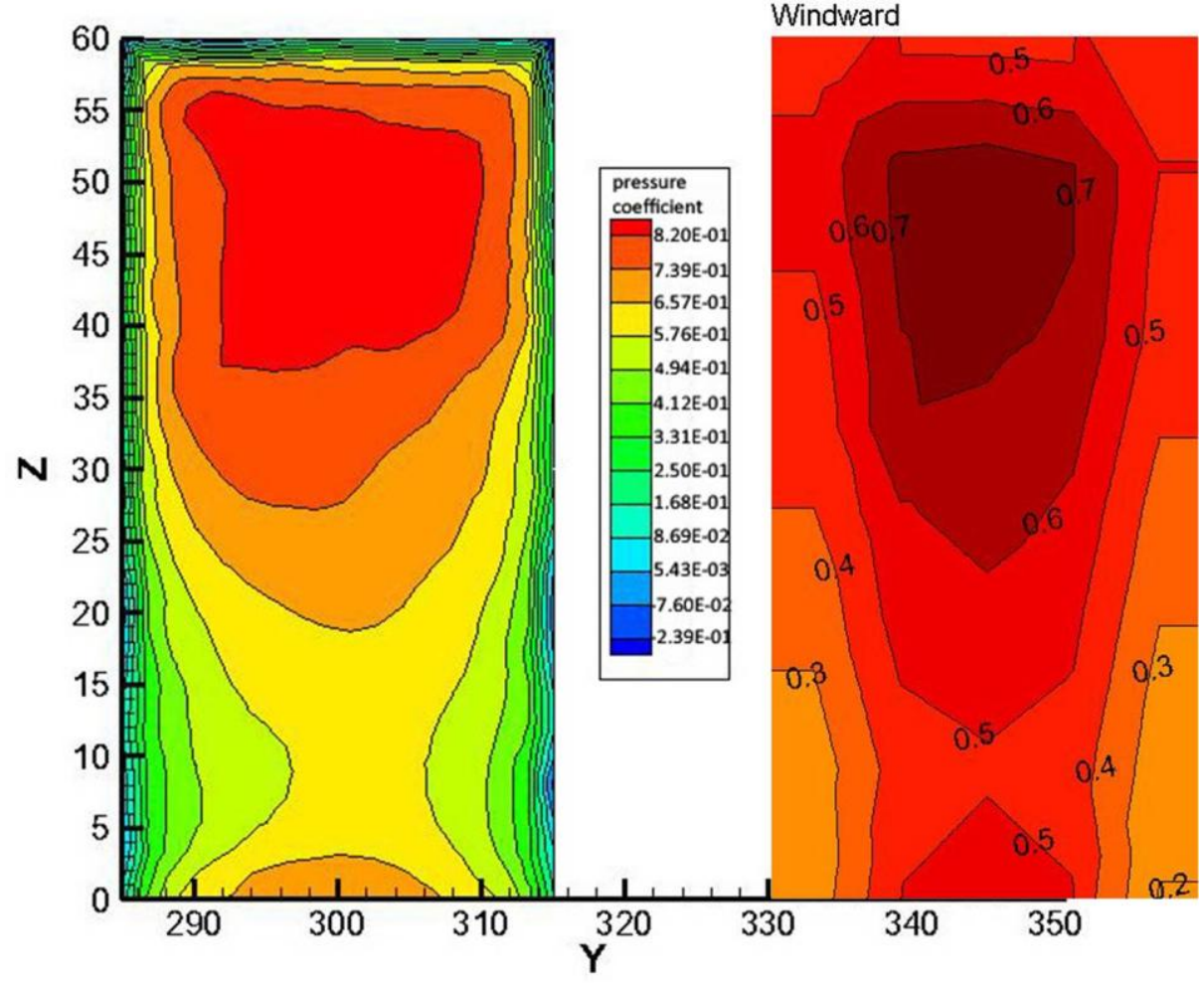

Figure 6-5: Testing results of windward surface. (L) CFD results; (R) TPU database

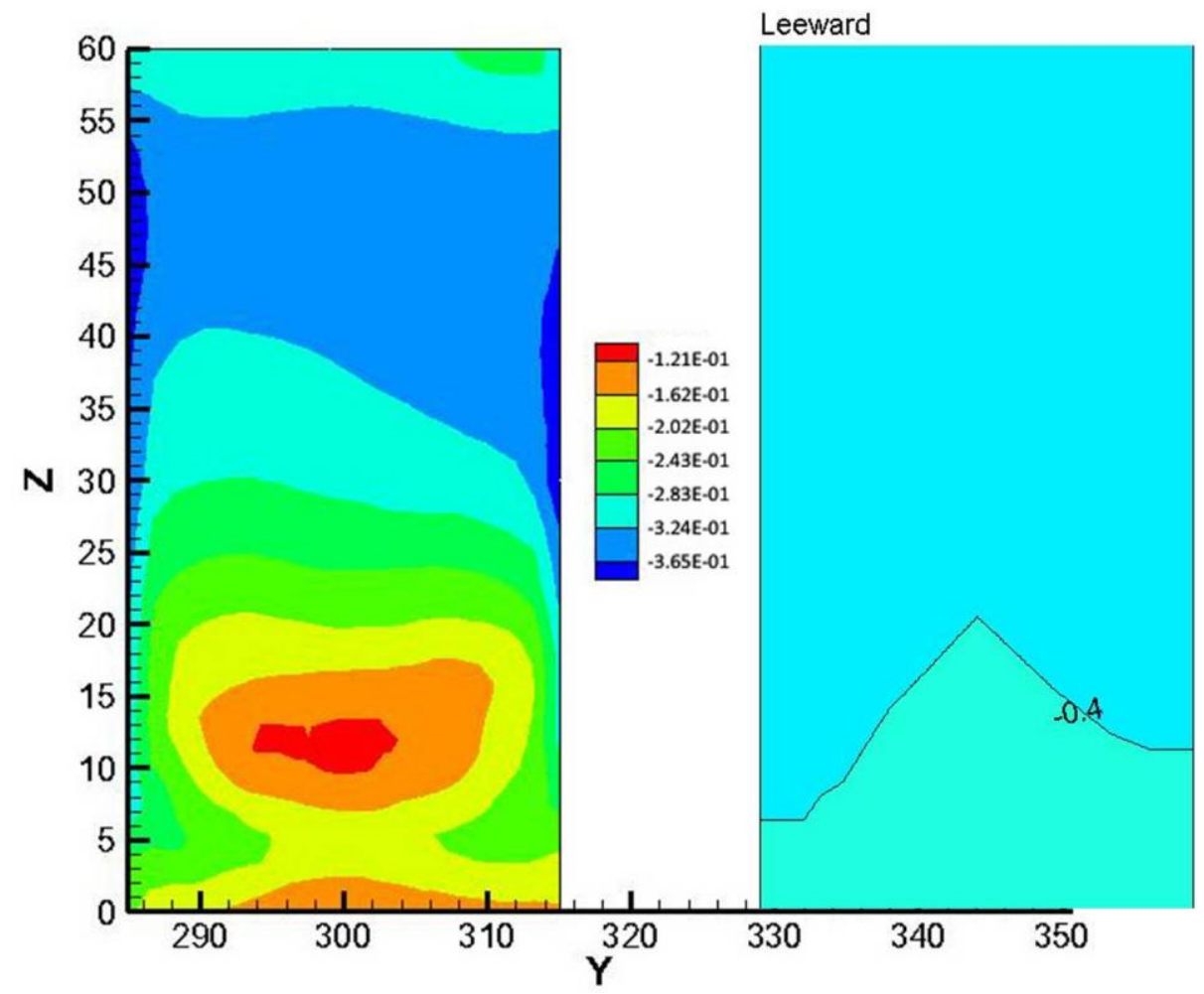

Figure 6-6: Testing results of leeward surface. (L) CFD results; (R) TPU database 


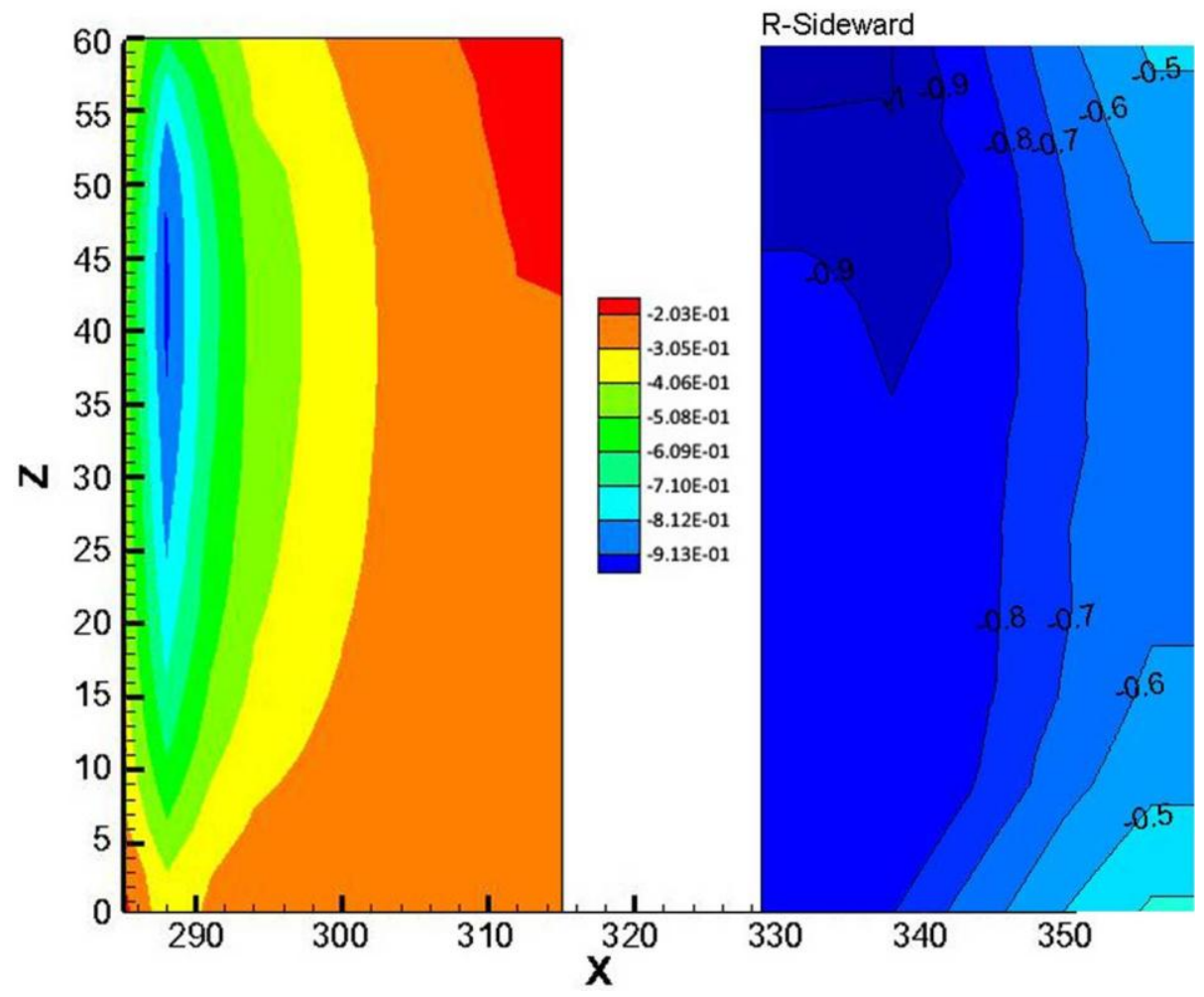

Figure 6-7: Testing results of side surfaces. (L) CFD results; (R) TPU database

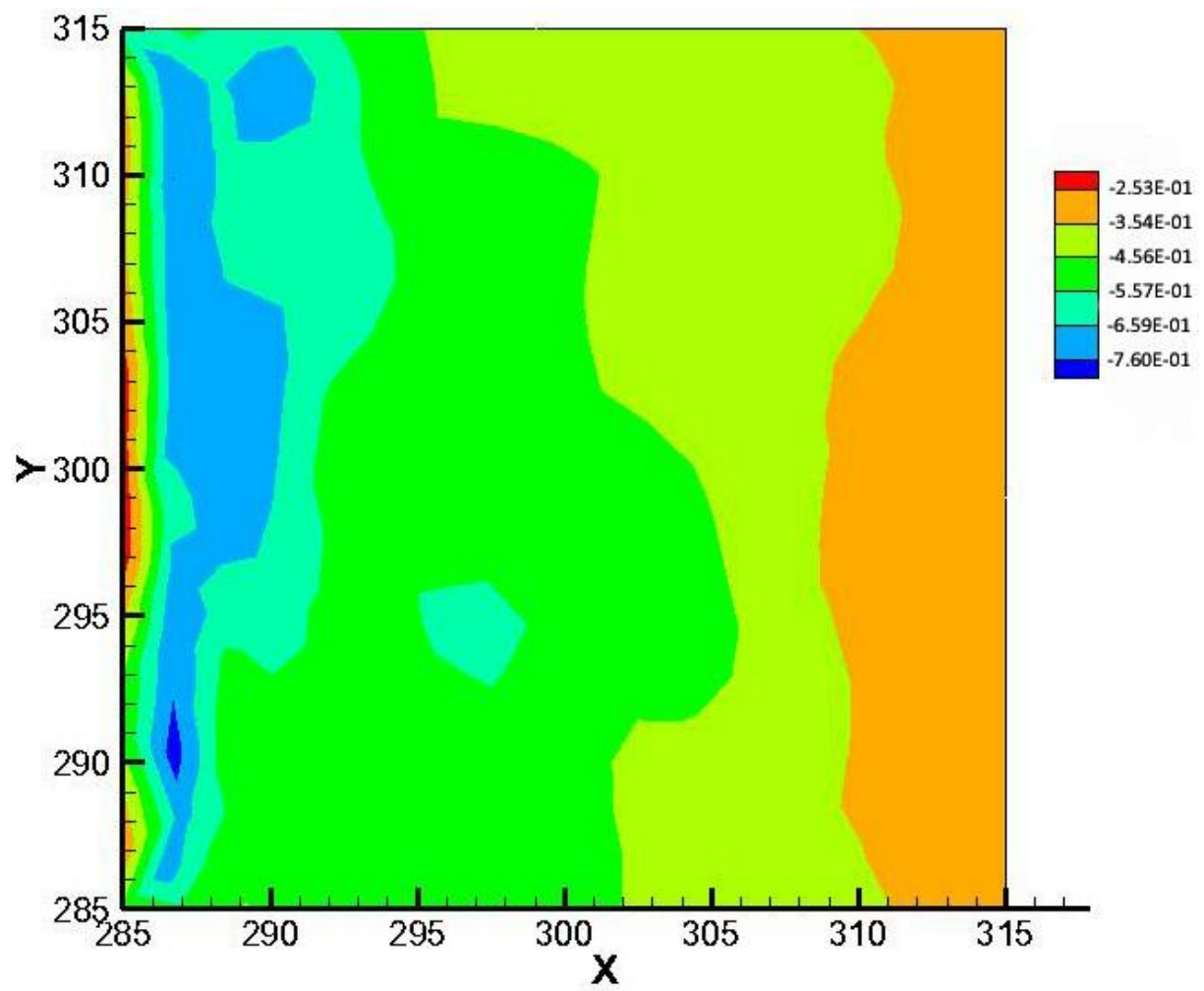

Figure 6-8: Testing results of top surface: CFD results 


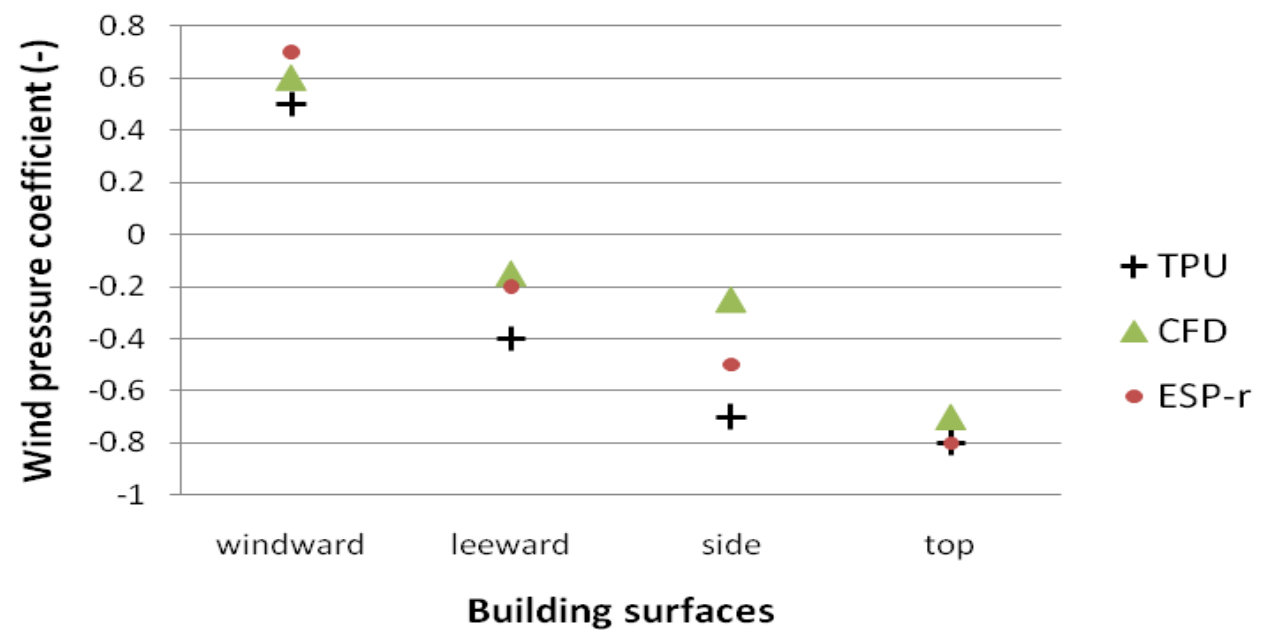

Figure 6-9: The surface averaged wind pressure coefficients from different dataset 


\subsection{Whole building CFD simulation}

For this section, the internal air and temperature distributions of the whole building (regardless of the external flow field) is of interest. The boundary conditions for the CFD simulations are derived from the hourly basis simulation results from ESP-r at a particular time-step. The modelling technique of single domain CFD modelling within ESP-r and the stand alone FLUENT-CFD is summarized in Section 6.3.1. The modelling results of single domain CFD approach within ESP-r and the full CFD simulation in FLUENT are investigated respectively in Section 6.3.2 and Section 6.3.3 as follows.

\subsubsection{The modelling technique of Single domain CFD modelling within ESP-r and the stand alone FLUENT-CFD}

For the proposed building configuration of the main investigations (Fig. 2-40), the office spaces (cells) have one node in each; while the tall atrium and ventilated façade segments are divided into multiple zones (one node per 3 5 storeys). For most real world applications, the homogenous conditions within those predefined zones might not be satisfied. Therefore, investigations by the use of the single domain CFD modelling (with coarse-gridding manner) within ESP-r are proposed for the initial understanding on the local air and temperature distribution of a selected space. In the case of single domain CFD modelling within ESP-r, the coupling between the thermal and that particular CFD domain is allowed. For the single domain CFD modelling within ESP-r, data on coupling type, geometry, gridding, solution variables, boundary conditions, solver parameters, output files etc. are required for the CFD model. Two types of coupling methods, namely the BES-CFD and AFN-CFD, are available in ESP-r. The necessity of coupling within ESP-r is evaluated from view points of sufficient resolution on local distribution as well as computing efficiency and technical convenience. The corresponding modelling technique is summarized from the online source of the ESRU (Energy Systems Research Unit, University of Strathclyde) website. 
For the first type of coupling (BES-CFD), the CFD model can be integrated within the thermal domain (zone basis). One zone is chosen to be modelled by CFD and the remaining of the building is simulated by the conventional approach (thermal simulation with an air flow network). The surface convection heat transfer coefficients for BES are calculated from the CFD-predicted flow and temperature fields. This is referred to the BES-CFD thermal coupling type. The BES here denotes 'Building Energy Simulation'. There is no interaction between the airflow network and CFD. In such cases, fixed mass flow rates are assumed for the opening boundaries. The aim for this type of coupling is to investigate the ventilated cooling effects and the corresponding temperature distribution within the CFD domain. As described by Beausoleil-Morrison (2000), the integration is optional and a CFD flag is placed in the zone operation file. One thing to be noted is that only one CFD domain is allowed to be coupled with other thermal domains per simulation.

The second type of coupling (AFN-CFD) within ESP-r focuses on the instant air flow distribution where the airflow network is coupled with particular CFD domain for specific time steps. In other words, the opening boundary conditions would vary with the corresponding mass flow connections during the specific time steps. A single air flow network node is replaced by a CFD domain, thus dropping the assumption of well-mixed conditions for that zone. However, fixed internal surface temperature should be defined for the solid boundaries and there is no interaction on the thermal level.

For the BES-CFD thermal coupling type and AFN-CFD air-flow coupling type of coupling in ESP-r, the results obtained can be compared with those from the BESAFN approach (dynamic thermal simulation with an air flow network). For the BES-CFD coupling type, the coupling on the thermal level is concerned. That is, the output on the temperature distributions of the single CFD domain is compared with those under well-mixed assumption. The AFN-CFD coupling type, however, the comparison results in terms of flow rates through the openings of that particular CFD domain are of interest. The ranges of improvement and computing 
costs of coupling simulation within ESP-r can then be demonstrated. From the computing point of view, the BES-AFN approach takes only few minutes to run the year-round data on hourly basis. A coupled BES-CFD approach, on the other hand, would generally require more computing power than the thermally coupled mass flow network model. A two-day period simulation could take 3 hours to run in a machine with $2 \mathrm{G}$ ram. The CFD alone approach of ESP-r is on coarse-grid basis and only one CFD domain is allowed per run. This may not be realistic in terms of overall ventilation performance in tall buildings with multi-zones models. Consequently, to assess whether a dynamically coupled simulation within ESP-r can bring significant benefits to current research issues before committing into a more sophisticated method is necessary.

This study focuses on the overall ventilation performance of the proposed building configuration, where the ventilation flow rates, flow pattern, and the overall thermal environment are concerned. The simulation results from dynamically coupled single domain CFD approach within ESP-r suggest the insignificance of the improved result resolution of that particular CFD domain per simulation run. Also, the resultant difference between two modelling approach, namely the BES-CFD and BES-AFN, is insignificant for the occupants to detect. For example, the temperature difference between two approaches is lower than $1 \mathrm{~K}$ for the CFD domain in the location of mid-level office space. The remaining of the building which is simulated by the conventional approach shows no significant difference (in terms of well-mixed air temperature and resultant flow rates through the associated offices) with the adoption of coupling approach. Additionally, a third-party program (Tecplot or Matlab) is required for visualizing the calculated results from the coupling approaches within ESP-r. Because of the coarse-gridding manner of the CFD model within ESP-r, the resolution level of the simulation results is not sufficient for the problem investigated. Furthermore, only one CFD domain is allowed per BES-CFD run, which may not fulfil the need for the whole building CFD simulation. The number of simulations required 
would depend on the quantity of CFD domains interested, which is regarded as a time-consuming act during the initial design stage.

In view of the computing costs and level of result improvement for overall ventilation performance of the proposed building configuration, the BES-CFD and AFN-CFD coupling types are therefore not suggested in the early design phase of a building project and are consequently not considered in the proposed generic design procedure of this study. Alternatively, the CFD-alone approach within ESP-r is chosen for looking at coarse-grid temperature and air flow distribution of the chosen CFD domain for the initial whole building CFD investigations of this study. The coupling between CFD and the multi-zone model in the CFD-alone approach of ESP-r is not dynamically; while it is to conduct a whole building simulation first using a conventional multi-zone model (BES). And then the results of specific time-step are manually provided as boundary conditions for a selected CFD domain in ESP-r, where the well-mixing assumption is not realistic. The boundary conditions of the CFD-alone approach should be defined in advance. Hence the time-step reports on internal surface and opening node temperatures from previous run (but the same time step) are used for solid and opening boundary conditions of the corresponding CFD domain. The CFD results (with $0.5 \mathrm{~m}$ resolution) from the single domain CFD simulation in ESP-r are presented in Section 6.3.2. For which provide an initial insight for the local air and temperature distribution of an occupied space.

Furthermore, a more sophisticated CFD program, FLUENT, is adopted to examine and verify the CFD modelling results from ESP-r. The aim is to obtain the whole building ventilation performance (only one CFD domain is allowed in ESP-r) from a more advanced CFD tool, which also has more options for the solution algorithm, turbulence models and convergence of solution as compared to the CFD-alone approach in ESP-r. The boundary conditions required for the FLUENT CFD are also derived from the BES results of ESP-r at the same timestep. More details descriptions on the model and the corresponding simulation results are presented as Section 6.3.3. 


\subsubsection{The initial whole building CFD investigations: The single domain CFD within ESP-r}

\section{(a) Problem definition}

The building geometry and gridding system of this section is presented as Figure 6-10. The coarse-grid number used is $\mathrm{X}(24), \mathrm{Y}(24)$ and $\mathrm{Z}(6)$ with grid size of 0.5 (m) respectively. The solution variables used for the modelling cases are listed as Table 6-6. One of the focuses in this study is to examine the potential cooling effects due to ventilation air under the naturally available driving forces. The local thermal comfort conditions could then be understood through the temperature distribution within the space. The problems investigated by the use of single domain CFD approach within ESP-r of this section are defined as follows.

One typical day in March is chosen for demonstrating the ventilation performance of that particular CFD domain. The date is selected because it represent the typical week of mid-seasons in Taipei. Three typical weeks of a year are chosen from the weather data of Taipei. The typical weeks are found by scanning the climate date for a week in each season which has the least variation in heating degree days, cooling degree days and solar radiation. The heating and cooling base temperature are assumed to be $10{ }^{\circ} \mathrm{C}$ and $28{ }^{\circ} \mathrm{C}$ respectively. The weighting for heating degree days, cooling degree days and solar radiation could be assigned. The defaults are equal weightings for each. The typical week for the spring of Taipei is between $22^{\text {nd }}$ March and $28^{\text {th }}$ March. $19^{\text {th }}$ to $25^{\text {th }}$ of June and $29^{\text {th }}$ September to $5^{\text {th }}$ October are for the summer and autumn season respectively. Following that, varied mass flow rates are adopted for investigating the range of influence of ventilation flow rates on the thermal domain. The simulation cases

for this problem type include volume flow rates of $1.7,4.2$, and $6.7 \mathrm{~m}^{3} / \mathrm{s}$ (equals to $2,5,8 \mathrm{~kg} / \mathrm{s}$ in the definition of ESP-r modelling) with identical thermal boundary conditions on $22^{\text {nd }}$ March. 

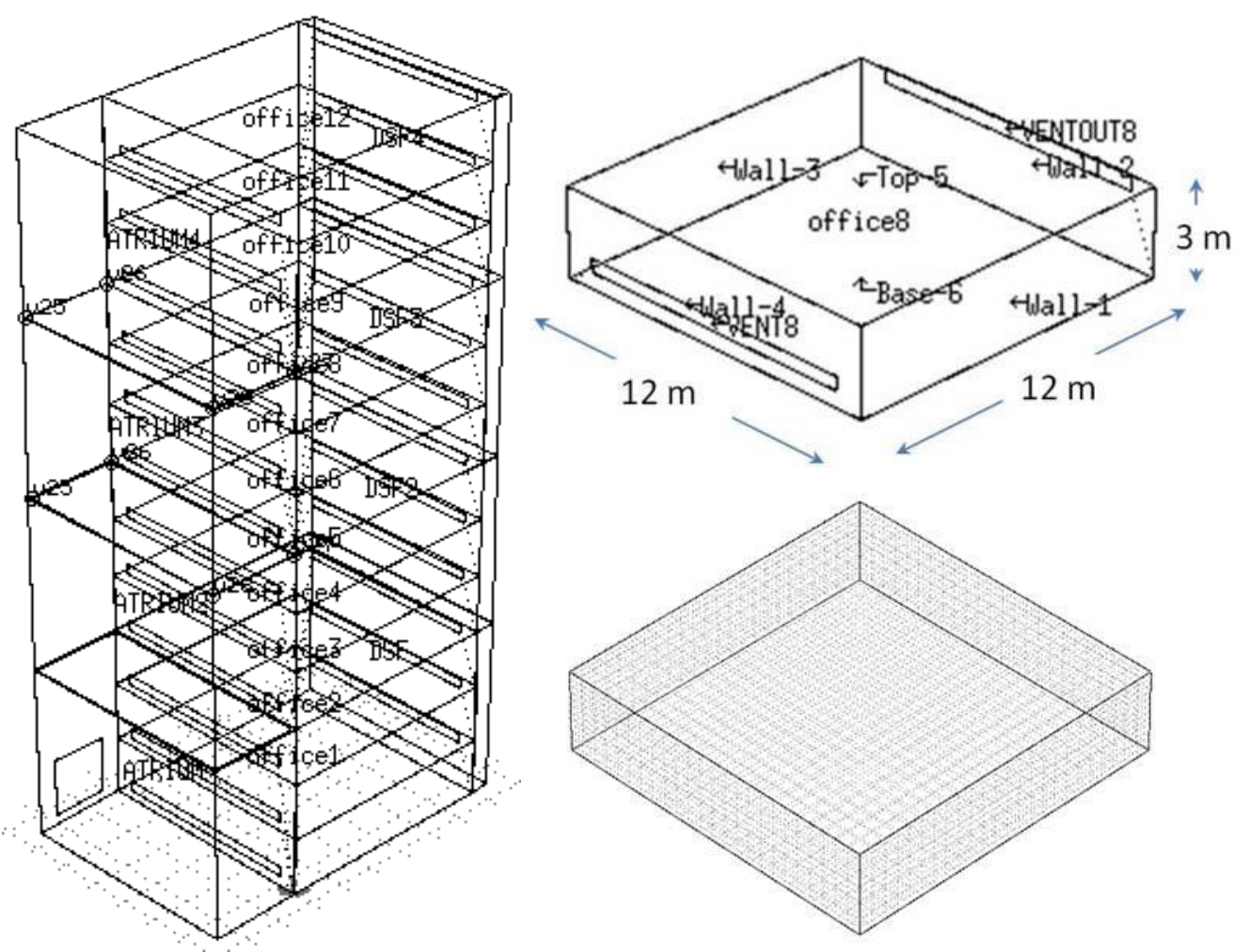

Figure 6-10: Building geometry and gridding system of the single CFD domain adopted in ESP-r

Table 6-6: Solution variables of BES-CFD coupled approach

\begin{tabular}{|l|l|}
\hline Solution variables & Descriptions \\
\hline Velocity & $\begin{array}{l}\text { X: Initial V 0.001; relaxation factor 0.2 } \\
\text { Y: Initial V 0.001; relaxation factor 0.2 } \\
\text { Z: Initial V 0.001; relaxation factor 0.2 }\end{array}$ \\
\hline Temperature & Initial T 20.00; relaxation factor 0.9 \\
\hline Turbulence model & $\begin{array}{l}\text { k-e turbulence } \\
\text { Initial k 0.005; relaxation factor } 0.7 \\
\text { Initial e 0.005; relaxation factor } 0.7\end{array}$ \\
\hline Buoyancy & $\begin{array}{l}\text { Boussinesq approx } \\
\text { Ref. temperature } 25^{\circ} \mathrm{C}\end{array}$ \\
\hline Mean age of air & Not solved \\
\hline Convergence criteria & $\begin{array}{l}\text { Maximum iteration: } 500 \\
\text { Max sum of residual: } 0.02\end{array}$ \\
\hline Monitoring cell $(\mathrm{i}, \mathrm{j}, \mathrm{k})$ & $(3,3,3)$ \\
\hline
\end{tabular}




\section{(b) Results and discussions}

The results presented below are the CFD-alone approach of ESP-r. The reasoning for this modelling approach is presented in Section 6.3.1. For the first simulation case, the temperature and air flow distributions of office in the $8^{\text {th }}$ level at the time-step of 14:00 on 22th March are illustrated (Fig. 6-11 and 6-12). The date is chosen for it represents the averaged performance of a typical day of spring. The volume flow rates of $5.3\left(\mathrm{~m}^{3} / \mathrm{s}\right)$ from the thermally coupled mass flow network approach of previous run at the same time step is adopted for the opening boundary condition in CFD domain. The visualized results by the use of third party program Tecplot (the trial version) present the temperature distribution referring to the CFD domain height. The distributions of air flow speed and flow pattern are illustrated as well. Following that, the test cases with varied volume flow rates, 1.7, 4.2, and $6.7 \mathrm{~m}^{3} / \mathrm{s}$ (or $2,5,8 \mathrm{~kg} / \mathrm{s}$ ), under the identical thermal boundary conditions are examined. The results demonstrate the potential cooling effect due to increase of mass flow rates (Fig. 6-13 and Fig. 6-14). These visualized results provide some insight for the ventilation performance of the typical office zone under specific boundary condition.

Thought the coarse-grid simulation results (Fig. 6-11 14) can provide some insight for local air and temperature distribution, only one zone can be visualized at a time with the help of a third party program. The result resolution is not sufficient for local ventilation performance assessment because of the available numerical models and coarse-grid method adopted in CFD-alone approach of ESP-r. From the coupling point of view, Zhai and Chen (2006) suggested a reference table on average solution improvement possibilities and computing costs of coupling simulation. They concluded that although those data might vary with cases studied and methodologies used, it provided users a sense of potential pros and cons of coupled simulation. The dynamically coupled simulation within ESP-r may be adopted (BES-CFD or CFD-AFN), specifically when the convective cooling effect of specific space is of interest. For this particular study, however, the effect of segmentation on the resultant flow rates is of interest. This 
can be achieved by comparison between different building configurations using the thermal simulation with an air flow network model. The information obtained from the hourly basis year-round data is sufficient for the early design phase.

Nevertheless, the CFD simulation is still of importance in this study in terms of local air flow and temperature distribution under specific boundary conditions. For which is also required for ensuring the selection of comfort boundary in the Building Bioclimatic Charts (Section 6.4). As concluded in Section 6.3.1, a CFDalone approach within ESP-r is sufficient for the initial understanding on the local ventilation performance of an interested space as compared to other dynamically coupled approach (BES-CFD or AFN-CFD). Following that, the next step of this study is moving to the investigation of overall ventilation performance of the whole building while incorporating the surface boundary conditions from ESP-r at the same time-step. It is then desirable to use more sophisticated tool (FLUENT) for the whole building CFD simulation. The need for this type of integration is clarified in Section 6.3.3.
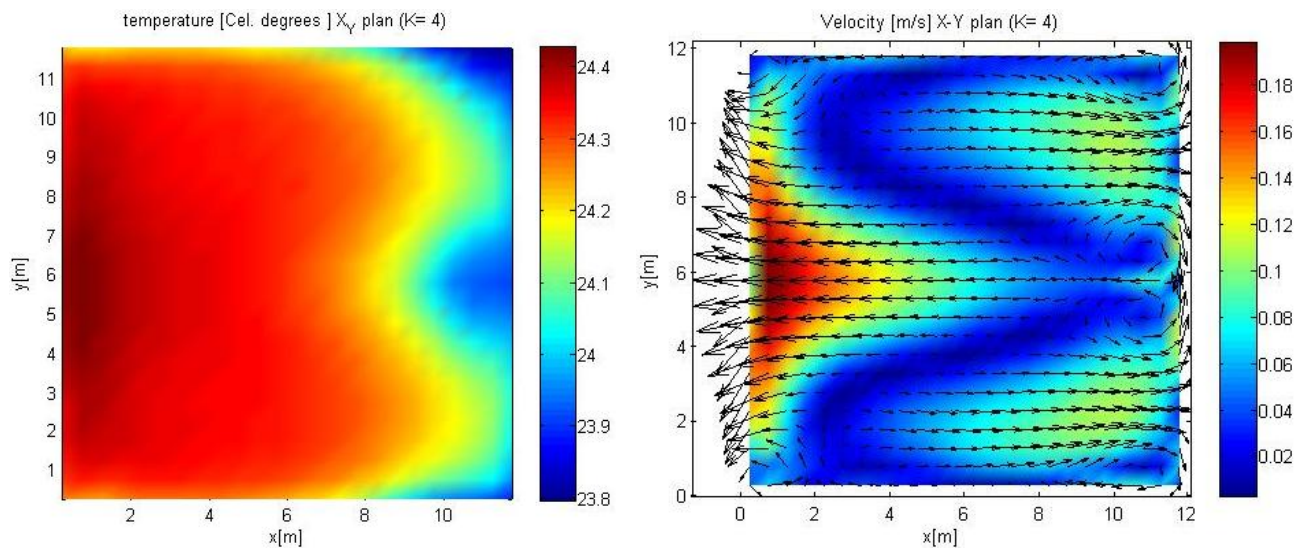

Figure 6-11: The temperature and flow speed distributions of office room at 14:00 pm of 22th March_Z=2 (m)
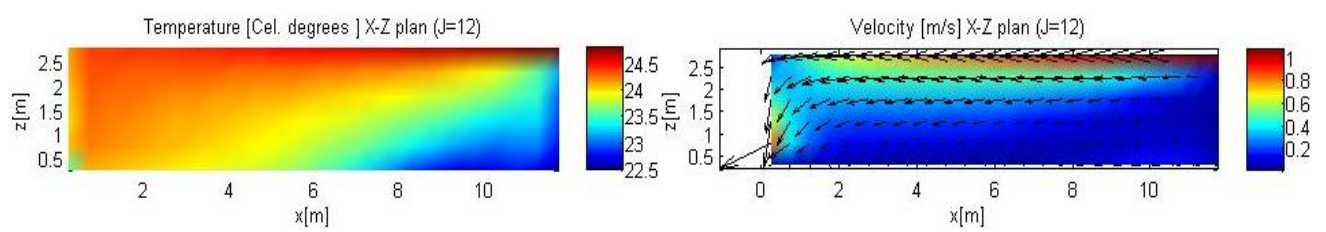

Figure 6-12: The temperature and flow speed distributions of office room at 14:00 pm of 22th March_Y $=6(\mathrm{~m})$ 


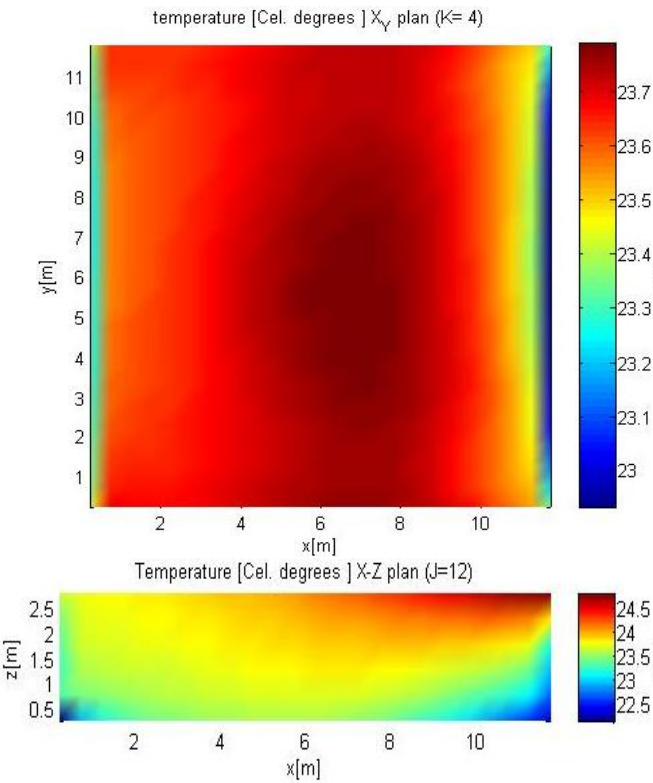

a) $2(\mathrm{~kg} / \mathrm{s})$

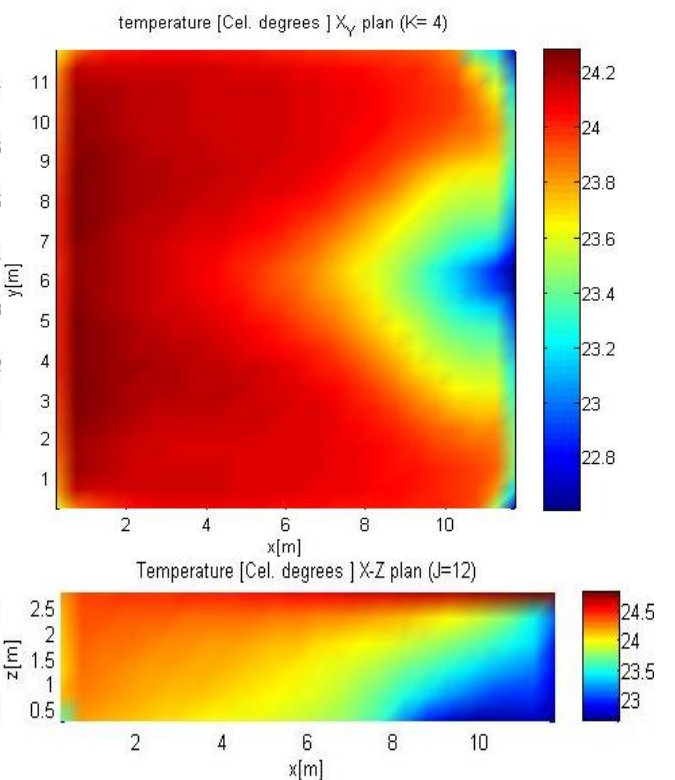

b) $8(\mathrm{~kg} / \mathrm{s})$

Figure 6-13: The temperature distribution at $2 \mathrm{pm}$ of 22th March under mass flow rates of 1.7, 4.2, and $6.7\left(\mathrm{~m}^{3} / \mathrm{s}\right)$
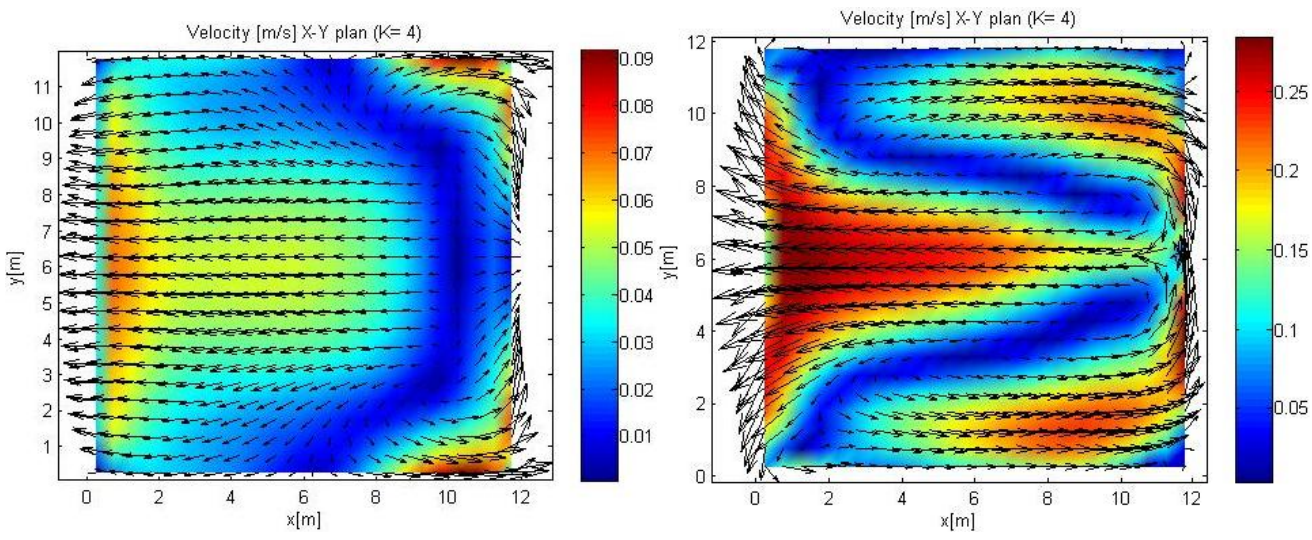

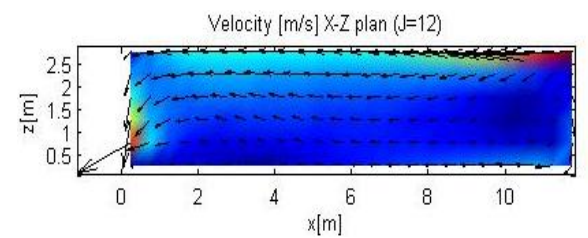

a) $2(\mathrm{~kg} / \mathrm{s})$

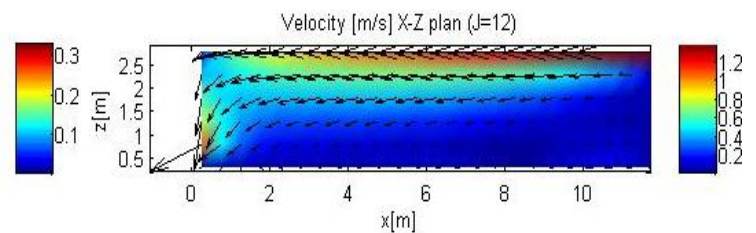

b) $8(\mathrm{~kg} / \mathrm{s})$

Figure 6-14: The air flow speed distribution at $2 \mathrm{pm}$ of $22^{\text {nd }}$ March under mass flow rates of 1.7, 4.2 , and $6.7\left(\mathrm{~m}^{3} / \mathrm{s}\right)$ 


\subsubsection{The main CFD investigations: The stand-alone FLUENT-CFD}

The FLUENT-CFD is adopted because of the capability of whole building simulation with more advanced numerical models as well as the arrangement for finer grid sizes. This section illustrates the potential scenario of air flow and temperature distribution of extreme cases under specific boundary conditions by the use of stand-alone CFD program with more sophisticated numerical models as compared to the single domain CFD within ESP-r. The required boundary conditions are derived from the ESP-r modelling at the same time-step. The highlights of coupling between the building energy simulation and CFD for natural ventilation are discussed in Section 3.3.3. The local ventilation performance of the proposed tall office building configuration in the main investigations of this study (Fig. 2-40 and Fig. 2-41) can then be known. The integration method chosen for this section is the one-way (one-step) static integration between ESP-r (dynamic thermal simulation with an air flow network) and FLUENT. Only particular time-steps are chosen for clarifying the potential air flow distribution under the proposed building configuration. Consequently, the unsteady effect over a longer period of time is not considered in the full CFD simulation of this study. Detailed descriptions on how the ESP-r outputs are used as boundary conditions of CFD modelling are as follows.

Firstly, the whole building simulation by the use of the dynamic thermal simulation with an air flow network is carried out in ESP-r. Secondly, the boundary conditions required for the full CFD modelling are then derived from the hourly basis simulation results of ESP-r. The available parameters from ESP-r results during specific time step and the required boundary conditions for the CFD modelling are listed as Table 6-7. The external and internal surface boundary conditions are defined accordingly for detailed indoor CFD simulation. One thing to be noted is that only the wind and buoyancy combined condition of ESP-r modelling is considered for following CFD investigations. 


\subsection{2-1 Boundary conditions}

For the inlet boundary conditions, two types of boundary conditions within FLUENT, namely pressure and mass flow inlet, are studied. The pressure inlet is often used in the buoyancy-driven flows or a free boundary in an external or unconfined flow; while a mass flow inlet is adopted when it is more important to match a prescribed mass flow rate than to match the total pressure of the inflow stream. The information needed for the pressure inlet includes the total (stagnation) pressure, total temperature, flow direction, static pressure and turbulence parameters. The information for mass flow inlet condition of this section is derived from the ESP-r results where the total volume flow rates through inlet at specific time step are used.

The outflow boundary conditions are used in this section for modelling flow exits where details of the flow velocity and pressure are not known prior to solution of the flow problem. Nevertheless, it is always suggested to use the pressure outlet boundary conditions when a problem includes pressure inlet boundaries. The outlet temperature is unknown in the modelling case of this section. It might not be appropriate to fix the air flow temperature to a specific value under the pressure outlet condition. The convergence could not be achieved under the pressure boundary conditions for this problem type as well.

For the wall boundary conditions, the external walls of the proposed building configuration are provided with fixed heat flux in watt per meter square. The internal walls, which assume to be adiabatic, could be assigned with fixed temperature values to represent zero heat flux through the walls. Boundary conditions for two-sided walls, where the wall zone has a fluid region (in this problem type) on each side, are available in FLUENT. When a grid with this type of wall zone is read into FLUENT, a 'shadow' zone will automatically be created so that each side of the wall is a distinct wall zone. Different thermal conditions can be specified on each zone, or to couple the two zones. For the internal openings, the 'interior' boundary type is defined and requires no further 
information from the user. All the wall boundary conditions required for CFD simulation are derived from ESP-r results at specific time-step.

Table 6-7: Boundary conditions for the full CFD simulation

\begin{tabular}{lcc}
\hline \multicolumn{1}{c}{$\begin{array}{c}\text { Boundary } \\
\text { conditions }\end{array}$} & ESP-r & FLUENT \\
\hline Inlet & $\begin{array}{c}\text { Mass flow rate }(\mathrm{kg} / \mathrm{s}) \\
\text { Pressure at node }\end{array}$ & $\begin{array}{c}\text { Mass flow rate + total temperature } \\
\text { Gauge total pressure + total temperature }\end{array}$ \\
\hline Outlet & --- & Outflow \\
\hline Internal walls & Pressure at node & Gauge total pressure + total temperature \\
\hline External walls & Surface heat flux & Heat flux $\left(\mathrm{W} / \mathrm{m}^{2}\right)+$ wall thickness \\
\hline Internal glazing & Surface heat flux & Heat flux $\left(\mathrm{W} / \mathrm{m}^{2}\right)+$ wall thickness \\
\hline External glazing & Surface heat flux & Wall thickness + couples condition \\
\hline Floor plate & Surface heat flux & Wall thickness + couples condition \\
\hline Internal openings & Internal unknown pressure node & Heat flux $\left(\mathrm{W} / \mathrm{m}^{2}\right)+$ wall thickness \\
\hline
\end{tabular}

\subsection{2-2 Model descriptions}

In this section, the overall air flow pattern against floor height and temperature distributions of the occupied spaces are of interest. The indoor air flow distribution under the specific boundary conditions is investigated. The indoor temperature and air flow velocity magnitude are then used in Section 6.4 for the selection of thermal comfort boundary in the Building Bioclimatic charts (BBCCs). Full CFD simulations are carried out to determine the flow in an enclosure with the geometry shown in Figure 6-15. The inlet and outlet with opening sizes of $12 \mathrm{~m}^{2}$ are adopted throughout the simulations. The equally distributed heat source in the floor plate is assumed to represent the internal gains. In all cases, the strength of the heat source is set to $30 \mathrm{~W} / \mathrm{m}^{2}$. The $\mathrm{k}-\varepsilon$ RNG model is used in the CFD simulation because this model has advantages of steady and easily convergent. Mesh independence is checked by running FLUENT with finer mesh for each case. In view of the influence of grid number in numerical results, grid independency tests must be made to ensure the accuracy of simulations. The grid number is increased till the grid size will not affect the numerical results. In this study, the root-mean-square error in temperature, as shown in Equation 6-12, of less than $2 \%$ is used as the criterion for grid independence. Where $\mathrm{T}_{\mathrm{n}-1}$ is the 
temperature in the formal grid number, $T_{n}$ is the temperature in the current grid number, $\mathrm{T}_{0}$ is the ambient temperature and $\mathrm{N}$ is the number of the examined sample points. The final gridding system is then set to $0.25(\mathrm{~m})$ for each dimension of all spaces, while the internal openings (vents) and the outlet have finer grid $(0.125 \mathrm{~m})$ in the short-side. The total cell number for the 12 storey case with this resolution is 726419 . The grid dependency tests for the 12 storey case are summarized as Table 6-8. The visualized mesh is presented as Figure 6-15. The default convergence criterion for all residuals is set to a value of $1 \times \mathrm{e}^{-3}$, except the energy residual, where the default criterion is $1 \times \mathrm{e}^{-6}$.

$$
\sqrt{\frac{\sum_{i=1}^{N}\left(\frac{T_{n-1}-T_{n}}{T_{0}}\right)^{2}}{N}}
$$

Table 6-8: Mesh sizes for the grid dependency tests of the 12 storey case

\begin{tabular}{l|c|c|c}
\hline $\begin{array}{l}\text { Mesh } \\
\text { name }\end{array}$ & $\begin{array}{l}\text { Mesh length scale of building width, } \\
\text { depth, \& height (m) }\end{array}$ & $\begin{array}{l}\text { Total number of } \\
\text { cells }\end{array}$ & $\begin{array}{l}\text { The Root Mean Square } \\
\text { Deviation }\end{array}$ \\
\hline Mesh1 & 1 & 217056 & $11.6 \%$ \\
Mesh2 & 0.5 & 668508 & $7.9 \%$ \\
Mesh3 & 0.25 & 926419 & $2.1 \%$ \\
Mesh 4 & 0.2 & 933606 & $1.3 \%$ \\
\hline Note: \\
The mesh length scale on the internal vents and the outlet have finer grid of $0.125(\mathrm{~m})$ in the short- \\
side for all case
\end{tabular}

Four sets of simulation are undertaken for the base case and the lifted building configurations respectively (Fig. 2-41). The steady flow pattern is determined in each simulation case. The velocity inlet boundary is based on the calculated hourly velocity through the inlet from ESP-r modelling. The extreme cases are selected and defined where the maximum velocity magnitude through the inlet is over $6(\mathrm{~m} / \mathrm{s})$. This value is from previous studies on pedestrian wind comfort (Blocken and Carmeliet, 2004). The statistical distributions (Figure 6-16) on numbers of hours with reference to velocity magnitude through inlet suggested that there are $7 \%$ occurrence for the velocity magnitude over $6(\mathrm{~m} / \mathrm{s})$ between 
March and August. The highest occurrence of inlet velocity during the examined period is between 1 and $2(\mathrm{~m} / \mathrm{s})$. Consequently, the $2 \mathrm{~m} / \mathrm{s}$ case is selected as another scenario to be investigated. The cases investigated in this section are listed as Table 6-9.

Table 6-9: Scenarios of the full CFD simulation

\begin{tabular}{c|c|c}
\hline \multicolumn{3}{c}{ Base case building configuration } \\
\hline & Condition 1 (6 storey segmentation) & Condition 1 (12 storey segmentation) \\
\hline SET 1 & $2 \mathrm{~m} / \mathrm{s}$ & $2 \mathrm{~m} / \mathrm{s}$ \\
SET 2 & $6 \mathrm{~m} / \mathrm{s}$ & $6 \mathrm{~m} / \mathrm{s}$ \\
\hline \multicolumn{3}{|c}{ Lifted building configuration } \\
\hline & Condition 1 (6 storey segmentation) & --- \\
\hline SET 3 & $2 \mathrm{~m} / \mathrm{s}$ & --- \\
\hline SET 4 & $6 \mathrm{~m} / \mathrm{s}$ & --- \\
\hline
\end{tabular}

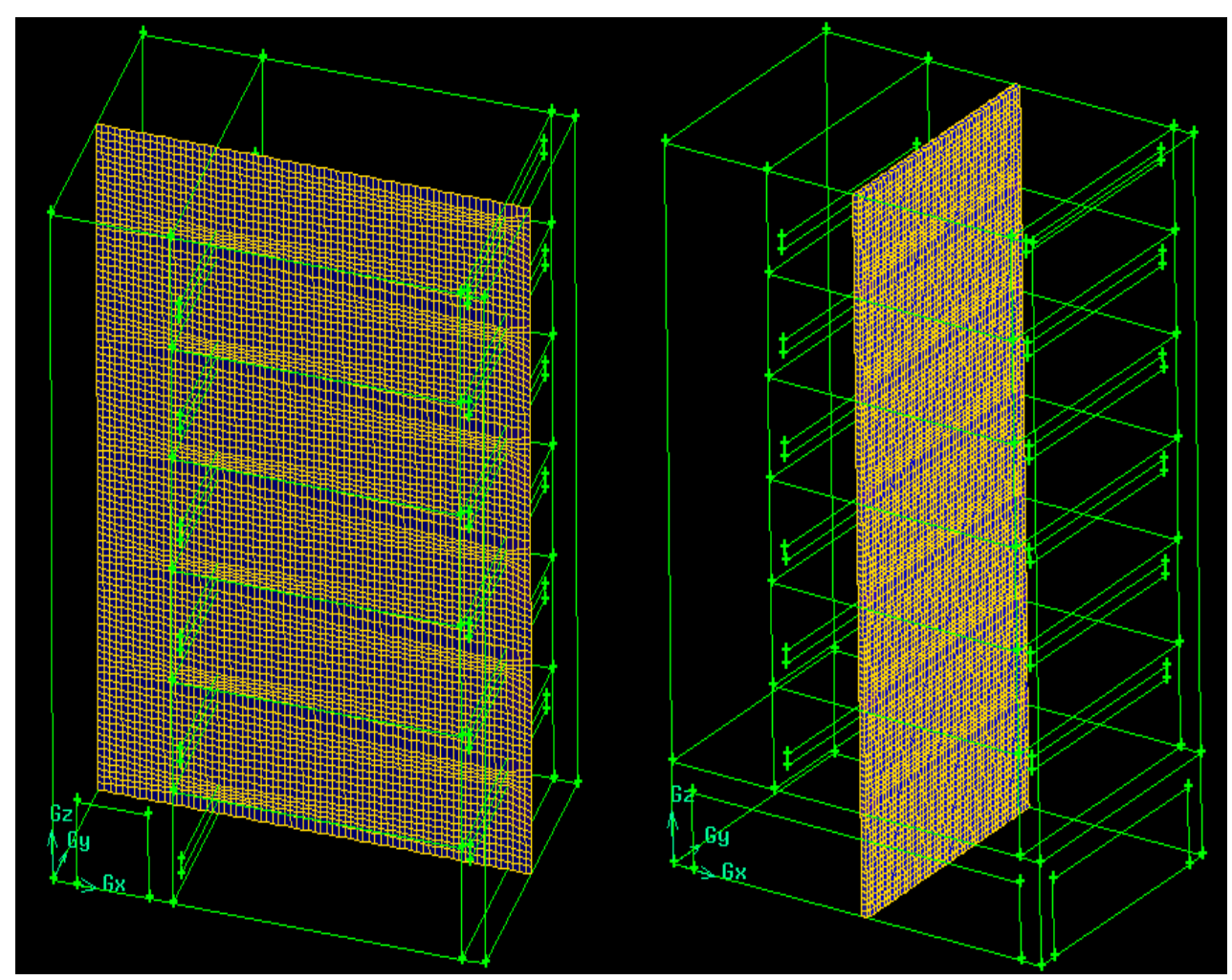

(a)

(b)

Figure 6-15: The building geometry and gridding system. (a) Base case, (b) Lifted case 


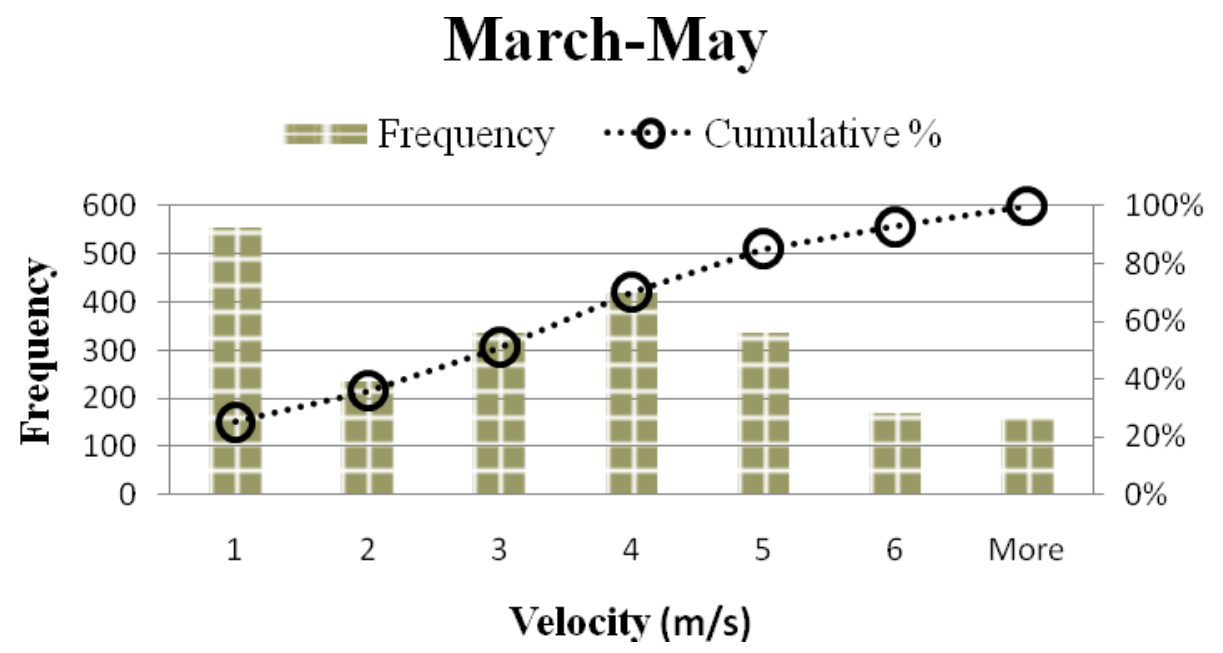

(a)

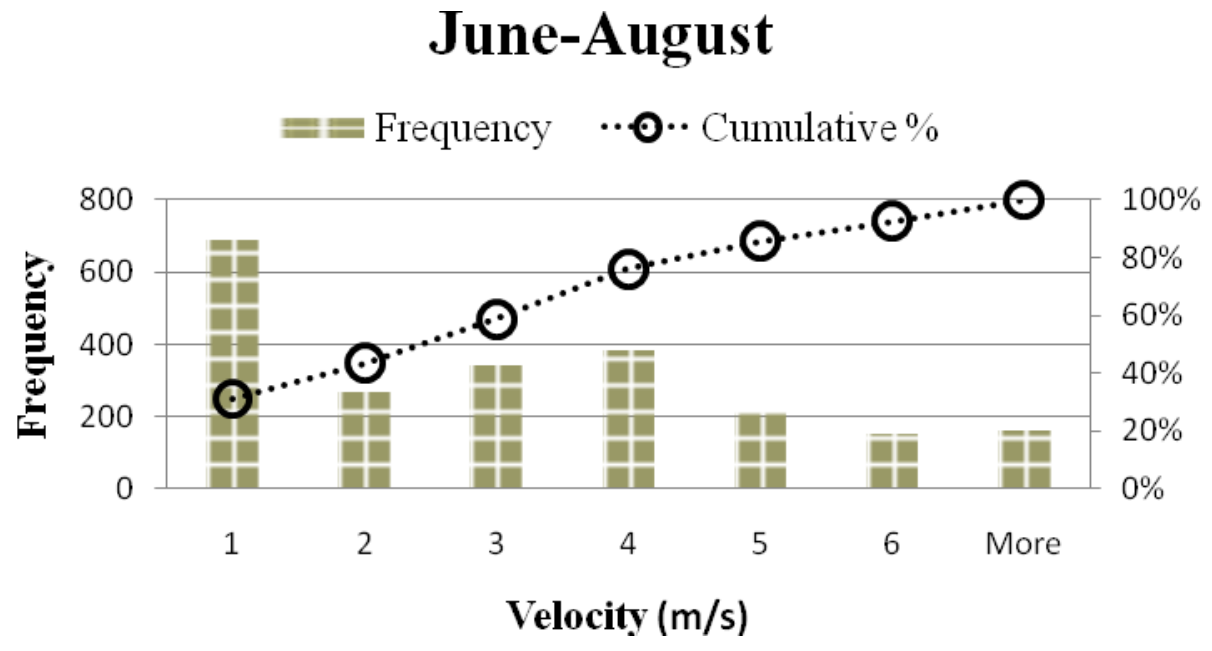

(b)

Figure 6-16: The statistical distributions (Frequency and Cumulative) of inlet velocity magnitude. (a) March-May, (b) June-August 


\subsection{2-3 Results and discussions}

\section{(A) The local ventilation performance of the base case building configuration}

In this sub-section, the highest occurrence of ambient velocity magnitude as well as the extreme case with strong wind environment is examined by the use of whole building simulation in CFD. For the case with the highest occurrence of ambient velocity magnitude, the aim is to evaluate the local comfort environment of the corresponding occupied spaces with reference to the local velocity and temperature distribution. The simulated local wind speed distribution is adopted to select the comfort range of the BBCCs in Section 6.4 as well. The midinterface along the width direction of the building geometry is determined by plotting the steady contour of velocity magnitude. The indoor air velocity distributions with two different velocity inlet boundary conditions as proposed in Table 6-8 are illustrated accordingly. It is supposed that similar ventilation patterns should be observed in the same building configuration, where the driving force is varied by predefined air velocity.

For example, uniform velocity of 2 and $6(\mathrm{~m} / \mathrm{s})$ is supplied for the inlet of the 12 storey segmentation case respectively. Consequently, fixed mass flow rates through the inlet are defined because uniform air velocity is assumed for the inlet boundary. The resultant air flow velocity throughout the office spaces would be reduced by a considerable amount because smaller total amount of flow rates are contributed to those spaces (Fig. 6-17). The convective cooling effect is constrained accordingly due to less cool air is supplied to remove the internal heat gains. The visualized contours of total temperature are presented as Figure 6-18. The general air flow pattern against building height calculated by full CFD simulation is shown as Figure 6-19. The desired flow pattern is observed because the fixed direction is defined for the velocity inlet. For this set of simulation, the fresh air enters from the lower inlet of the atrium and feeds into each office space through individual vents connected with offices. The stale air of each office space 
is then discharged into the high-end vents connected to the DSF cavity. Finally, the accumulated warm and stale air exhausts through the outlet on top of the DSF cavity.

Additionally, it can be seen that the local air velocity near the inner corner of intake vent of the bottom floor office is about $1.5(\mathrm{~m} / \mathrm{s})$ when the inlet velocity of $2(\mathrm{~m} / \mathrm{s})$ is applied through the $12\left(\mathrm{~m}^{2}\right)$ inlet. This may not satisfy the comfort wind environment for stationary work. However, the air speed in other locations of the bottom floor office is within the acceptable range $(0.3 \sim 0.7 \mathrm{~m} / \mathrm{s})$. The same scenario is found in the top office level of the 12 storey segmentation case. Detailed velocity vectors coloured by velocity magnitude can be seen in a chosen plan at the height of intake vent level (Fig. 6-20).

It is also observed that the extreme case with the inlet velocity of $6(\mathrm{~m} / \mathrm{s})$ further worst the comfort working environment of the base case building configuration in terms of air draught. In Chapter 5, it is suggest that the lifted cases with appropriate inlet opening size could achieve the desired flow pattern $\left(>0 \mathrm{~m}^{3} / \mathrm{s}\right)$ on the bottom two-third of the segment irrespective of the weather condition under the buoyancy alone condition. The desired flow pattern for this particular is important because of the unwanted warmer air may be driven into the occupied spaces. The overall flow rates would be much improved and the desired flow pattern could also be achieved with the help of wind. Thereby, it is supposed that the multi-orientation inlets can help to secure the flow rates supplied into the occupied spaces despite of the weather conditions. The comfort wind environment in terms of air draught can also be ensured when larger total inlet areas are applied under the specific weather conditions. The lifted case is then evaluated under the same boundary conditions as those being applied in the base case model. The reason for the selection of inlet velocity is described in Section 6.3.2-2. In the next section, the base and lifted cases with 6 storey segmentation are investigated and compared under the scenario where the sufficient volume flow rates are secured for removing the internal heat gains as suggested in Equation 3.2-1. 


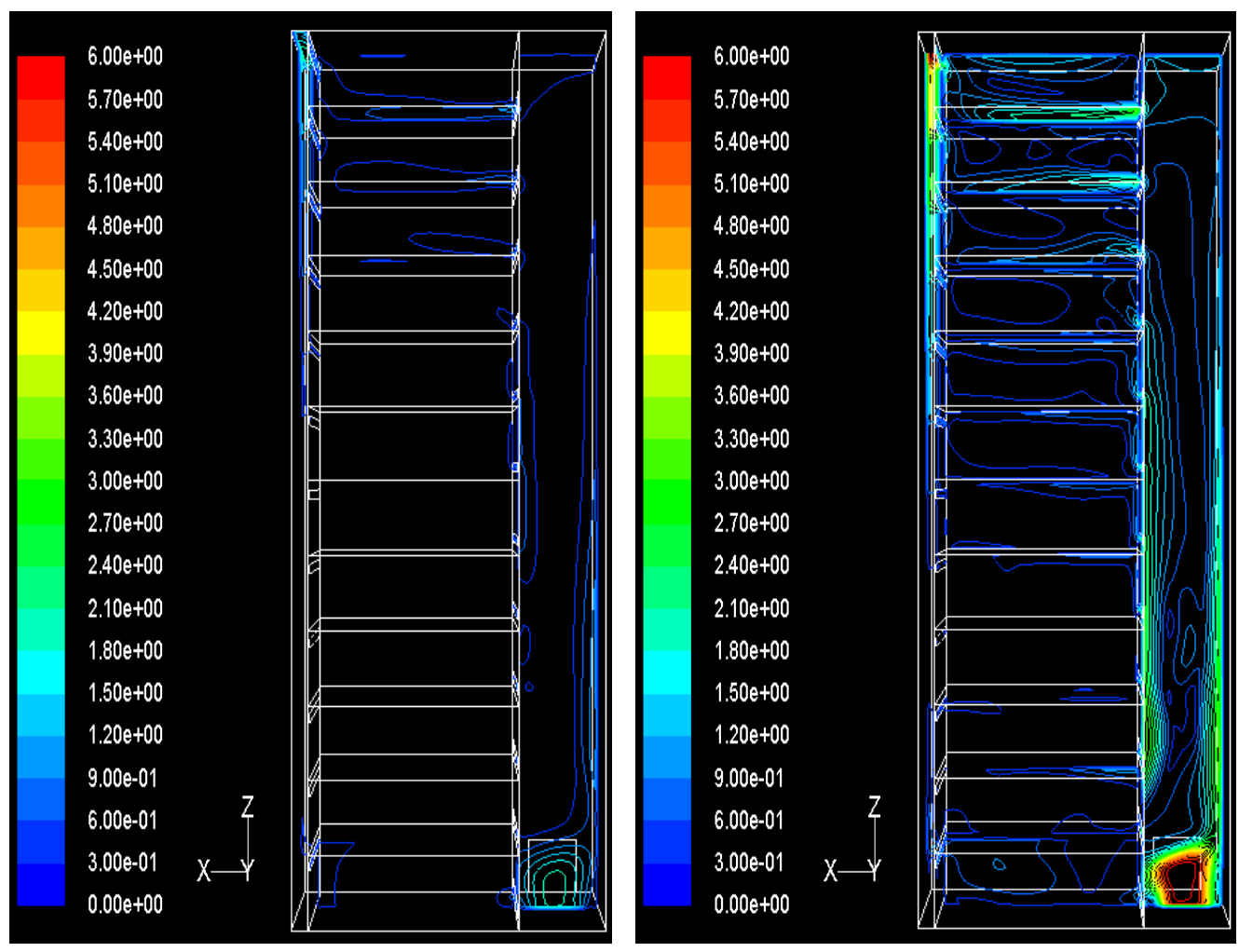

Figure 6-17: Contours of velocity magnitude (Y=6 m). (a) $2 \mathrm{~m} / \mathrm{s}$, (b) ) $6 \mathrm{~m} / \mathrm{s}$

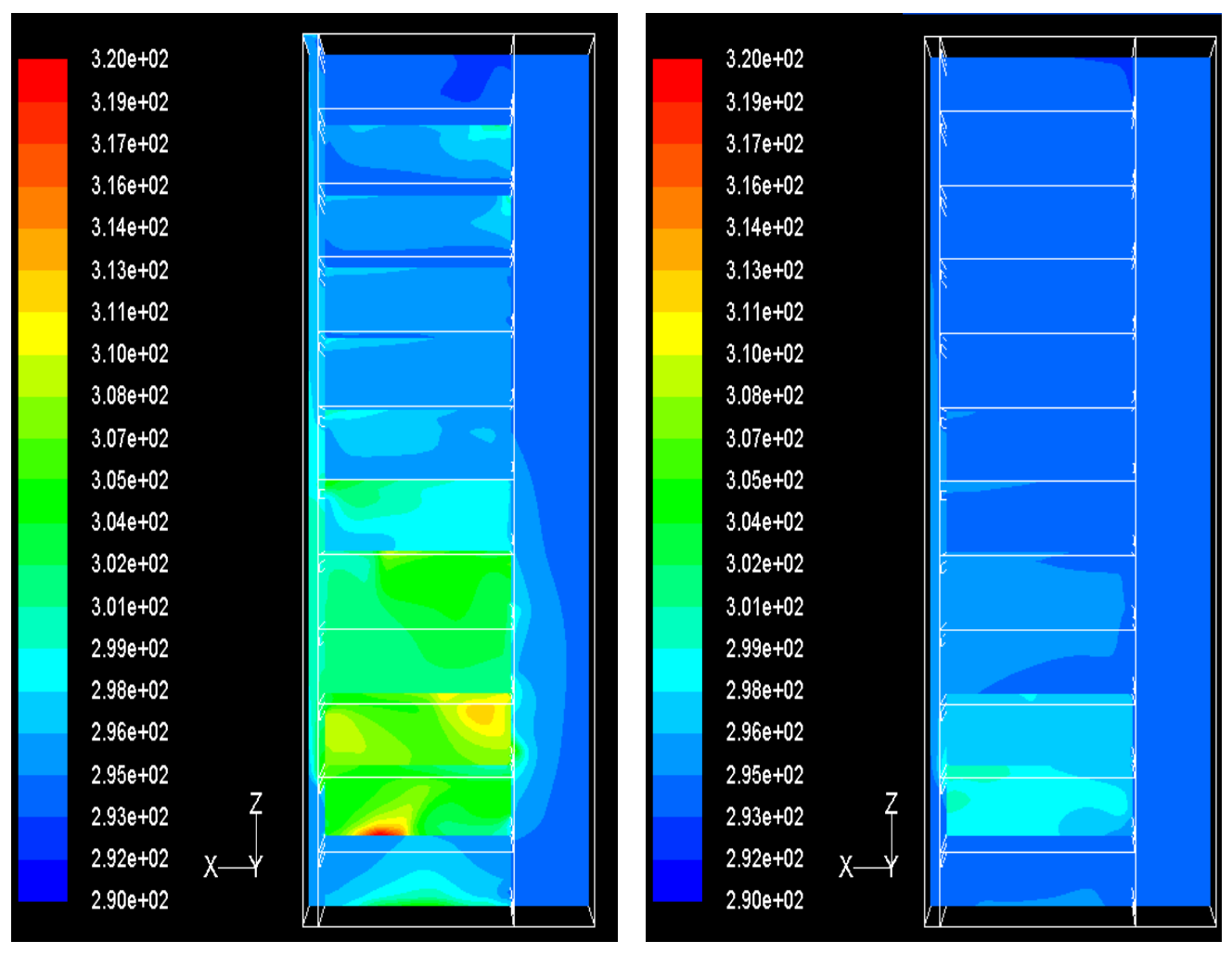

Figure 6-18: Contour of total temperature against building height_ 12 storey. a) $2 \mathrm{~m} / \mathrm{s} ;$ b) $6 \mathrm{~m} / \mathrm{s}$ 


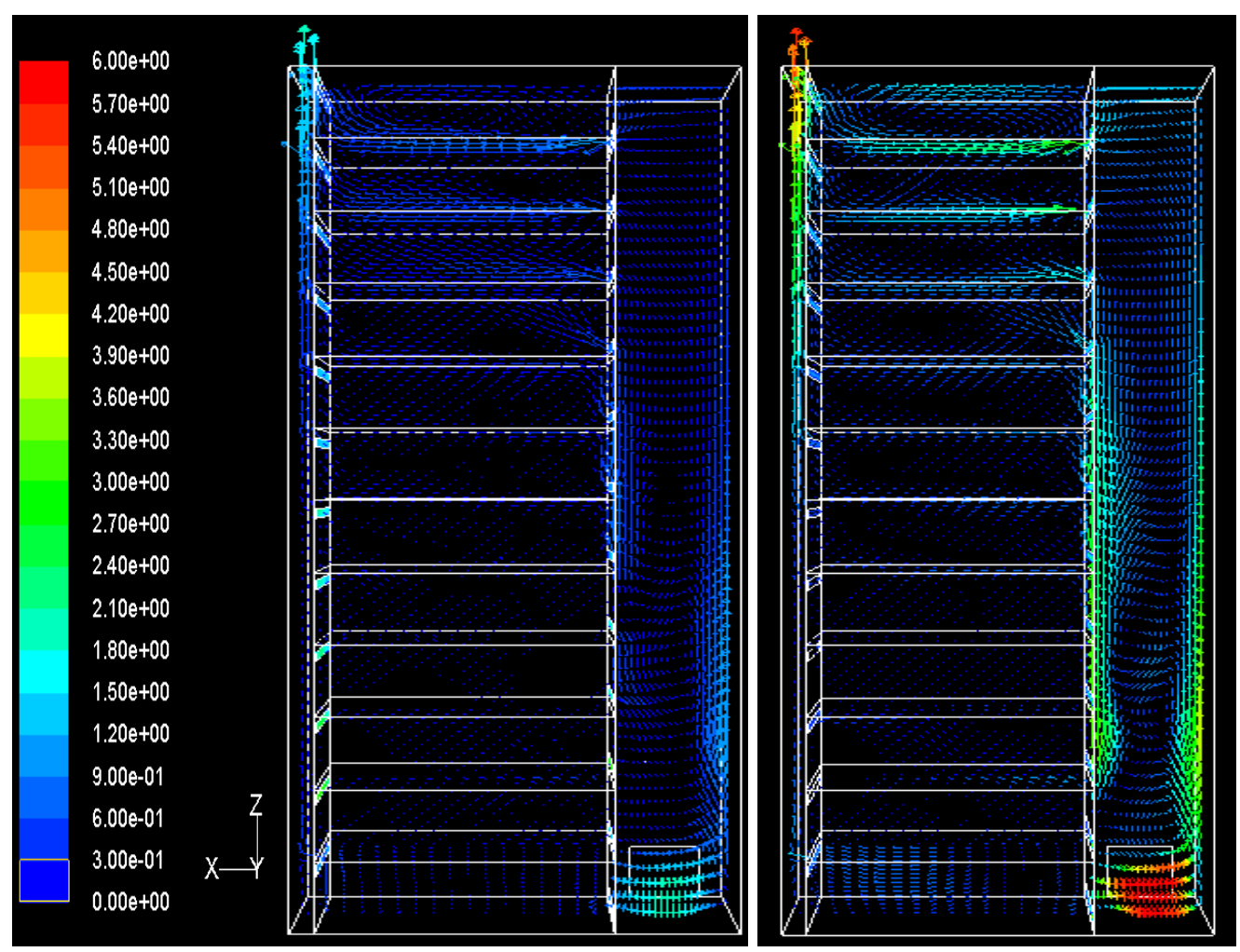

Figure 6-19: Velocity vectors coloured by velocity magnitude_Y=6 m. (a) $2 \mathrm{~m} / \mathrm{s}$, (b) $6 \mathrm{~m} / \mathrm{s}$

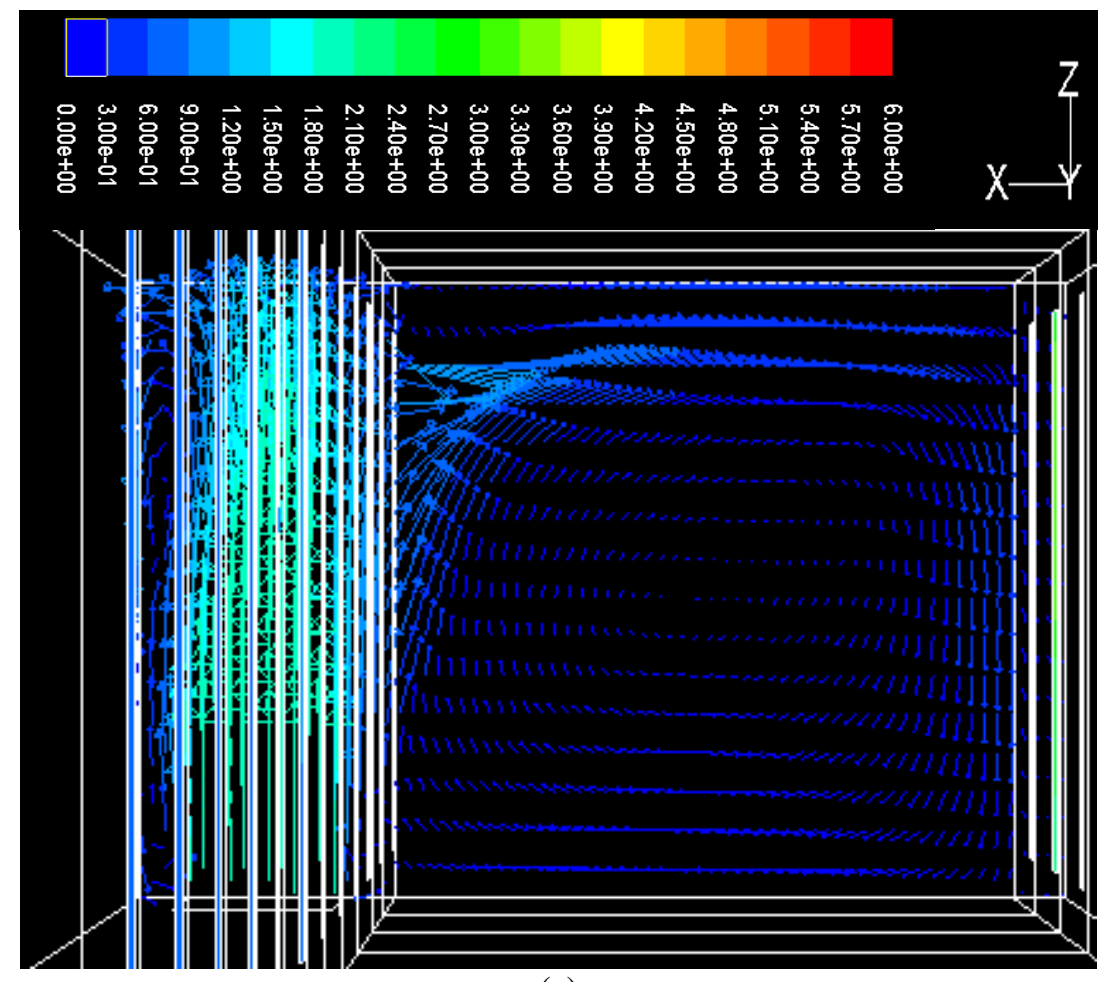

(a) 


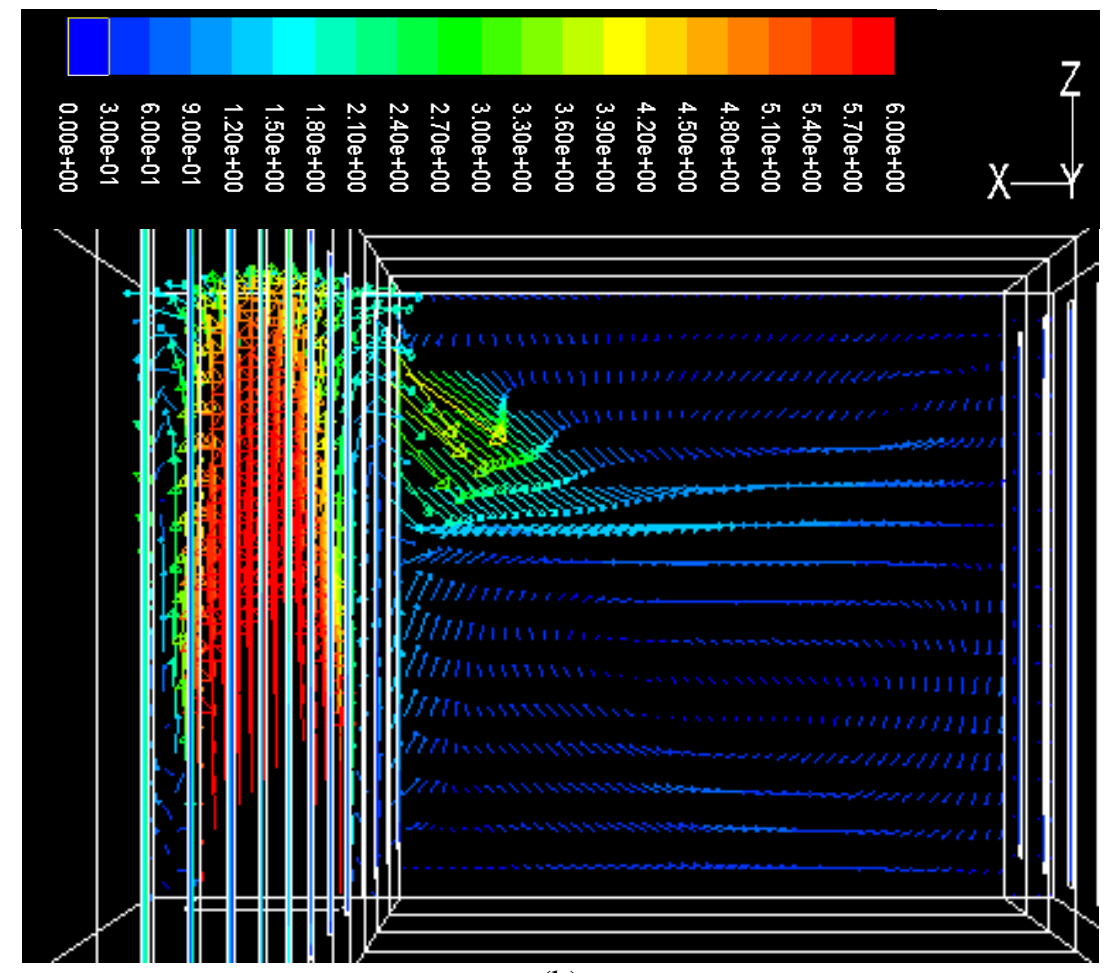

(b)

Figure 6-20: Velocity vectors coloured by velocity magnitude_Z=0.75 m. (a) $2 \mathrm{~m} / \mathrm{s}$, (b) $6 \mathrm{~m} / \mathrm{s}$

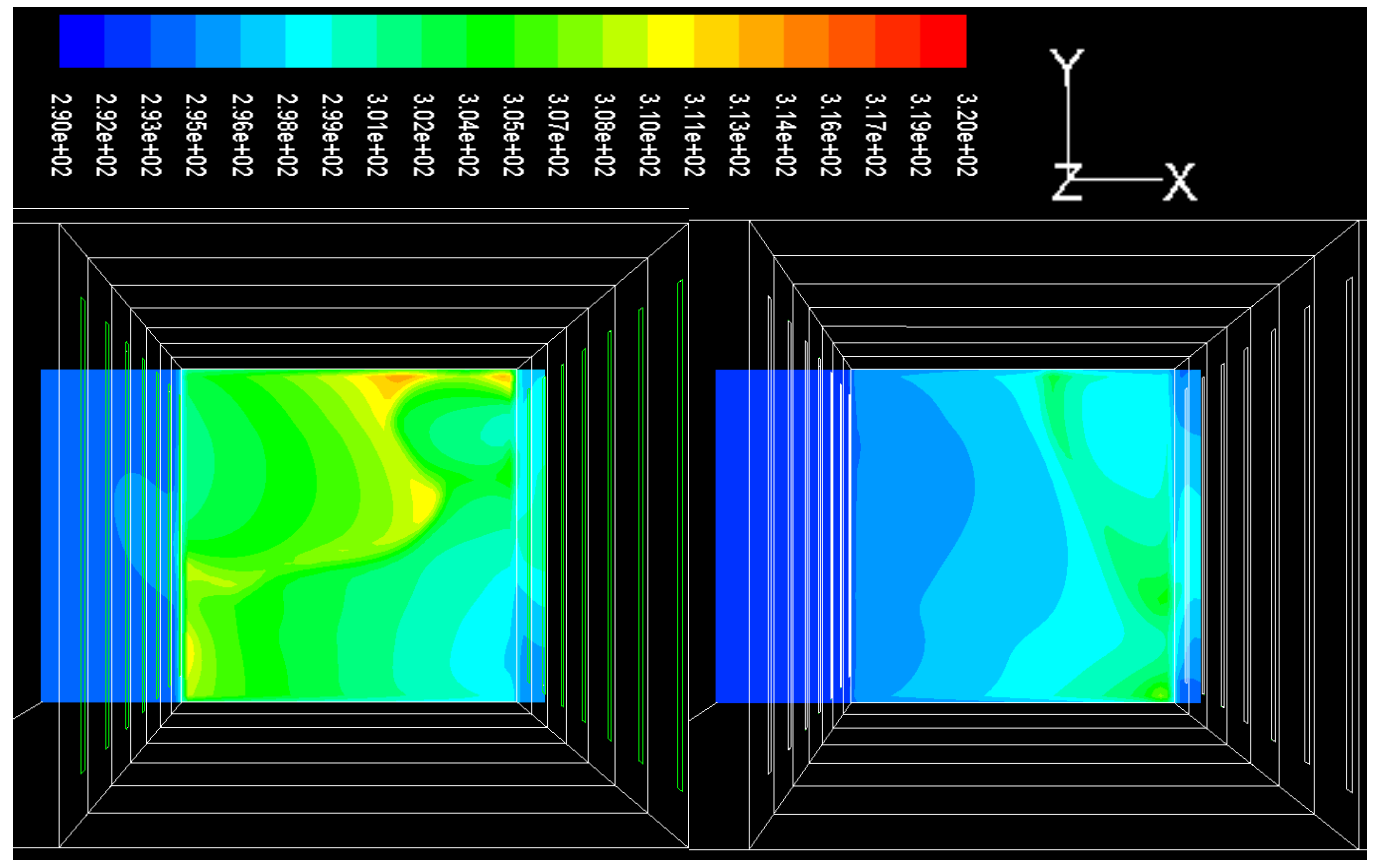

Figure 6-21: Contour of total temperature of a building plan in the mid-level. a) $2 \mathrm{~m} / \mathrm{s} ; \mathrm{b}$ ) $6 \mathrm{~m} / \mathrm{s}$ 


\section{(B) Evaluation of comfort wind environment of different building configurations}

To achieve a comfortable wind environment in the pedestrian level, the total mass flow rates of $60\left(\mathrm{~m}^{3} / \mathrm{s}\right)$ through the inlets (the extreme case) are applied in two different building configurations, namely the base and lifted cases as proposed in Figure 6-15. The lifted case here refers to the revised building configuration with an open wind floor strategy at the bottom segment of the building as illustrated in Figure 5-13. Two-side inlet is selected for the lifted case because of its encouraging ventilation performance predicted by the thermally coupled mass flow network approach in Chapter 5. Detailed discussions can be found in Section 5.3.4. For the lifted case, an open plan with two air intakes is defined in the ground level of the bottom building segment. The open floor interacts directly with the pedestrian level of the ambient environment. It is supposed that the optimum inlet sizes may minimize the resultant air velocity through the envelope opening so that the comfort wind environment surrounding those openings can then be satisfied.

The 6 storey segmentation case is chosen for comparison study between the base and lifted case in this section. Firstly, the resultant flow rates, which are driven into individual office spaces of two building configurations, under the specified boundary conditions (velocity inlet) are presented as Figure 6-22. This figure suggests that sufficient amounts of cooler air are supplied to all office spaces for ventilated cooling purpose irrespective of building configuration adopted. The mid-interface along the width direction of the building geometry is determined by plotting the contour of velocity magnitude. It can be seen from Figure 6-23 and 6-

24 that the overall wind environment in the pedestrian level is improved by the adoption of open plan in the bottom level of building segment. The comfort wind environment can also be ensured in most of the occupied spaces of the lifted case, where satisfactory local air velocity distribution is observed. Additionally, the temperature distributions against building height as well as building plan are plotted as illustrated in Figure 6-25 and Figure 6-26. 
Generally speaking, the lifted building configuration demonstrates the possibility to improve the comfort wind environment as compared to the base case building configuration with reference to the local temperature and velocity distribution of the ground level. The satisfactory air flow rates for the occupied spaces of the lifted case can also be ensured at the same time. Furthermore, more flexible control can be applied in openings of the open wind floor, because of its ranges of areas to be opened, without affecting the function as a lobby in the ground level of the bottom building segment. However, the optimum inlet size would be affected by the external temperature as suggested in Section 5.3.4. The ventilated cooling could not be achieved due to the warmer air being driven into the occupied spaces during the unfavourable weather conditions. The thermal environment during the typical day of summer as illustrated in Figure 6-25 and 6-26, which suggest that the distributions of free-running temperature of the occupied spaces is around 295 $\mathrm{K}\left(22^{\circ} \mathrm{C}\right)$ for a typical day $\left(22^{\text {nd }}\right.$ March $)$ in the mid-season of Taipei. Some local temperature of the base case building configuration may reach $300 \mathrm{~K}\left(27^{\circ} \mathrm{C}\right)$; while the lifted case is relatively consistent with the same boundary conditions applied. The thermal comfort is then being verified as those being concluded in Section 5.4.

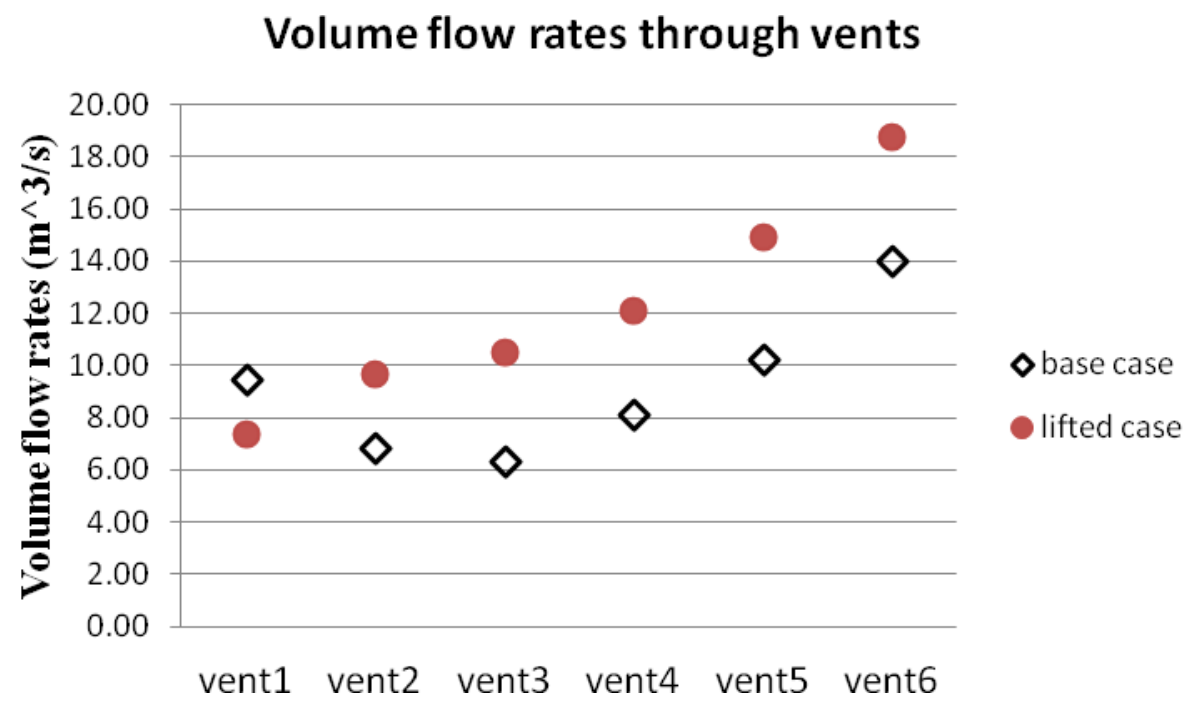

Figure 6-22: Mass flow rates through vents of office spaces under different building configuration 

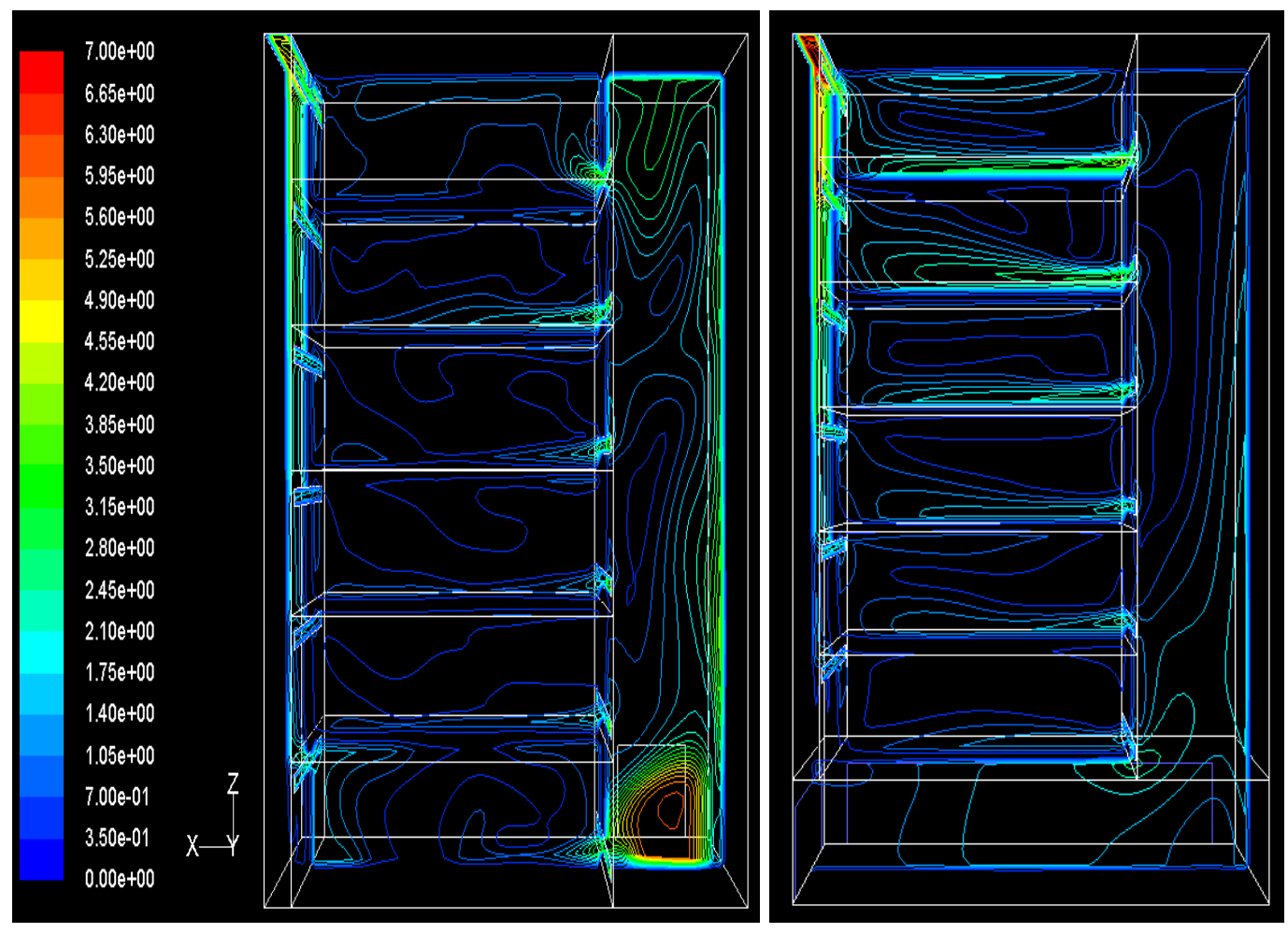

Figure 6-23: Contours of velocity $(\mathrm{Y}=6 \mathrm{~m})$ _ total volume flow rates of $60\left(\mathrm{~m}^{3} / \mathrm{s}\right)$ through the inlet. (a) Base case, (b) Lifted case

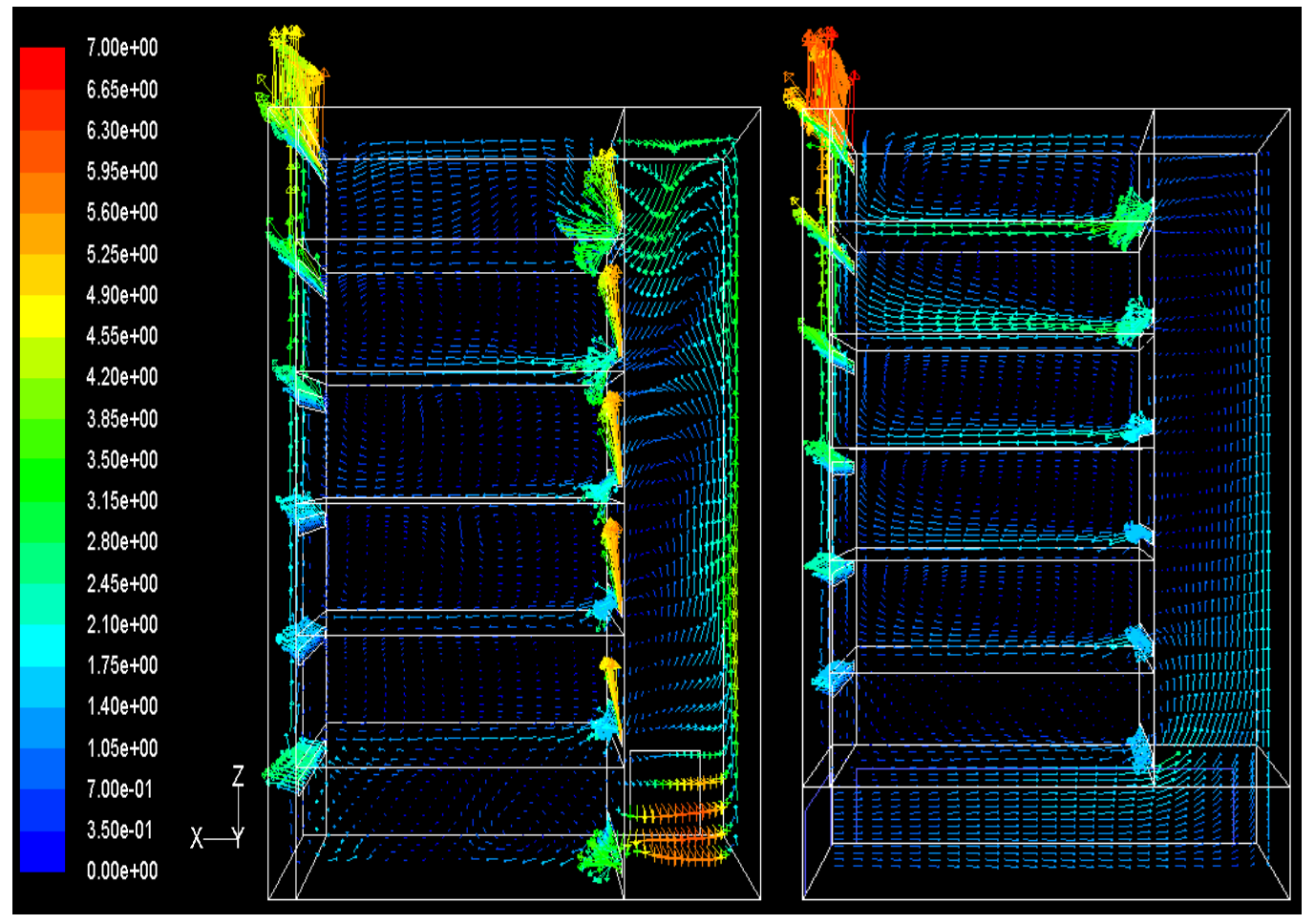

Figure 6-24: Velocity vectors coloured by velocity magnitude $(\mathrm{Y}=6 \mathrm{~m})$ _ total volume flow rates of $60\left(\mathrm{~m}^{3} / \mathrm{s}\right)$ through the inlet. (a) Base case, (b) Lifted 


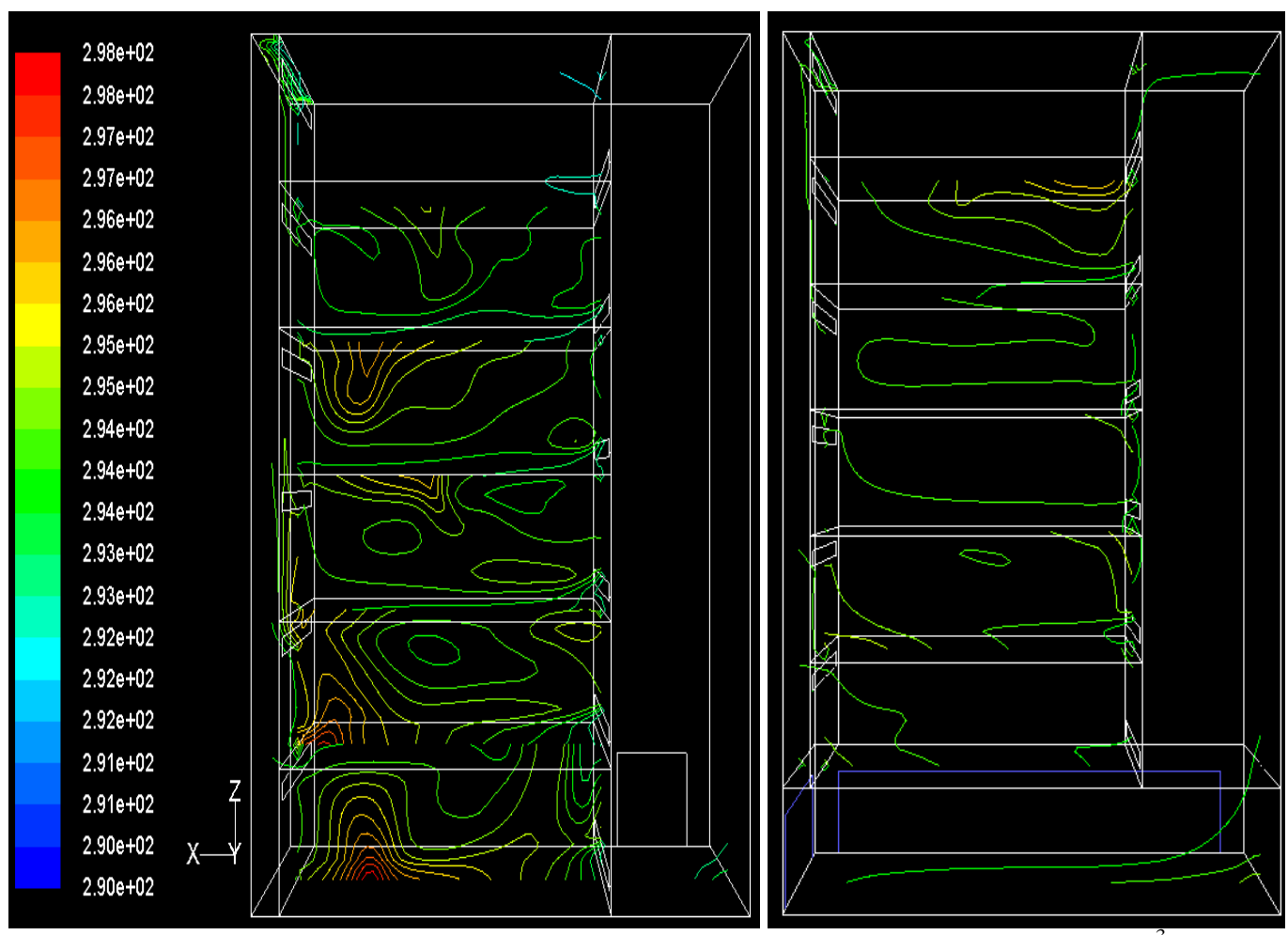

Figure 6-25: Contours of total temperature $(\mathrm{Y}=6 \mathrm{~m})_{-}$total volume flow rates of $60 \mathrm{~m}^{3} / \mathrm{s}$ through the inlet. (a) Base case, (b) Lifted case

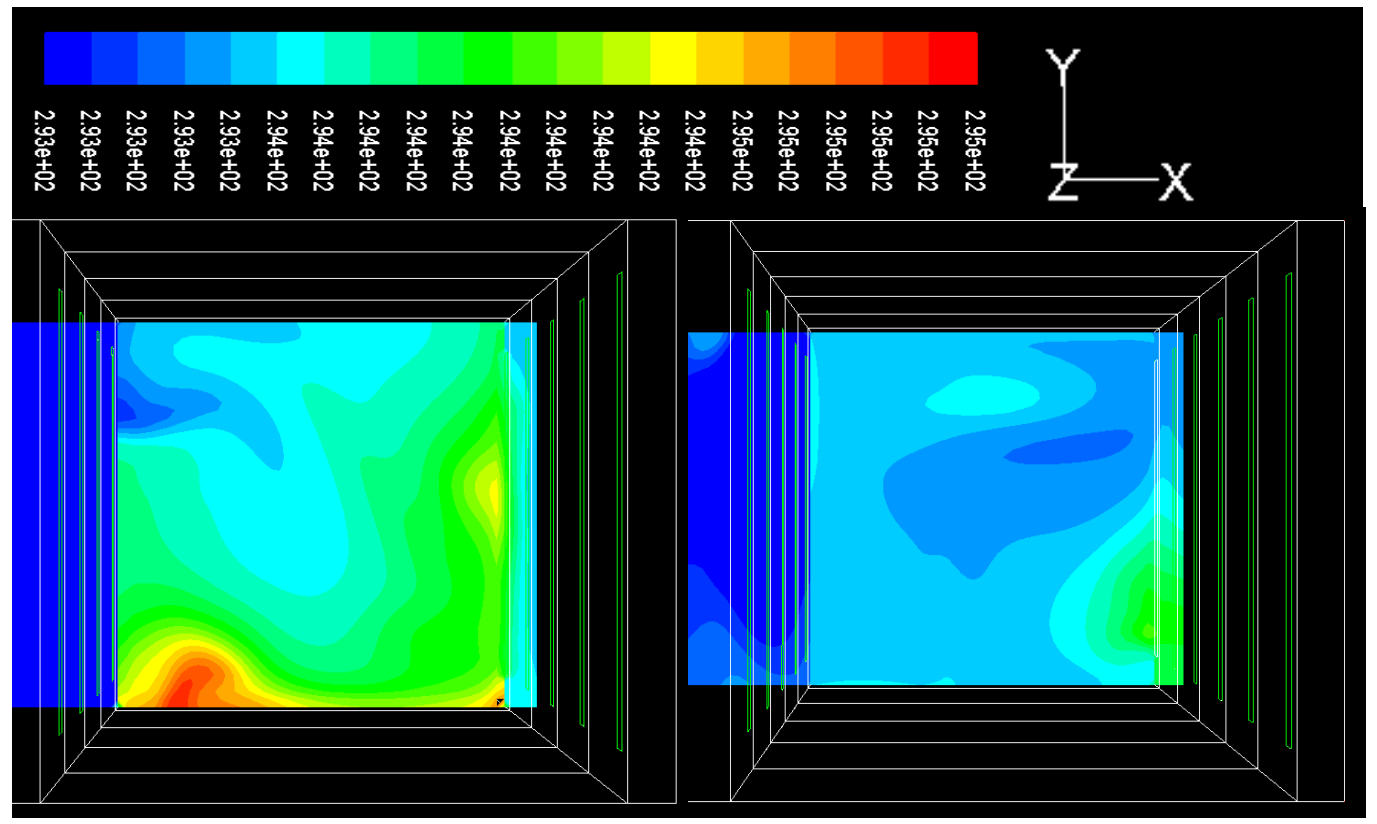

Figure 6-26: Contours of total temperature of an occupied space in the mid-level $(\mathrm{Z}=9 \mathrm{~m})_{-}$total volume flow rates of $60 \mathrm{~m}^{3} / \mathrm{s}$ through the inlet. (a) Base case, (b) Lifted case 


\subsection{The feasibility for comfort ventilation of the proposed generic design by the use Building Bioclimatic charts (BBCCs)}

In this study, the thermal comfort boundaries as suggested by Givoni (1998) are considered reasonable according to previous studies on the adaptive comfort theory particularly in the climatic context of a hot and humid climate and thus are used to assess the performance of ventilated cooling. Detailed literature reviews on the adaptive thermal comfort theory for a hot and humid climate is presented in Section 3.4.3. By the way of building bioclimatic charts (BBCCs), the effect of latent heat is taken into consideration, for which is not available with the equation 3.2-1. The thermal comfort assessment in this section is achieved by plotting the calculated dry-bulb temperature and relative humidity from ESP-r into BBCCs. The local air flow speed distribution from CFD modelling as presented in Section 6.3.3 is then adopted to ensure the selection of specific comfort boundary in the BBCCs. The acceptable comfort boundaries of a hot and humid climate for this study are presented and illustrated in Section 3.4.4. The predicted comfort ventilation performance of the proposed generic building configurations in the selected months are shown as Figure 6-27 to Figure 6-34.

By way of illustration (Fig. 6-27), the hourly basis data points of March indicate that thermal comfort will not be obtained for $35 \%$ of time in the climatic context of Taipei ( 259 of 744 data points lie outside the still air boundary). For which most of time outside the comfort boundary is between 10:00 and 14:00 of the day. To plot the hourly values for the occupied period only, namely from 08:00 to 20:00, $77 \%$ of time would lie inside the comfort boundary when the wind speed of $1.5 \mathrm{~m} / \mathrm{s}$ is applied. The illustrated results are shown as Figure 6-28.

As for the modelling results in May (Fig. 6-29 and Fig. 6-30), there are 84 percentage of time during the occupied period inside the comfort boundary of still 
air condition. For the hot summer (August), however, the data points lie to the left and above the comfort boundary, which suggests that mechanical cooling may be needed when the design condition cannot be achieved. Detailed results are shown as Figure 6-31 and Figure 6-32.

Scaling the result to the mid-season and hot summer, namely between March and August, the BBCCs (Fig. 6-33 and Fig. 6-34) indicates that comfort ventilation will be effective for 83 and 68 percentage of time during the occupied hours when the comfort boundary under the wind speed of $1.5(\mathrm{~m} / \mathrm{s})$ is adopted. Further CFD investigations are required for identifying local air flow speed distribution for assurance the selection of comfort boundary. More discussions regarding the viable time for ventilated cooling are presented in Section 5.4.2, where the design criteria are confined to the acceptable comfort temperature and required flow rates for cooling, disregard of the local wind speed.

Generally speaking, though the observations in BBCCs suggest that thermal comfort can be achieved for over $50 \%$ of the year (disregard of the winter period from December to February), some concerns and questions are raised as well. Firstly, the non-domestic building maybe heavily glazed in the perimeter zones. The level of internal heat gains due to radiation may be felt more at the perimeter than in the centre areas of the space. That is, the well-mixed assumption of each zone in the dynamic thermal simulation may not be appropriate for evaluating the local discomfort. The illustrated results in BBCCs can only be used to suggest the roughly viable time for comfort ventilation. Secondly, the spaces far away from the source of ventilation air may not be able to enjoy the cooling benefits because of uneven distribution of air flows. Also, the selection of comfort boundary is uncertain because of the local air flow distribution may be blocked by furniture or internal small partitions. The overall ventilation performance should be evaluated along with the CFD investigation in terms of local airflow and temperature distribution. 


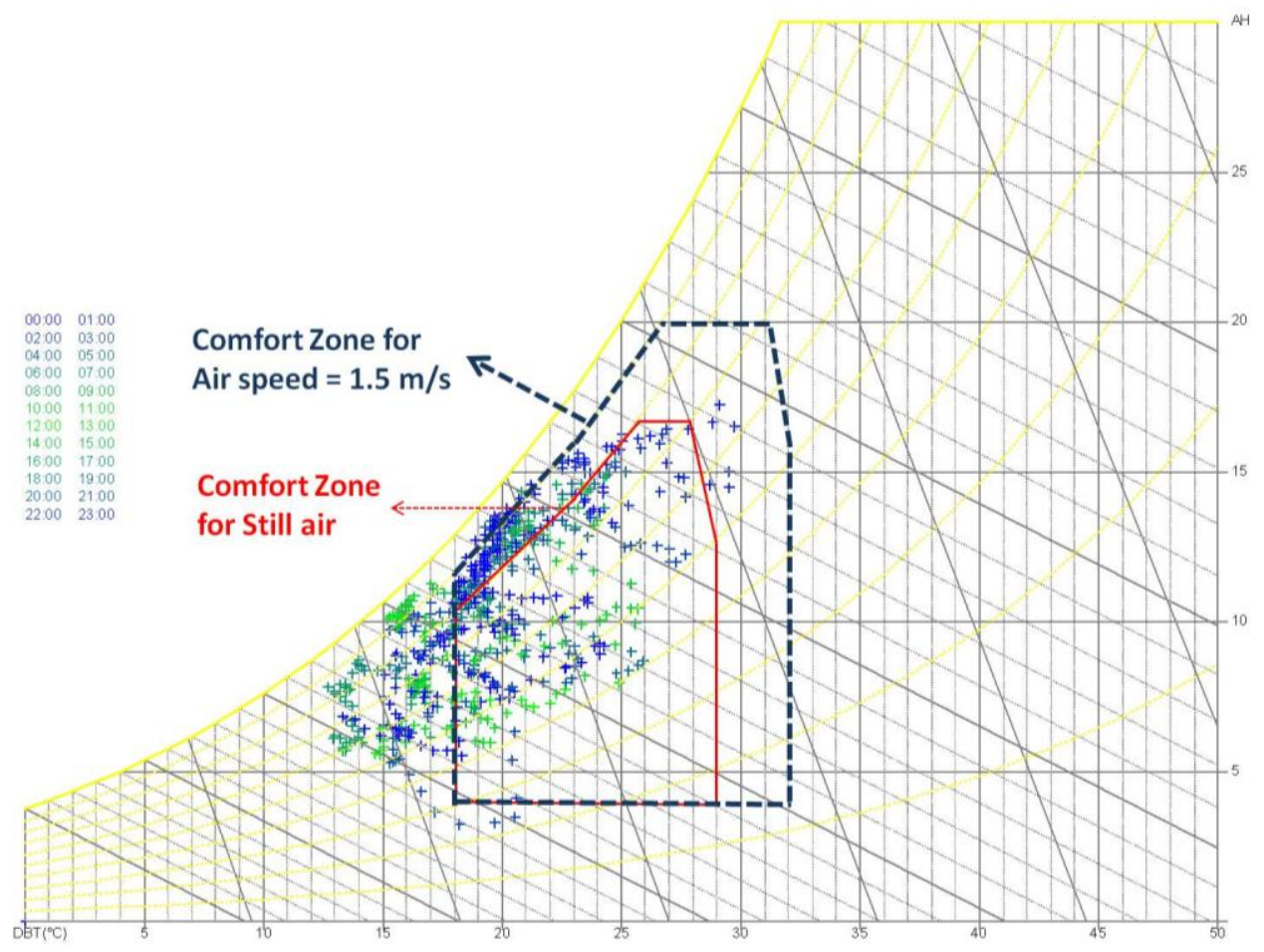

Figure 6-27: The hourly data points in March_The bottom level office space

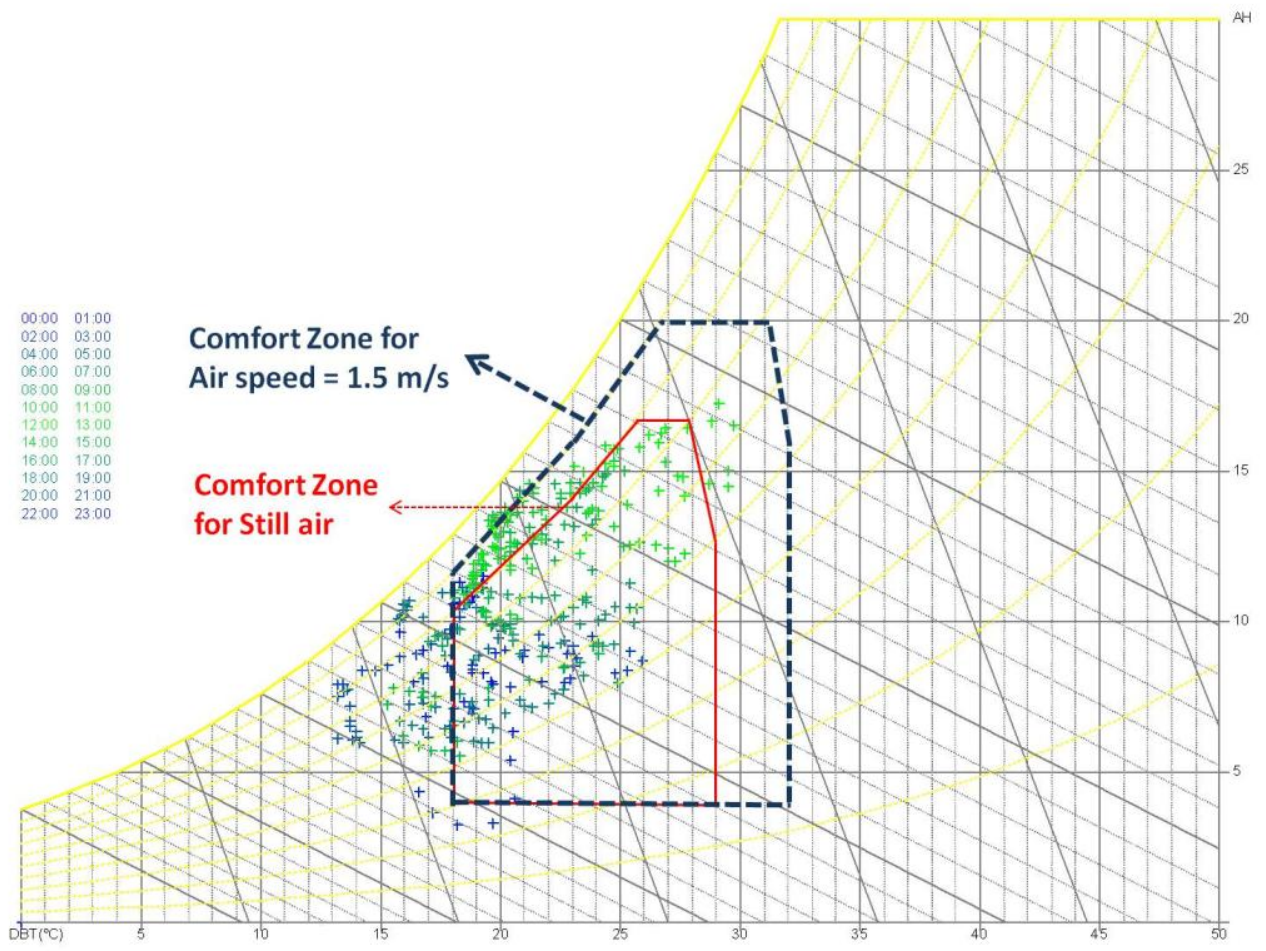

Figure 6-28: The hourly data points over the occupied hours in March_ The bottom level office space 


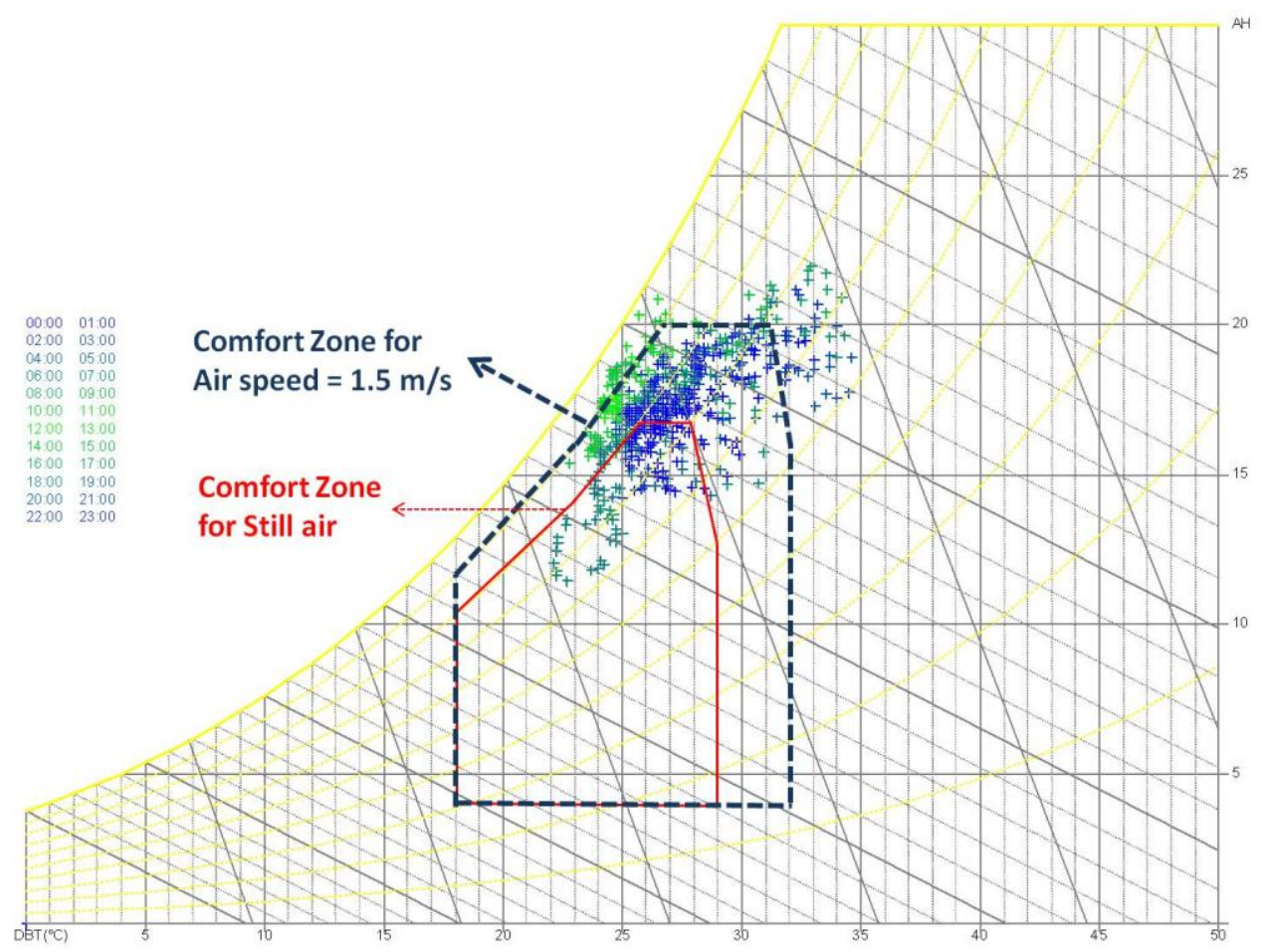

Figure 6-29: The hourly data points of May_ The top level office space

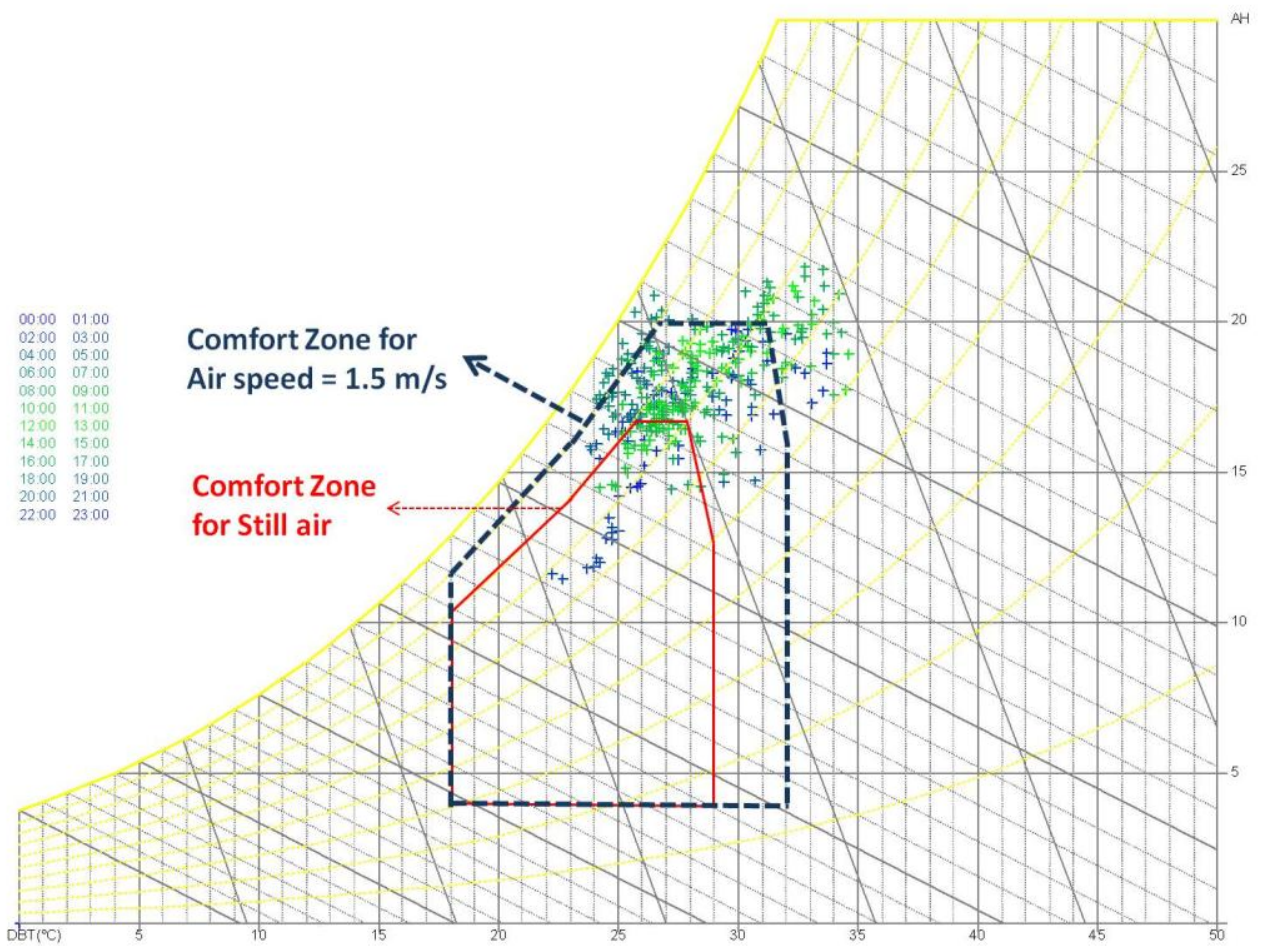

Figure 6-30: The hourly data points over the occupied hours in May_ The top level office space 


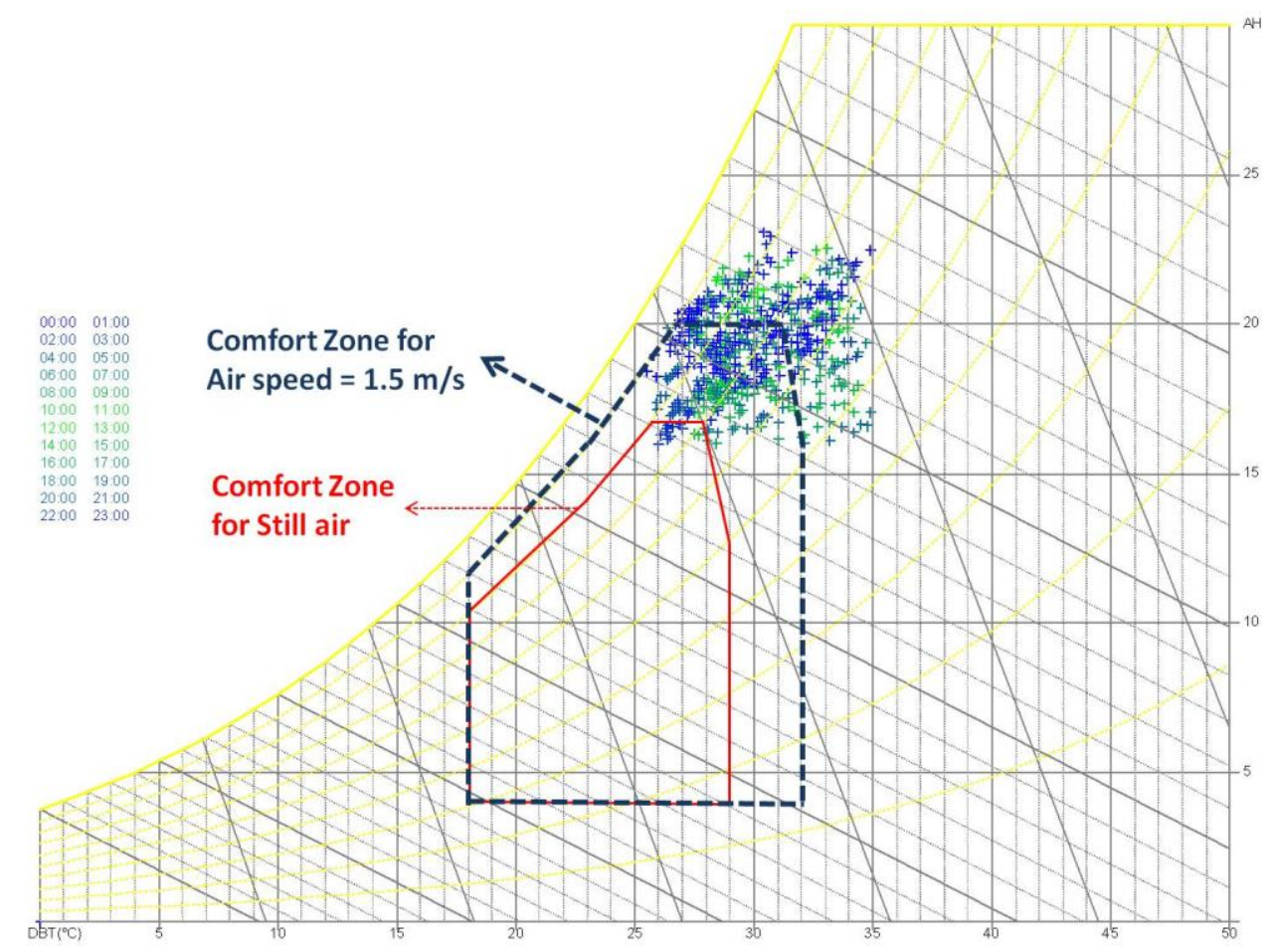

Figure 6-31: The hourly data points of August_ The top level office space

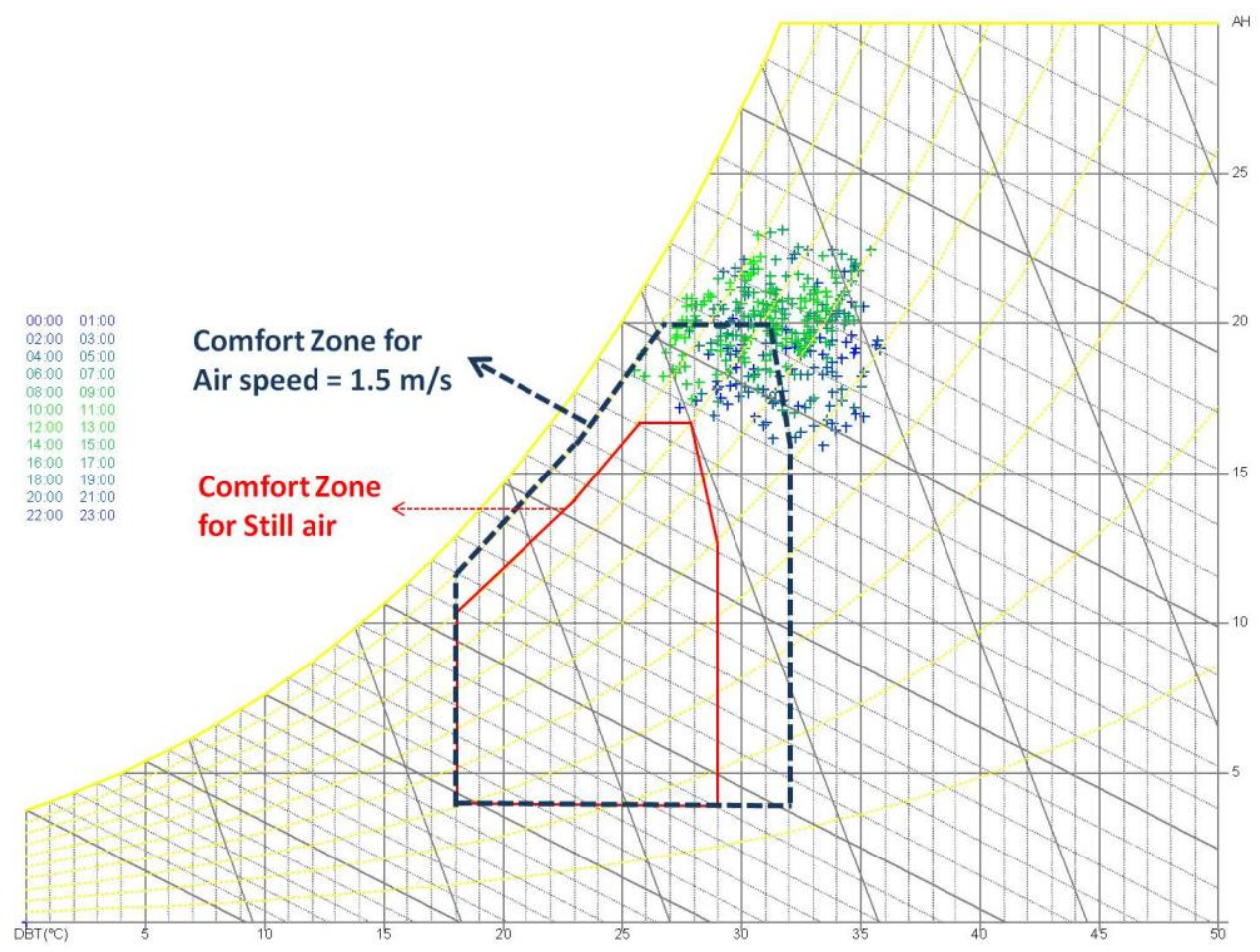

Figure 6-32: The hourly data points over the occupied hours in August_ The top level office space 


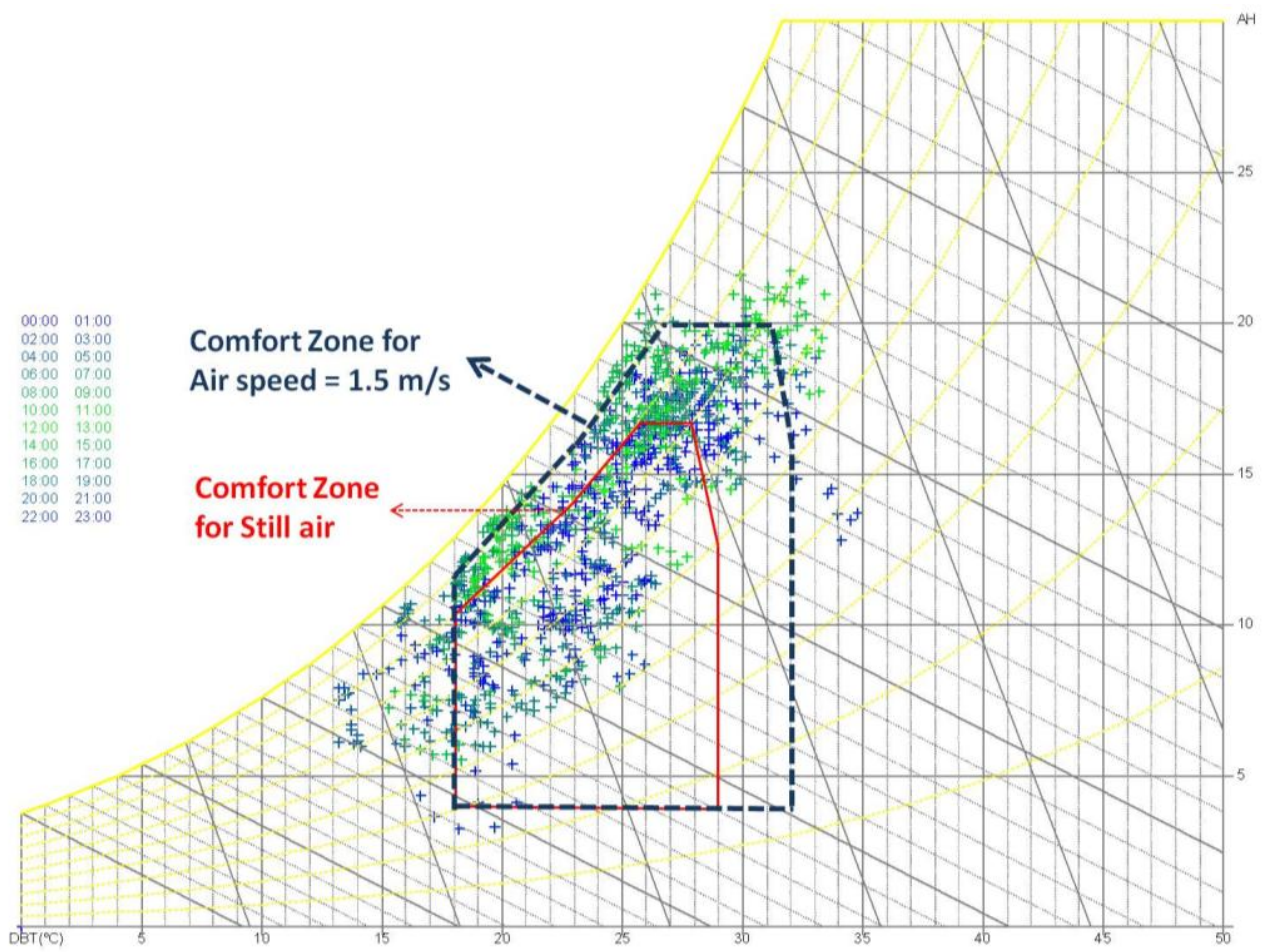

Figure 6-33: The hourly data points over the occupied hours between March and May_ The bottom level office space

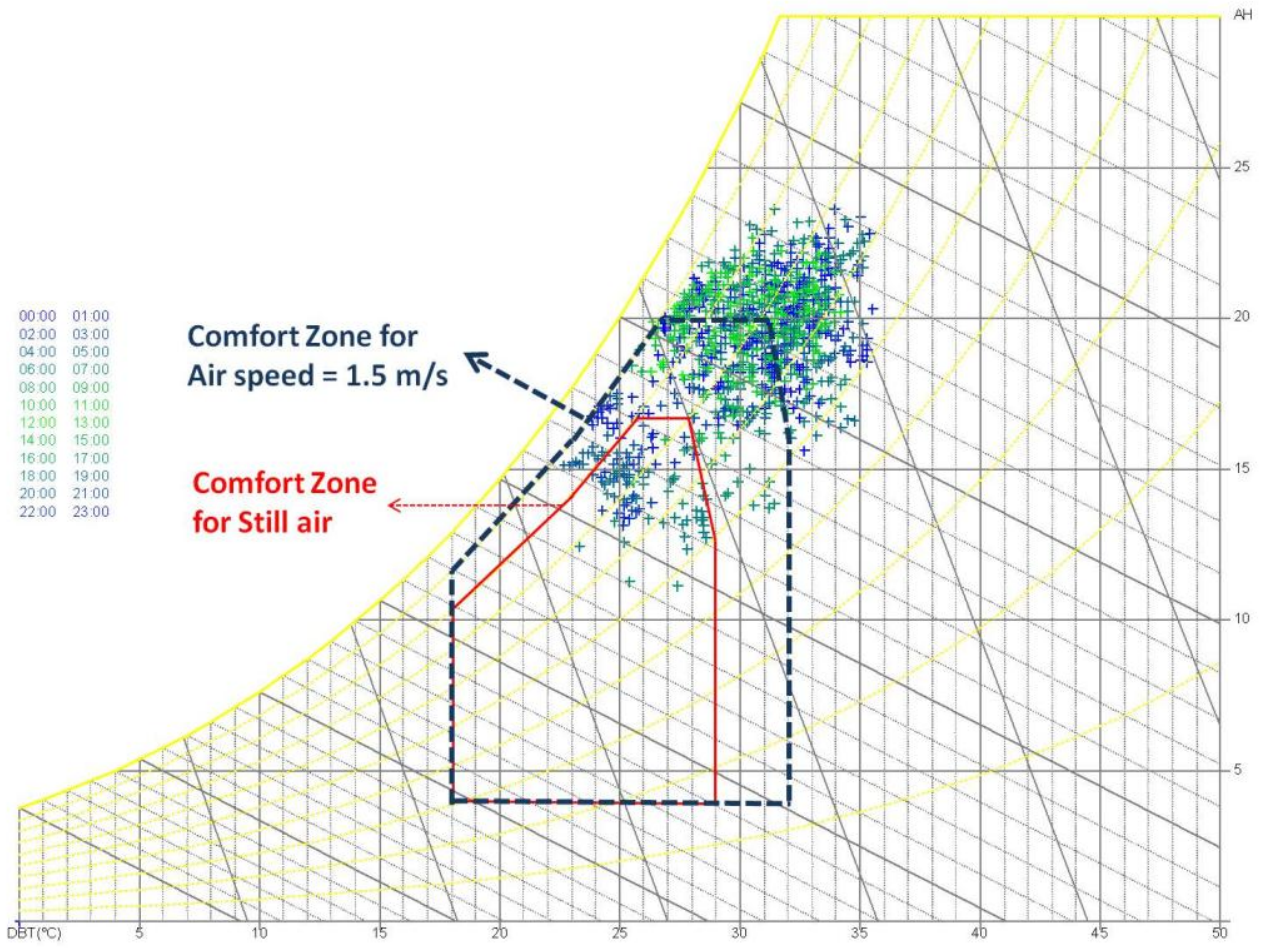

Figure 6-34: The hourly data points over the occupied hours between June and August_ The bottom level office space 


\subsection{Summary}

In this chapter, Section 6.1 starts with an overview of the choice for more advanced modelling tools in terms of research questions of this study. The issues being investigated by the use of CFD approach in this Chapter is summarized in Table 6-1. In Section 6.2, the reliability of wind pressure coefficient dataset used in the thermally coupled mass flow network approach of ESP-r is discussed. The simulated surface pressure coefficient from the CFD modelling in FLUENT are compared with the web-based TPU aerodynamic database and those being adopted in the ESP-r modelling. The accuracy of modelled flow rates using the mass flow network approach of ESP-r is then identified.

Following that, the local air and temperature distributions is investigated by the use of single domain CFD approach as well as the stand-alone CFD program (FLUENT). The modelling technique of Single domain CFD modelling within ESP-r and the stand alone FLUENT-CFD is summarized in Section 6.3.1. The necessity of coupling methods between the thermal and CFD domains within ESP-r is also evaluated in terms of resolution level, computing efficiency and technical convenience. According to the initial investigations on the dynamically coupled single domain CFD approach within ESP-r, it is suggested that the difference between two coupling approach, namely the BES-CFD and BES-AFN, is insignificant for the occupants to detect (less than $1 \mathrm{~K}$ ). The coupling between CFD and the multi-zone model is then directed to the CFD-alone approach within ESP-r. It is to conduct a whole building simulation first using a conventional multi-zone model (BES), and the results of specific time-step are manually provided as boundary conditions for a selected CFD domain in ESP-r, where the

well-mixing assumption is not realistic. The detailed results are described in Section 6.3.2. 
Nevertheless, more sophisticated CFD tool is required because only one CFD domain is allowed in the CFD-alone approach within ESP-r, which is not realistic in terms of overall ventilation performance of the entire building. The need for the adoption of further CFD tools is also necessary in terms of options available for the numerical models for the presentation of real world physical phenomena. The whole building simulation is then carried out by the use of stand-alone CFD program (FLUENT) in section 6.3.3. The task for full CFD simulation in this section is to predict the local air flow distribution under the predefined boundary conditions, which the highest occurrence of potential condition as well as the extreme case is identified by the statistical analysis.

The simulated air velocities of the occupied spaces are then applied in the selection of comfort boundary in the Building Bioclimatic Charts in Section 6.4. The observations in BBCCs suggest that thermal comfort can be achieved for over $50 \%$ of the year. However, those results in BBCCs can only be used to suggest the roughly viable time for comfort ventilation. The specific time for the proposed naturally ventilated tall office building design to achieve the desired ventilation performance would require a combination of tools being suggested in previous chapters of this study, namely the envelope flow model, dynamic thermal simulation with an air flow network, whole building CFD simulation, and the Building Bioclimatic Charts.

To sum up, this chapter aims to indentify where the CFD method stands in the overall ventilation design procedure and the adequacy of different CFD modelling approach inbuilt in the proposed modelling tools. The potential pros and cons of different CFD modelling approach on proposed research questions at hand are clarified. It can be concluded that a building thermal simulation with an air flow network model as presented in Chapter 5 is sufficient for the early design phase with reference to the hourly basis bulk flow and flow pattern. For the evaluation of local air and temperature distribution, the adoption of single domain CFD 
approach within ESP-r is proposed in the early stage of CFD simulation. However, more sophisticated CFD tool is required in terms of the need for the whole building simulation (particularly for the issues of segmentation and overall ventilation performance throughout the building) as well as the available numerical models for the real world applications. The whole building simulation is conducted under the predefined boundary conditions using the FLUENT program. These boundary conditions are derived from a particular time-step of conventional ESP-r modelling, which the highest occurrence of boundary conditions is identified by the statistical analysis. The overall ventilation performance of the entire building under a particular scenario is then clarified. The effect of inlet sizes is also investigated along with the 'open wind floor' strategy, particularly for the bottom floor of each building segment. The results show that the optimum inlet sizes would minimize the resultant air velocity through the opening. The comfort wind environment surrounding the openings could be clarified accordingly.

From the aspect of the adequacy of wind pressure coefficient, the reliability of wind pressure coefficient datasets within ESP-r is justified by the use of full CFD simulation in FLUENT. The comparison results between the ESP-r, CFD and TPU datasets show that the modelled flow rates using the thermally coupled mass flow network approach is acceptable if the driving wind force is either from the windward or leeward direction; while the resultant flow rates caused by wind from side directions might be questionable. The $\mathrm{Cp}$ value $(-0.8)$ adopted for the outlet of the ESP-r model is reliable because it has relatively small variation between three different database. Further investigations on level of influence regarding the resultant flow rates with reference to varied wind pressure coefficient are presented in Section 7.3.4. 


\section{Parametric Studies}

\subsection{A method overview for parametric study}

Parametric study is a tool for optimization and it can also offer useful information for gauging the accuracy of simulation. Many previous studies as summarized below also referred the parametric study to sensitivity analysis for the assessment of range of influence of a particular design parameter on the overall system performance. As suggested by Lam and Hui (1996), sensitivity techniques can be a powerful tool for the study of thermal response of buildings and error analysis when integrated with building energy simulation methods. If the relationship and relative importance of parameters are known, we will be able to achieve optimum building performance through proper selection of design variables and conditions. The first step for an effective parametric study is to obtain a crude estimate of the impact of the uncertainties and to reveal the main contributors to the resulting uncertainty. Several parametrical studies have been done in the context of building performance which identifies the level of uncertainty of different parameter in building simulations.

Vytlačil and Moos (1993) presented an example of thermal transfer through the envelope of a building using the sensitivity analysis. A sensitivity function, sensitivity characteristics and the relationship between sensitivities and tolerances were described in detail. They tried to examine the question that to what extent the thermal transfer was sensitive to the given percentage of variation of a particular parameter. Lam and Hui (1996) examined the sensitivity of energy performance of office buildings in Hong Kong. The sensitivity coefficients (Table 7-1) for each parameter examined were determined. They also suggested that direct comparison of the sensitivity values in strict quantitative terms was not always practical and fair. Interpretations should be taken in context with clear understandings of the implications and limitations. To make the best use of 
sensitivity methods, designers should focus more on problem definitions, understanding of the sensitivity theory and better interpretation of the simulation results.

Moreover, Wit (1997) reported the results of a parametric study on the thermal comfort performance of a naturally ventilated office building without cooling plant. His study aimed to quantify the modelling uncertainty due to a lack of knowledge in particular aspects. The factorial sampling technique was applied to estimate the mean parameter effects and to reveal the relative importance of nonlinear effects and parameter interactions. He concluded that four parameters/submodels primarily contribute to the variability in the thermal comfort performance, which were the wind reduction factor, the wind pressure coefficient data set, the deviation of the local ambient temperature from the local meteorology, and the choice of a model for the internal heat transfer coefficients respectively. The effects of uncertainty on the modelling of the external heat transfer coefficients and the indoor thermal stratification are less striking, but still of importance. Contributions of parameter interactions and non-linear parameter effects were found to be insignificant.

As concluded by Hanby (1994), the simplest approach of sensitivity analysis is to repeatedly vary one parameter at a time while holding others fixed. A sensitivity ranking can be obtained quickly by increasing each parameter by a given percentage while leaving all others constant, and quantifying the change in model output. A more powerful test of local sensitivity examines the change in output as each parameter is individually increased by a factor of its standard deviation. This sensitivity measure takes into account the parameter's variability and the associated influence on model output.

For this study, the overall aim is to ensure that the proposed tall building configurations can deliver acceptable comfort environment for the occupant through natural ventilation alone. The range of influence of different ventilation related parameters on the overall comfort environment is of interest. Data used to model and interpret building performance are susceptible to variations and errors. 
Sources of error and uncertainty in building performance prediction have been addressed by previous studies (Wit, 1997; Fürbringer and Roulet, 1999). For this study, the input errors from users are not discussed because all the input for simulations in ESP-r are derived from a real building design (Chapter 5) and available technical reference (ASHRAE_2004, BCO_2009 and CIBSE AM10_2005). This study then focuses on the assessment of uncertainties with reference to the variability of input parameters to the overall ventilation performance. The uncertainty may be from the design specification, which includes the shape and materials of the building construction and building components etc. It may also be from the test conditions (scenario), where a performance prediction at the design stage can be interpreted as the outcome of a simulation under well-defined test conditions. In such case, test conditions may include time-series weather data, behaviour of occupants, control of set points and other data concerning the operation of the building. For this particular study, the uncertainties are evaluated by the variance of parameters and their corresponding range of influence on the overall comfort environment with reference to the flow velocities from bulk flow and the free-running temperatures.

Generally speaking, the parametrical approach of this study is adopted to examine the level of uncertainty for different input parameters on simulation outputs, as compared to a base case situation. The general goal is to investigate how the ventilation related parameters influence the ventilation bulk flow, flow velocity and free running temperatures of the proposed building configuration. The range of influence of the selected parameters on the overall ventilated cooling performance is then expressed by statistical terms of 'standard deviation' and 'correlation coefficient' in the following subsections. The key variables for this particular study are identified and described in Section 7.2. Details on how the variance being decided is described accordingly. The discussions on how much the impact of individual ventilation related parameters on the overall comfort environment are presented in the Section 7.3 and Section 7.4 as follows. 


\subsection{Plan for parametric study on ventilation related parameters}

A sensitivity study requires a base case model, upon which the influential parameters can be intentionally adjusted item by item to examine the particular effect of the individual parameter on the whole system. Selected parameters for natural ventilation design of this particular study are discussed in this section. Their influence on the resultant flow rates of associated spaces can then be investigated. Seven ventilation related parameters are selected and categorized into two main groups as shown in Table 7-1. The two groups are the design specification and boundary conditions respectively. For the design specification, the selected parameters include the building segmentation and envelope opening sizes. The boundary conditions include internal heat gains, time-series weather condition (ambient temperature, temperature difference between indoors and outdoors and wind speed) and wind pressure coefficient. Generally speaking, the influence range of a particular parameter is determined by its corresponding output in respect of air flow rates and flow velocity through the openings of associated offices. More descriptions are provided as follows.

\section{(A) Design specifications}

From the aspect of design specification, the building construction and building components are concerned. The base case building configuration of the main investigation of this study has already assumed a level of good design in terms of construction materials and their corresponding thermal envelope. That is, this study then focuses on the ventilation related building components. Two variances are selected for their potential influence on the driving forces of natural ventilation in tall buildings. Firstly, the effect of building segmentation is investigated. The impact of segmentation height to the resultant flow rates as well as the velocities from bulk flow rates of the openings of associated office spaces is discussed. Also, the deviation of flow rates against floor height is adopted for demonstrating their potential influence on maintaining the satisfactory flow rates 
of occupied spaces on a floor-by-floor basis. Different ventilation conditions, namely the buoyancy alone and wind and buoyancy combined conditions are examined. The comparisons with reference to different building segmentation height are presented in Section 7.3.1.

Secondly, the influence of envelope opening sizes to the overall ventilation performance is investigated in Section 7.3.2. Their range of influence is interpreted by the deviation of resultant flow rates between cases as well as the estimate velocities from bulk flow for potential personal cooling. The envelope openings in this study refer to the air inlet at the bottom of atrium and the outlet at the top of the double-skin facades with reference to the proposed building segmentation (Fig. 2-40). The output (flow rates) is plotted against floor levels in this modelling case. The flow rates and the resultant flow velocities between the base case and otherwise selected cases (different arrangements of envelope opening sizes) is compared. Different ventilation conditions (buoyancy alone and wind and buoyancy combined conditions) under the extreme case (maximum envelope opening sizes due to constraints of building structure) is examined and compared to a base case as well.

\section{(B) Boundary conditions}

From the aspect of boundary conditions, the input information required for the modelling of a free-running building in ESP-r include the time-series weather data, behaviour of occupants, and other data concerning the operation of the building. In terms of the operation of the building, the schedule as well as the heat gains from the occupants, lighting, and equipments should be defined. From the aspect of ventilated cooling, the heat entering the building is assumed to be removed with the ventilation air. Consequently, the influence of internal heat gains with the combination of solar, occupant, lighting and equipment gains is firstly considered in this study. In section 7.3.3, the total internal heat gains of 30,40 and $50 \mathrm{~W} / \mathrm{m}^{2}$ 
are selected according to different level of stationary work inside of the offices for investigating their corresponding impact on the resultant flow rates. The flow rates are plotted against the internal opening height (measured from the ground level) of associated occupied spaces. The internal openings here refer to those of associated office spaces, which connected to the double-skin facades and their height are $2.65 \mathrm{~m}$ above the individual floor level. In this case, the sensitivity coefficient is determined by the changes in output (flow rates) divided by the changes in input (internal heat gains) for demonstrating its range of influence.

From the aspect of the time-series weather data, the investigations on the wind related boundary conditions are conducted in Section 7.3.4 with reference to wind pressure coefficient being adopted in the ESP-r program; while the temperature related parameters are discussed separately in Section 7.4 with the buoyancy alone cases. The effect of wind speed alone is examined in Section 4.3.3 using the envelope flow model approach. The sensitivity of wind speed on the flow rates is not discussed in this chapter, because the calculated hourly flow rates are derived from the time-dependent weather data in the ESP-r modelling; while it is impossible to vary the wind speed by a given percentage at a time within ESP-r.

For the proposed building configuration (Fig. 2-40), the wind pressure coefficient at the locations of inlet and outlet (envelope openings) should be defined for modelling the flow rates through that particular building segment. To enable the calculation of wind-induced surface pressures within ESP-r, the database of direction dependent pressure coefficients is provided. In the ESP-r database, wind pressure coefficients are pressure coefficients for surfaces in typical positions and within several different exposure categories. The wind pressure coefficient $\left(C_{p}\right)$ of the outlet is kept as -0.8 for the investigation; while the $C_{p}$ of the inlet is varied from $0.9,0.8$ and -0.2 to represent the windward and leeward conditions as well as the discrepancy from different available wind pressure coefficient database. Those values are derived from the investigation of different wind pressure coefficient database as presented in Section 6.2. The sensitivity of pressure difference between the inlet and outlet to the flow rates through a specific office 
space (i.e. the office in the bottom level) is expressed by the standard deviation values of flow rates as well as the resultant flow velocities. The standard deviation $(\sigma)$ here refers to the variation of flow rates from the average value of the three different $C_{p}$ arrangements at a particular time-step. The $\sigma$ value is adopted because that it is relatively easy to interpret the influence of a particular variance on the overall ventilation performance. The flow velocities through the corresponding occupied spaces are derived later from the calculated bulk flow for estimating the potential effect on personal cooling.

Furthermore, the buoyancy alone cases are investigated in Section 7.4 for clarifying the impact of temperature related parameters on the resultant flow rates. The isolated and segmented cases are adopted respectively for investigating the influence of segmentation on the overall ventilation flow rates under the low or no wind speed condition. The sensitivity of different temperature related parameters to the overall ventilation performance is expressed by the correlation values $\left(\mathrm{R}^{2}\right)$ for clarifying their relative importance. The correlation coefficient $\left(\mathrm{R}^{2}\right)$ is adopted to determine the relationship between two properties (i.e. between ambient temperature and the flow rates).

Table 7-1: Plan for Sensitivity Analysis of Ventilation Related Parameters

\begin{tabular}{|l|l|c|}
\hline \multicolumn{1}{|c|}{ Input parameter } & Base case & Perturbations \\
\hline$*$ Design specification & \multicolumn{1}{|c|}{5 storeys } & $8 / 9 / 10 / 15 / 18 / 20$ storeys \\
\hline 1) Storeys of building segment & Inlet $=10 \mathrm{~m}^{2} /$ Outlet $=10 \mathrm{~m}^{2}$ & Inlet $=40 \mathrm{~m}^{2} /$ Outlet $=20 \mathrm{~m}^{2}$ \\
\hline 2) Inlet / outlet opening sizes & \multicolumn{1}{|c|}{$30\left(\mathrm{~W} / \mathrm{m}^{2}\right)$} & $40\left(\mathrm{~W} / \mathrm{m}^{2}\right) / 50\left(\mathrm{~W} / \mathrm{m}^{2}\right)$ \\
\hline$*$ Boundary conditions & $\begin{array}{l}\text { To be defined from typical } \\
\text { weeks of Taipei weather } \\
\text { data }\end{array}$ & N/A \\
\hline 3) Internal heat gains & Inlet $=0.7 /$ outlet $=-0.8$ & $\begin{array}{l}\text { Inlet }=0.9 / \text { outlet }=-0.8 \\
\text { Inlet }=-0.2 / \text { outlet }=-0.8\end{array}$ \\
\hline 4) Ambient temperature
\end{tabular}




\subsection{The influence of ventilation related parameters on the overall comfort environment of the proposed building configuration}

\subsubsection{The impact of building segmentation}

The impact of building segmentation on the overall ventilation performance is investigated in this section by plotting the air flow rates against building segmentation height as well as the flow velocity calculated from the bulk flow of the associated openings. The standard deviation $(\sigma)$ is adopted to examine the variation of flow rates of individual floor level from the average of a specific segmentation height. Standard deviation analysis is applied in this sub-section because it shows how much variation exists from the average (mean) value with reference to the chosen parameter. The impact of building segmentation can then be identified. The information obtained may be helpful for more manageable flow rates of individual floor level regarding the occupant control.

Firstly, the influence of building segmentation on the flow rates of associated office spaces is investigated under different ventilation conditions. The standard deviation of flow rates ( $\sigma$ value) are plotted against building segmentation height as Figure 7-1, which show the monthly basis standard deviation $(\sigma)$ with reference to the volume flow rates. In this case of investigation, the $\sigma$ values increase with the external temperature under the buoyancy alone condition irrespective of segmentation height adopted; while the wind and buoyancy combined condition tends to be more stable in terms of monthly variation in $\sigma$ values. For example, the $\sigma$ values of the cases over 8 storeys segmentation height under the wind and buoyancy combined condition tend to be smaller than those with the same segmentation height under the buoyancy alone condition. For the 5 storeys segmentation case, however, the wind force appears to have more impact on the overall deviation of flow rates between floors. This can be explained by the fact that the stack effect being less significant in the case with limited segmentation height, where the wind force may dominate. 
Furthermore, the seasonal variation of $\sigma$ values with reference to segmentation height is illustrated as Figure 7-2. It can be seen that the lowest $\sigma$ value during the mid-seasons is $0.52\left(\mathrm{~m}^{3} / \mathrm{s}\right)$ for the 10 storeys segmentation case under the wind and buoyancy combined condition; while it is $0.79\left(\mathrm{~m}^{3} / \mathrm{s}\right)$ under the buoyancy alone condition at the same building segmentation. As for the hot summer, namely from June to August, the 8 and 9 storeys cases present the better results in terms of variations of volume flow rates between floor levels. They are respectively $0.41\left(\mathrm{~m}^{3} / \mathrm{s}\right)$ for the 9 storeys segmentation under the wind and buoyancy combined condition and $0.79\left(\mathrm{~m}^{3} / \mathrm{s}\right)$ for the 8 storeys segmentation under the buoyancy alone condition. Generally speaking, the $\sigma$ values are quite steady in the mid-seasons when the segmentation height of over 9 storeys is adopted. Some odd points occur in the 10 and 15 storeys segmentation cases during July and August when the buoyancy alone condition is applied. The 5 storeys segmentation case has the largest deviation between floors irrespective of simulation periods and ventilation conditions applied. The resultant variation of air flow velocity from the calculated bulk flow for the 5 storey and those over 8 storeys are about $1 \mathrm{~m} / \mathrm{s}$ and $0.2 \mathrm{~m} / \mathrm{s}$ respectively (Fig. 7-3). For the case with air flow speed over $1 \mathrm{~m} / \mathrm{s}$ (smaller segmentation height), the air draught may have potential impact on the stationary work of the occupied spaces. The findings above also correspond to those in Chapter 5, for which the optimum segmentation height may be around 8 storeys or more.
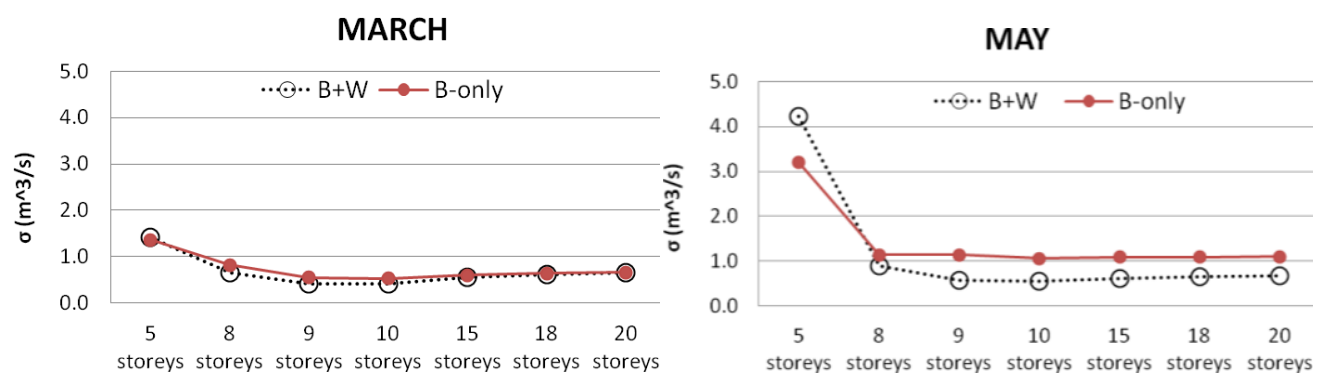
JUNE

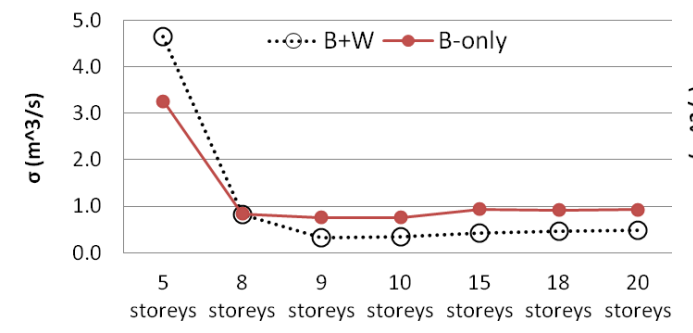

AUGUST

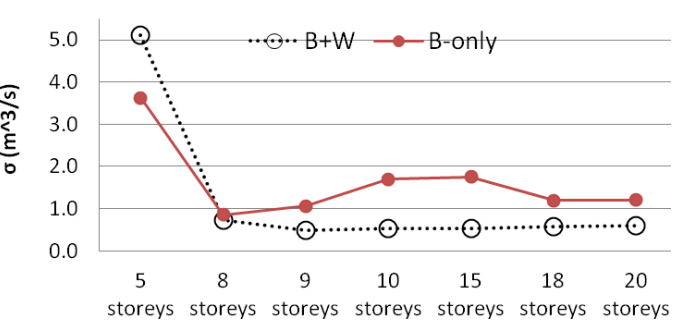

Figure 7-1: The monthly standard deviation of flow rates under different ventilation conditions
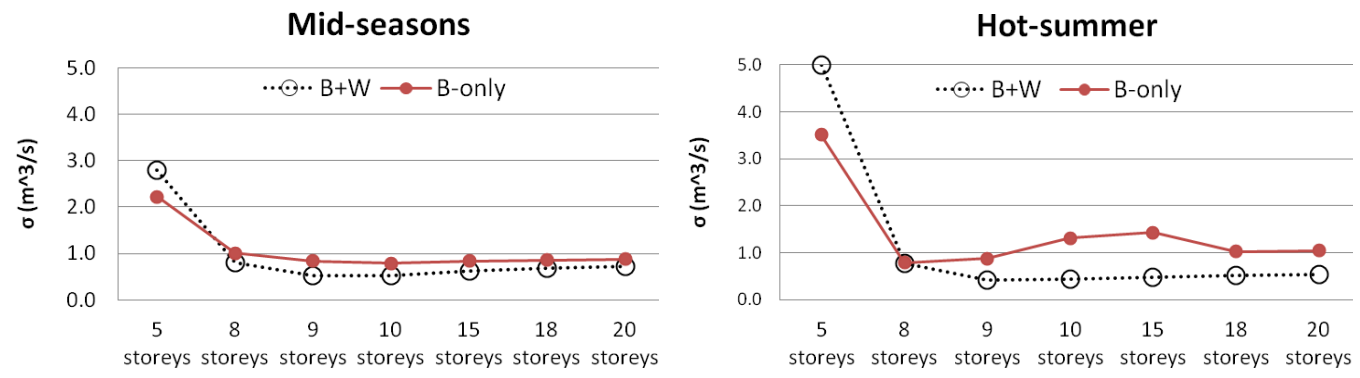

Figure 7-2: The seasonal standard deviation of flow rates under different ventilation conditions

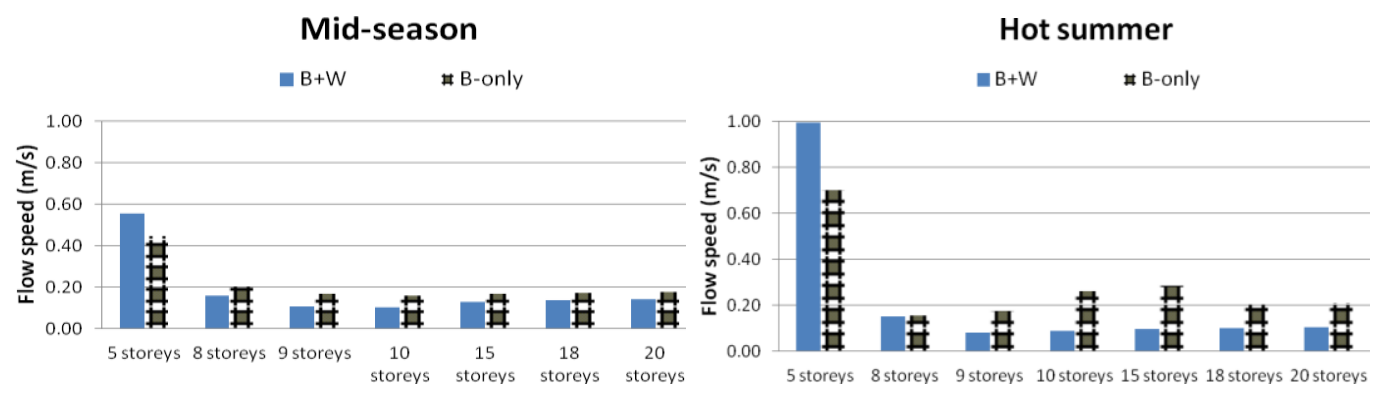

Figure 7-3: The resultant variation of flow velocities with reference to the seasonal standard deviation of flow rates by different building segmentation

Two scenarios with less manageable flow rates against floor levels are identified as follows, which may require extra expertise to run the proposed natural ventilation system successfully.

- The largest $\sigma$ value is observed for the case with smaller segmentation height (the 5 storey case) during the warmer months, irrespective of ventilation conditions adopted. 
- The larger $\sigma$ value is observed for all segmentation cases under the buoyancy alone condition in comparison with the wind and buoyancy combined condition.

In the climatic context of Taipei, there is only $7 \%$ of time (611 out of 8760 hours) that the external wind speed is lower than $0.5 \mathrm{~m} / \mathrm{s}$ (refer to the buoyancy alone condition). The monthly number of hours with wind speed lower than $0.5 \mathrm{~m} / \mathrm{s}$ is illustrated as Figure 7-4. Through this preliminary climate analysis, it may then suggest that the wind and buoyancy combined condition deserves more concern for the most of time. In such case, the segmentation height over 8 storeys is necessary for achieving more manageable flow rates of the proposed building configuration during the examined months, namely between March and August. Although the ventilation performance, in terms of the $\sigma$ value, of the segmentation height over 8 storeys is quite consistent, the upper bound for the segmentation height may exist because of the jurisdiction for fire safety. In the case of building regulations of Taiwan, the continuous staircases with height of over $50 \mathrm{~m}$ or 16 storeys in tall buildings should have special concern for fire safety. Consequently, the optimum segmentation height may range between 8 to 16 storeys with reference to satisfactory flow rates and jurisdiction for fire safety; while extra consideration in terms of floor plate efficiency of typical multi-storey office buildings is discussed in Section 2.4.2.

\section{Low wind speed $(<0.5 \mathrm{~m} / \mathrm{s})$ distributions}

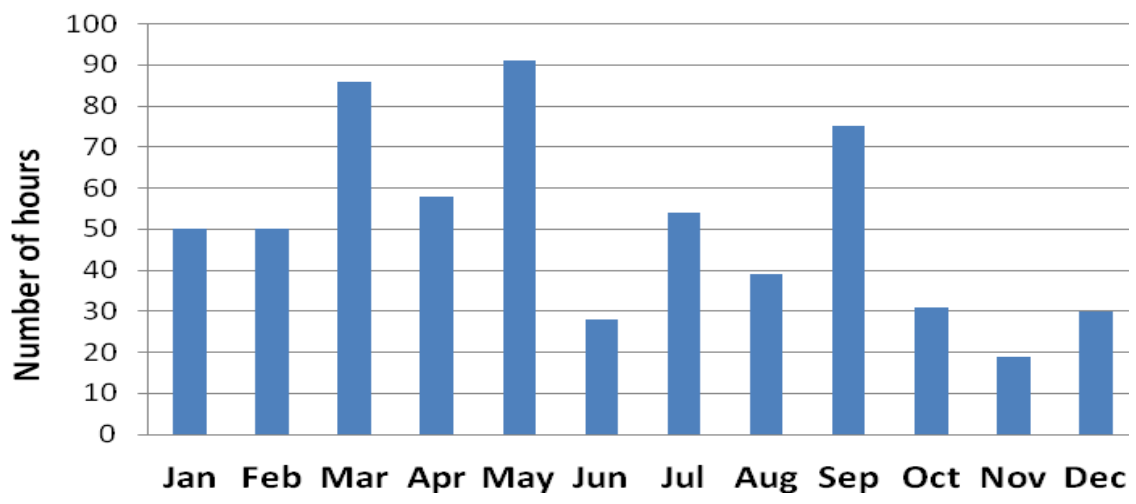

Figure 7-4: The low wind speed distributions in the climatic context of Taipei 


\subsubsection{The influence of envelope opening sizes}

Various arrangements for the inlet and outlet sizes are evaluated in this subsection. The location of the inlet is at the bottom part of the atrium segment; while the outlet is at the top of the double-skin facades segment (Fig. 2-41). Three different investigations are conducted as follows. Firstly, the 8 storey segmentation case is chosen for examining the influence of inlet/outlet sizes on the flow rates under two different ventilation conditions. The flow rates are plotted against floor levels along with the standard deviation values $(\sigma)$ between different envelope opening arrangements. The standard deviation here shows how much variation exists from the average flow rates of a particular floor level between six different envelope opening arrangements, for which the range of influence in terms of air flow rates is identified. The selected months, namely April and August, for the proposed investigation are illustrated as Figure 7-5, where the INLET10_OUTLET20 denotes the inlet and outlet openings with sizes of $10 \mathrm{~m}^{2}$ and $20 \mathrm{~m}^{2}$ respectively. It can be seen that the deviations of flow rates increase with external temperature (refer to April and August) irrespective of floor levels. These results imply that the influence of envelope opening sizes is more significant during the warmer periods. Also, the larger inlet and outlet sizes are not always of benefit when the external temperature gets higher than the simulated internal temperature, where the warmer air may be driven into the occupied space and cause thermal discomfort.

Secondly, the 10-storey segmentation case is used for examining the influence of inlet/outlet sizes on the monthly flow rates under different ventilation conditions, namely the buoyancy alone and wind and buoyancy combined conditions. Two extreme cases with the minimum and maximum external opening arrangements of the proposed building configuration (Fig. 2-40) are investigated. The case with

minimum external opening sizes should fulfil the requirement in terms of sufficient flow rates for cooling; while the maximum case is derived from the condition, where the opening layout is constrained by the building structure. The 
simulation results are evaluated by averaging the hourly data during the occupied hours of a specific month.

For the wind and buoyancy combined case, the modelling results (Fig.7-6) suggest that, as expected, the increase of opening size would enhance the absolute values of flow rates to some extent irrespective of external temperature. For the buoyancy alone cases (Fig.7-7), however, the increase of inlet and outlet sizes is not beneficial in terms of desired flow pattern during the warmer months. The reversed flow pattern occurs, though larger absolute values of flow rates are observed. Although the reversed flow pattern may not always be an issue, it may cause the thermal discomfort and air quality problem when the warmer air is driven into the occupied space. The monthly standard deviation of flow rates against floor levels under different envelope opening arrangements varies from 0.32 to $1.13\left(\mathrm{~m}^{3} / \mathrm{s}\right)$ for the buoyancy alone case; while it is between 0.35 and 0.51 $\left(\mathrm{m}^{3} / \mathrm{s}\right)$ for the wind and buoyancy combined case. The standard deviation for this case refers to how widely flow rates are dispersed from the average value (the mean) under two envelope opening arrangements. In terms of resultant air flow speed through the occupied spaces, the variation is less than $0.8 \mathrm{~m} / \mathrm{s}$ in general (Fig. 7-8). The negative flow speed represents the flow direction, which opposite to the design condition. The impact of envelope openings is relatively smaller than those caused by the building segmentation height as discussed in Section 7.3.1, where the smaller segmentation may cause the resultant flow speed over 1 $\mathrm{m} / \mathrm{s}$.

Furthermore, the influence of wind under the maximum envelope opening design condition (inlet $=40 \mathrm{~m}^{2}$; outlet $=20 \mathrm{~m}^{2}$ ) is examined by plotting its flow rates under two different ventilation conditions (Fig. 7-9). The results suggest that the required flow rates and desired flow patterns can be achieved with the help of wind forces. The standard deviation of flow rates is plotted against floor level to demonstrate the deviation between two different ventilation conditions (Fig. 7-9). The standard deviation $(\sigma)$ for this case refers to how widely flow rates are dispersed from the average value (the mean) under two ventilation conditions. 
The range of influence in terms of different arrangements of external opening sizes on the resultant internal air flow speed under different ventilation conditions is illustrated as Figure 7-10. The summer condition suggests that the maximum and minimum external opening arrangements may cause the variation of resultant air speed for about $0.2 \mathrm{~m} / \mathrm{s}$ between the two envelope opening arrangements, irrespective of ventilation conditions. For which is less than the impact caused by different building segmentation as discussed in Section 7.3.1.

From the design specification point of view, both the segmentation height and the sizes of envelope openings deserve equal concerns at the development of planning and design though with minor discrepancy between the two parameters. The issue for the external opening sizes should focuses on sufficient flow rates for cooling as well as undesired air draught through the ventilation openings with regards to the comfort wind environment. The sufficient flow rates for cooling have already been discussed massively in Chapter 5; while the comfort wind environment for the ventilation inlet of the bottom segment of the building in particular is presented in Section 5.3.4 and Section 6.3.2. For this subsection, the impact of envelope opening size is interpreted by the calculated flow rates as well as the resultant flow speed.

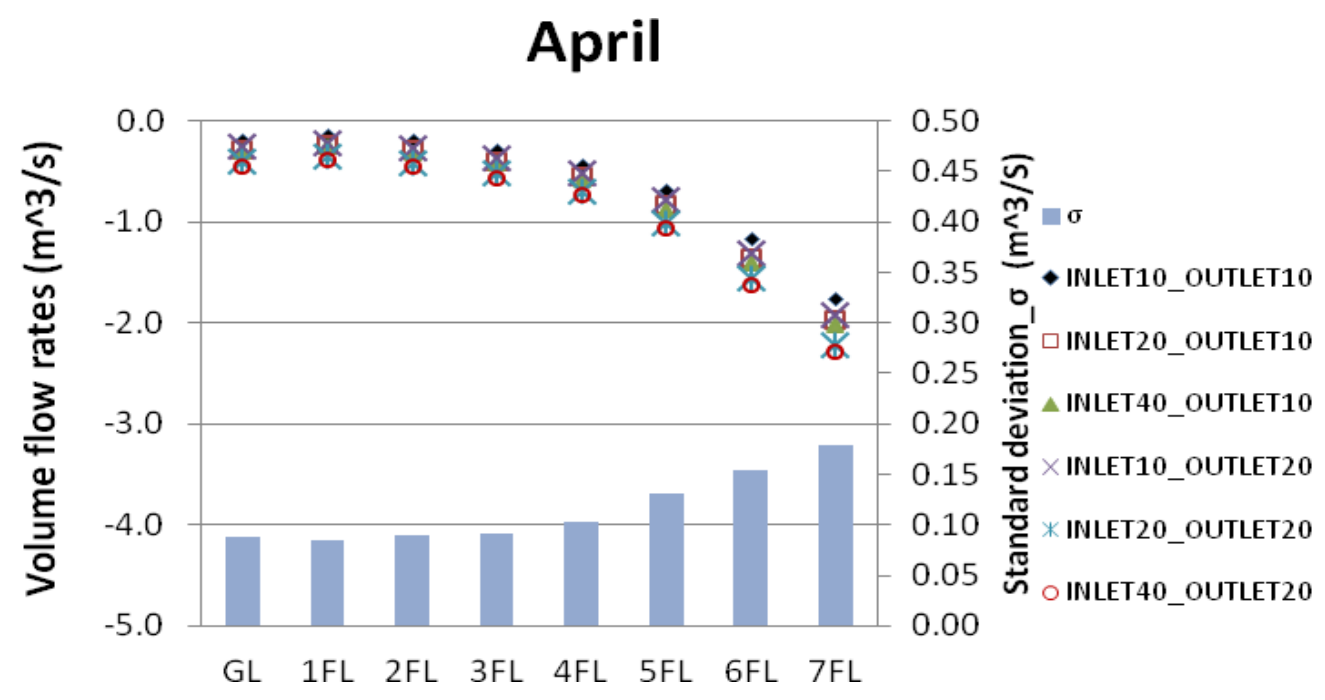




\section{August}

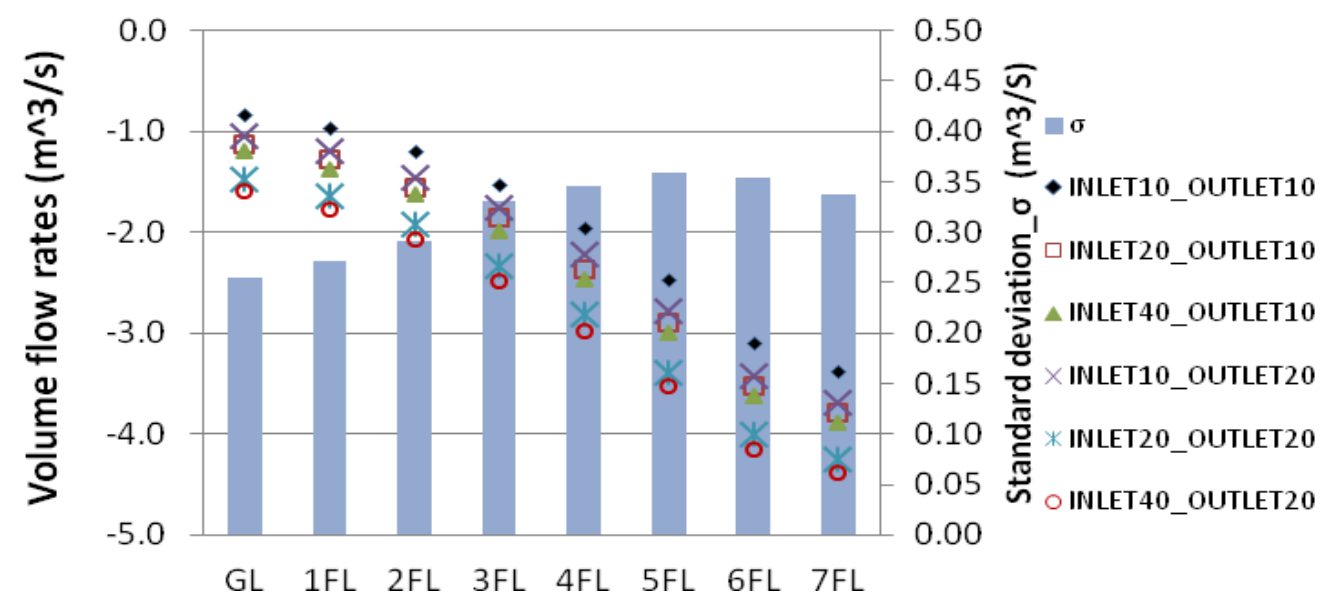

Figure 7-5: The effect of inlet/outlet sizes to the resulting flow rates. The 8 storeys segmentation case

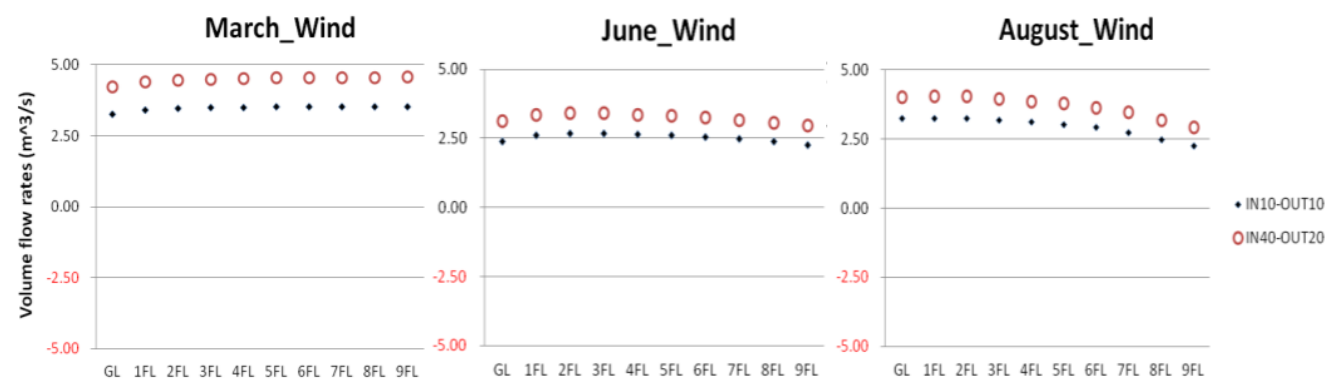

Figure 7-6: The effect of inlet/outlet sizes on flow rates/ Wind and buoyancy combined case/ 10 storey

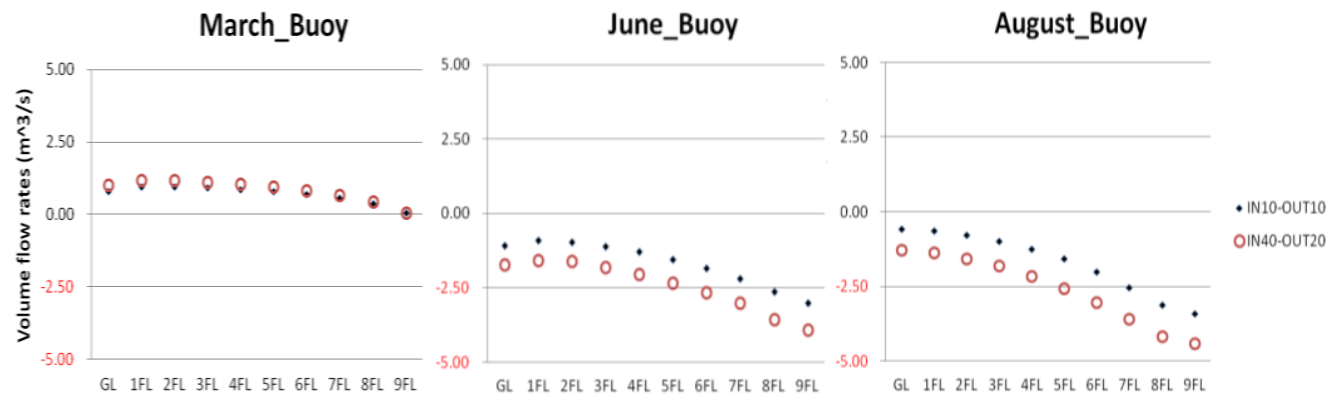

Figure 7-7: The effect of inlet/outlet sizes to flow rates/ Buoyancy alone case/ 10 storeys 

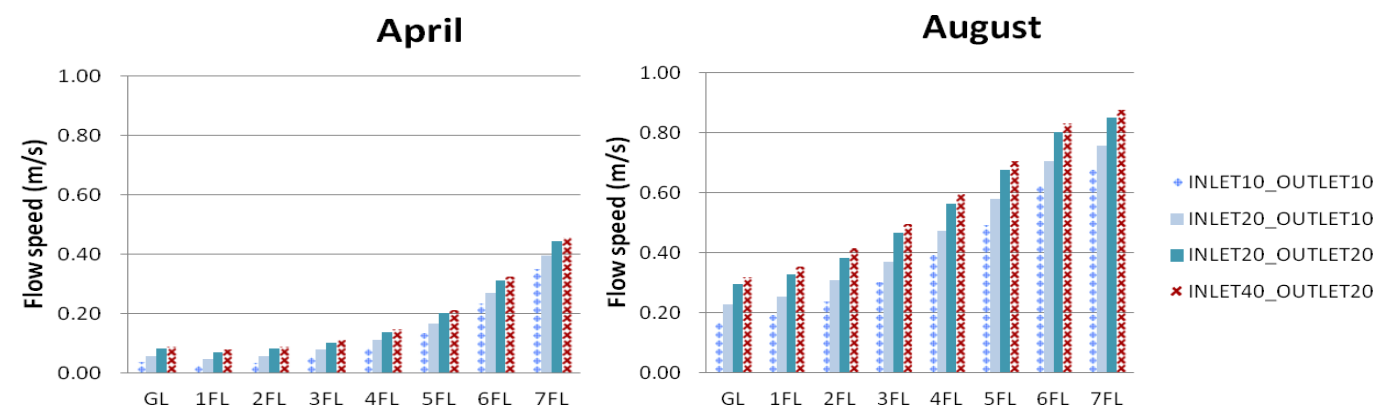

Figure 7-8: The deviation of flow velocities in terms of different external opening arrangements
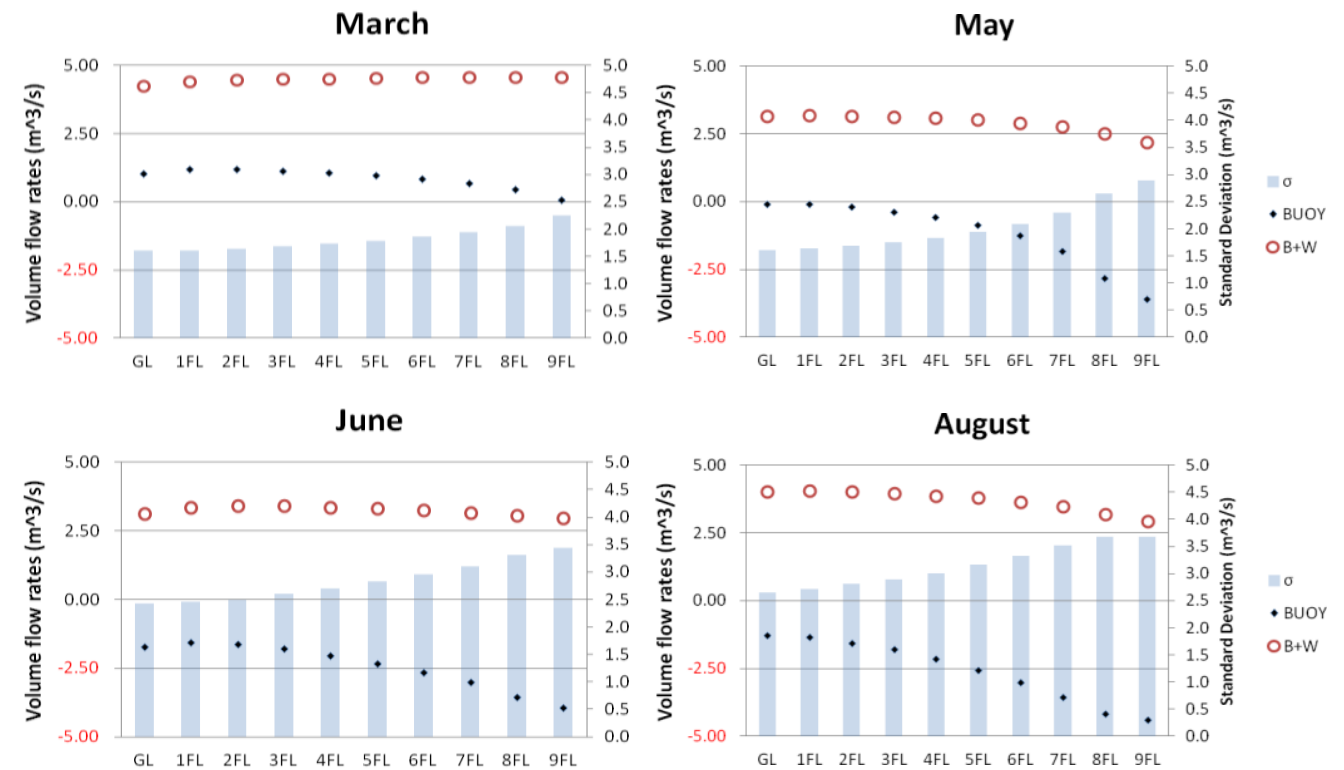

Figure 7-9: The effect of wind under the maximum opening design condition (inlet $=40 \mathrm{~m}^{2}$; outlet $=20 \mathrm{~m}^{2}$ )

August_IN10-OUT10

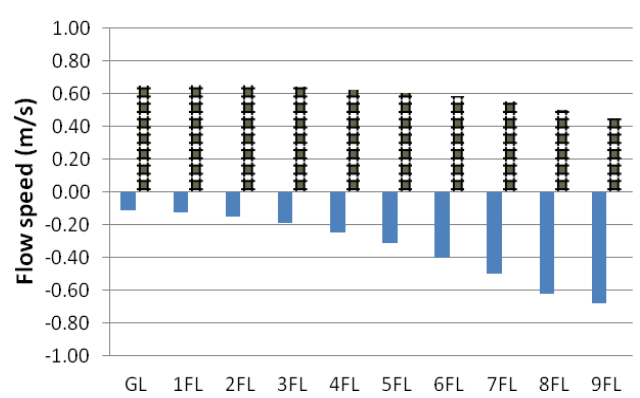

August_IN40-OUT20

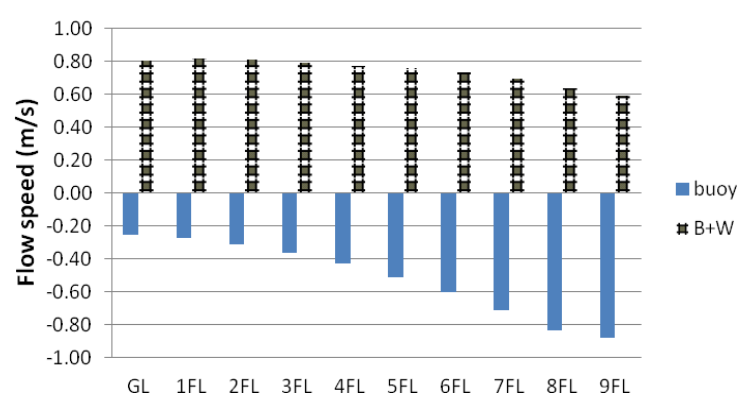

Figure 7-10: The range of influence with reference to flow velocity of different envelope opening arrangements under different ventilation condition 


\subsubsection{Internal heat gains}

In this sub-section, the 6 storey segmentation case is adopted. Three different internal heat gains with the combination of occupants, lighting and equipment gains are adopted for elucidating its influence on overall ventilation rates under the buoyancy alone condition. The heat gains due to the solar radiation are derived from the weather data on selected periods of simulation. The proposed building configuration has assumed a level of good design with regards to the thermal envelope, where the shading control is represented by different percentage of internal gains as presented in Figure 7-12. Accordingly, the impact of solar radiation and building orientation is expressed by different level of internal gains of the occupied spaces in this sub-section. The influence of internal gains on the resultant flow rates of associated office spaces can be investigated as well. The variance of the internal heat gains in this section are defined according to available references (ASHRAE, 2009 and BCO, 2009), which also correspond to different level of stationary work inside of the offices. The range of influence in terms of different arrangements of internal heat gains is expressed by the resultant flow rates against opening height as well as the hourly free running temperature of an occupied space on typical days of mid-season and hot summer.

The volume flow rates are plotted against opening height, which is defined from the ground level to the centre of the opening. The results (Fig. 7-11) suggest that the flow rates decrease gradually with the opening height. The openings here are the vents connected to the double-skin facades. The stack height between the vent at the top floor of building segment and the outlet located on top of the facades is limited, which constrain the resultant flow rates accordingly. Although the ventilation flow rates increase with the greater amount of internal heat gains (buoyancy effect), the internal temperatures are increased by 2 to $6{ }^{\circ} \mathrm{C}$ (depends on the variations of solar radiation in a day). The free running temperatures of an office in the mid-level of building segment are presented in Figure 7-12. It can be concluded that the impact of shading control is crucial for the resultant internal heat gains (along with solar, occupants, lighting and equipments). For the 
interpretation of comfort ventilation, the simulated free running temperatures (sensible cooling) as well as the velocity from bulk flow (personal cooling) are selected for this study.
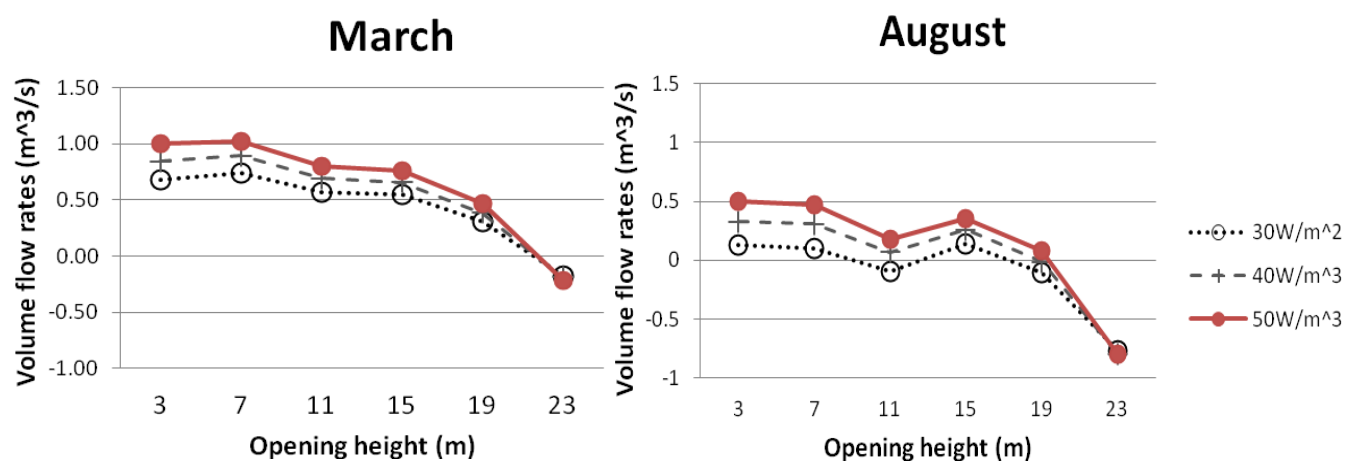

Figure 7-11: Volume flow rates against opening height by ranges of internal heat gains.

\section{8th March}
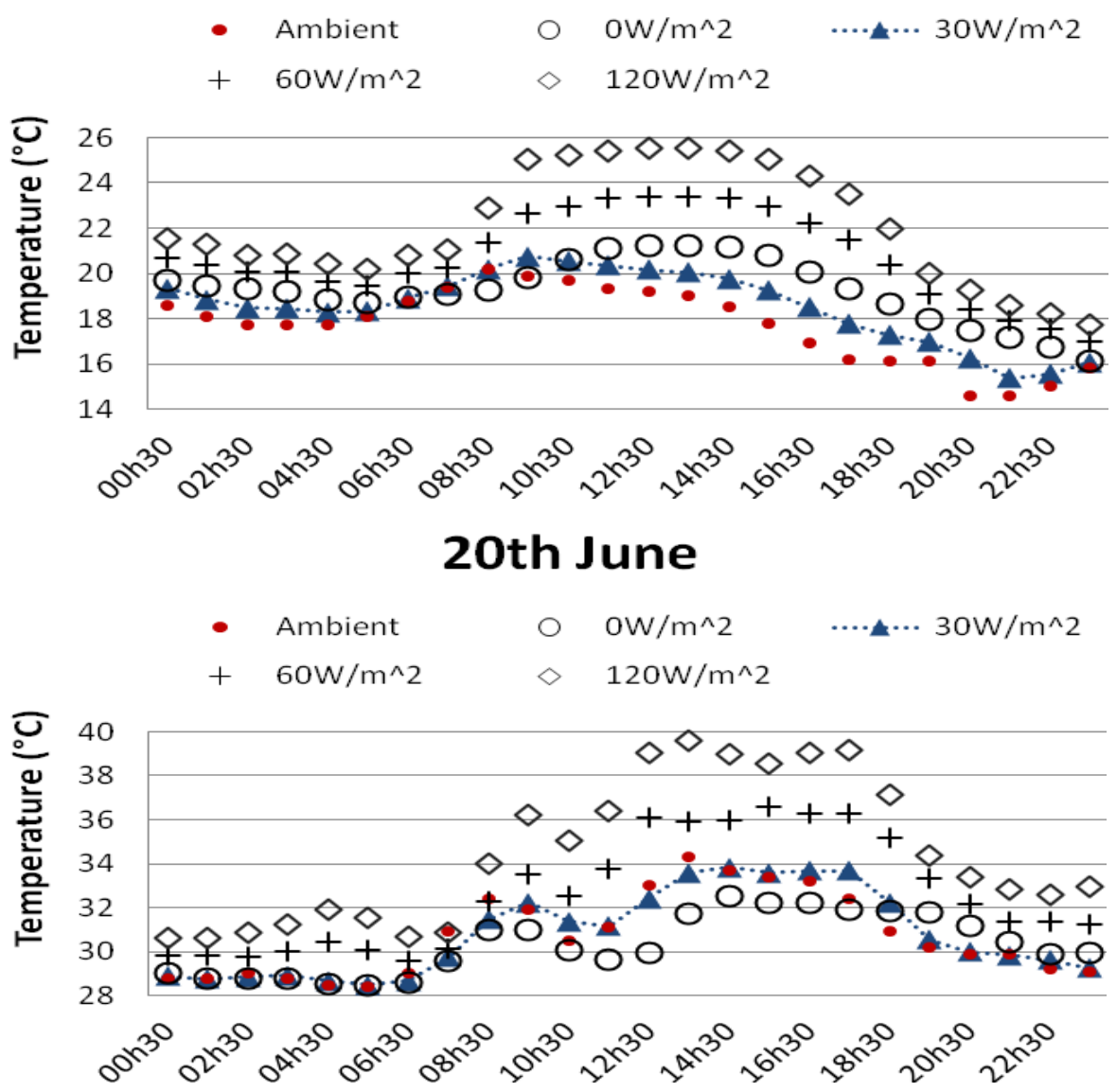

Figure 7-12: The free running temperature of the 3rd-level office by different arrangements of internal heat gains on typical days of mid-season and hot summer 


\subsubsection{Wind pressure coefficient}

For this sub-section, the influence of wind pressure coefficient on the resultant flow rates of chosen floor levels is examined. The base case building configuration as presented in Figure 2-40 is adopted for the following investigations. Three different set of wind pressure coefficient arrangements at the inlet and outlet are applied on the 12 storeys building segmentation case. For the proposed building configuration, the inlet locates in the bottom level of the southfacing side of the atrium segment; while the outlet is on the top of double-skin facades. The hourly modelling results on the date of $19^{\text {th }}$ of June are selected in this subsection. Theoretically, the wind direction and $C_{P}$ are unique functions of each other. So an assumed variation in $C_{P}$ could be considered to be a change in wind direction (the $C_{P}$ distribution is directly related to wind direction). Consequently, the influence of the wind direction on air flow rates can be derived from the sensitivity analysis referring to the wind pressure coefficient. The hourly plot of wind speed and wind direction on the day of $19^{\text {th }}$ of June is presented in Figure 7-13.

The modelling results as shown in Figure 7-14 demonstrate the influence of pressure difference across inlet and outlet on the resultant flow rates of the bottom floor. The deviation ( $\sigma$ ) of flow rates between three different $C_{P}$ arrangements vary from 0.5 to $3.2\left(\mathrm{~m}^{3} / \mathrm{s}\right)$. The standard deviation $(\sigma)$ for this case refers to the variation of flow rates from the average value at a particular hour, for which the average is derived from three different sets of pressure difference. The $\sigma$ value here can be compared with those in previous subsections. However, the approximate estimates of velocities from bulk flow rates may have more direct reflection from the aspect of personal cooling. That is, the resultant air flow speed of associated office spaces during mid-season and hot summer is plotted against floor level in Figure 7-15. The results suggest that the impact of the pressure difference on the resultant flow speed of the occupied spaces may be over $1.5 \mathrm{~m} / \mathrm{s}$ regardless of flow direction. In other words, the range of influence of wind 
pressure coefficient is more significant than those caused by internal heat gains, envelope opening sizes, and the building segmentation height as suggested in Section 7.3.1, 7.3.2, and 7.3.3, i.e. less than $0.8(\mathrm{~m} / \mathrm{s})$ for the impact of envelope opening size on the resultant flow speed through the internal opening.

It can be said that uncertainties in $C_{P}$ may lead to unreliability in the resultant flow rates. In this particular study, the $C_{P}$ values are only required for the inlet and outlet (the envelope openings). It is the difference of $C_{P}$ values between two envelope openings that matters. Similarly flow rate should be virtually proportional to wind speed when direction is constant and temperature difference between indoor and outdoor is small. Inappropriate assumption of the $C_{P}$ values may cause significant impact on the simulated flow rates (i.e. sensitive to wind direction). Investigations in terms of the reliability of the use of wind pressure coefficient dataset within ESP-r are discussed in Section 6.2. For which the adoption of pressure coefficient dataset is compared among the web-basis aerodynamic database, the full CFD simulations, and the inbuilt database of ESP-r program. The adequacy of the pressure coefficient being adopted in this study is demonstrated accordingly.

\section{9th June}

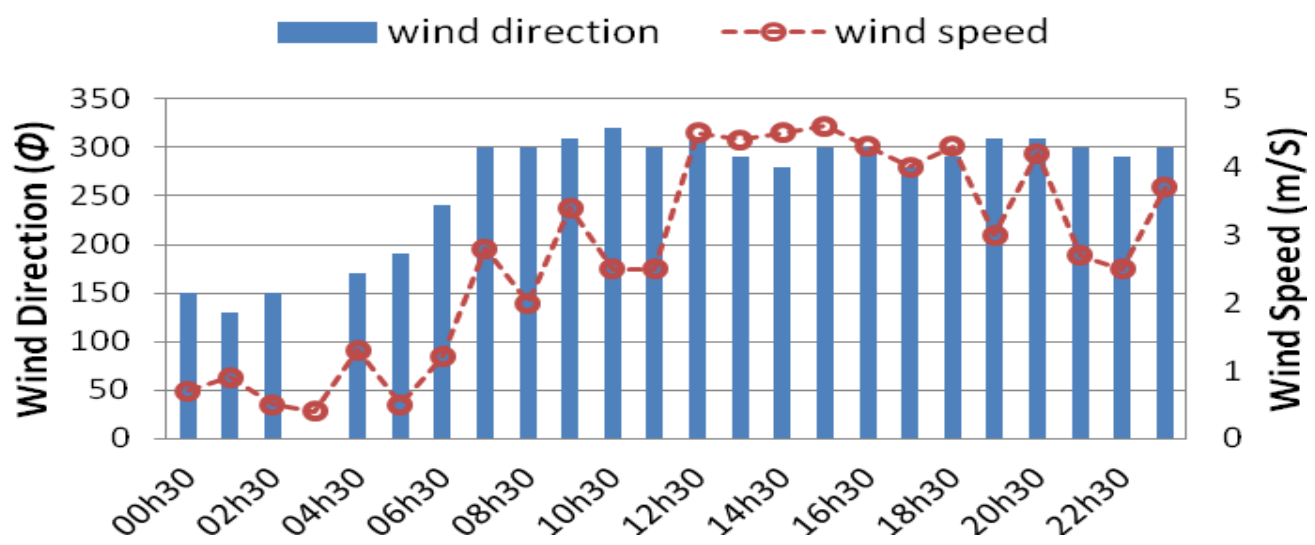

Figure 7-13: The hourly wind speed and wind direction on $19^{\text {th }}$ of June 


\section{Ground floor_19 June}

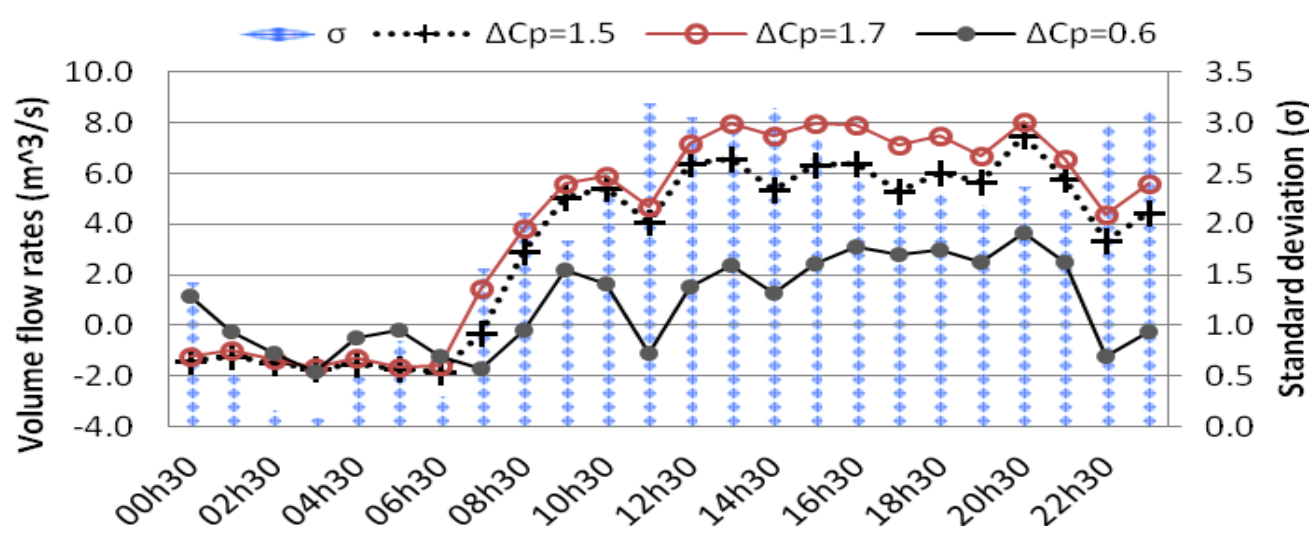

Figure 7-14: The influence of $\Delta \mathrm{C}_{\mathrm{P}}$ on the resultant flow rates and the hourly basis standard deviations between three modelling cases

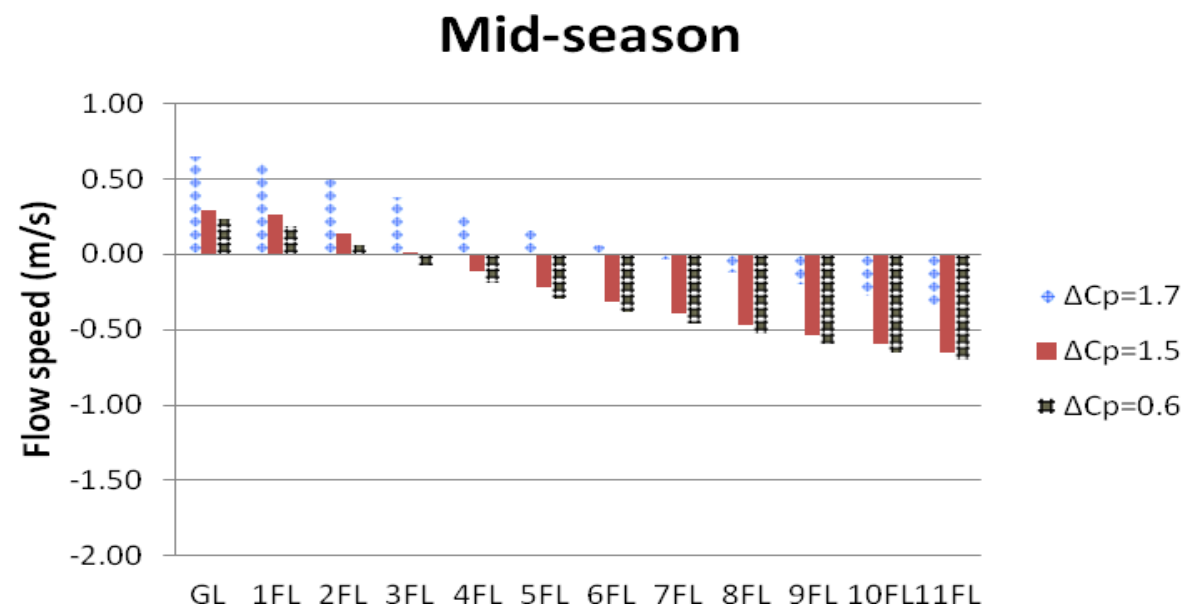

\section{Hot summer}

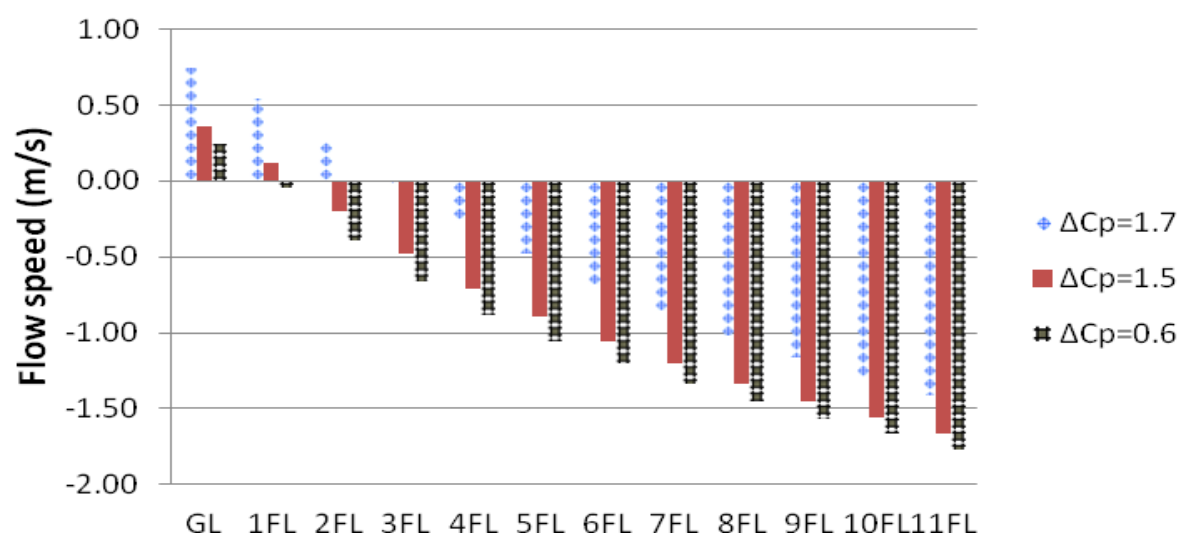

Figure 7-15: The estimated air flow speed from the ventilation bulk flow on typical days of the mid-season and hot summer 


\subsection{Temperature related parameters and the resultant flow rates}

In this section, the effect of temperature related parameters on the flow rates is investigated under the buoyancy alone condition. The isolated and segmented cases are adopted respectively for investigating the effect of segmentation under the low or no wind condition. The influence of buoyancy driven flow by the adoption of ventilated cavities (segmented atrium and double-skin facades) can then be found.

\subsubsection{The isolated case}

Firstly, the isolated case with two ventilated cavities (isolated atrium and doubleskin facade) on either side of the office space is examined (Fig. 7-16). In the case of isolated office space, consequently, the ventilation flow rates may be contributed by the temperature difference between indoors and outdoors or between two connecting zones. The connecting zones in this simulation case are between office space and ventilated cavities on either side. The simulated daily average volume flow rates (over the occupied hours) in months of March and August are plotted along with the external and simulated DSF temperatures under the same time-line. For the two selected months, the results show that the resultant flow rates of the isolated case are highly related to the ambient (external) temperature irrespective of simulation period applied ( $\mathrm{R}^{2}$ of 0.95 in March and $\mathrm{R}^{2}$ of 1.0 in August). However, the correlation coefficient $\left(R^{2}\right)$ against the temperature of ventilated cavities is relatively lower and may vary monthly (Fig. 7-17). The correlation coefficient is adopted to determine the relationship between two properties (i.e. between ambient temperature and the flow rates).

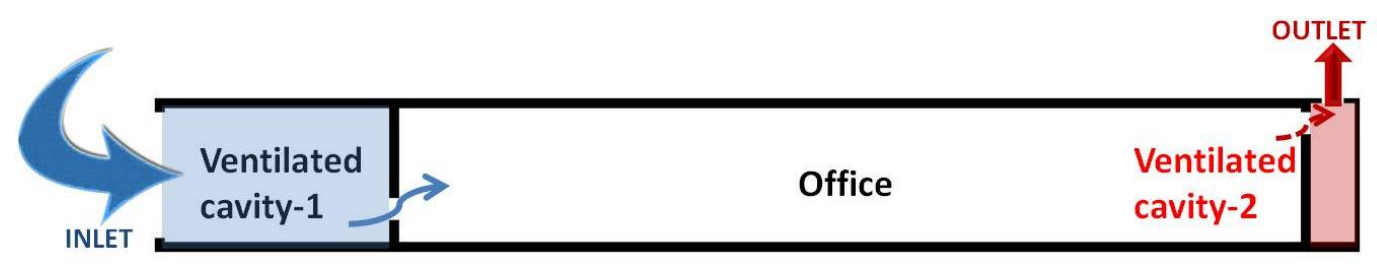

Figure 7-16: Section of the isolated case 
For the simple isolated case with no ventilated cavities, we would expect the total flow rates to be proportional to root $\Delta T$ (temperature difference between indoor and outdoor) according to the theory. However, with two ventilated cavities, two other temperatures are introduced as parameters, and the simple relation between flow rate and $\Delta T$ is less likely to be observed. This can be seen in Figure 7-18. The hourly flow rates are plotted against the corresponding root $\Delta T$ in this chart, which suggest that the correlation between these two parameters varies hourly. The model used in ESP-r is a dynamic model wherein thermal exchanges are modelled dynamically yet dynamic effects associated with the coupled air flow due to air inertia are not. It is suspected that the ventilated cavities continuously adjust their performance not only to the radiative heat transfer (heat being penetrate through the DSF into the adjacent zone and being captured by the DSF), but also to the convective cooling (the heat being removed by the cavity air). Also, the air flow network within ESP-r is based on the mass flow balance, for which the resultant flow rates may be constrained by either side of the cavities. It is therefore the calculated temperature of the DSF and/or office may not be appropriate for deriving the temperature difference for the correlation analysis between the resultant flow rates and root $\Delta T$. Previous studies (Manz and Frank, 2005; Kalyanova et al., 2007) suggested that further empirical experiments may be needed to validate the modelling results of a naturally ventilated double-skin façade system.

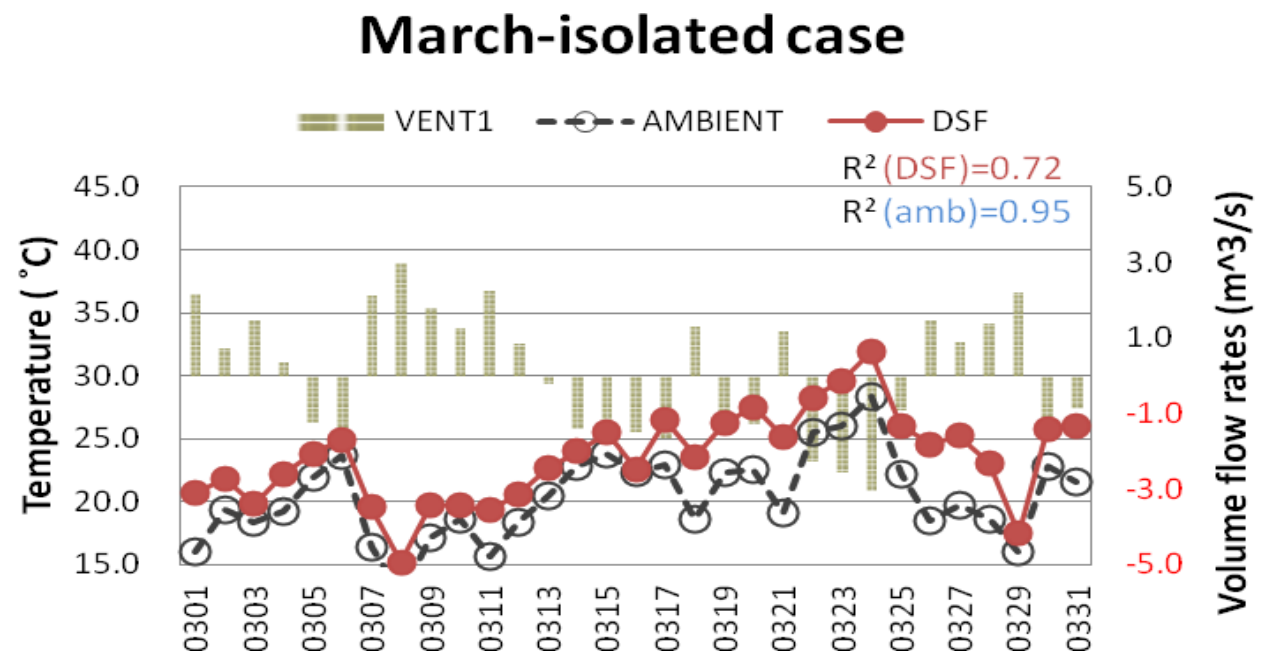

(a) 


\section{Augst-isolated case}

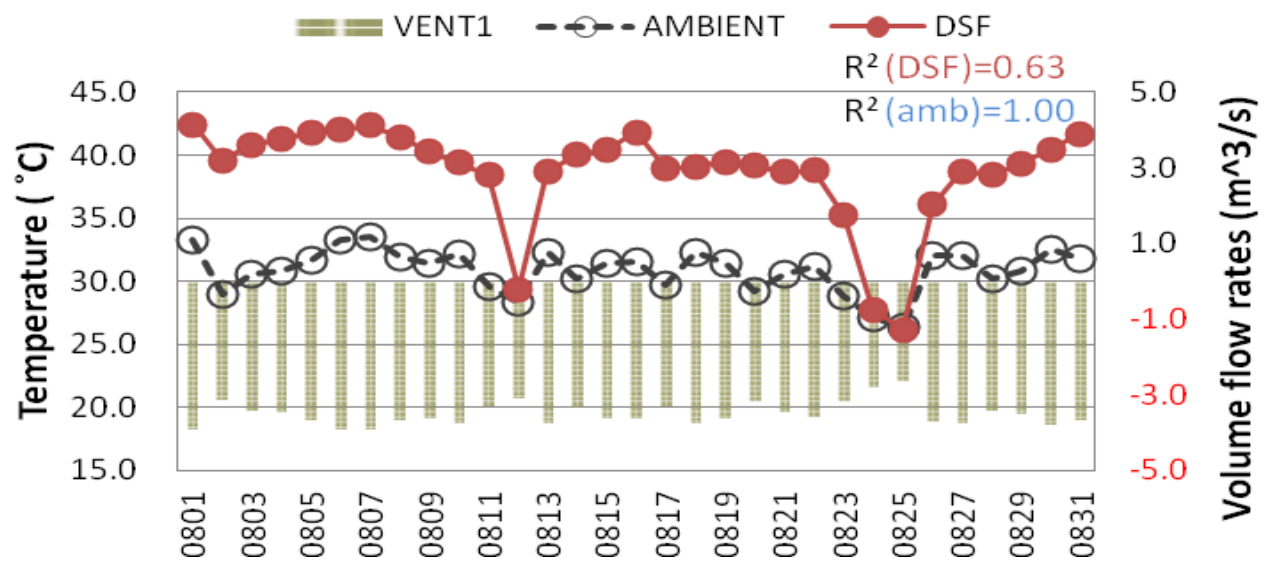

(b)

Figure 7-17: The daily plot of volume flow rates against external and ventilated cavity temperatures_ Isolated cases. The $\mathrm{R}^{2}$ is provided in the top-right corner of the graph. (a) March; (b) August

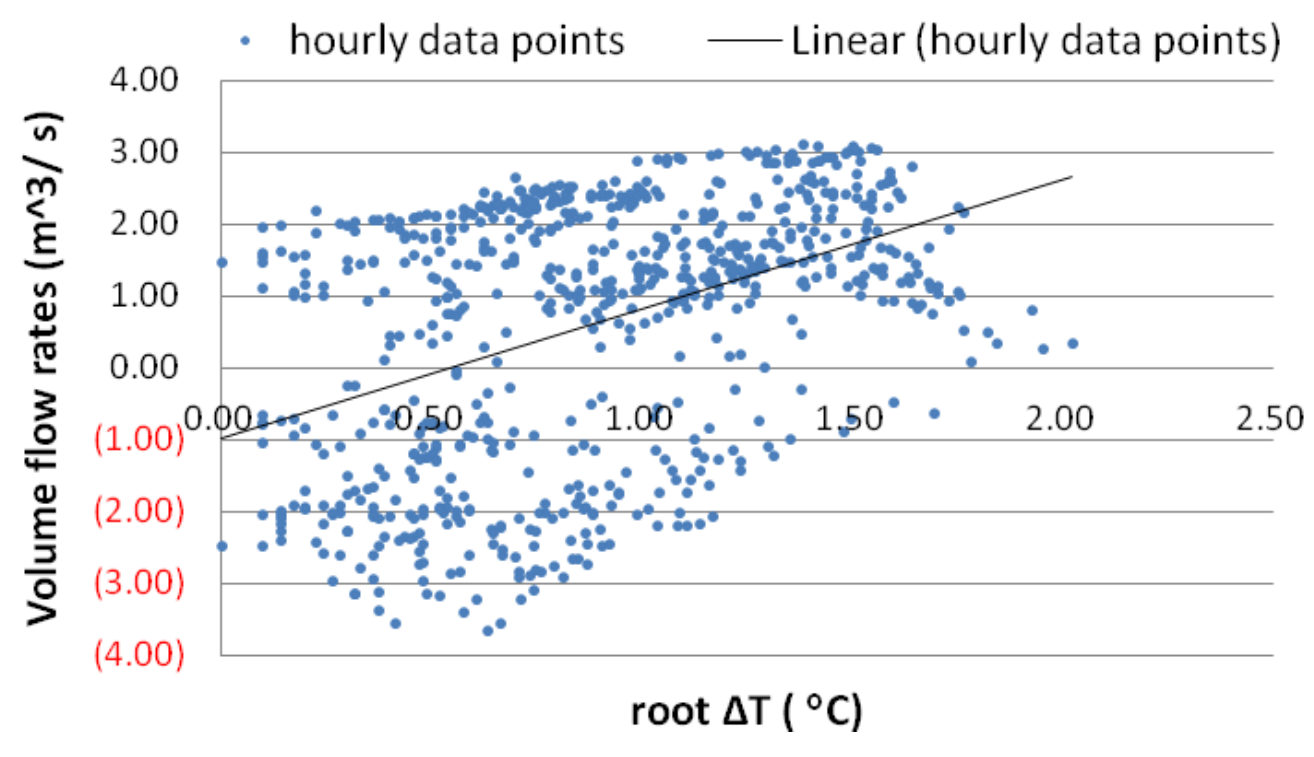

Figure 7-18: Illustration of the calculated hourly volume flow rates through the DSF cavity against the root temperature difference between the DSF cavity and ambient temperature for the buoyancy alone condition. 


\subsubsection{The segmented case}

The base case building configuration (Fig. 2-40) with 12 storeys segmentation height is adopted as the study model in this sub-section. The same analysis approach as adopted in the isolated case is applied for the segmented case. However, the hourly volume flow rates of the typical weeks rather than the daily average data over a month are plotted along with temperature related parameters to examine its corresponding correlation values. Two weeks in March and June are selected respectively for representing the typical week of that particular season. The typical week for the spring of Taipei is between $22^{\text {nd }}$ March and $28^{\text {th }}$ March; while $19^{\text {th }}$ to $25^{\text {th }}$ of June is for the summer. The method adopted to decide the typical week was described in Section 6.3.2.

The temperature related parameters as well as the stack height are regarded as the potential drivers for buoyancy driven flows in the proposed building configuration. The associated temperatures on the bottom and top of the building segment as presented in Figure 7-19 are selected for examining the buoyancy effect on the resultant flow rates. Firstly, the external temperature is plotted along with the volume flow rates of the bottom and top floor. The results as presented in Figure 7-20 and Figure 7-21 suggest that the flow rates are negatively correlated to the external temperature. Higher correlation, in terms of relationship between the flow rates and external temperature, is observed in the top floor because of the limited stack height of this floor. The overall buoyancy effect of the top office is dominated by the external temperature in this case. The bottom floor, however, extra buoyancy force due to stack height between the vent intake of the bottom floor and the outlet at the top of DSF should be taken into consideration. Consequently, the ventilation performance of the top floor of the segmented case can be regarded as the same as that in the isolated case. For which the overall flow rates are more sensitive to the external temperature (Fig. 7-17). 


\section{2th 28th March_bottom}

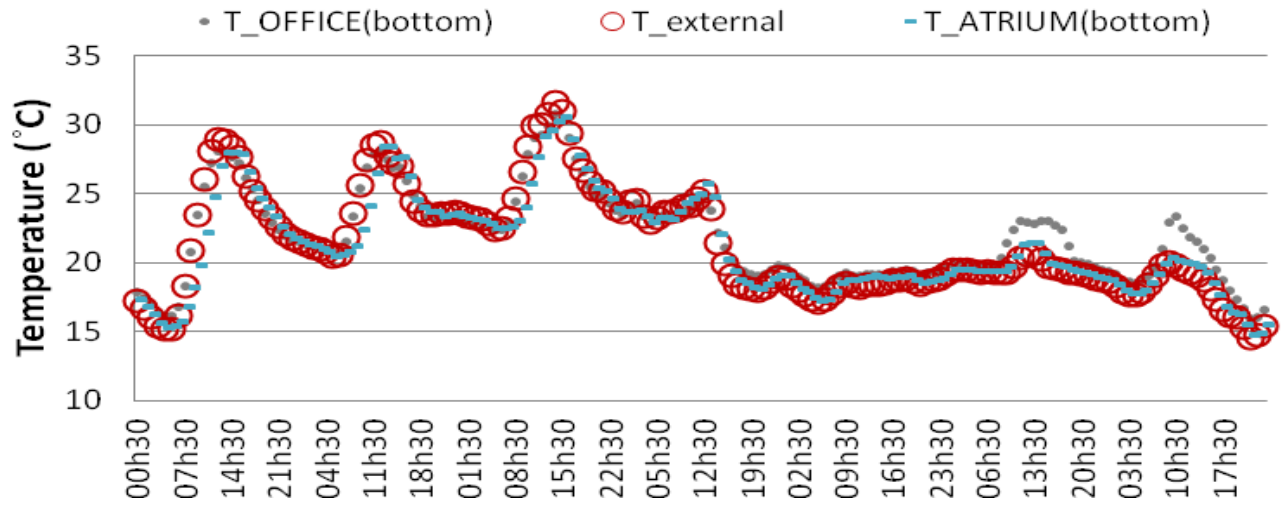

(a)

\section{9th 25th June_top}

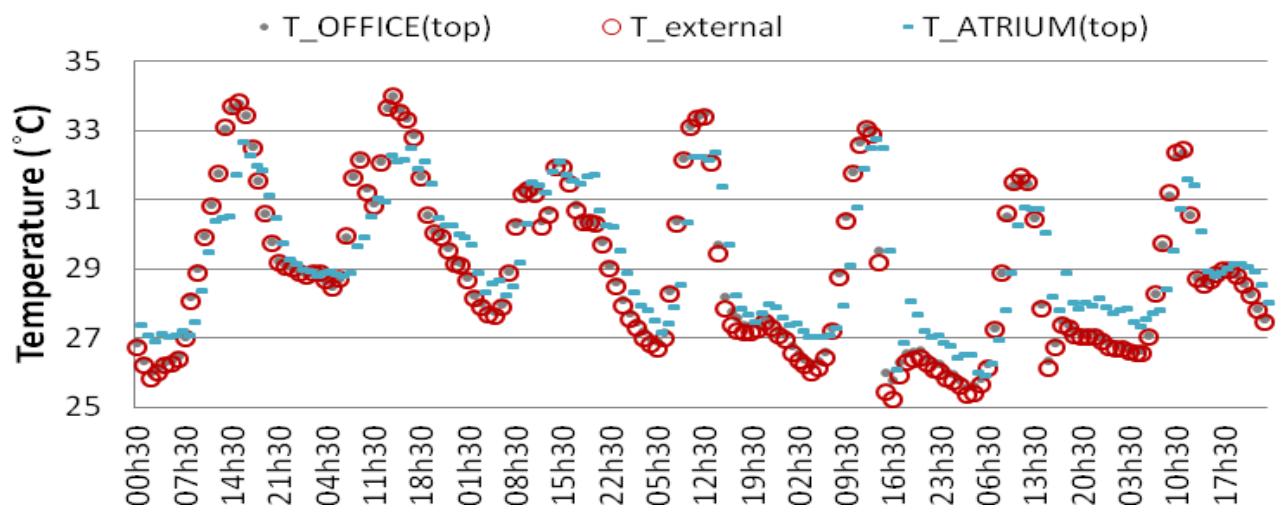

(b)

Figure 7-19: The temperature plot of selected building spaces in the typical weeks. (a) The bottom floor of spring period; (b) The top floor of summer period

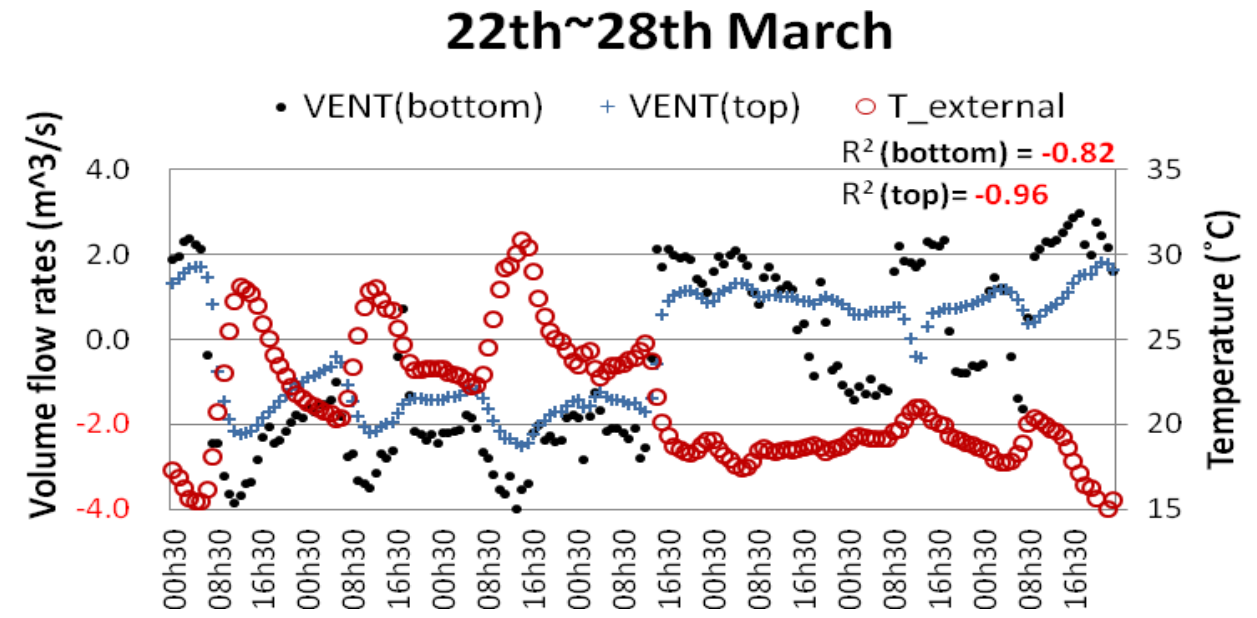

Figure 7-20: Correlation analysis for the $T_{\text {external }}$ V.s volume flow rates $\_22^{\text {th }}-28^{\text {th }}$ March 


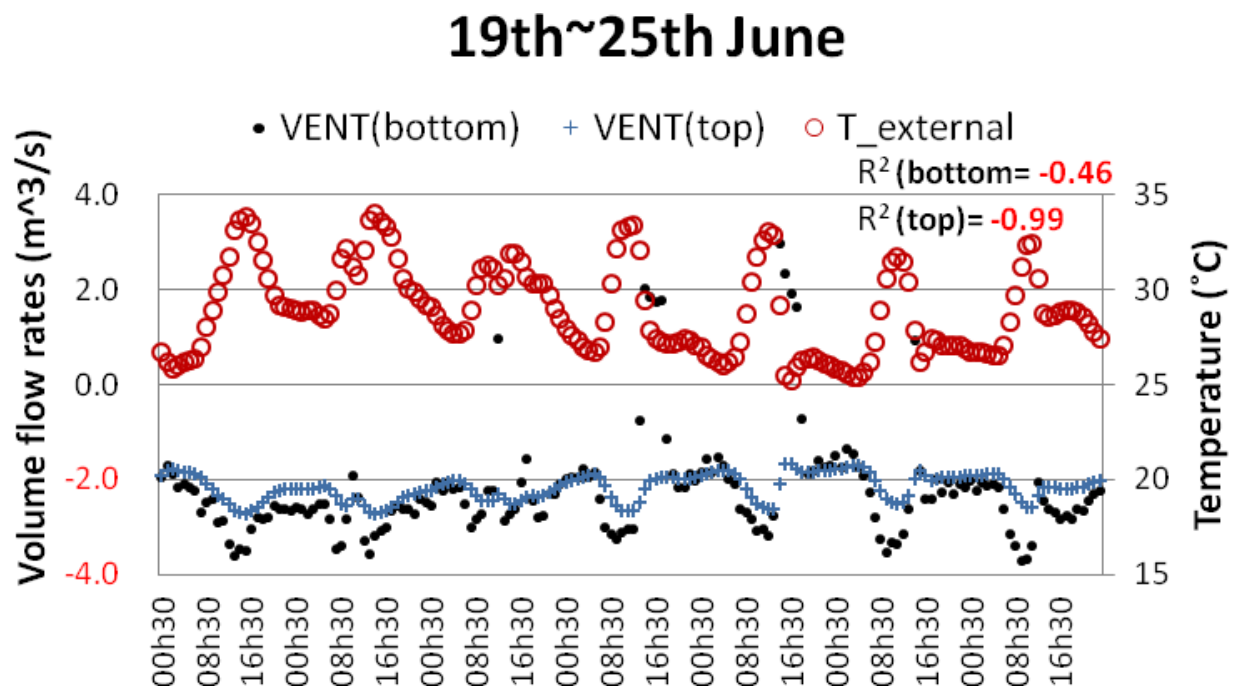

Figure 7-21: Correlation analysis for the $T_{\text {external }}$ V.s volume flow rates $-19^{\text {th }}-25^{\text {th }}$ June

Furthermore, the correlation between the $\Delta T$ (temperature difference between indoors and outdoors, where the $\Delta T=T_{\text {indoor }}-T_{\text {ambient }}$ ) and the resultant flow rates is investigated. Although the total flow rates are not really proportional to root $\Delta T$ as observed in the isolated case, the relative sensitivity can be demonstrated by comparing the $\mathrm{R}^{2}$ values by floor levels as well as by varied segmentation height basis in the segmented case. As seen (Fig. 7-22 and Fig. 7-23), the results are positively correlated to the volume flow rates in the lower floors and the correlation decreases with floor levels accordingly for both typical weeks. These results show that the flow rates increase with larger temperature difference between indoors and outdoors as expected. For which the larger indoor temperature or lower ambient temperature may increase the resultant flow rates (disregarding flow direction) to some extent. As addressed earlier, the ventilation performance of the top floor of the segmented case can be regarded as the isolated case. It is observed that the $\mathrm{R}^{2}$ value between the flow rates and $\Delta T$ of the top floor is smaller than that in the bottom level. It is supposed that exhausted heat flow would accumulate in the offices of upper levels where the office temperature is not solely contributed by the internal artificial heat gains and external solar radiation. That is, the correlation for temperature difference in high levels is smaller than those of lower floors under the buoyancy alone condition. 
Generally speaking, the influence of weather data on the input side can be examined by studying the sensitivity of the climatic variables in the weather file by the use of envelope flow model. However, quantitative generalizations regarding the influence of external climate on the thermal behaviour of a building structure are very difficult to make. Sensitivity analysis of building energy performance for time-varying variables will require an integration of time series techniques (averages) into building energy analysis as suggested by Lam and Hui (1995). This is what is done for the isolated case at the beginning of Section 7.4.

For the segmented case, however, the effect of stack height is included along with the temperature difference between indoors and outdoors for evaluating their overall influence on the resultant flow rates. Thus, the hourly data of a typical week is selected for verifying the corresponding interaction between ventilation flows and temperature related parameters. Although the same issue in terms of reliability of modelling the naturally ventilated double facades as addressed in Section 7.4.1 still exists, the comparison results with reference to the $\mathrm{R}^{2}$ values between the bottom and top floors of the building segment do provide an initial understanding for the effect of segmentation on the flow rates through the associated office spaces under the low or no wind condition.

\section{2th 28th March}

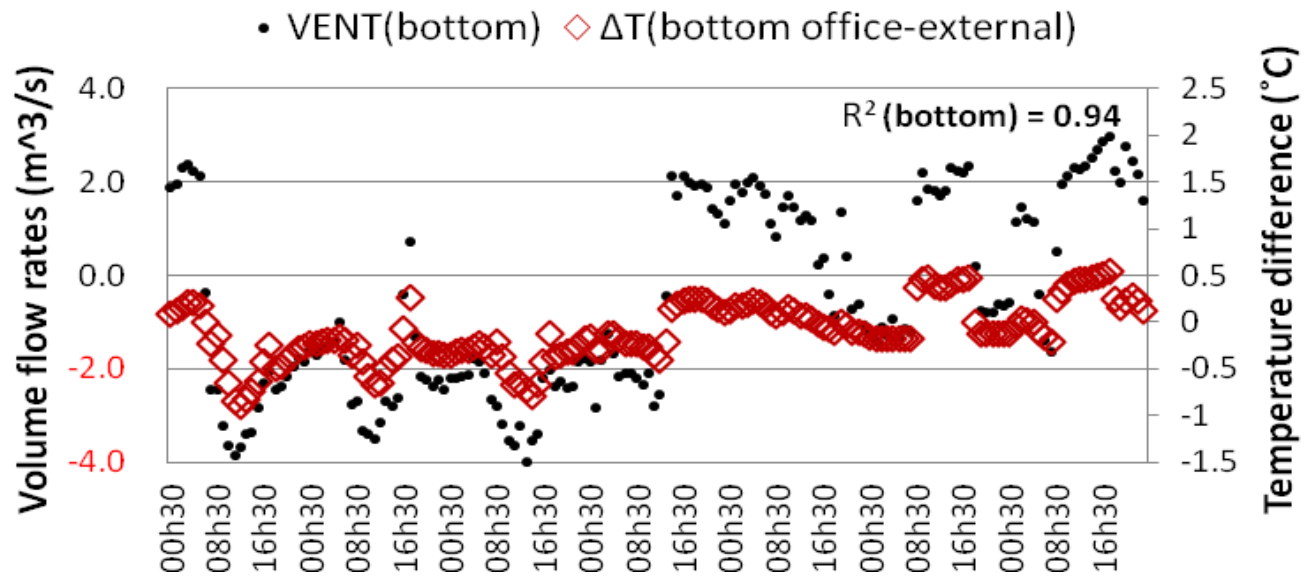

(a) 


\section{2th 28th March}

+ VENT(top) $\square \Delta T$ (top office-external)

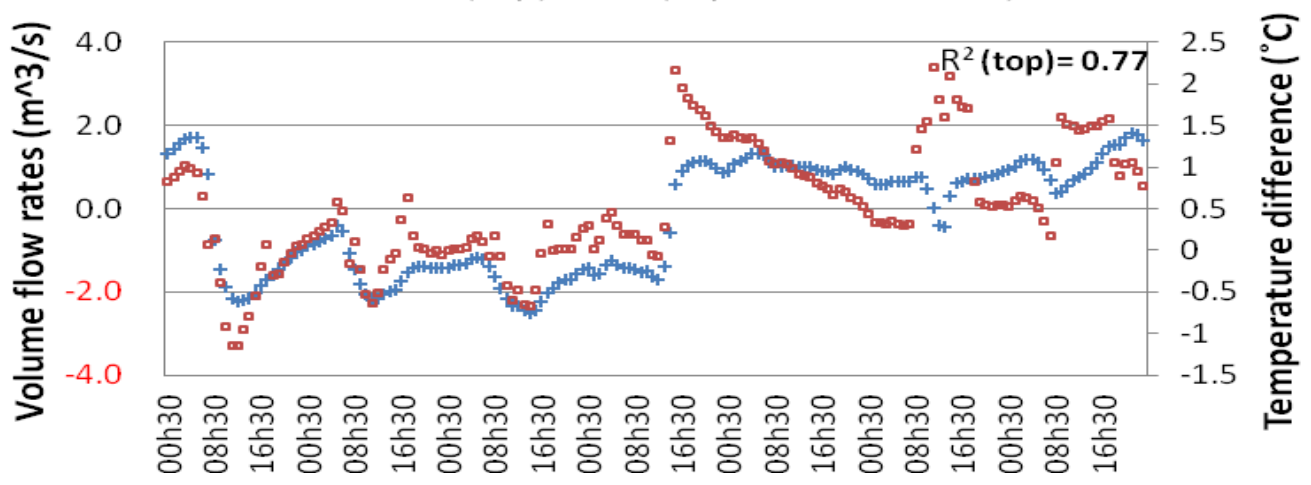

(b)

Figure 7-22: Correlation analysis for the temperature difference between indoors and outdoors v.s volume flow rates_ $22^{\text {th }}-28^{\text {th }}$ March. (a) The bottom floor; (b) The top floor

\section{9th 25th June}

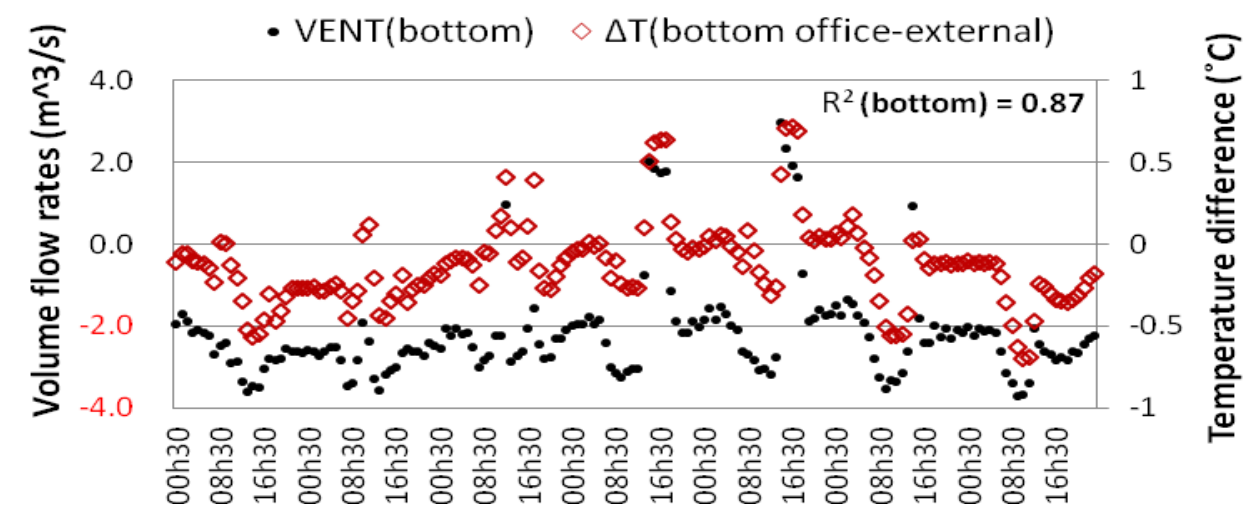

(a)

\section{9th 25th June}

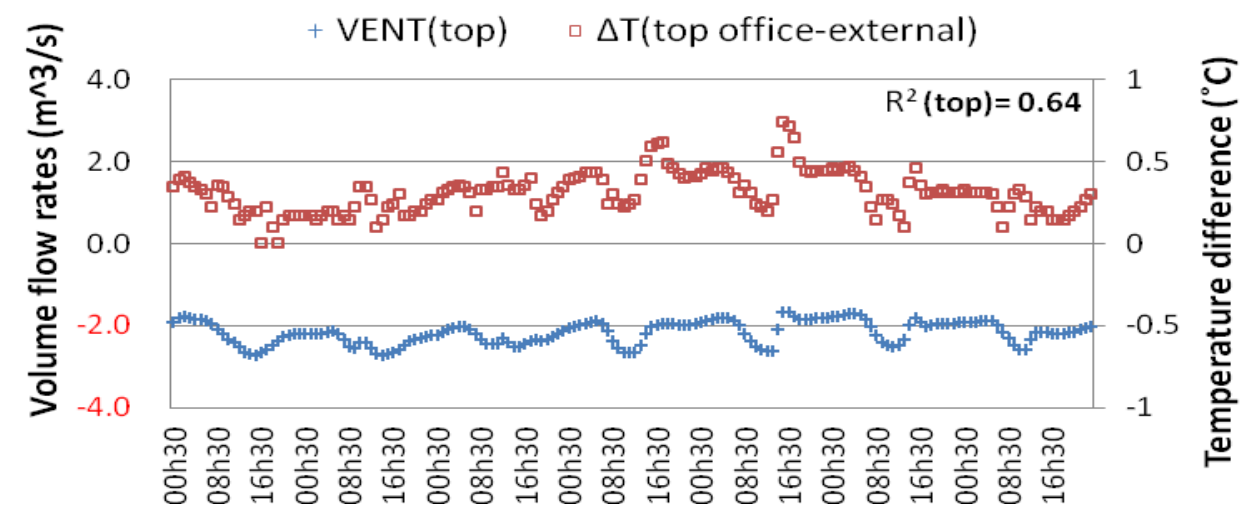

(b)

Figure 7-23: Correlation analysis for the temperature difference between indoors and outdoors v.s volume flow rates $\_19^{\text {th }}-25^{\text {th }}$ June. (a) The bottom floor; (b) The top floor 


\subsubsection{Sensitivity analysis with reference to building segmentation height}

In this sub-section, the level of sensitivity of varied segmentation height to the temperature related parameters is investigated under the buoyancy alone condition. The correlation coefficient $\left(\mathrm{R}^{2}\right)$, in terms of the relationship between flow rates and external temperature and to the $\Delta T$ respectively, is evaluated under different segmentation height. Specific segmentation height (the seven-storey case), where the variation trend (in terms of $\mathrm{R}^{2}$ values) changes, is selected for further parametric analysis with reference to all others temperature related parameters in the later sub-section.

Firstly, 5 different building segmentations are chosen for examining the corresponding correlation between flow rates and external temperature. The variation trend against floor levels is illustrated as Figure 7-24. It is found that the variation trend in terms of $R^{2}$ values may change (i.e. the $R^{2}$ values increase with floor level) when the segmentation height of over 7 storeys is adopted. The $\mathrm{R}^{2}$ value for this case can be interpreted as the proportion of the variance in flow rates to the variance in external temperature. For the cases with segmentation height over 8 storeys, the $\mathrm{R}^{2}$ increases with floor levels irrespective of simulation periods being adopt. The $\mathrm{R}^{2}$ values of the 5 storey segmentation case, however, decreases with floor height. The same trend is observed for the lower levels of the 7 storeys case irrespective of simulation periods (Fig. 7-24).

Additionally, the correlation between flow rates and $\Delta T$ (temperature difference between indoors and outdoors is investigated and presented as Figure 7-25. It can be seen that the $\mathrm{R}^{2}$ values between the resultant flow rates of associated office spaces and the $\Delta T$ are decreasing gradually irrespective of simulation periods, when the building segmentation height over 8 storeys is applied. Different variation trend is observed for the cases with smaller segmentation height, namely below 7 storeys. Theoretically, one would expect to see a strong correlation between flow rates and $\Delta T$. This is clearly the case for most floors. The upper 
floor, however, where with the least correlation is not acting as what we would expect. It is stipulated that the ventilation performance of the top floor of the segmented case is similar to that of the isolated case for its limited stack height. Therefore, the results obtained from the isolated case may be applied, which suggest that the flow rates through the isolated offices are much affected by the response of ventilated cavities to the radiative heat transfer and the heat being removed by the cavity air under the low or no wind condition.

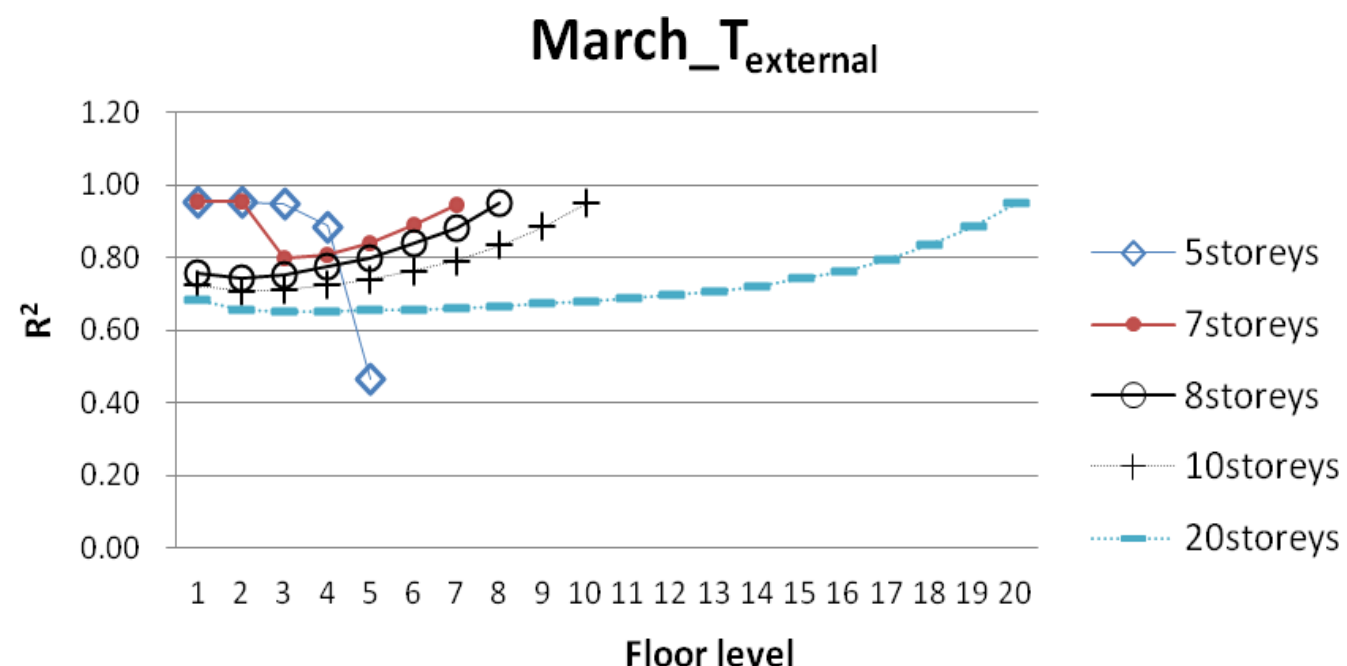

(a)

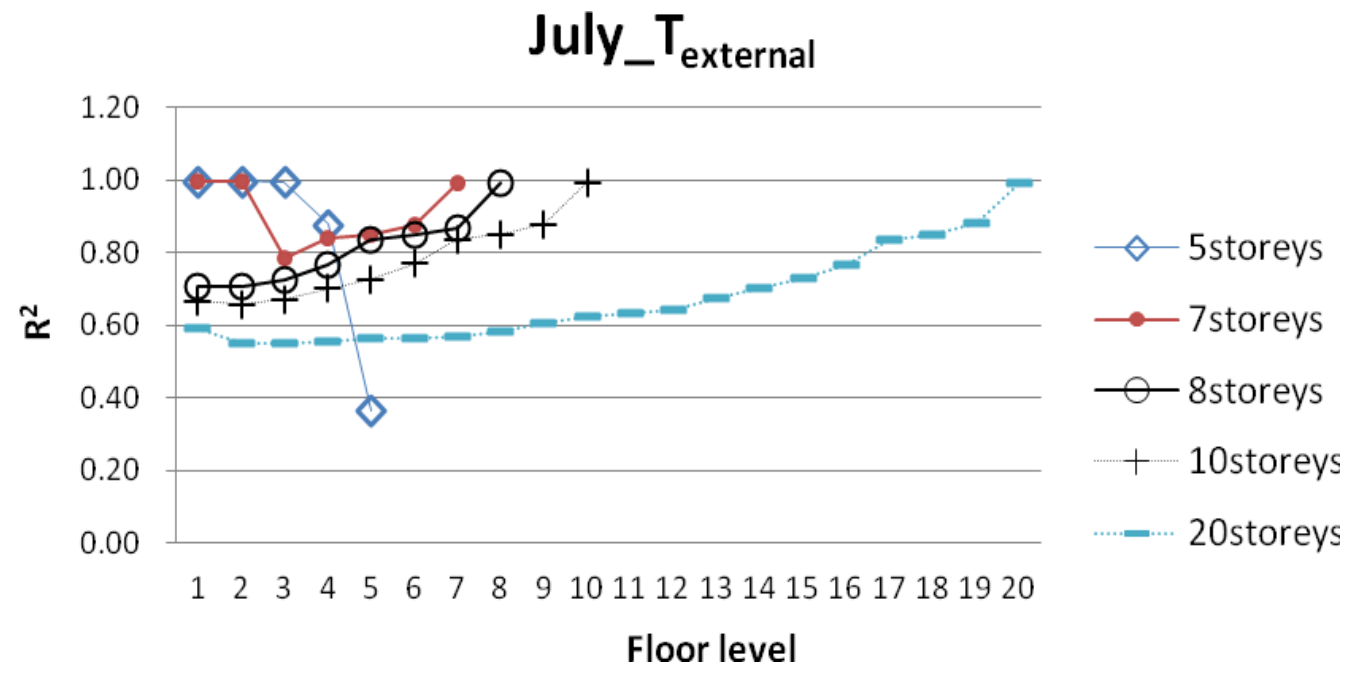

(b)

Figure 7-24: The correlation between flow rates and external temperature against floor levels by different building segmentation height. (a) January; (b) March; (c) July 


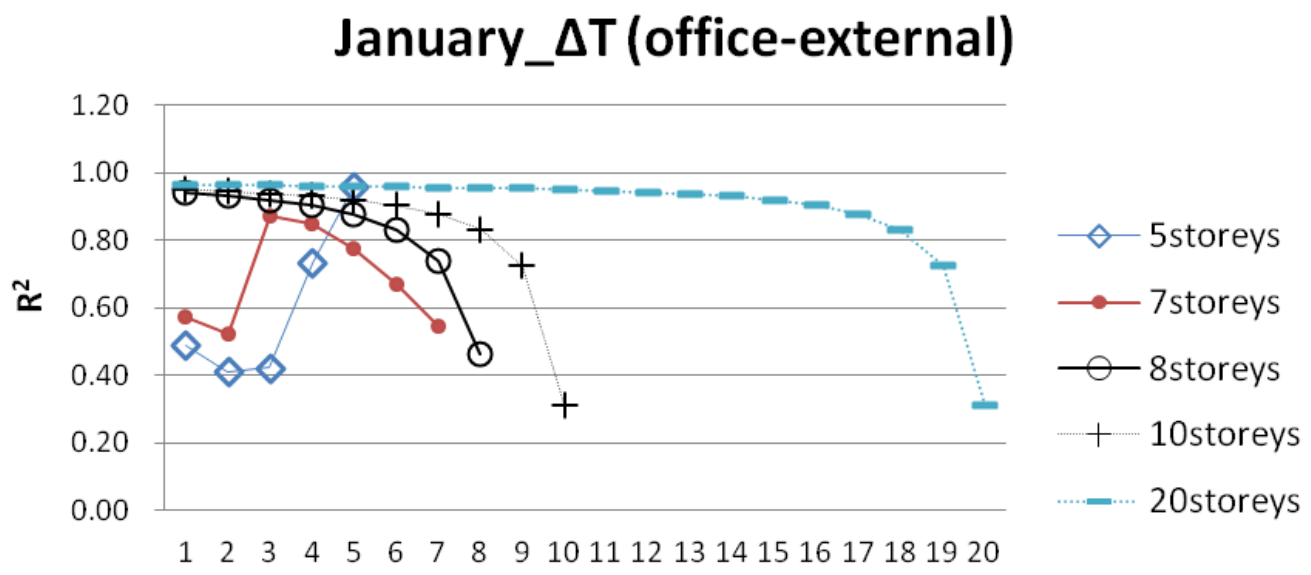

Floor level

(a)

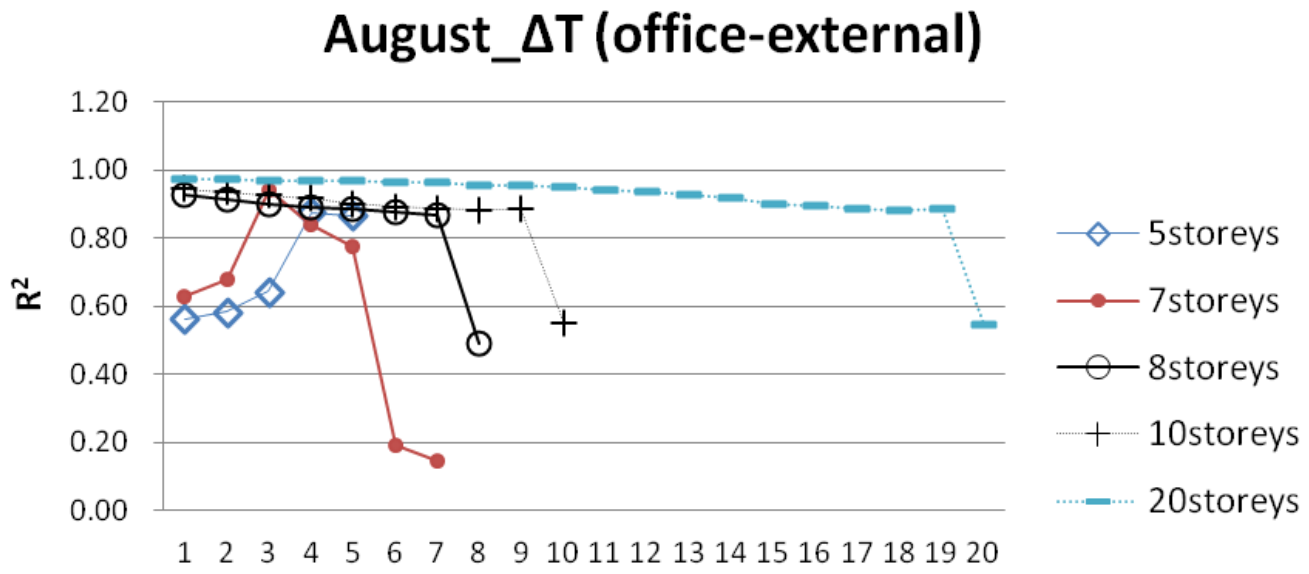

Floor level

(b)

Figure 7-25: The correlation between flow rates and temperature difference between indoors and outdoors by different building segmentation height. (a) January; (b) August

From the above observation, it is interesting to note that the transitional relationship between flow rates and temperature related parameters is observed in the 7 storeys segmentation case. That is, further analysis is conducted for the 7 storeys segmentation case for elucidating the corresponding relationship between flow rates and individual temperature related parameters. The correlation results as shown in Figure 7-26 suggest that zone temperatures, namely the atrium, office 
and DSF, are positively correlated to the flow rates through the occupied spaces. The temperature difference between the indoors and outdoors as well as the temperature difference between the DSF and office, however, are negatively correlated to the resultant flow rates of associated occupied spaces. Higher correlation is found between the ambient temperature and the resultant flow rates irrespective of floor levels (with negative correlation coefficient of -0.9) when compared with otherwise temperature related parameters.

An interesting point is found between the 2nd and 3rd level of the 7-storey segmentation case (an opposite variation pattern). The influence of temperature difference between indoors and outdoors is more significant to the volume flow rates in these two levels. The results as shown in Figure 7-26 suggest that the first two floors of the 7-storey case are highly and negatively correlated to the ambient and room temperature; while the mid levels, from 3rd to 5th level, are influenced greatly by the ambient temperature as well as temperature difference between indoors and outdoors. It is speculated that the opposite driving forces exist in the 2nd and 3rd level which cause such a variation pattern.

As seen, the temperature difference between indoors and outdoors is highly and positively correlated to the flow rates in the $3^{\text {rd }}$ floor level irrespective of simulation periods, where the $\Delta T=T_{\text {indoor }}-T_{\text {external }}$. These results imply that the flow rates would increase with larger $\Delta T$. In other words, the larger indoor temperature or lower ambient temperature might increase the flow rates to some extent. The $2^{\text {nd }}$ floor level, however, is more sensitive to the ambient and office room temperature. Its negative correlation coefficient suggests that the higher office room and ambient temperature will result in reduction of flow rates of the $2^{\text {nd }}$ floor. The conclusion for the $2^{\text {nd }}$ level is opposite to those made in the $3^{\text {rd }}$ floor level in terms of office room temperature. Consequently, the reason why an opposite variation trend being observed between the $2^{\text {nd }}$ and $3^{\text {rd }}$ level is explained. 
As a general rule, $Q_{t o t}$ increases with $\Delta T$, where $Q_{t o t}$ is the total ventilation rates of a building. The individual flow rates through openings may not behave in this way, but it would not be surprising if they did. Generally speaking, the segmentation height of over eight storeys is beneficial in terms of control issue, for which the dominating factors for the flow rates under the buoyancy alone condition are consistent. Although the low or no wind condition rarely happens in the climatic context of Taipei (as identified in Section 7.3.1), it still provide an insight for dealing the weather extremes or the scenario when the wind is blocked by surrounding obstructions.

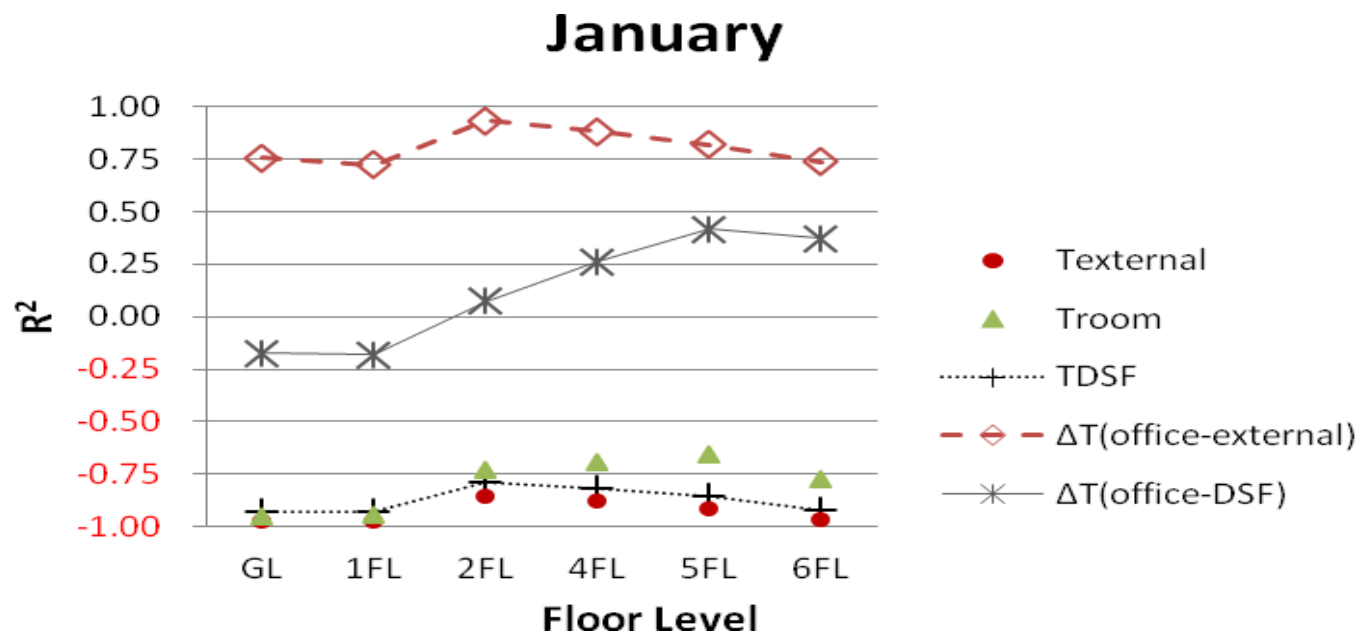

(a)

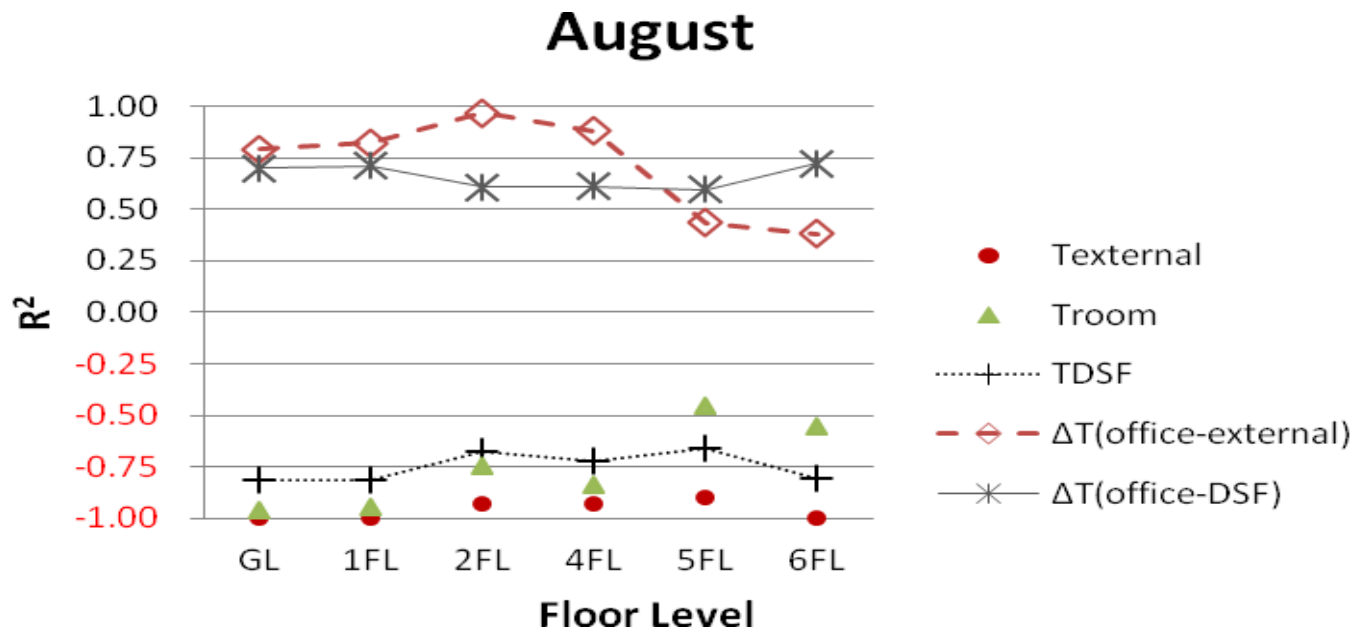

(b)

Figure 7-26: Correlation between the temperature related parameters and flow rates_7 storeys segmentation case. (a) January; (b) August 


\subsection{Summary}

In this chapter, the purpose of a parametric study is to determine which input parameters exert the most influence on simulation output. The significance and impact of various ventilation related parameters on the calculated flow rates and resultant flow velocities from the calculated bulk flow are provided for demonstrating the potential influence on personal cooling; while the free-running temperatures are useful for some direct insight for sensible cooling. It is hoped that the information obtained would provide some guidance at the planning and development of a naturally ventilated tall building design. The theory background and relevant reviews on parametric study are summarized in Section 7.1. The approach for carrying out the proposed investigations is decided and clarified accordingly. In Section 7.2, the plan for parameter study as well as the key variables and their corresponding variance for this particular study are identified and described. The results on the relative importance of the chosen ventilation related parameters for this particular study are discussed in Section 7.3 and Section 7.4 respectively. The same solar control assumption as applied in Chapter 5 is used in this Chapter as well, where that a certain level of shading control is assumed within the atrium space. The corresponding outcomes are summarized as follows.

From the aspect of design specification, firstly, the effect of building segmentation height and external opening sizes are discussed. It is found that the largest $\sigma$ value is observed for the case with smaller segmentation height (the 5 storey case) during the warmer months, irrespective of ventilation conditions adopted. Also, the larger $\sigma$ value is observed for all segmentation cases under the buoyancy alone condition in comparison with the wind and buoyancy combined condition. The resultant variation of air flow velocity for the 5 storey and those over 8 storeys are about $1 \mathrm{~m} / \mathrm{s}$ and $0.2 \mathrm{~m} / \mathrm{s}$ respectively. For the case with air flow speed over $1 \mathrm{~m} / \mathrm{s}$ (smaller segmentation height), the air draught may have potential impact on the stationary work of the occupied spaces. These results suggest that segmentation height of over eight storeys is required for achieving 
more manageable flow on floor-by-floor basis (in terms of flow rates and flow velocity), particularly for the worst case scenario when the external wind speed is extremely low. However, the concern for jurisdictions in terms of fire safety should be considered along with natural ventilation design in tall office buildings.

Secondly, the impact of inlet and outlet sizes (envelope openings) of the proposed building configuration is investigated. It is concluded that the increase of external opening size is not always of benefit under varied ventilation conditions. The warmer air may be driven into the occupied space and cause thermal discomfort, where the external temperature is higher than the simulated internal temperature. In addition, the monthly $\sigma$ values of flow rates against floor levels under the minimum and maximum external opening arrangements vary from 0.32 to 1.13 $\left(\mathrm{m}^{3} / \mathrm{s}\right)$ for the buoyancy alone case; while it is between 0.35 and $0.51\left(\mathrm{~m}^{3} / \mathrm{s}\right)$ for the wind and buoyancy combined case. In terms of resultant flow velocity through the occupied spaces, the variation is less than $0.8 \mathrm{~m} / \mathrm{s}$ between different envelope opening arrangements in general. The summer condition suggests that the maximum and minimum external opening arrangements may cause the variation of air velocity for about $0.2 \mathrm{~m} / \mathrm{s}$, irrespective of ventilation conditions (buoyancy alone or wind and buoyancy combined). It can be concluded that the impact of envelope openings is relatively smaller than those caused by different building segmentation height, where the smaller segmentation may cause the resultant flow velocity for over $1 \mathrm{~m} / \mathrm{s}$. From the design specification point of view, both the segmentation height and the sizes of envelope openings deserve equal concerns at the development of planning and design.

From the aspect of boundary conditions, the time-series weather data, behaviour of occupants, and other data concerning the operation of the building are considered because they are the required input information for ESP-r modelling. In terms of the operation of the building, the schedule as well as the heat gains from the occupants, lighting, and equipments is investigated by varying the internal heat gains according to different level of stationary work inside of the offices. It is found that though the ventilation flow rates increase with the greater 
amount of internal heat gains (buoyancy effect as expected), the internal temperatures are increased by $0.5{ }^{\circ} \mathrm{C}$ according to the free running temperatures of an office in the mid-level of building segment. The impact of internal heat gains is less significant in terms of sensible (the free running temperatures) as well as personal cooling (the velocity from bulk flow) as compared with other parameters being selected for this study in general.

In terms of the time-series weather data, the investigations on the wind related boundary conditions of this chapter are evaluated with reference to wind pressure coefficient being adopted in the ESP-r program; while the temperature related parameters are discussed separately with the buoyancy alone cases. The effect of wind speed alone is examined by the envelope flow model approach because it is impossible to vary the wind speed by a given percentage at a time within ESP-r.

The investigations of the influence of wind pressure coefficient arrangements suggest that the deviation of flow rates would vary from 0.5 to $3.2\left(\mathrm{~m}^{3} / \mathrm{s}\right)$ with reference to the predefined pressure difference acting across the inlet and outlet (envelope openings) upon the presence of prevailing wind direction. This is more significant than those caused by internal heat gains. The resultant air flow velocities from the calculated bulk flows also suggest that the range of influence is over $1.5 \mathrm{~m} / \mathrm{s}$ regardless of flow direction. In other words, the impact of wind pressure coefficient deserves more attention than those caused by internal heat gains, envelope opening sizes, and the building segmentation height as discussed early on. Thereby, inappropriate assumption of the $C_{P}$ values may cause significant impact on the simulated flow rates. The reliability of wind pressure coefficient datasets within ESP-r is justified by comparing results between the ESP-r, CFD and a web-based TPU aerodynamic datasets. The results suggest that the $\mathrm{Cp}$ values adopted in the present study is acceptable if the driving wind force is either from the windward or leeward direction; while the resultant flow rates caused by wind from side directions might be questionable. The Cp value $(-0.8)$ adopted for the outlet of the ESP-r model is reliable because it has relatively small variation between three different database. 
Finally, the correlation coefficient $\left(\mathrm{R}^{2}\right)$ is adopted to demonstrate the relative importance of individual temperature related parameters to the resultant flow rates of different building configurations (isolated and segmented cases) under the buoyancy alone condition. Theoretically, we would expect the total flow rates to be proportional to root $\Delta T$ when there are only two temperatures involved (i.e. the simple isolated case with no ventilated cavities). In this particular study, the simulations involve two ventilated cavities, which two other temperatures are introduced as parameters. It is therefore the simple relation between flow rate and $\Delta T$ is less likely to be observed. The results inevitably demonstrate the need of further empirical experiments for validating the modelling results on naturally ventilated double-skin façade system. As for the segmented case, a strong correlation between flow rates and $\Delta T$ is observed for most floors except for the upper floor. The upper floor of the segmented case presents similar results (with reference to the $\mathrm{R}^{2}$ values) as those suggested by the isolated case because of its limited stack height. It is supposed that the relative sensitivity can be demonstrated by comparing the $\mathrm{R}^{2}$ values between floor levels as well as on varied segmentation height basis. Consequently, the modelling uncertainty as identified in the isolated case can be ignored. Nevertheless, the actual of influence with regard to quantitative presentation of flow rates may be questionable.

To sum up, the objective of identifying the relative importance of different ventilation related parameters is achieved. The range of influence of selected test parameters is identified by comparing their calculated flow rates and resultant flow velocities from bulk flow. The results suggest that the segmentation height, envelope opening size as well as the wind pressure difference acting across the inlet and outlet deserve more concern under the wind and buoyancy combined condition. Furthermore, although the low or no wind condition rarely happens in the climatic context of Taipei, it still provides an insight for dealing the weather extremes or the scenario when the building is blocked by surrounding obstructions. 


\section{Conclusions}

\subsection{Summary of the thesis}

The aim of this study is to propose a design approach for naturally ventilated tall office buildings in Taiwan. The potential for comfort ventilation under the proposed building configuration is identified by the use of three different modelling tools in different design stages. The objective is to assess the relative performance of design options rather than the actual performance of a particular building design. It is therefore the proposed models have already been assumed a considerable degree of good design in terms of orientation, insulation and shadings.

This thesis starts with discussions on issues of naturally ventilated tall office buildings in a hot and humid climate in Chapter 1. Chapter 2 then continues with case studies of naturally ventilated tall office buildings design worldwide. The design issues and ventilation strategies adopted in those real-world applications are reviewed. The concerns for applicability of natural ventilation in tall office buildings are raised. The problems and limitations of naturally ventilated tall office buildings design in the climatic context of Taiwan are discussed as well. Furthermore, the proposed naturally ventilated building configurations for this study are determined for the corresponding modelling stage. Aspects to be considered for the generic design, in terms of plan layout and sectional treatments, of naturally ventilated tall office buildings in Taiwan are raised.

The methodology adopted for this study is introduced in Chapter 3. Tools for natural ventilation assessment of this study are presented accordingly. The criterion for the performance of comfort ventilation is defined for the hot and humid climate in particular. Detailed result and discussions are presented in 
Chapters 4, 5 and 6 respectively according to the modelling tool adopted. The assumptions and boundary conditions for the specific modelling tools are defined. Additionally, a parametric study is introduced in Chapter 7 to determine which input parameters exert the most influence on air flow rates, flow velocities, and the free running temperatures. It is hoped that the information obtained can help with the design decision at the planning and development of the naturally ventilated tall office buildings. It is hoped to provide a route and options with proven technical analysis for naturally ventilated tall office building design in the climatic context of Taiwan. 


\subsection{Concluding remarks}

The main conclusions corresponding to the objectives and expected outcomes of this thesis are summarized in the following subsections.

\subsubsection{Design procedure for naturally ventilated tall office buildings}

Four design phases, namely the conceptual design, design development, performance evaluation and design optimization, are proposed in the current study. The novelty lies in the design process and the tools for the assessment of overall performance of comfort ventilation. The objectives and expected outcomes of the design phase are outlined as Table 1-1. Among the four design phase, three different modelling tools are adopted for the three corresponding design stages, which are included in the second and third design phase (namely design development and performance evaluation) respectively. The proposed design procedure as illustrated in Figure 3-1 is summarized as follows.

Firstly, for the conceptual design phase, the ventilation requirements are defined according to the ventilation purpose. The cooling mechanism for comfort being explored in this particular study, for a hot and humid climate, includes the direct cooling of indoor space (sensible cooling) and the physiological cooling of the human body (personal cooling). The boundary conditions and conceptual air flow pattern are determined for the proposed building configuration.

During the second phase (design development), the explicit method and implicit method of the envelope flow model (EFM) are adopted for sizing the initial external openings (inlet and outlet) and investigating the preliminary off-design condition respectively. The adoption of the envelope flow model can also be regarded as the first modelling stage of the proposed main investigations in this study.

In the third design phase, the performance evaluation includes two different modelling stages, namely the dynamic thermal simulation with an air flow 
network (ESP-r) and CFD simulation. The main findings from the three modelling stages (EFM, ESP-r and CFD) are concluded with reference to the effect of segmentation on the resultant flow rates as well as the overall thermal comfort condition of corresponding office spaces. In the final design phase, the building bioclimatic chart (BBCC) is adopted to demonstrate the viability of comfort ventilation according to the predefined comfort boundary. The aim is to identify whether the natural ventilation alone can provide a satisfactory environment for the occupants during the majority of the time.

The proposed design procedure aims to provide an insight for design of naturally ventilated tall office buildings during the early stage of a building project. The four design phase starts from gathering design requirements and boundary conditions of a particular building project. Three different modelling tools, which provide diverse resolution levels, are then adopted to evaluate the performance of proposed ventilation strategies. The criteria for comfort ventilation are defined from the reviews on satisfactory comfort environment, particularly in the climatic context of Taiwan. In terms of design optimization, it may not be desirable for the architects to conduct their own parametric study for a particular building project during the early stage of design. That is, the considerations for natural ventilation design of tall office buildings in a hot and humid climate are suggested in this study. Concerns for the ventilation related parameters relate to overall thermal conditions and to thermal comfort criteria in the occupied spaces are addressed. More findings with regard to building segmentation and design considerations for naturally ventilated tall office buildings of a hot and humid climate are summarized in Section 8.2.2 and 8.2.3. 


\subsubsection{Design performance in terms of building segmentation}

In this research, an isolated office space, segmented and non-segmented atrium buildings are adopted as study models. Although the non-segmented case may not be allowed in some jurisdictions in terms of the fire safety issue, the detailed investigation of flow rates and flow patterns with and without segmentation is of interest. Consequently, the effect of segmentation is evaluated by comparing the overall ventilation performance under different building configurations. The aim is to ensure that the required magnitudes of the air flow rates, the desired flow pattern, and flow velocities through the envelope openings as well as the comfortable free running temperatures can be achieved over a range of specified conditions. The evaluations are divided into three stages and the objectives are basically the same; while the resolution level might vary. Three different modelling tools are adopted for different modelling stages respectively. The remarks for this sub-section are directed to the ventilation performance with regard to building segmentation.

\section{(1) The envelope flow model approach (The preliminary investigations)}

For the first modelling stage (as presented in Chapter 4), a single-cell envelope flow model (EFM) is adopted for evaluating the off-design conditions. The steady-state bulk flows through openings are evaluated under a specified design condition. It is found that the isolated cases tend to have relatively stable flow rates across floors and are relatively easier for flow pattern control. To account for the worst case scenario with low external wind speed (or the buoyancy-alone case), the atrium type (i.e. non-isolated) buildings are much preferred for supplying sufficient fresh air flow rates with the help of stack effect. Segmented cases, especially, are much preferred for their relatively small variation of flow rates against segment height. The potential risk of large pressure difference acting through the full height of the building can be reduced accordingly. 
The desired flow direction throughout floors during the hot summer (from June to August) can only be achieved with the help of segmentation strategy; while the reversed flow pattern (negative flow rates) occurs in lower floors when the external temperature gets higher than the set internal temperature $\left(28{ }^{\circ} \mathrm{C}\right.$ as defined in Section4.2). Although the reversed flow pattern may not always be an issue, it may cause the thermal discomfort and air quality problem when the warmer air is driven into the occupied space. In addition, higher correlation for the monthly ventilation performance is found between the isolated case and the top-most floor of atrium type buildings. This can be explained by the stack effect being small in the higher floors of atrium buildings, which is a characteristic of isolated floors.

\section{(2) The dynamic thermal simulation with an air flow network (The main}

\section{investigations)}

To cope with potential magnitude of impinging wind at high levels, a ventilated DSF is proposed along with the segmentation concept in the tall office buildings. The dynamic effects are evaluated by the use of dynamic thermal simulation incorporating an air flow network (ESP-r), because of the particular importance of the thermal behaviour of the DSF. The chosen thermal model utilises a multi-cell airflow network model (AFN) since the buildings can no longer be described by a single-cell model.

Generally speaking, optimum segmentation could offer a major advantage for reducing the overall variation of flow rates between floors. But the optimum segmentation may vary in terms of the sizes of the envelope opening and the corresponding excitations (weather data) applied. It is then suggested that the use

of dampers between cavities could be adopted for managing the optimum segmentation height, and consequently to regulate the ventilation rates. The same conclusion is made in the first modelling stage using the single-cell envelope flow 
model. This study used the same opening size for modelling air flows through individual floors. In reality, satisfactory flow rates between floors can be achieved by varying the areas of openings according to occupants' needs.

For multi-story ventilated cavity (double-skin facades and tall atrium in this study), the vertical height of the cavity creates stronger uplift forces due to increased stack effect. However, the upper stories of the shaft can be overheated, leading to thermal discomfort in the adjacent office floor. From the desired flow pattern point of view, the larger segmentation could offer more opportunities for flow pattern control according to the modelling results presented in Chapter 5. The modelling results also suggest that it is unlikely to obtain the design goal with the buoyancy alone strategy when the ambient temperature gets higher than the simulated internal temperature, which occurs from late April in the climatic context of Taipei. However, there is only $1.3 \%$ of time (117 out of 8760 hours) that the external wind speed is lower than $0.5 \mathrm{~m} / \mathrm{s}$ (refer to the buoyancy alone condition) as suggested in Figure 7-4. This can potentially improve the above addressed issue with the help of prevailing wind force. In terms of ventilated cooling potential, although the required minimum flow rates (calculated from Equation 3-1) for removing the internal heat gins are obtained, the thermal comfort cannot be guaranteed, because of the warmer air being driven into the occupied space. The acceptable thermal comfort boundary in the climatic context of Taiwan may be evaluated further in terms of the post-occupancy evaluations for identifying the overall satisfactory comfort ventilation.

Additionally, the parametric study also suggests that the deviation values between floors increases with the external temperature under the buoyancy alone condition, irrespective of segmentation height adopted; while the wind and buoyancy combined condition tends to be more stable in terms of monthly variation in deviation values. However, this study adopts the same internal opening size in each floor for comparison. The internal opening size should be regulated according to the occupants' need in the real practice. During the extreme weather condition (low wind speed and high external temperature), 
supplementary cooling such as desk fans, cooled workstations etc should be supplied for the desired thermal comfort. The parametric study suggests the largest $\sigma$ value for the case with smaller segmentation height (the 5 storey case) during the warmer months, irrespective of ventilation conditions adopted (i.e. for the 5 storeys segmentation case, the wind force appears to have more impact on the overall deviation of flow rates between floors). The resultant variation of flow velocity for the 5 storey case is about $1 \mathrm{~m} / \mathrm{s}$, which may have potential impact on the stationary work of the occupied spaces regarding the air draught. Generally speaking, the standard deviation values between floors are quite steady when the segmentation height over 8 storeys is adopted during the mid-seasons. The range of influence of different building segmentation height is identified by comparing their calculated flow rates, resultant flow velocities from bulk flow, and the overall free running temperatures. The results from previous chapters suggest that the segmentation height, envelope opening size as well as the wind pressure difference acting across the inlet and outlet deserve more concern under the wind and buoyancy combined condition.

Because of the low probability (1.3\% of time during a year) of the low or no wind condition (refer to the buoyancy alone condition) in the climatic context of Taipei, it is therefore the optimum segmentation height is determined under the wind and buoyancy combined case. However, there may be a scenario, where the wind is blocked by the surrounding obstructions (particularly in the urban areas), that the sufficient flow rates to be driven into the building are restricted. Also, the stack effect in tall buildings is a natural phenomenon that cannot be avoided. It is therefore the buoyancy alone condition is still of interest for indentifying the potential extremes (worst cases) in this particular study.

By the use of building bioclimatic charts (BBCCs), the 10 storey segmentation case demonstrates the feasibility of comfort ventilation for over $60 \%$ of midseasons in Taipei. The overall comfort ventilation performance is evaluated by plotting the hourly temperature and relative humidity data into the BBCCs, where the comfort boundary is determined according to the simulated local flow 
velocities from CFD. For the time when the design goal cannot be obtained, the control of air intake sizes as well as adjustment of segmentation by the use of dampers between cavities can be adopted for regulating the ventilation rates and flow velocities. Some supplementary mechanical cooling with low energy demand (such as desk fans and cooled workstations etc.) may be required during the weather extremes (low or no wind speed along with high external temperature over $\left.28^{\circ} \mathrm{C}\right)$.

\subsubsection{Considerations for naturally ventilated tall office building design in the climatic context of Taiwan}

By way of cross ventilation, comfort ventilation can be achieved under the condition where an indoor air speed of 1.5 2 (m/s) occurs and the outdoor maximum temperature does not exceed about 28 to $32{ }^{\circ} \mathrm{C}(7599$ hours out of a year in the climatic context of Taipei). This is regarded as the simplest strategy for low-rise buildings in hot and humid climates. In tall office buildings, however, the greater magnitude of wind and buoyancy forces in high levels, the greater are the challenges for close control of satisfactory comfort ventilation. One of the aims of this study is to investigate the effect of building segmentation when the conventional cross ventilation strategy is not applicable in high levels of office buildings because of high wind speed (wind gust). Considerations for a generic design of naturally ventilated tall office buildings in hot and humid climates are identified as follows.

\section{(1) Building plan layout}

The key considerations for the generic design of naturally ventilated tall office buildings regarding architectural features are discussed with reference to floorplate sizes, core distributions and sectional treatment in the current study because of their potential influence on natural ventilation. The suggestions for plan layout, which includes issues of plan depth and core distributions, are summarized in this 
subsection. To take the building configuration as proposed in the main investigations of this study for demonstration, the potential options for the arrangement of plan layout for natural ventilation are presented as Figure 2-35 and 2-36. The distribution of the passive zones identifies the potential application for conventional cross ventilation; while the adoptions of double-skin facades and tall atrium help to increase the overall bulk flow from stack effect.

Two viable options in terms of core design are suggested, though each of them has both pros and cons in many aspects. For the centre core arrangement (Fig. 235 ), an access corridor is provided which divides the centre core into two parts and serves the floor with single or possible multiple tenants. However, the centrecore configuration may not be the most appropriate design for buildings with smaller typical floor plates, buildings with certain site conditions, or buildings with special functions such as trading floors.

As for the offset core arrangement (Fig. 2-36), the core is distributed into four smaller cores and is pushed to the four corners of the building layout. But this proposition is restricted to a shallower plan when the escape distances are concerned. The centre atrium can be extended or remain as it is in the centre core arrangement. As stated by Yeang $(1999,2000)$, peripheral service cores provide many benefits. They eliminate the need for mechanical ventilation and fireprotection pressurization duct in the cores, which is prevalent in internal core staircases. The offset core can also provide natural ventilation and light to the lift lobby and stairs, thus resulting in lower energy consumption and lower operating costs. Additionally, a view out with greater awareness of place for users can be provided as well. For this particular study, the offset core arrangement can open to the exterior environment and allow for natural ventilation. Also, the core can shade the office space from the sun. The usable area can usually be organized into one space. Nevertheless, its use is limited on large floor plates becaues travel distances to the fire stairs and elevators may not meet code requirements. 


\section{(2) Building section}

The sectional treatment for this study is discussed with reference to the adoption of segmented atrium and ventilation cavities. Lessons learned from case studies demonstrate how the sky garden and the ventilated cavities (double skin facades and tall atrium in this particular study) can be used as air intake and extraction chimney respectively. The modelling results as presented in Chapters 4 and 5 also suggest that the potentially greater magnitudes of wind and buoyancy can be reduced with the adoption of segmentation strategy.

From the aspect of atrium design, the open atrium solution is selected, because they can be used to assist the operation of mixed mode and natural ventilation solutions in shallow plan. Furthermore, the floor plate efficiency can be improved and more creative space planning options are available by the employment of building shapes based on atria. Atria can also provide the opportunity to create a social hub for occupant interaction. As for the concept of ventilated cavity, its benefits of providing a climatic buffer zone between internal environmentally controlled space and external environment are always appreciated. This is also being demonstrated by the free running temperatures of the atrium space as presented in Chapter 5. The segmentation concept can then prevent the temperature differences from acting over the full height of the building. Consequently, the potential risks associated with the greater magnutudes of pressure difference between the bottom and top floors can be avoided.

Additionally, the concept of 'wind floor', as introduced in the Liberty Tower of Meiji University, is adopted for every 16 storey of the proposed building configuration in this study (it is called the lifted case in this study). The openings of the 'wind floor' in the current study are opened to four directions; while they may be regulated to 2-sided or single-sided openings depend on the weather condition. It is supposed that the feasibility for natural ventilation can be improved with the adoption of a 'wind floor' along with the segmentation concept. Detailed modelling results to support the claimed benefit are presented in Section 5.3 and Section 6.3. The results suggest that the possibility to achieve comfort 
ventilation decreases with higher ambient temperature irrespective of building configuration (here refers to the base case and the lifted case) applied. The overall percentage for comfort ventilation of the lifted case varies from $5 \%$ to $62 \%$ during the examined months (from March to August). The wind and buoyancy combined strategy is more beneficial for the base case building configuration; while the same ventilation condition may not be always helpful for the lifted case. It is observed that much warmer air is driven into the occupied spaces of the lifted case with inadequate design of the envelope opening sizes, which may cause thermal discomfort and air quality issues.

\section{(3) Wind pressure coefficient $\left(\mathbf{C}_{\mathbf{P}}\right)$}

The wind direction and $C_{p}$ are interrelated of each other. So an assumed variation in $C_{p}$ could be considered to be a change in wind direction. For the proposed building configuration of this particular study, the inlet is located in the bottom level of the south-facing side of the atrium segment; while the outlet is at the top of the ventilated façade segment. The deviation $(\sigma)$ of flow rates between three different $C_{p}$ values arrangements would vary from 0.5 to $3.2\left(\mathrm{~m}^{3} / \mathrm{s}\right)$. This is more significant than the deviation caused by internal heat gains $\left(\sigma<0.2 \mathrm{~m}^{3} / \mathrm{s}\right)$. The resultant air flow velocities from the calculated bulk flows also suggest that the range of influence is over $1.5 \mathrm{~m} / \mathrm{s}$ regardless of flow direction. In other words, the impact of wind pressure coefficient deserves more attention than those caused by internal heat gains, envelope opening sizes, and the building segmentation height. Consequently, inappropriate assumption of the $C_{p}$ values may cause significant impact on the simulated flow rates. The credibility of wind pressure coefficient datasets adopted in this study (ESP-r) has been justified by comparing results between the ESP-r, CFD and TPU datasets in Section 6.2. It is found that the $C_{p}$ values used in the dynamic thermal simulation with an air flow network are justified for the wind from either the windward or leeward direction; while the resultant flow rates caused by wind from side directions might be questionable. 


\section{(4) Envelope opening sizes}

The envelope openings are referred to as the inlet and outlet openings of the proposed building configurations (Fig. 2-41), namely the base and lifted cases, in this study. Various arrangements for the inlet and outlet sizes are investigated according to their overall impact on the calculated flow rates and resultant flow velocities. The air intake size of an open wind floor in the bottom level of a building segment (i,e, the "lifted" case) is evaluated in particular, because of its potential influence on the comfort wind environment in the pedestrian level. The design aim for the lifted building configuration is to allow more flexibility for the design of air intakes and consequently to avoid undesired air draught through the inlet.

Generally speaking, the increase of inlet size is not always of benefit and would cause flow reversal when the external temperature gets higher than the simulated internal temperature, especially for the buoyancy alone condition. This may be an issue when the warmer air is driven into the occupied spaces and causes the thermal discomfort or air quality problem. The optimum size for the air intake should fulfil the requirement in terms of sufficient flow rates for cooling; while maintaining satisfactory flow velocities for the nearby spaces.

In terms of flow velocities through the occupied spaces, it is found that the variation is less than $0.8 \mathrm{~m} / \mathrm{s}$ between different envelope opening arrangements in general. The summer condition suggests that the maximum and minimum external opening arrangements may cause the variation of air velocity for about $0.2 \mathrm{~m} / \mathrm{s}$, irrespective of ventilation conditions (buoyancy alone or wind and buoyancy combined). Although the results from whole building CFD simulation confirm that the multi-orientation inlets can help to secure the required flow rates supplied into the occupied spaces, the optimum inlet sizes should be considered for satisfactory air flow velocity through the openings and consequently to the adjacent spaces (for the bottom segment in particular). Thereby, the comfort wind environment with regard to air draught issue can be ensured. 


\section{(5) Solar shading control}

In hot and humid climatic regions, high temperatures are accompanied by very high humidity levels leading to immense discomfort. Cross ventilation is hence very essential in this climatic context. Adequate shading measures are also necessary to protect the building from direct solar radiation. As being found in the preliminary model validation process, the ESP-r program may underestimate the solar gains entering into large transparent surfaces. It is therefore certain level of shading control is assumed, as to account for the perceived underestimation of solar gains into the occupied spaces. The amount of temperature deviations with and without solar control is justified in Section 5.2. 


\subsection{Originality and contribution to knowledge}

High-density urban development encourages the boom of tall buildings in Taiwan. Tall office buildings, in particular, consume a great amount of energy due to the employment of air-conditioning system. This study provides an understanding of how tall office buildings can be designed and operated to provide a viable (comfortable and affordable) alternative to air-conditioning system in the climatic context of Taiwan. The proportion of the year that natural ventilation can provide comfort conditions in tall office buildings of Taiwan is identified in Section 6.4, which suggests that over $50 \%$ of a year can benefit from the comfort ventilation. Nevertheless, for the periods of time when the thermal comfort cannot be achieved under the proposed natural ventilation strategies, namely during the hot summer, the mixed-mode ventilation is necessary. It is also supposed that the supplementary mechanical cooling with low energy demands, such as desk fans or cooled workstations etc., may be provided as an intermediate solution during the weather extremes. This study provides an understanding of how the overall building design affects the ventilation performance and, ultimately, indoor thermal comfort of occupied spaces. The feasibility for naturally ventilated tall office buildings under the proposed building configuration in Taiwan is clarified accordingly.

The originality of this work can be directed to following points:

I. This study proposed a viable design procedure for the naturally ventilated tall office buildings (for Taiwan in particular). It is believed that the proposed design procedure can fit well with the current development of a design project and lead to claimed benefits of natural ventilation. The designer may react to the findings of this study (for the time when natural ventilation is not applicable) in terms of supplementary mechanical cooling, and controls. 
II. The novelty of this work lies not in the methodology (which uses available models), but in the evaluation of segmented and non-segmented tall buildings in the climatic context of Taiwan. The detailed investigation of flow rates and flow patterns with and without segmentation is analyzed. The air flow rates, flow velocities and patterns, as well as the free running temperatures observed within the proposed building configurations are compared, for otherwise identical conditions. Potential conditions where the design goals may not be ensured are identified in Chapters 4, 5 and 6.

III. A generic building configuration with reference to building plan layout and building section is proposed to promote viable natural ventilation strategies for tall building. Design options are suggested in terms of the plan depth, core arrangements and sectional treatments (with atrium and ventilated facades). It is believed that the two suggested potential options can provide an insight for building configuration design of naturally ventilated tall office buildings.

IV. A parametric study is conducted for clarifying the issue of how the ventilation related parameters relate to overall ventilation performance and to thermal comfort criteria of the occupied spaces of tall buildings. The relative importance of each parameter to be considered for the design of naturally ventilated tall office buildings in Taiwan is suggested.

The remarks for the contribution to knowledge are outlined in terms of quantification of the effects of various parameters on tall office buildings. They are summarized as follows.

\section{- Effect of building segmentation}

The concept of segmentation is introduced for the building configuration with the adoption of tall ventilated cavities (atrium and double-skin 
facades in this study), because the non-segmented case may not be allowed in some jurisdictions, particularly for the fire safety issue. The effect of segmentation is evaluated by comparing the overall ventilation as well as thermal performance, in terms of the required flow rates and flow velocities, desired flow pattern, and free running temperatures under different arrangement of building segments.

\section{- Relative importance of ventilation related parameters}

The ventilation related parameters with reference to design specification (building segmentation and the sizes of envelope openings) and boundary conditions (internal heat gains, weather conditions and wind pressure coefficient) are studied by the parametrical analysis. Their relative importance and the ranges of influence are identified.

- The feasibility of naturally ventilated tall office buildings in a hot and humid climate

The calculated hourly results (temperature and relative humidity) from ESP-r modelling are plotted in a building bioclimatic chart (BBCCs); while the simulated local air speed distribution from CFD simulation is adopted for ensuring the selection of specific thermal comfort boundary. The illustrated results in BBCCs provide an insight for the feasibility of natural ventilation of the proposed building configuration under the predefined boundary conditions. Although it may not be realistic in terms of the actual values of ventilation rates (because of the assumptions used), this study demonstrates the relative performance through the inter-model comparison. The potential for the application of a naturally ventilated tall office building in the climatic context of Taiwan is clarified accordingly. 


\subsection{Suggestions for future work}

Previous research in this field has provided a wide assessment of natural ventilation applications, for the low-rise buildings in particular. However, the adoption of natural ventilation in tall and non-domestic buildings is less common, because of a potential risk to a successful design. This risk arises from the fact that practical design experience and accessible proven technical information of real buildings is relatively limited compared to the low-rise buildings.

To account for the above addressed issues, this study proposes a design approach and ventilation strategies specifically for tall office buildings. The modelling results demonstrate the feasibility of naturally ventilated tall office buildings in the hot and humid climates with the proposed building configurations. It is believed that natural ventilation can provide the desired thermal comfort for the tall office buildings in the climatic context of Taiwan for nearly $50 \%$ of a year. In particular, the effect of segmentation is shown to be of value. Nevertheless, some issues not being addressed in the current study are worthy of further investigation, and are outlined as follows.

\section{(1) Building orientations}

Consideration of the influence of building orientations on performance requires further investigation. In this study, only the influence of windward, leeward and side-facing directions are examined. The effect of wind direction is considered by the use of wind pressure coefficient $\left(C_{P}\right)$ in this study. Though an assumed variation in $C_{P}$ could be considered to be a change in wind direction, only three sets of $\Delta C_{P}$ arrangements across the locations of inlet and outlet were investigated. The results demonstrate the sensitivity of $\Delta C_{P}$ on the resultant flow rates of associated office spaces rather than the direct interpretation of influence of wind direction on the ventilation flow rates. Designers may be more interested in the explicit expression of wind directions for natural ventilation design. It is supposed that the impact of wind effect upon specific wind attack angles with reference to 
the proposed building configuration can be tabulated for more practical application in the future.

\section{(2) Fire regulations}

In terms of fire safety, strategies embodied in the Building Regulations of Taiwan are the use of automatic suppression, phasing or staging of evacuation, and the use of lifts for the fire brigade in protected and ventilated stairs. The main fire safety features, with reference to vertical spaces for a tall building over 50 metre height (or 16 storeys), include floor-by-floor compartmentation with protection of shafts that link floors and fire brigade access via lifts in well protected firefighting shafts. In the context of the current study, it is supposed that the segmentation as well as the wind floor concept can be extended to an integration design between ventilation system and fireproof refuge floor. More simulations can be conducted in terms of the zoning arrangements in the context of fireproof regulations in Taiwan.

\section{(3) Concerns of double-skin façade design}

In terms of double skin façade design for office buildings, the cavity geometry and the combination of the type of panes and shading devices are important for proper ventilation of the cavity. The purpose is to avoid overheating of the cavity and the interior space. From the aspect of cavity geometry, Lee et al. (2002) and Compagno (2002) both suggested that the width and height of the cavity and the size of the openings could be crucial for the intermediate temperatures and for the airflow if the cavity was naturally ventilated. However, the influence of the depth of ventilated cavity is not examined in this study (the depth is kept as $1 \mathrm{~m}$ ). It is therefore desirable to have further sensitivity analysis with reference to the geometry of ventilated cavity against ventilation flow rates.

Another important parameter to be considered is the positioning of the shading devices. Oesterle et al. (2001) and Lee et al. (2002) described the proper position of the sun shading. As they claimed, the shading devices should be positioned in 
the outer half of the intermediate space. Stec et al. (2000) also suggested that "half of the inner façade should be insulated if natural ventilation with comfort is the objective. Otherwise mechanical cooling should be applied".

Lee et al. (2002) pointed out that inadequate air flow around the blind may occur and conductive and radiative heat transfer to the interior would increase if the blind was placed too close to the interior façade. He suggested that the blind should be placed toward the exterior pane with adequate room for air circulation on both sides. Nevertheless, the shading control within the ESP-r program, blinds within the DSF cavity, is activated only when solar radiation exceeds $270 \mathrm{~W} / \mathrm{m}^{2}$ for this particular study. It is supposed that the radiative transfer within the CFD model and, in particular, the effect of absorption and re-emission of radiation due to water vapour content of the air should be taken into consideration for better representation of a real building.

\section{(4) Control strategies}

The main concern in free-running buildings is the control of the natural ventilation system. In the case of mixed-mode ventilation system, it would require extra expertise to run them successfully. Opening windows in higher floors may cause papers to fly about and make it difficult for desk work. It should be noted that the assumption made regarding the cool draught may change according to the comfort criteria and/or the type of work environment. In view of adaptive comfort under the naturally ventilated condition, it may be reasonable to consider a slightly higher mean velocity for the claimed comfort.

It is supposed that the comfort ventilation can be improved by modifying the design of the windows so as to better regulate airflow. In the current study, the openings are assumed to be fully opened. The size of opening is defined in the conceptual design phase under the summer design condition (the maximum scenario). It is therefore suggested that further control algorithm with reference to type and form of ventilation openings should be developed for better control of 
free running office buildings. An occupant based control is also important to be considered as part of an 'adaptive' approach to thermal comfort. A seasonal control algorithm can be developed to provide the desired flow pattern and sufficient flow rates for cooling as well as satisfactory air flow rates between floors. More detailed estimation about the proportion of a year when the natural ventilation is viable and the arrangement for the mixed-mode ventilation (combination of natural ventilation with mechanical cooling) can be calcified accordingly.

\section{(5) Perception for comfort ventilation}

Brager and deDear (2000) suggested that psychological adaptations would widen the range of acceptable interior temperatures. In other words, acclimatization or physiological adaptations are likely to result in changes for comfort perception. It is therefore suggested that occupants of those new buildings who are accustomed to air-conditioned space should be made aware of the design intent of naturally ventilated buildings. It is believed that the expectations for thermal comfort of the occupants may be more relaxed given this information. Further post-occupancy evaluations can be conducted to demonstrate the claimed comfort cooling performance. The information obtained will be helpful for the promotion of naturally ventilated tall office buildings in the future. 


\section{Reference}

1. ANSYS FLUENT, 2006. FLUENT 6.3 User's Guide. [Online] Available at http://hpce.iitm.ac.in/website/Manuals/Fluent 6.3/fluent6.3/help/index.htm

2. ASHRAE, 2004. Standard 55-2004: Thermal Environmental Conditions for Human Occupancy. Atlanta, GA: American Society of Heating, Refrigerating, and AirConditioning Engineers.

3. ASHRAE, 2009. Handbook of Fundamentals. Atlanta, GA: American Society of Heating, Refrigerating, and Air-Conditioning Engineers.

4. Baker, N. and Standeven, M., 1994. Comfort Criteria for Passively Cooled Buildings A PASCOOL Task. Renewable Energy, 5(2), pp. 977-84.

5. Baker, N. and Standeven, M., 1996. Thermal Comfort for Free-running Buildings. Energy and Buildings, 23, pp.175-82.

6. Baker, N. and Steemers, K., 1996. LT Method 3.0- a strategic energy-design tool for Southern Europe. Energy and Buildings, 23, pp.251-56.

7. Baker, N. and Steemers, K., 2000. Energy and environment in architecture: a technical design guide. London: E. \& FN. Spon.

8. Beausoleil-Morrison, I., 2000. The Adaptive Coupling of Heat and Air Flow Modelling Within Dynamic Whole-Building Simulation. PhD Thesis. Glasgow: University of Strathclyde.

9. Blaser, W., 2004. Post tower: Helmut Jahn, Werner Sobek, Matthias Schuler. Birkhauser Verlag AG.

10. Blocken, B., Carmeliet, J., 2004. A review of wind-driven rain research in building science. Journal of Wind Engineering and Industrial Aerodynamics, 92(13), 1079-1130.

11. Brager, G. and de Dear, R., 2000. A Standard for Natural Ventilation. ASHRAE Journal, 42(10), pp.21-28.

12. British Council for Offices, 2009. 2009 guide to specification / British Council for Offices. British Council for Offices, London.

13. Busch, F., 1992. A tale of two populations: thermal comfort in air-conditioned and naturally ventilated offices in Thailand. Energy and Buildings, 18, pp.235-49.

14. Chen, Q., 2007. Computer simulations and experimental measurements of air distributions in buildings: past, present, and future. HVAC\&R Research, 13(6), 849-997.

15. Chen, Q., 2009. Ventilation performance prediction for buildings: A method overview and recent applications. Building and Environment, 44(4), 848-58.

16. Chen, Q., Lee, K., Mazumdar, K., Poussou, S., Wang, L, Wang, M., and Zhang, Z., 2010. Ventilation performance prediction for buildings: Model assessment. Building and Environment, 45(2), 295-303. 
17. CIBSE Application Manual AM10, 2005. Natural ventilation in non-domestic buildings. The Chartered Institution of Building Services Engineers, London, UK.

18. Clovis, R.M., 2001. Issues on the integration of CFD to building simulation tools. In: Proceeding of the Seventh International IBPSA Conference (BS2001), Vol. 1, Rio de Janeiro, Brazil, August 2001, pp. 29-40.

19. Compagno, A., 2002. Intelligent Glass Facades (5th revised and updated edition). Berlin: Birkhäuser.

20. Cramer, N., 1997. Europe's Tallest Tower. Architecture, Vol. 86 (8), pp.26.

21. Dassler, F.H., 2003. Post Tower in Bonn: State of the Art. XIA Intelligente Architetektur, vol. 41, pp. 22-37.

22. Davey, P., 1997. High expectations. The Architectural Review, 202 (1), pp.205- 26.

23. Davies, Colin ed. Birkhauser and Jenkins, David ed. Norman Foster Works Vol. 4. Munich; New York: Prestel, c2002.

24. de Dear, R and Brager, G., 2002. Thermal comfort in naturally ventilated buildings: revisions to ASHRAE Standard 55, Energy and Buildings, 34 (6), pp.549-61.

25. de Dear, R., 1998. A Global Database of Thermal Comfort Field Experiments. American Society of Heating, Refrigerating and Air-Conditioning Engineers Transactions, 104(1B), pp.1141-52.

26. Ding, W., Hasemi, Y., Yamada, T., 2005. Natural ventilation performance of a doubleskin façade with a solar chimney. Energy and Buildings, 37, pp.411-18.

27. Djunaedy, E., Hensen, J. L. M., Loomans, M. G. L. C., 2004. Selecting an appropriate tool for airflow simulation in buildings. Building Services Engineering Research and Technology, 25(3), pp.289-298.

28. Djunaedy, E., Hensen, J. L. M., Loomans, M. G. L. C., 2005. External coupling between CFD and energy simulation: implementation and validation. ASHRAE Transactions, 111(1), pp. 612-624.

29. Eisele, J. and Kloft, E., 2003. High-rise manual: typology and design, construction and technology. Birkhäuser GmbH, Germany.

30. Eisele, J., Kloft, E. (2003) High Rise Manual: Typology and Design, Construction and Technology, Birkhauser, Basel.

31. ESRU, 2002. ESP-r Tutorial. Available at: http://www.esru.strath.ac.uk/

32. Etheridge, D., 2002. Nondimensional method for natural ventilation design. Building and Environment, 37, pp. 1057-72.

33. Etheridge, D.W. and Ford, B.H., 2008. Natural ventilation of tall buildings - options and limitations. In: CTBUH 8th World Congress, Dubai. 3-5 March 2008. pp.226 - 32.

34. Evola, G. and Popov, V., 2006. Computational analysis of wind driven natural ventilation in buildings. Energy and Buildings, 38(5), pp.491-501. 
35. Ferziger, J.H. and Peric', M., 2002. Computational Methods for Fluid Dynamics, third ed. Springer, Berlin, Heidelberg, New York.

36. Fischer, V., 1997. Sir Norman Foster and Partners: Commerzbank, Frankfurt am Main. Stuttgart: Axel Menges.

37. Ford B.H., Schiano-Phan, R. 2005. Double Skin Facades -improving performance and reducing cost. In: Proceedings of PLEA 200, Environmental Sustainability: The Challenge of Awareness in Developing Societies, Beirut, Lebanon 13-16 November 2005.

38. Franke, J., 2006. Recommendations of the COST action C14 on the use of CFD in predicting pedestrian wind environment. In: The Fourth International Symposium on Computational Wind Engineering, Yokohama, Japan, July 2006.

39. Franke, J., Hirsch, C., Jensen, A.G., Kru“s, H.W., Schatzmann, M., Westbury, P.S., Miles, S.D. Wisse, J.A., Wright, N.G., 2004. Recommendations on the use of CFD in wind engineering. In: van Beeck, J.P.A.J. (Ed.), COST Action C14, Impact of Wind and Storm on City Life Built Environment. Proceedings of the International Conference on Urban Wind Engineering and Building Aerodynamics, 5-7 May 2004. Von Karman Institute, Sint-Genesius-Rode, Belgium.

40. Fürbringer, J.M., Roulet, C.A., Borchiellini, R., 1999. An overview of the evaluation activities of IEA ECBCS Annex 23. Energy and Buildings, 30, pp.19-33.

41. Givoni, B., 1994. Passive and Low-Energy Cooling of Buildings. Van Nostrand Reinhold, New York.

42. Givoni, B., 1998. Climate Considerations in Building and Urban Design. Van Nostrand Reinhold, New York.

43. Gonçalves, J. and Bodes, K,. 2011. The Importance of Real Life Data to Support Environmental Claims for Tall Buildings. CTBUH Journal, no. 2, pp. 24-29.

44. Goncalves, J. C. S., 2010. The Environmental Performance of Tall Buildings. Routledge, London.

45. Gratia, E., Herde, AD., 2007. Guidelines for improving natural daytime ventilation in an office building with a double-skin façade. Solar Energy, 81, pp.435-48.

46. Haase, M., Marques, da., Silva, F. and Amato, A. 2009. Simulation of ventilated facades in hot and humid climates. Energy and Buildings, 41, pp.361-73.

47. Hanby, D.M., 1994. A review of techniques for parameter sensitivity analysis of environmental models. Environmental Modelling and Assessment, 32, pp.135-154.

48. Harriman, L.G., Lstiburek, J.W., 2009. The ASHRAE Guide to Hot and Humid Climates, 2nd ed. American Society of Heating, Refrigerating and Air-Conditioning Engineers. Atlanta, GA.

49. Heiselberg, P., 2006. Design of Natural and Hybrid Ventilation. Denmark: Aalborg University. 
50. Helmut, J., Werner, S. and Matthias, S., 2004. Post Tower. Birkhäuser Basel.

51. Hensen, J., Bartak, M., Drkal, F., 2002. Modelling and simulation of a double-skin façade system. ASHRAE Transcations, 108(2) pp.125-59.

52. Hensen, J.L.M., 1991. On the thermal interaction of building structure and heating and ventilating systems. PhD Thesis, Eindhoven University of Technology.

53. Holmes, M.J., Lam, J.K.W., Ruddick, K.G. and Whittle G.E., 1990. Computation of Conduction, Convection, and Radiation in the Perimeter Zone of an Office Space. In: Proceeding of ROOMVENT'90, Oslo Norway.

54. Huang K.T., Lin H.T., (2007) "Development of Simplified Estimation Method of Chiller Energy Use for Office Buildings in Taiwan-Estimated from Maximum Chiller Capacity", ASHRAE Annual Meeting, Long Beach, CA, USA.

55. Huang, K.T., 2006. A Study on Simplified Prediction Method for Annual AirConditioningEnergy Consumption of Office Building. Journal of Architecture, 58, pp.131-147 (in Mandarin Chinese)

56. Jahnkassim, P. S. \& Ip, K., 2006. Linking bioclimatic theory and environmental performance in its climatic and cultural context - an analysis into the tropical high-rises of Ken Yeang," paper presented at PLEA 2006 Conference on Passive and Low Energy Architecture, Geneva, Switzerland, 6-8 September.

57. Jankassim, P. S., 2004. The Bioclimatic Skyscraper: A critical analysis of the theories and designs of Ken Yeang. PhD thesis, University of Brighton.

58. Ji, Y., Lomas, K. and Cook, M., 2009. Hybrid ventilation for low energy building design in south China. Building and Environment, 44 (11), pp. 2245-55.

59. Jitkhajornwanich, K. Pitts, A. Malama, A. \& Sharples, S., 1998. Thermal comfort in transitional spaces in the cool season of Bangkok. ASHRAE Transactions, 104 (1), pp.1181-93.

60. Kalyanova, O., Jensen, R.L. and Heiselberg, P., 2007. Measurement of air flow rate in a naturally ventilated double skin facade. Proceedings of Roomvent 2007: Helsinki, Finland 13-15 June 2007.

61. Kato, S., Chikamoto, T., 2002. The Liberty Tower of Meiji University-Case Study. Japan: Meiji University.

62. Kohn, A. and Katz, P., 2002. Building type basics for office buildings. John Wiley \& Sons, New York

63. Lam, J.C. and Hui, S.C.M., 1996. Sensitivity analysis of energy performance of office buildings. Building and Environment, 31(1), pp.27-39.

64. Lambot, I. and Davids, C., 1997. Commerzbank Frankfurt Prototype for an Ecological High-Rise. Birkhauser Verlag AG, Watermark Publications, London. 
65. Lambot, Ian. Commerzbank Frankfurt: Prototype for an Ecological High-Rise. Boston: Watermark Birkhäuser, 1997.

66. Lee, E., Selkowitz, S., Bazjanac, V., Inkarojrit, V., and Kohler, C., 2002. HighPerformance Commercial Building Façades. Building Technologies Program, Environmental Energy Technologies Division, Ernest Orlando Lawrence Berkeley National Laboratory (LBNL), University of California, Berkeley, USA (LBNL - 50502) Web address: http://gaia.lbl.gov/hpbf/documents/LBNL50502.pdf.

67. Liddament, M.W., 1996. A Guide to Energy Efficient Ventilation. Air Infiltration and Ventilation Centre, Bracknell, UK.

68. Lin, H.T., 2006. Tropical and Subtropical Characteristics of Building Energy and Climatic Context of Architecture. In: iNTA Conference 2006 : Harmony in Culture and Nature, The 2nd International Conference on Sustainable Architecture and Urban Design in Tropical Regions, Jogjakarta, Indonesia, 3-5 April 2006.

69. Lin, H.T., Chang, Y.S., Huang, K.T. and Sun, C.Y., 2007. Energy Saving and Carbon Dioxide Reduction Effect for the Energy Conservation Design of Building Envelope as a National Building Energy Policy. Final report of the project of the Architecture and Building Research Institute, Ministry of the Interior, Taiwan 2007 (in Mandarin Chinese)

70. Lomas, K.J. Fiala, D. Cook, M.J. Cropper, P.C. 2004. Building bioclimatic charts for non-domestic buildings and passive downdraught evaporative cooling. Building and Environment, 39, pp.661 - 676

71. Lomas, K.J., 2007. Architectural design of an advanced naturally ventilated building form. Energy and Buildings, 39(2), pp.166-88.

72. Manz, H. and Frank, T., 2005. Thermal Simulation of Buildings with Double-Skin Facades. Energy and Buildings, 37, pp.1114-1121.

73. McGuirk, J. (2006), 'Torre Cube; Architects: Carme Pinos', Icon, No. 036, June, p. 43.

74. Mergi, A.C. and Al-Dawoud, A., 2007. Integration of Ventilation in the Design of Commercial Buildings- Application to Atrium Buildings in Hot/Humid Climate. Architecture and Environment, 6(1), pp. 14-27.

75. Moujalled, B. Cantin, R. \& Guarracino, G., 2008. Comparison of thermal comfort algorithms in naturally ventilated office buildings. Energy and Buildings, 40, pp.2215-23.

76. Negrão C.O.R., 1995. Conflation of Computational Fluid Dynamics and Building Thermal Simulation. PhD Thesis, University of Strathclyde, Glasgow UK.

77. NF EN ISO Standard 7730. 2003, Moderate Thermal Environments-Determination of the PMV and PPD Indices and Specification of the Conditions for Thermal Comfort, AFNOR, Paris, France.

78. Nicol, J.F. and Humphreys, M.A., 2002. Adaptive thermal comfort and sustainable thermal standards for buildings. Energy and Buildings, 34(6), pp.563-72. 
79. Oesterle, E., Lieb, R-D., Lutz, M., \& Heusler, W., 2001. Double Skin Facades Integrated Planning. Prestel Verlag: Munich, Germany.

80. Oldfield, P., Trabucco, D. and Wood, A., 2008. Five energy generations of tall buildings: an historical analysis of energy consumption in high rise buildings In: CTBUH 8th World Congress. Tall \& Green: Typology for a Sustainable Urban Future. Dubai, 3 - 5 March, 2008 , pp.300-310.

81. Pagliari, F. (2006), 'Cube Tower. Guadalajara, Mexico. Estudio Carme Pinos', The Plan, No. 14, May/June, pp. 31-45

82. Peter Irwin et al., 2008. Wind and tall buildings: negatives and positives. The Structural Design of Tall and Special Buildings, Special Issue: CTBUH 2nd Annual Special Edition: Tall Sustainability, 17(5), pp.915-28.

83. Post Tower. Built visions. [Online] Available at http://www.dpdhl.com/content/dam/ueber_uns/tower_broschuere_en.pdf?\&lang=en_us\&output=json

84. Salib, R., 2008. Natural Ventilation in High Rise Office Buildings. University of Nottingham, The Master in Architecture Thesis, pp.94-114.

85. Sapian, A.R., 2004. The effect of high-rise open ground floor to wind flow and natural ventilation. SENVAR5- The fifth international seminar on sustainable Environmental Architecture, Universiti Teknologi Malaysia.

86. Schittich, C., 2007. Torre Cube in Guadalajara, Mexico,” Detail, no. 9, vol. 47, pp. 962964, 1076.

87. Strelitz, Z., 2007. Tall buildings: a strategic design guide. RIBA Publishing, London.

88. The Commerzbank Bank. [Online] Available at http://www.fosterandpartners.com.content.essays

89. Tominaga, Y. et al., 2008. AIJ guidelines for practical applications of CFD to pedestrian wind environment around buildings. Journal of Wind Engineering and Industrial Aerodynamics, 96, pp.1749-61.

90. Tominaga, Y., Yoshie, R., Mochida, A., Kataoka, H., Harimoto, K., Nozu, T., 2005. Cross comparisons of CFD prediction for wind environment at pedestrian level around buildings, Part 2: Comparison of results for flowfield around building complex in actual urban area. The Sixth Asia-Pacific Conference on Wind Engineering, September 2005, Seoul, Korea.

91. TPU Aerodynamic Database, Wind Pressure Database for High-Rise Building:Wind pressure database based on wind tunnel experiment for high-rise building. [Online] Available at http://wind.arch.t-kougei.ac.jp/system/eng/contents/code/tpu [Accessed December 2010].

92. van Hoof, J., 2008. Forty years of Fanger's model of thermal comfort: comfort for all. Indoor Air, 18, pp.182-201. 
93. Vytlačil, D. and Moos, P., 1993. The Sensitivity Analysis of Building Thermal network elements. Building and Environment, 28(1), pp.63-68.

94. Wang, L.P. and Nyuk Hien Wong, N.H., 2008. Coupled simulations for naturally ventilated residential buildings. Automation in Construction, 17(4), pp. 386-398.

95. Wang, L.P. and Nyuk Hien Wong, N.H., 2009. Coupled simulations for naturally ventilated rooms between building simulation (BS) and computational fluid dynamics (CFD) for better prediction of indoor thermal environment. Building and Environment, 44(1), pp.95-112.

96. Welfonder, T. Design and Evaluation of Bioclimatic Buildings. WWW at the Transsolar

97. Wigginton, Michael, and Jude Harris. Intelligent skins. Oxford: Butterworth-Heinemann, 2002.

98. Wit, S., 1997. Influence of modeling uncertainties on the simulation of building thermal comfort performance. In: BUILDING SIMULATION, 5, Prague. Proceedings IBPSA: Prague, 1997.

99. Wong, N.H. Feriadi, H. Lim, P.Y. Tham, K. W. Sekhar, C. \& Cheong,K.W., 2002. Thermal comfort evaluation of naturally ventilated public housing in Singapore. Journal of Building and Environment, 37, pp.1267-77.

100.Wong, P.C., Prasad, D., Behnia, M., 2008. A new type of double-skin façade configuration for the hot and humid climate. Energy and Buildings, 40, pp.1941-45.

101.Wood, A. and Salib, R., Guide to Natural Ventilation in High Rise Office Buildings. Routledge, 2012.

102.WWW page at: < http://www.pmhb.org/repdoc/59572-200682145355.pdf>Brochure of Deutsche Post DHL Corporate Communications, 2009.

103.Xia, Y. Niu, J. Zhao, R. \& Burnett, J., 2000. Effects of turbulent air on human thermal sensations in a warm isothermal environment. Indoor Air, 10, pp.289-96.

104.Yang, K.H., 2004. Review on Building Energy Conservation Strategies and Recent Research Programs in Taiwan. In: Proceedings of the Joint NSC-NRC Workshop on Construction Technologies, April 26-27, 2004, Taipei, Taiwan, IRC Research Report RR-192.

105.Yang, T., Wright, N.G., Etheridge, D.W. and Quinn, AD., 2006. A Comparison of CFD and Full-scale Measurements for Analysis of Natural Ventilation. The International Journal of Ventilation, 4(4), pp337-48.

106. Yeang, K., 2000. Service Cores -Detail in Building. Wiley-Academy, Italy.

107.Zhai, Z. and Chen, Q., 2003. Solution characters of iterative coupling between energy simulation and CFD programs. Energy and Buildings, 35(5), 493-505.

108.Zhai, Z. and Chen, Q., 2006. Sensitivity analysis and application guides for integrated building energy and CFD Simulation. Energy and Buildings, 38(9), pp.1060-68. 
109.Zhai, Z., Chen, Q., Haves, P. and Klems, J.H., 2002. On approaches to couple energy simulation and computational fluid dynamics programs. Building and Environment, 37, 857-864.

110.Zhou, J., Chen, Y., 2010. A review on applying ventilated double-skin façade to buildings in hot-summer and cold-winter zone in China. Renewable and Sustainable Energy Reviews, 14, pp.1321-28. 